
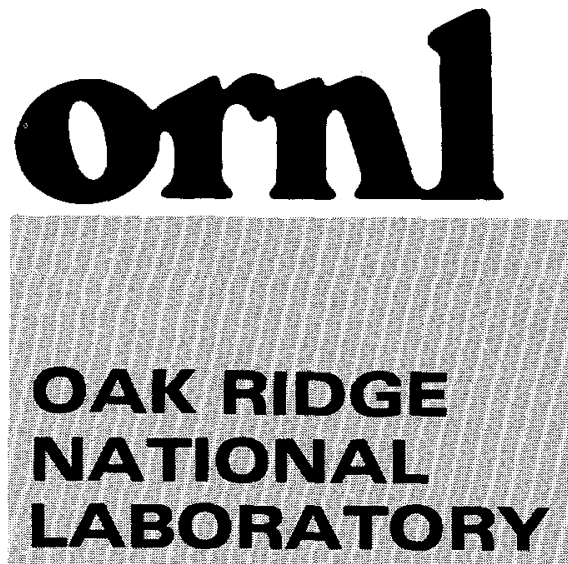

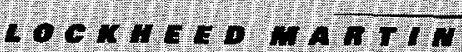

Environmental Sciences Division

\section{Laboratory Evaluation of In Situ Chemical Oxidation for Groundwater Remediation, Test Area North, Operable Unit 1-07B, Idaho National Engineering and Environmental Laboratory}

Volume Three - Appendix F

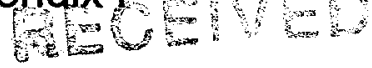
JUW 301939
S. R. Cline
J. M. Giaquinto
D. L. Denton
R. C. Starr

STI

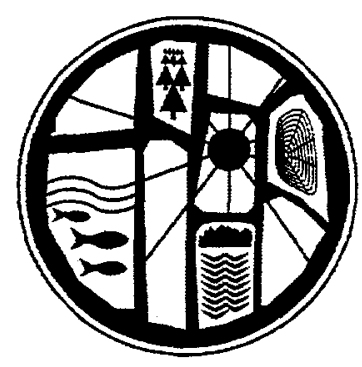


This report has been reproduced from the best available copy.

Reports are available to the public from the following source.

National Technical Information Service

5285 Port Royal Road

Springfield, VA 22161

Telephone 703-605-6000 (1-800-553-6847)

TDD 703-487-4639

Fax 703-605-6900

E-mail orders@ntis.fedworld.gov

Web site http://www.ntis.gov/ordering.htm

Reports are available to U.S. Department of Energy (DOE) employees, DOE contractors, Energy Technology Data Exchange (ETDE) representatives, and International Nuclear information System (INIS) representatives from the following source.

Office of Scientific and Technical information

P.O. Box 62

Oak Ridge, TN 37831

Telephone 423-576-8401

Fax 423-576-5728

E-mail reports@ adonis.osti.gov

Web site http://www.osti.gov/products/sources.html

Reports produced after January 1, 1996, are generally available via the DOE Information Bridge.

Web site http://www.doe.gov/bridge 
ORNL/TM-13711/V3

ENVIRONMENTAL SCIENCES DIVISION

\title{
LABORATORY EVALUATION OF IN SITU CHEMICAL OXIDATION FOR GROUNDWATER REMEDIATION, TEST AREA NORTH, OPERABLE UNIT 1-07B, IDAHO NATIONAL ENGINEERING AND ENVIRONMENTAL LABORATORY
}

\author{
Volume Three - Appendix F \\ S. R. Cline, J. M Giaquinto, M. K. McCracken, D. L. Denton \\ Oak Ridge National Laboratory \\ R.C. Starr \\ Idaho National Engineering and Environmental Laboratory \\ Environmental Sciences Division \\ Publication No. 4838 (Volume 3)
}

April 1999

Prepared for the Idaho Operations Office

U.S. Department of Energy

under budget and reporting code 647058101 (EW 201010 2)

\author{
Prepared by the \\ OAK RIDGE NATIONAL LABORATORY \\ Oak Ridge, Tennessee 37831-6285 \\ managed by \\ LOCKHEED MARTIN ENERGY RESEARCH CORP. \\ for the \\ U.S. DEPARTMENT OF ENERGY \\ under contract DE-AC05-96OR22464
}




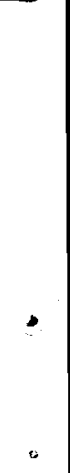




\section{DISCLAIMER}

This report was prepared as an account of work sponsored by an agency of the United States Government. Neither the United States Government nor any agency thereof, nor any of their employees, make any warranty, express or implied, or assumes any legal liability or responsibility for the accuracy, completeness, or usefulness of any information, apparatus, product, or process disclosed, or represents that its use would not infringe privately owned rights. Reference herein to any specific commercial product, process, or service by trade name, trademark, manufacturer, or otherwise does not necessarily constitute or imply its endorsement, recommendation, or favoring by the United States Government or any agency thereof. The views and opinions of authors expressed herein do not necessarily state or reflect those of the United States Government or any agency thereof. 


\section{DISCLAIMER}

Portions of this document may be illegible in electronic image products. Images are produced from the best available original document. 


\section{CONTENTS}

\section{VOLUME THREE}

PREFACE

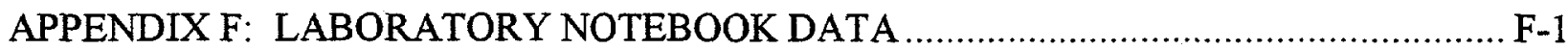

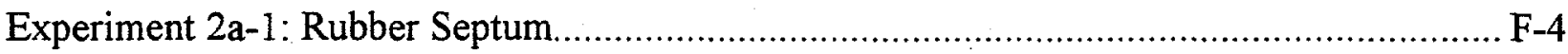

Experiment 2a-2: Pressure Relief ..................................................................................... F-7

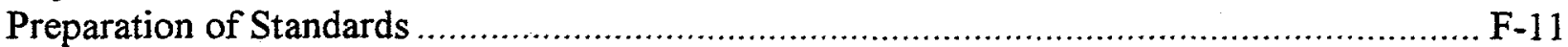

Experiment 2a-3: Test Reactor Performance .......................................................... F-12

Experiment 2b-1: Extraction Times.................................................................. F-14

Experiment 2c-1: Basalt Equilibrium ............................................................. F-19

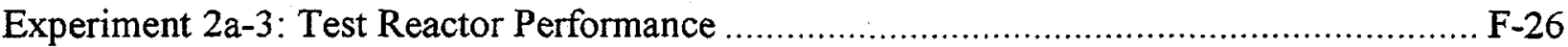

Permanganate Calibration Curve .......................................................................... F-29

Additional Lab Test \#1 ............................................................................. F-30

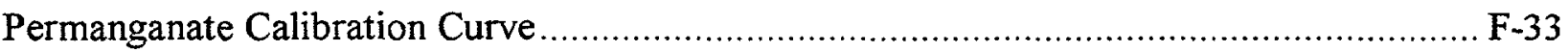

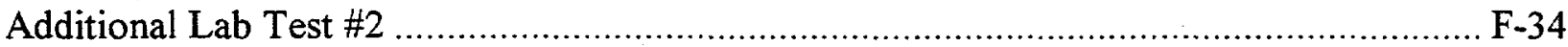

Experiment 3a-R1: Oxidant Demand ........................................................................ F-35

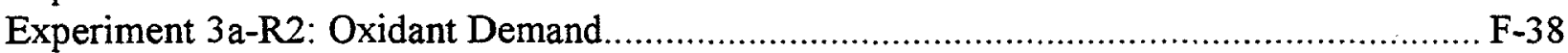

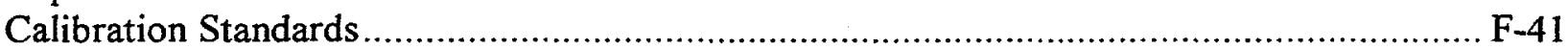

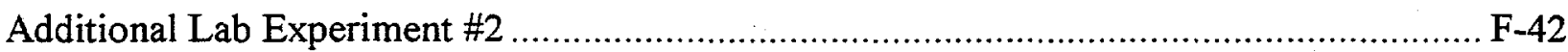

Experiment 3a-R3: Oxidant Demand .................................................................... F-46

Experiment 2c-1b: Repeat Sorption Kinetics ......................................................... F-49

Repeat exp. 2a-3: Test Reactor Performance .......................................................... F-53

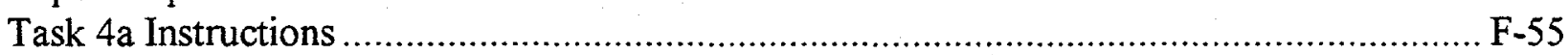

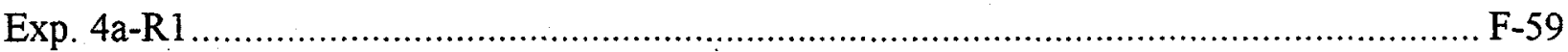

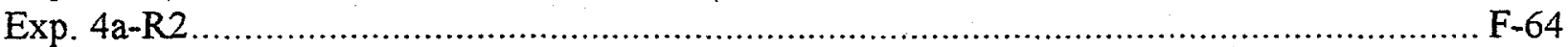

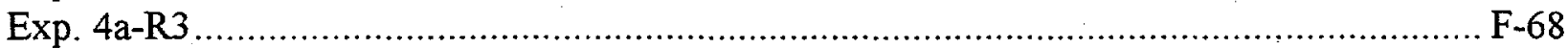

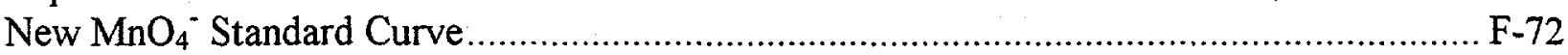

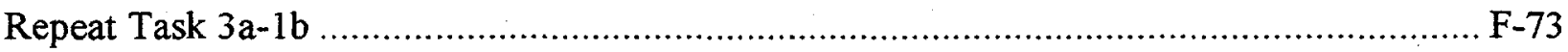

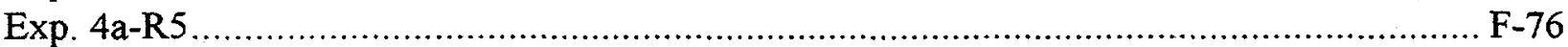

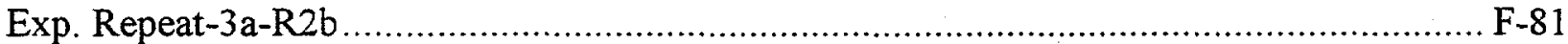

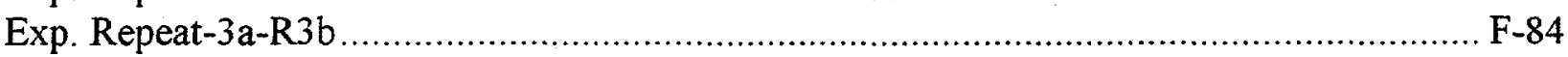

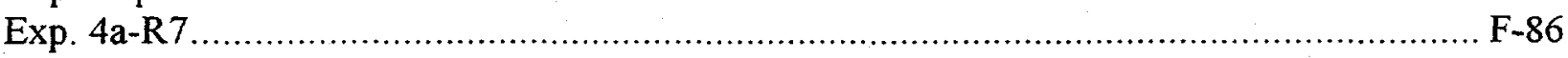

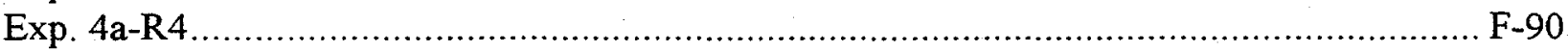

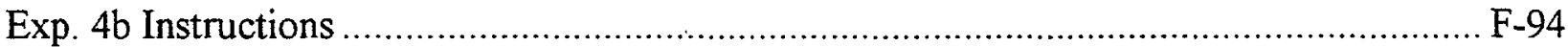

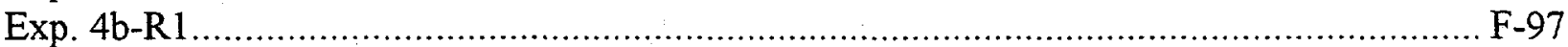

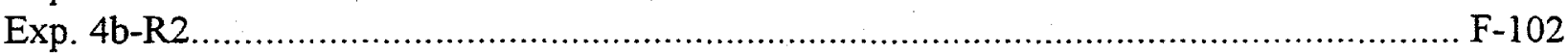

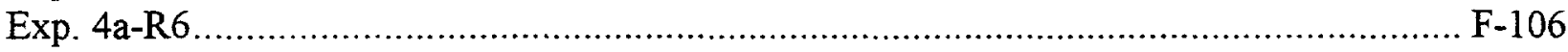

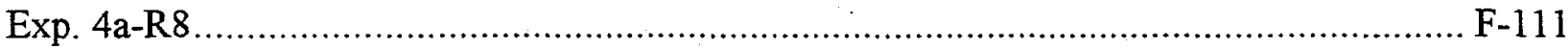

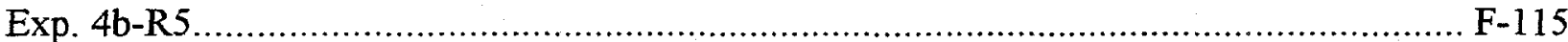

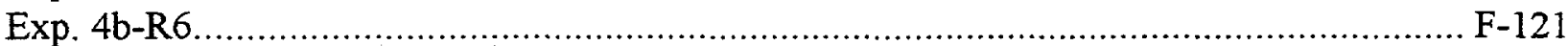

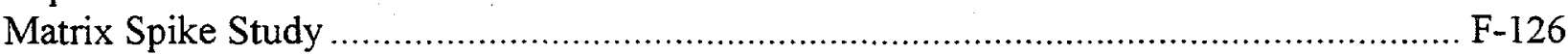

082698 Calibration Curve Information ........................................................... F-128

RMAL Data Sheets and Notebook Data .......................................................... F-130 


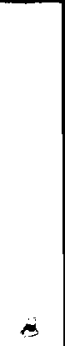




\section{PREFACE}

This appendix supports the results and discussion of the laboratory work performed to evaluate the feasibility of in situ chemical oxidation for Idaho National Environmental and Engineering Laboratory's (INEEL) Test Area North (TAN) which is contained in ORNL/TM-13711/V1.

This volume contains Appendix $\mathrm{F}$.

Appendix $\mathrm{F}$ is essentially a photocopy of the ORNL researchers' laboratory notebooks from the Environmental Sciences Division (ESD) and the Radioactive Materials Analytical Laboratory (RMAL). 
Assigned No. Bopo025

Duner: CLINE, STEUE

Date $12 / 03 / 1998$

Badge: 35073

Bldg 1505 MS 6036

Division: Enuirónmental Sciences

Project:INEEL TAN SITE PROJECT

MARTIN MARIETTA ENERGY SYSTEMS, INC.

Site Address

Research and Technical Notebook No.

Assigned to: Date:

Division:

Dept./Section:

Program/Project:

\section{Content}

Research/Technical

Description(s)/

Experiment 2a-12 Rubborseptum

Experimet t2a-2: Atessure rehef $+1 / 28-2 / 2$

Experimet t2a-2: Atessure rehef $+1 / 28-2 / 2$

Experiment 2a-3. Test Ractor Peformance

Experiment $2 b-1:$ Extraction Times

Experiment $2 c-1:$ Basalt Equil.

Experiment 2a-3: Testheactor Performance Permanganate catibration Curve

Additional Lab Test \#1

Permang a nate Calibation Curve

Adtitial Lab Test $\#_{2}$ (dilution)

Experineat $3 a-R_{1}$ : Oxidant Demand $(a)$

Experment 3a- $l_{2}:$ Oxidat Demand (b)

Calibration Standards

Additional Lab Exp. \#2

Experiment $3 a R 3 i$ Oxidat Demad $d(c)$

Experiment 2c-1biRefeat kivetion

Repict exp 2a-3: Testreactor peif.

Iask ta instructions

$$
\text { Exp ta-R }
$$

UCN-6201

Inclusive Dates

\begin{tabular}{|c|c|}
\hline $\begin{array}{c}\text { Notebock } \\
\text { Pages } \\
6-8\end{array}$ & $\begin{array}{l}\text { App. } \\
\text { Page } \\
\text { F-4 }\end{array}$ \\
\hline $9-12$ & \\
\hline 13 & $F-11$ \\
\hline $14-15$ & $F-12$ \\
\hline $16-20$ & $F \cdot 14$ \\
\hline $21-27$ & $F-19$ \\
\hline $28-30$ & $F-26$ \\
\hline $3 L$ & $E-2^{C}$ \\
\hline $32-34$ & $F-30$ \\
\hline 35 & $F-33$ \\
\hline 36 & $F-34$ \\
\hline $37-39$ & $F=3$ \\
\hline $40-42$ & $F-38$ \\
\hline 43 & $=41$ \\
\hline $44-47$ & $F \cdot 42$ \\
\hline $48-50$ & $F-46$ \\
\hline $51-54$ & F- 4 \\
\hline $55-56$ & $\mathrm{~F}-53$ \\
\hline $57-60$ & \\
\hline $6 L-65$ & \\
\hline
\end{tabular}

Notebock App.

$=-4$

$F=7$

$F-11$

$=-19$

$F-26$

$F-29$

$F-30$

$416 / 98=$

$4 / 8 / 98$

4) भ 198

$4 / 16 / 98-4 / 17 / 98$

$4 / 21 / 98-4 / 22 / 98$

$4 / 24 / 98$

$4 1 2 8 \longdiv { 9 8 - 4 / 2 9 / 9 8 }$

$4 / 30 / 98-5 / 1 / 98$

$5 / 4198-5 / 6 / 98$

$5 / 12 / 98-5 / 4 / 28$

$5 / 19 / 98$

$5 / 20 / 98-5 / 27 / 98$ $r-33$

$=-35$

$=-38$

F. 41

F.42

$F-46$

F- 49

F-53

F.5S

F 59 


\section{Content}

Research/Technical

Descriptions(s)/

$4 a-R 2$

$$
8 a^{-2} 3
$$

$\mathrm{New}_{\mathrm{MnO}}$ - Cistazdard

Reveat Tesk3i-1b

$4 a-R_{5}$

Exo. Ke jeat-3a-R2b

Exp.Repeat-2a-R3b $4 a-27$ $4 a-R 4$

Exp.4binstructions. $4 b-k_{1}$ $4 b-R_{2}$ $4 a-R 6$ $4 a-R 8$ $4 b-R 5$ $4 b-R 6$

MATEX SPIKE STUOK
Inclusive Dates

$\frac{5-25-95-5-29-98}{6-1-78-6-4-98}$

$\frac{6-1-78-6-4-98}{6-1-98}$

$6-10-98-6-11-98$

$6-15-98-6-19-98$

$6-23-18-6-24-98$ $6-25-98-6-26-98$ $7-7-98-7-10 / 98$ $7-14-98-7-16-98$ $8-10-98$

$8-11-98-8-12-98$

$8-13-98-8-14-98$

$8-17-98-8-20-98$

$8-25-98-8-26-98$

$8-26-98-8-28-98$

$8-31-98-9-2-98$

$9-8-98-9-10-98$
Notebrok App.

Pages Pages

$66-69$ F 64

$70-73$ F- 68

$74 \quad F-72$

$75-77 \quad F-73$

$78-81 \quad=-76$

$82-84 \quad F-81$

$85-26 \quad F-84$

$87-90 \quad F-86$

$91-94 \quad F .90$

$95-97 \quad F-94$

$98-101 \quad F-97$

$102-105$ F-102

$106-10980106$ $110-113$ F 111

$115-7 \$ 119715$

$120-124 \quad F-121$

$126-127 \quad F-126$ 


\section{Content}

Research/Technical Descriptions(s)!

Inclusive Dates

Deschiplons(s)

$\bar{\square}$

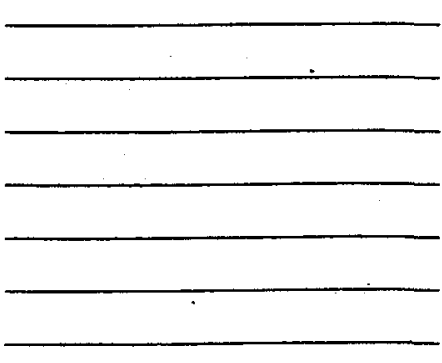

\section{Preparation of Calibration Standards}

prupared o/ /14/98 by K. MECacke-

Source:

J.T. Baker PURE TCE $1.456 \mathrm{~g} / \mathrm{mL}$

Prepare 1000 ppm STOCK Solution

Add 17.2 $\mu \mathrm{L}$ PURE TCE to $25 \mathrm{~mL}$ Flask and fill to volume with hexane.

(Weigh and record syringe when full and then when empty)

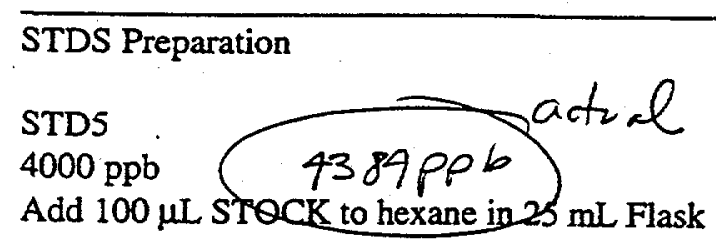

STD4

$1000 \mathrm{ppb}$

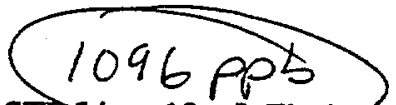

Add $2.5 \mathrm{~mL}$ of the STDSinto $10 \mathrm{~mL}$ Flask and fill to volume with hexane

STD3

$200 \mathrm{ppb}$

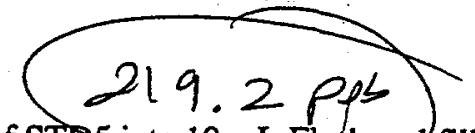

Add $0.5 \mathrm{~mL}$ of STDSinto $10 \mathrm{~mL}$ Flask and fill to volume with hexane

STD2

$100 \mathrm{ppb}$

109.6 pps

Add $0.25 \mathrm{~mL}$ of STD5 into TO mL.Flask and hill to volume with hexane

STD 1

$10 \mathrm{ppb}$

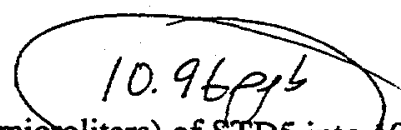

Add $0.025 \mathrm{~mL}$ ( 25 microliters) of STD5 into $10 \mathrm{~mL}$ Flask and fill to volume with hexane

Place these standards in vials for storage in the 211 Freezer

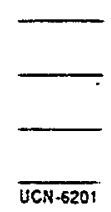

$17.2 \mathrm{~d}$.

syringet

TCE

sisinge

$=14.3559$

$18.82 \mu L$

actuals atted 
Subject Task 2a Exporiment-1

Task 2a Experiment Descriptions
INEEL TAN -Site Chemox Treatability Study
Task Number: 2a
Purpose/Scope:

The following laboratory experiments will evaluate the performance of the test reactors pianned for use during the treatability reaction studies. In particular, the amount of TCE expected to be lost from the reactor system will be quantified via a mass balance approach.

\section{Experiment 2a-1. Evaluation of the nubber septum to reduce TCE losses.}

(To be conducted at ORNLESD)

One or more of the reactor sampling ports may be fitted with a thick rubber septum for the purpose of sample collection via a wide bore needle. Thus, this experiment will assess how well the fitting between the septum and the ground glass port opening minimizes TCE losses. The effect of performing repeated aliquot sampling through the septum will also be evaluated.

To focus this experiment on septum performance only, a $500 \mathrm{~mL}$ reactor with muitiple port openings will not be used here. Instead, $2100 \mathrm{~mL}$ erlenmeyer flask or equivalent having only a single $24 / 40$ std taper opening will be used. This experiment will be conducted at room temperature.

$$
\begin{aligned}
& \text { सrifla } \\
& 660 \mathrm{~mL}
\end{aligned}
$$

1. A $100 \mathrm{mg} / \mathrm{L}$ aqueous TCE solution ( $=200 \mathrm{~mL}$ ) will be prepared and allowed to equilibrate for at least 30 minutes. The solution will be prepared in a Tedlar Bag using DI water and pure TCE. Measure the mass of spiking syringe filled and then after spiking to record the total TCE mass added to the reactor (a QC check on the initial TCE analysis). Information regarding the preparation of the spiking solution will be recorded in the laboratory research notebook or equivalent (project data sheets).

2. Dispense the solution into 2 tared test containers, re-weigh and record the mass of TCE spike solution added to each. Duplicate $0.5 \mathrm{~mL}$ samples of the spike solution will be collected immediately before the septa is added to the test containers in order to determine the initial TCE concentration.

3. The aliquot samples will be added to a pre-weighed sample container holding a known volume of hexane. Each sample container will be weighed again after sample addition to determine the volume of sample added. (A calibration check of the gravimetric scale will be performed each day of use.) All such exuracts will be placed on a horizontal shaker for 30 minutes then diluted as appropriate for G.C. analysis. Store the extracts at $4^{\circ} \mathrm{C}$ until G.C. analysis.

4. Record the time that these duplicate samples are collected and the septum is placed onto each container. (Complete zero headspace conditions cannot be achieved here since excess water cannot be expelled from the containers as the septa are applied.)

S.R. Cline Last Updated: 01/21/98

Filename: 2a-Experimental Descriptions.doc

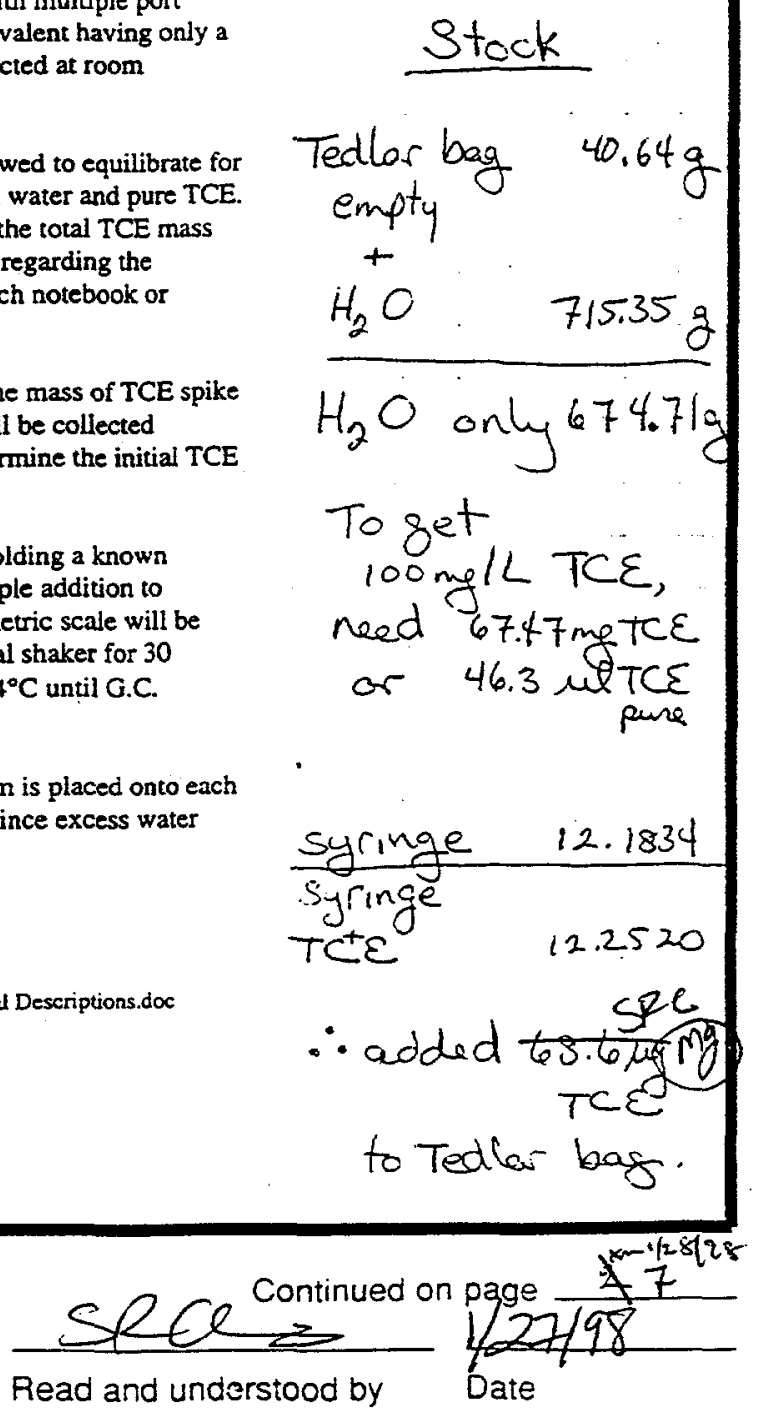


Subject Task 2 a Expariment - 1

2

Date

21

1998

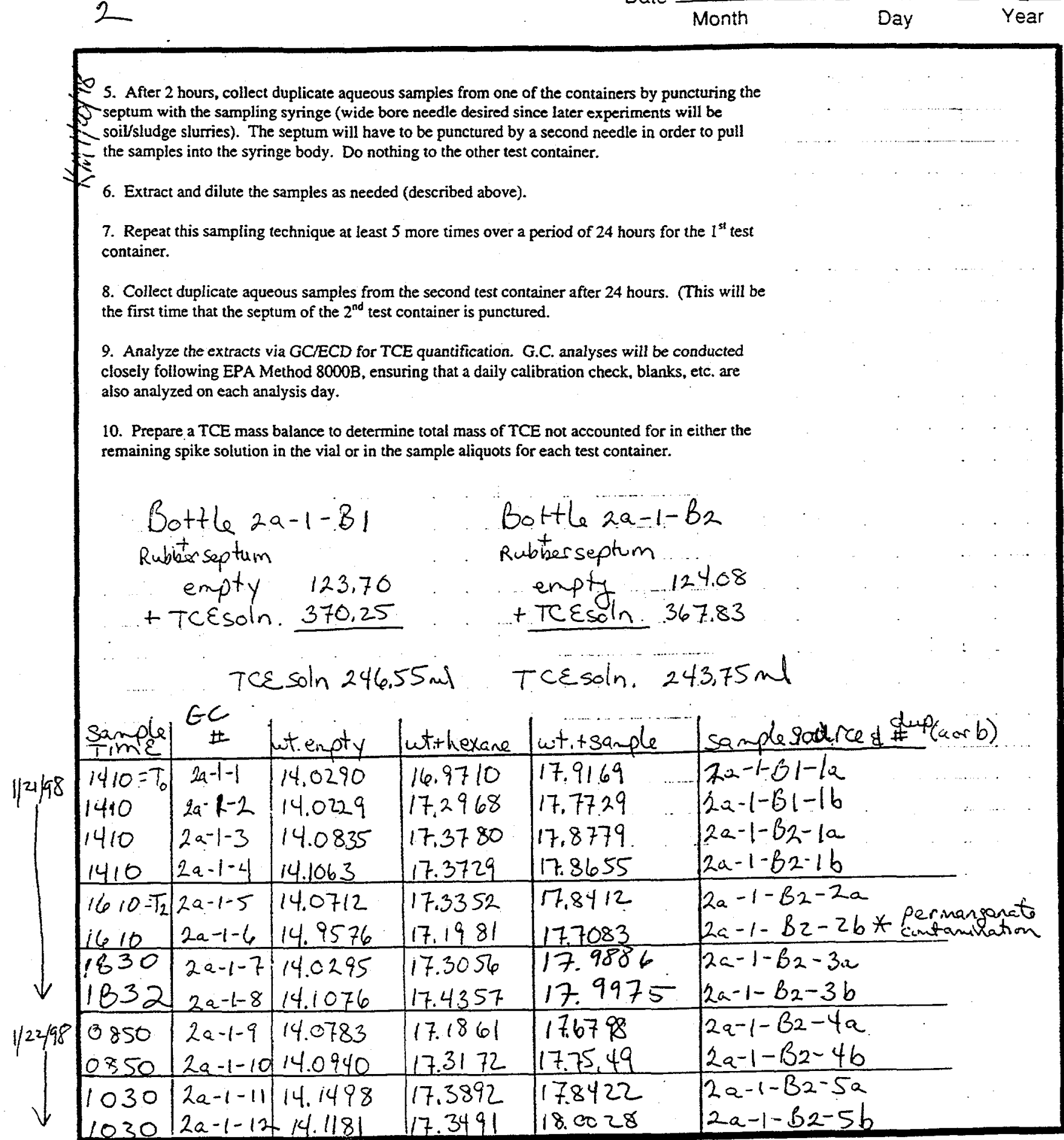

K.Mccracken

Recorded by

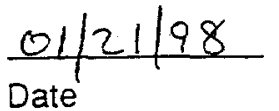

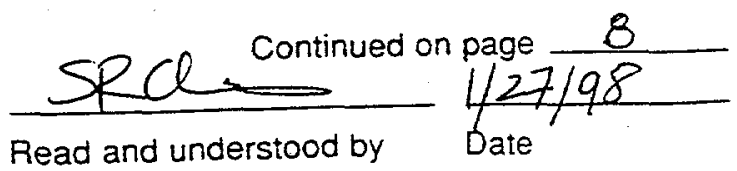

Read and understood by
Date 
su ct Task za Experiment-1

Date $\begin{array}{ccc}01 & 21 & 1998 \\ \text { Month } & \text { Day } & \text { Year }\end{array}$

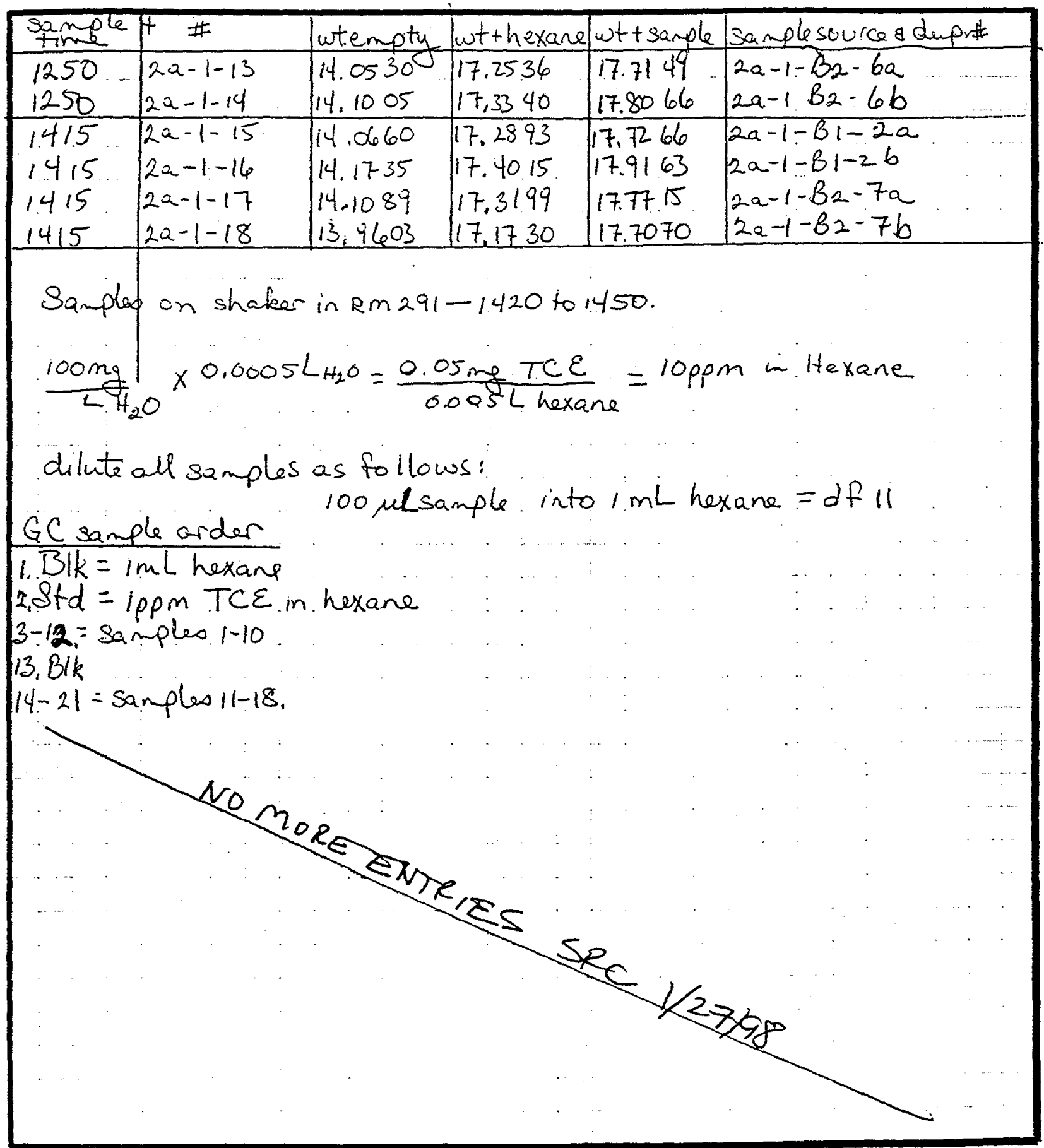

$\frac{K \cdot n C C \text { Cacken }}{\text { Recorded by }} \frac{01 / 21,98}{\text { Date }}$

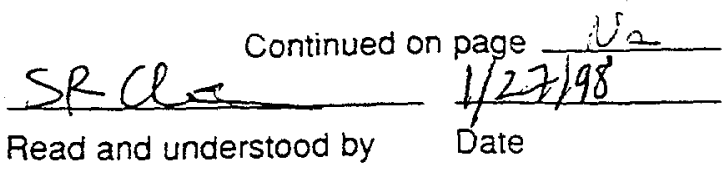


Subject Exporiment $2 a-2$

\begin{tabular}{|c|c|c|}
\hline & 01 & 28 \\
\hline & Month & Day \\
\hline
\end{tabular}

Experiment $2 \mathrm{a}-2$. Evaluation of the pressure relief fitting to minimize and quantify TCE losses (To be conducted at ORNL/ESD)

A shakedown experiment already conducted has shown that a thin layer of Parafilm $M$ material (wax based) is easily ruptured when placed on an otherwise sealed container in less time than required to remove a rubber septum when a constant volume and rate of air is added to the container. However, a high degree of TCE diffusion is suspected through this type of material. A similar test was performed using aluminum foil as the thin film covering the bottom of the adapter. While desirable in the fact that TCE diffusion is likely minimal, the aluminum foil possessed a great deal of tensile strength in this configuration and could not be easily ruptured by pressurization of an erlenmeyer flask. For the purpose of this experiment four (4) different conditions will be evaluated: (a) no thin film. (b) Parafilm M, (c) aluminum foil punctured with a single pinhole (to reduce tensile strength), and (d) DuraSea ${ }^{\text {TM }}$, a solvent resistant LDPE film. Erienmeyer flasks ( $125 \mathrm{~mL}$ ) or equivalent containers having a 24/40 std. Taper opening will be used in this experiment. There will not be an attempt to pressurize these containers. The "no thin film" set-up will represent the ruptured film case. This experiment will be conducted at room temperature.

1. Prepare $24 / 40$ std. Taper adapters as described above (a-d), securing the edges of each thin film by addition of a Teflon sleeve onto the ground glass fitting.

2. Assemble the ORBO-32 Tubes. Two ORBO-32 tubes will be used in series for each container in the event that the TCE adsorption capacity of the first mbe is exceeded. Using Pliers, break the ends of two ORBO tubes. Smooth the broken ends with a file and connect them in series using tygon tubing. Orient them such that the " $\mathrm{A}$ " charcoal bed of each tube is first in line. vaigh bottlest pelief fitting essimblies before after uddition of [" $\mathrm{A}$ " is the larger of the two (100 $\mathrm{mg}$ charcoal), "B" contains $50 \mathrm{mg}$ charcoal.] NOTE: STORE THE OPENED ORBO TUBES OUTSIDE OF THE LABORATORY FUME HOODS. THE HOODS LIKELY HAVE THE GREATEST POTENTIAL FOR "CONTAMINATING" THE TUBES WITH TCE AND OTHER VOCs.

$$
1200 \mathrm{~mL}
$$

3. A $100 \mathrm{mg} / \mathrm{L}$ agueous TCE solution (=tog $\mathrm{mL}$ ) will be prepared in a Tedlar bag and allowed to equilibrate forestion to being distributed into each container. (Preparing only one spiking solution, allows for each test set-up to have the same initial conditions). Measure the mass of spiking syringe when filled and then after spiking to record the total TCE mass added to the reactor (a QC check on the initial TCE analysis). Information regarding the preparation of the spiking solution will be recorded in the laboratory research notebook or equivalent (project data sheets).

4. Duplicate $0.5 \mathrm{~mL}$ samples of the spike solution will be collected immediately before the containers are seajed in order to determine the initial TCE concentration.

5. The duplicate aliquot samples will be added to pre-weighed sample containers holding a known volume of hexane. Each sample container will be weighed again after sample addition to determine the volume of sample added. (A calibration check of the gravimetric scale will be

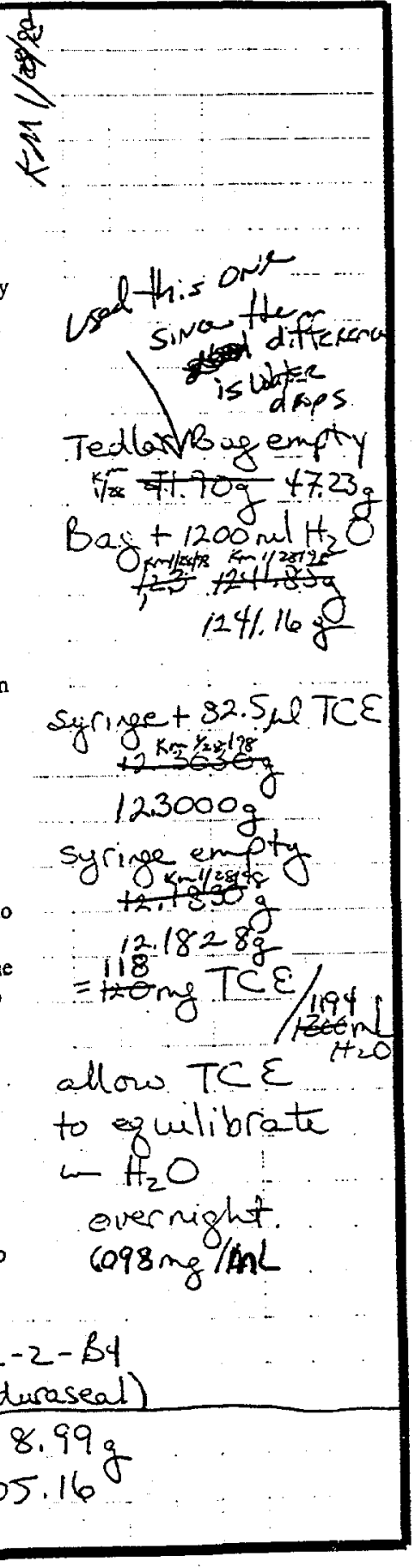

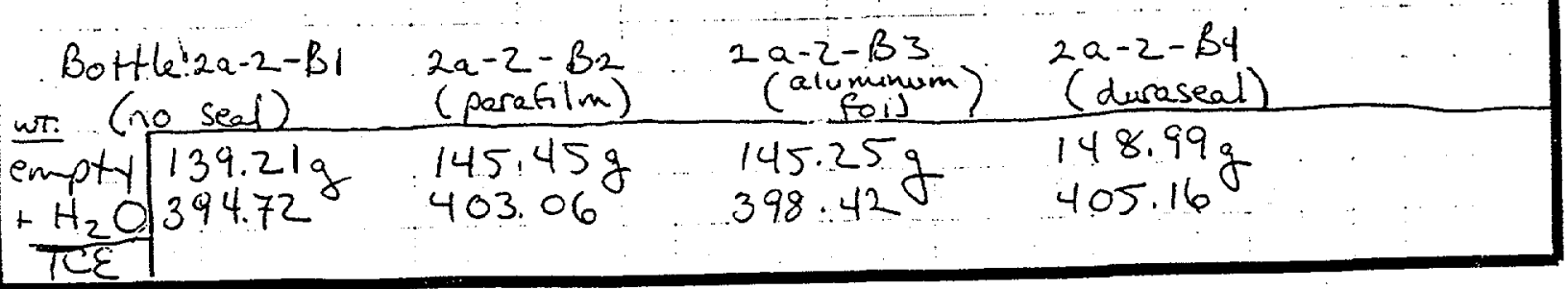

\section{K.MCCacker}

Recorded by

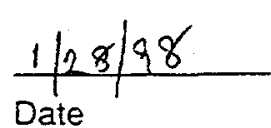

$\frac{1 / 28 / 98}{\text { Date }}$

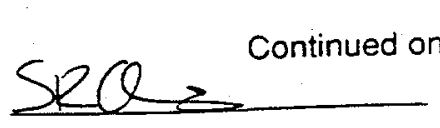

Read and understood by
2) $3 1 \longdiv { 9 8 }$

Date 
Subject Experiment $2 a-2$

Date $\frac{01}{\text { Month }} 28-2919 \frac{98}{\text { Year }}$

performed each day of use.) All such extracts will be placed on a horizontal shaker for 30 minutes. Store the extracts at $4^{\circ} \mathrm{C}$ until G.C. analysis.

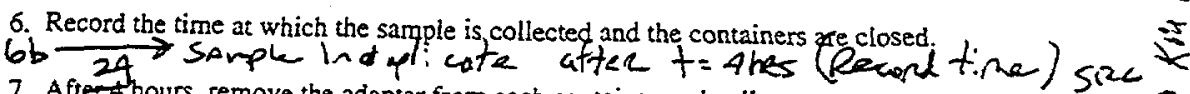

7. Aftert hours, remove the adapter from each container and collect an aqueous sample $(0.5 \quad 2 / 3 / 98$

$\mathrm{mL}$ ) Extract and dilute the samples as needed for G.C. analysis for eventual analysis of the

remaining TCE concentration in the solution. Store the extracts at $4^{\circ} \mathrm{C}$ until G.C. analysis.

8. For each container, separate the contents of each charcoal bed into separate vials pre-weighed with a known volume of hexane then reweigh the vials to determine the mass of charcoal present.

9. Extract these samples for 30 minutes and dilute as needed for G.C. analysis as done for the aqueous aliquots.

10. Analyze the extracts via GCIECD for TCE quantification. G.C. analyses will be conducted closely following EPA Method $8000 \mathrm{~B}$, ensuring that a daily calibration check, blanks, etc. are also analyzed on each analysis day. Formal data packages, as outlined in Section 2.4.3.3 of the Chapter 2 Implementation Plan will not be prepared for this experiment.

11. Prepare a TCE mass balance on each container to determine which thin film configuration best minimized the mass of TCE that escaped from the reaction chamber. Also place any waste materials generated from the experiment in the appropriate satellite accumulation area.

$$
2 a-2-81 \quad \frac{T C E \text { soln }}{2 a-2-B z} 2 a-2-B 3 \quad 2 a-2-\beta 4
$$

\begin{tabular}{|c|c|c|c|c|c|c|}
\hline $\begin{array}{l}\text { Sample } \\
\text { Time }\end{array}$ & $\begin{array}{c}G C \\
\#\end{array}$ & $\begin{array}{l}\text { wt. } \\
\text { empty }\end{array}$ & $\begin{array}{l}\text { wt } \\
+ \text { hexane }\end{array}$ & $\begin{array}{l}\text { wt. } \\
\text { + Sample }\end{array}$ & $\begin{array}{l}\text { Sample source } \\
\text { idupl. }\end{array}$ & $\begin{array}{l}G C \text { (w/hane) } \\
\text { dilution }\end{array}$ \\
\hline 1140 & 19 & 14.1825 & 17.4569 & 17.9488 & $2 a-2-B i-1 a$ & 101 \\
\hline 11.40 & 20 & 14.0933 & 17.4081 & 17.9004 & $2 a-2-b_{1}-1 b$ & \\
\hline 11.42 & 21. & 14.1210 & 17.4194 & 17.9159 & $2 a \cdot 2-B 2-1 a$ & \\
\hline 11.42 & 22 & 13.9452 & 17.2270 & 17.7236 & $2 a-2-32-16$ & \\
\hline 1144 & 23 & 14.0964 & 17.3710 & 17.8675 & $2 a-2-33-1 a$ & \\
\hline 1144 & 24 & 14.0570 & 17.3140 & 17.8110 & $2 a-2-B_{3}-16$ & \\
\hline 1146 & 25 & 14.0668 & 17.3308 & 17.8269 & $2 a-2-B y-1 a$ & \\
\hline 1146 & 26 & 14.1199 & 17.3664 & 17.8642 & $2 a-2-B y-1 b$ & \\
\hline 1545 & 27 & 14.2159 & 17.4678 & 17.9660 & $2 a-2-B,-2 a$ & \\
\hline 45 & 28 & 14.1485 & 17.4326 & 17.9282 & $2 a-2-6 !-2 b$ & \\
\hline 1546 & 29 & 14.0122 & 17.2946 & 17.7933 & $2 a-2-6 z-2 a$ & \\
\hline 1546 & 30 & $1 / 4899$ & 117.4559 & 1179500 & $2 a-2-B_{2}-2 b$ & $\infty$ \\
\hline
\end{tabular}

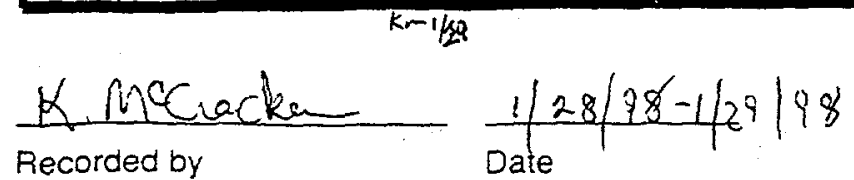

Recorded by

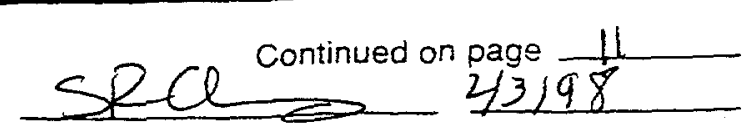

Read and understood by Date 
Subject Expezument za-2

Date $\begin{array}{ccc}01 & 29 & 1998 \\ \text { Month } & \text { Day } & \\ \text { Year }\end{array}$

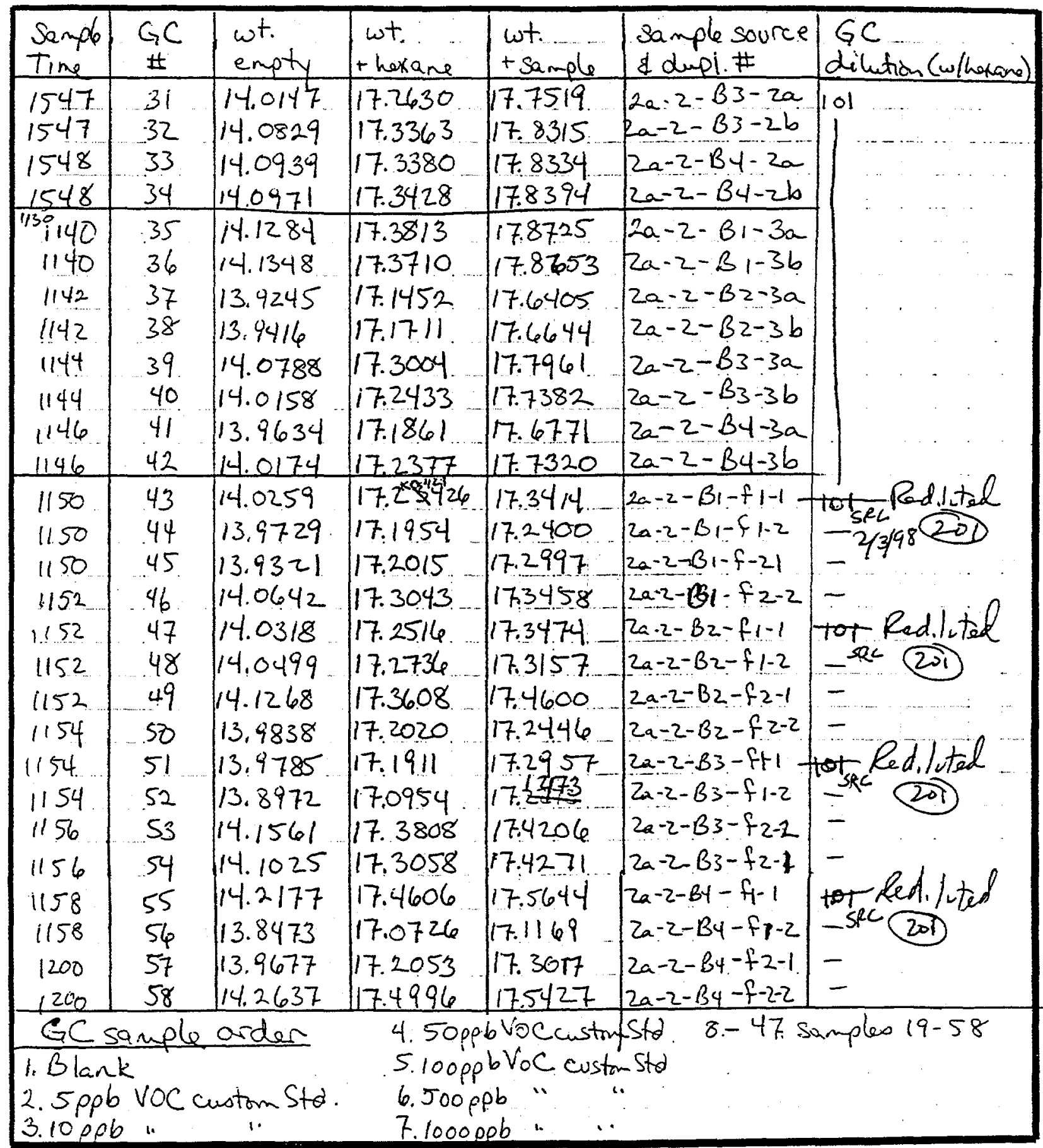

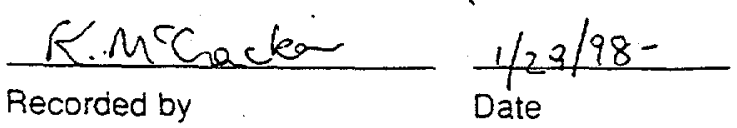

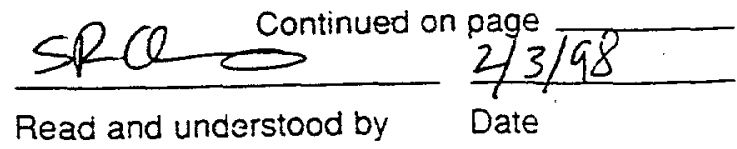


Subject Experiment $2 a-2$

Date $\frac{02}{\text { Month }} \quad \frac{02}{\text { Day }} 19 \frac{98}{\text { Year }}$

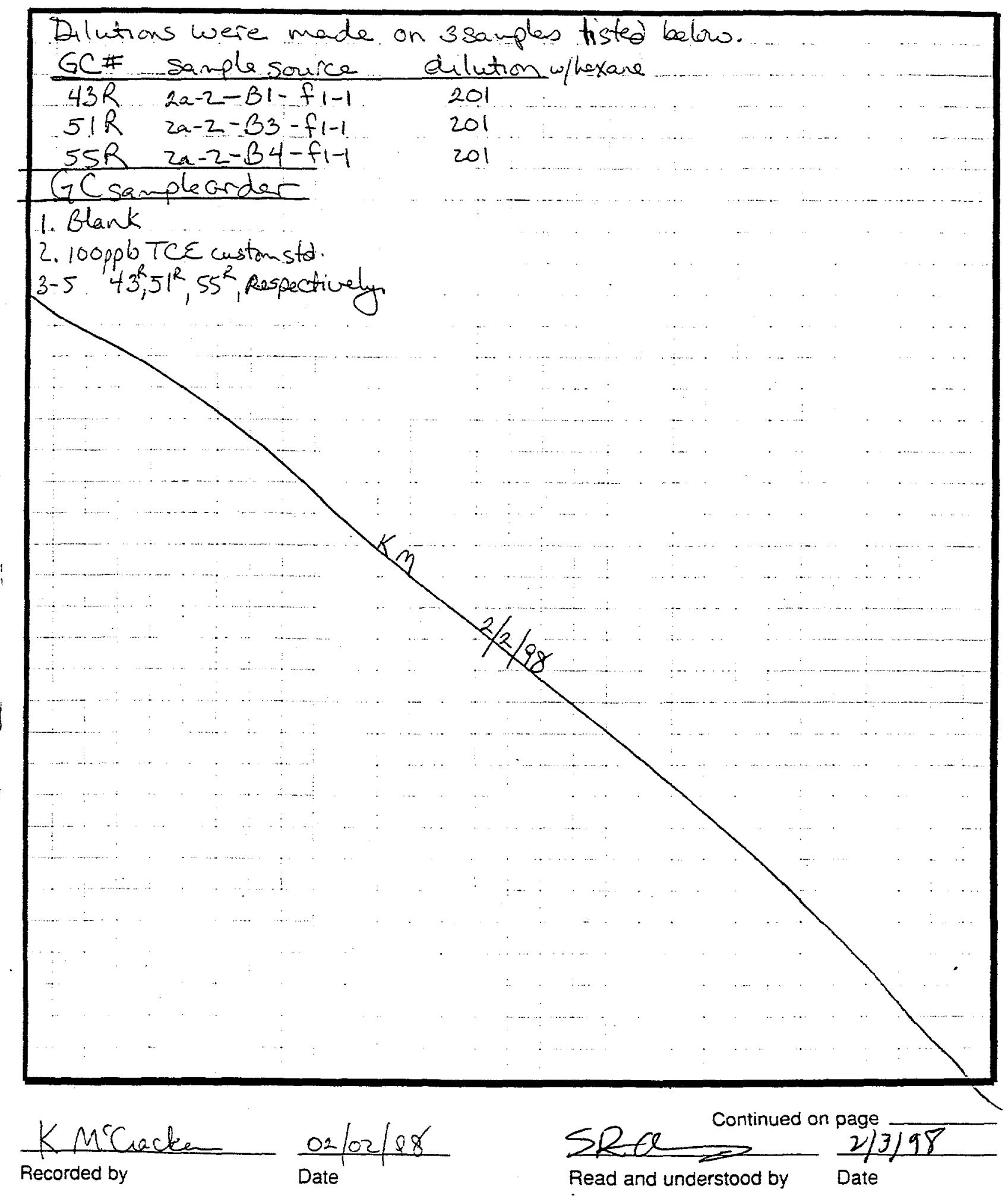


Subject Prepration of Calibration Standards

\begin{tabular}{|c|c|c|}
\hline Date & 01 & 30 \\
\hline & Month & Day \\
\hline
\end{tabular}

\section{Preparation of Calibration Standards (From VOC custom mixes)}

Source:

Supelco Custom Mix Standard, $200 \mathrm{mg} / \mathrm{L}$ each Compound

DATE PREPARED 1/30/98 WH

LOT No. LA 73307

Prepare $10 \mathrm{mg} / \mathrm{L}$ working STOCK Solution

Add $0.5 \mathrm{~mL}$ of Custom Mix (Ampule) to $10 \mathrm{~mL}$ Flask filled to volume with hexane

(Weigh and record syringe when full and then when empty)

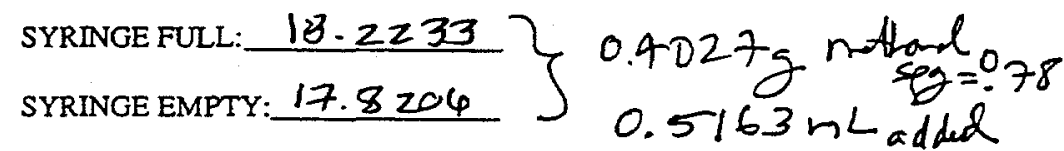

Preparation of Calibration Standards $\therefore(.5163)(200 \mathrm{Ppm})=(10 \mathrm{~mL})($ Ypp $)$
$1000 \mathrm{ppb}$

$1000 \mathrm{ppb}$

Add $2.5 \mathrm{~mL}$ STOCK Solution to hexane in $25 \mathrm{~mL}$ Flask $1033 \mathrm{ppb}$

$500 \mathrm{ppb}$

Add $5 \mathrm{~mL}$ of 1000 PPB STD into $10 \mathrm{~mL}$ Flask and fill to volyme thexare

$100 \mathrm{ppb}$

$516.3 \mathrm{PPb}$

Add $1 \mathrm{~mL} 1000$ PPB STD into $10 \mathrm{~mL}$ Flask and fill to volume wh hexane

$50 \mathrm{ppb}$

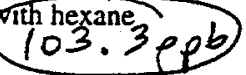

Add 0.5

$10 \mathrm{ppb}$

51.63906

Add $0.1 \mathrm{~mL}$ of 1000 PPB STD into $10 \mathrm{~mL}$ Flask and fill to yotume with hiexane

$5 \mathrm{ppb}$

$10.33 p^{6}$

Add $0.05 \mathrm{~mL}(50 \mu \mathrm{L})$ of 1000 PPB STD into $10 \mathrm{~mL}$ Flask and mforotum with hexane

Place these standards in vials for storage in the 211 Freezer.
Place the Certificate of Analysis into the Laboratory Research Notebook.

$$
\text { prepared by William Holden. }
$$

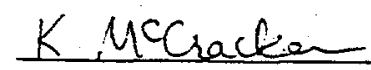

Recorded by i) $30 / 98$

Date

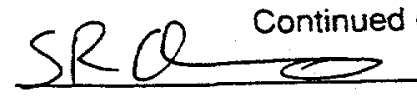

Read and understood by
$1 / 3 0 \longdiv { 9 8 }$ 
Subject Exparimet $2 a-3$

Date $\frac{2}{\text { Month }} \quad \frac{13}{\text { Day }} 19 \frac{98}{\text { Year }}$

Experiment 2a-3. Overall performance of the test reactor

(To be conducted at ORNL/ESD)

In this experiment a complete reactor will be set up using the most optimal component(s) from the pravious Task 2a experiments described above. To be consistent, a $100 \mathrm{mg} L$ TCE spike solution will be used here as well. This experiment will be conducted at approximately $12-15^{\circ} \mathrm{C}$.

1. Set up a gias Kettle reactor, ensuring that Teflon sleeves are fitted onto each of the glass adapters to be uset The top of each adapter will be sealed (Teflon stopper) during spiking and equilibration to min pize the mass of TCE lost.

2. Remove one of the stoppers and fill the reactor with distilled water, minimizing the headspace volume inside of the reacto. The volume created by the "convex" shaped lid is also filled. A record of the DI water volume ydded will be maintained.

3. Spike the reactor with TCE, Dested Concentration: $100 \mathrm{mg} / \mathrm{L}$

(Add a mass of pure phase TCE (dens) of $1.456 \mathrm{~g} / \mathrm{mL}$ ) to the liquid volume inside of the reactor that will yield a TCE solution of $\$ O \mathrm{mg} / \mathrm{L}$. Measure the mass of the spiking syringe when filled and then after spiking to record to total TCE mass added to the reactor (a QC check on the initial TCE analysis). Information regatding the preparation of the spiking solution will be recorded in the laboratory research notebook or exyivalent (project data sheets).

4. Replace the removed stopper back onto the adapter and allow the solution to equilibrate at least overnight in an incubator maintained at $12-60$ (R)eord the equilibration period and temperature).

$11-13^{\circ} \mathrm{C}$

5. During equilibration period. prepare an ORBO-32 assembly in tandard taper adapter and cover the bottom end of the adapter with the selected thin film [parantox Xnly one desortion tube will be used. Since this paricular experiment will not be conducte yefler pressurization, only one adapter will need to be fitted as a pressure relief adapter.

STORE UN-SEALED ORBO TUBES OUTSIDE OF THE LABORATORY IUVA NOODS.

THE HOODS LIKELY HAVE THE GREATEST POTENTLAL FOR "CONTANOTIMG"

THE TUBES WITH TCE AND OTHER YOCS.

6. After equilibration, collect duplicare aqueous samples from the reactor (from the glass dapter that is sealed with a stopper) The aliquot samples will be added to pre-weighed sample containers holding a known volume of hexane. Each sample container will be weighed again after sample addition to determine the volume of sample added. (A calibration check of the

forizontal shaker for 30 minutes. Store the extracts at $4^{\circ} \mathrm{C}$ until G.C. analysis.

7. Replace one of the adapters sealed with a stopper with the one fitted with the charcoal desorption tube assembly from Step 5, Record the time the samples in the step above are collected and the desorption tube is added as Start Time=0.

Kettle reactor wt. 506.699

Reactor $+\mathrm{H}_{2} \mathrm{O}$ 957.42

water volume $450.73 \mathrm{ml}$

$\frac{100 \mathrm{mg}}{1000 \mathrm{ml}} \cdot 450.7 \mathrm{ml}=45.07 \mathrm{mg}$

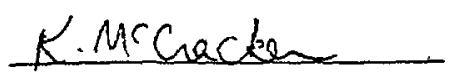

Recorded by

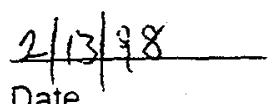

Date

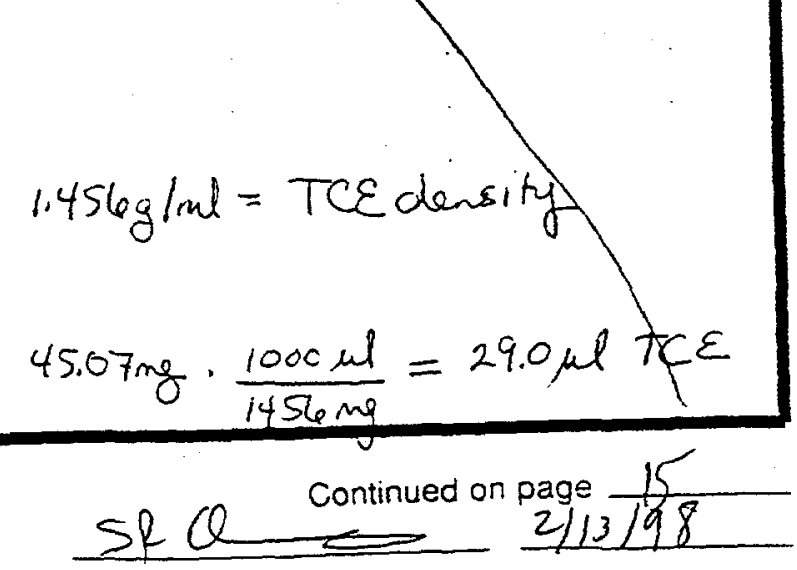

Read and understood by Date 
Subject Experiment $2 a-3$

Date $\frac{2}{\text { Month }} \frac{13}{1998}$

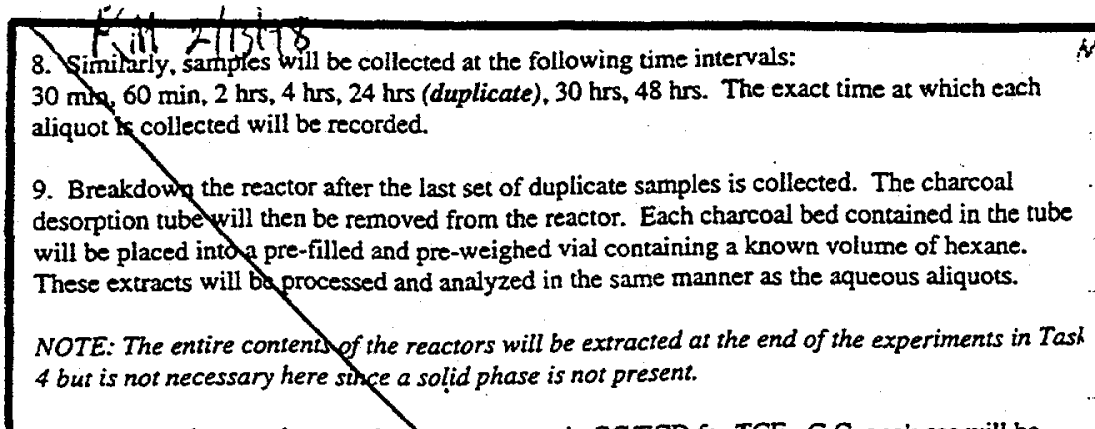

10. Analyze the samples and charctal extracts via GC/ECD for TCE. G.C. analyses will be conducted closely following EPA Method $8000 \mathrm{~B}$, ensuring that a daily calibration check, blanks etc. are also analyzed on each analysis d4. Formal data packages, us outlined in Section 2.4.3.2 of the Chapter 2 Implementation Plan will hot be prepared for this experiment.

11. Perform a mass balance for the reactor, taking sample aliquot volumes, initial concentrations, etc. into account to determine the deerall reactor performance to maintain gastight conditions. Also place any waste materials gentated from the experiment in the appropriate satellite accumulation area.

$$
\begin{aligned}
& \text { v } \\
& \text { syringe }+T C E \\
& 14.3715 \mathrm{~g} \\
& \text { syunge after } \\
& 14.32729 \\
& 44.3 \mathrm{mg} T \mathrm{CE} \\
& \text { added. } \\
& \text { to } \\
& \text { Reactor } \\
& \text { on } 2 / 13 / 98 \text { \& } 1450 \text {. }
\end{aligned}
$$

Recctor + a queous TCE Dlaced incubator i $1505, \mathrm{Rm}_{377}$. Incubator temp $=11.5^{\circ} \mathrm{C}$.

$-1 / 6 / 98$

prepare single or Bo Tule for use Reactor

cover inside end of adapter w/parafilm sodd teflon slowe.

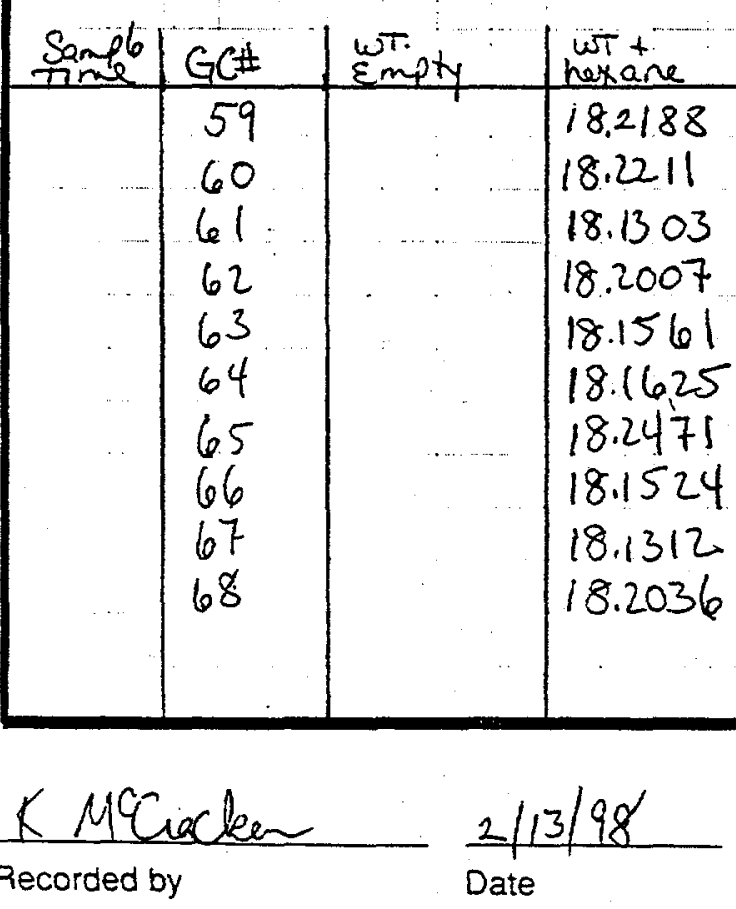

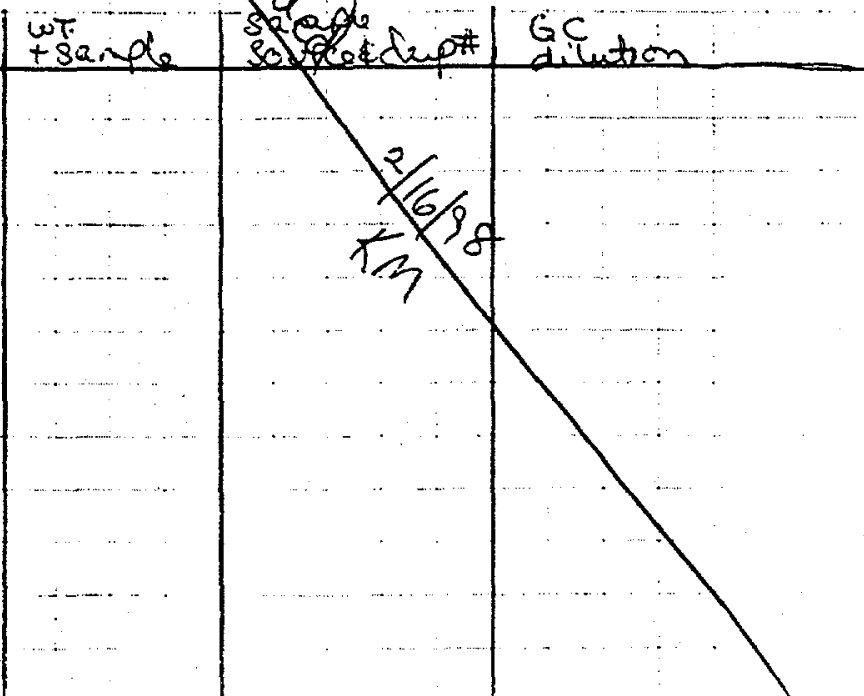


Subject Experiment $2 b-1$

Date $\begin{array}{ccc}02 & 17 & 1998 \\ \text { Month } & \text { Day } & \text { Year }\end{array}$

2.2 Determine Time Required for Hexane Extraction of TCE from Organic Sludge, Sediment, and Basalt (Task 2b)

A 30 minute extraction time period was used for the Task 2 a Reactor Development experiments involving only aqueous TCE solutions; however, this task will help determine what the most effective extraction period is for each medium being evaluated: groundwater or groundwater with

Zrushed basalt, aggregate basait (following experiment $2 c-1$ ), sludge, or sediment at a 4:1

Diquid/Solid ratio. (Note that the hexane extraction period for aggregate basait cannot be

Levaluated until after Task $2 c$. "TCE equilibration with aggregate basalt" is completed.) In this

batch experiment, several aliquot samples will be taken with time as a TCE spiked mixture is

Theing extracted with hexane. Samples will be taken of both the solvent and aqueous phases. The

aqueous phase will be further evaluated by determining the fraction of TCE present in both the

Yiiquid and solid phases at each time interval. All media to be used in this experiment will be

Zoven-dried. and the groundwater will be sparged to remove any initial TCE in order to conduct this test under controlled laboratory conditions. Each media type will be evaluated in duplicate. For these experiments, only a single initial TCE concentration will evaluated: $1 \mathrm{mg} / \mathrm{L}$ TCE for the reactive zone media and $100 \mathrm{mg} / \mathrm{L}$ TCE for the hot spot media. The contaminant

equilibration period will be conducted at $12-15^{\circ} \mathrm{C}$; however, the hexane extraction portion of the experiment will be conducted at room temperature.

Experiment 2b-1. Hexane Extraction Test for the Reactive Zone Media

(To be conducted at ORNLESD)

1. Prepare a STOCK (Saturated) TCE solution ( $2000 \mathrm{mg} / \mathrm{L}$ ) by adding $100 \mu \mathrm{L}$ of Pure TCE into a $12 \mathrm{~mL}$ VOA vial filled to volume with DI Water and allow to equilibrate ovemight at roor temperature. (Use of a STOCK solution rather than pure phase TCE to prepare the spiking solution affords better accuracy in obtaining the target concentration.)

2. Obtain the tare weight of the container to be used to prepare the spike solution (tedlar bag, flask, or equivalent). Fill with approximately $300 \mathrm{~mL}$ of groundwater from TAN-40 previously sparged of any residual TCE $8 \%$ other VOCs that may have been present. (Properly indicate usage of this media in the treatability study tracking logbook.). By gravimetric methods, determine the amount of groundwater added to the container, and then place in an environmental chamber at $12-15^{\circ} \mathrm{C}$ overnight. (A calibration check of the gravinetric seale will be performed each day of use.)

3. After temperature equilibration of the groundwater, remove the container from the incubator and add the appropriate quantity of the Saturated STOCK TCE solution to produce a TCE spike concentration of $1.0 \mathrm{mg} / \mathrm{L}$. (Reactive zone media will only be spiked at 0.1 and $1 \mathrm{mg} / \mathrm{L}$ TCE during the Task 4 degradation studies.) This solution can be mixed and.equilibrated within a few minutes.

4. After mixing, obtain duplicate aqueous samples $(-3 \mathrm{~mL})$ of the spike solution to obtain the initial TCE concentration of the spiked groundwater. The duplicate aliquot samples will be added to pre-weighed sample containers holding a known volume of hexane $(=S \mathrm{Sil})$. Each sample container will be weighed again after sample addition to deternine the actual volume of

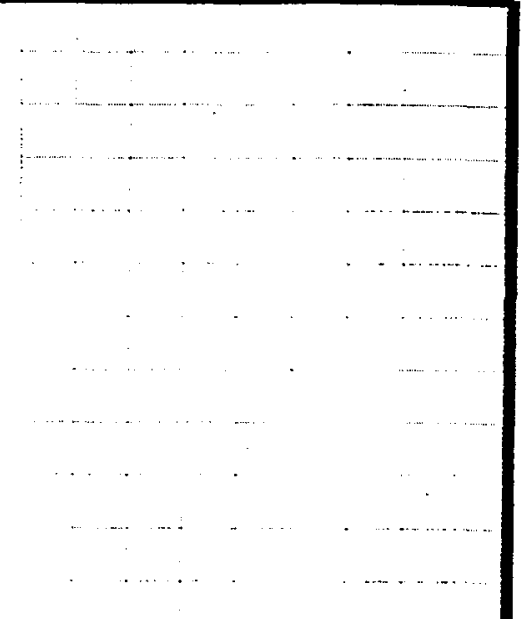

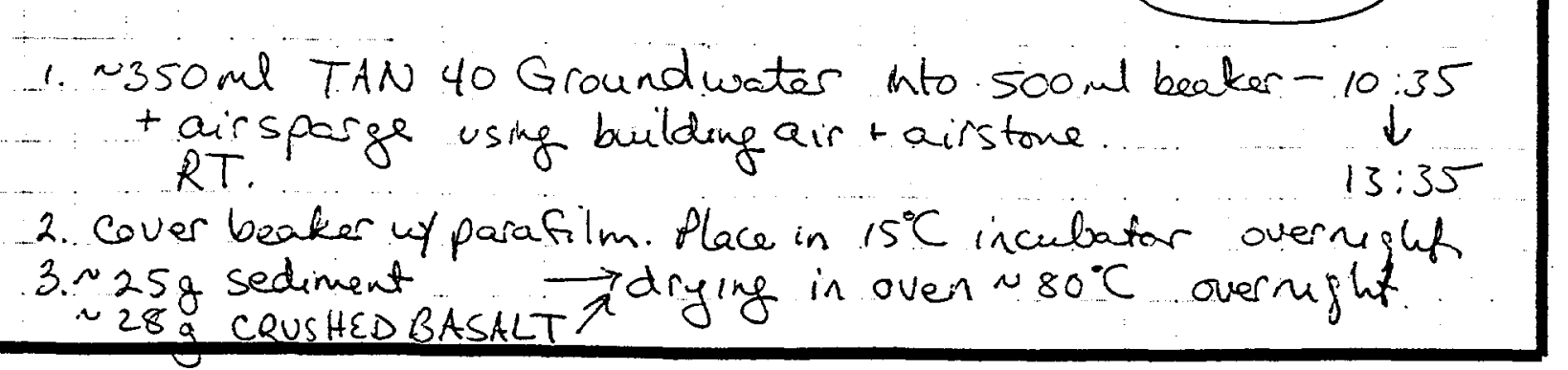

RiMquacke

Recorded by

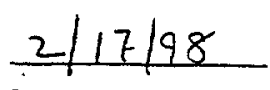

Date

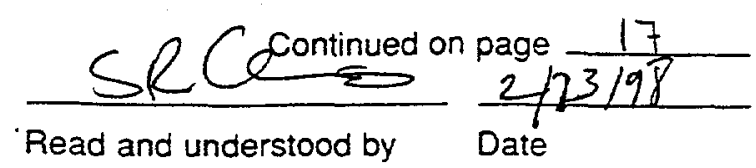


Subject Experiment $2 b-1$

Date $\frac{02}{\text { Month }} \frac{17}{\text { Day }} \frac{1998}{\text { Year }}$

sample added. These extracts will be placed on a honzontal shaker tor su munutes. sture uie exuracts at $4^{\circ} \mathrm{C}$ until G.C. analysis.

95. Obtain the tare weight of six (6) $40 \mathrm{~mL}$ VOA vials. Add approximately $10 \mathrm{~g}$ of crushed (< $4 / 8^{\prime \prime}$ size fraction) basalt to two of these vials, and approximately $10 \mathrm{~g}$ of sediment to two more Sof the vials. These materials should be previously dried to remove any residual TCE that might Thave been present. Re-weigh the vials to determine the exact masses added. (Properly indicate $\{5$

7. Completely fill the remaining volume of the $40 \mathrm{~mL}$ vials with the spiked groundwater, and reweigh each vial to determine the total volume of spike solution added. Record the time each vial is filled and capped. Place the vials on an orbital shaker maintained at $12-15^{\circ} \mathrm{C}$ and allow the spike solution and media (if applicable) to equilibrate overnight.

7. Obtain a tare weight on six empty containers to be used for the hexane extractions ( $125 \mathrm{~mL}$ VOA bottles with Teflon lined caps). Add $40 \mathrm{~mL}$ of hexane to each of these and reweigh.

8. Remove the $40 \mathrm{~mL}$ vials from the shaker/incubator. Pour the entire contents of each $40 \mathrm{~mL}$ vial into a separate $125 \mathrm{~mL}$ extraction bottle. Reweigh each extraction bottle and record the time as "extraction time $=0$ ". (The amount of TCE that mny have been lost during contaminant equilibration will not be directly determined, but would be expected to be approximately the same for each $40 \mathrm{~mL}$ vial.)

9. Place each extraction jar on a horizontal reciprocating shaker at room temperature. Collect 2 $1 \mathrm{~mL}$ aliquot of the hexane layer from each extraction bottle at the following time periods: 5 minutes, 30 minutes, 2 hour, 3hour and 24 hrs. Place these samples directly into a GC Vial (2 $\mathrm{mL}$ ). (Calibrate the piperte used to collect the aliquot) Record the time the sample was collected. Store at $4^{\circ} \mathrm{C}$ until analyzed (no dilution will be necessary). Km Changed sampling hnepts.

10. Also collect (using a disposable syringe with a luer-lok tip) a 6 mL aliquot of the aqueous layer from the extraction bottle at the same time periods used in Step 9: 5 minutes, 30 minutes, 1 hour, 3 hours, and 24 hrs. Dispense $1 / 2$ of the aliquot $\left(-x^{3} \mathrm{~mL}^{\mathrm{mL}}\right.$ ) directly into a into $12 \mathrm{~mL}$ VOA. vial or equivalent that is pre-weighed and pre-filled with hexane $(-5 \mathrm{hL})$. Using a $0.45 \mu \mathrm{m}$ syringe filter, filter the remaining aliquot volume in the syringe ( $k(n L)$ into another $12 \mathrm{~mL}$

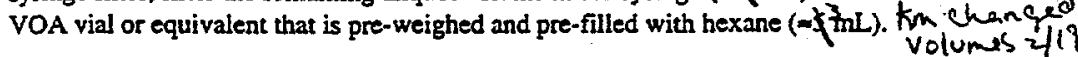

11. Re-weigh each of these $12 \mathrm{~mL}$ VOA vials in the above step to determine the total sample volume added to each. Place these samples on 2 reciprocating shaker for at least 30 minutes. Store these extractions at $4^{\circ} \mathrm{C}$ if not analyzed immediately.

12. Analyze via GCEECD for TCE, diluting if necessary. G.C. analyses will be conducted closely following EPA Method $8000 \mathrm{~B}$, ensuring that a daily calibration check, blanks, etc. are also analyzed on each analysis day. Formal data packages, as outlined in Section 2.4.3.3 of the Chapter 2 Implementation Plan will not be prepared for this experiment.

13. Using the analytical results (TCE in the hexane phase, aqueous phase, and solid phases), select the extraction time period that is most effective and efficient for each media type evaluated. Also place any waste materials generated from the experiment in the appropriate satellite accumulation area.

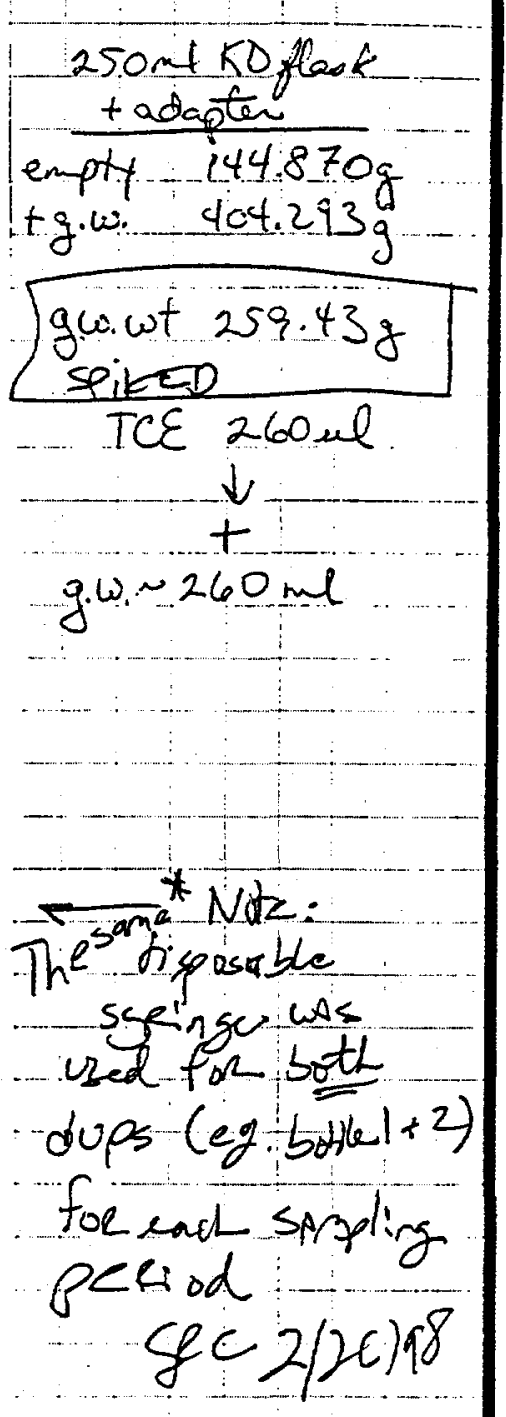

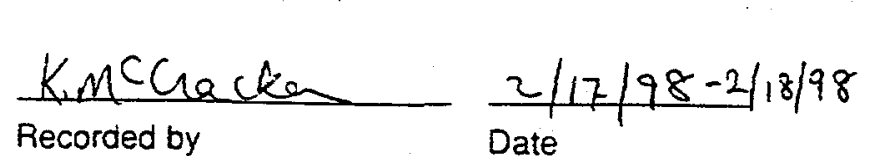

Recorded by
Date

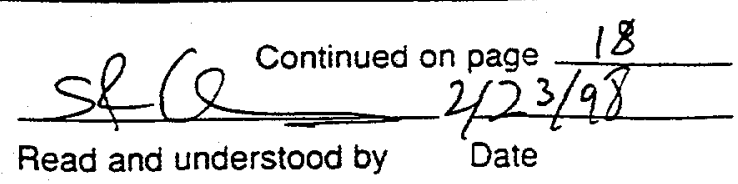


Subject Experime t $2 b-1$

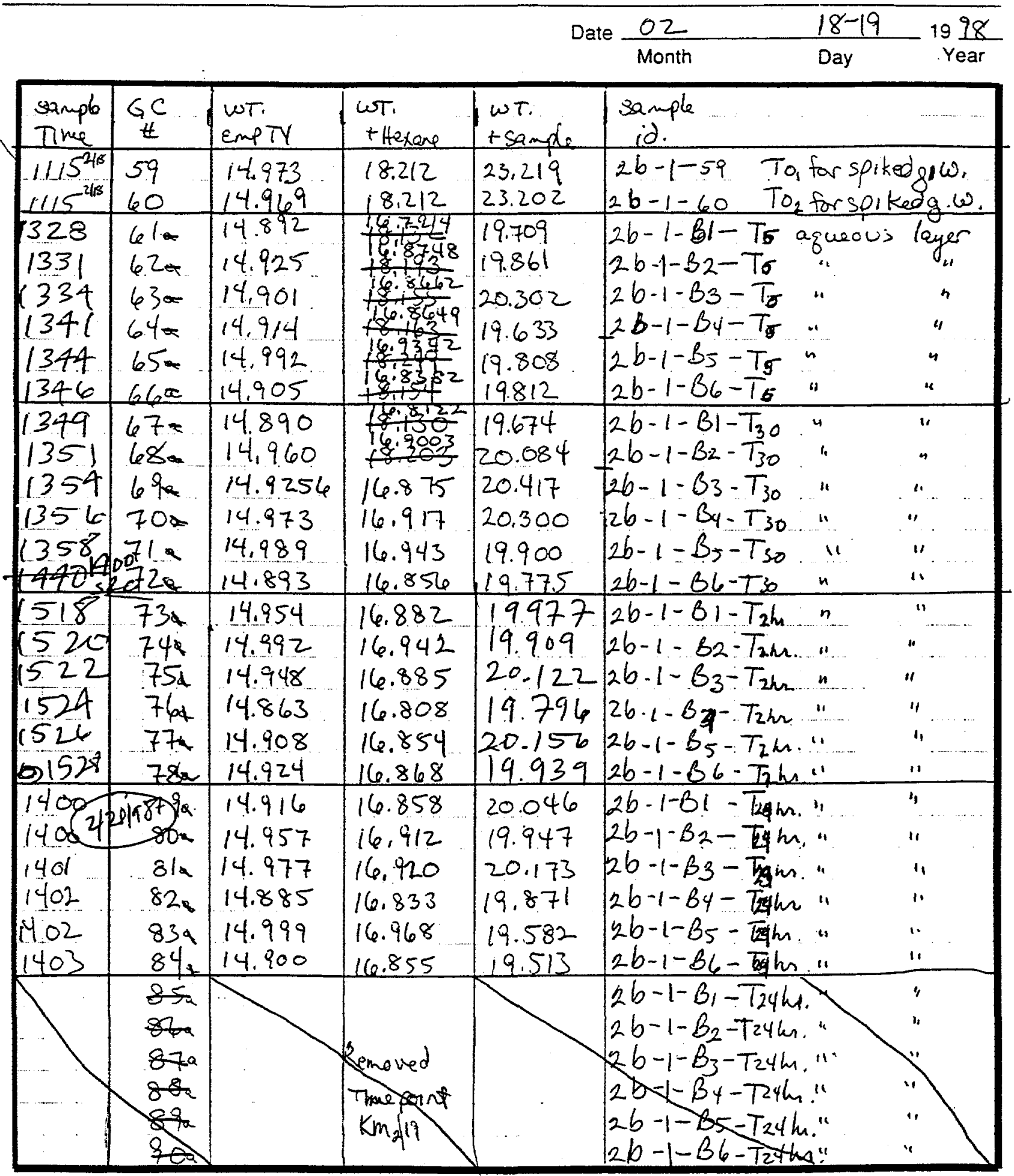

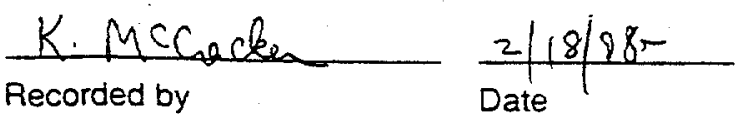

$\frac{S R C e}{\text { Read and understood by }} \frac{2 / 23 / 98}{\text { Date }}$


Subject Experiment $2 b-1$

$$
\text { Date } \frac{02-x}{\text { Month }} \frac{18-19}{\text { Day }} 19 \frac{98}{\text { Year }}
$$

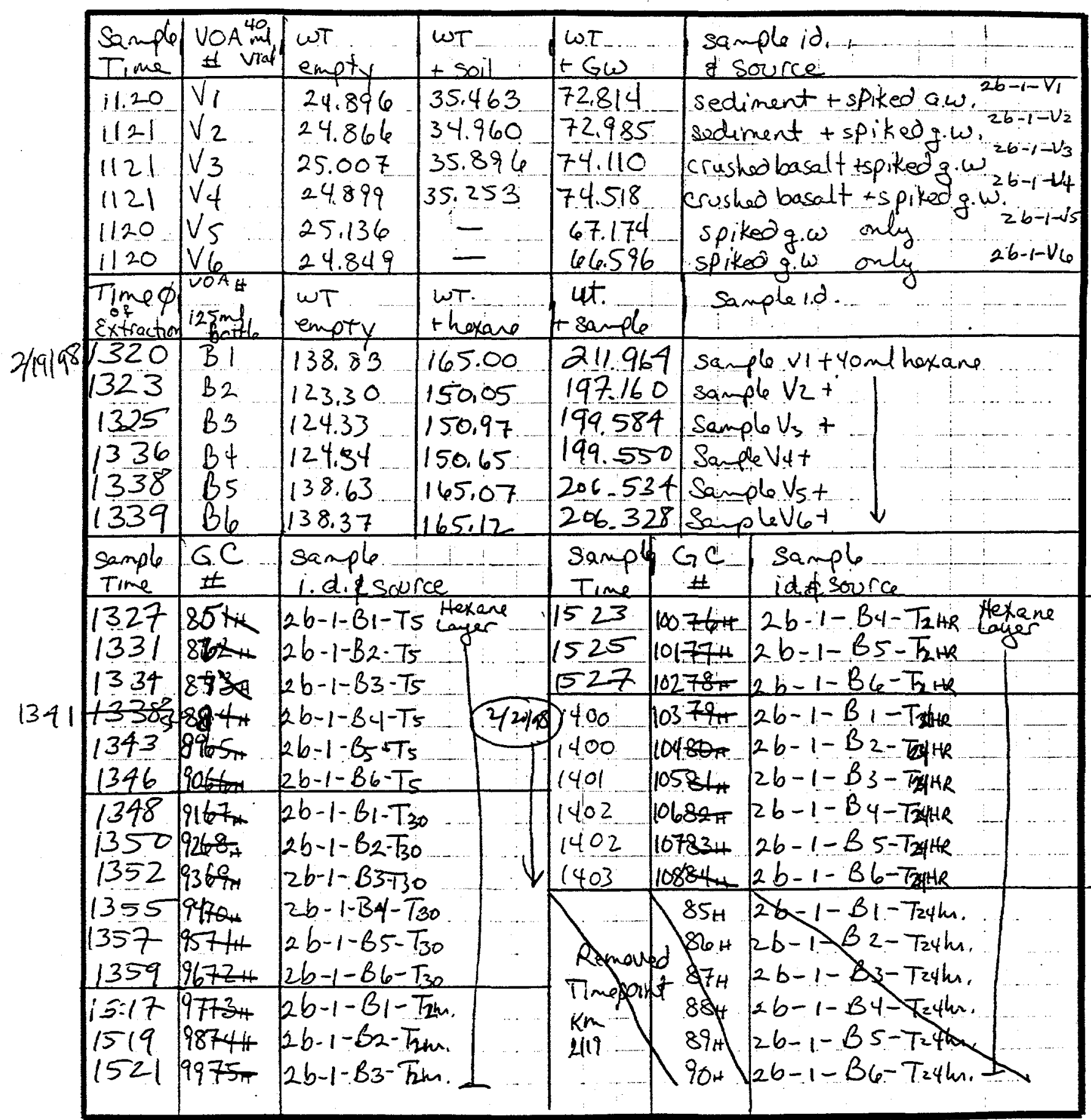

$\frac{K \text { MCGacker }}{\text { Recorded by }} \frac{2 / 18 / 98-}{\text { Date }} \quad \frac{5 \& C e \text { Continued on page } \frac{20}{2 / 23 / 98}}{\text { Read and understood by }}$ 
Subject Experiment $2 b-1$

Date \begin{tabular}{lll}
02 & $18-19$ & 19 \\
\hline Month & Day & 98 \\
Year
\end{tabular}

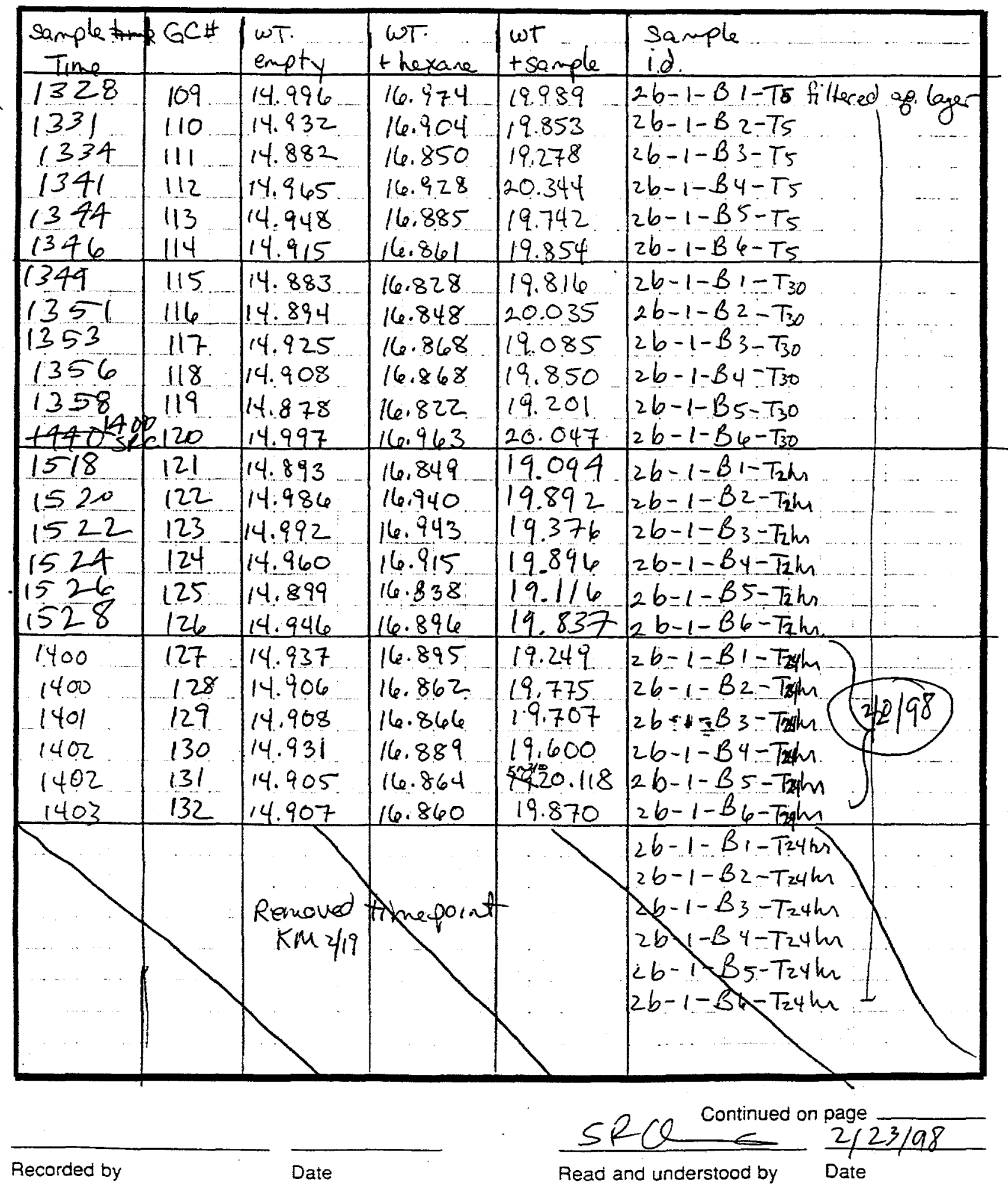




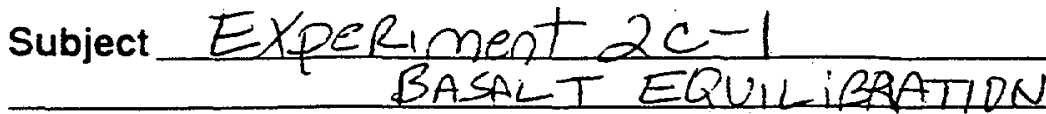

Date $\frac{03}{\text { Month }} \quad$ Day 1998

$03 / 2419811: 00$ sparged $\approx 3100 \mathrm{~mL}$ TANAD GW

FdR $\approx 3$ hR3 Thep mokel to 15 C incubator

fae terp. equilibation.

spliked w/ 1000 ppin TCE

placed $=350 \mathrm{~g}$ Custed Basatt $=250 \mathrm{~g}$ Aggregate Basalf into 80 o aven To Rerore any lisidual The orente

03109198 i3.47 dereh vials tedd died basalt. $2 c-1-2-1$ to $2 c-1-24$ ground a

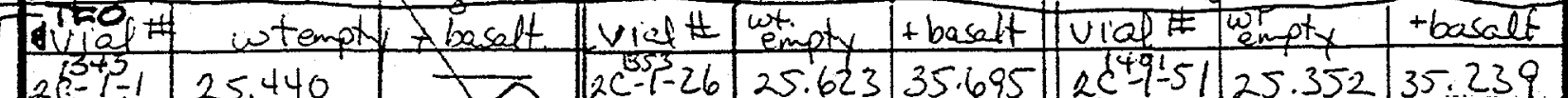

$2 \cos _{13} 44^{-1} 25.440$ $3 / 10492 C-7-2 \quad 25.270$ sec

\begin{tabular}{|c|c|c|c|c|c|}
\hline 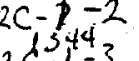 & र. & & $13 \mathrm{Cu}^{-1}$ & & \\
\hline & 25240 & & & $1<<0$ & $\mid \begin{array}{l}03.200 \\
25\end{array} 440$ \\
\hline & 25.456 & & & 25284 & 35.320 \\
\hline $1344^{8}$ & 25.640 & & $23 x$ & 25.187 & 35.246 \\
\hline & 25.319 & & & 25.284 & 35.421 \\
\hline & 25.523 & & & 25.352 & 35.449 \\
\hline & 25.271 & & 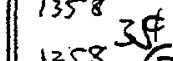 & $b^{2} 5,3 \neq$ & 35.429 \\
\hline & 25.471 & & & 2545 & 35.493 \\
\hline & 25467 & & 100736 & 25.204 & 35.220 \\
\hline $1380^{12}$ & 25.352 & & 140037 & 25.83 & 35,441 \\
\hline $1357^{13}$ & 25.383 & & 14060 & 25.2362 & 5.273 \\
\hline $1450^{14}$ & 25.283 & & 141839 & 25.431 ? & 255477 \\
\hline & 25.391 & & $1417 \%$ & 25.386 & $35.4 \times 5$ \\
\hline & 25.545 & &, 41841 & 25.5003 & 35.562 \\
\hline 1 & 25.322 & & $1419^{42}$ & 25.493 & 35.716 \\
\hline 141418 & 25.225 & & $1420 \quad 45$ & $\begin{array}{l}25.345 \\
25.310\end{array}$ & $\begin{array}{l}35.400 \\
35.351\end{array}$ \\
\hline & 25.353 & & 142045 & 25.203 & 35.376 \\
\hline & 25,236 & & 142546 & 25.216 & $35: 357$ \\
\hline & 25.494 & & 142547 & 25.353 & 35.383 \\
\hline & 25.501 & & 4248 & 25.287 & $=35.367$ \\
\hline & 25.442 & & 49 & 125.328 & 35.741 \\
\hline 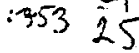 & 25.309 & 35.364 & 50 & 125.247 & 35.4 \\
\hline
\end{tabular}

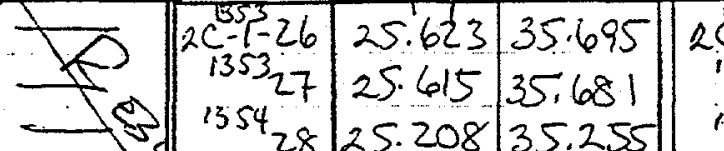

14025325.394

$140354 \mid 25.561$

5525.342

14045625.490

14055725.591

14055825227

35.414

1406.59 .25 .147 .35 .233

$606.6025 .153 \quad 35.373$

14076125.45835 .507 $14086225 \cdot 136 \quad 35.212$ $1096325.504 \quad 35.439$ 6425.54935 .826 4226525.33235 .282 $142366) 25.43235 .676$ ${ }^{1423} 67 / 25.294 \quad 35.268$ 1424
$\times 425$ 6825.18235 .475

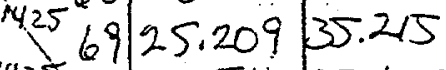
14257025.51135 .428 1426 秋 25.45935544 142672225.29235 .429 $2 c-1-1+024=9$ roud wecter $2 c-1-25$ to $48=$ crutho $2 c-1-496072=$ cignolocate

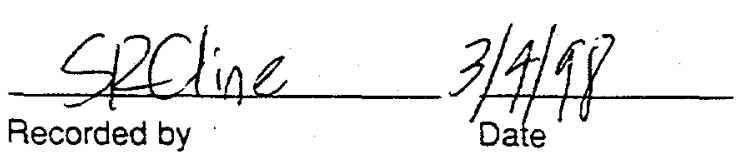

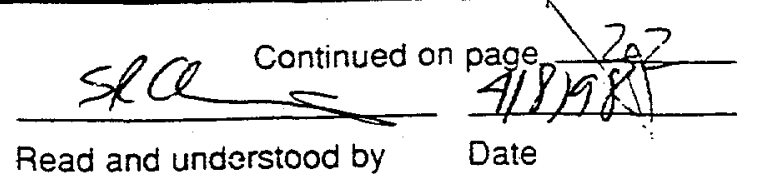




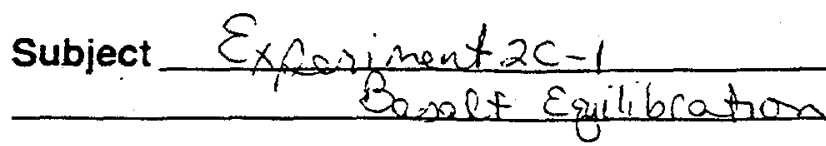

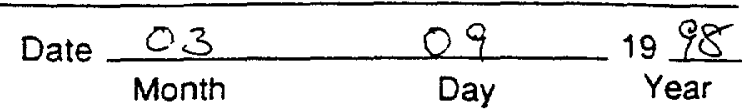

\begin{tabular}{|c|c|c|c|c|c|}
\hline $\begin{array}{l}\text { Sounplo. } \\
\text { Tims. }\end{array}$ & GC. & $\begin{array}{l}\text { wet: } \\
\text { enotu }\end{array}$ & $\begin{array}{l}\text { Wf } \\
\text { thexune }\end{array}$ & $\begin{array}{l}\text { Wt } \\
\text { t sande }\end{array}$ & sanfle $1 . d$, \\
\hline $3 / 10-13: 41$ & 133 & 11.146 & 14.405 & 19421 & To-Tellar bag - a. \\
\hline $3(10-13: 4)$ & 134 & 11.126 & 14.392 & 19.379 & To-Tedlar bag- $b$ \\
\hline $3 / 10-15: 40$ & 135 & 11,276 & 14.546 & 19.549 & $2 c-1-10-2 h r$ \\
\hline $310 \cdot 15: 40$ & 136 & 11,101 & 14.380 & 19.394 & $2 c-1-1 b^{-2 h} d \mathrm{~d} d$ \\
\hline $310-15 \cdot 47$ & 137 & 11.112 & 14.393 & 19.232 & $2 c-1-2-2 h n$ \\
\hline $3110-15: 44$ & 138 & 10.175 & 14.504 & 19.192 & $2 c-1-25-2 h$ \\
\hline $3 L 10-15: 45$ & 339 & 11,044 & 14.373 & 18.873 & $2 c-1-26-2 h r$ \\
\hline $3 / 10-15,47$ & 140 & 11.146 & 14.413 & 19.369 & $2 c+49-2 h$ \\
\hline 3. $(10-15: 48)$ & 141 & 11.051 & 14.357 & 18.963 & $2 c-1-50-2 h$ \\
\hline $3 /=-170$ & 142 & 11.071 & 14,285 & 18.662 & $2 c-1-3-35 h r$ \\
\hline $3110-1705$ & 143 & 11.067 & 14.3 .77 & 18.793 & $2 c-1-4-3.5 h \alpha$ \\
\hline$3 \longdiv { 1 0 - 1 7 0 6 }$ & 144 & 11.040 & 14.383 & 18.863 & $2 c-1-27-3.5 \mathrm{hu}$ \\
\hline $3 / 10-170 \pi$ & 145 & 11.061 & 14.300 & 18.790 & $2 c-1-28-3.5 \mathrm{~h} \Omega$ \\
\hline $3\{10-170\}$ & 146 & 11.124 & 14,422 & 18.890 & $2 c-1-51-3,5 h 2$ \\
\hline $3110-1710$ & 147 & 11.114 & 14.352 & 19.168 & $2 C-1-52-3,5 h_{2}$ \\
\hline $3 / 101843$ & 148 & 11.124 & 14.416. & 18.606 & $2 c-1-5-5 h$ \\
\hline 31.1845 & 149 & 11.144 & 14423 & 18.6064 & $2 c-1-6-5 h$ \\
\hline $3 / 101846$ & 150 & 11.111 & 14.378 & $18<27$ & $2 c-1-29-5 h$ \\
\hline $3 / 101847$ & 151 & 11.102 & 14.390 & 1864 & $2 c=1-30-s h$ \\
\hline $3 / 101899$ & 152 & 11.000 & 14,271 & 19.094 & $2_{c}-1-53-5 m$ \\
\hline $3 / 01850$ & 153 & 10.979 & 14.277 & 18.785 & $2 \leq-1-54-5 h x$ \\
\hline $3 / 101849$ & 154 & 10.981 & 14.303 & $19: 137$ & $2 c-1-53 b-5 h$ \\
\hline $1110-0935$ & 155 & 11.015 & 14.200 & 18.596 & $2 c-h-7-20 \mathrm{hr}$ \\
\hline $3 / 11-0937$ & 156 & 11.129 & 14.470 & 18.854 & $2 c-1-k-20 h r$ \\
\hline $3 / 11-0937$ & 157 & $i 1,110$ & 14.573 & 18.247 & $2 c-1-3 i<0 h r$ \\
\hline $3 / 11-0938$ & 158 & 11.064 & 14.321 & 18.716 & $2 c-1-32-2 g h r 1$ \\
\hline $3111-0939$ & 159. & 11.107 & 14.409 & 18.855 & $2 c-1-55-20 \mathrm{~A}$ \\
\hline $3 / 11-0940$ & 160 & 11.217 & 14.454 & 18.887 & $2 c-1-56-20 h r$ \\
\hline $\begin{array}{l}3111-1325 \\
3 / 1-1327\end{array}$ & $\begin{array}{l}161 \\
162\end{array}$ & $\begin{array}{l}10.755 \\
10.951\end{array}$ & $\begin{array}{l}14.211 \\
14294\end{array}$ & $\begin{array}{l}18.600 \\
18.731\end{array}$ & $2 c-1-9-24 h$. \\
\hline $3111-1328$ & 163 & 100 & 14.417 & 18.922 & $2 c-1-33-24 h$ \\
\hline $3|11-1328|$ & 164 & 11.129 & 14.451 & 18.937 & $2 c-1-33-24 h d$ \\
\hline
\end{tabular}

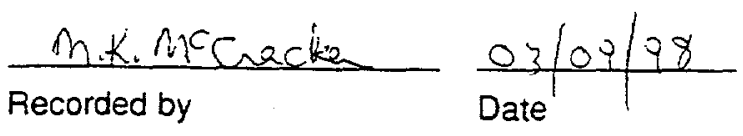

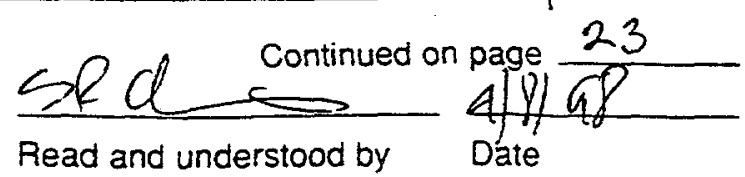


Subject Expirment $2 c-1$

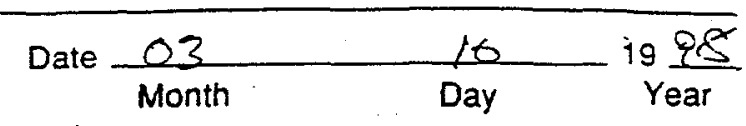

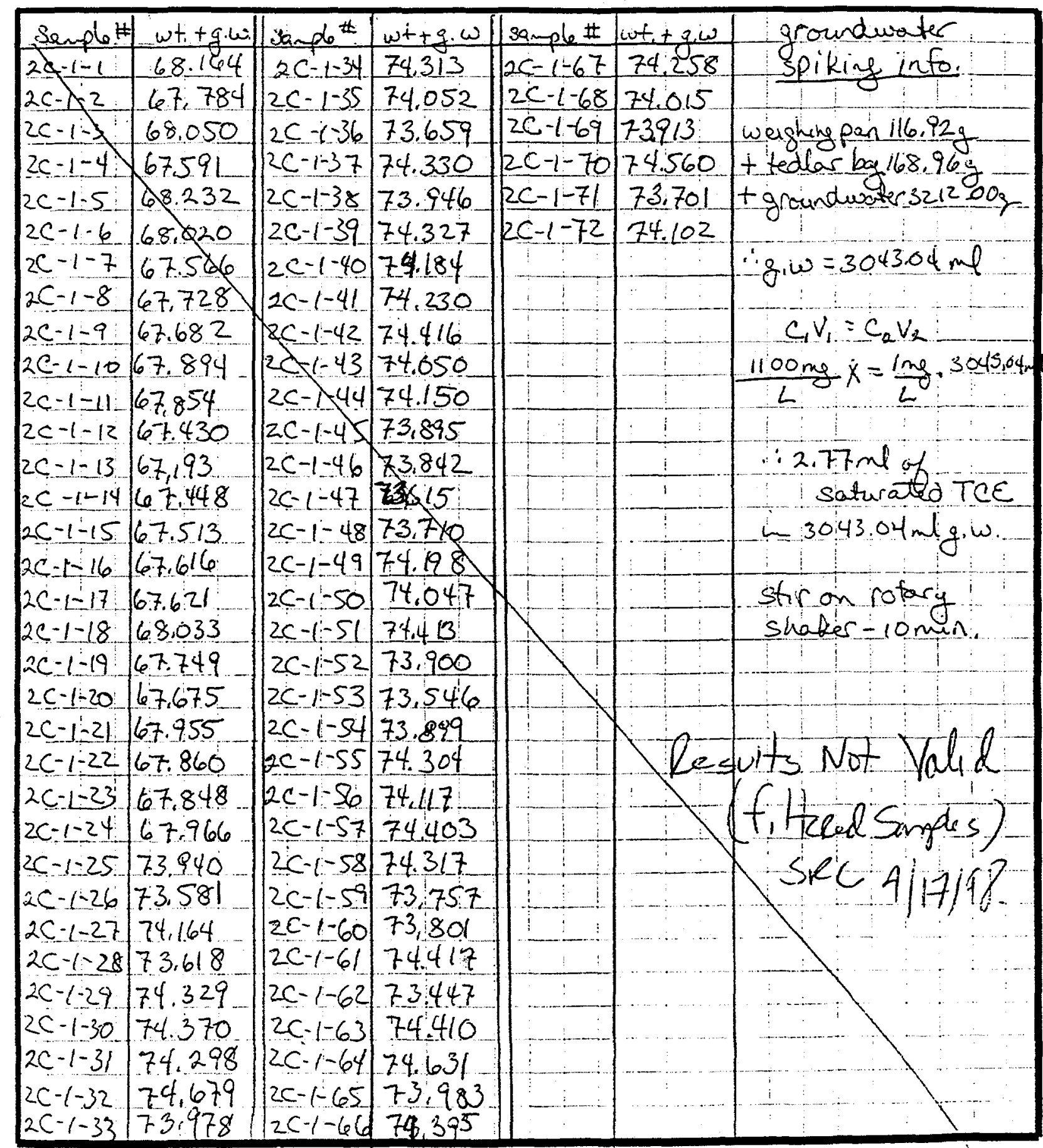

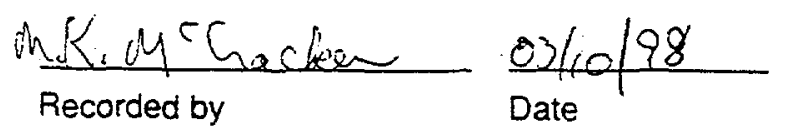

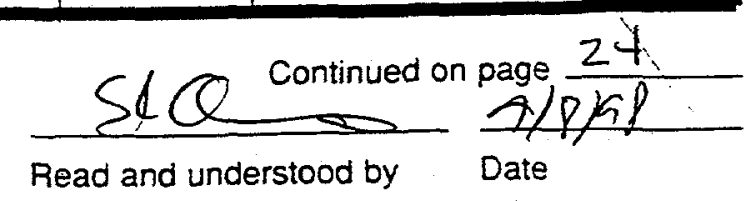


Subject Exprinent $2 C-1$

Basalt Equilibrition

$$
\text { Date } \begin{array}{lll}
03 & 13 & 19 \frac{98}{\text { Month }} \\
\text { Year }
\end{array}
$$

\begin{tabular}{|c|c|c|c|c|c|}
\hline tipli & $G C \#$ & $\omega t \cdot$ empty & wt. thexane & wot tsenple & sanple 1.d. \\
\hline $341-1329$ & $\sqrt{165}$ & 11.103 & .14 .427 & 18.937 & $2 c-1 \div 34-24 \mathrm{~h}$. \\
\hline $3\{11-1330$ & 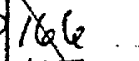 & 11.098 & 14.438 & 18.877 & $2 c-1-57-24 \mathrm{~ms}$ \\
\hline $3|11-133|$ & 167 & $11.24 i$ & 14.526 & 18.963 & $2 c-1-58-24 \mathrm{hn}$ \\
\hline $3 / 151423$ & 168 & 11.102 & 14391 & 19.93 & $2 c-1-4 c-13$ \\
\hline$y_{15} 1923$ & 169 & 11.078 & 14.420 & 18.773 & $2 c-1-18 \leqslant-14$ \\
\hline 7151924 & 170 & 11.219 & 14.579 & 19.332 & $2 c-1-355<-3$ \\
\hline 1151425 & $f|7|$ & $\lambda 0.956$ & 14.230 & 19.030 & $2 c-1-36 \leq 4$ \\
\hline 3,151426 & 172 & 11. $x 04$ & 14.445 & 19.091 & $2 c-1-5 q^{5}$ \\
\hline 1527 & 173 & 10.978 & 14.321 & 18.920 & $2 c-1-22^{5}$ \\
\hline $3 / 161315$ & 174 & $11,111>$ & 14.333 & 18.660 & $2 c-1-11-6 d$ \\
\hline $3 / 161316$ & 175 & 11.178 & $14.516_{2}$ & 18.8 .43 & $2 c-1-12-6 \phi a$ \\
\hline $3 / 161316$ & 176 & 11.146 & $44 . \frac{345}{40}$ & 18.675 & $2 c-1-12-6 d b c$ \\
\hline $3 / 161377$ & 177 & 11.228 & $14 . \sin _{0.8}$ & 18.833 & $2 c-1-35-6 d$ \\
\hline $3 / 161318$ & 178 & 11.072 & 1.4.3 & 19.079 & $2 c-1-36-60$ \\
\hline $3 / 16 \quad 13 \quad 18$ & 179 & 11.108 & 1.4 .427 & 18.740 & $2 c-1-59-6 d$ \\
\hline $3 / 161319$ & +180 & 11.126 & 14.454 & 19.063 & $2 c-1-60-6 \phi$ \\
\hline 37500 & 181 & 11.102 & 14.485 & 18.903 & $2 c-1-15-7 d$ \\
\hline $3 / 21501$ & 182 & 11.079 & 14.360 & 18.741 & $2 c-1-16-7 d$ \\
\hline $3 / 77150 r$ & 183 & 11.070 & 14.292 & $18: 542$ & $2 c-1-39-7 d$ \\
\hline $3 / 171503$ & 184 & 11.129 & 14.472 & 18.844 & $2 c-1-40-7 d$ \\
\hline $3 / 171504$ & 185 & 11.102 & 14.443 & 18.947 & $2 c-1-63-7 d$ \\
\hline $3 / 17 \cdot 1505$ & 186 & 11.112 & 14.462 & 18.909 & $2 c-1-64-7 d$ \\
\hline$=1131329$ & 187 & 11,115 & 14.436 & 18.802 & $2 c-1-17-8 d$ \\
\hline $3 / 181329$ & 188 & 11.023 & 14.337 & 18.666 & $2 c-1-18-8 d$ \\
\hline 3101330 & 189 & 11.076 & 14.405 & 18.760 & $2 c+1-41-8 d$ \\
\hline 31881331 & 190 & 11.049 & 14.305 & 18.675 & $2 c-1-42-80$ \\
\hline 3181333 & 191 & 11.070 & 14.371 & 18.877 & $2 c-1-65-8 d$ \\
\hline $3 / 181334$ & 192 & $11 ., 138$ & 14,446 & 18.983 & $2 C-1-66 a-8 d$ \\
\hline $3 / 18 \quad 1335$ & 193 & 11.104 & 14,366 & $\$ 8557$ & $2 c-1-66)($ anp $)-8 d$ \\
\hline $3 / 23+515$ & 212 & 11.018 & 14.223 & 18.792 & $2 C-1-19-132 \quad 0$ O \\
\hline $3 / 23 \div 575$ & 213 & 11.118 & 14.419 & 18.934 & $2 c-1-20-13 d$ \\
\hline $3 / 231516$ & 214 & 11.261 & 14,517 & 19.003 & $2 c-1-43-132$ \\
\hline $3 / 237516$ & 215 & 11.148 & 14.342 & 18.770 & $|2 c-1-2| 4-12 d$ \\
\hline
\end{tabular}

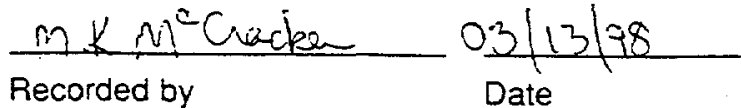

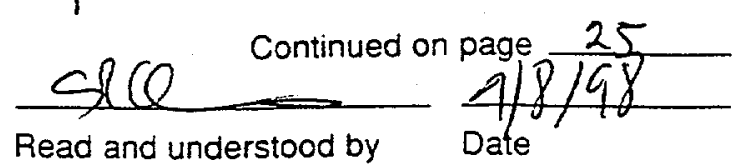




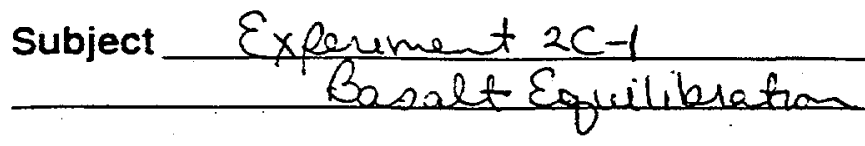

Date $\frac{03}{\text { Manth }} \quad \frac{18}{1998}$

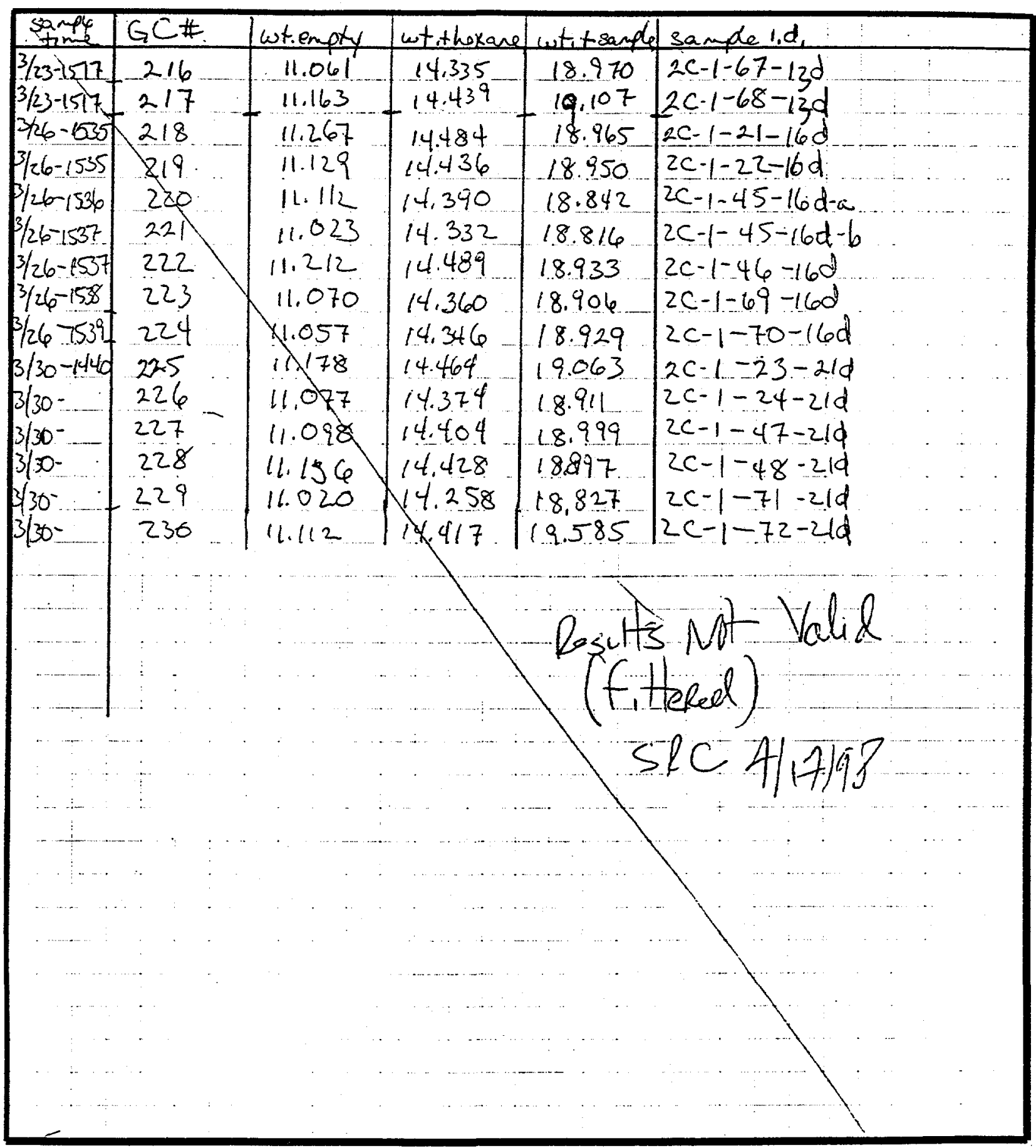

$\frac{\text { M.K.MCCacken }}{\text { Recorded by }} \frac{3(18 / 98}{\text { Date }}$

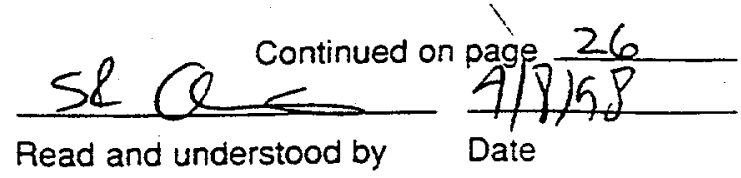




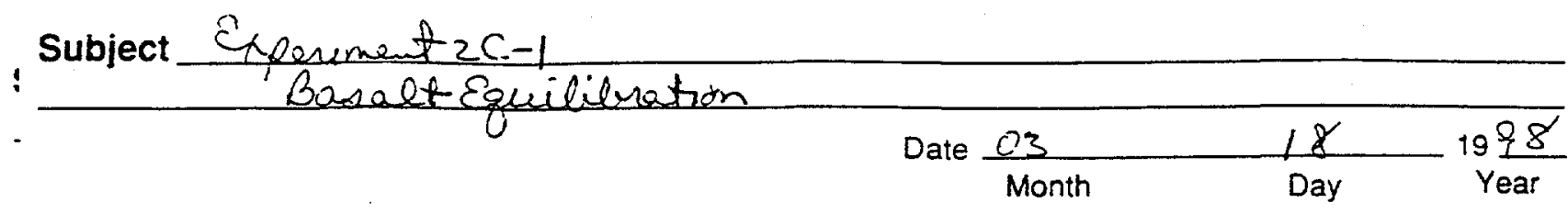

Experiment 2c-1. Sorption Kinetics Test for Crushed and Aggregate Basalt.

(To be conducted at ORNLFSD)

1. All soil and groundwater to be used in these experiments (TAN-40 groundwater, TAN-37 crushed and aggregate basalt) will be prepped by sparging and/or drying to remove any residual TCE present on the media. (Properly indicate usage of this media in the treatability study tracking logbook.) Doing so will allow this experiment to be conducted with consistent and controlled initial TCE concentrations via contaminant spiking.

2. Prepare a STOCK (Saturated) TCE solution ( $2000 \mathrm{mg} / \mathrm{L}$ ) by adding $100 \mu \mathrm{L}$ of Pure TCE into Ja $12 \mathrm{~mL}$ VOA vial filled to volume with DI Water and allow to equilibrate overnight at room Temperature. (Use of a STOCK solution rather than pure phase TCE to prepare the spiking Jsolution affords better accuracy in obtaining the target concentration.)

3. Sparge approximately $3100 \mathrm{~mL}$ of groundwater from TAN-40 of any residual TCE or other VOCs that may have been present and then place the groundwater into an incubator at $12-15^{\circ} \mathrm{C}$. After temperature equilibration of the groundwater (likely overnight), remove the container from the incubator.

4. Obtain the tare weight of the container to be used to prepare the spike solution (tedlar bag). Fill with the Tediar bag with the chilled TAN $-40 \mathrm{GW}$. By gravimetric methods, determine the amount of groundwater added to the container. (A calibration check of the gravimetric scale will be performed each day of use.) All information regarding the preparation of the spiking solution will be recorded in the laboratory research notebook.

5. Add the appropriate quantity of the Saturated STOCK TCE solution into the tedlar bag to produce a TCE spike concentration of $1.0 \mathrm{mg} / \mathrm{L}$. SHOULD BE APPROXIMATELY 3 ML Record volume and/or weight added. (Reactive zone media will only be spiked at 0.1 and 1 mg/L. TCE during the Task 4 degradation studies.) This solution can be mixed and equilibrated within a few minutes.

6. After mixing, obtain duplicate aqueous samples $(=5 \mathrm{~mL})$ of the spike solution to obtain the initial TCE concentration of the spiked groundwater. The duplicate aliquot samples will be added to pre-weighed sample containers holding a known volume of hexane $(=5 \mathrm{~mL})$. Each sample container will be weighed again after sample addition to deternine the actual volume of sample added. These extracts will be placed on a horizontal shaker for 2 hours. Store the extracts at $4^{\circ} \mathrm{C}$ until G.C. analysis.

7. Obeain the tare weights of seventy two (72) $40 \mathrm{~mL}$ VOA vials. Add approximately $10 \mathrm{~g}$ of aggregate basalt to 24 of the vials and $10 \mathrm{~g}$ of the crushed basalt to another 24 of the these vials. Gravimetrically determine the actual amount of solid media added.

8. Dispense the spiked groundwater from the tedlar bag into each of the 72 VOA vials that have been prepared, filling them completely with no headspace and cap them. Record the time that each vial is filled as " $T=0$ " for that vial.

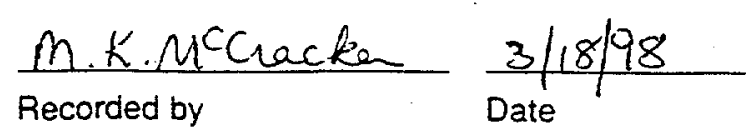

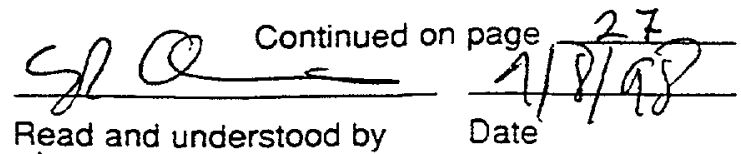




$\frac{\text { Subject Exporinet } 2 c-1}{\text { Basalt Equilibuation }}$

9. Re-weigh each vial after it is completely filled to determine the actual volume of spiked groundirater added to it. Place the vials back into the environmental chamber at $12-15^{\circ} \mathrm{C}$ Slowly agitace the vials during this step.

The remaining steps will be performed at the time intervals of approximately 2

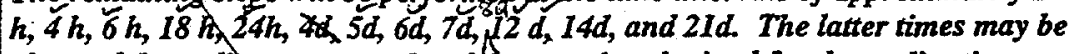
changed depending upon results of the samples obtained for the earlier time periods.

10. Remove six (6) $40 \mathrm{~mL}$ ials from the incubator (two with groundwater only, two with forushed basalt, and two containing aggregate basalt.) Collect an aqueous sample $(\approx 5 \mathrm{~mL})$ from geach vial using a disposable syritge with luer lok needle. Record the time the sample is i

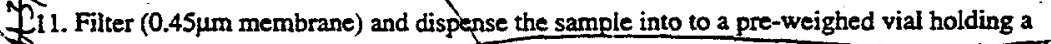
1 knougn volume of hexare ( $=5 \mathrm{~mL})$ :-This sample vial will be weighed again ater sampte addition to determine the actural volume of sample added. A new syringe and filter will be used for each sample. All such extracts will be placed on a horizontal shaker for 2 hours. Store the extracts at $4^{\circ} \mathrm{C}$ until G.C. analysis.

12. Randomly collect and process (steps 10 and 11 ) a duplicate VOC sample from one of the six VOA vials during every other sampling period.

13. FOR.THE LAST SAMPLING PERIOD STUDIED ONLY: Extracthe remaining contents of each vial with hexane. (The mass of any remaining TCE on the solid phase can be determined with this extraction when a mass balance is performed using data from the aqueous aliquot sample) To accomplish this, transfer the remaining sample in the six $40 \mathrm{~mL}$ VOA vials (including basalt material) into a $125 \mathrm{~mL}$ extraction jar that has been pre-weighed and holding a known volume of hexane $(=35 \mathrm{~mL})$. The extraction jar will be weighed again after sample addition to determine the actual mass of sample (solid +Liquid) added.

14. FOR THE LAST SAMPLING PERIOD STUDIED ONLY: The extratss in the above step will be placed on a horizontal or reciprocating shaker for 2 hours. A $1 \mathrm{~mL}$ aliguot of the hexane phase will be placed into a $2 \mathrm{~mL} \mathrm{G.C.} \mathrm{vial} \mathrm{and} \mathrm{stored} \mathrm{at} 4^{\circ} \mathrm{C}$ until analysis.

\section{GC ANALYSIS of VOCs}

All VOC analyses for this experiment will be conducted using a G.C.ECD detector. The instrument will calibrated for TCE using a 5 point calibration curve with standard concentrations ranging from $10-1000 \mu \mathrm{g} / \mathrm{L}(\mathrm{ppb})$

The VOC analyses of the hexane extracts will closely follow EPA Method 80008 . Significant deviations from this method will be clearly documented.

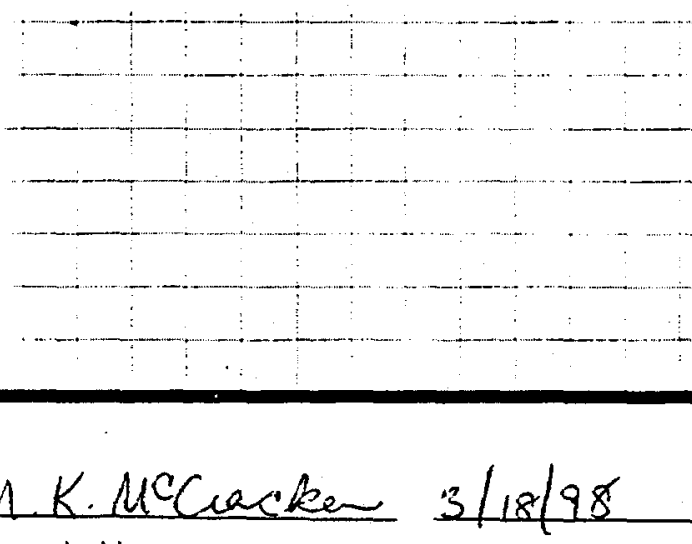

Recorded by
Date

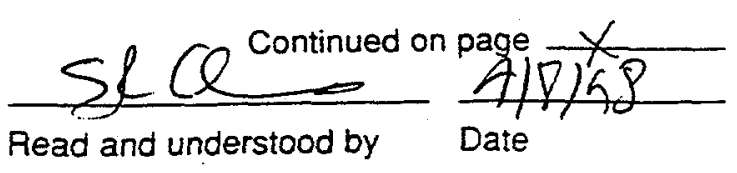




Date $\begin{array}{lll}03 & 18 & 1998 \\ \text { Month } & \text { Day } & \text { Year }\end{array}$

\section{Experiment 2a-3. Overall performance of the rest reactor}

(To be conducted at ORNLESD)

In this experiment a complete reactor will be set up using the most optimal component(s) from the previous Task $2 \mathrm{a}$ experiments described above. To be consistent, a $100 \mathrm{mg} / \mathrm{L}$ TCE spike solution will be used here as well; however, this experiment will be conducted at approximately $12-15^{\circ} \mathrm{C}$.

1. Set up a reactor, ensuring that a Teflon sleeve is fitted onto the glass adapter to be used. The top of the adapter will be sealed (Teflon stopper) during spiking and equilibration to minimize the mass of TCE lost.

2. Fill the reactor with distilled water, minimizing the headspace volume inside of the reactor. A record of the Dl water volume added will be maintained.

3. Spike the reactor with TCE, Desired Concentration: $100 \mathrm{mg} /$

Add a mass of pure phase TCE (density of $1.456 \mathrm{~g} / \mathrm{mL}$ ) to the liquid volume inside of the reactor that will yield a TCE solution of $100 \mathrm{mg} / \mathrm{L}$. Measure the mass of the spiking syringe when filled and then after spiking to record the total TCE mass added to the reactor (a QC check on the initial TCE analysis). Information regarding the preparation of the spiking solution will be recorded in the laboratory research notebook.

4. Replace the removed stopper back onto the adapter and ailow the solution to equilibrate at least overnight in an incubator maintained at $12-15^{\circ} \mathrm{C}$. (Record the equilibration period and temperature).

5. During the equilibration period, prepare an ORBO-32 assembly in the standard taper adapter and cover the bottom end of the adapter with the selected thin film [parafilm].

STORE UN-SEALED ORBO TUBES OUTSIDE OF THE LABORATORY FUME HOODS. THE HOODS LIKEL Y HAVE THE GREATEST POTENTLAL FOR "CONTAMDNATIN" THE TUBES WITH TCE AND OTHER VOCS.

6. After equilibration, collect duplicate ( $5 \mathrm{~nL}$ ) aqueous samples from the reactor (from the glass adapter that is sealed with a stopper) The aliquot samples will be added to pte-weighed sample containers holding a known volume of hexane $(=5 \mathrm{~mL})$. Each sample container will be weighed again after sample addition to determine the actual volume of sample added. (A calibration check of the gravimetric scale will be performed each day of use.) All such extracts will be placed on a horizontal shaker for 30 minutes. Store the extracts at $4^{\circ} \mathrm{C}$ until G.C. analysis.

7. Replace the adapter sealed with the stopper with one fitted with the charcoal desorption tube assembly from Step 5 . Record the time the samples in the step above are collected and the desorption tube is added as Start Time $=0$.

Batance Cátil $\$ 1 / 3 \quad \times 177440$

wt. $50 \mathrm{~g}$ scal. $49.96 \mathrm{~g} V$ $318 \times 177339$

Babance Calib. wit.ig ocab 0.9988
Babance Cabib. $3119 \times 177339$

wt. $50 \mathrm{~g}$ scal. $49.96 \mathrm{~g} V$

$$
\text { wt. ig scale } 1.6000 \checkmark
$$

piset calite $3 / 19$ SCOOz P5000

M.K.MChacken

Recorded by

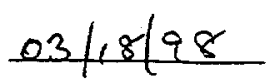

Date
Reactor + glass + tefl
Stopper sleo
WT. EmpTy $256.16 \mathrm{~g}$

$\omega T+H_{2} \mathrm{O} \quad 785.19$

$m l=529.03$

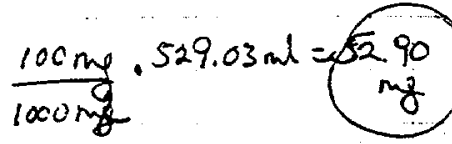

$52.90 \mathrm{gg} \cdot \frac{1000 \mathrm{ml}}{1450 \mathrm{mg}}$

$=36.2 \mu l$

purephase TCE

Syunge $+T C E$

13.7479

igrejge ofth $T C E$

13.6939

TCEadded:

$3 / 18198-1430$

\&

bagan inculation.

at $12^{\circ} \mathrm{C}$.

Incubation ended

at $12^{\circ} \mathrm{C}$

$3 / 19 / 98-0910$

.. 
Subject Exarumet $2 a-3$

Test Reacter Performance

Date $\frac{03}{\text { Month }} \frac{18}{1998}$

8. Collect at the following time intervals in the same manner as performed in step 6: $30 \mathrm{~min}, 60$ $\min , 2 \mathrm{hrs}, 4 \mathrm{hrs}, 24 \mathrm{hrs}$ (duplicate), $30 \mathrm{hrs}, 48 \mathrm{hrs}$. The exact time at which each aliquot is collected will be recorded.

Balance calib. $3 / 20$ $x 177339$.

9. Breakdown the reactor after the last sample is collected. The charcoal desorption tube will then be removed from the reactor. Each charcoal bed contained in the tube will be placed into a pre-filled and pre-weighed vial containing a known volume of hexane $(\approx 5 \mathrm{~mL})$. These extracts will be processed and analyzed in the same manner as the aqueous aliquots.

NOTE: The contents of such a test reactor will be extracted at the end of the experiments in Task 4 but is not necessary here since a solid phase is not present.

$w+20.0$ scale 20.0001

10. Analyze the sample and charcoal extracts via GC/ECD for TCE. G.C. analyses will be conducted closely following EPA Method $8000 \mathrm{~B}$, ensuring that a daily calibration check, blanks, etc. are also analyzed on each analysis day. Formal data packages, as outlined in Section 2.4.3.3 of the Chapter 2 Implementation Plan will not be prepared for this experiment.

Balance calib. $3 / 21$ $X 177339$ $w+20.0$ scalo 20.0000

11. Perform a mass balance for the reactor, taking sample aliquot volumes, initial concentrations, etc. into account to determine the overall reactor performance in maintaining gastight conditions. Also place any waste materials generated from the experiment in the appropriate satelitite accumulation area.

\begin{tabular}{|c|c|c|c|c|c|}
\hline $\begin{array}{l}\text { Sanple } \\
\text { Inme }\end{array}$ & $\mathrm{GC}^{\#}$ & wt.empty & wt thexare & $\omega t+89 \operatorname{mol}$ & Semple id. Eulutions \\
\hline 190922 & 194 & 11.222 & 14.475 & 19.504 & $2 a-3-35 T_{0}-1$ \\
\hline $3 / 190922$ & 185 & 11.083 & 14.475 & 19.448 & $2 a-3-T_{0}-2$ \\
\hline $3 / 190952$ & 196 & 11,101 & 14.460 & 19.457 & $2 a-3-30 \operatorname{mn}-1$ \\
\hline 3190953 & 197 & 11059 & 14.374 & 19.383 & $2 a-3-30$ min -2 \\
\hline $3 / 19 \cdot 1022$ & 198 & 11.139 & 14.456 & 19.476 & $2 a-3=1 h r-1$ \\
\hline $3 / 19-1022$ & 199 & 11.874 & 14.401 & 19.386 & $2 a-3-1 h r-2$ \\
\hline $13-1122$ & 200 & 10.924 & 14.209 & 19.217 & $2 a-3-2 h r s-1$ \\
\hline $19-1122$ & 201 & 11.047 & 14.327 & 19.309 & $2 a-3-2 h r-2$ \\
\hline $19-132$ & 202 & 11.159 & 14.414 & 19.417 & $2 a-3-4 h r-18$ \\
\hline $9-1342$ & 203 & 11.035 & 14.257 & 19,274 & $2 a-3-4 h r-2$ \\
\hline $20-0925$ & 204 & 10.848 & 14.087 & 18.947 & $2 a-3-24 h r-1$ \\
\hline$|20-0.25|$ & 205 & 11.116 & 14.436 & 19.335 & $2 a-3-24 h r-2$ \\
\hline$5 \longdiv { 6 2 2 }$ & 206 & 11.010 & 14.305 & 19.249 & $2 a-3-3 \ln r-1$ \\
\hline $0-1622$ & 207 & 11.072 & 14.361 & 19.33 .3 & $2 a-3-3 j h r-2 \quad(31 / h r)$ \\
\hline$|4-1634|$ & 208 & 11.094 & 14.369 & 19.347 & $2 a-3-48 h r-1 \quad\left(55 h r_{5}\right)$ \\
\hline $4-1635$ & 209 & 11.084 & 14.351 & 19.330 & $2 a-3-4 h h r-2(55 h r)$ \\
\hline $1 / 21-1636$ & 210 & 10.986 & 14.201 & 14.243 & $2 a-3-c h r d-1$ \\
\hline $1-1636$ & 211 & 11.002 & 14.243 & 14.283 & $2 a-3-c h r c l-2$ \\
\hline
\end{tabular}

MK MCcacker Recorded by

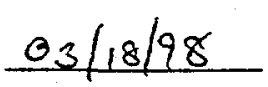

Date

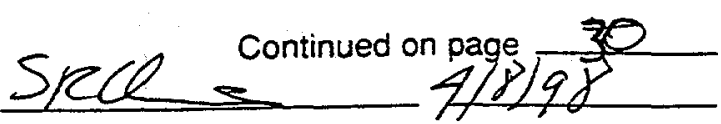

Read and understood by 


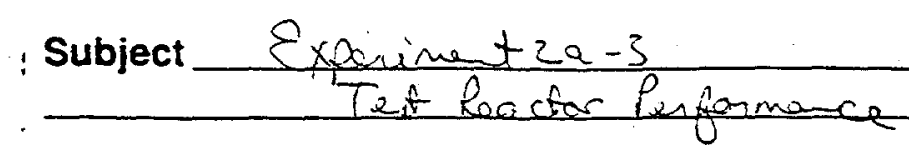

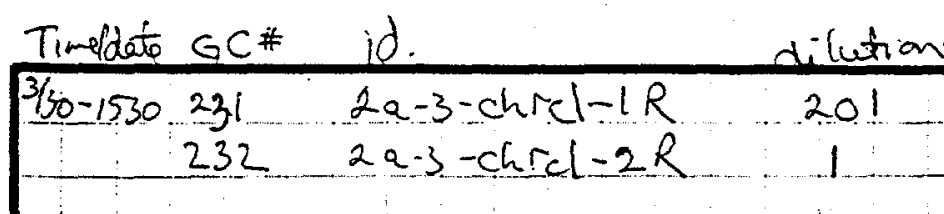

$\frac{M \cdot K M \text { MCraclear }}{\text { Recorded by }} \frac{03 / 30 / 98}{\text { Date }}$ $\underset{\text { Read and understood by }}{S R Q \text { Continued on page }} \frac{\sqrt{7 / 9 \delta}}{\text { Date }}$ 
Subject Permangonate Caliluation Curve

Date $\frac{04}{\text { Month }} \quad \frac{06}{\text { Day }}{ }_{\text {Year }}$

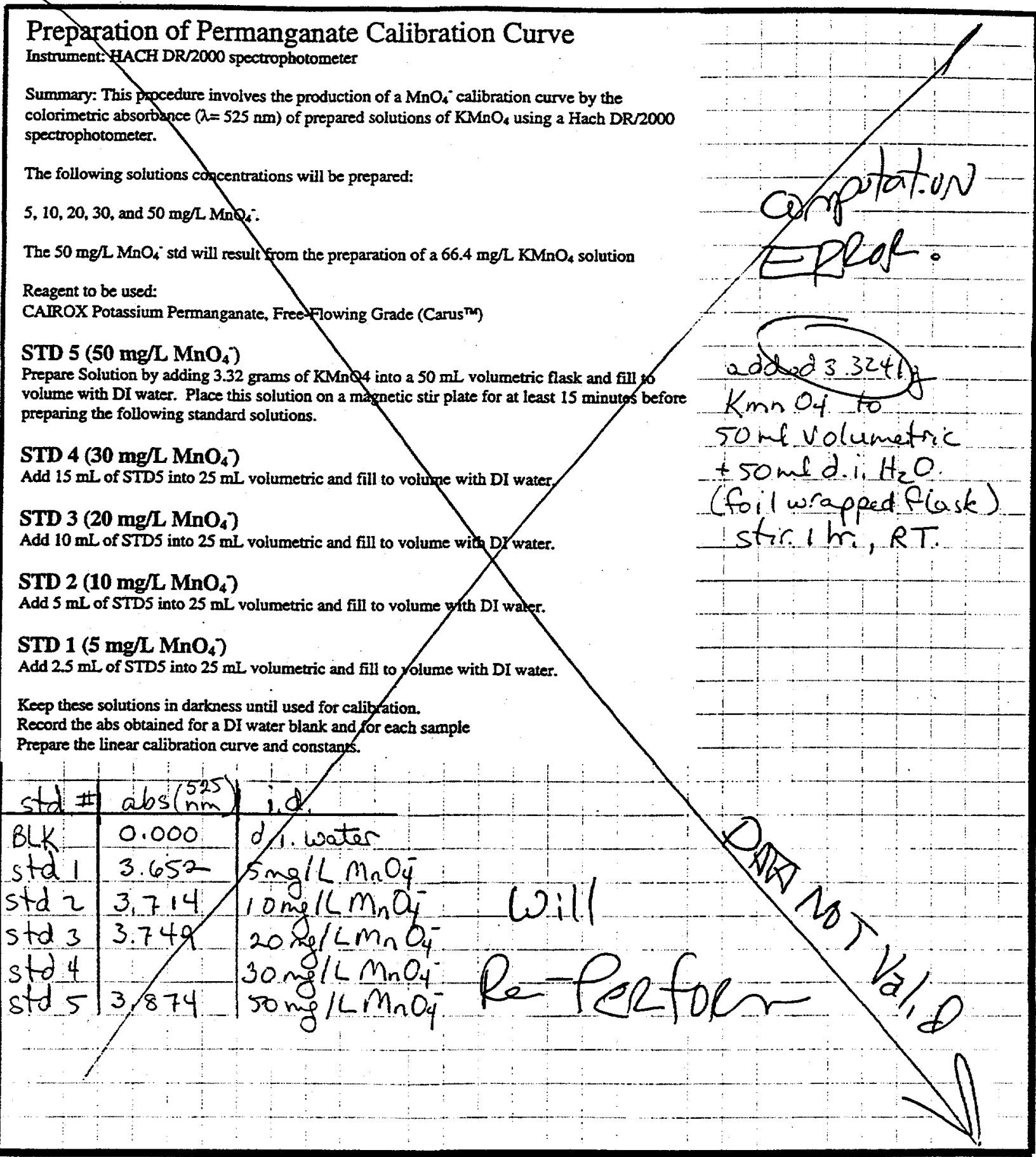

A. K. MrCacke

Recorded by $\frac{04 / 06 / 98}{\text { Date }}$

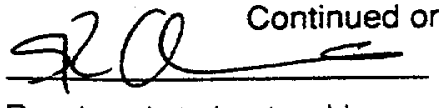

Read and understood by

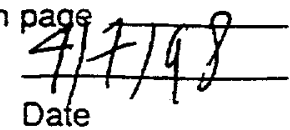


Subject Additional lab Test \#1

Date $\frac{04}{\text { Month }}$ Day $\frac{1998}{\text { Year }}$

Additional Lab Experiment

Note: This experiment is being in conducted in addition to the tasks set forth in the statement of work.

1. All groundwater to be used in this experiment (TAN-40 groundwater) will be prepped by sparging to remove any residual TCE present on the media. Doing so will allow this experiment to be conducted with consistent and controlled initial TCE concentrations via contaminant spiking. (Properly indicate usage of this media in the treatability study tracking logbook.)

2. Prepare a STOCK (Saturated) TCE solution (2000 mg/L) by adding $100 \mu \mathrm{L}$ of Pure TCE into a $12 \mathrm{~mL}$ VOA vial filled to volume with DI Water and allow to equilibrate overnight at room temperature. (Use of a STOCK solution rather than pure phase TCE to prepare the spiking solution affords better accuracy in obtaining the target concentration.)

3. Obtain the tare weight of the 1 liter (small) Tediar bag to be used to prepare the spike solution. Fill with approximately $520 \mathrm{~mL}$ of $12^{\circ} \mathrm{C}$ TAN-40 groundwater. By gravimetric methods, determine the amount of groundwater added to the container. (A calibration check of the gravimetric scale will be performed each day of use.) Place the bag into the incubator at $12^{\circ} \mathrm{C}$ until it is spiked.

4. Obtain the tare weight of twelve (12) $40 \mathrm{~mL}$ VOA vials.

5. Remove the Tedlar bag from the incubator and add the appropriate quantity of the Saturated STOCK TCE solution to produce a $1 \mathrm{mg} / \mathrm{L}$ TCE spike solution. (The volume of samated STOCK TCE needed should be on the order of $0.5 \mathrm{~mL}$ ). This solution can be mixed and equilibrated within 20 misutes. All Information regarding the preparation of the spiking solution will be recorded in the laboratory research notebook.

6. Prepare a $2660 \mathrm{mg} / \mathrm{L} \mathrm{KMnO4}$ solution by adding $66.44 \mathrm{mg}$ (0.0664 grams) Carus ${ }^{\text {TM }}$ Free Flowing Technical Grade $\mathrm{KMnO} 4$ into a $25 \mathrm{~mL}$ volumetric flask and fill to volume with $\mathrm{DI}$ water. (This solution should have a $\mathrm{MnO}_{4}^{*}$ concentration of $2000 \mathrm{mg} / \mathrm{L}$ )

7. After mixing for at least 1 hour, collect an aliquot of this solution for $\mathrm{KMnO} 4$ analysis. (A calibration check should not be needed since we just prepared the calibration curve). The sample will have to be diluted to less than $50 \mathrm{mg} / \mathrm{MnO}_{4}$. (on the order of $1.25 \mathrm{~mL}$ into a $100 \mathrm{~mL}$ flask)

8. Dispense the following volumes of the $\mathrm{KMnO}$ solution into the $40 \mathrm{~mL}$ viais and reweigh each: Vials 36 K NONE

Vials $38.1 \mathrm{~mL}$ (will yield approximately $5 \mathrm{mg} / \mathrm{L} \mathrm{MnO}_{4}$ )

Vials 5\&6: $0.3 \mathrm{~mL}$ (will yield approximately $15 \mathrm{mg} / \mathrm{L} \mathrm{MnO}_{4}$ )

Vials 7\&8: $0.8 \mathrm{~mL}$ (will yield approximately $40 \mathrm{mg} / \mathrm{MnO} \mathrm{Mn}_{4}$ )

Vials 9\&10: $1.6 \mathrm{~mL}$ (will yield approximately $80 \mathrm{mg} / \mathrm{L} \mathrm{MnO}_{4}$ )

Vials 11\&12: $2 \mathrm{~mL}$ (will yield approximately- $\mathrm{mg} / \mathrm{MnO} 4$ )
Tedlar bay
47.209
39.629
$+430.562 .34 y$

$\mathrm{H}_{2} \mathrm{O}=522.72 \mathrm{~g}=\mathrm{ml}$

added $523 \mu$

TCE saturated soln.

shake ay ratary shateer sorpm. $12^{\circ} \mathrm{C}$

added $0.0664 \mathrm{~g}$ $\mathrm{KMnO}_{4}$ to $25 \mathrm{mldiH} \mathrm{H}_{2} \mathrm{O}$ in. foil wrapped volumetric. stir ihr.

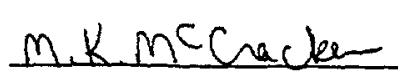

Recorded by

Recorded by

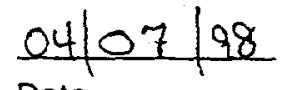

Date

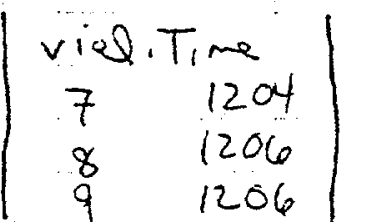

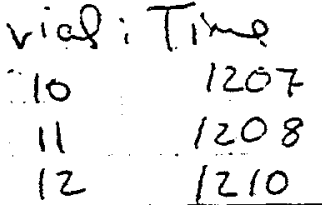

viaf: Time

11

1210

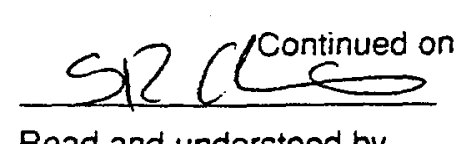

Read and understood by

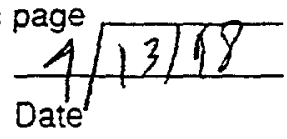




Date $\frac{04}{\text { Month }} \quad \frac{07}{19} \frac{98}{\text { Year }}$

9. Quickly dispense the spike solution into each of the reactors to be used. Completely fill each reactor to minimize free beadspace. Immediately re-seal each vial, record the "REACTION

START TIME" and reweigh each to determine the actual amount of spiked groundwater added.

Vigorously hand shake each vial at the beginaing of the reaction time and then place the samples in the $12 \mathrm{C}$ incubator/shaker.

.

10. At approximately 1 hour from the reaction start time, remove the reactors from the incubator and collect a $10 \mathrm{~mL}$ aliquot (using a syringe with a Luer Tip). Record the time the sample is collected.

$S^{2}$

11. Add a $0.45 \mu \mathrm{m}$ syringe filter unto the end of the syringe and dispense (filtered) approx. $5 \mathrm{~mL}$ Tof the sample into a pre-weighed vial holding a known volume of hexane $(\approx 5 \mathrm{~mL})$. This sample Evial will be weighed again after sample addition to determine the actual weight of sample added. All such extracts will be placed on a horizontal shaker for 2 hours. Store the extracts at $4^{\circ} \mathrm{C}$ until IG.C. analysis.

12. This step needs to be done fairly quickly since the reaction is not yet "quenched"!?

Dispense (filtered) the remaining portion of the sample in the syringe $(\approx 5 \mathrm{~mL})$ into a beaker for $\mathrm{MnO}_{4}^{-}$analysis. (Some samples may have to be diluted with $\mathrm{DI}$ water so that its spectrophotometric absorbance (at $\lambda=\$ 25 \mathrm{~nm}$ ) is less than that of the highest standard to be prepared ( $\left.50 \mathrm{mg} / \mathrm{LnO}_{4}\right)$. Check standards ( 10 and $\left.50 \mathrm{mg} / \mathrm{LnO}_{4}\right)$ will be prepared with reagent grafe $\mathrm{KMnO}_{4}$ and measured each analysis day. A new 5 point calibration curve will be prepared if the absorbance of these check standards differs from the expected value by $>15 \%$.

13. Also place any waste materials generated from the experiment in the appropriate satellite accumulation area.

14. GC ANALYSIS of VOCS

All VOC analyses for this experiment will be conducted using a G.C.JECD detector. The instrument will calibrated for TCE using a 5 point calibration curve with standard concentrations ranging from 5-1000 $\mathrm{\mu g} / \mathrm{L}$ (ppb). The VOC analyses of the hexane extracts will closely follow EPA Method 8000 B. Significant deviations from this method will be clearly documented.

Formal data packages will not be prepared for these analyses.

\begin{tabular}{|c|c|c|c|c|c|}
\hline Sa startetimp: & vial & wt emp & $\omega t+\mathrm{KMnn}_{4}$ & ut.tsoikesoln & sapple i.d. \\
\hline $4 / 7 / 98-1200$ & 1 & 25.18 .8 & 25.288 & 67.300 & $\mathrm{KmAO}_{\mathrm{m}}-0.1 \mathrm{ml}$ \\
\hline 1202 & 2 & 25.273 & 25.374 & 68.046 & $H_{0} K_{m n} O_{4}-0.1 \mathrm{ml}$ \\
\hline 1202 & 3 & 25.469 & 25.469 & 67.859 & NoKmnOt \\
\hline 1203 & .4 & 25.237 & 25.237 & 67.376 & $\mathrm{NOKnnO}_{4}$ \\
\hline 1204 & 5 & 25.494 & 25.801 & 68.181 & $\mathrm{KMnO}_{4}-0.3 \mathrm{ml}$ \\
\hline 1204 & 6 & 25.482 & 25.790 & 67.830 & $\mathrm{Km}_{\mathrm{n}} \mathrm{O} 4-0.3 \mathrm{~m}$ \\
\hline 1204 & 7 & 25.449 & 26.254 & 67.793 & $\mathrm{KMnO}_{4}-0.8 \mathrm{ml}$ \\
\hline 1206 & 8 & 25.230 & 26.033 & 67.798 & $K M_{n} O_{4}-0.8=$ \\
\hline 1206 & 9 & 25.259 & 26.857 & 67.644 & $K M_{1} 04-1.6 \mathrm{~m}$ \\
\hline 1207 & 10 & 25.296 & 26.898 & 67.617 & $\mathrm{KMnO}_{4}-1.6 \mathrm{ml}$ \\
\hline 1208 & 11 & $25.45 i$ & 27.447 & 68.018 & $\sin x^{2}-\infty$ \\
\hline 1210 & 12 & 25.227 & 27.220 & 67.389 & $\mathrm{KMn}_{n} \mathrm{O}_{4}-2.0 \mathrm{~m}$ \\
\hline
\end{tabular}

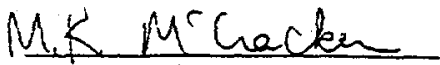

Recorded by
Date

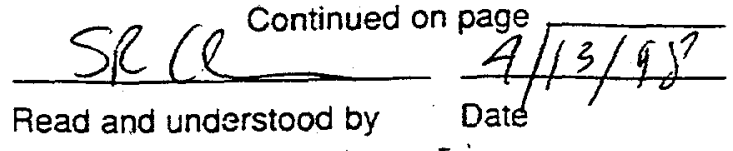

\section{Reaction Start time}


Subject Additional Lab Test \#1

Date $\begin{array}{ccc}04 & 07 & 19 \frac{98}{\text { Month }}\end{array}$

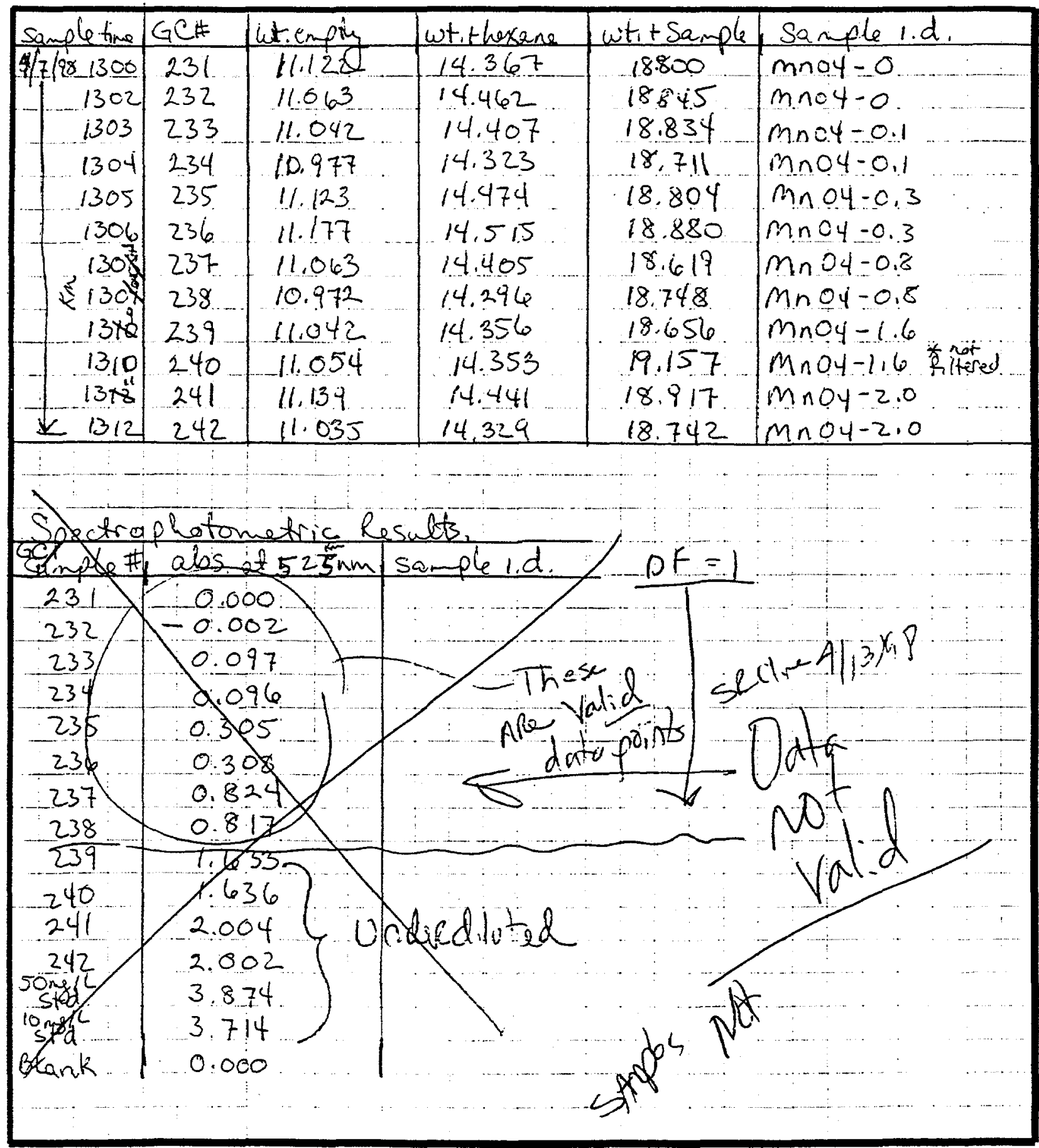

$\frac{\text { K.MSCracker }}{\text { Recorded by }} \frac{04 / 07 / 98}{\text { Date }}$

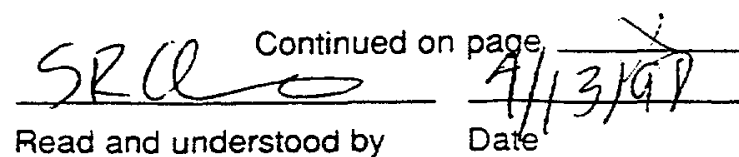


subject Permenganate Calibration Curve

\begin{tabular}{|c|c|}
\hline Date -04 & 08 \\
\hline Month & Day \\
\hline
\end{tabular}

\section{Preparation of Permanganate Calibration Curve Instrument: HACH DR/2000 spectrophotometer}

Summary: This procedure involves the production of a $\mathrm{MnO}_{4}{ }^{-}$calibration curve by the colorimetric absorbance $(\lambda=525 \mathrm{~nm})$ of prepared solutions of $\mathrm{KMnO}_{4}$ using a Hach DR/2000 spectrophotometer.

The following solutions concentrations will be prepared:

$5,10,20,30$, and $50 \mathrm{mg} / \mathrm{LnO}_{4}$.

The $50 \mathrm{mg} / \mathrm{MnO}_{4}$ std will result from the preparation of a $66.4 \mathrm{mg} / \mathrm{KMnO}_{4}$ solution

Reagent to be used:

CAIROX Potassium Permanganate, Free-Flowing Grade (Carus ${ }^{\text {TM }}$ )

STD 5 (50 $\mathrm{mg} / \mathrm{L} \mathrm{MnO}_{4}$ )

Prepare Solution by adding $33.2 \mathrm{mg}$ of $\mathrm{KMnO} 4$ into a $500 \mathrm{~mL}$ volumetric flask and fill to volume with DI water. Place this solution on a magnetic stir plate for at least 15 minutes before preparing the following standard solutions. $\quad 0.03374$ tati $50 \mathrm{c} d$ PI ulatax

$\operatorname{STD} 4\left(30 \mathrm{mg} / \mathrm{L} \mathrm{MnO}_{4}\right)$

$1845+14 d 0$ e $23-$

Add $15 \mathrm{~mL}$ of STDS into $25 \mathrm{~mL}$ volumetric and fill to volume with $\mathrm{DI}$ water.

STD 3 (20 $\mathrm{mg} / \mathrm{L} / \mathrm{MnO}_{4}$ )

Add $10 \mathrm{~mL}$ of STDS into $25 \mathrm{~mL}$ volumetric and fill to volume with $\mathrm{DI}$ water.

$$
\begin{aligned}
& \text { Pipethe } \\
& \text { colibunted } e \\
& 5.01 \\
& 2.509
\end{aligned}
$$

STD $2\left(10 \mathrm{mg} / \mathrm{L} \mathrm{MnO}_{4}{ }^{-}\right)$

Add $5 \mathrm{~mL}$ of STDS into $25 \mathrm{~mL}$ volumetric and fill to volume with DI water.

STD $1\left(5 \mathrm{mg} / \mathrm{L} \mathrm{MnO}_{4}\right)$

Add $2.5 \mathrm{~mL}$ of STDS into $25 \mathrm{~mL}$ volumetric and fill to volume with DI water.

Keep these solutions in darkness until used for calibration.

Record the abs obtained for a DI water blank and for each sample

Prepare the linear calibration curve and constants.

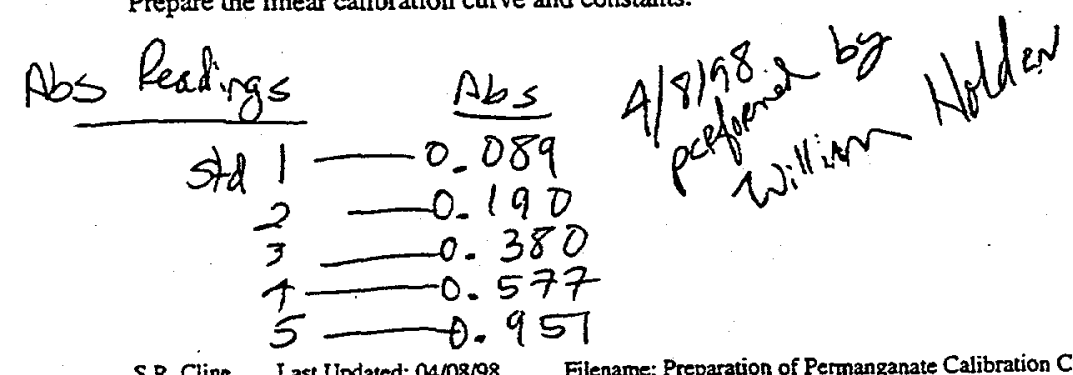

S.R. Cline Last Updated: 04/08/98 Filenarne: Preparation of Petmanganate Calibration Curve.doc
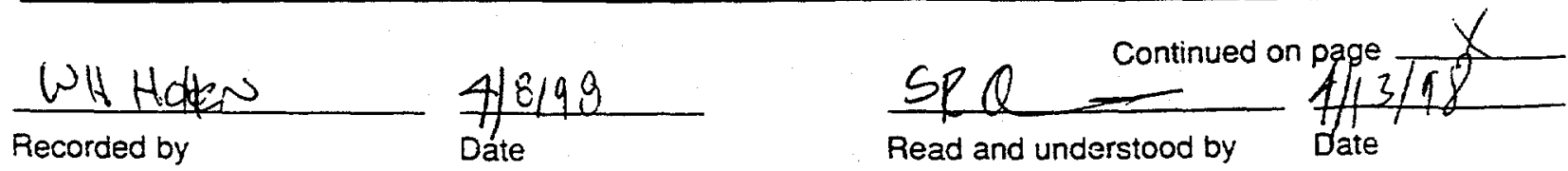
s Subject Hiritival LibTest II
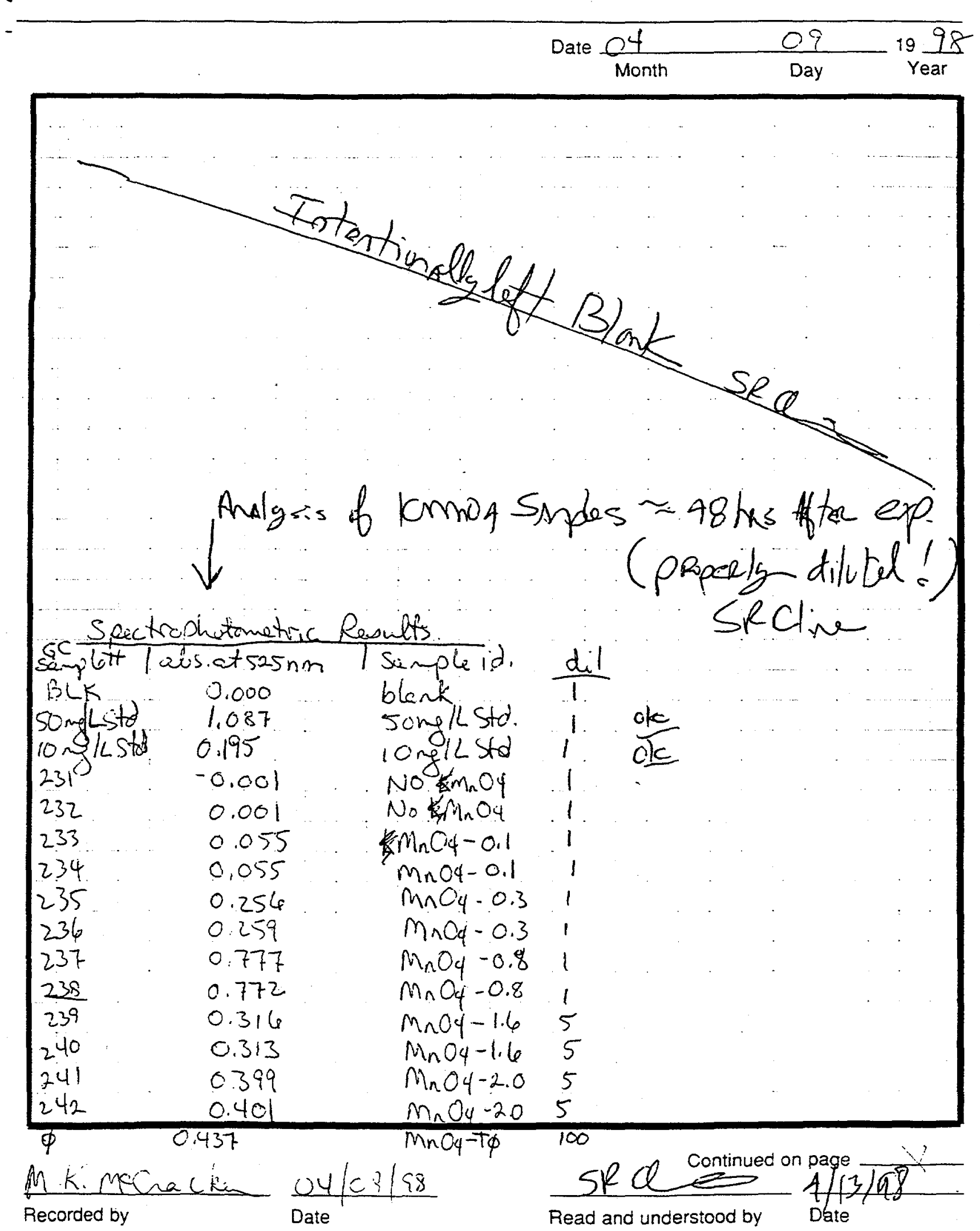

$\mathrm{F}-34$ 
Subject $:$ pperimet $3 a-R_{1}$

$$
\text { Date } \frac{O 4}{\text { Mon }}
$$

General Procedure for Task 3a Experiments - Oxidant Demand of Reactive Zone Media

To be conducted at ORNL/ESD)

1. All soil and groundwater to be used in these experiments (TAN-40 groundwater. TAN-37

crushed and aggregate basalt, and sediment) will be prepped by sparging and/or drying to remove

any sesidual TCE present on the media. Doing so will allow this experiment to be conducted

F with a consistent and controlled initial TCE concentration $(\approx 0 \mathrm{mg} / \mathrm{L})$. Properly indicate usage of

this media in the treatability study tracking logbook.

2. Follow Table 2-3 in Chapter 2 of the Implementation Plan to obtain which test conditions to

evaluate (soil type, oxidant concentration, etc.) The use of glass, wide-mouth erlenmeyer flasks,

beakers, or equivalent will be used. It is currently planned to run four (4) test conditions from

Table 2-3 each time this procedure is used. Thus, 8 reactors will be used during each run of this procedure.

3. Obtain the tare weight of each reactor. Add approximately $100 \mathrm{~g}$ of solid media to the reactors in Table 2-3 that require it Re-weigh the reactors to determine the actual mass added. To each reactor, add $400 \mathrm{~mL}$ of $\mathrm{TAN}-40$ ). Re-weigh each reactor to determine the actual weight of

solution added. (A calibration check of the gravimetric scale will be performed each day of use.)

4. Place the reactors in the incubator at $12^{\circ} \mathrm{C}$ and allow to equilibrate to that temperature.

Slowly agitate the reactors during this step.

5. Once temperature equilibrium is reached, remove the reactors from the incubator and collect a $5 \mathrm{~mL}$ aliquot (using a disposable syringe) of the water and/or slurry from each for $\mathrm{pH}$ analysis.

6. The pH analyses will be conducted using conventional pH meters/electrodes, calibrated each day of use via a minimum of two standard buffer solutions $(4,7$, and 10$)$. Values obtained for each sample will be recorded. A calibration check will also be conducted following the last sample to be measured each day. Values obtained for the samples will be corrected if a significant drift (i.e., $>15 \%$ ) occurred.

7. Add the appropriate mass of cystalline $\mathrm{KMnO}_{4}$ (Carus ${ }^{\mathrm{TM}}$ Free Flowing Technical Grade) into each reactor according to which test condition in Table 2-3 is being evaluated. The exact mass of $\mathrm{KMnO}_{4}$ added to each reactor will be determined gravimetrically and recorded. The time that

$\mathrm{KMnO}_{4}$ is added to each individual reactor shall also be recorded (reaction start time)

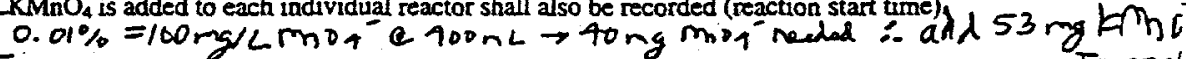

8. Place each reactor back into the $12^{\circ} \mathrm{C}$ incubator as the oxidant consumption renction proceeds. To ezal

For each reactor, remove the reactor from the incubator at approximately $5-10$ minutes from the reaction start time, and collect a $5-10 \mathrm{~mL}$ aliquot (using a disposable plastic syringe with a Luer Tip). Record the time the sample was collected and replace the reactor back into the incubator.

9. Add a $0.45 \mu \mathrm{m}$ syringe filter onto the end of the syringe and filter approximately $1-2 \mathrm{~mL}$ into a beaker. Remove the syringe filter and dispense the remaining (unfiltered) portion of the sample

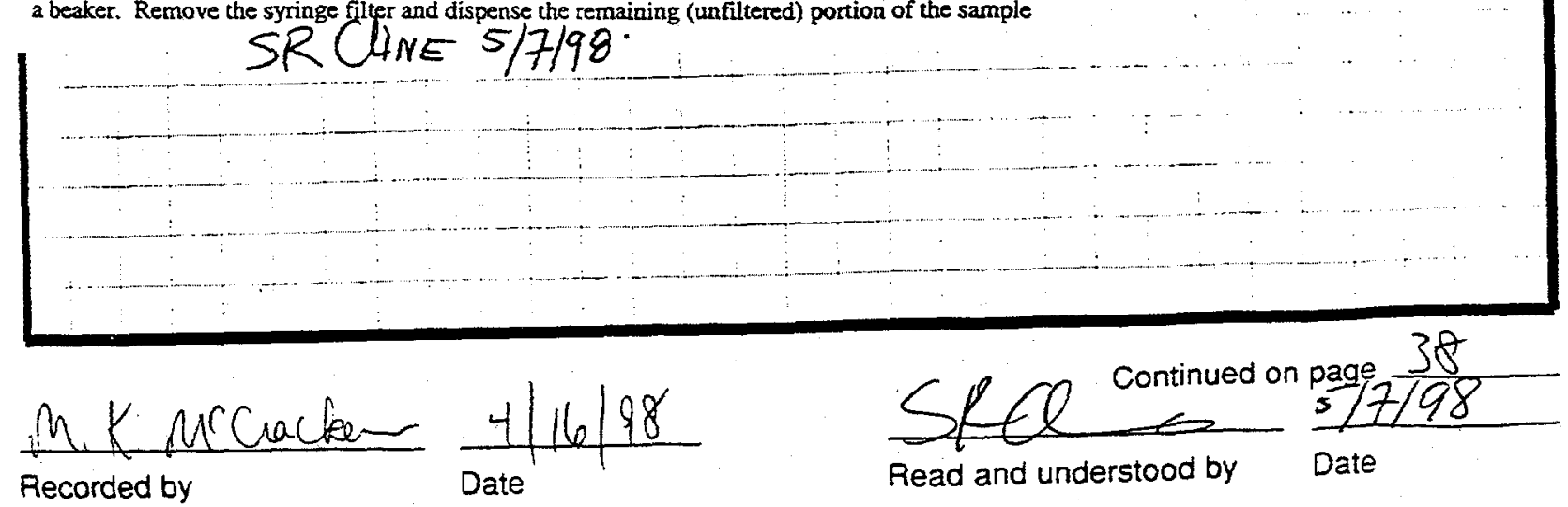


Subject Experiment $3 a-R_{1}$

Date $\frac{O 4}{16} \quad 19 \frac{98}{\text { Month }}$

into another beaker for $\mathrm{pH}$ analysis. Measure and record the $\mathrm{pH}$ of each sample as done in Step 6.

10. Perform a $\mathrm{MnO}_{4}$ analysis on the filtered sample from the previous step. The sample is filtered to remove particulate matter that could interfere with the analysis.) The filtered sample will likely have to be diluted with DI water so that its spectrophotometric absorbance (at $\lambda=525$ $\mathrm{nm}$ ) is less than that of the highest standard to be prepared ( $50 \mathrm{mg} / \mathrm{L} \mathrm{MnO4-)}$. Check standards (10 and $50 \mathrm{mg} / \mathrm{L}$ MnO4-) will be prepared with reagent grade $\mathrm{KMnO}_{4}$ and measured each analysis day. A new 5 point calibration curve will be prepared if the absorbance of these check standards differs from the expected value by $>15 \%$.

11. Collect and analyze aliquots from each reactor for $\mathrm{pH}$ and $\mathrm{KMnO}_{4}$ (Steps 8-10) at the following ADDITIONAL time periods: lhr, $2 \mathrm{hrs}, 4 \mathrm{hrs}, 18 \mathrm{hrs}$, and $24 \mathrm{hrs}$.

12. Interpret results and clean up the reactors for re-use in the next run of the experiment. Also place any waste materials generated from the experiment in the appropriate satellite accumulation area.

Table 2-3. Oxidant consumption by reactive zone media.

\begin{tabular}{|c|c|c|c|c|c|c|}
\hline & Media & $\begin{array}{l}\text { Basalt } \\
\text { Form }\end{array}$ & $\begin{array}{c}\text { Liquid: Solid } \\
\text { Ratio }\end{array}$ & $\begin{array}{c}\text { Initial TCE } \\
\text { Concentration } \\
(m g / L)\end{array}$ & $\begin{array}{c}\text { Initial Organic } \\
\text { Co-Contaminant } \\
\text { Concentration } \\
\text { (m\&l) } \\
\end{array}$ & $\begin{array}{c}\text { Initial } \\
\text { Permanganate } \\
\text { Concentration } \\
(\%) \\
\end{array}$ \\
\hline \multirow{8}{*}{ RUN 1} & Groundwater & NA & $\mathrm{NA}$ & 0 & 0 & 0.01 \\
\hline & Groundwater & NA. & NA & 0 & 0 & 0.01 \\
\hline & Ground water/basalt & Crushed & $4: 1$ & 0 & 0 & 0.01 \\
\hline & Ground waterfbasalt. & Crushed & $4: 1$ & 0 & 0 & 0.01 \\
\hline & Groundwater/aasalt & Aggregate & $4: 1$ & 0 & 0 & 0.01 \\
\hline & Groundwaterfoasalt & Aggregate & $4: 1$ & 0 & 0 & 0.01 \\
\hline & Groundwater/sediment & $\mathrm{NA}$ & 4:1 & 0 & 0 & 0.01 \\
\hline & Groundwater/sediment & NA & $4: 1$ & 0 & 0 & 0.01 \\
\hline
\end{tabular}
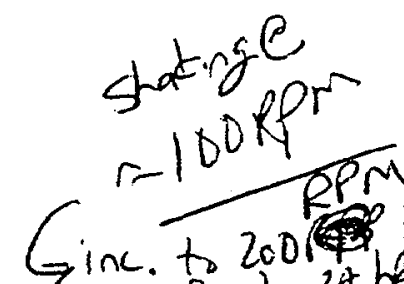

$\rightarrow$ inc. to 200 r ate +24 th? cellected $=\operatorname{trn} L$ aliguet eachtine

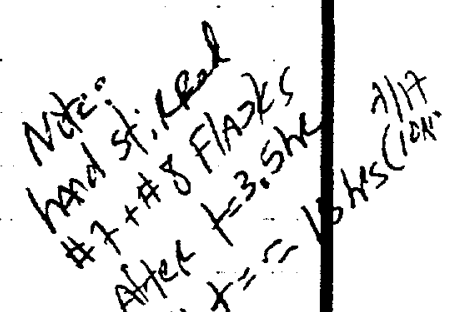

\begin{tabular}{|c|c|c|c|c|}
\hline Sample\# & Haskwt. & flask+medium & $\mathrm{flask}+\mathrm{H}_{2} \mathrm{O}$ & sample id \\
\hline 1 & 214.56 & $\ldots$ & 610.87 & groundwater \\
\hline 2 & 152.05 & & 548.67 & dweter \\
\hline 3 & 151.17 & 251.49 & 650.81 & Crushed basalt \\
\hline 4 & 223.92 & 324.34 & 725.49 & crushed basalt \\
\hline 5 & 161.24 & 261.04 & 658.38 & asgregato losalt \\
\hline 6 & $2,3.94$ & 313.99 & 7.14 .20 & ajgregate basalt \\
\hline 7 & 219.68 & 319.79 & $7 / 4.20$ & sediment \\
\hline 8 & 161.88 & 262.06 & 657.02 & sedment \\
\hline
\end{tabular}

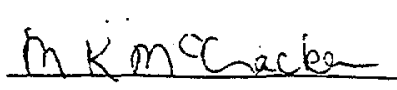

Recorded by

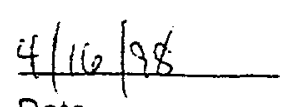

Date

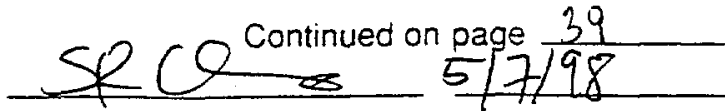

Read and undorstood by
Date 
Subject Experiment $3 a-k 1$

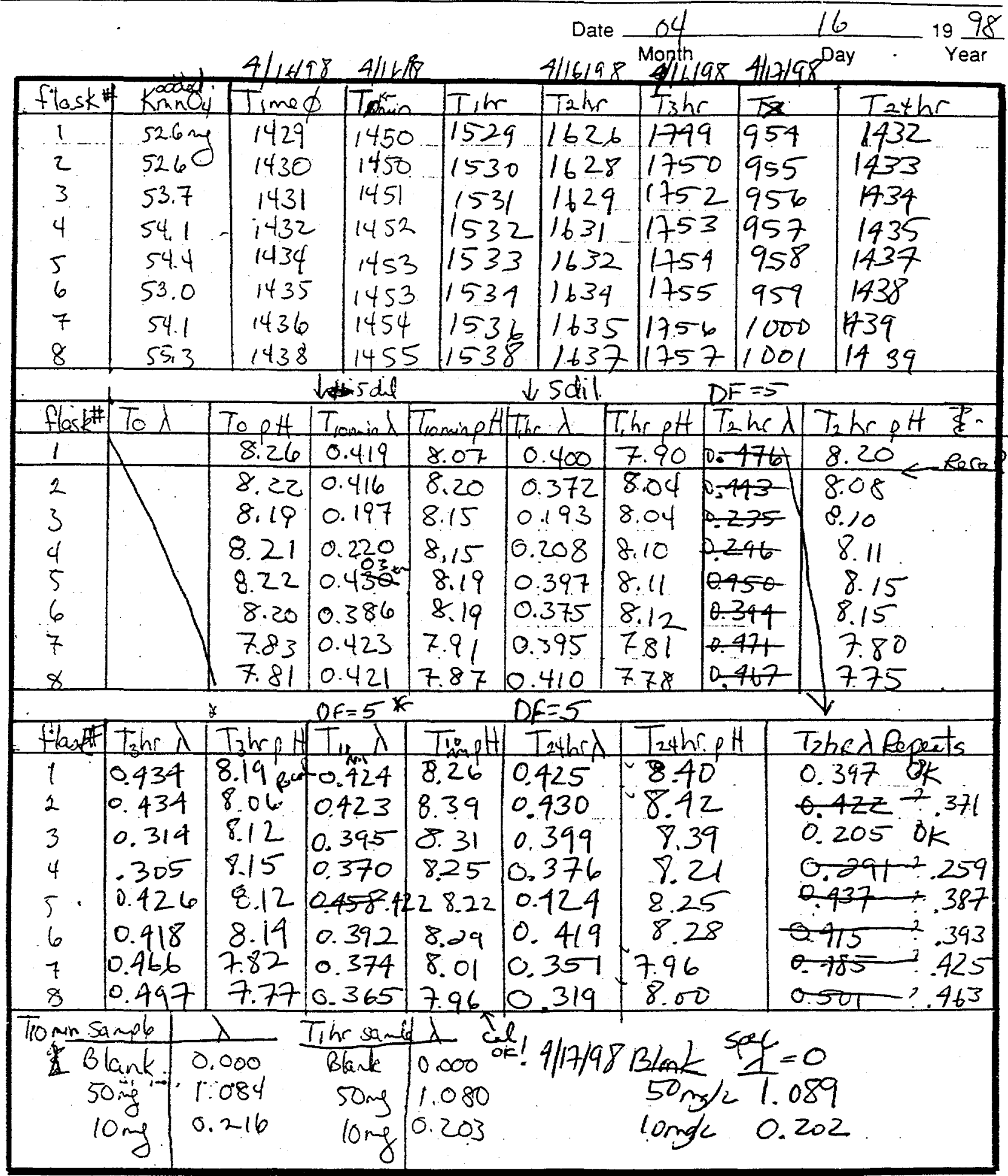

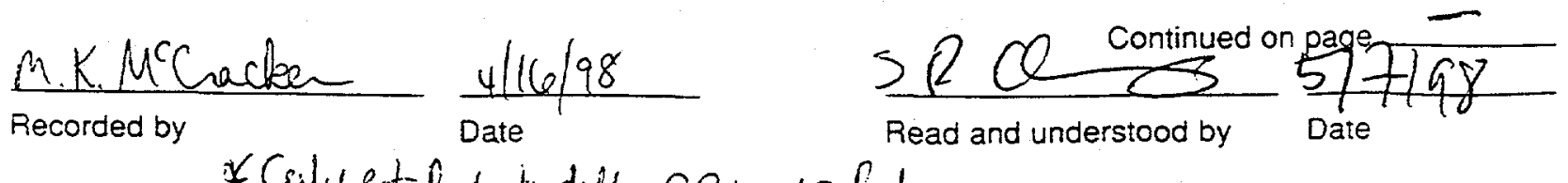

$$
\text { * Cilibratid but ditl Pribersed! }
$$




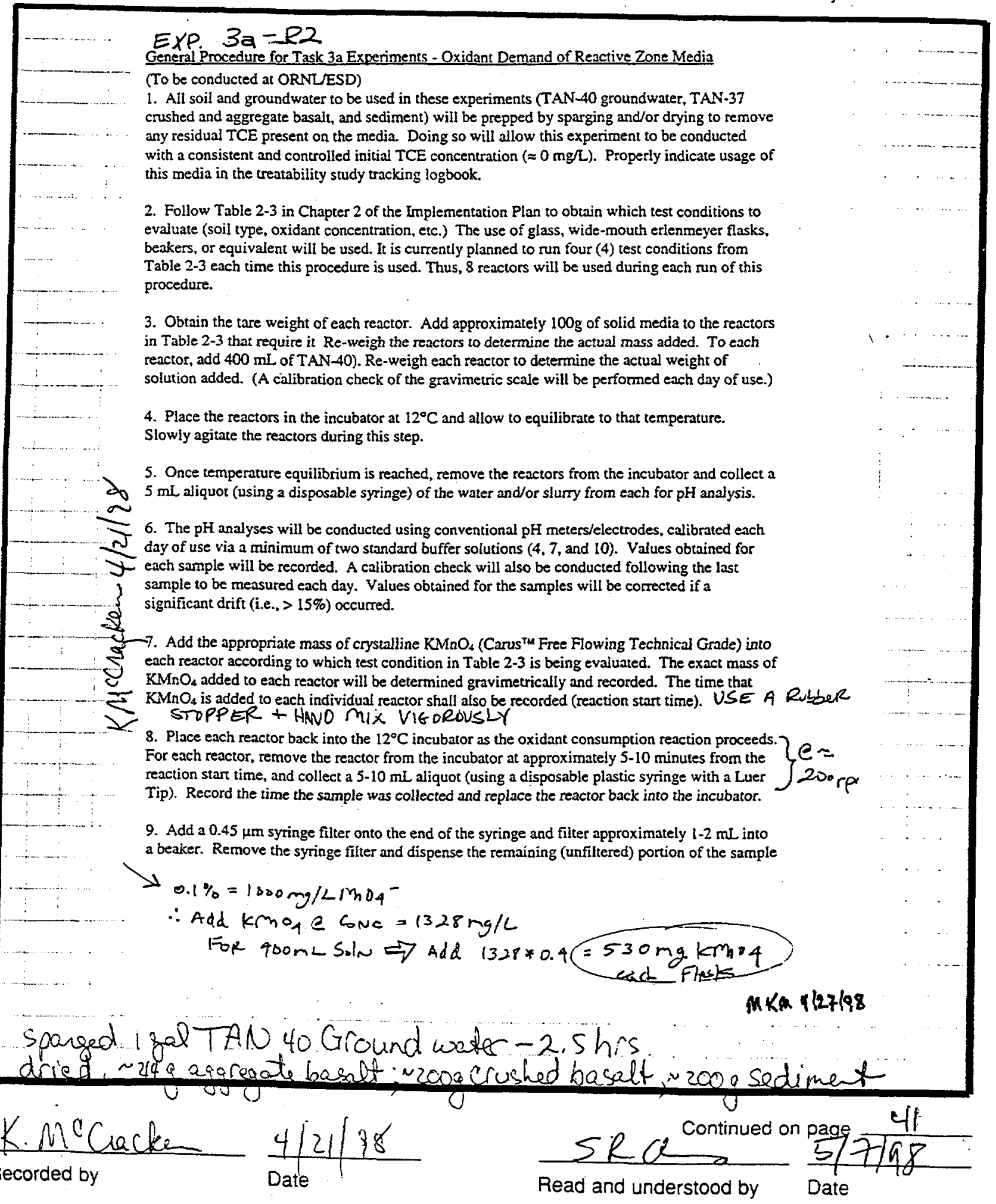


Subject $20092 \cdot+2$

Date $\frac{24}{\text { Month }} \frac{21}{\text { Day }} 19 \frac{98}{\text { Year }}$

into another beaker for $\mathrm{pH}$ analysis. Measure and record the $\mathrm{pH}$ of each sample as done in Step

6.

10. Perform a MnO, analysis on the filtered sample from the previous step. The sample is filtered to remove particulate matter that could interfere with the analysis.) The filtered sample

will likely have to be diluted with DI water so that its spectrophotometric absorbance (at $\lambda=525$

$\mathrm{nm}$ ) is less than that of the highest standard to be prepared ( $50 \mathrm{mg} / \mathrm{MnO4}$ ). Check standards

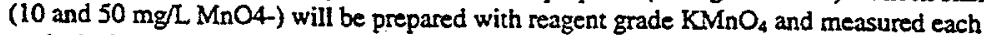

analysis day. A new 5 point calibration curve will be prepared if the absorbance of these check

standards differs from the expected value by $>15 \%$.

11. Collect and analyze aliquots from each reactor for $\mathrm{pH}$ and $\mathrm{KMnO}_{4}$ (Steps 8-10) at the

following ADDITIONAL time periods: $1 \mathrm{hr}, 2 \mathrm{hrs}, 4 \mathrm{hrs}, 18 \mathrm{hrs}$, and $24 \mathrm{hrs}$.

12. Interpret resuits and clean up the reactors for re-use in the next run of the experiment. Also place any waste materials generated from the experiment in the appropriate satellite accumulation arca.

A DF $=50$ staild uark .imL SAnple $\rightarrow 5 \mathrm{mz}$ DF Watze $[$ Aatualy, OF $=51]$

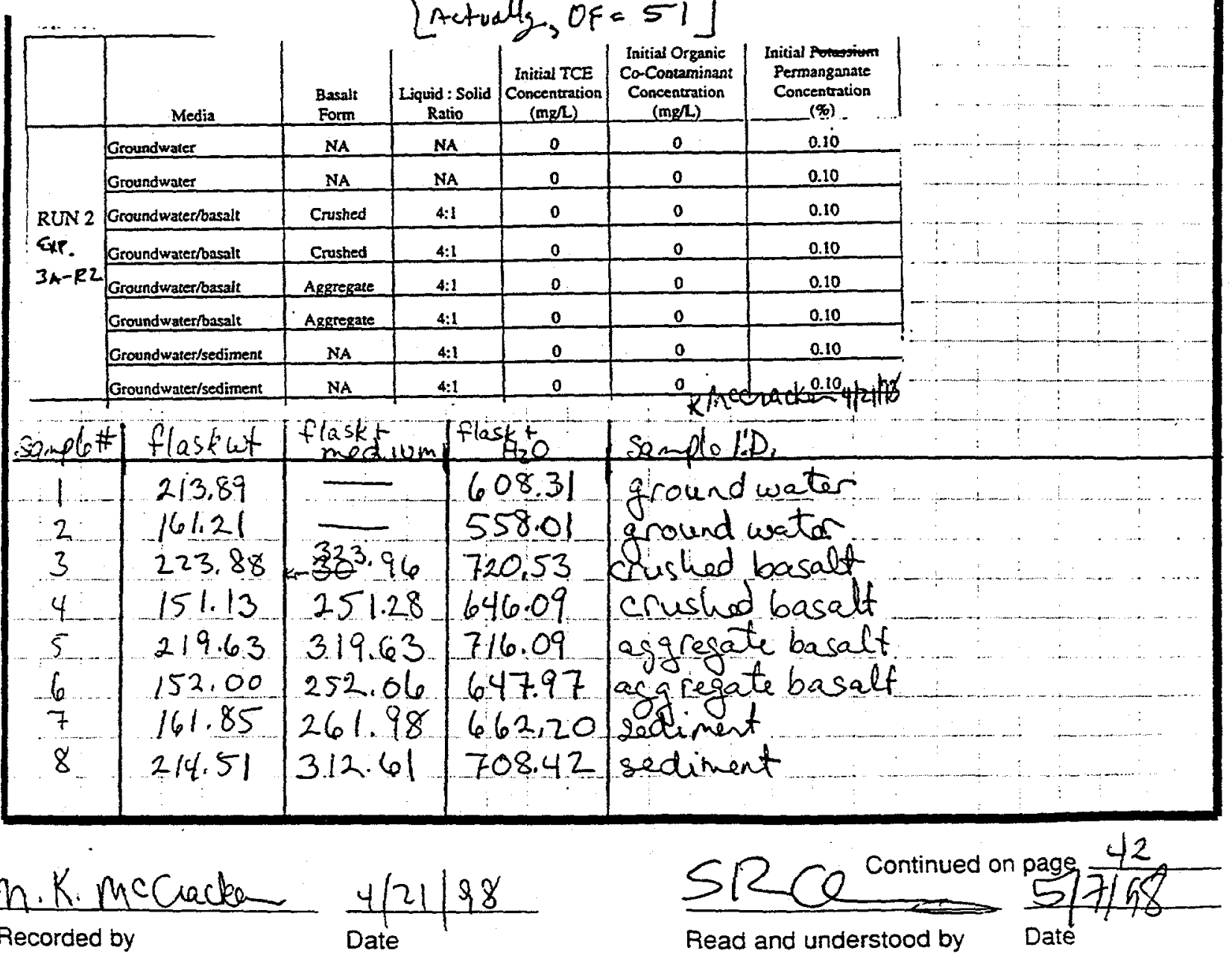


Subject $\sum_{x} \rho .3 a-R z$

Date

$\frac{O 4}{\text { Month }}$

21

Day

$19 \frac{98}{4 e a r}$

Year

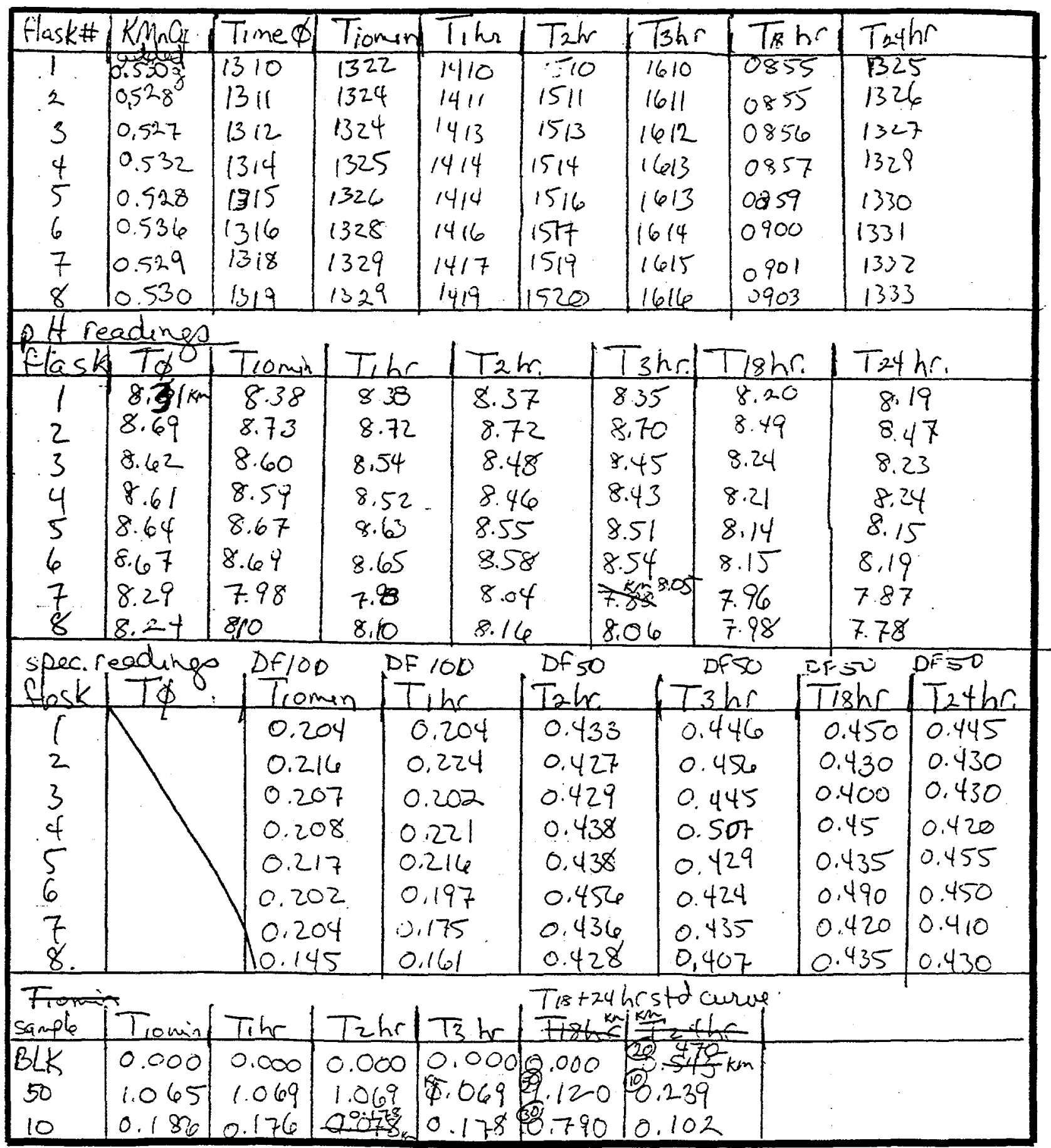

$\frac{M \cdot K \cdot M^{C} C a c k e}{\text { Recorded by }} \frac{4 / 21 / ; 8}{\text { Date }}$

Continued on page

Read and understood by Date 
Subject Calibration Sio dardo

Date $\begin{array}{lll}4 & 24 & 1998 \\ \text { Month } & \text { Day } & \text { Year }\end{array}$

Preparation of Calibration Standards

(From VOC custom mixes)

Source:

Supelco Custom Mix Standard, $200 \mathrm{mg} / \mathrm{L}$ each Compound

DATE PREPARED $4 / 22 / 98$

LOT No. LA 73307

Prepare $10 \mathrm{mg} / \mathrm{L}$ working STOCK Solution

Add $0.5 \mathrm{~mL}$ of Custom Mix (Ampule) to $10 \mathrm{~mL}$ Flask filled to volume with hexane

(Weigh and record syringe when full and then when empty)

SYRINGE FULL: $\frac{17.5875}{17.1712} \therefore 0.4163 \mathrm{~g}$ (rostm MiX Albel

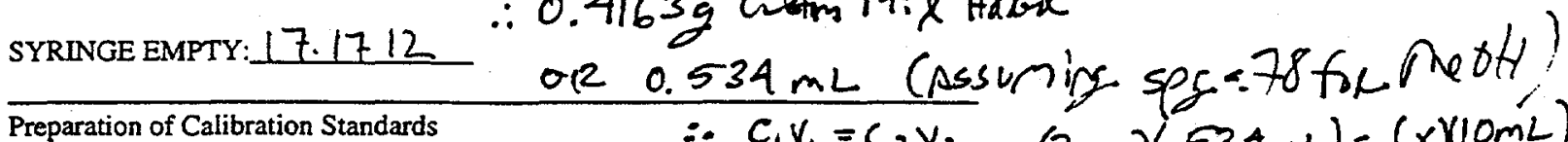

$$
\left.\therefore c_{1} v_{1}=c_{2} v_{2} \quad 000\right)(.534 \mathrm{~mL})=(\times)\left(10 \mathrm{~mL}^{2}\right)
$$

$1000 \mathrm{ppb}$ Add $2.5 \mathrm{~mL}$ STOCK Solution to hexane in $25 \mathrm{~mL}$ Flask. Ac tual $=1068 \mathrm{ppb}$

$\rightarrow$

pem $x=10.68 \mathrm{PPM}$

NAdd $5 \mathrm{~mL}$ of 1000 PPB STD into $10 \mathrm{~mL}$ Flask and fill to volume with hexane Actucl $=534 \mathrm{ppb}$

$\$$

$100 \mathrm{ppb}$

3

$30 \mathrm{ppb}$

JAdd $0.5 \mathrm{~mL} 1000$ PPB STD into $10 \mathrm{~mL}$ Flask and fill to volume with hexane A of ud $=53.4 \mathrm{pP}$

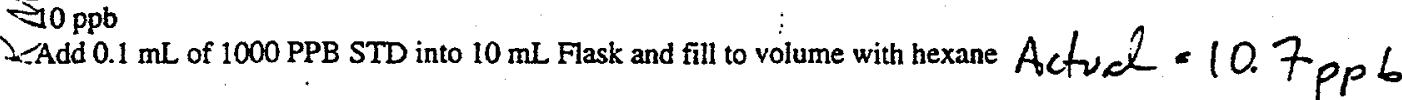

$5 \mathrm{ppb}$

Add $0.05 \mathrm{~mL}(50 \mu \mathrm{L})$ of 1000 PPB STD into $10 \mathrm{~mL}$ Flask and fill to volume with hexane

Place these standards in vials for storage in the 211 Freezer.

Actucl $=5.2$ felo

Place the Certificate of Analysis into the Laboratory Research Notebook.

bilance calib. $\times 177339$ wt: $10.0 \mathrm{~g} \rightarrow 9.9998 \mathrm{~g}$

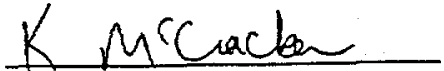

Recorded by

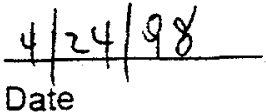

Date

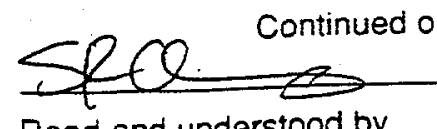

Read and understood by
426198

Date 
Subject Additional Exp. Fz

Date $\frac{04}{\text { Month }} \frac{28}{\text { Day }} 19 \frac{98}{\text { Year }}$

Additional Lab Experiment \#2

Note: This experiment is being in conducted in addition to the tasks set forth in the statement of work.

1. All groundwater to be used in this experiment (TAN -40 groundwater) will be prepped by sparging to remove any residual TCE present on the media. Doing so will allow this experiment to be conducted with consistent and controlled initial TCE concentrations via contaminant spiking.

dे (Properly indicate usage of this media in the treatability study tracking logbook.) S

If 2. Prepare a STOCK (Saturated) TCE solution (1100 mg/L) by adding $100 \mu \mathrm{L}$ of Pure TCE into a of $12 \mathrm{~mL}$ VOA vial filled to volume with DI Water and allow to equilibrate overnight at room ol temperature. (Use of a STOCK solution rather than pure phase TCE to prepare the spiking solution affords better accuracy in obtaining the target concentration.)

2A-Kitty: It would be nice to measure the conc of the Saturated solution for our own information. Please extrast $10 \mu \mathrm{L}$ of this $S T O C K$ into $20 \mathrm{~mL}$ hexane for 2 hours, then put $1 \mathrm{~mL}$ of the hexane phase into a ge vial for analysis $(D F=2000)$.

3. Obtain the tare weight of the 1 liter (small) Tedlar bag to be used to prepare the spike solution. Fill with approximately $850 \mathrm{~mL}$ of TAN-40 groundwater. By gravimetric methods, determine the amount of groundwater added to the container. (A calibration check of the gravimetric scale will be performed each day of use.)

Stock TCE (safurated)

4. Add the appropriate quantity of the Saturated STOCK TCE solution to produce a $1 \mathrm{mg} / \mathrm{L}$ TCE spike solution. (The volume of saturated STOCK TCE needed should be approx. $0.78 \mathrm{~mL}$ for 850 miL of GW). Place the Bag in the incubator at $12 \mathrm{C}$ overnight. All Information regarding the preparation of the spiking solution will be recorded in the laboratory research notebook.

5. Obtain the tare weight of twenty (20) $40 \mathrm{~mL}$ VOA vials.

6. Prepare a $2660 \mathrm{mg} / \mathrm{L} \mathrm{KMnO4}$ solution by adding $66.44 \mathrm{mg}$ ( 0.0664 grams) Carus ${ }^{\text {TM }}$ Free Flowing Technical Grade KMnO4 into a $25 \mathrm{~mL}$ volumetric flask and fill to volume with DI water. (This solution should have $\mathrm{MnO}_{4}{ }^{+}$concentration of $2000 \mathrm{mg} / \mathrm{L}$ ) $* w_{4}$ w:ll need $\approx 2 \sim \mathrm{mL}$ of :

7. After mixing for at least 1 hour. collect an aliquot of this solution for $\mathrm{KMnO} 4$ analysis. The sample will have to be diluted to less than $50 \mathrm{mgl} \mathrm{MnO}_{4}^{\circ}$. (DF=80-.625 $\mathrm{mL}$ into a $50 \mathrm{~mL}$ flask will work great!)

TNEXT DAY

8. Dispense the following volumes of the $\mathrm{KMnO} 4$ solution into the $40 \mathrm{~mL}$ vials and reweigh eac

Vials 1-6: $0.3 \mathrm{~mL}$ (will yield approximately $15 \mathrm{mg} / \mathrm{MnO} \mathrm{Mn}_{4}$ )

Vials 7-12: $1.2 \mathrm{~mL}$ (will yield approximately $60 \mathrm{mg} / \mathrm{L} \mathrm{MnO}$ )

Viais 13-18: $2 \mathrm{~mL}$ (will yield approximately $100 \mathrm{mg} / \mathrm{MnO}_{4}^{-}$)

Viais 19-20: NONE

9. Remove spike solution from incubator and quickly dispense the spike solution into each of the reactors to be used. Completely fill each reactor to minimize free headspace. Immediately re-seal $\vec{\nabla}$ each vial, record the "REACTION START TIME" and reweigh each to determine the acrual

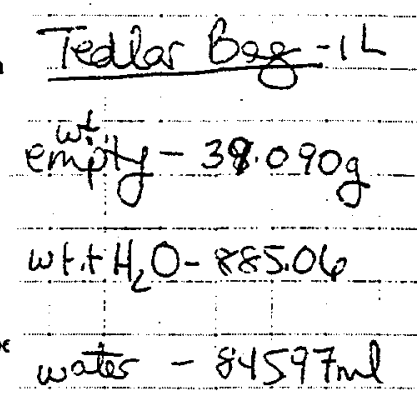

S.R. Cline Last Updated: 04/24/98

Filename: Additional Lab Experiment *2.doc

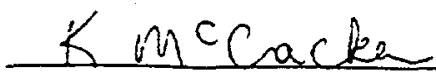

Recorded by

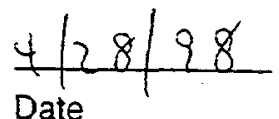

Date

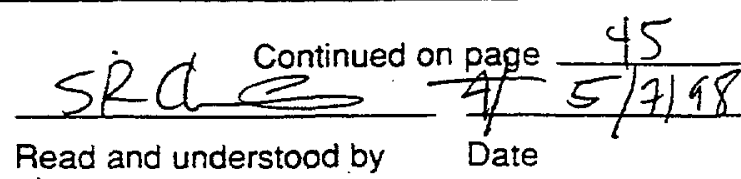


Subject kng Additional Exp. \#2

Date $\frac{O 4}{\text { Month }} \quad$ Day 1998

amount of spiked groundwater added. Vigorously hand shake each vial at the beginning of the reaction time and then place the samples in the $12 \mathrm{C}$ incubator/shaker. C $20 \mathrm{DPPM}$

10. At 2 hours from the reaction start time, remove vials $1,2,7,8,13,14$ from the incubator and collect a $10 \mathrm{~mL}$ aliquot (using a syringe with a Luer Tip). Record the time the sample is collected. (We are now "done" with these $40 \mathrm{~mL}$ vials)

11. Dispense (UN filtered) approx. $5 \mathrm{~mL}$ of the sample into a pre-weighed vial holding a known volume of hexane $(\approx 5 \mathrm{~mL})$. This sample vial will be weighed again after sample addition to determine the actual weight of sample added. All such extracts will be placed on a horizontal shaker for 2 hours. Store the extracts at $4^{\circ} \mathrm{C}$ until G.C. analysis. The hexane phase of these extracts will NOT have to be diluted for analysis.

12. This step needs to be done fairly quickly since the reaction is not yet "quenched"!!

Filter (via $0.45 \mu \mathrm{m}$ syringe filter) the remaining portion of the sample in the syringe $(\approx 5 \mathrm{~mL})$ into a beaker for $\mathrm{MnO}_{4}$ analysis. (Some samples may thave to be diluted with $\mathrm{DI}$ water so that its spectrophotometric absorbance (at $\lambda=525 \mathrm{~nm}$ ) is less than that of the highest standard to be prepared ( $50 \mathrm{mg} / \mathrm{MnO}_{4}$ ).

VIALS 1-6 NO Dilution will be Needed

VIALS 7-18 A DF $=3$ will work fine

Check standards ( 10 and $50 \mathrm{mg} / \mathrm{MnO}$ ) will be prepared with reagent grade $\mathrm{KMnO}_{4}$ and measured each analysis day. A new 5 point calibration curve will be prepared if the absorbance of these check standards differs from the expected value by $>15 \%$.

13. At 4-5 hours after the start of the reaction, repeat Steps 10-12 using Vials 3,4,9.10,15,16

14. At 24 hours after the start of the reaction, repeat Steps 10-12 using Vials 5,6,11,12,17,18.

15. After the 24 hrs samples are processed, remove the Controls (Vials 19 and 20) from the incubator and collect a $5 \mathrm{~mL}$ sample from each, dispensing it (UN Filtered) into a pre-weighed vial holding a known volume of hexane $(\approx 5 \mathrm{~mL})$. This sample vial will be weighed again after samplo addition to determine the actual weight of sample added. All such extracts will be placed on a horizontal shaker for 2 hours. Store the extracts at $4^{\circ} \mathrm{C}$ until G.C. analysis. The hexane phase of these two extracts will need a dilution of 101.

\section{GC ANALYSIS of VOCs}

All VOC analyses for this experiment will be conducted using a G.C./ECD detector. The instrument will calibrated for TCE using a 5 point calibration curve with standard concentrations ranging from 5-1000 $\mu \mathrm{g} / \mathrm{L}$ (ppb). The VOC analyses of the hexane extracts will elosely follow EPA Method 8000 B. Significant deviations from this method will be clearly documented. Formal data packages will not be prepared for these analyses.

17. Also place any waste materiais generated from the experiment in the appropriate satellite accumulation area.
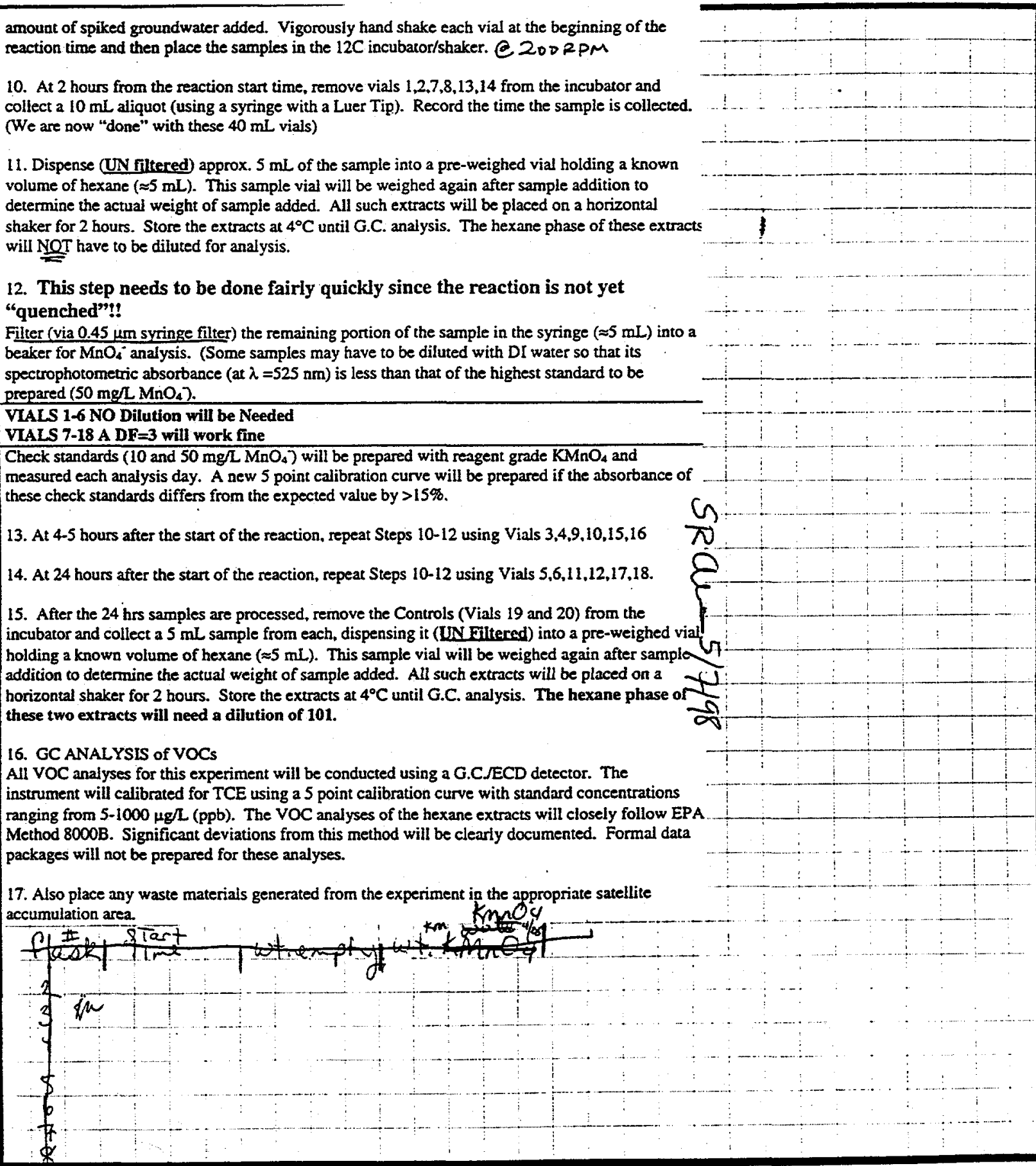

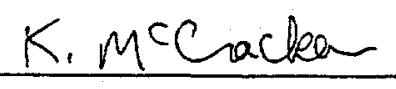

Recorded by

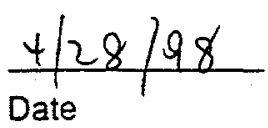

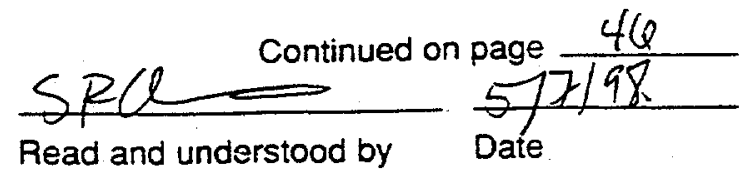


Subject Extra $\varepsilon_{x p}, \mathbb{Z}_{2}$

Date oy

28

$19 ? 8$

Month Day

Year

\begin{tabular}{|c|c|c|c|c|c|c|}
\hline To & $V \mid a l \#$ & wt.empty & $\omega t,+\mathrm{KM}_{\mathrm{NO}} \mathrm{O}_{4}$ & spike soin. & \multirow{3}{*}{\multicolumn{2}{|c|}{ 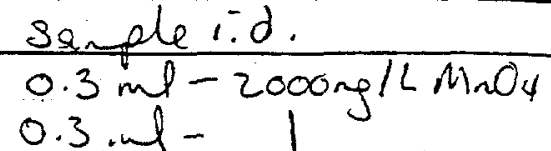 }} \\
\hline 1152 & 1 & 21.857 & 25.154 & 66.657 & & \\
\hline 1153 & 2 & 25.082 & 25.389 & 67.549 & & \\
\hline 1154 & 3 & 25.078 & $=25.374$ & 68.549 & \multicolumn{2}{|l|}{$0.3 \mathrm{ml}-$} \\
\hline 1,54 & 4 & 25.280 & 25.575 & 67.958 & \multicolumn{2}{|l|}{$0.3 \mathrm{ml}-$} \\
\hline 1155 & 5 & 25.047 & 25.345 & 67.371 & \multicolumn{2}{|l|}{$0.3 \mathrm{ml}^{-}$} \\
\hline 1156 & 6 & 25.238 & 25.532 & 67.691 & \multicolumn{2}{|l|}{ O3 mil- } \\
\hline 1156 & 7 & -25.164 & 26.351 & 67.098 & \multicolumn{2}{|l|}{$1.2 \mathrm{ml}$} \\
\hline 1157 & 8 & 24.942 & 26.137 & 66.941 & \multicolumn{2}{|l|}{$1.2 \mathrm{~m}$} \\
\hline 1157 & 9 & 25.227 & 26.427 & 67.405 & \multicolumn{2}{|l|}{$1.2 \mathrm{ml}$} \\
\hline 1158 & 10 & 25.088 & 26.291 & 67.205 & \multicolumn{2}{|l|}{$1.2 \mathrm{mil}$} \\
\hline 1159 & 11 & 25.209 & 26.405 & 67.449 & \multicolumn{2}{|l|}{$1.2 \mathrm{mal}$} \\
\hline 1159 & 12 & 24.862 & 26.065 & 67.571 & \multicolumn{2}{|l|}{$1.2 \mathrm{ml}$} \\
\hline 1200 & 13 & 23.763 & 25.716 & 66.797 & \multicolumn{2}{|l|}{$20 \mathrm{ill}$} \\
\hline 1200 & 14 & 24.505 & 26.478 & 66,942 & \multicolumn{2}{|l|}{$2.0 \mathrm{mel}$} \\
\hline 1201 & 15 & 24.530 & 26488 & 66.810 & \multicolumn{2}{|l|}{$2.0 \mathrm{ml}$} \\
\hline 1201 & 16 & 25.134 & 27.102 & 67.617 & \multicolumn{2}{|l|}{$2.0 \mathrm{ml}$} \\
\hline 1202 & 17 & 25.131 & 27.083 & 67.953 & \multicolumn{2}{|l|}{$2.0 \mathrm{ml}$} \\
\hline 1202 & 18 & 25.270 & 27.226 & 67.312 & \multicolumn{2}{|l|}{$2.0 \mathrm{ml}$} \\
\hline 1203 & 19 & 24.961 & - & 68.004 & \multicolumn{2}{|l|}{$-o m \mathrm{KMnO}_{4}$} \\
\hline 1203 & 20 & 24.996 & & 67.410 & \multicolumn{2}{|l|}{$=0 \mathrm{ml} \mathrm{Km}_{2} \mathrm{O}_{4}$} \\
\hline \multicolumn{7}{|c|}{ Spec. Rooults } \\
\hline vicl\# & \multicolumn{2}{|c|}{1 Abs.at 525} & diluthons & \multirow{2}{*}{$\frac{\text { Vial } \#}{11}$} & abs.ats25 & doustions \\
\hline 1 & \multicolumn{2}{|c|}{0.281} & 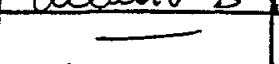 & & \multirow{4}{*}{$\begin{array}{r}0.348 \\
0.285 \\
0.690 .609 \\
0.631\end{array}$} & \\
\hline 2 & & 284 & & 12 & & \\
\hline 3 & & 281 & & 13 & & 3 \\
\hline 4 & & 276 & - & 14 & & 3 \\
\hline 5 & & 263 & - & 15 & 0.627 & 3 \\
\hline 6 & & 258 & - & 16 & 0.594 & 3 \\
\hline 7 & & 365 & 3 & 17 & 0.529 & 3 \\
\hline 8 & & 363 & 3 & 18 & 0.564 & 3 \\
\hline 9 & & 389 & 3 & 19 & 0.005 & \\
\hline 10 & & 378 & 3 & 20 & & \\
\hline
\end{tabular}

$\frac{K \cdot M C e a c l e s}{\text { Recorded by }} \frac{4 / z^{2} \mid}{\text { Date }}$

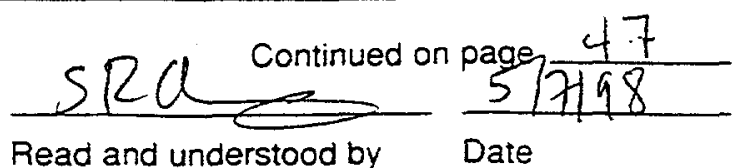


Subject Extra Exp \#2

Date $\frac{4}{\text { Month }} \quad$ Day $19 \frac{98}{\text { Year }}$

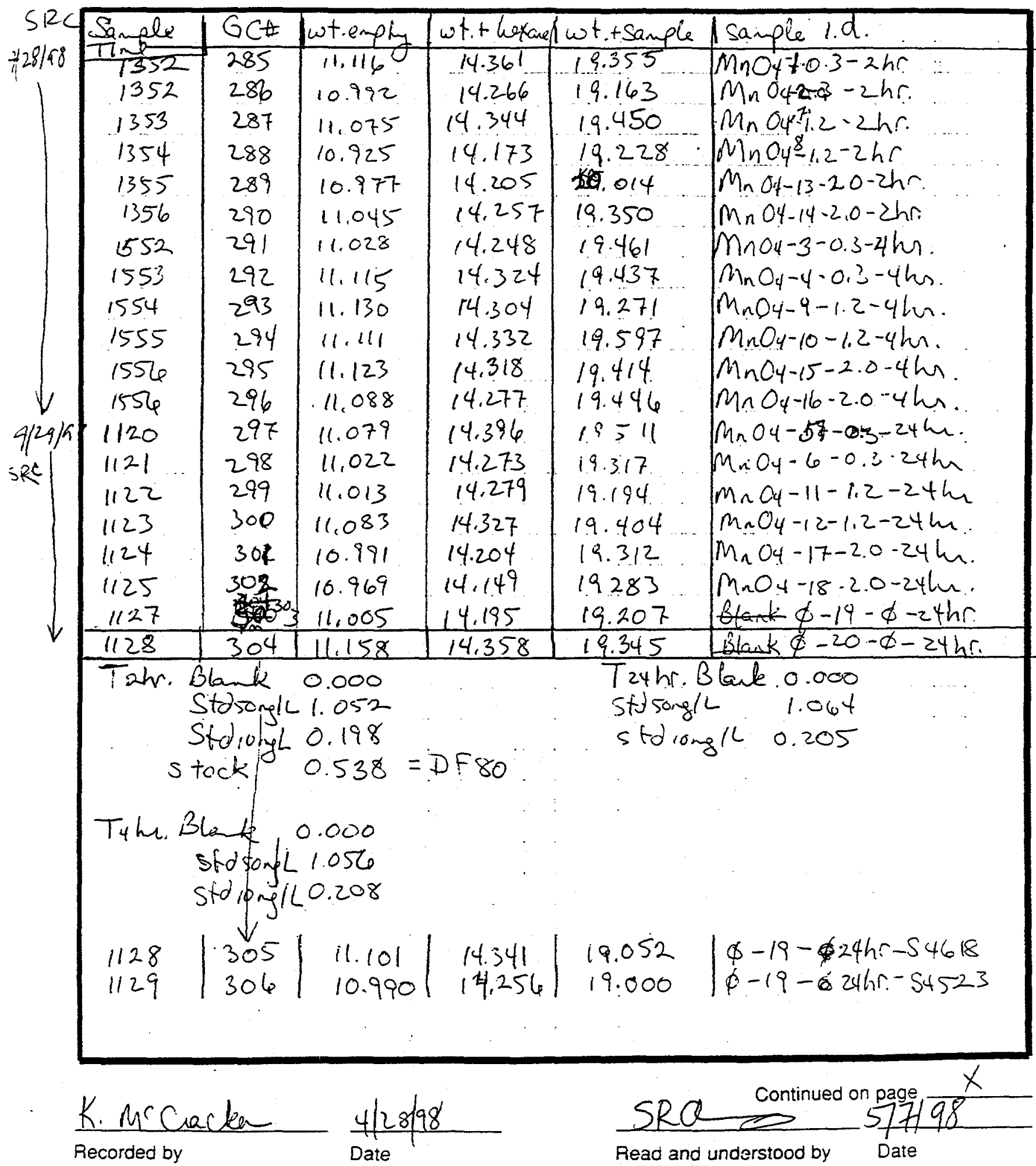




\begin{tabular}{|c|c|c|}
\hline & 04 & 30 \\
\hline & Month & Day \\
\hline
\end{tabular}

\section{ExP. $3 a-R 3$}

General Procedure for Task 3a Experiments-Oxidant Demand of Reactive Zone Media (To be conducted at ORNL/ESD)

1. All soil and groundwater to be used in these experiments (TAN-40 groundwater. TAN-37 crushed and aggregate basalt, and sediment) will be prepped by sparging and/or drying to remove any residual TCE present on the media. Doing so will allow this experiment to be conducted with a consistent and controlled initial TCE concentration $(\approx 0 \mathrm{mg} / \mathrm{L})$. Properly indicate usage of this media in the treatability study tracking logbook.

2. Follow Table 2-3 in Chapter 2 of the Implementation Plan to obtain which test condrtions to $\&$ evaluate (soil type, oxidant concentration, etc.) The use of glass, wide-mouth erlenmeyer flasks, beakers, or equivalent will be used. It is currently planned to run four (4) test conditions from Table 2-3 each time this procedure is used. Thus, 8 reactors will be used during each run of this procedure.

3. Obtain the tare weight of each reactor. Add approximately $100 \mathrm{~g}$ of solid media to the reactors in Table 2-3 that require it Re-weigh the reactors to determine the actuai mass added. To each reactor, add $400 \mathrm{~mL}$ of TAN-40). Re-weigh each reactor to determine the actual weight of solution added. (A calibration check of the gravimetric seale will be performed each day of use.)

4. Place the reactors in the incubator at $12^{\circ} \mathrm{C}$ and allow to equilibrate to that temperature. Stogitate the reactors during this step. $=200 \mathrm{RPM}$.

5. Once temperature equilibrium is reached, remove the reactors from the incubator and collect a $5 \mathrm{~mL}$ aliquot (using a disposable syringe) of the water and/or slurry from each for $\mathrm{pH}$ analysis.

6. The $\mathrm{pH}$ analyses will be conducted using conventional $\mathrm{pH}$ meters/electrodes, calibrated each day of use via a minimum of two standard buffer solutions $(4,7$, and 10$)$. Values obtained for each sample will be recorded. A calibration check will also be conducted following the last sample to be measured each day. Values obtained for the samples will be corrected if a significant drift (i.e., > 15\%) occurred.

7. Add the appropriate mass of crystalline $\mathrm{KMnO}_{4}$ (Carus ${ }^{\text {TM }}$ Free Flowing Technical Grade) into each reactor according to which test condition in Table 2-3 is being evaluated. The exact mass of $\mathrm{KMnO}_{4}$ added to each reactor will be determined gravimetrically and recorded. The time that $\mathrm{KMnO}_{4}$ is added to each indikidual reactor shall also be recorded (reaction start time). Shate wht bytand (Rubler Stoper) e STRT TOAss. st in getting it into sol tion. 8. Place each reactor back into the $12^{\circ} \mathrm{C}$ incubator as the oxidant consumption reaction proceeds. For each reactor, remove the reactor from the incubator at approximately 5-10 minutes from the = reaction start time, and coilect a $5-10 \mathrm{~mL}$ aliquot (using a disposable plastic syringe with a Luer Tip). Record the time the sample was collected and replace the reactor back into the incubator.

9. Add a $0.45 \mu \mathrm{m}$ syringe filter onto the end of the syringe and filter approximately $1-2 \mathrm{~mL}$ into a beaker. Remove the syringe filter and dispense the remaining (unfiltered) portion of the sample

$\rightarrow$ FoR $1 \% \mathrm{MnO}_{4}^{-}$, we nead $1.32 \% \mathrm{KMnO}_{4}$ OR. 13.277 mg/L Theafoee For $=400 \mathrm{~mL}$ soln we reed 5.3 grams per flask!

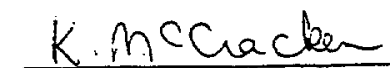

Recorded by

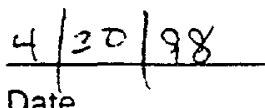

Date

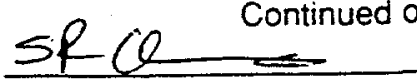

Read and understood by 
Subject Exp.3a-R3

Date $\frac{04}{\text { Month }} \quad 30 \quad$ Day $19 \frac{98}{\text { Year }}$

into another beaker for $\mathrm{pH}$ analysis. Measure and record the $\mathrm{pH}$ of each sample as done in Step 6.

10. Pefform a $\mathrm{MnO}_{4}{ }^{-}$analysis on the filtered sample from the previous step. (The sample is filtered to remove particulate matter that could interfere with the analysis.) The filtered sample will likely have to be diluted with DI water so that its spectrophotometric absorbance (at $\lambda=525$ $\mathrm{nm}$ ) is less than that of the highest standard to be prepared ( $50 \mathrm{mg} / \mathrm{L} \mathrm{MnO4-)}$. Check standards (10 and $50 \mathrm{mg} / \mathrm{LnO}$-) will be prepared with reagent grade $\mathrm{KMnO}_{4}$ and measured each analysis day. A new 5 point calibration curve will be prepared if the absorbance of these check standards differs from the expected value by $>15 \%$. DF neeled $\simeq 500 \mathrm{mag}$ be best

11. Collect and analyze aliquots from to do this in a 1

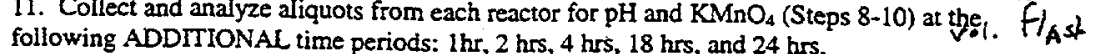

12. Interpret results and clean up the reactors for re-use in the next run of the experiment. Also place any waste materials generated from the experiment in the appropriate satellite accumulation area.

\begin{tabular}{|c|c|c|c|c|c|c|}
\hline & Media & $\begin{array}{l}\text { Basalt } \\
\text { Form } \\
\end{array}$ & $\begin{array}{c}\text { Liquid : Solid } \\
\text { Ratio }\end{array}$ & $\begin{array}{c}\text { Initial TCE } \\
\begin{array}{c}\text { Concentration } \\
\text { (mg/) })\end{array} \\
\end{array}$ & $\begin{array}{c}\text { Initial Organic } \\
\text { Co-Contaminant } \\
\text { Concentration } \\
\text { (mell) }\end{array}$ & $\begin{array}{c}\text { Initial Poturium } \\
\text { Permanganate } \\
\text { Concentration } \\
(\%)\end{array}$ \\
\hline & Groundwater & NA & NA & 0 & 0 & 1.00 \\
\hline $34-R 3$ & Groundwater & NA & NA & 0 & 0 & 1.00 \\
\hline $\bar{F}_{\mathrm{RUN} 3}$ & Groundwater/ basalt & Crushed & 4:1 & 0 & 0 & 1.00 \\
\hline & Ground water/ basalt & Crushed & 4:1 & 0 & 0 & 1.00 \\
\hline & Groundwater/ basalt & Aggregate & $4: 1$ & 0 & 0 & 1.00 \\
\hline & Groundwater/ basalt & Aggregate & $4: 1$ & 0. & 0 & 1.00 \\
\hline & Groundwater/sediment & NA & 4:1 & 0 & 0 & 1.00 \\
\hline & Groundwater/sediment & $\mathrm{NA}$ & $4: 1$ & 0 & 0 & 1.00 \\
\hline
\end{tabular}

\section{sample \#laskwt. flask+nodim flask $+\mathrm{H}_{2} \mathrm{O}$ san-ple id.}

\begin{tabular}{c|c|c|c|c|}
\hline 1 & 223.780 & - & 644.18 & groundurater \\
\hline 2 & 214.424 & - & 640.56 & grounduater \\
\hline 3 & 213.836 & 313.836 & 732.50 & crushed basalt \\
4 & 161.133 & 261.335 & 688.14 & crushed basalt \\
5 & 219.567 & 319.672 & 737.17 & aggregate basalt \\
6 & 151.070 & 251.470 & 677.87 & aggregate basalt \\
7 & 161.800 & 262.026 & 687.05 & dediment \\
\hline 8 & 151.954 & 251.978 & 669.17 & sediment \\
\hline
\end{tabular}

K.MC Cacler

Recorded by

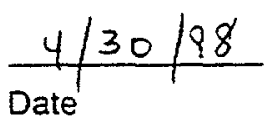

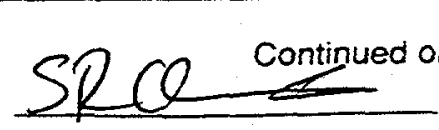

Read and understood by

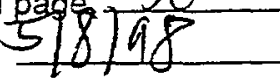

Date 
Subject $\sum_{x}>3 a_{1}-23$

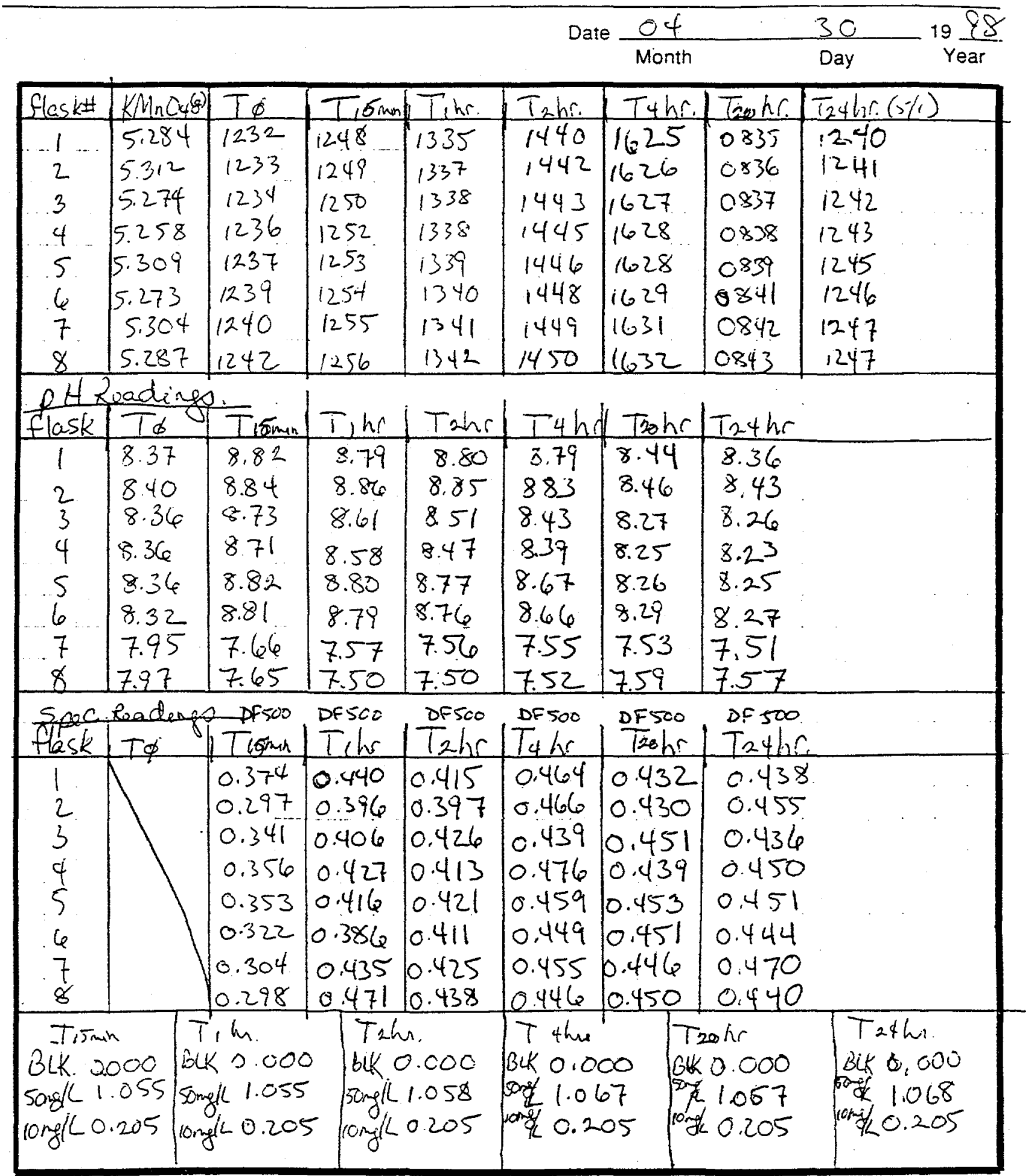

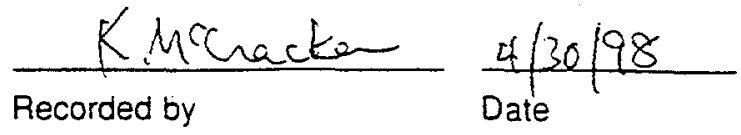

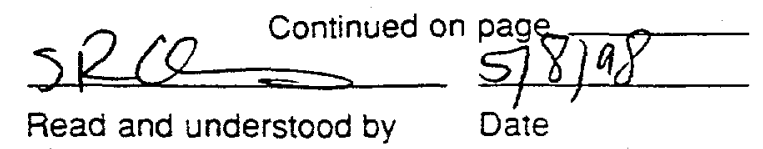


Subject kepeat Experiment $2 C-1 B$

Date $\frac{05 \text { of }-05}{\text { Month }} \frac{19.98}{\text { Year }}$

REPEAT EXPERMMENT:

Experiment 2c-1B. Sorption Kinetics Test for Crushed and Aggregate Basait.

(To be conducted at ORNLESD)

1. All soil and groundwater to be used in these experiments (TAN-40 groundwater. TAN-37

crushed and aggregate basalt) will be prepped by sparging and/or drying to remove any residual

TCE present on the media. (Properly indicate usage of this media in the treatability study

tracking logbook.) Doing so will allow this experiment to be conducted with consistent and

controlled initial TCE concentrations via contaminant spiking.

2. Prepare a STOCK (Saturated) TCE solution $(2000 \mathrm{mg} / \mathrm{L}$ ) by adding $100 \mu \mathrm{L}$ of Pure TCE irtip

a $12 \mathrm{~mL}$ VOA vial filled to volume with DI Water and allow to equilibrate overnight at room

th temperature. (Use of a STOCK solution rather than pure phase TCE to prepare the spiking

solution affords better accuracy in obtaining the target concentration.)

3.' Sparge approximately $1600 \mathrm{~mL}$ of groundwater from TAN-40 of any residual TCE or other

VOCs that may have been present.

4. Obtain the tare weight of the container to be used to prepare the spike solution (Tedlar bag). Fill the Tedlar bag with the sparged TAN $-40 \mathrm{GW}$. By gravimetric methods, determine the

Amount of groundwater added to the container. (A calibration check of the gravimetric scale will be performed each day of use.) All information regarding the preparation of the spiking solution will be recorded in the laboratory research notebook.

5. (TUESDAY AFTERNOON) Add the appropriate quantity of the Saturated STOCK TCE solution into the Tedlar bag to produce a TCE spike concentration of $1.0 \mathrm{mg} / \mathrm{L}$. SHOULD BE APPROXIMATELY 1.6 ML Record volume and/or weight added. (Reactive zone media will only be spiked at 0.1 and $1 \mathrm{mg} / \mathrm{L}$ TCE during the Task 4 degradation studies.) This solution can be mixed and equilibrated at least overnite at $12^{\circ} \mathrm{C}$ in the incubator.

6. After mixing, obtain duplicate aqueous samples using a glass syringe with a valve stopcock and luer needle $(5 \mathrm{~mL})$ of the spike solution to obtain the initial TCE concentration of the spiked groundwater. Weigh the syringe when filled and then again after the sample is dispensed to the P\&T. The duplicate aliquot samples will be analyzed immediately using the Lab 211 P\&T (30 minutes each).

7. Obtain the tare weights of thirty six (36) $40 \mathrm{~mL}$ VOA vials. Add approximately $10 \mathrm{~g}$ of aggregate basalt to 12 of the vials and $10 \mathrm{~g}$ of the crushed basalt to another 12 of the these vials. Gravimetrically determine the actual amount of solid media added.

8. Dispense the spiked groundwater from the Tediar bag into each of the 36 VOA vials that have been prepared, filling them completely with no headspace and cap them. Record the time that each viai is filled as " $\mathrm{T}=0^{\mathrm{n}}$ " for that vial.

$$
\begin{aligned}
& \text { Tedlan Bgz } \omega t:=51.87 \mathrm{~g} \\
& \text { Tedlar Bag }+\mathrm{H}_{2} \mathrm{O} \text { ot }=1651.65 \mathrm{~g}
\end{aligned}
$$

$$
\mathrm{H}_{2} \mathrm{O}=1600 \mathrm{ml} \longrightarrow \text { add } 1,60 \mathrm{ml} \text { Saturated TCE soln. }
$$

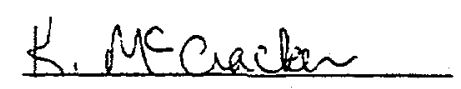

Recorded by

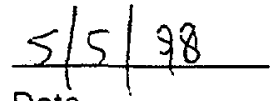

Date

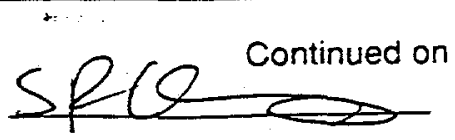

Read and understood by

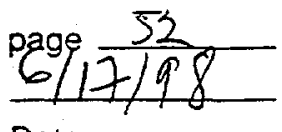

Date 
Subject Repeat Experimet $2 C-1 B$

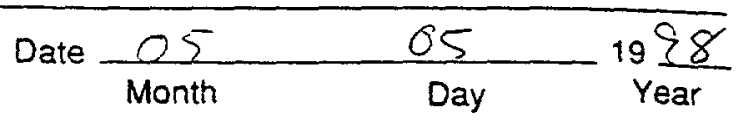

9. Re-weigh each vial after it is completely filled to determine the actual weight of spiked groundwater added to it. Place the vials back into the environmental chamber at $12^{\circ} \mathrm{C}$ Agitate the vials during this step ( $200 \mathrm{rpm}$ or greater)

The remaining steps will be performed at the time intervals of approximately 4 $h r s, 24 h, 2 d, 5 d, 7 d$, and $T B D$. The latter times may be changed depending upon results of the samples obtained for the earlier time periods.

10. Remove six (6) $40 \mathrm{~mL}$ vials from the incubator (two with groundwater only, two with crushed basalt, and two containing aggregate basalt.) Collect an aqueous sample $(\approx 5 \mathrm{~mL})$ (allow the crushed basait to settle a little before sampling) from each vial using a glass with valve stopcock and luer needle.

11. Weigh the full syringe and Record the time the sample is collected. Reweigh the syringe after the sample is dispensed into the P\&T.

(12) Randomly collect and process (steps 10 and 11) a duplicate VOC sample from one of the six VOA viais during each sampling period.

13. FOR THE LAST SAMPLING PERIOD STUDIED ONLY: Extract the remainingcontents of each vial with hexane. (The mass of any remaining TCE on the solid phase can be determined with this extraction when a mass balance is performed using data from the aqueous aliquot sample) To accomplish this, transfer the remaining sample in the six $40 \mathrm{~mL}$ VOA vials (including basalt material) into a $125 \mathrm{~mL}$ extraction jar that has been pre-weighed and holding a known volume of hexane $(\approx 35 \mathrm{~mL})$. The extraction jar will be weighed again after sample addition to determine the actual mass of sample (solid + Liquid) added.

14. FOR THE LAST SAMPLING PERIOD STUDIED ONLY: The extracts in the above step will be placed on a horizontal or reciprocating shaker for 2 hours. A $1 \mathrm{ml}$ aliquot of the hexane phase will be placed into a $2 \mathrm{~mL}$ G.C. vial and stored at $4^{\circ} \mathrm{C}$ until analysis.
$X \cdot 177440$ caluteratix $5 / 5$

w.t.

$\mathrm{SO}_{0} \mathrm{O}$

actuaf

49.989
S/1 balincecalib

$x-17733$ wt. 50 g

\begin{tabular}{|c|c|c|c|c|c|c|c|}
\hline Vial & GCH & whterety & wt.tmediun & $\omega t+\mathrm{H}_{2} \mathrm{O}$ & samplel. & To & Timeded \\
\hline 34 & 334 & 25.020 & 35.167 & 74.455 & $2 c+1 d \geq 77 d-a b a$ & 1029 & $1616 \% / 3$ \\
\hline 35 & & 25,205 & 35.294 & 73.933 & $2 c+6=3$ & 1030 & \\
\hline 36 & & 24.791 & & 74.219 & $2(a+b)-50$ & 1030 & \\
\hline
\end{tabular}

\begin{tabular}{|c|c|c|c|c|c|}
\hline syringe $\#$ & GC\# & $\omega t+$ san $p l$ & wt effes injection & Sample 1D & $\left.\operatorname{Time}_{32}{ }_{2}\right)\left(T_{0}\right)$ \\
\hline $\begin{array}{r}10 \\
-2\end{array}$ & $\begin{array}{l}307 \\
308\end{array}$ & $\begin{array}{l}70.2210 \\
70.1707\end{array}$ & $\begin{array}{l}65.1106 \\
65.0550\end{array}$ & $\begin{array}{l}2 C-1 B-T \phi-a \\
2 C-1 B-T \phi-b\end{array}$ & $\begin{array}{l}0910 \\
0930\end{array}$ \\
\hline
\end{tabular}

\section{K.Mccracten}

Recorded by

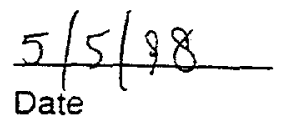

Date

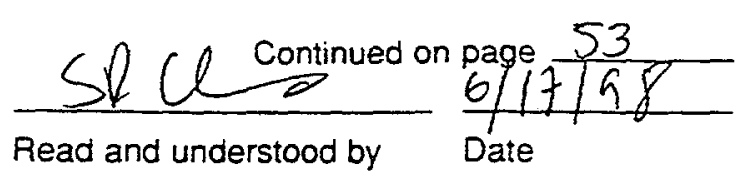


Subject Repeat experimat 2C-1B

Date $\frac{05}{0.05} 19 \frac{98}{\text { Month }} \quad$ Day

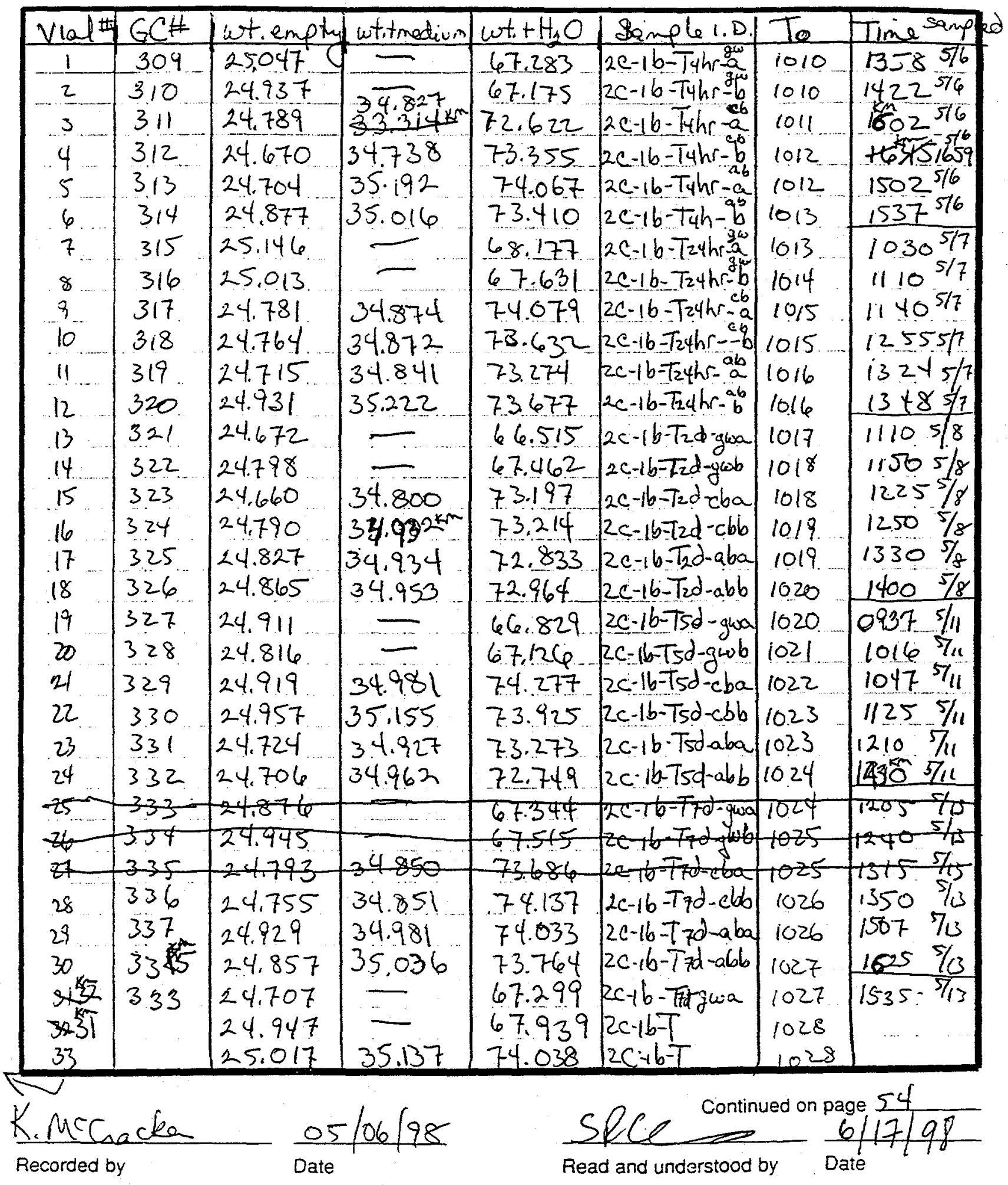


Subject Repeat Experinet 2C-1B

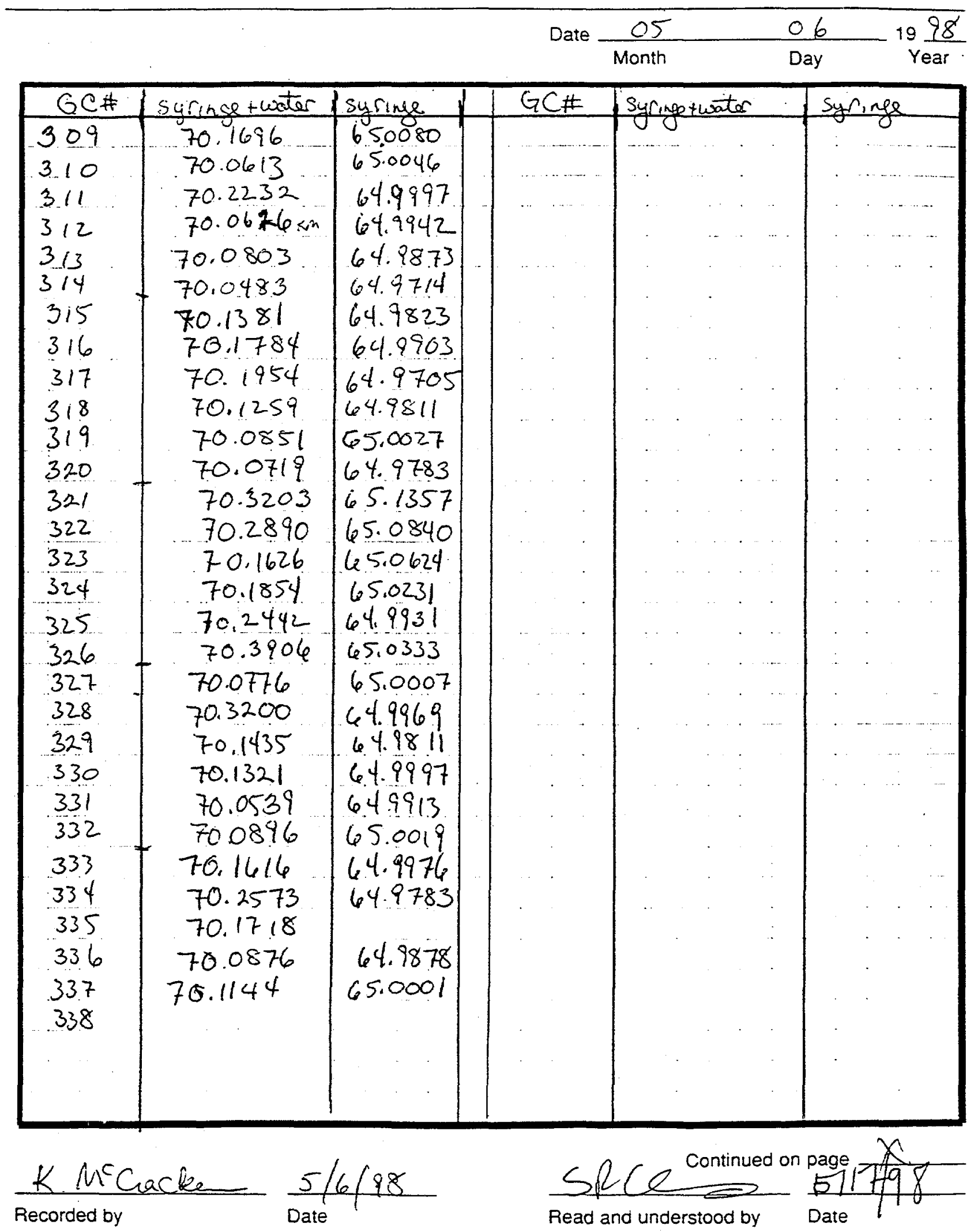




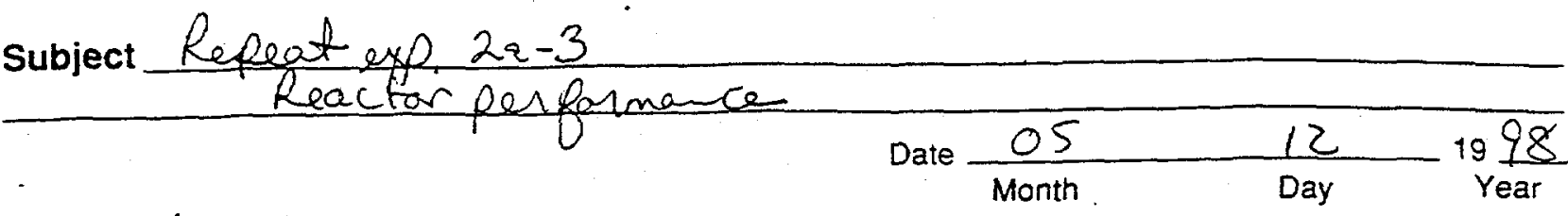

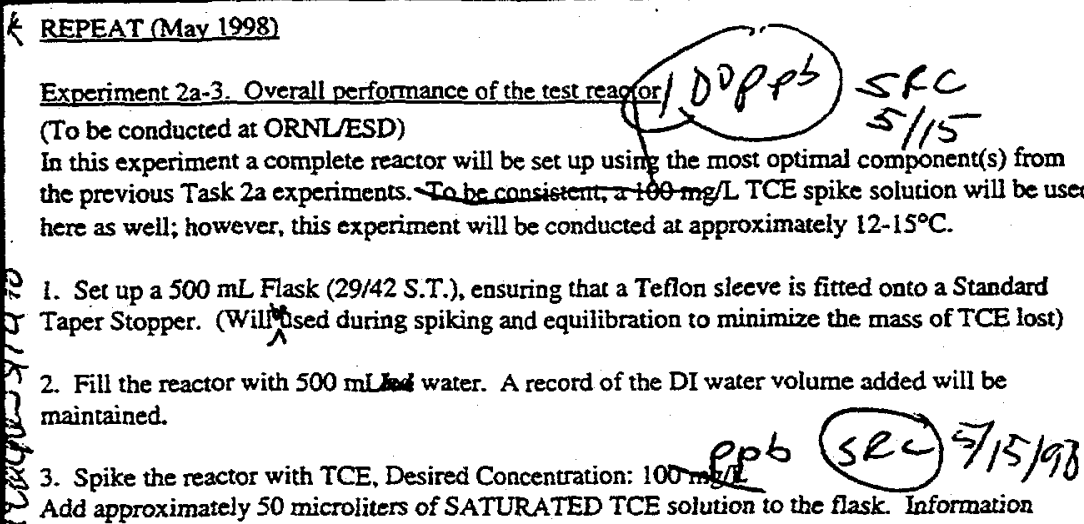
regarding the preparation of the spiking solution will be recorded in the laboratory research notebook.

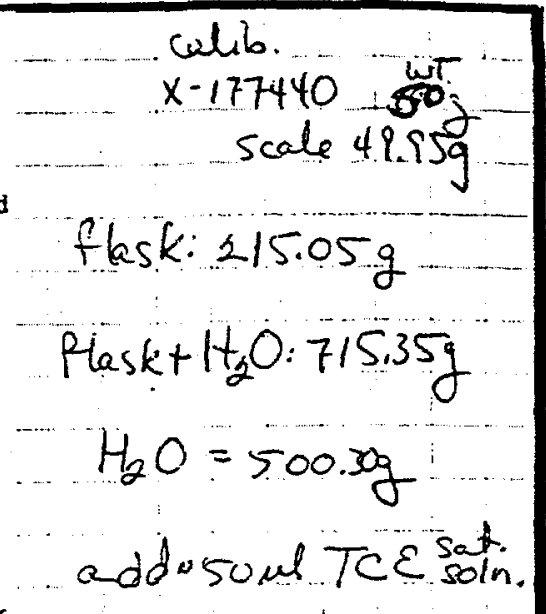

4. Replace the stopper ind and allow the solution to equilibrate at least overnight in an incubator maintained at $12-15^{\circ} \mathrm{C}$. (Record the equilibration period and temperature).

5. During the equilibration period, prepare an ORBO-32 assembly and connect it to the stopcoch adapter.

STORE UN-SEAIED ORBO TUBES OUTSDE OF THE LABORATORY FUME HOODS. THE HOODS LIKELY HAVE THE GREATEST POTENTIAL FOR "CONTAMNATING" THE TUBES WITH TCE AND OTHER VOCS.

C $5 \mathrm{ml}$

6. After equilibration replace the stopper with the stopcock assembly.

7. Collect duplicate ( inserting the long sampling needle. (collect one using a glass syringe and one using a plastic disposable syringe) The aliquot samples will be added to pre-weighed sample

is containers holding a known volume of hexane $(\approx 5 \mathrm{~mL})$. Each sample container will be

Weighed again after sample addition to deternine the actual weight of sample added. (A)

P. calibration check of the gravimetric scale will be performed each day of use.) All such extracts will be placed on a horizontal shaker for 2 hours. Store the extracts at $4^{\circ} \mathrm{C}$ until G.C. analysis.

8. Record the time the last sample in the step above is collected and record as Time=0.

9. Collect at the following time intervals in the same manner as performed in step 7: 1 hour. 2 hrs, 4 hrs, 18 hours , and 24 hrs (in duplicate-collect one using a glass swinge and one using a plastic disposable syringe). The exact time at which each aliquot is collected will be recorded.

10. Breakdown the reactor after the last sampie is collected. The charcoal desorption tube will then be removed from the reactor. Each charcoal bed contained in the tube will be placed into a pre-filled and pre-weighed vial containing a known volume of hexane $(\approx 5 \mathrm{~mL})$. These extracts will be processed and analyzed in the same manner as the aqueous aliquots.

11. Analyze the sample and charcoal extracts via GC/ECD for TCE. G.C. analyses will be conducted closely following EPA Method $8000 B$, ensuring that a daily calibration check, blanks, etc. are also analyzed on each analysis day. Formal data packages, as outlined in Section 2.4.3.3 of the Chapter 2 Implementation Plan will not be prepared for this experiment.

12. Perform a mass balance for the reactor, taking sample aliquot volumes, initial concentrations, etc. into account to determine the overall reactor performance in maintaining gastight conditions. Also place any waste materials generated from the experiment in the appropriate satellite accumulation area.

K.Mchatear

Recorded by

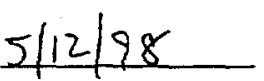

Date

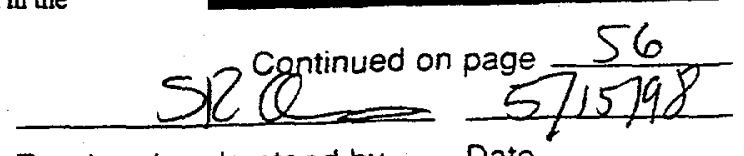

Read and understood by
Date 
Subject Exp $\frac{2 a-3}{\text { Reacter }}$

Reactor Performence

Date \begin{tabular}{ccc}
05 & 12 & $19 \frac{98}{\text { Month }}$ \\
\cline { 2 - 3 } & Day &
\end{tabular}

\begin{tabular}{|c|c|c|c|c|c|c|c|}
\hline Sarpe & GC\# & butenety & wot.t hakne & $\omega t$ tseande & Sampleid. & $V_{\text {,ul }} \neq$ & dil \\
\hline $5 / 31110$ & 338 & $11.03 \mathrm{O}$ & 14.280 & 19.204 & $2 a-3 b-T \phi-p^{*}$ & 1 & 1 \\
\hline $5 / 131112$ & 399 & 10.985 & 14.289 & 19.150 & $2 a-3 b-T_{\phi}-q$ & 2 & 1 \\
\hline $5 / 131207$ & 340 & 11.035 & 14.339 & 19.571 & $2 a-3 b-T i h r=$ & 3 & 1 \\
\hline $5 / 131210$ & 342 & 11.135 & 14.465 & 19.294 & $2 a-3 b-T / h r$ & 4 & 1 \\
\hline $7 / 131316$ & 342 & 10.933 & 14.236 & 19.210 & $2 a-3 b-T_{2} h r-p$ & 5 & .1 \\
\hline $5 / 131318$ & 344 & 11.0 .93 & 14,403 & 19630 & $2 a-3 b-T_{2} h r-q$ & 6 & 1 \\
\hline $57 / 31510$ & 344 & 11,120 & 14.420 & 19.586 & $2 a-3 b-T 4 h r-8$ & 7 & 1 \\
\hline 5113.1511 & $345 !$ & 11.046 & 14.324 & 19.535. & $2 a-3 b-T 4 h r-g$ & 8 & 1 \\
\hline 5,190815 & 3468 & 10.909 & 14.191 & 19.124 & $2 a-3 b-T 21 h c-a$ & 9 & 1 \\
\hline $5 / 140815$ & 348 & 10.015 & 14.261 & 19.165 & $2 a-3 b-T=1 h r-g$ & 10 & 1 \\
\hline $7 / 141110$ & 348 & 11.052 & 14,273 & 19.108 & $2 a-3 b-T_{2}+h r-$ & 11 & $!$ \\
\hline 57.41111 & 349 & 11.033 & 14.276 & 19.007 & $2 a-3 b-T_{2} 4-h r-$ & 12 & \\
\hline
\end{tabular}

\begin{tabular}{|l|l|l|l|l|l|}
$5 / 141112$ & 3.50 & 11.027 & 14.291 & 14.383 & $2 a-36$-eharcall $\# 13$ \\
7141112 & 351 & 11.107 & 14.382 & 14.431 & $2 a-36$-charcoal 2 19
\end{tabular}

K.mccracker

Recorded by

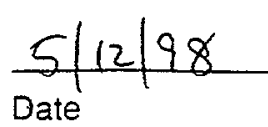

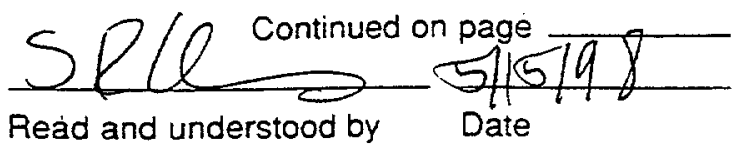


Subject Task $4 a$ Experiments.

Date $\frac{65}{\text { Month }} \frac{19}{\text { Day }} 19 \frac{98}{\text { Year }}$

Gencral Procedure for Task 4a Experiments - Measure the oxidation rate of organic contaminants in the Reactive Zone Media

(To be conducted at ORNLESD)

NOTE: This experiment will be used to conduct the various test conditions presented in Table 25 in Chapter 2 of the Implementation Plan. Control samples will be prepared and sampled. throughout the reaction period to quantify changes in concentration due to mectanisms other than oxidation. In addition to the duplicate control samples, it is currently planned to run two (2) test conditions (in duplicate) from Table $2-5$ each time this procedure is used. Thus, 6 reactors will be used during each run of this procedure, and this procedure will be conducted 8 times. The controls and the treatment reactors will all contain the same media type and initial contaminant concentrations (i.e., all conditions will be the same for each run of this procedure with the exception of the $\mathrm{MnO} 4$ concentration used).

1. Soil Prepping

All soil and groundwater to be used in these experiments (TAN-40 groundwater, TAN-37 crushed and aggregate basalt, and sediment) will be prepped by sparging and/or dying to remove any residual TCE present on the mediz. Doing so will allow this experiment to be conducted with consistent and controlled initial TCE concentrations via contaminant spiking. (Properly indieate usage of this media in the treatability study tracking logbook) TAN-40 GW will also be temperature equilibrated to $12^{\circ} \mathrm{C}$ in this experiment.

2. TCE Stock Solution Preparation

Prepare a STOCK (Saturated) TCE solution $(\approx 1100 \mathrm{mg} / \mathrm{L}$ ) by adding greater than $100 \mu \mathrm{L}$ of Pure TCE into a $12 \mathrm{~mL}$ VOA vial filled to volume with DI Water and keep refrigerated. (Use of If a STOCK solution rather than pure phase TCE to prepare the spiking solution affords better accuracy in obtaining the target concentration.) This can easily be stored and used again in subsequent experiments.

3. TCE Spike Solution Preparation, PART I

Obtain the tare weight of the container to be used to prepare the spike solution (Tedlar bag, flask. or equivalent). Fil with approximately $3100 \mathrm{~mL}$ of $12^{\circ} \mathrm{C}$ TAN-40 groundwater. By gravimetric methods, determine the amount of groundwater added to the container. (A calibration check of E the gravimetric scale will be performed each day of use.)

4. TCE Spike Solution Preparation, PART II

Add the appropriate quantity of the Saturated STOCK TCE solution to produce a TCE spike solution with the concentration prescribed in Table 2-5 for the particular test series being ran. The reactive zone media will only be spiked at 0.1 and 1 mg/L TCE during this experiment, thus the volume of saturated STOCK TCE needed should be on the order of $0.3 \mathrm{~mL}$ and $3.0 \mathrm{~mL}$, respectively. This solution can be mixed and equilibrated withia a few minutes. All Information regarding the preparation of the spiking solution will be recorded in the laboratory research notebook. Place the spike solution in the incubator overnight at $12 \mathrm{C}$ for temperature equilibration.

5. Obtain Tare Weights of Reactors

Prepare the test reactors to be used. (The gas-tight reaction vessels acquired and tested in Task $2 \mathrm{a}$ will be used as the reactors in this experiment.) Obtain the tare weight of each, including the weight of a ground glass standard taper stopper fitted with a Teflon sleeve.

6. Fill with Solid Phase Media

Add approximately $100-110 \mathrm{~g}$ of the solid phase material desirod for this particuiar test series (See Table $2-5$ in the Implementation Plan). Re-weigh each reactor to determine the actual amount of solid media added (when applicable).

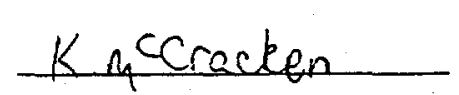

Recorded by

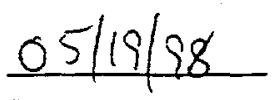

Date

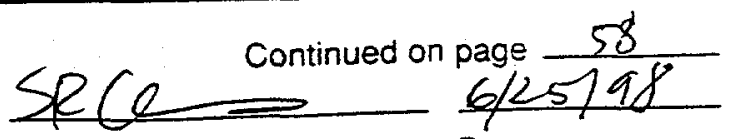

Read and understood by 
Subject Task ta Experiments.

Date $\begin{array}{cc}05 & 19 \\ \text { Month } & \text { Day }\end{array} \frac{98}{\text { Year }}$

7. Collection of Initial Spike Solution Samples

Remove the spike solution from the incubator, and obtain duplicate aqueous samples ( $\approx 5 \mathrm{~mL}$ ) of

the spike solution to obtain the initial TCE concentration of the spiked groundwater. Recond the time the sample is collected. The duplicate aliguot samples will be added to pre-weighed sample containers holding a known volume of hexane $(\approx 5 \mathrm{~mL})$. Each sample container will be weighed again after sample addition to determine the actual weight of sample added. These extracts will be piaced on a horizontal shaker for 2 hours. Store the extracts at $4^{\circ} \mathrm{C}$ until G.C. analysis.

8. Distribution of Spike Solution to Reactors

Quickly dispense the spike solution into each of the reactors to be used. Add $\approx 500 \mathrm{~mL}$ to each reactor. Immediately replace the ground glass stopper and re-weigh each to determine the actual weight of spiked groundwater.

9. Soilspike Equilibration - SKI PPED fOR RUN $1+R U N 2$

Place the reactors in the incubator at $12^{\circ} \mathrm{C}$ and allow the spike solution to equilibrate for 24 hours. (For aggregate basalt, equilibrate for the length of time determined in Exp. 2c-1., uniess shorter than 24 hours) Agitate the reactors at $\approx 200$ rpm during this step.

10. Preparation of Stock $\mathrm{MnO}_{4}^{-}$Solution (4 wt\%)

Add $2.66 \mathrm{~g}$ of erystalline $\mathrm{KMnO} 4$ (Carus ${ }^{\mathrm{m}}$ Free Flowing Technical Grade) into a $50 \mathrm{~mL}$ Flask and fill to volume with DI water, and allow to mix for at least 2 hours.

11. Prepare Reactor Closure/Carbon Tube

During equilibration period, prepare the standard taper adapters/stopeock valve. (Only one ORBO tube will be used for each reactor, the vertical sampling port will be fitted with a small septum) STORE UN-SEALED ORBO TUBES OUTSIDE OF THE LABORATORY FUME HOODS. THE HOODS LIKEL Y HAVE THE GREATEST POTENTIAL FOR "CONTAMINATING" THE TUBES WITH TCE AND OTHER VOCs.

12. Collection of Pre-Reaction Sample from Each Reactor

After equifibration, collect a $\approx 10 \mathrm{~mL}$ aqueous sample using a long need and disposable syringe from each of the reactors and quickly reseal. Recond the time the sample is collected and note -whether solids were present in the aqueous sample (particularly the groundwater/sediment reactors). If significant solids are present, a portion of this aliquot volume may be used for a total solids analysis.

13. Preparation of Pre Reaction TCE Sample

Dispense (unfiltered) $\approx 3 \mathrm{~mL}$ of this aliquot sample into to a pre-weighed vial holding a known volume of hexane $(\approx 3 \mathrm{~mL})$. This sample vial will be weighed again after sample addition to determine the actual weight of sample added. All such extracts will be placed on a horizontal shaker for 2 hours. Store the extracts at $4^{\circ} \mathrm{C}$ until G.C. analysis. Record the time this sample is taken.

14. Measurement of Pre Reaction pH Value

Tare a small beaker for $\mathrm{pH}$ analysis. Add a 0.45 micron fitter to the sample syringe and dispense (fittered) the remaining portion of the sampk in the syringe $(\approx 7 \mathrm{~mL})$ into the tared beaker.

Reweigh the beaker to determine the volume of the sample (assuming that the solids fraction is negligible). The $\mathrm{pH}$ anaiyses will be conducted using conventional pH meters/electrodes. calibrated each day of use via a minimum of two standard buffer solutions. Values obtained for each sample will be recorded. A calibration check will also be conducted following the last sample to be measured each day. Values obtained for the samples will be corrected if a significant drift (ie., > 15\%) occurred.

15. Addition of Stock MnO4- Solution into Reactors

Quickly remove the ground glass stopper and add the needed volume of stock $\mathrm{KMnO}_{4}$ to obtain $b_{1}^{\text {the }} \mathrm{MnO}_{4}$ concentrations in Table $2-5$ (approximately $1.25 \mathrm{~mL}$ and $12.5 \mathrm{~mL}$ for the 0.01 and 1. fitted with the stopeock and charcoal desorption tubes and quickly hand shake each reactor to ensure rapid dissolution of the oxidant. (No oxidant will be added to the control reactors). The time that the stock $\mathrm{KMnO}_{4}$ is added to each individual reactor shall also be recorded (reaction start time). Place each reactor back into the $12^{\circ} \mathrm{C}$ incubator.

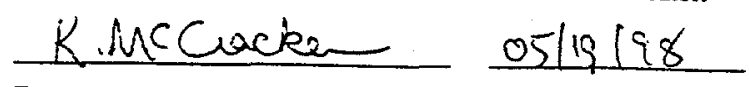

Recorded by
Date

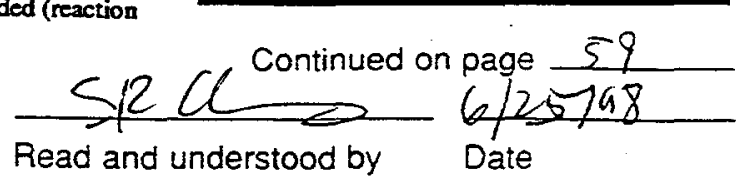


subject Task ta Experivents

Date $\frac{05}{\text { Month }} \frac{19}{\text { Day }} 19 \frac{98}{\text { Year }}$

16. 30 Minute Sampling

At approximately 30 minutes from the reaction start time, remove the reactors from the incubator and collect a $10 \mathrm{~mL}$ aliquot (using a long needle and syringe with a Luer Tip). Record the time the sample is collected. Replace the reactor(s) back into the incubator.

17. Preparation of 30 Minure TCE Sample

Dispense (unfitered) $\approx 3 \mathrm{~mL}$ of the collected aliquot into a pre-weighed vial holding a known

volume of hexane $(\approx 3 \mathrm{~mL})$. This sample vial will be weighed again after sample addition to

determine the actual weight of sample added. All such extracts will be placed on a horizontal

shaker for 2 hours. Store the extracts at $4^{\circ} \mathrm{C}$ until G.C. analysis.

18. $\mathrm{pH}$ Analysis of 30 Minute Sample

Tare a small beaker. Add a $0.45 \mu \mathrm{m}$ syringe filter unto the end of the syringe and dispense

(filtered) the remaining portion of the sample in the syringe $(\approx 7 \mathrm{~mL})$ into a tared beaker for $\mathrm{pH}$ analysis. Reweigh the beaker to determine the volume of the sample (assuming that the solids fraction is negigible). Measure and record the $\mathrm{pH}$ of the sample as done in Step 13

19. $\mathrm{MnO}_{4}{ }^{*}$ Analysis of the 30 Minute Sample

Use a portion of the filtered $\mathrm{pH}$ sample to perform a $\mathrm{MnO}_{4}^{\circ}$ analysis. The sample may have to be diluted (likely DF3 and DF30 for the .01 and $0.1 \%$ MnO4- loadings, respectively) so that its spectrophotometric absorbance (at $\lambda=525 \mathrm{~nm}$ ) is less than that of the highest standard to be

prepared ( $50 \mathrm{mg} / \mathrm{L} \mathrm{MnO} 4$ ). Check standards ( 10 and $50 \mathrm{mgl} \mathrm{MnO4}$ ) will be prepared with reagent grade $\mathrm{KMnO}_{4}$ and measured each analysis day. A new 5 point calibration curve with be prepared if the absorbance of these check standards differs from the expected value by $>15 \%$.

20. Collection and Analysis of Additional Aliquot Samples Collect and analyze aliquots from each reactor for TCE, pH. and KMnO, (Steps 16-19) at the following ADDITIONAL time periods: $2 \mathrm{hrs}, 4 \mathrm{hrs}, 6 \mathrm{hrs}, 20 \mathrm{hrs}$, and $24 \mathrm{hrs}$.

IMPORTANT-For each reactor collect and extract a duplicate sample (Steps 16-19) from one of the 6 time intervals being evaluated.

2. Extraction of Residual TCE in Reactor

The entire contents of each reactor will be extracted with hexane. First, obtain a tare weight on six (6) empty containers to be used for the hexane extraction (1 liter VOA bottles). Measure out $400 \mathrm{~mL}$ of hexane into two (2) $200 \mathrm{~mL}$ volumetric flasks. Add $200 \mathrm{~mL}$ of the hexane directly into the $1 \mathrm{~L}$ extraction bottle. Quickly pour the contents of each test reactor into a separate extraction bottle. Use the remaining $200 \mathrm{~mL}$ flask of hexane to rinse any residual slurry from the test reactor into the extraction bottle. Weigh and record the mass of the filled extraction bottle to determine the mass of the slurry and hexane added (taking into account the fact that hexane has a specific gravity of 0.66 ).

The mass of any remaining TCE on the solid phase can be determined with this extraction when a mass balance is performed using data from the aqueous aliquot sampling that was conducted throughout the test.)

22. Reactor Extraction Continued

Place each extraction bottle on a horizontal reciprocating shaker for a minimum of 2 bours (May be longer for aggregate basalt samples, depending upon the results of Exp. 2b-2.) then collect duplicate $1 \mathrm{~mL}$ hexane aliquots from each extraction bottle and place into $2 \mathrm{~mL}$. G.C. vials (dilution is not expected to be necessary).

23. Extraction of Chareoal Desorption Tubes

Remove the charcoal desorption tube(s) from each reactor. Each charcoal bed contained in the tube(s) will be placed into pre-filled and pre-weighed vials containing a known volume of bexane $(\approx 5 \mathrm{~mL}$ ). These extracts will be processed and analyzed in the same manner as the aqueous aliquots for TCE.

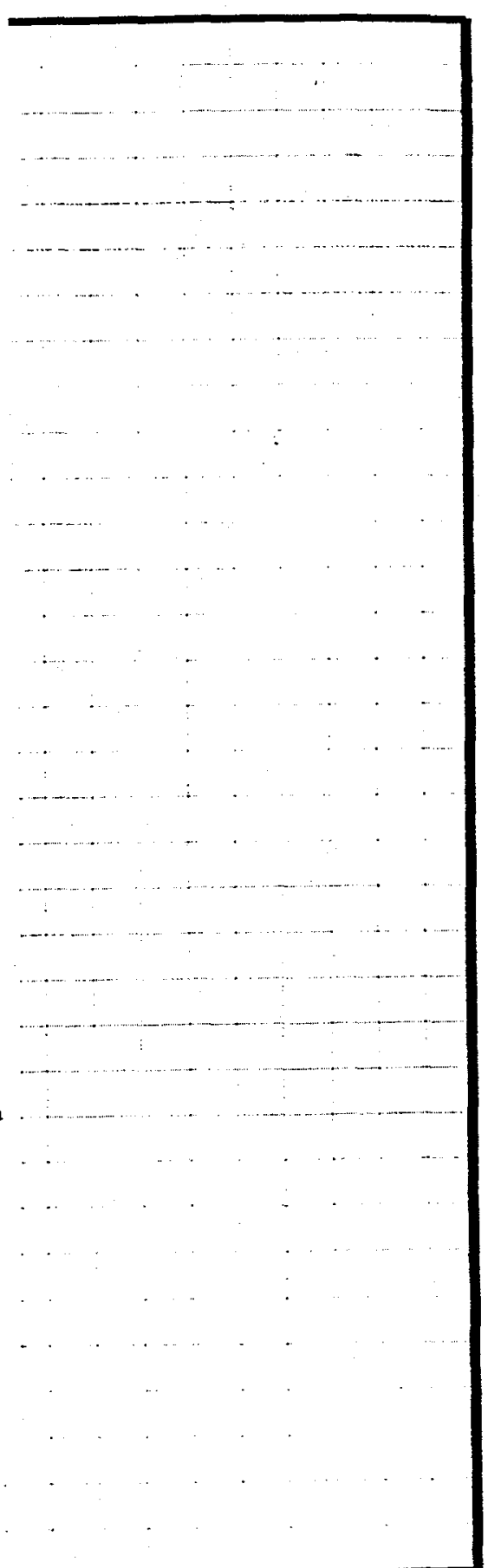

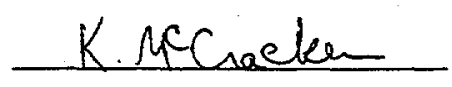

Recorded by

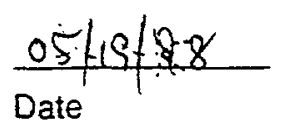

Date

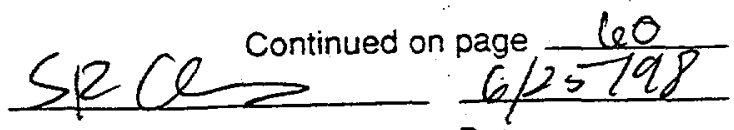

Read and understood by
Date 
24. Clean up

Clean up the reactors for re-use in the next run of the experiment. Also place any waste materials generated from the experiment in the appropriate satellite accumulation area.

\section{GC ANALYSIS of VOCs}

All VOC analyses for this experiment will be conducted using a G.C.ECD detector. The instrument will calibrated for TCE using a 5 point calibration curve with standard concentrations ranging from $5-1000 \mu g /$ (ppb)

The VOC analyses of the hexane extracts will closely follow EPA Method 8000B. Significant deviations from this method will be clearly documented.

Forral data packages will be prepared for the analyses performed for all Task 3 and 4 samples will be prepared as discussed in Sections 2.4.3 and 2.4.4 in Chapter 2 of the Iraplementation Plan. The major QA/QC items pertaining to the VOC analyses include:

Catibration standands will be prepared from a certified, custom VOC mix stock solution containing each analyte of interest. The lot number of this custom mix will be included on each initial calibration data form.

The working calibration curve will be verified through injection of a QC check standard (100 $\mu g / L$ ) at least once each analysis day. If the response for any analyte varies from the predicted response by more than $\pm 15 \%$, a new calibration curve will be prepared.

A blank hexane sample will be analyzed between every 10 test samples.

A sample will be diluted and reanalyzed if its GC peak area response is greater than that of the bighest calibration standard being used that analysis day.

\section{Kerackar}

Recorded by

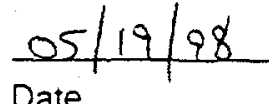

Date

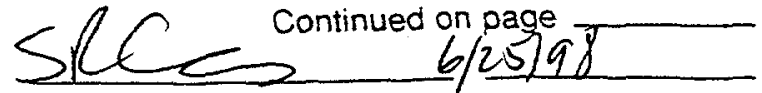

Read and understood by
Date 
Subject $E_{x} . \psi_{2}-R_{1}$

Date $\frac{05}{\text { Month }} \quad \frac{20}{\text { Day }}{ }^{19} \frac{98}{\text { Year }}$

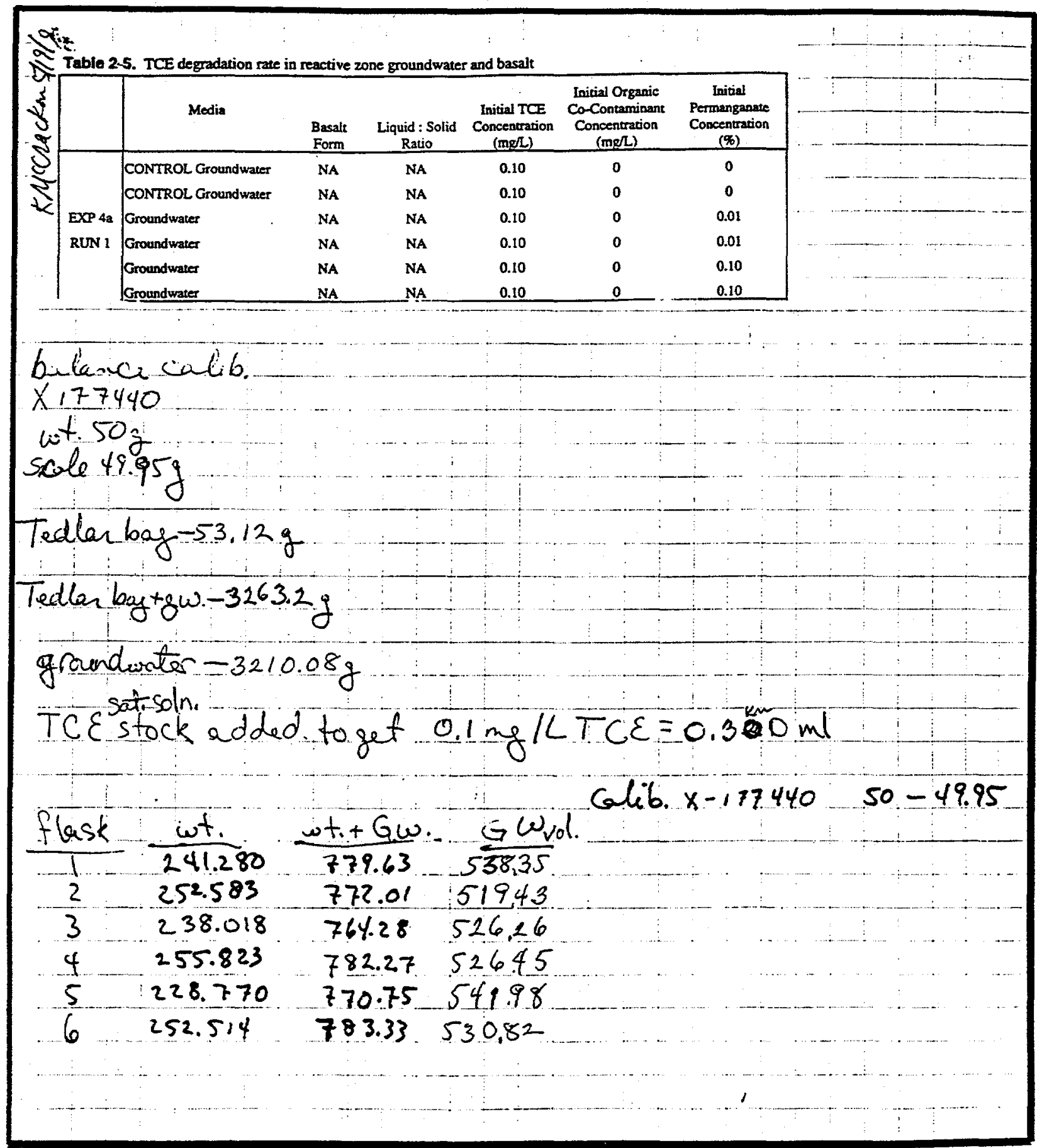

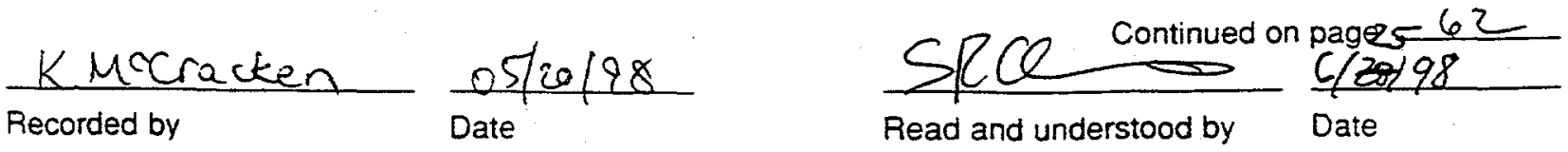


Subject Exp.4a-RI

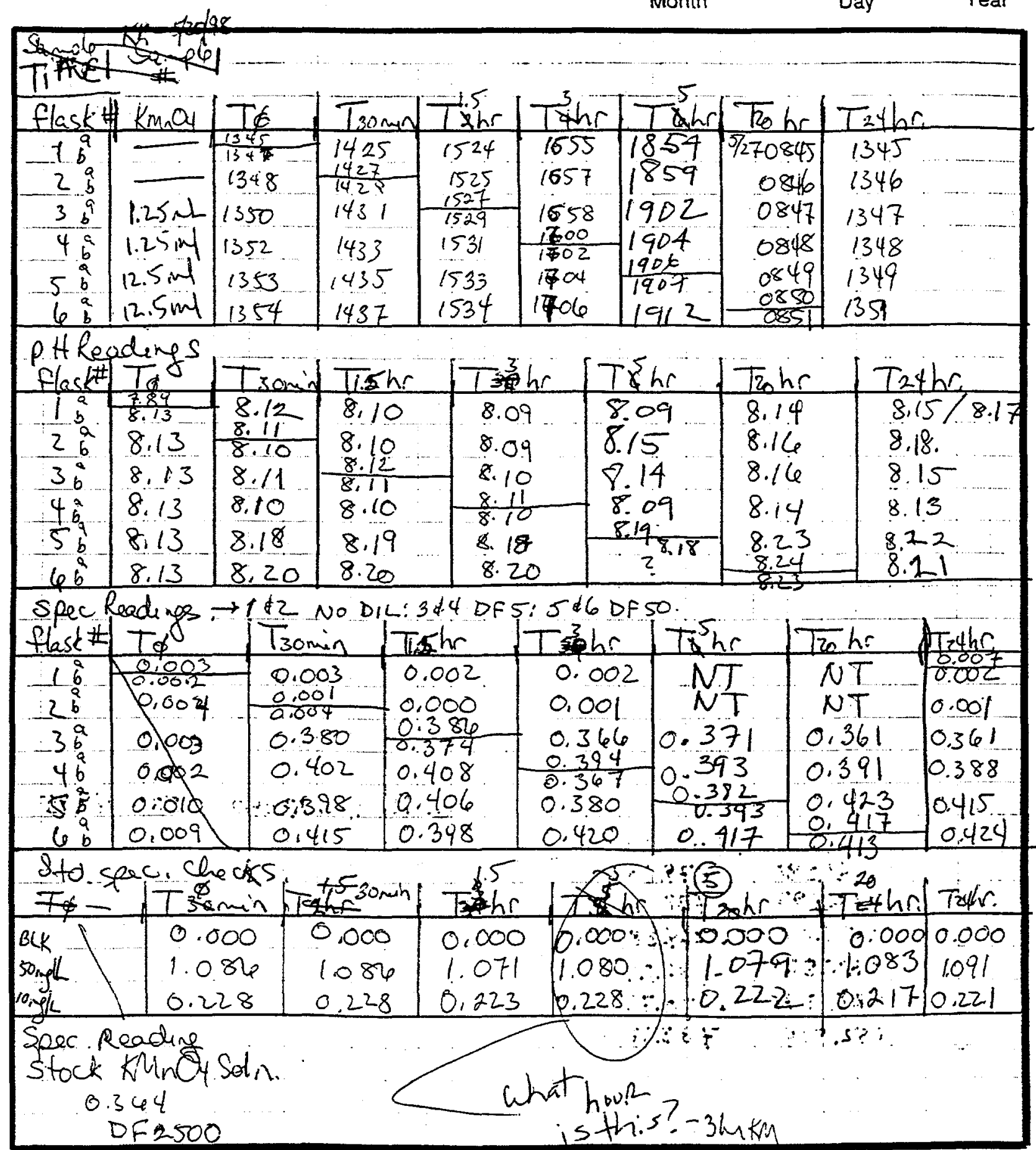

$\frac{k \text { Mcciacken }}{\text { Recorded by }} \frac{5 / 26 / 98}{\text { Date }}$

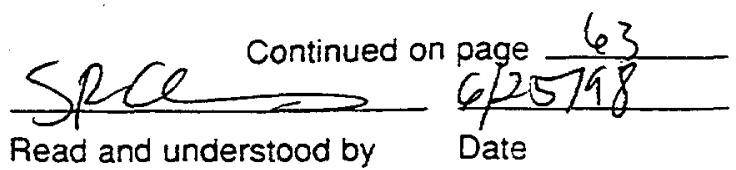


$\operatorname{Exp} 4 a-R_{1}$

Date $\frac{05}{\text { Month }} \quad \frac{20}{\text { Day }} 19 \frac{98}{\text { Year }}$

\begin{tabular}{|c|c|c|c|c|c|}
\hline SanpleT & GC\# & & & wottsample & \\
\hline 0845 & 352 & 10.979 & 4.050 & 19,82 & $B^{*}-a$ \\
\hline 0845 & 353 & 11.068 & 73.87000 & 19.758 & $T B-b$ \\
\hline 1345 & 354 & 15.4 & 13.052 & 16.379 & To-lo \\
\hline 1347 & 355 & 000 & 12.923 & 16.224 & $\varphi_{a}-R_{1}-T_{\phi}-1 b$ \\
\hline 1348 & 356 & 11.064 & 1248 & 16.308 & $4 a-R_{i}-T \phi-2$ \\
\hline 1350 & 357 & 11.011 & 12.897 & 16.461 & $4 a-R I-T \phi-3$ \\
\hline 1352 & 358 & 11.117 & 13,000 & 16,402 & $T \phi-4$ \\
\hline 1353 & 358 & 11.027 & 12.824 & 15.838 & \\
\hline 1354 & 360 & 115 & 12,871 & 213 & \\
\hline 1425 & 361 & .105 & 12.833 & 16.335 & Tongan \\
\hline 1427 & 362 & 11.004 & 12.008 & 16.012 & $T z^{3 p a n}-2 a$ \\
\hline 1429 & 363 & $150^{\circ}$ & 12.923 & 16.406 & $\sin -26$ \\
\hline 1430 & 364 & .077 & 12.931 & 15.937 & $2 x-3$ \\
\hline 1431 & 365 & .051 & 12.905 & 15.821 & $4 a-R_{1}-T \sin 4$ \\
\hline 1433 & 366 & 1.021 & 12.892 & 16.448 & $4 a-R_{1}-T_{3 g_{n}+5}$ \\
\hline 1435 & 367 & 11 & 12.909 & 16.614 & $4 a-R_{1}-T_{\sin }-6$ \\
\hline 1524 & 368 & .119 & 13,046 & 16.742 & $4 a-R i-T-1+T, 5 h r-1$ \\
\hline 1525 & 369 & 10.989 & 12.903 & 15.986 & 4a-Ri-TH z-Tishr-2 \\
\hline $15^{2}-6$ & 370 & 10.960 & 13.006 & 16,224 & $4 a-R i-T-3 a-T i s h r-3 a$ \\
\hline 1528 & 371 & 11.026 & 12.817 & 15.642 & $4 a-R_{1}-3 b-\pi \cdot 5 h r-3 b$ \\
\hline 1530 & 372 & $0 / 6$ & 12.935 & 16.244 & $4 a-R_{1}-T_{2} h r-4$ T.5hr-4 \\
\hline 1532 & 373 & 173 & 13.109 & 16.556 & $4 a-R 1-F h r-5$ T.5hr-5 \\
\hline$\frac{1239}{165}$ & 374 & 11.129 & 12.903 & 16.034 & $4 a \cdot R_{1}-T h=6-T_{1.5} h r-6$ \\
\hline$\frac{1055}{1657}$ & 375 & 11.104 & 12.907 & 15.924: & $4 a-R_{1}-T h+T 3 h r-1$ \\
\hline & .376 & 11.062 & 13010 & 16.245 & $4 a-R_{1}-I_{4} h r z$ Tshr-2 \\
\hline$\frac{1038}{1700}$ & 377 & 11.9 .94 & 13,039 & 16,314 & $4 a-R_{1}-F 4 h-3-T 3 h r-3$ \\
\hline & 378 & 11.002 & 13.009 & 16,071 & $4 a-R_{1}-F_{4}{ }^{2}+a-T g h r-4 a$ \\
\hline+602 & 373 & 11.056 & 13.090 & 16.223 & $4 a-R-74=4 b-6 h r-4 b$ \\
\hline 16055 & 380 & 11.130 & 13.151 & 16,318 & $4 a-R l-T_{h} h-5 T_{3} h c-5$ \\
\hline$+655+$ & 381 & 11.037 & 13.043 & 16.252 & $4 a-R_{1}-46$ T3hr-6 \\
\hline 1854 & 382 & 11.195 & & 16.200 & $4 a-R_{1}-T_{6} h+T_{5} h r-1$ \\
\hline 1859 & 383 & 11.189 & 13.228 & 16.129 & 4a-R1-开ht-2 T5hr-z \\
\hline
\end{tabular}

*TL = Tedlar kag

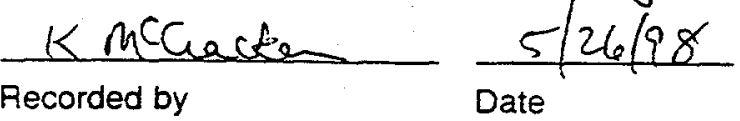

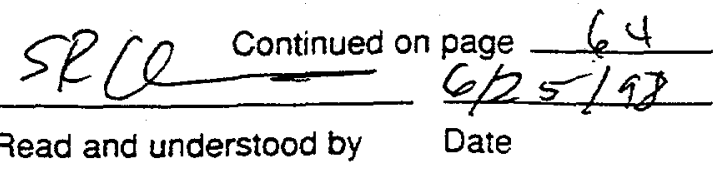


Subject

Exp ta-R

Date $\frac{05}{\text { Month }}$

(ब)

Day

$19 \frac{98}{Y e a r}$

\begin{tabular}{|c|c|c|c|c|c|}
\hline Sanpletinuel & GC\# & wt.empty & wt.t herang & wt tsample & Sample ID \\
\hline 1902 & 384 & 11.099 & 13.119 & 16.315 & $4 a \cdot R_{1}-T_{6}+$ \\
\hline 1904 & 385 & 11.120 & 13.112 & 16.222 & $4 a-R_{1}-F_{6}$ \\
\hline 1906 & 386 & 11.137 & 13.672 & 16.489 & $h+5 x$ \\
\hline 1907 & 387 & 11.038 & 13.044 & 16.369 & $F+1 \leq 5 b-75 h r-56$ \\
\hline 1912 & 388 & 11.002 & 13.093 & 16.247 & $h r-6-T_{5} h r-6$ \\
\hline $5 / 2+0845$ & 389 & 11.092 & 13.275 & 16.050 & $h c-1$ \\
\hline 0846 & 390 & 11.145 & 13.229 & 16.300 & $h c-2$ \\
\hline 0847 & 391 & 11.062 & 13.172 & 16.386 & $5 h r-3$ \\
\hline 0848 & 392 & 11.127 & 13,239 & 16.318 & $T_{0} h r-4$ \\
\hline 0.849 & 393 & 11.042 & 13.153 & 16.112 & ohe- -5 \\
\hline 0850 & 394 & 11.074 & 13.190 & 16.319 & her-le \\
\hline 0851 & 395 & 11.053 & 13.153 & 16.687 & $h r-6$ \\
\hline 1345 & 396 & 11.067 & 13.178 & 16.511 & $4 h r-1$ \\
\hline 1346 & 397 & 11,023 & 13.087 & 16.444 & T24hr-16 \\
\hline 1347 & 398 & 11.063 & 13.204 & 16.268 & $T_{24} 4 r-2$ \\
\hline 1348 & 399 & 10.980 & 13,071 & 16.187 & $-4 h-3$ \\
\hline 1349 & 400 & 11.053 & 13.125 & 16.078 & $4 h r-4$ \\
\hline 1350 & 401 & 11.026 & 13.135 & 16.274 & $4 a-R_{1}-T_{2} 4 h r-5$ \\
\hline 1351 & 402 & 11.000 & 13.097 & 16.103 & $4 a-R 1-T 24 h r-6$ \\
\hline 1408 & 403 & 11.161 & 13.262 & 13.346 & $4 a-R_{1}-c f_{0} a c c a l_{1}-$ \\
\hline 1408 & 404 & 11.153 & 13.298 & 13340 & -6 \\
\hline 1409 & 105 & 11.170 & 13.100 & 13,174 & \\
\hline 1910 & 406 & 10.967 & 12.936 & $1 x^{2}, 982$ & fa- $R_{1}$-charcoal 2 te \\
\hline 1411 & 9.07 & 11.122 & 13.078 & 13.176 & 1 charcoal $3 a$ \\
\hline 142 & 908 & 10.107 & 13.073 & 13.117 & Ri-Charcoal 36 \\
\hline 140 & 909 & 61.086 & 13.059 & 13.155 & ta-Richarcoal 4a \\
\hline 1413 & 410 & 11.204 & 13.176 & 13.217 & 4a-Richa \\
\hline 1414 & $f(1$ & 11.048 & 13.013 & 13,110 & $\operatorname{col} 5 a$ \\
\hline 1415 & 412 & 11.099 & 13.068 & 13,110 & $4 a-f / c h a r c o a l 5 b$ \\
\hline 1416 & 413 & 11.017 & 12.977 & 13.076 & $4 a-R_{1}$ charcoal $6 a$ \\
\hline 1417 & 414 & 11.051 & 12.999 & +3.640 & charcoal $6 b_{w T+n}$ \\
\hline 1400 & 415 & 493.11 & 627.04 & Hoil iq & \\
\hline 1403 & 416 & 491.85 & 625 & $120 \% 19$ & \\
\hline
\end{tabular}

$\frac{\text { KiMCCracken }}{\text { Recorded by }} \frac{5 / 27 / 98}{\text { Date }}$

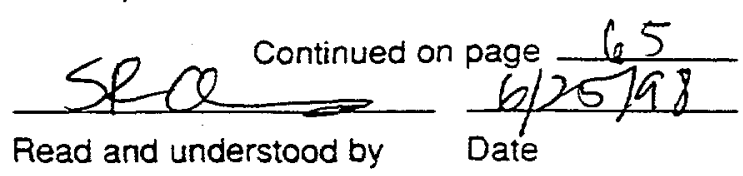


subject $\quad E \times \varphi_{1}+R_{1}$

\begin{tabular}{|c|c|c|}
\hline Date & 05 & 26 \\
\hline & Month & Day \\
\hline
\end{tabular}

\begin{tabular}{|c|c|c|c|c|c|c|}
\hline $\operatorname{sen}_{\text {the }}$ & GCH & wtengty & $\omega t+$ hexane & $\omega t+\sin \alpha 6$ & 1 & wt.t morehore \\
\hline 1405 & 417 & 493.36 & 627.11 & 1233.74 & $4 a-R_{1}-P_{5}$ & \\
\hline 1408 & 418 & 492.52 & 626.09 & 122245 & $4 a-R_{1}-f_{6}$ & \\
\hline
\end{tabular}

$5 / 27$ callo $\times 177446.50 \mathrm{~g} 49.95 \mathrm{~g}$

repeat $\& C$ an $\$ 5 \begin{aligned} & 387 \\ & 368\end{aligned}$

369 ! $\frac{\text { K. MCGacke }}{\text { Recorded by }} \frac{5 / 27 / 98}{\text { Date }}$
$52 \mathrm{Ce}$ Continued

Read and understood by on page

$6 / 2579$

Date 
Subject $2404 a-R_{2}$

Date $\begin{array}{ccc}05 & 28 & 1998 \\ \text { Month } & \text { Day } & \text { Year }\end{array}$

\section{calib: \\ $X(7.7440 \quad 50 \mathrm{~g} \quad 49.85 \mathrm{~g}$}

please NOTE: deviation from plan

* sparged ground water was incubated over night to bring Temp to $12^{\circ} \mathrm{C}$,

Then spiked w/TCE saturated soln, mixed 2 hrs.
\&used in flasks.

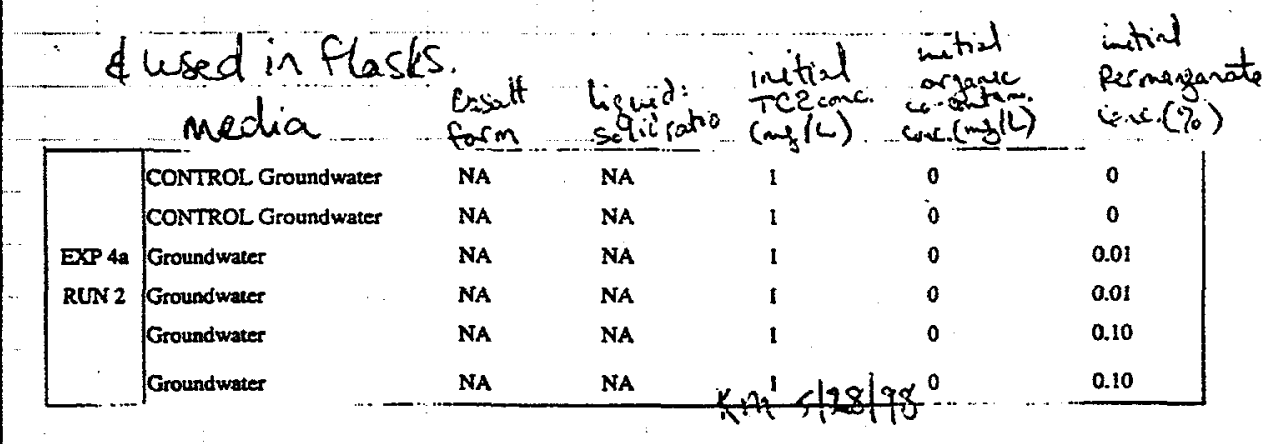

to abto

abtain

a

uniform soln: $\begin{array}{rl}a l i b . & \\ \times 177558-50 \mathrm{~g} & 50.0 \mathrm{~g}\end{array}$

Tedlar bog $56.76 \mathrm{~g}$

Tedlar Bag tolu: $3215.50 \mathrm{~g}$

Gw

3158.74

TCESat. Soin added $3.000 \mathrm{ml}$

-1......

$\cdots$ flas
1
2
3
4
5
6

\begin{tabular}{l|} 
wt. \\
250.12 \\
250.20 \\
238.26 \\
247.49 \\
230.24 \\
251.68
\end{tabular}

$$
\text { . }
$$

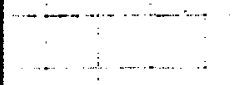


Subject $\quad \varepsilon_{x} .4 a-R_{2}$

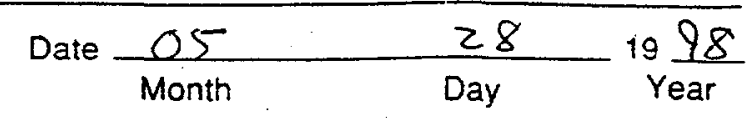

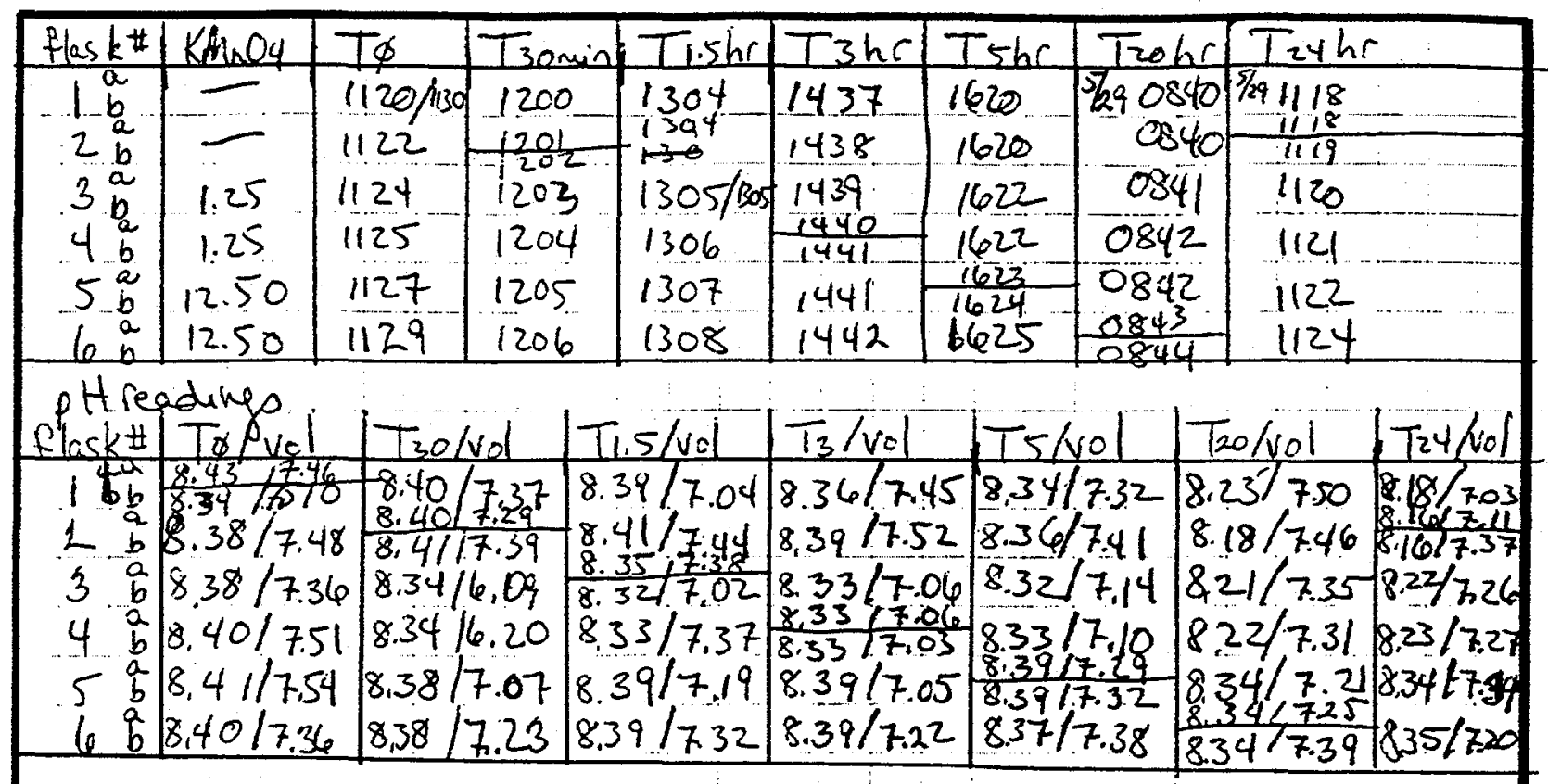

\begin{tabular}{|c|c|c|c|c|c|c|c|}
\hline flas & Te 0 & $T_{30}$ & $T .5$ & $T_{3}$ & $T_{5}$ & T20 & T24 \\
\hline $1 \begin{array}{c}a \\
b\end{array}$ & NT/ $/ 001$ & $N T$ & 0.008 & 0003 & 0.003 & 0.003 & 0.003 \\
\hline $2 \frac{a}{b}$ & 0,002 & NT 10.004 & 0.002 & 0,002 & 0.003 & 0.003 & \\
\hline $3 a$ & 0.001 & 0.353 & $0.357 / 0.370$ & 0.354 & 0.340 & $0.20 y$ & 0.304 \\
\hline $4 a$ & $N T$ & 0.414 & 0.396 & $0.375 / 0.387$ & 0.389 & 0.269 & 0.308 \\
\hline 5. &.$N T$ & 0.420 & 0.418 & 0.425 & $0.411 \% 0.417$ & 0.428 & 0.419 \\
\hline 10 & NT & 0.422 & 0.417 & 0.437 & 0.427 & $0.436 \% .404$ & 0.416 \\
\hline
\end{tabular}

\begin{tabular}{|c|c|c|c|c|c|c|c|}
\hline & $T_{\phi}$ & $T>0$ & $T_{1.5}$ & $T_{3}$ & $T 5$ & T20 & Tet \\
\hline & 0.000 & 0.000 & 0.000 & 0.000 & 0.000 & 0.000 & 0.000 \\
\hline $50 \mathrm{~m} / \mathrm{h}$ & 1.068 & 1.070 & 1.068 & 1.065 & 1.068 & 1.070 & 0.063 \\
\hline $0 \mathrm{mb} / \mathrm{h}$ & 0.202 & 0.200 & 0.196 & 0.191 & 0.191 & 0.184 & 0.182 \\
\hline
\end{tabular}
Sper readig-stock $\mathrm{KMnO}_{4} \underset{\mathrm{Soln}}{\mathrm{Abs}=0.354 \text { DF250O }}$

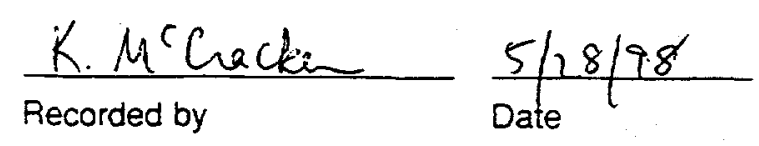

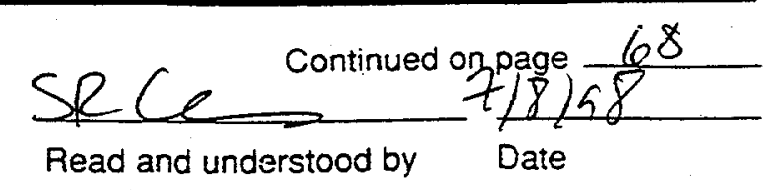


Exp. $4 a-R_{2}$

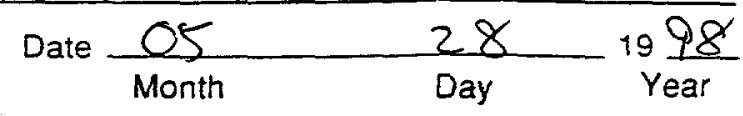

\begin{tabular}{|c|c|c|c|c|c|}
\hline sainple tire & $G C \#$ & wtenpty & wtit hexae & $\omega t \cdot+\sin m p l_{6}$ & sample ID \\
\hline 1622 & 520 & 10.959 & 12.939 & 16.066 & $h r-4$ \\
\hline 1622 & 521 & 10.976 & 12.953 & 16.082 & $r-5 a$ \\
\hline 1623 & 522 & 11.070 & 13.048 & 16029 & $5 h-5 b$ \\
\hline 1624 & 523 & 10.913 & 12.908 & 15.822 & $5 h-6$ \\
\hline 990840 & 524 & 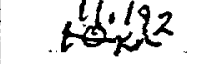 & F. & 16.183 & $h r-1$ \\
\hline 0840 & 525 & 10.975 & $\frac{13.54}{209}$ & 16.103 & $n r-2$ \\
\hline 6841 & 526 & 11.104 & 3.046 & 16.046 & $a r-3$ \\
\hline 0842 & 527 & 10.863 & $\frac{13.84}{13.059}$ & 15.988 & $x-4$ \\
\hline 0842 & 528 & 11.067 & H.043 & 16.301 & $5-5$ \\
\hline 0843 & 529 & 11.135 & 13.109 & 16.211 & $56 a$ \\
\hline 0844 & 530 & 11,053 & 13.031 & 16.082 & 766 \\
\hline $1 / 18$ & 531 & 11.161 & 13.077 & 16.150 & $m-1$ \\
\hline 1119 & 532 & 140404 & 13.077 & 16.187 & $r-2 a$ \\
\hline 1120 & 533 & 11.061 & 13.002 & -16.227 & 26 \\
\hline 1121 & 534 & .11 .108 & 13.056 & 16.274 & $!$ \\
\hline 1122 & 535 & 11.054 & 12.967 & 16.015 & 1 \\
\hline 1123 & 536 & 11.022 & 12.982 & 16.116 & 1 \\
\hline 1124 & 537 & 10.955 & 12.895 & 16687 & 1 \\
\hline 1132 & 538 & 11.074 & 13.021 & 13,122 & 1 \\
\hline .1132 & 539 & 16.146 & 13.101 & 13.154 & \\
\hline .1133 & 540 & 10.947 & 12.905 & 13.001 & 1 \\
\hline 1133 & 541 & 11.043 & 12.991 & 13,039 & ..... \\
\hline 1134 & 542 & 11.186 & 13.131 & 13.233 & $\ldots$ \\
\hline 1134 & 543 & 11.076 & 13.007 & 13.060 & cher-3b \\
\hline .1135 & 544 & 11.064 & 13.023 & 13.124 & $n-4 a$ \\
\hline .1135 & 545 & 10.974 & 12.942 & 12.992 & 46 \\
\hline 1136 & 546 & 11.114 & 13.066 & 13.175 & $1-5 a$ \\
\hline 1136 & 547 & 11.202 & 13.150 & 13.194 & 6 \\
\hline 1137 & 548 & 11.065 & 13.023 & 13.128 & $!$ \\
\hline $\begin{array}{l}1137 \\
1226 \\
1228 \\
1230 \\
1231\end{array}$ & $\begin{array}{l}549 \\
550 \\
551 \\
552 \\
553\end{array}$ & 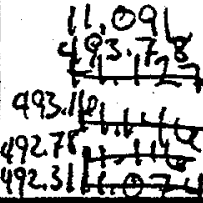 & $\begin{array}{l}13.044 \\
624.62 \\
626.60 \\
625.80 \\
625.42\end{array}$ & $\begin{array}{l}13.102 \\
1169.10 \\
1160.00 \\
1199970\end{array}$ & $\begin{array}{l}\text { har }-6 b \\
-R_{2}-f 3 \\
-R_{2}-R_{4} \\
-R_{2}-f_{5} \\
=-R_{2}-f 6\end{array}$ \\
\hline
\end{tabular}
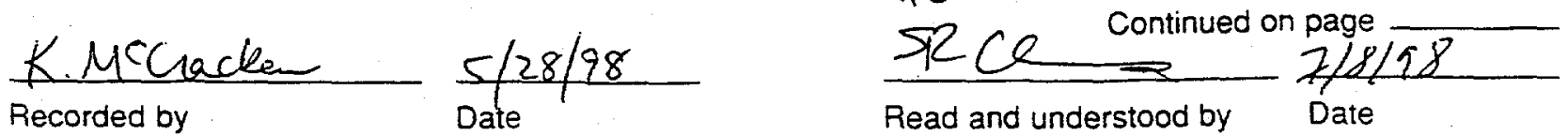
Subject Exp tak3

Date $\frac{O l e}{\text { Month }}$
$1 9 \longdiv { 8 8 }$

Day

Year

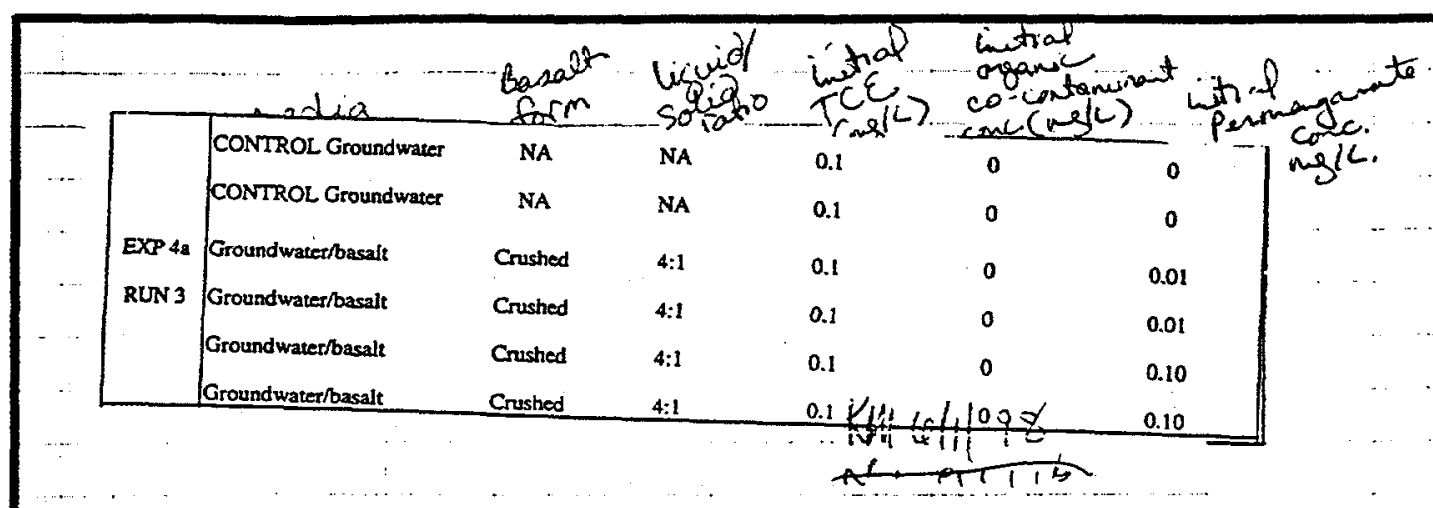

Tedlar bag

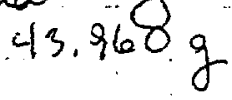

Baked lavalt

ovemight.

Thedlan bag $+\mathrm{H}_{2} \mathrm{O}$

Groudwater
310.94 45 toin TCE stockadded:
0.31.palkm

spiked $4 / 1 / 98$ overnght at $12^{\circ} \mathrm{C}$

$\vdots$

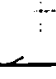

fios $\therefore 1$

2

3

4

5

6

$245.87 \div$

252.22

236.26

255.83

227.93

248.94

336.36

356.10

328.63

349.55

ot

-.... 
Subject Exp. $4 a k^{3}$

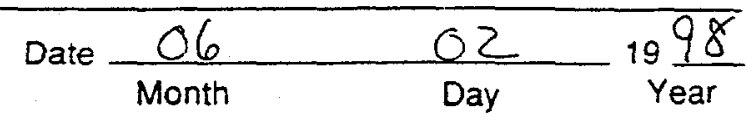

\begin{tabular}{|c|c|c|c|c|c|c|c|c|}
\hline flask \# & $\mathrm{KMnO}_{4}$ & Iक & T30min & Tishe & T3hr & Is hr & Tohr & Fethr \\
\hline 1 & $\equiv$ & $\frac{7130}{1131}$ & 1205 & 1305 & 1430 & 1630 & $6 / 40830$ & 1140 \\
\hline 2 & - & 1133 & $\frac{1207}{1209}$ & 1306 & 1431 & 1631 & 0831 & $1 / 41$. \\
\hline 3 & $1.25 \mathrm{nd}$ & 1134 & 1210 & $\frac{1307}{1308}$ & 1432 & 1632 & 0832 & $\frac{1142}{1.43}$ \\
\hline 4 & $1.25 \mathrm{NA}$ & 1136 & 12 & 1309 & 4433 & 16 & 0833 & 1144 \\
\hline 5 & $12.5 \mathrm{ml}$ & 1137 & 1214 & 1310 & 1432 & $\frac{163}{163}$ & 0834 & 1145 \\
\hline 10 & $12.5 \mathrm{~m}$ & 1138 & 1215 & 1311 & 1435 & 163 & $\frac{0.835}{0.36}$ & 1146 \\
\hline
\end{tabular}

$\mathrm{pH}$ Radading

Flasks To Nol T3om/vol Ti.sh/vol T3h/voll Tsh/voll Troh/vol/Tzih/h

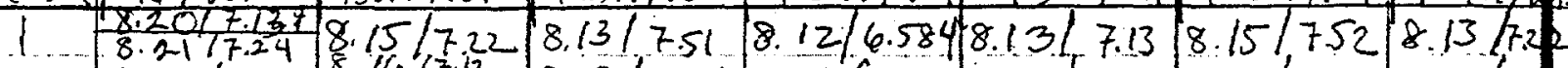

$2 \quad 8.21 / 7.20 \frac{8.1617 .22}{8.1817 .42} 8.18 / 7.44|8.18 / 7.33| 8.17 / 7.16 \mid 8.16 / 7.26 / 8.19 / 736$

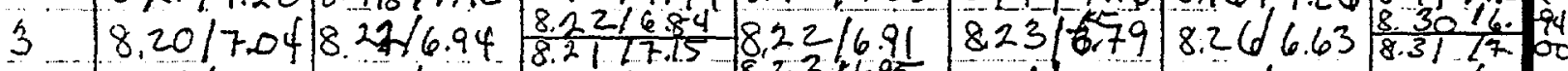

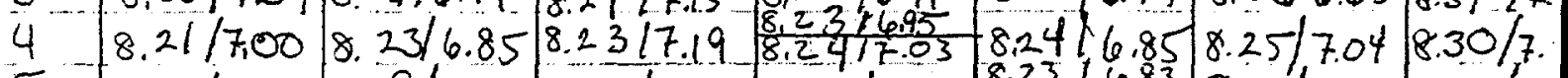

$5 \quad 8.22 / 7.118 .29 / 7.00 / 8.27 / 7.178 .24 / 7.12 \frac{8.23}{8.23 / 6.83} 8.23 / 6918.24 / 7.0$

$6 / 8.20 / 7.05 / 827 / 7.08 / 8.25 / 7.10 \mid 8.23 / 7.04 / 8.21 / 5.99 / 8.2016 .98 / 8.23 / 255$

\begin{tabular}{|c|c|c|c|c|c|c|c|}
\hline flask & T\& & $130 \mathrm{~m}$ & T.5h & Tih & T5h & $T_{20} h$ & $T_{24 h}$ \\
\hline 1 & $\frac{0.004}{0.006}$ & 0.034 & 0.008 & .0009 & 0.010 & 0.013 & \\
\hline 2 & 0.007 & $\frac{0.007}{0.007}$ & 0.007 & 0.008 & 0.010 & 0.012 & \\
\hline 3 & 0.002 & 0.463 & & 0.436 & 0.422 & 874 & \\
\hline 4 & 0.004 & 0.465 & 0.466 & $\frac{0.466}{0.467}$ & 0.459 & 0.830 & \\
\hline 5 & 0.004 & 0.487 & 0.472 & 0.480 & $\frac{0.466}{0.482}$ & 0.464 & 0 \\
\hline 6 & 0.004 & 0.4 .94 & 0,462 & 0.486 & 0.477 & $\frac{0.45}{0.470}$ & 0.47 \\
\hline
\end{tabular}

\begin{tabular}{|c|c|c|c|c|c|c|c|}
\hline$B C K$ & To 0,000 & T30m & $T 1.5 h^{0.000}$ & $3 h^{0.000}$ & $5 h^{0.000}$ & Tzoh & $2000724 \mathrm{~h}$ \\
\hline$m$ & 1.074 & 1.068 & 1.074 & 1.072 & 1.075 & 1.078 & 1.076 \\
\hline$m o l l$ & 0.212 & 0.212 & 0.212 & 0.212 & 0.212 & 0,212 & 0.212 \\
\hline
\end{tabular}

KmnOy Stack solm $=0.369$ DF 2500 Km

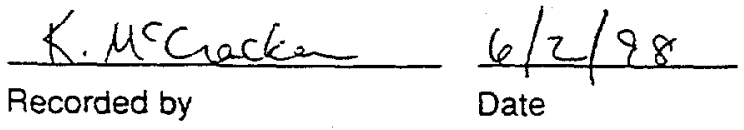

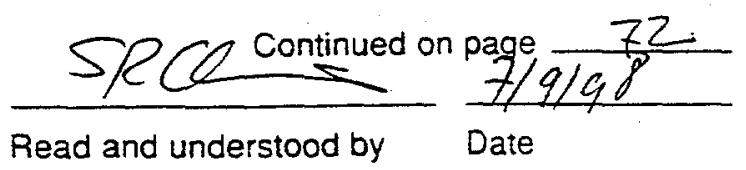




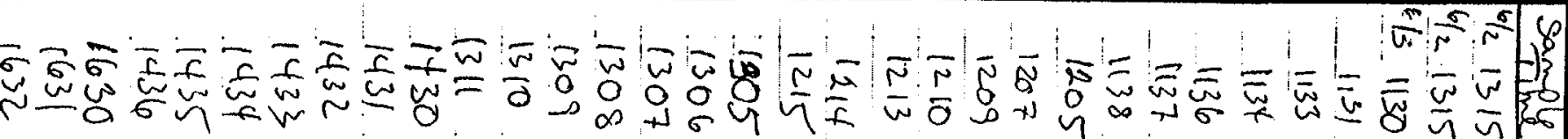

รБ

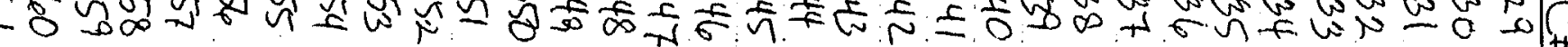

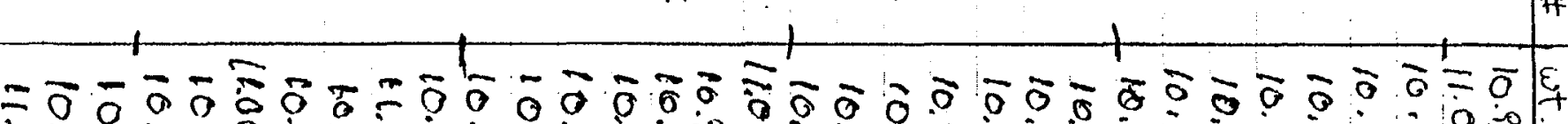

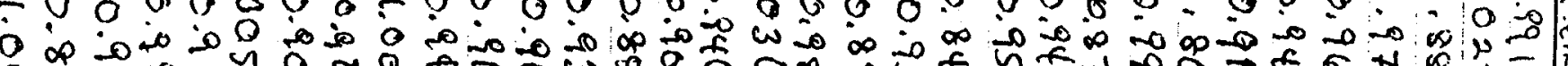

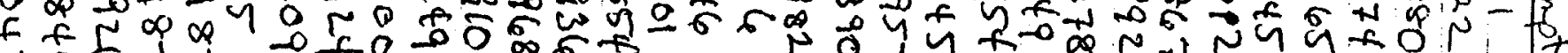

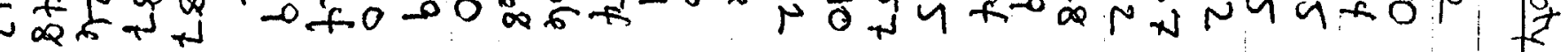

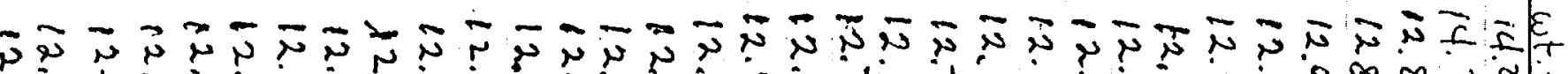
舟

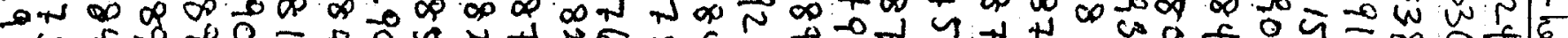

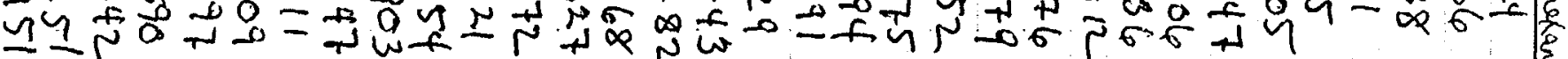

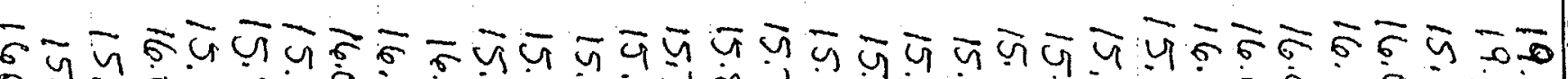

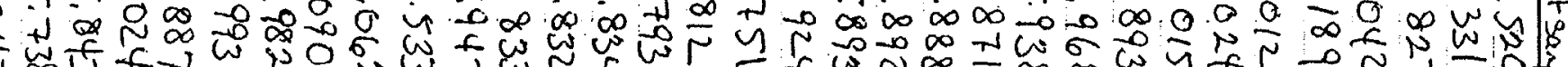
出出过

c ᄃ다.

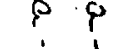

$\rightarrow x^{2}$

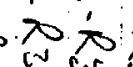

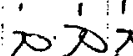
$\pi x^{2}>$ -1 1 -1 1 -1 -1 -1

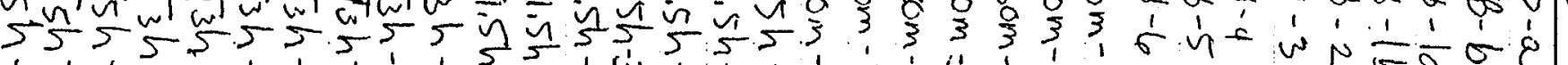

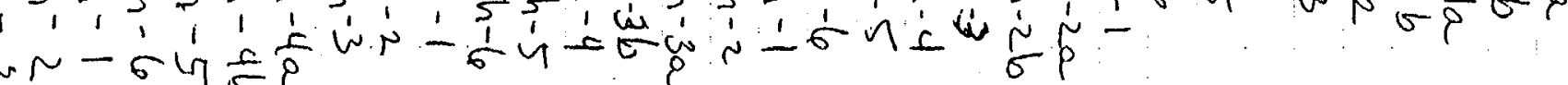


Subject Exp.4a-R3

Date $\frac{O 6}{\text { Month }}$ Day $19 \frac{98}{\text { Year }}$

\begin{tabular}{|c|c|c|c|c|c|c|}
\hline San-ple & GC\# & wt empty & wt therane & wt.tsample & Sample ID & Df \\
\hline 1634 & 662 & 10.918 & 12.836 & 15.818 & $4 a-R 3-T 5 h-4$ & \\
\hline 1635 & 663 & 10.926 & 12.835 & 15.998 & $4 a-R_{3}-T 5 h-5 a$ & \\
\hline 1636 & 664 & 10.908 & 12.821 & 15.846 & $4 a \cdot R_{3}-T_{5} h-5 b$ & \\
\hline 1637 & 665 & 10.975 & 12.894 & 15.882 & $4 a-R_{3}-T 5 h-6$ & \\
\hline $6 / 40830$ & 666 & 10.911 & 12.799 & .5 .789 & $4 a-R_{3}-T_{20 h}-1$ & \\
\hline 0831 & 667 & 10.973 & 12.884 & 15.883 & $\mathrm{Ha}_{a} R_{3}-T_{20 h}-2$ & \\
\hline 0832 & 668 & 10.947 & 12.853 & 16.030 & $4 a-R_{3}-T_{20} h-3$ & \\
\hline 0832 & 669 & 10.910 & 12.808 & 15.942 & $4 a \cdot R_{3}-T_{20 h}-4$ & \\
\hline 0833 & 670 & 10.896 & $12.7_{x} 96 \mathrm{t}$ & 1.5966 & $4 a \cdot R 3-T 20 h-5$ & \\
\hline 0834 & $67 !$ & 10.988 & $12.811 \mathrm{~km}=$ & 15.926 & $4 a-R_{3}-T_{20 h}-6 a$ & \\
\hline .0835 & 672 & 10.980 & 12.890 & $16.098^{60}$ & $4 a-R_{3}-T_{20} h-6 b$ & \\
\hline 1140 & 673 & 10.894 & 12.816 & 15.939 & $4 a \cdot R_{3}-T_{2} 4 h-1$ & \\
\hline 1141 & 674 & 10.992 & 12.913 & 15.923 & $4 a-R 3-124 h-2$ & \\
\hline $11+2$ & 675 & 10.949 & 12.851 & 15.990 & $4 a-R_{3}-T_{2} 4 h-3 a$ & \\
\hline $11+3$ & 676 & 10.892 & 12.804 & 15.910 & $4 a-k 3-124 h-3 b$ & \\
\hline 114.4 & 677 & 11.040 & 12.915 & 16.019 & $4 a-R_{3}-T 24 h-4$ & \\
\hline 1145 & 678 & 10.961 & 12.876 & 15.881 & $40-R_{3}-T_{2} 4 h-3$ & \\
\hline 146 & 679 & 10.970 & 12.873 & 16.255 & $4 a-R_{3}-T_{2} 4 h-6$ & \\
\hline 1205 & 680 & 10.899 & 12,800 & 12.883 & 4a-R3 char - la & \\
\hline 1205 & 681 & 10.950 & 12.872 & $12.9 / 8$ & $4 a \cdot R_{3}-c_{h a r}-1 b$ & \\
\hline 1207 & 682 & 11.043 & 12.969 & 13.050 & $4 a-R_{3}$-char-2a & \\
\hline 1207 & 683 & 11.029 & 2.944 & 12.977 & $\left\{a-R_{3}-c h a r-2 b\right.$ & \\
\hline 1209 & 684 & 11.002 & 12.917 & 13.006 & $4 a \cdot R_{3}-C_{h} a r-3 a$ & \\
\hline 1209 & 685 & 16.934 & 12.839 & 12.884 & $R_{3}-\operatorname{coar} 36$ & \\
\hline 1211 & 686 & 10.957 & 12.857 & 12.930 & $4 a-R z-c \cos 4 a$ & \\
\hline 1211 & 687 & 10.844 & 12.760 & $12.800^{\circ}$ & $4 a-R_{3}-c h a r$ is & \\
\hline 1213 & 688 & 10.886 & 12.800 & 12.895 & $4 a-R 3 \cdot c a r-5 a$ & \\
\hline .1213 & 689 & 11.008 & 12.910 & 12.946 & $4 a \cdot R_{3} \cdot d a r-5 b$ & \\
\hline 1214 & 690 & 11.023 & 12.924 & 13.014 & $4 a-R_{3}$-char - $6 a$ & \\
\hline$\frac{1214}{1150}$ & $\begin{array}{l}691 \\
699\end{array}$ & -10.952 & 12.909 & 12.933 & $\begin{array}{l}4 a-R_{3}-c_{2}=-6 b \\
40-R_{3} f_{3}\end{array}$ & \\
\hline 1154 & $\begin{array}{l}412 \\
693 \\
689\end{array}$ & $\begin{array}{l}442.16 \\
492,75 \\
4028\end{array}$ & $\begin{array}{l}624.44756 .44 \\
625.09,1857.09\end{array}$ & $\begin{array}{l}198.21 \\
11980\end{array}$ & $\begin{array}{l}4 a-k 3+3 \\
4 a-R_{3}-f^{4}\end{array}$ & \\
\hline $\begin{array}{l}120 \\
1200\end{array}$ & 695 & 492.43 & $625.24 / 7563$ & 1232.37 & $\begin{array}{l}4 a-83 \cdot 55 \\
4 a-b_{3} \cdot-6\end{array}$ & \\
\hline
\end{tabular}

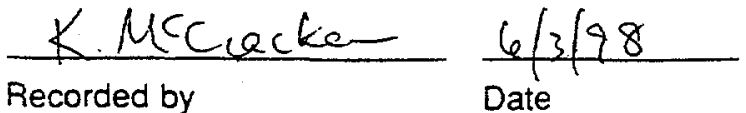

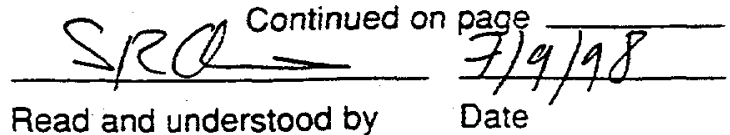




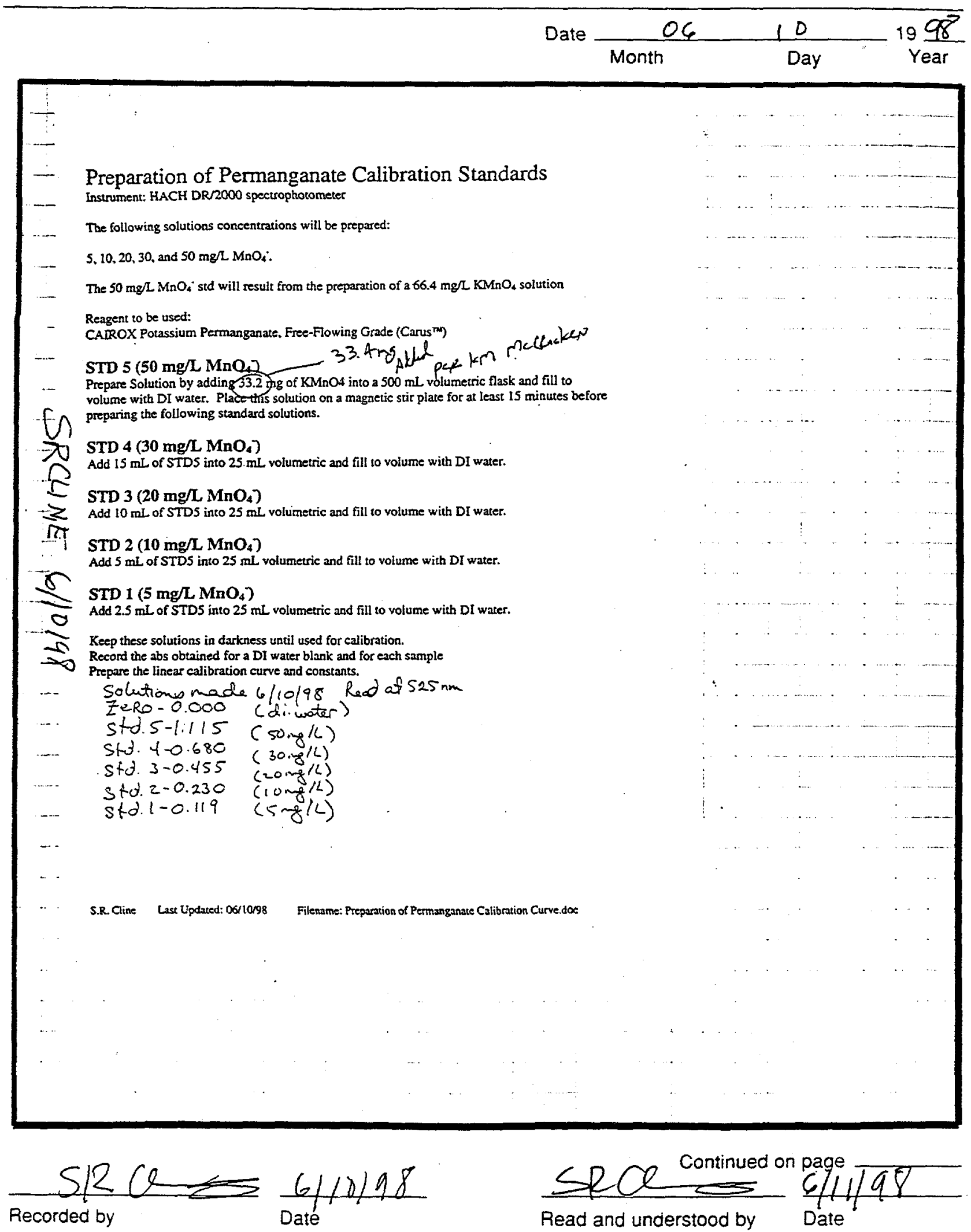


Subject Task3a-rapeat - iB

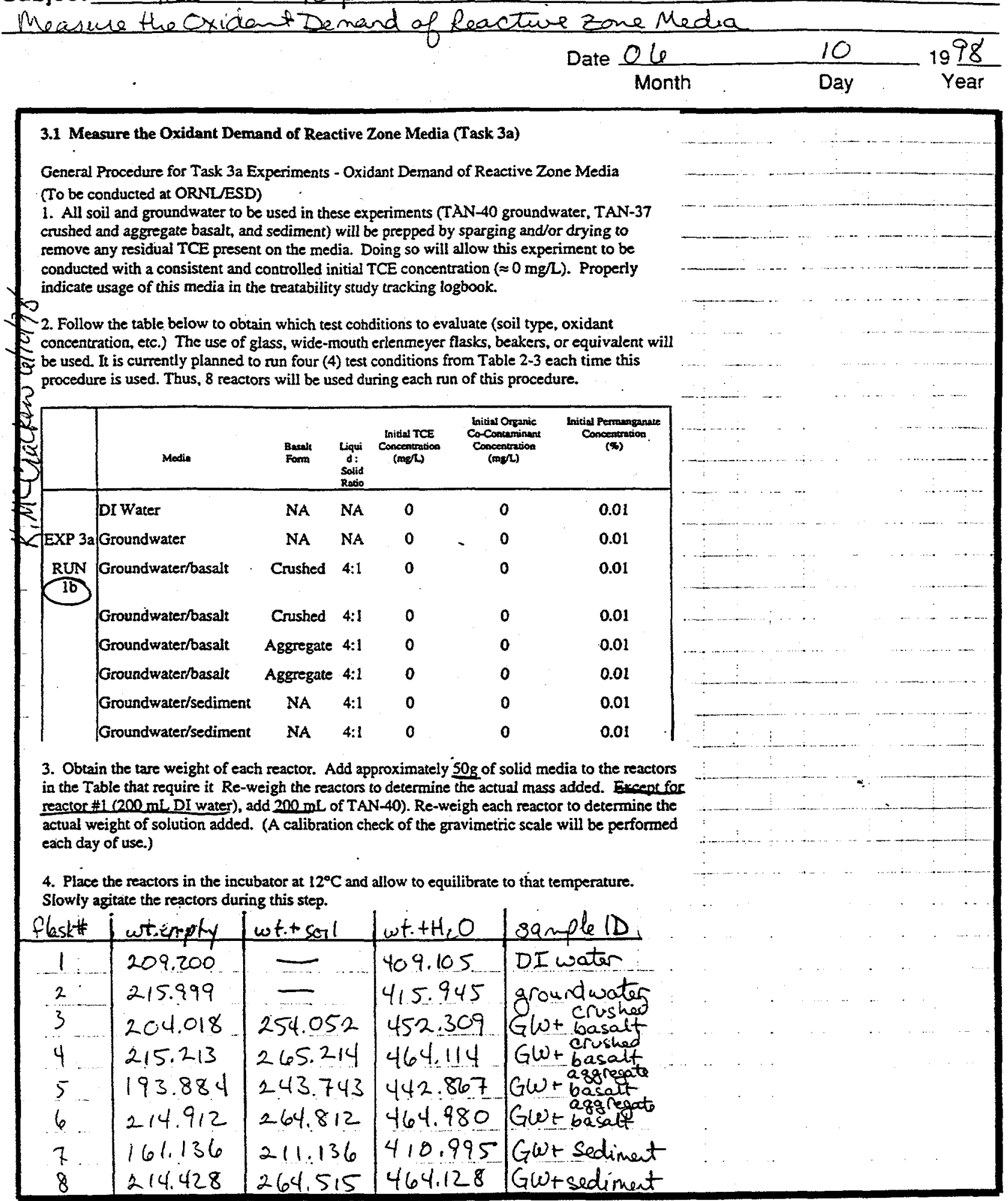

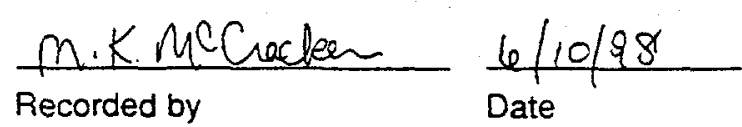

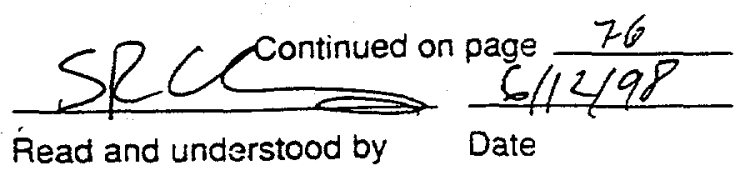




\begin{tabular}{|c|c|}
\hline Date 06 & 10 \\
\hline Month & Day \\
\hline
\end{tabular}

\section{For Loadings of .01wt\% $\mathrm{MnO}_{4}^{*}$}

Preparation of Stock $\mathrm{MnO}_{4}^{-}$Solution (4 wt\%)

Add $2.66 \mathrm{~g}$ of crystalline $\mathrm{KMnO}$ (Carus ${ }^{\text {tw }}$ Free Flowing Technical Grade) into a $50 \mathrm{~mL}$ Flask and fill to volume with DI water, and allow to mix for at least 2 hours.

\section{For Loadings of $.01 \mathrm{wt} \% \mathrm{MnO}_{4}{ }^{\circ}$}

Addition of Stock MnO4- Solution into Reactors

Quickly remove the ground glass stopper and add the needed volume of stock $\mathrm{KMnO}_{4}$ to obtain the $\mathrm{MnO}_{4}$ concentrations in the above Table (approximately $0.5 \mathrm{~mL}$ for the $0.01 \% \mathrm{MnO}_{4}{ }^{-}$ concentration)

7. Replace the glass ground stoppers and quickly hand shake each reactor to ensure rapid dissolution of the oxidant. The time that the stock $\mathrm{KMnO}_{4}$ is added to each individual reactor shall also be recorded (reaction start time). Place each reactor back into the $12^{\circ} \mathrm{C}$ incubator and $200 \mathrm{rpm}$.

8. For each reactor, remove the reactor from the incubator at approximately 30 minutes from the reaction start time, and collect a $5 \mathrm{~mL}$ aliquot (using a disposable plastic syringe with a Luer Tip). Record the time the sample was collected and replace the reactor back into the incubator.

9. Add a $0.45 \mu \mathrm{m}$ syringe filter onto the end of the syringe and filter the sample.

10. Perform a $\mathrm{MnO}_{4}^{-}$analysis on the filtered sample from the previous step. (The sample is filtered to remove particulate matter that could interfere with the analysis.) The filtered sample will likely have to be diluted with DI water so that its spectrophotomecric absorbance (at $\lambda=525$ $\mathrm{nm})$ is less than that of the highest standard to be prepared $(50 \mathrm{mg} / \mathrm{L} \mathrm{MnO4}-$ ). Check standards (10 and $50 \mathrm{mg} / \mathrm{L} \mathrm{MnO4-)}$ will be prepared with reagent grade $\mathrm{KMnO}_{4}$ and measured each analysis day. A new 5 point calibration curve will be prepared if the absorbance of these check standards differs from the expected value by $>15 \%$.

dieted

11. Collect and analyze aliquots from each reactor for $\mathrm{KMnO}_{4}$ (Steps 8-10) at the following ADDTTIONAL time periods: 1hr, 2 hrs, 4 hrs, 18 hrs, and 24 hrs.

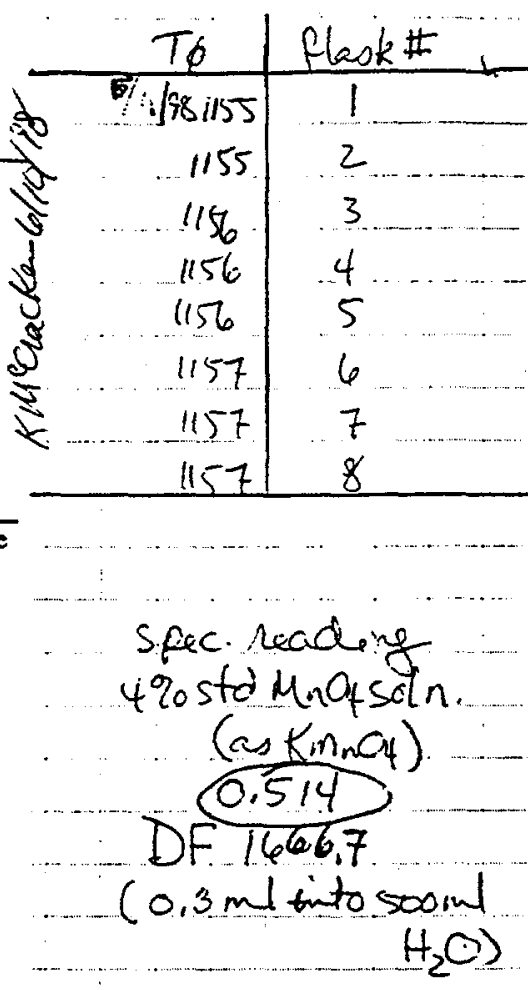

12. Interpret results and clean up the reactors for re-use in the next run of the experiment. Also place any waste materials generated from the experiment in the appropriate satellite accumulation area

K.MCGaciem

Recorded by
Date

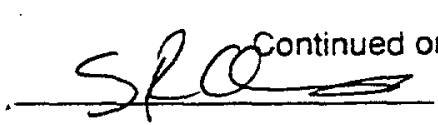

Read and understood by

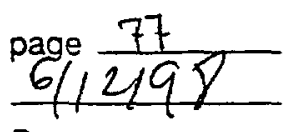

Date 
Subject Task $3 a-1 b$

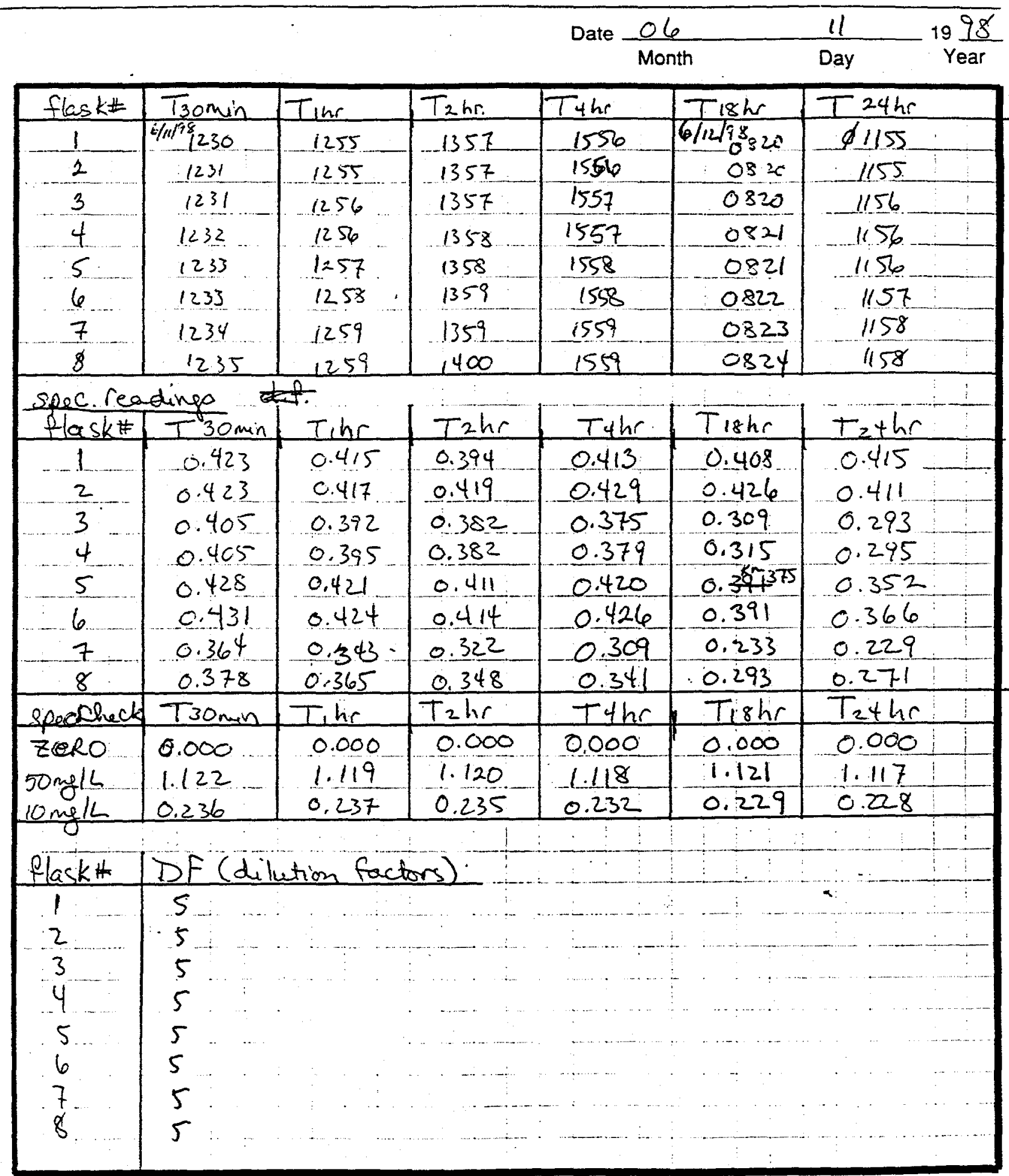

K.MCacter

Recorded by
Date
$\frac{S R d^{\text {Continued on page }}}{6 / 12 / 98}$ 
subject Exp.4A-R5

Date $\begin{array}{lll}06 & 15 & 1998 \\ \text { Month } & \text { Day }\end{array}$

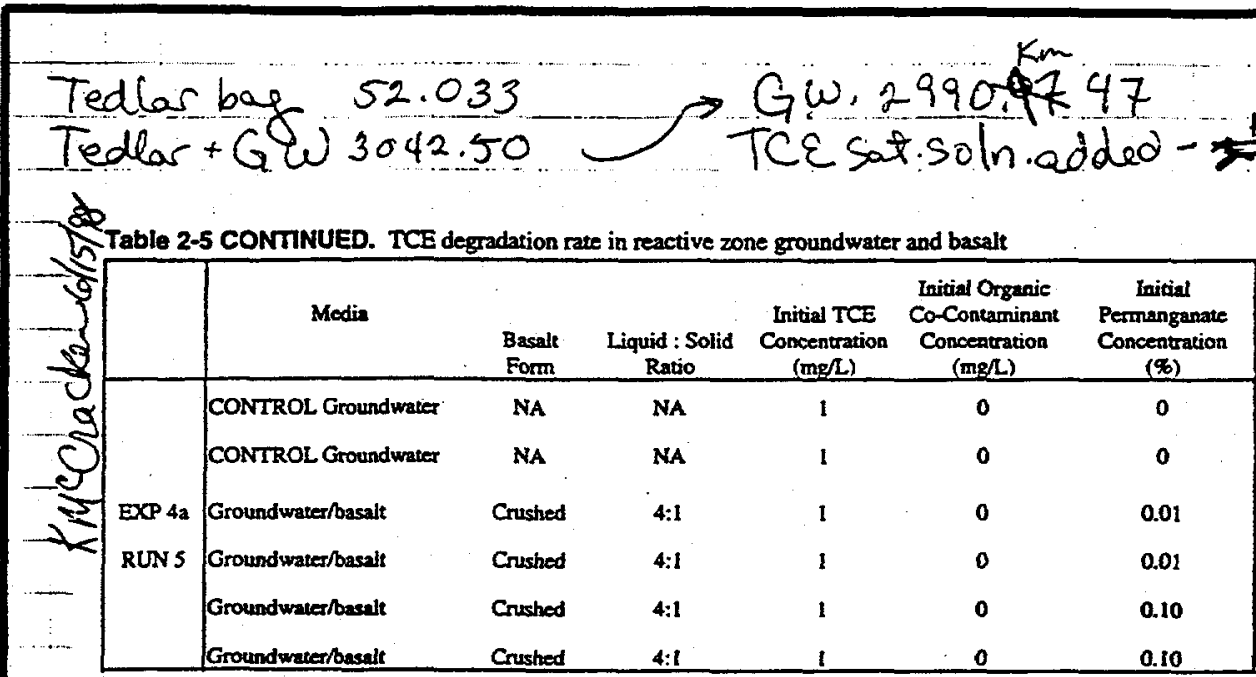

spiked E equilibrated overnight at $12^{\circ} \mathrm{C} .6 / 5 / 98$

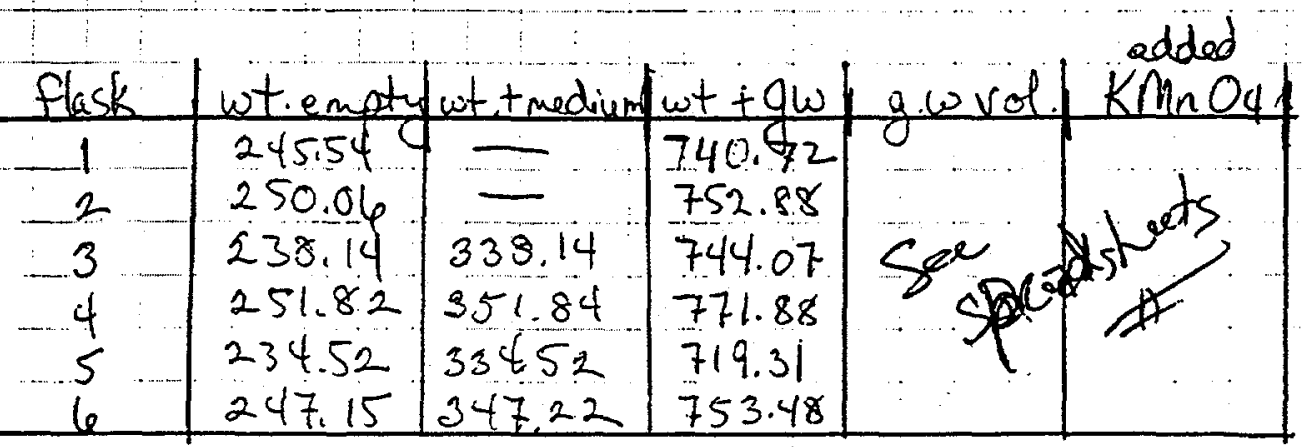

K.McCacker

Recorded by
${ }_{\text {Date }}^{6 / 15 / 98}$

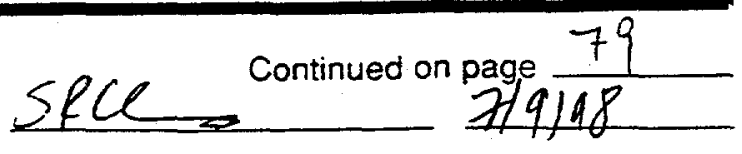

Read and understood by
$3.00 \mathrm{ml}$ 
Subject Exp.4A-R5

\begin{tabular}{|c|c|c|c|c|c|c|c|}
\hline & & & & Date _ & $\frac{06}{\text { Month }}$ & $\frac{15}{\text { Day }}$ & $-\frac{1998}{\text { Year }}$ \\
\hline flask \# & $T \phi$ & T30min & T $1.5 \mathrm{hr}$ & T3hr. & T5hr. & Trohr. & $T_{24 h}$ \\
\hline 1 & $\frac{\frac{\psi}{1000}}{1101}$ & 1133 & 1300 & 1410 & 1605 & $6 / 190830$ & 10 \\
\hline 2 & 1101 & $\frac{1138}{1634}$ & 1301 & 1410 & 1606 & 0820 & \\
\hline 3 & 1102 & .1135 & $\frac{301}{.130^{2}}$ & 1411 & 1607 & 0831 & \\
\hline 4 & 1103 & 1136 & 1302 & $\frac{1, i, 2}{.14 / 3}$ & 1608 & 0831 & \\
\hline 5 & 1103 & 1136 & 303 & 1415 & $\frac{1.08}{1609}$ & 0832 & \\
\hline 6 & 1104 & 1137 & 1303 & 14,5 & 1609 & $\frac{6833}{0834}$ & \\
\hline $\begin{array}{l}\text { fHR } \\
\text { flosk }\end{array}$ & adings. & $13 \mathrm{~m} / \mathrm{rol}$. & Tish/vol. & $T_{3 h} / \mathrm{Vol}$ & Tsh/vol: & Troh/vol & Tzih/vol \\
\hline 1 & \begin{tabular}{c|c|c|c|}
8.13 & 7.07 \\
3.14 & 7.21
\end{tabular} & \begin{tabular}{l|l}
8.17 & 761
\end{tabular} & \begin{tabular}{l|l}
8.15 & 7.39
\end{tabular} & $8.12 / 7.33$ & 8.146 .95 & 8.137 .48 & \begin{tabular}{l|l|l}
8.13 & 7.35 \\
\end{tabular} \\
\hline 2 & 8.0078 .99 & $\frac{8}{8.15} 7.44$ & $8.15=.27$ & $8.14 \mid 7.22$ & $1813 \mid 7.18$ & $8.15 \sqrt[7.22]{ }$ & $8,14] t, 22$ \\
\hline 3 & $8.17 \mid 7.25$ & 8.10 the & \begin{tabular}{l|l}
8.107 .06 \\
\end{tabular} & 8.116 .78 & 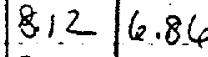 & 8.2460 .99 & 8266,78 \\
\hline 4. & $8.17 \mid 6.88$ & $8.09 / 7.22$ & 8.0917 .01 & 8.0916 .67 & $48.1 \mathrm{6} 6.79$ & 8.276 .95 & $\frac{1.22(6.87}{5.226 .86}$ \\
\hline 5 & 8.1577 .11 & 8.1117 .05 & 8.1017 .12 & \begin{tabular}{ll|l}
8.10 & 710
\end{tabular} & \begin{tabular}{|l|l|l|l|l}
8.107 .05 \\
\end{tabular} & 8.247 .10 & $8.25 / 6.90$ \\
\hline 6 & 8.1417 .12 & 8.0916 .89 & 8.0716 .84 & $807 \mid 7.01$ & 8.076 .71 & \begin{tabular}{l|l}
812 \\
813
\end{tabular} & 8.56 .75 \\
\hline spec. R & leadings & & & & & & \\
\hline Hask & $\frac{T \dot{s}}{0.02}$ & T30m & Ti.sh & Ish & $15 h$ & Tzeh & I2yh \\
\hline 1 & 0.003 & $\begin{array}{l}0.003 \\
0.003\end{array}$ & .0004 & 0.002 & 0.007 & 0.004 & 0.004 \\
\hline 2 & 0.002 & 0.003 & $\begin{array}{l}0.004 \\
0.452\end{array}$ & 0.000 & 0.003 & 0.004 & 0.003 \\
\hline 3 & 0.002 & 0.472 & 0.456 & $\begin{array}{l}0.438 \\
0.432\end{array}$ & 0.439 & 0.401 & 8.408 \\
\hline 4 & $0: 003$ & 0.459 & 0.444 & 0.438 & 0.417 & 0.399 & $\frac{0.40}{0.401}$ \\
\hline 5 & 0.002 & 0.547 & 0.540 & 0.546 & $\frac{.54}{0.533}$ & -0.539 & 0.536 \\
\hline 6 & 0.002 & 0.531 & 0.522 & 0.522 & 0.522 & $\frac{0.528}{0.522}$ & 0.522 \\
\hline spec.ce & reck. & & & & & & \\
\hline stds & $I_{\phi}$ & T30m & T.5 h & $T_{3} h$ & Ish & Izoh & $T_{24 h}$ \\
\hline$B(K$ & 0.000 & 0.000 & 0.000 & 0.000 & 0.000 & 0.000 & 0.000 \\
\hline $50 \mathrm{mg} / \mathrm{L}$ & 1.109. & 1.109 & 1.115 & 1.120 & 1.126 & 1.128 & 1.127 \\
\hline $10 \mathrm{mg} / \mathrm{L}$ & 0.218 & 0.218 & 0.217 & 0.217 & 0.219 & 0,219 & 0.219 \\
\hline 0 & & & & & & & \\
\hline & Readi & & & & & & \\
\hline & & & $A b s=0$. & $=0.51$ & & & \\
\hline & & & & & & & \\
\hline
\end{tabular}

$\frac{K \cdot M^{C} \text { Cacken }}{\text { Recorded by }} \frac{6 / 16 / 88}{\text { Date }}$

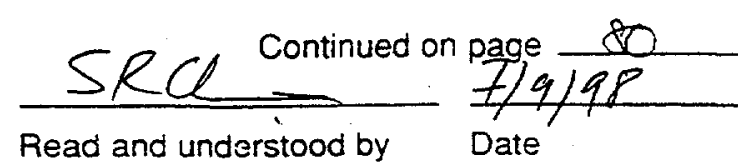


Subject Exp. $4 A-25$

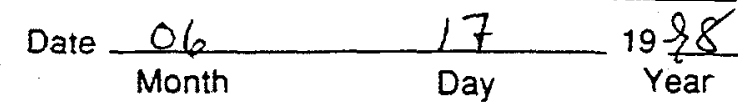

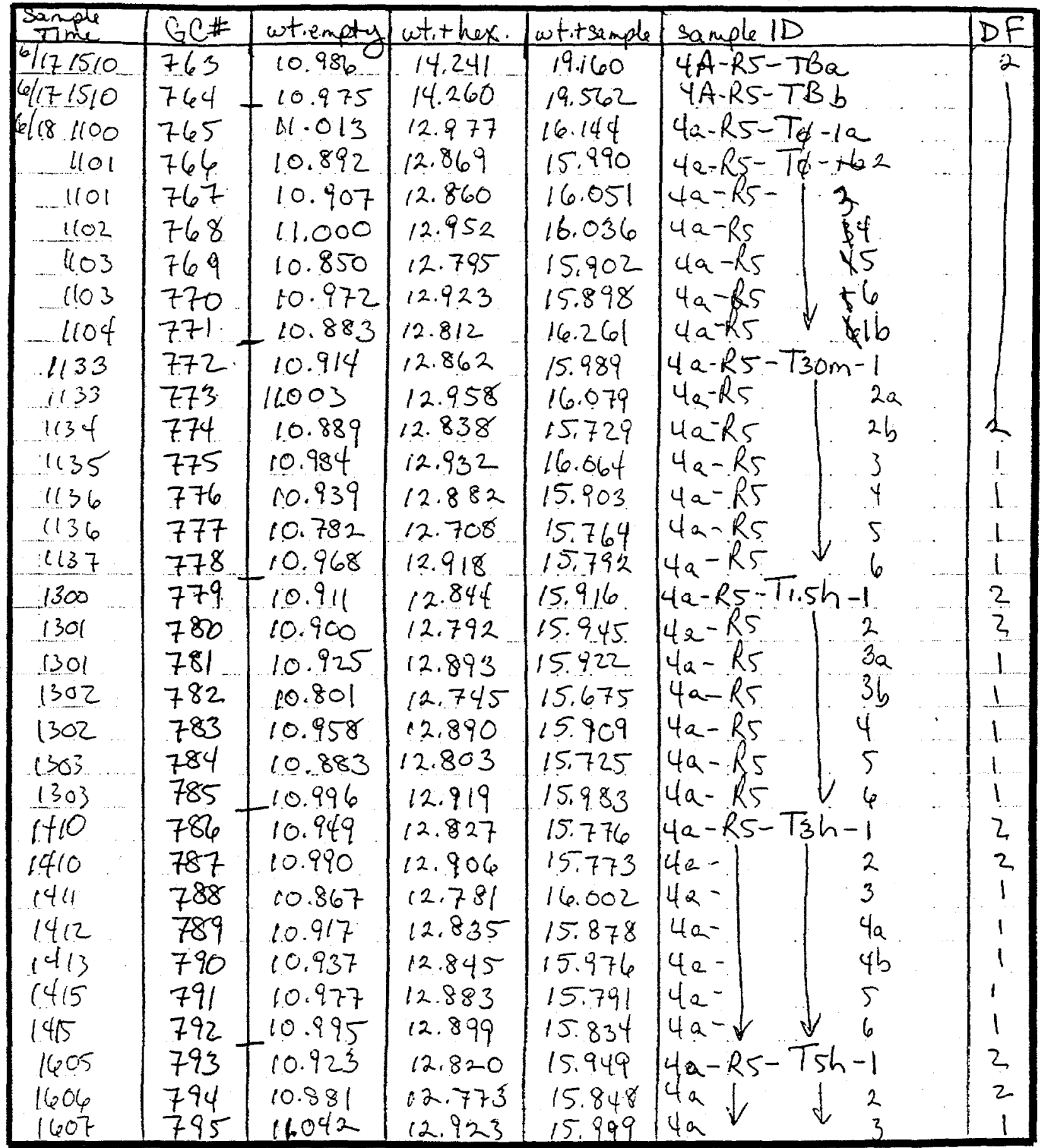

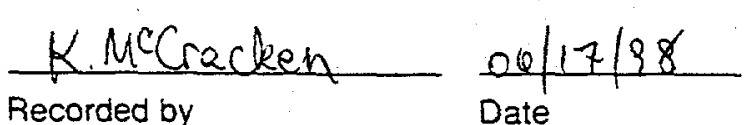

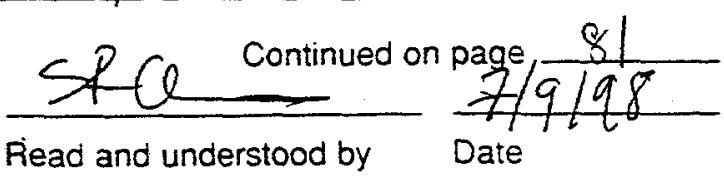


Subject Rxp. 4A-R5

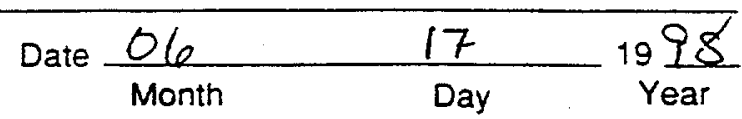

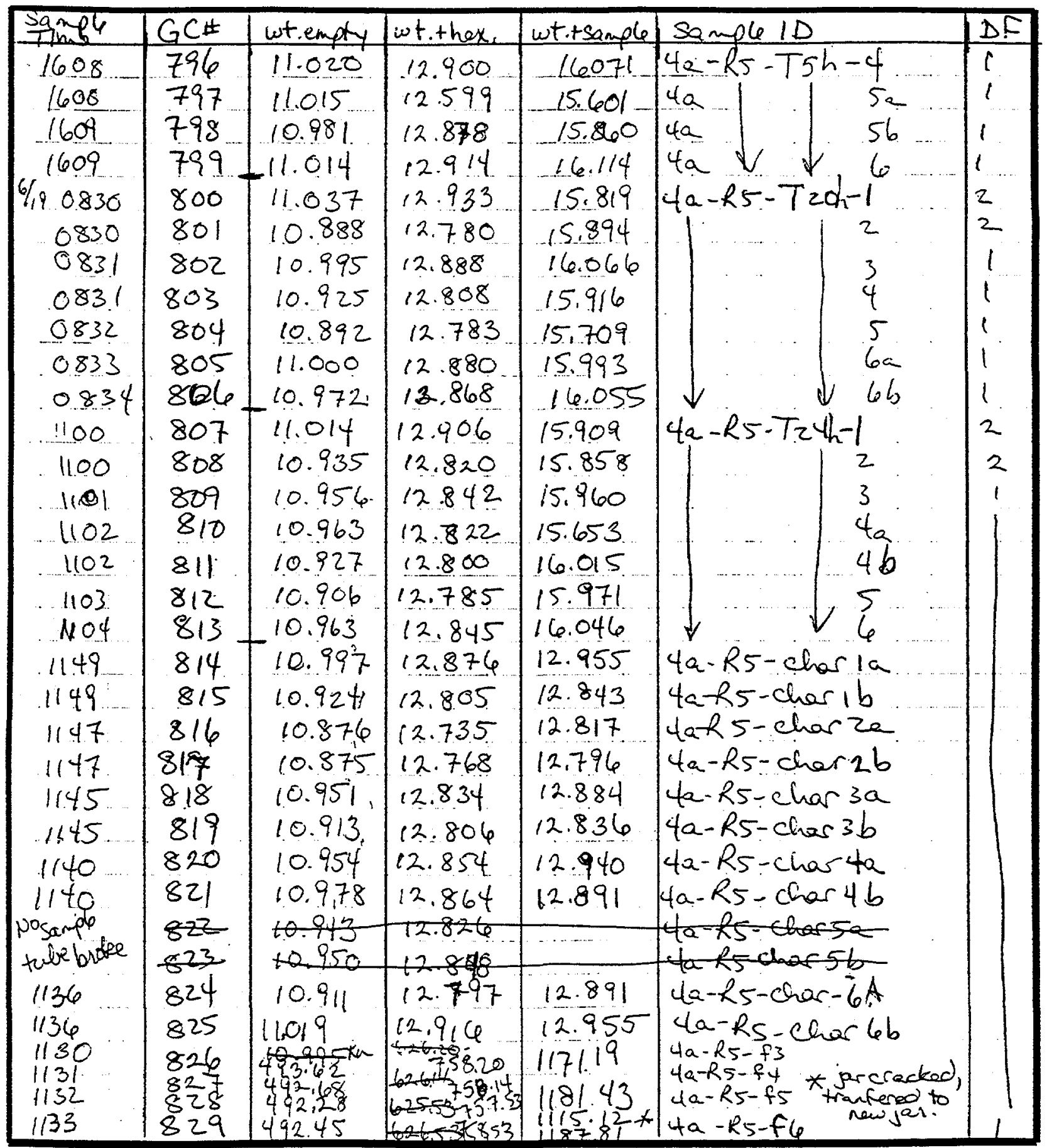
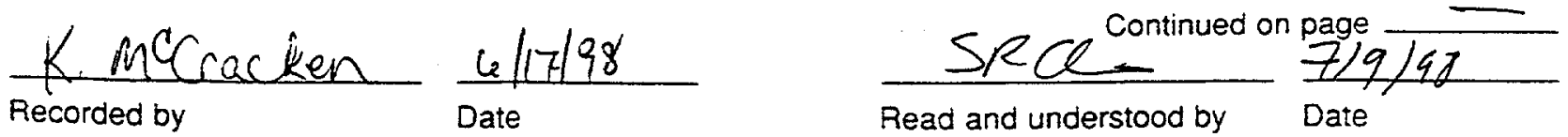
Subject Exp.3e- $\alpha_{2} l$

Date

23

Month

Day

Year

REPEATED EXP 3A-R2b

(No $\mathrm{pH}$ measurements will be made!)

1. All soil and groundwater to be used in these experiments (TAN-40 groundwater, TAN-37

crushed and aggregate basalt, and sediment) will be prepped by sparging and/or drying to

remove any residual TCE present on the media. Doing so will allow this experiment to be

conducted with a consistent and controlled initial TCE concentration $(\approx 0 \mathrm{mg} / \mathrm{L})$. Properiy

indicate usage of this media in the treatability study tracking logbook.

2. Follow the table below to obtain which test conditions to evaluate (soil type, oxidant

concentration, etc.) Glass, wide-mouth erlenmeyer flasks will be used. It is currentiy planned to

oun four (4) test condition sin duplicate. Thus, 8 reactors will be used during this procedure.

\begin{tabular}{|c|c|c|c|c|c|c|}
\hline & Modin & $\begin{array}{l}\text { Bosolt } \\
\text { Forma }\end{array}$ & $\begin{array}{c}\text { Liqui } \\
d: \\
\text { Solid } \\
\text { Ratio } \\
\end{array}$ & $\begin{array}{c}\text { Initiul TCE } \\
\text { Concentumion } \\
(m g / L)\end{array}$ & 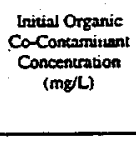 & $\begin{array}{l}\text { Itritial Permanganate } \\
\text { Concentrastion } \\
\text { (x) }\end{array}$ \\
\hline & DI Water & NA & NA & 0 & 0 & 0.10 \\
\hline & Groundwater & NA & NA & 0 & 0 & 0.10 \\
\hline \multirow{6}{*}{$\begin{array}{l}\text { RUN } \\
2 b\end{array}$} & Groundwater/basalt & Crushed & $4: 1$ & 0 & 0 & 0.10 \\
\hline & Groundwater/basalt & Crushed & $4: 1$ & 0 & 0 & 0.10 \\
\hline & Groundwater/basalt & Aggregate & $4: 1$ & 0 & 0 & 0.10 \\
\hline & Groundwater/basalt & Aggregate & $4: 1$ & 0 & 0 & 0.10 \\
\hline & Groundwater/sediment & NA & $4: 1$ & $\mathbf{0}$ & 0 & 0.10 \\
\hline & Groundwater/sediment & NA. & $4: 1$ & 0 & 0 & 0.10 \\
\hline
\end{tabular}

3. Obtain the tare weight of each reactor. Add approximately $50 \mathrm{~g}$ of solid media to the reactors in the Table that require it. Re-weigh the reactors to determine the actual mass added. Except for reactor \#1 (200 mL DI water), add $200 \mathrm{~mL}$ of TAN-40). Re-weigh each reactor to deternine the actual weight of solution added. (A calibration check of the gravimetric scale will be performed each day of use.)

4. Place the reactors in the incubator at $12^{\circ} \mathrm{C}$ and allow to equilibrate to that temperature.

Slowly agitate the reactors during this step.

\section{For Loadings of $0.1 \mathrm{wt} \% \mathrm{MnO}_{4}^{-}$}

Preparation of Stock $\mathrm{MnO}_{4}{ }^{-}$Solution (4 wt\%)

Add $2.66 \mathrm{~g}$ of crystalline $\mathrm{KMnO} 4$ (Carus ${ }^{\mathrm{T}}$ Free Flowing Technical Grade) into a $50 \mathrm{~mL}$ Flask and fill to volume with DI water, and allow to mix for at least 2 hours. tRun on spec.

S.R. Cline Last Updated: 06/17/98 Filename: procedure for Repeat 3a-R2 Experiment.doc

$$
\left[3 m_{2} \rightarrow 500 m L\right. \text { Flask }
$$

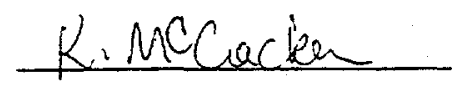

Recorded by

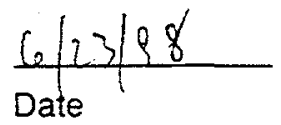

Date

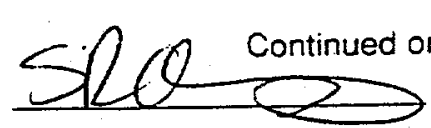

Read and understood by

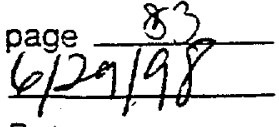

Date 
Subject Exp.3a-R2b

Date $\frac{06}{23} \frac{1998}{\text { Month }} \quad$ Day

\section{For Loadings of $0.1 \mathrm{wt} \% \mathrm{MnO}_{4}^{\circ}$}

Addition of Stock MnO4- Solution into Reactors

Quickly remove the ground glass stopper and add the needed volume of stock $\mathrm{KMnO}_{4}$ to obtain the $\mathrm{MnO}_{4}{ }^{-}$concentrations in the above Table (approximately $5 \mathrm{~mL}$ for the $0.1 \% \mathrm{MnO}_{4}{ }^{-}$ concentration)

7. Replace the glass ground/stoppers and quickly hand shake each reactor to ensure rapid dissolution of the oxidant. The time that the stock $\mathrm{KMnO}_{4}$ is added to each individual reactor shall also be recorded (reaction start time). Place each reactor back into the $12^{\circ} \mathrm{C}$ incubator and $200 \mathrm{rpm}$.

8. For each reactor, remove the reactor from the incubator at approximately 30 minutes from the reaction start time, and collect a $5 \mathrm{~mL}$ aliquot (using a disposable plastic syringe with a Luer Tip). Record the time the sample was collected and replace the reactor back into the incubator

9. Add a $0.45 \mu \mathrm{m}$ syringe filter onto the end of the syringe and filter the sample.

10. Perform a $\mathrm{MnO}_{4}^{-}$analysis on the filtered sample from the previous step. (The sample is filtered to remove particulate matter that could interfere with the analysis.) The filtered sample will likely bave to be diluted with DI water so that its spectrophotometric absorbance (at $\lambda=5250$ $\mathrm{nm}$ ) is less than that of the highest standard to be prepared ( $50 \mathrm{mg} / \mathrm{L} \mathrm{MnO} 4-)$. Check standards (10 and $50 \mathrm{mgl} \mathrm{MnO}-$ ) will be prepared with reagent grade $\mathrm{KMnO}_{4}$ and measured each anaiysis day. A new 5 point calibration curve will be prepared if the absorbance of these check standards differs from the expected value by $>15 \%$.

11. Collect and analyze aliquots from each reactor for $\mathrm{KMnO}_{4}$ (Steps 8-10) at the following ADDITIONAI time periods: $1 \mathrm{hr}, 2 \mathrm{hrs}, 4 \mathrm{hrs}, 18 \mathrm{hrs}$, and $24 \mathrm{hrs}$.

12. Interpret results and clean up the reactors for te-use in the next nun of the experiment. Also place any waste materials generated from the experiment in the appropriate satellite accumulation area.

\begin{tabular}{|c|c|c|c|c|c|c|c|}
\hline \# & wt.empty & Lt+medium & $\omega t_{0}+\theta_{2} \mathrm{C}$ & $K M_{n} O y$ added & Te & iेfo & somple ID \\
\hline 1 & $\approx 43.61$ & $\longrightarrow$ & 443.61 & sond & 50. & $6^{2} 3 ; ; 21$ & dit $H_{2} O$ \\
\hline 2 & 256.79 & $2 \div$ & 456.79 & $5.0 \mathrm{ml}$ & 50 & 1121 & 0.1. \\
\hline 3 & $236.375 x$ & $8>86.87$ & & $5.0 \mathrm{ml}$ & 50 & 1122 & joneo \\
\hline 4. & 251.61 & 301.92 & 401992 & somel & 50 & 1123 & \\
\hline 5 & 239.79 & 289.77 & 43979 & $5.0 \mathrm{ml}$ & 50 & 1123 & \\
\hline$\zeta$ & 251.64 & 30160 & $45+64$ & 5.onel & 50 & 1124 & \\
\hline 7 & 243.68 & 293.75 & 493.75 & s.0 mel & 50 & 1124. & sedimant \\
\hline 8 & 189.69 & 234.69 & 43469 & $5.0 \mathrm{ml}$ & 50 & 1125 & guitsediment \\
\hline
\end{tabular}

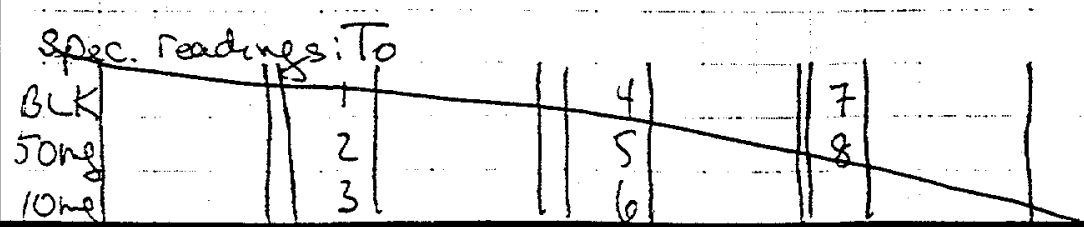

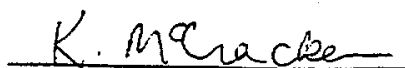

Recorded by

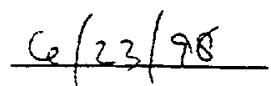

Date

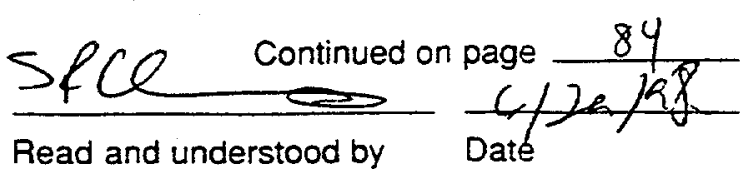


Subject Exp.3Afich

Date $\frac{06}{\text { Month }} \quad \frac{23}{\text { Day }}{ }_{\text {Year }}^{1996}$

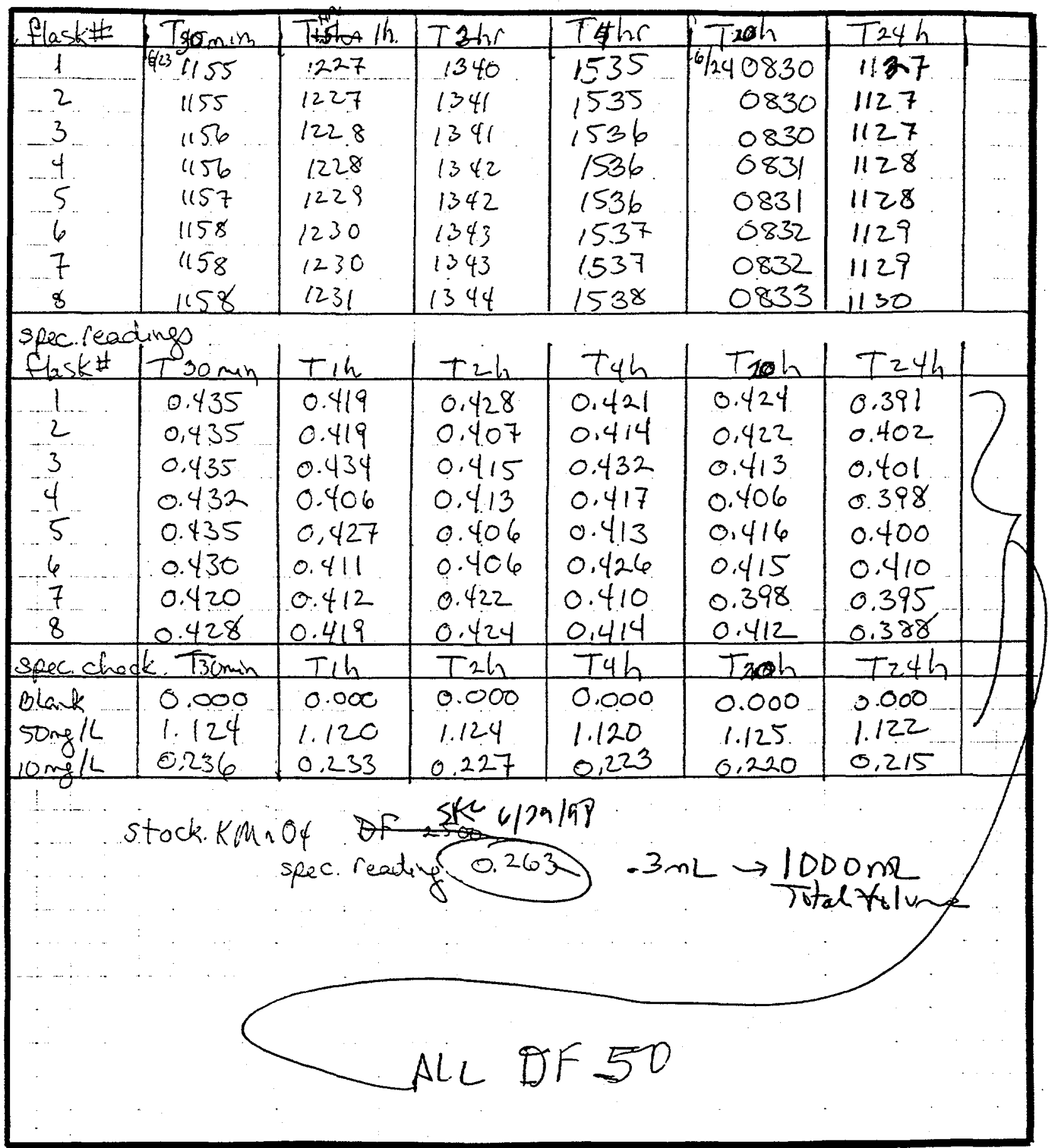

KMc Cacke

Recorded by $\underset{\text { Read and understood by }}{\mathrm{SCC} \text { Continued on page }} \frac{6 \mathrm{C} / \mathrm{2q198}}{\text { Date }}$ 
Subject $\exp 3 A R_{3} b$

Date $\frac{06}{\text { Month }} \quad \frac{25}{\text { Day }} 19 \frac{98}{\text { Year }}$

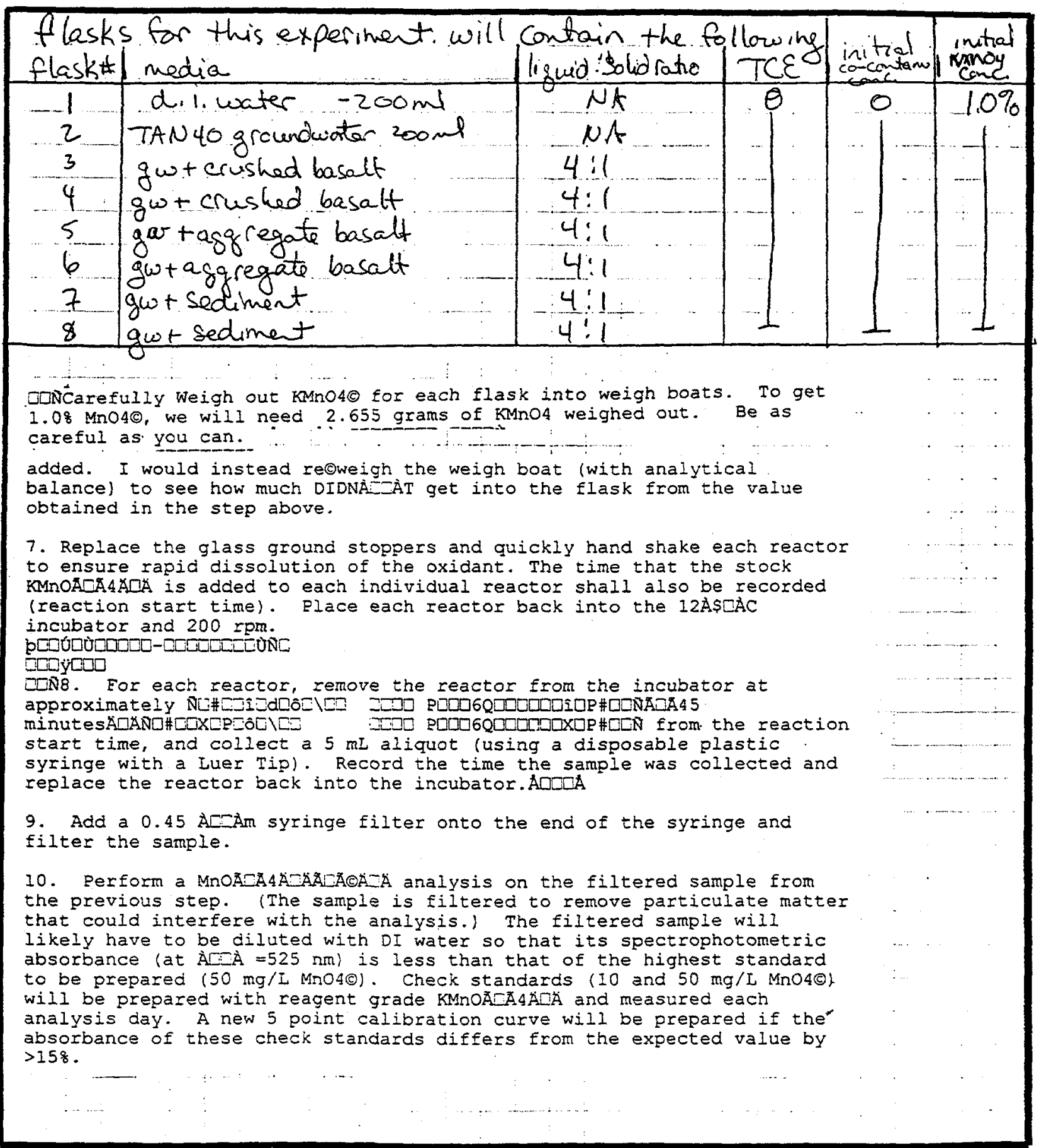

KMCracken

Recorded by
$6 / 25 / 98$

Date

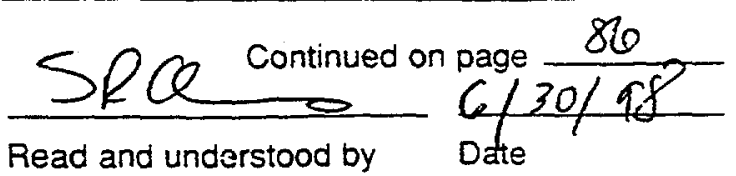


Subject Exp $3 A \cdot R 36$

Date

Month

25

Day

1998

Year

11. Collect and analyze aliquots from each reactor for KMnOACA 4 ACA

(Steps $8 \odot 10$ ) at the following ADDITIONAL time periods: 2 hrs, 3hrs, 4

hrs, 18 hrs, and 24 hrs.

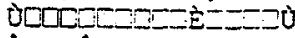

ADCDA12. Interpret results and clean up the reactors for reouse in the

next run of the experiment. Also place any waste materials generated

from the experiment in the appropriate satellite accumulation area. ADCDA

\begin{tabular}{|c|c|c|c|c|c|c|c|}
\hline flask * & wt.enpty & wt timedict & $\omega t_{1}+\mathrm{H}_{2} \mathrm{O}$ & $\mathrm{KMnO}_{4}$ addeo & $T \phi$ & $D F$ & Sample ID \\
\hline$L$ & $243.37\}$ & - & 443.377 & $2,6609-.0004$ & 1205 & 500 & $\mathrm{DI} \mathrm{H}_{2} \mathrm{O}$ \\
\hline 2 & 248.323 & - & 447.993 & $2.6595-0003$ & 1208 & & $j \omega$ \\
\hline 3 & 240.236 & 290.291 & 490.351 & $2.6601-.0000$ & 1212 & & bas \\
\hline 4 & 256.056 & 306.056 & 506.028 & $2.6605-.0000$ & 1215 & & bas. \\
\hline 5 & 242.385 & 292.566 & 492.295 & $2.6608-.0000$ & 1218 & & bas. \\
\hline 6 & 148.858 & 298.908 & 498.597 & $2.6601-.0001$ & 1220 & & bas. \\
\hline 7 & 243,745 & 293.747 & 493,489 & $2.6603-.0007$ & 1222 & & \\
\hline 8 & 189.757 & 239.777 & 439.419 & $2.6614-.0001$ & 1225 & & \\
\hline
\end{tabular}

Time

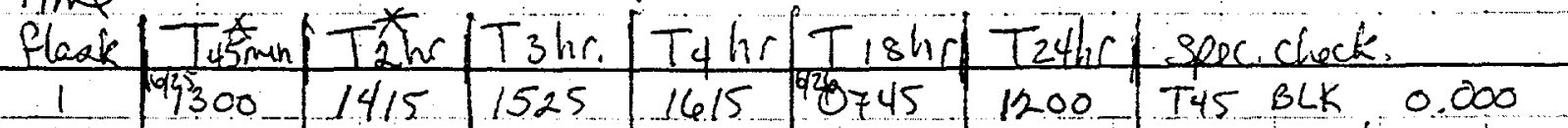

2

1301.1417

$1301 \quad 1418$

1526

1616

0745

1200

songh lillo

5

$5 \quad 1302 \quad 141$

$\begin{array}{lll}6 & 1302 \quad 1420\end{array}$

\begin{tabular}{l|l|l}
7 & 1303 & 142 \\
\hline 8 & 1303 & 142
\end{tabular}

1528

1617

0746

1528

1619

0.746

1201

long/h 0.225

8

1303

spe. 0.4294

$1 \sqrt{0.429} 1,450$

$2 \$ 0.438 \quad 272$

1529

1620

0.747

1201

Tohr BLK

0.000

1529

162

0747

1202

Sing/L 1.119

1530

16220748

1204

lomple

0.225

1530

1624

0748

1204

Tothr \&lk

somell 1.123

$0.454 \quad 0.452$

0.439

0.446

0.391

0.408

$10 \mathrm{mg} / \mathrm{L} 0.221$

$3 \frac{0.443}{1453}$

0,460

0.447

$4=0.440 \quad .451$

0.446

0.452

0.441

0.440

Bl

0.000

$5 \quad 3: 0.315$

1449

0.458

0.455

0.442

0.449

0.443

0.438

0.449

0.450

b. 0.315 .450

0.4580 .452

0.450

0.445

$\begin{array}{llllll}7 & 0.454 & 467 & 0.455 & 0.457\end{array}$

0.4420 .556

$\begin{array}{lllllll}468 & 0.461 & 0.461 & 0.445 & 0.453\end{array}$

*oleasenate soec. readines to 7145 \& $T_{2}$ hr dilutions

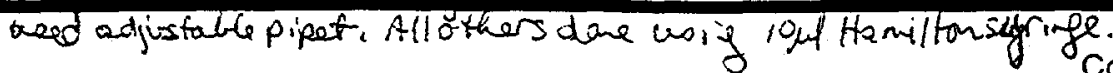

KM Mcracken

Recorded by

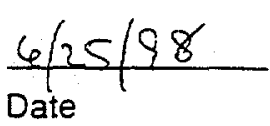

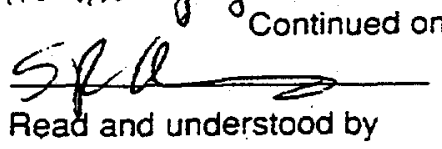

C
Songll 1.121

lomfll 0,219

Tishr. Blk 0.000

T5angtha 1.124

pongth 0.219

T24hr BCK 0.000 somelc 1.125 onglt 0.219

19


subject Exp.4a-R7

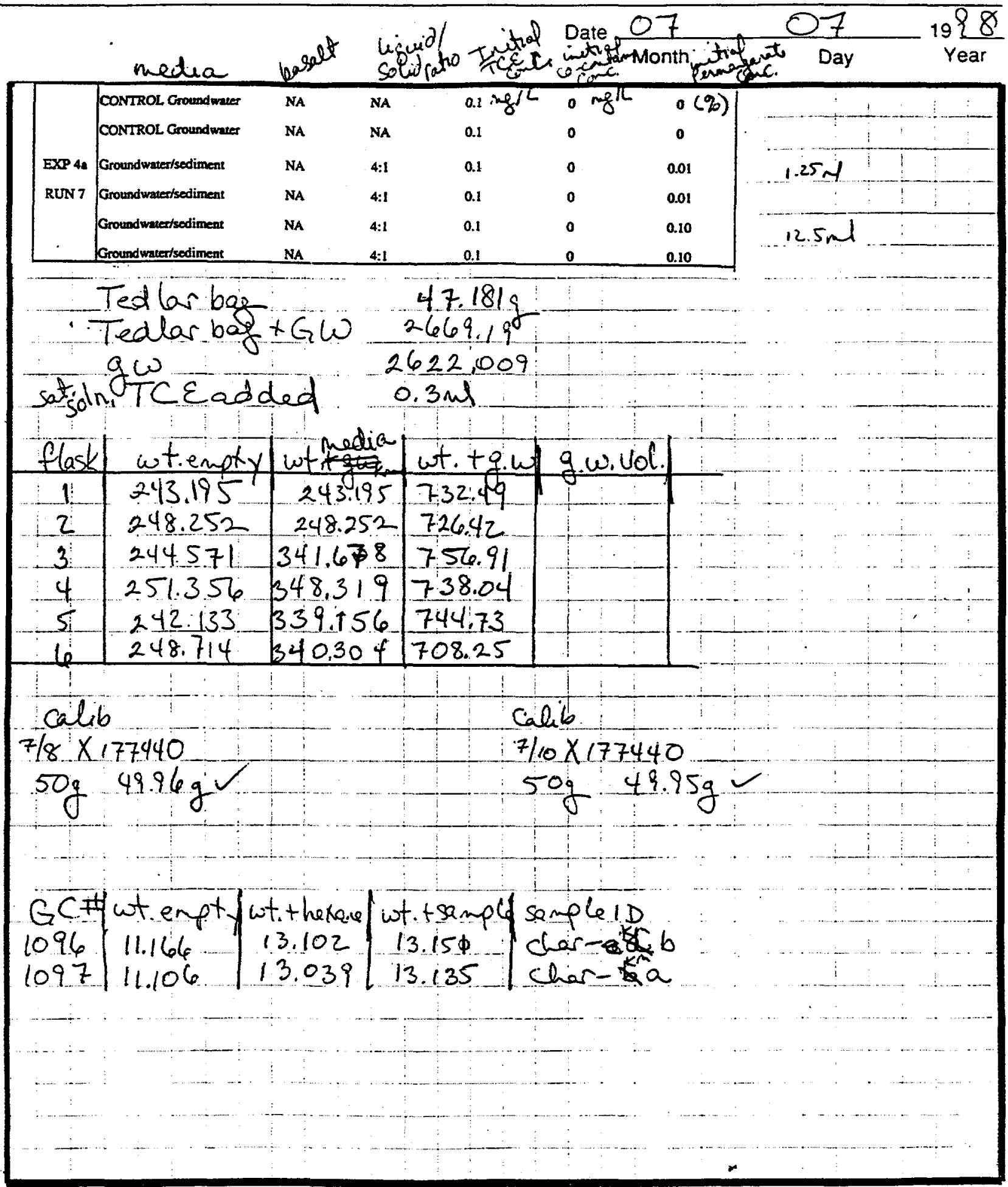

$\frac{\text { KMC Cacken }}{\text { Recorded by }} \frac{7 / 7 / 98}{\text { Date }}$

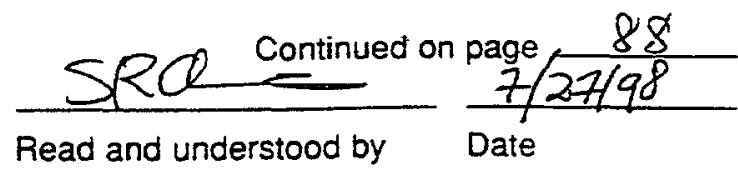


Subject $\varepsilon_{x}, 4 a \cdot R_{7}$

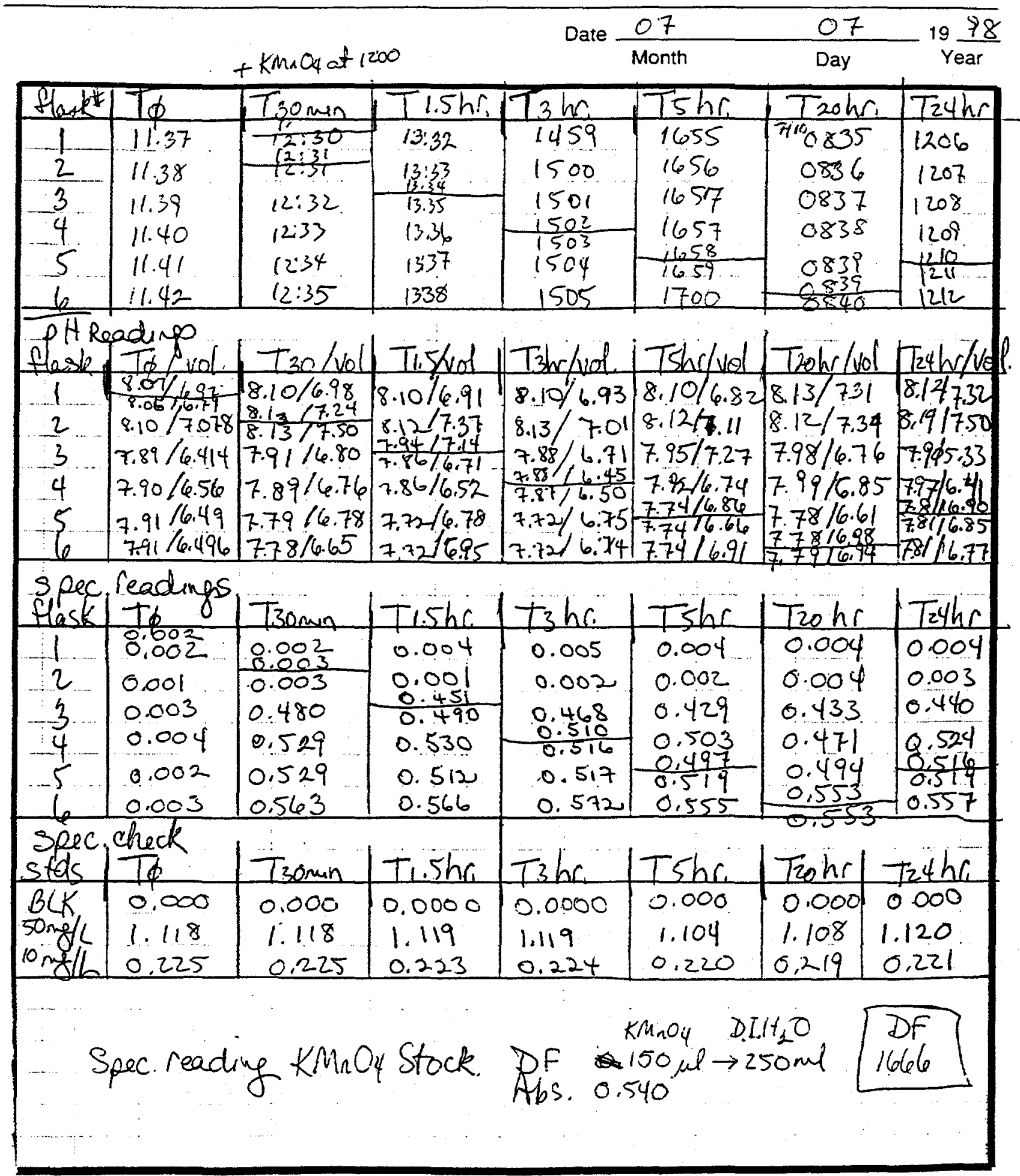

$\frac{\text { KMCCacke }}{\text { secorded by }}$ of/of/98 $\frac{\text { SRCe Continued on page } \frac{89}{7127 / 98}}{\text { Rate }}$ 


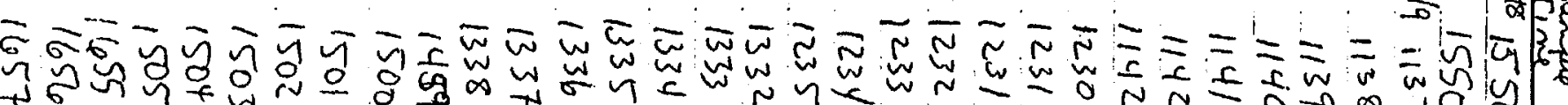

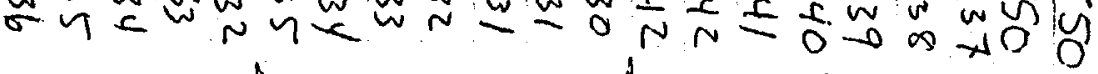

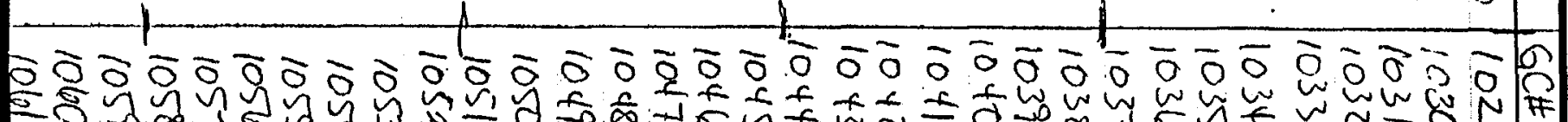

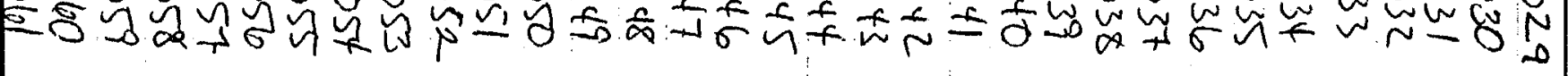

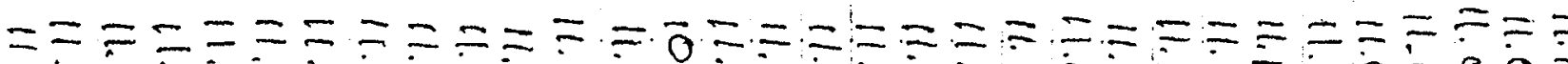

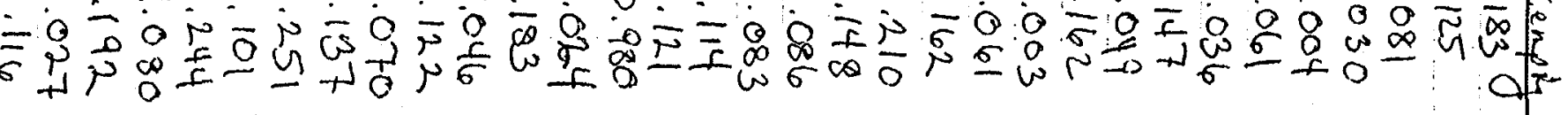

$\bar{\omega} \bar{\mu} \bar{\omega} \bar{\omega} \bar{\omega} \bar{\omega} \bar{\omega} \bar{\omega} \bar{\omega} \bar{\omega} \bar{N} \bar{\mu} \bar{\omega} \bar{\omega} \bar{\omega} \bar{\omega} \bar{\omega} \bar{\omega} \bar{\omega} \bar{\omega} \bar{\omega} \bar{\omega} \bar{N} \overline{\bar{\alpha}} \bar{\mu} \bar{\omega} \bar{c}$

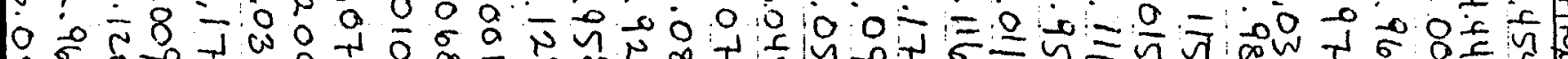

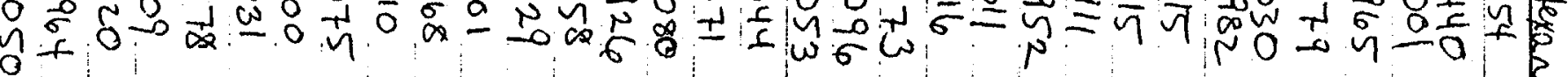

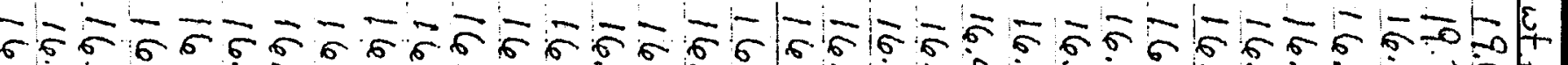

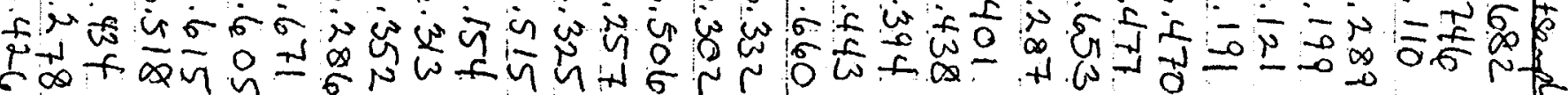

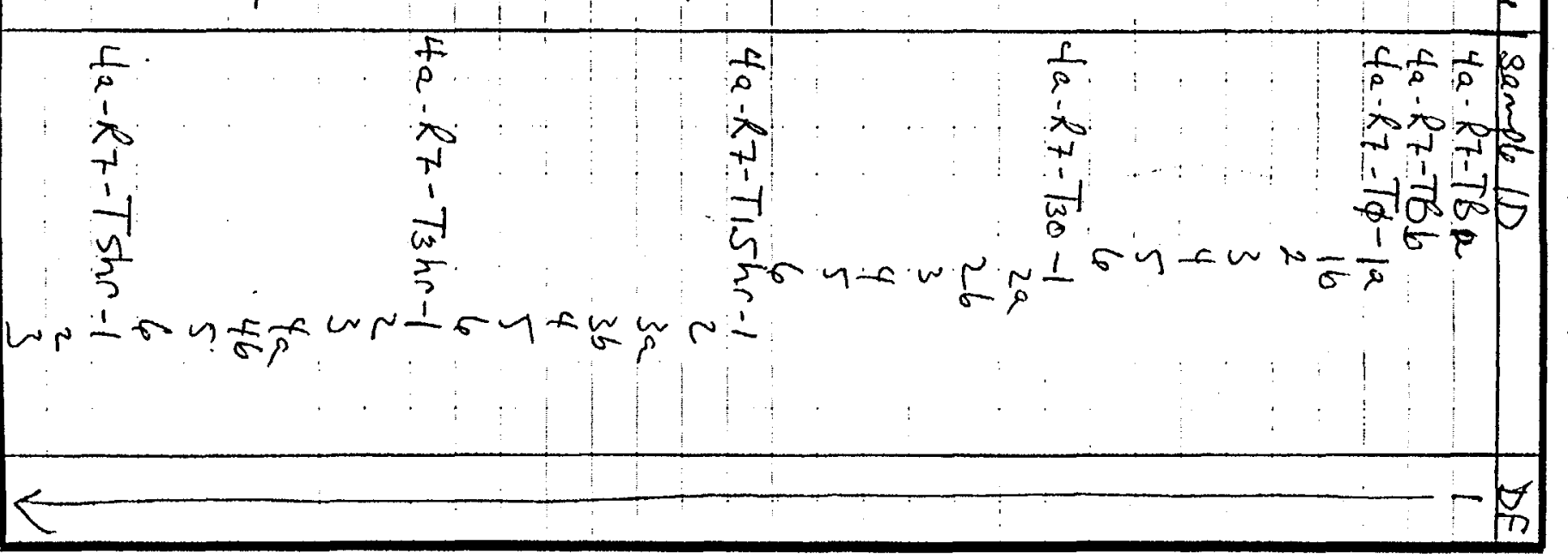


Subject $\quad \sum_{x} \cdot 4 a-R 7$

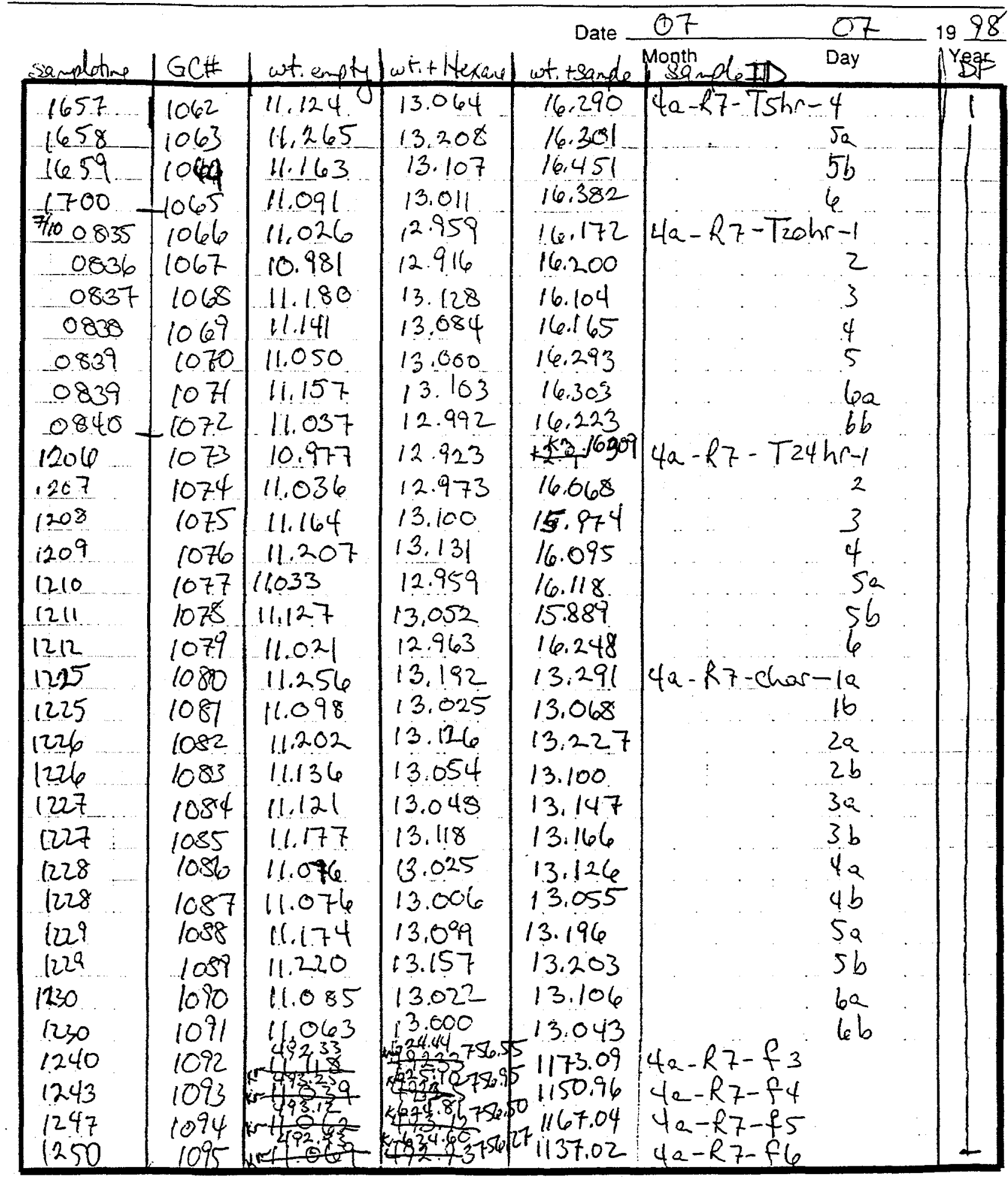
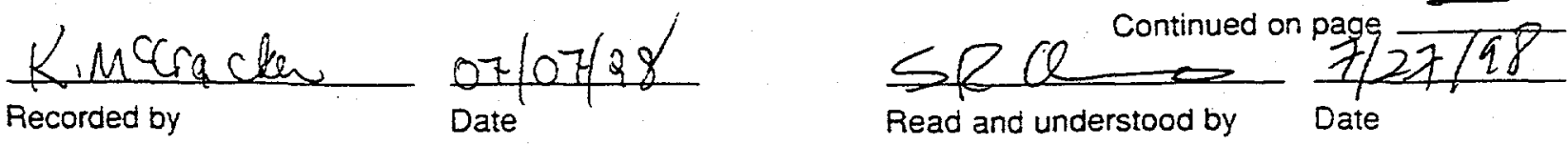
Subject Exp. $4 a-R_{4}$

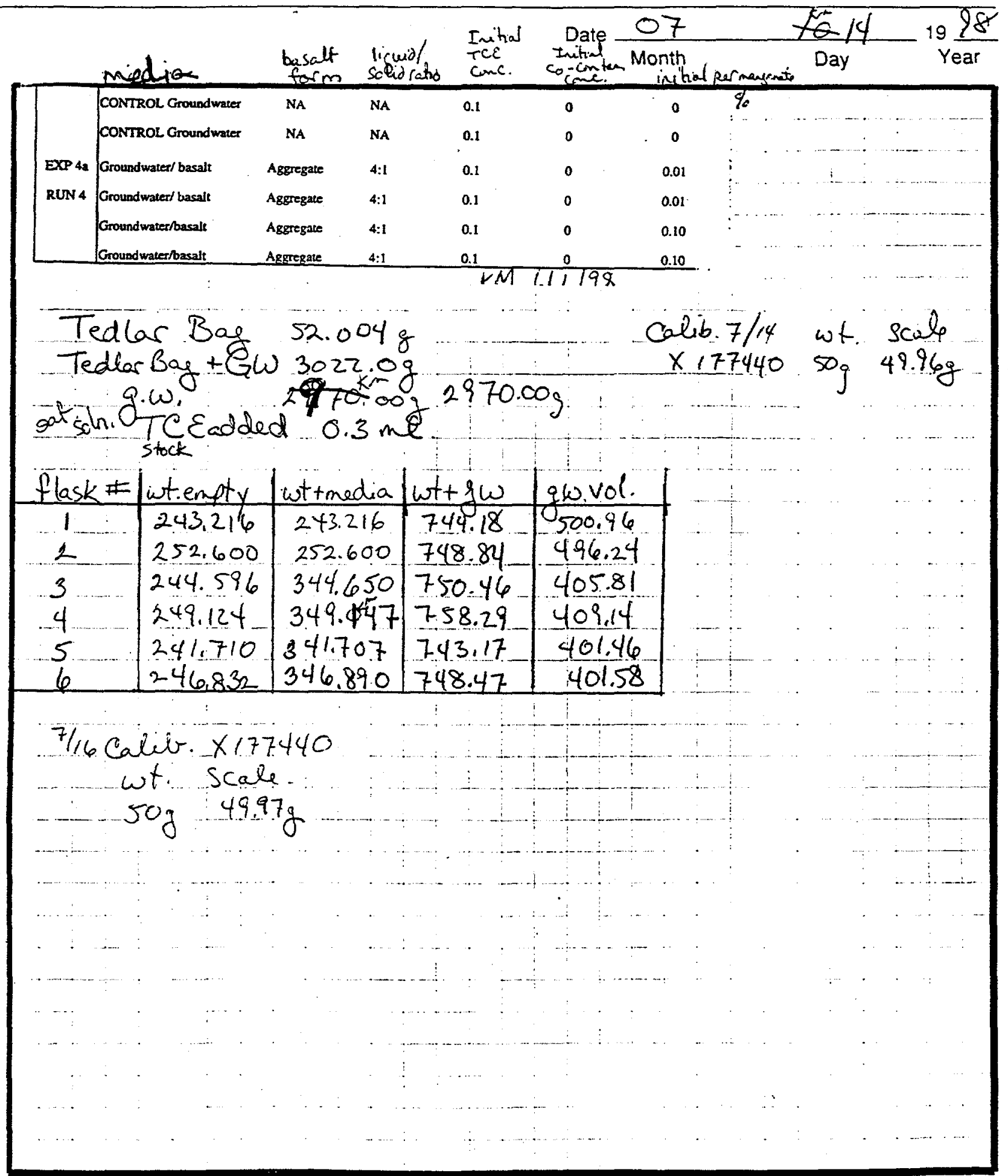

KMCacker

Recorded by

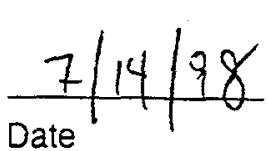

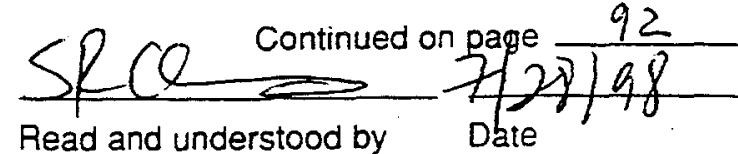

Read and understood by 
Subject Exp $4 a+4$

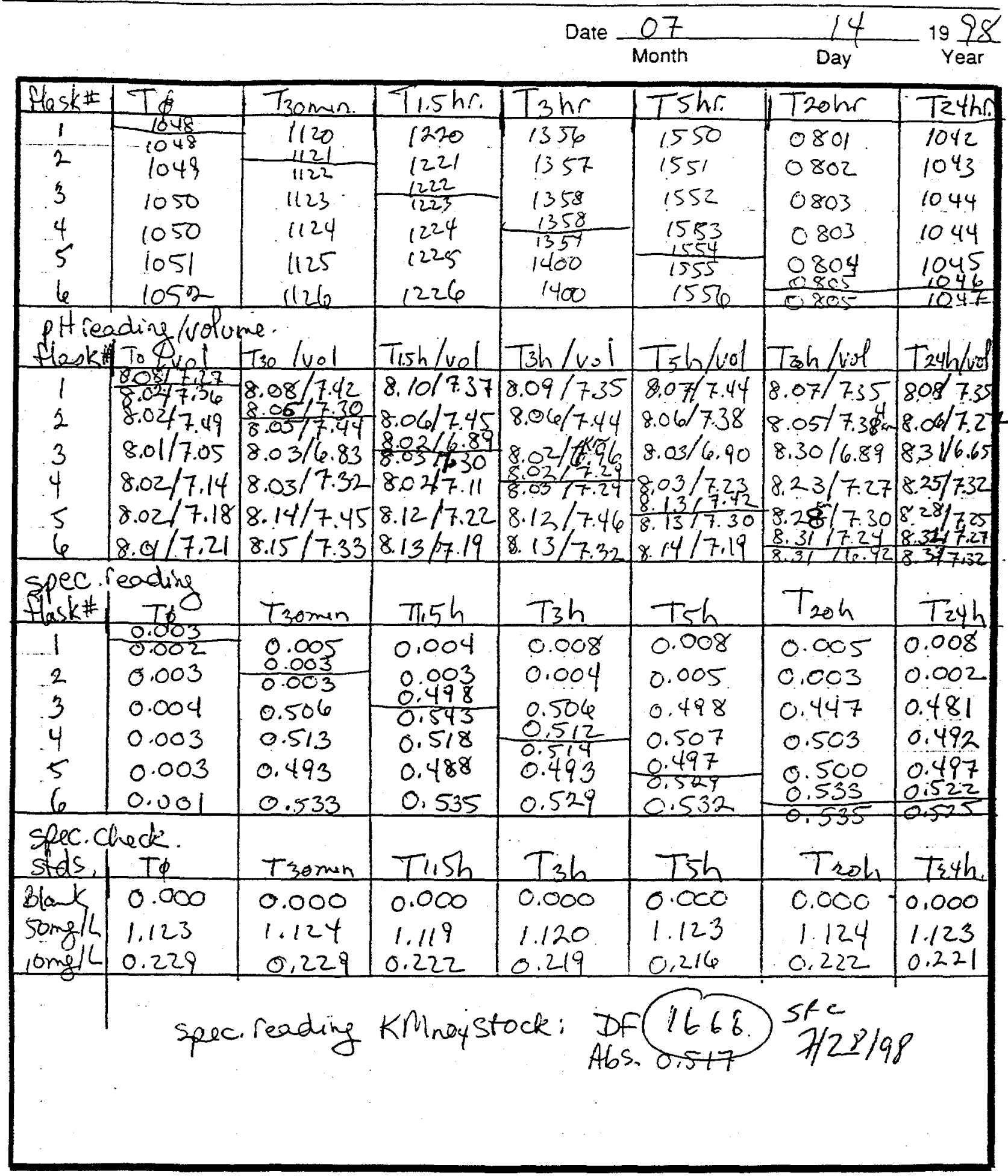
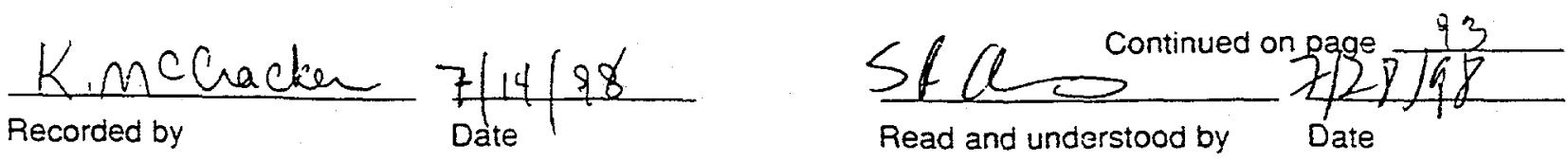


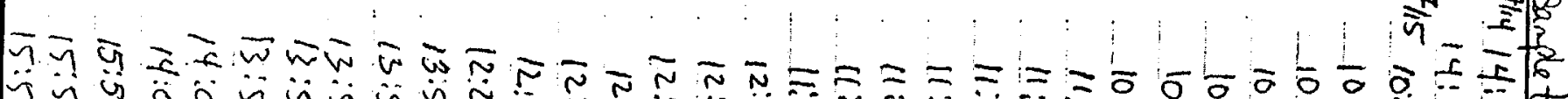

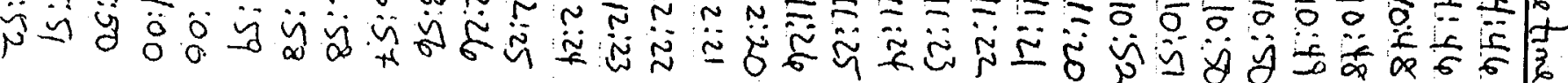

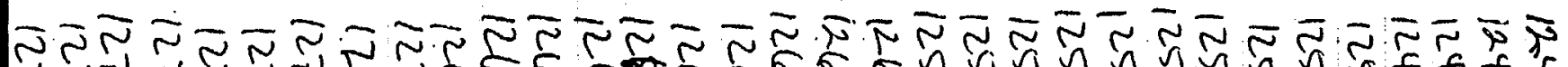

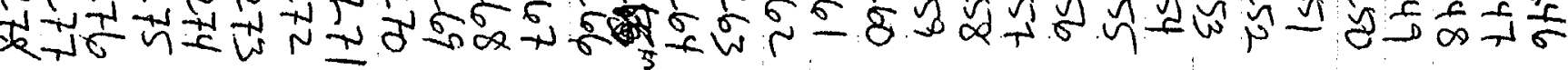

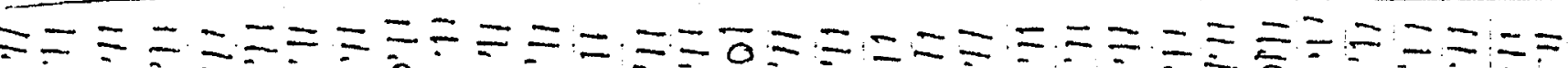

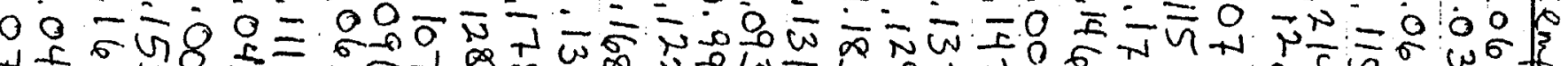

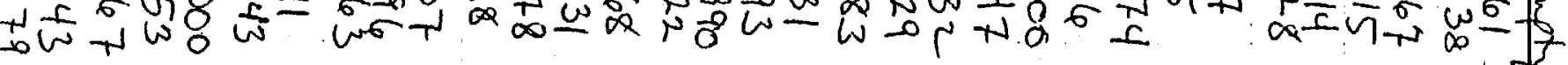

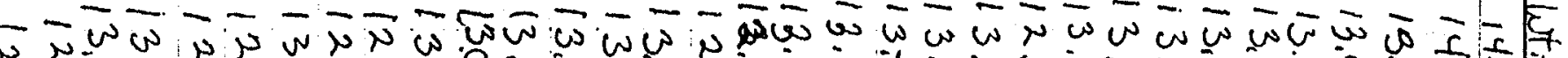

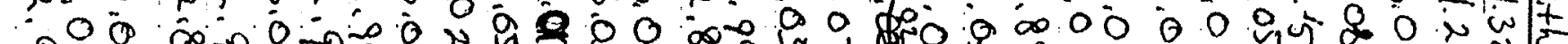

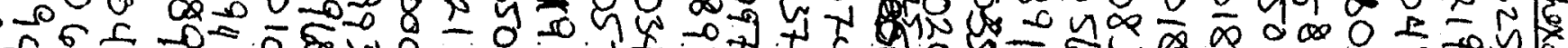

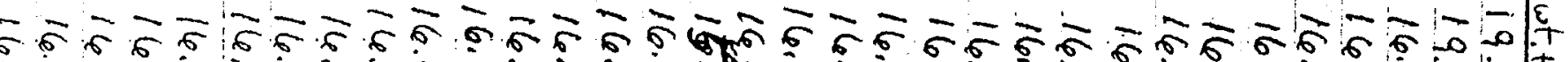

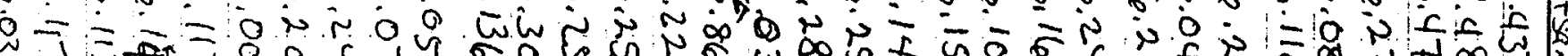

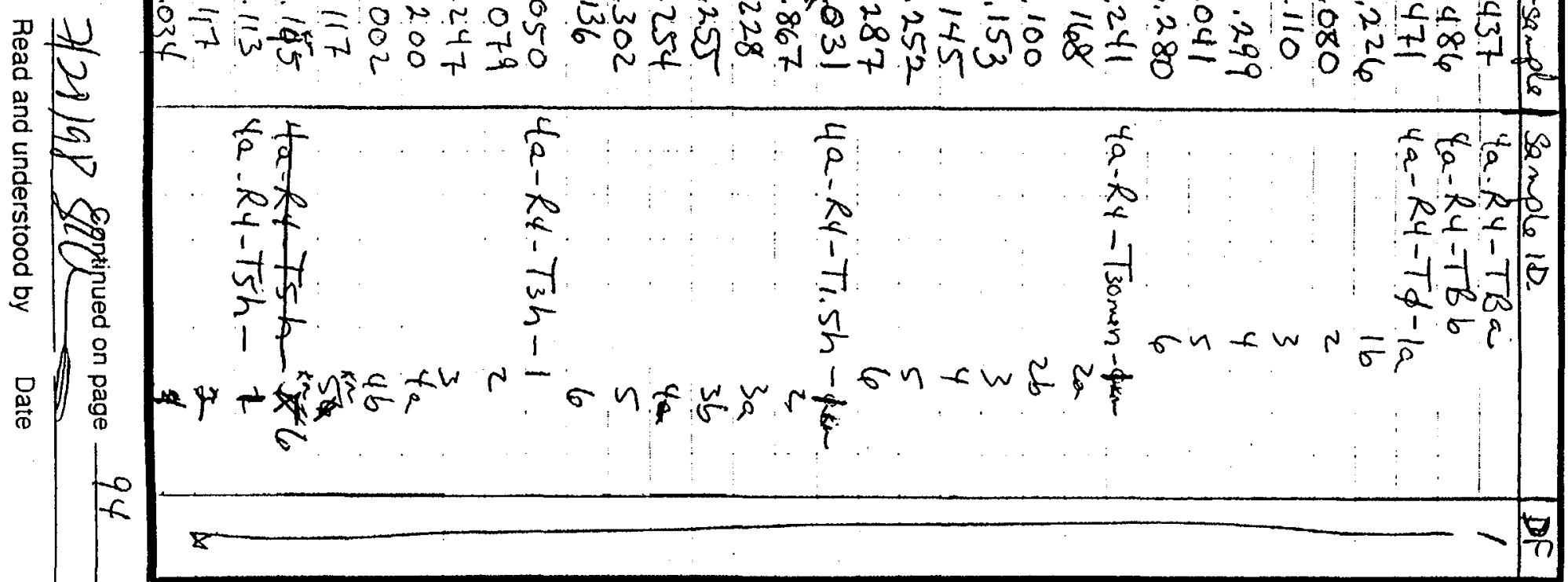


Subject $E_{x} \cdot 4 D-R_{1} \notin R_{2}$

\begin{tabular}{|c|c|}
\hline Date 08 & 10 \\
\hline Month & Day \\
\hline
\end{tabular}

42 Mesoure the Oxidation Rate of Organic Contaminants in Hot Spat Media (Task 4b)

General Procedure for Task 4h Experiments - Measure the oxidation rate of organic contaninants in the hot spot groundwater

(To be condueted by both ORNL/ESD and RMAL)

NOTE: This experiment will be used to conduct the various test conditions presented in Table 2 6 is Chapter 2 of the Implementation Plan.

Control samples (no $\mathrm{KMmO}_{4}$ ) will be prepared and sampled throughout the reaction period to quantify changes in concentration due to mechanisms other than oxidation. In addition to the duplicate control sampkes, it is currently planned to run two (2) test conditions (in dupticate) from Table $2-6$ each time this procedure is used. Thus. 6 reactors will be used during each run of this procedure. and this procedure will be conducted a total of 8 times ( 4 times at each facility). The controls and the treatment reactors will all contain the same initial contaminant concentrations (ic.., all conditions will be the same for each run of this procedure with the exception of the $\mathrm{KMMO}$, concentration used).

Note: The 2,000 mg/L TCE spike solution in Table 2-6 experiments canaot be prepared in the same manner as the spike solution for the 10 and $100 \mathrm{mg} / \mathrm{L}$ spike levels. Both spiking methods are included in this procedure.

1. Soil Prepping

All groundwater to be used in these experiments (TSF-05 groundwater) will be prepped by sparging to remove any residual TCE present on the media. Doing so will allow this experinent to be conducted with consistent and controlled iritial TCE concentrations via contaminant spiking. (Property indicate usage of this media in the treatability study tracking logbook.)

For the 10 and $100 \mathrm{mg} / \mathrm{L}$ Spike concentrations ONLY. -Proceed to step 9 if spiking at DNAPL levels (2,000 me/L TCE) in Table 2-6

2 TCE Stock Solution Preparation

Prepare a STOCK (Saturated) TCE solution ( $* 1100 \mathrm{mg} /$ ). (Use of a STOCK solution rather than pure phase TCE to prepare the spiking solution affords better accuracy in obtaining the target concentration.) This can casily be stored and used again in subsequeat experiments

* For 10 ppm TCE spiking (Runs 1 \& 2): Add >0.1 mL of Pure TCE into $65-70 \mathrm{~mL}$ of TSF-05 $\rightarrow$ foroundwater and keep refrigerated.

If For $100 \mathrm{ppm}$ TCE spiking (Runs 5\&6): Add $>0.6 \mathrm{~mL}$ of Pure TCE into $625 \mathrm{~mL}$ of TSF $=05 \mathrm{GW}$ 青 \& keep refrigerated.

3. TCE Spike Solution Preparation. PART 1

Obtain the tare weight of the container to be used to prepare the spike solution (Tedha bag, flask. or equivalent). Fill with unspiked $12^{\circ} \mathrm{C}$ TSF -05 groundwater ( $3070 \mathrm{~mL}$ or $\sim 2800 \mathrm{~mL}$ for the

10 and 100 mell spike condition, respectively). By gravimetrie methods, determine the amount of unspiked groundwater added to the container. (A calibration check of the gravimetric scak will be performed each day of use.)

vial wtiempty 100.5400 vial $+\mathrm{H}_{2} \mathrm{O} \quad 170.5568$ $\mathrm{H}_{2} \mathrm{O}$ 70.0168 syringe wt.t TCE 18.806
syringet. 18.572
$0.234 \mathrm{~g}$

4. TCE Spike Solution Preparation. PART II

Add the appropriate quantity of the Saturated STOCX TCE solution to produce a TCE spike solution with the concentration prescribed in Table 2-6 for the particular test series being ran The hot spot groundwater will only be spiked at 10 and $100 \mathrm{mg} /$ TCE via this method, thus the volume of saturated STOCK TCE needed should be on the order of $30 \mathrm{~mL}$ and $300 \mathrm{mLL}$. respectively. Please record the volume of STOCK TCE added (NOTE: with also added any contaminants required during this step.) Place the spike solution in the incubator overnight at 12C for temperature equilibration. Ensure that all Information regarding the preparation of the spixing solution will be recorded in the laboratory research notebook.

5. Obtain Tare Weights of Reactors

Prepare the rest reactors to be used. (The gas-tight reaction vessels acquired and tested in Task $2 a$ will be used as the reactors in this experiment) Obeain the tare weight of each. including the weight of a ground glass standard taper stopper fitted with a Teflon sleeve.

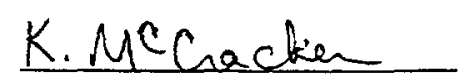

Recorded by

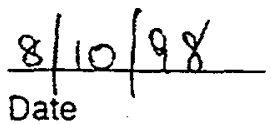

Date

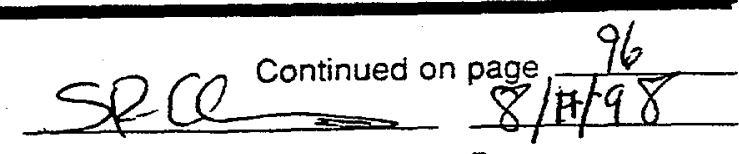

Read and understood by Date 


\section{Subject $\quad \varepsilon \times p+b \cdot R l q R_{2}$}

6. Collection of Initial Spike Solution Samples

Remove the spike solution from the incubator, and obtain duplicate aqueous samples $(\approx 5 \mathrm{~mL})$ of

the spike solution to obtain the initial TCE concentration of the spiked groundwater. Record the time the sample is collected. The duplicate aliquot samples will be added to pre-weighed sample containers holding a known volume of hexane $(\approx 5 \mathrm{~mL})$. Each sample container will be weighed again after sample addition to determine the actual weight of sample added. These extracts will be placed on a horizontal shaker for 2 hours. Store the extracts at $4^{\circ} \mathrm{C}$ until G.C. analysis.

7. Distribution of Spike Solution to Reactors

Quicidy dispense the spike solution into each of the reactors to be used. Add $000 \mathrm{mI}$ to each reactor. Immediately replace the ground giass stopper and re-weigh each to deternine the actual weight of spiked groundwater adted.

8. Keep Cool until Experinent is initiated.

Flace the reactors in the incubator at $12^{\circ} \mathrm{C}$ until the experiment is initiated. Agitate the reactors at -200 rpm during this step.

For the DNAPL Spiking Level (2,000 $\mathrm{mg} / \mathrm{L}$ TCE) in Table 2-6 ONLY -Proceed to Step 13 if spiking at 10 or $100 \mathrm{mg} / \mathrm{L}$

\section{9. $>2,000 \mathrm{mg} / \mathrm{L}$ Spiking: Obtain Tare Weights of Reactors}

Prepare the test reactors to be used. (The gas-tight reaction vessels acouired and tested in Task 2a will be used as the reactors in (his experiment.) Obeain the tare weight of each. including the weight of a ground glass standard taper stopper fitted with a Teflon sleeve.

10. $>2.000 \mathrm{mg} / \mathrm{L}$ Spiking: Reactor Filling

Dispense $\$ 000 \mathrm{~mL}$ un-spiked TSF-05 groundwater into each of the reactors to be used.

O Immediately replace the ground glass stopper/sleeve and re-weigh each to determine the actual weight of groundwater added

Dil. Rexctor Spiting ( $>2,000 \mathrm{mg} / \mathrm{L}$ TCE)

To each of the six reactors, add enough pure phase TCE to achieve a TCE concentration of 2,000 Ding/L (should be around $700 \mu \mathrm{L}$ pure TCE for $500 \mathrm{~mL}$ of groundwater). Measure the mass Dof the spiking syringe when fillod and then after spiking to deternine the setual contaminant mass added (a QC check on the initial TCE analysis). Information reganding the preparation of each spiking solution will be recorded in the haboratory research notebook.

12. Spike Solution Equilibration ( $>2.000 \mathrm{mg} / \mathrm{L}$. Spike Condition)

Place the reactors into the incubator at $\mathbf{2 0 0} \mathrm{rom}$ or greater and allow the spike solutions to equitibrate at $12^{\circ} \mathrm{C}$ (ikely overnight)

13. For Loadings of .01 and 0.1 wt $\% \mathrm{MnO}_{4}{ }^{-}$in Table 2-6 ONLY.

Preparation of Stock MnO; Solution (4 wt\%)

Add $266 \mathrm{~g}$ of crystalline $\mathrm{KMnO4}$ (Carus ${ }^{\mathrm{TM}}$ Free Flowing Technical Grade) into 250 maL Flask and fill to volume with DI water. and allow to mix for at least 2 hours.

14. Prepare Reactor Closure/Carbon Tube

During equilibration period. prepare the standard taper adapters/stopcock valve. (Two ORBO tubes will be used.) The vertical sampling port will be fitted with a small septum) STORF. UNSEALED ORBO TUBES OUTSIDE OF THE LABORATORY FUME HOODS. THE HOODS LKELY HAVE THE GREATEST POTENTIAL FOR “CONTAMINATING” THE TUBES WTH TCE AND OTHER VOCS.

15. Collection of Pre-Reaction Sample from Each Reactor

After equilibration, colleck a $\approx 10 \mathrm{~mL}$ aqueous sample using a long need and disposable syringe from each of the reactors and quickly reseal Record the time the sample is collected and note whether solids were present in the aqueous sample. If significant solids are present, a portion of this aliquot volume may be used for a total solids analysis.

16. Preparation of Pre Rencion TCE Sample

Dispense (unfittered) $\approx 3 \mathrm{~mL}$ of this aliquot sample into to a pre-weighed vial holding a known volume of hexane ( $\approx 3 \mathrm{~mL}$ ). This sample vial will be weighed again after sample addition to determine the actual weight of sample added. All such extracts will be placed on a horizontal staker for 2 hours. Store the extracts at $4^{\circ} \mathrm{C}$ until G.C. analysis. Record the time this sample is taken.

17. Measurement of Pre Reaction pH Value

Tare a small beaker for $\mathrm{pH}$ analysis. Add a 0.45 micron filter to the sample syringe and dispense (filtered) the remaining portion of the sample in the syringe ( $\approx 7 \mathrm{~mL})$ into the tared beaker.

Reweigh the beaker to determine the volume of the sample (assuming that the solits fraction is negligible). The pH analyses will be conducted using conventional pH meters/electrodes. calibrated each day of use via a minimum of two standard buffer solutions. Values obtained for each sampk will be recorded. A calibration check will ako be condueted following the last sample to be measured each day. Values obtained for the samples will be corrected if a significant drift (ic.. > 15\%) occurred.

reculueu uy

$=\quad$ arorackan vale

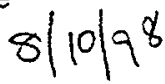


18. For Loadinges of 01 and $0.1 \mathrm{~m} \% \mathrm{MnO}$, in Table 2-6 ONLY.

Addition of Stock MnO4- Solution into Reactors

Quickly remove the ground glass stopper and add the needed volume of stefk $\mathrm{KMnO}$, to obtain the $\mathrm{MnO}_{4}$ concentrations in Table $2-6$ (approximately $1.25 \mathrm{~mL}$ and $125 \mathrm{~mL}$ for the 0.01 and $1 \% \mathrm{MnO}_{4}$ concentrations respectively). Replace the giāss ground stoppers with the adapters fitlod with the stopcock and charcoal desorption tubes and quickly hand shake each reactor to ensure rapid dissolution of the oxidant. (No oxidant will be added to the control reactors). The time that the stock $\mathrm{KMnO}_{4}$ is added to each individual reactor shall also be recorded (reaction start time). Place each reactor back into the $12^{\circ} \mathrm{C}$ incubator and 200 rpm or greater.

19. For the Oxidant Loadings of 1 and $3 w \% \mathrm{MnO}_{4}$ in Table 2-6 ONLY Addition of Crystalline KMnO4 to Reactors. Part I

Pre-weigh out (into disposable tare boats) the needed quantities of erystalline $\mathrm{KMnO}_{4}$ (Carut $\mathrm{Cu}^{\mathrm{T}}$ Free Flowing Technical Grade) that is aeeded for each reactor acconding to which test condition in Tabie $2-6$ is being evaluated. For the 1 and $3 \mathrm{wt} \% \mathrm{MnO}_{4}$ l loadings, $\approx 6.6 \mathrm{~g}$ and $\approx 20 \mathrm{~g}$ of $\mathrm{KMnO4}$ will be needed for each reactor, respectively. Record the actual mass of $\mathrm{KMnO}_{4}$ weighed out for each reactor.

20. For the Oxidant Loadings of 1 and 3wt\% $\mathrm{MnO}_{4}$ in Table 2-6 ONLY

Addition of Crystalline $\mathrm{KMnO4}$ to Reactors, Part II

Quickly remove the ground glass stopper and add these pre-weighed quantities of $\mathrm{KMnO}_{4}$ into the applicable reactors. Replace the glass ground stoppers with the adapters fitted with the charcoal desorption tube assemblies and quickly hand shake each reactor to ensure rapid dissolution of the oxidant. ( $\mathrm{No} \mathrm{KMnO}_{4}$ will be added to the control reactors). The time that $\mathrm{KMnO}_{4}$ is added to each individual reactor stall also be reconded (reaction start time). Place each feactor back into the $12^{\circ} \mathrm{C}$ incubator and at $200 \mathrm{mpm}$ of greater.

21. 30 Minute Sampling

At approximatcly 30 minutes from the reaction start time, remove the reactors from the incubato and colloct a $10 \mathrm{~mL}$ aliquot (using a long needle and syringe with a Luer Tip). Recond the time F the sample is collected. Replace the reactor(s) back into the incubator.

\section{Preparation of 30 Minute TCE Sample}

Dispense (unfiltered) $\approx 3 \mathrm{~mL}$ of the collected aliquot into a pre-weighed vial holding a known volume of hexane ( $\approx 3 \mathrm{~mL}$ ). This sample vial will be weighed again after sample addition to determine the actual weight of sample added. All such extracts will be placed on a horizontal shaker for 2 hours.' Store the extracts at $4^{\circ} \mathrm{C}$ unil G.C. analysis.

23. pH Analysis of 30 Minute Sample

Tare a small beaker. Add a $0.45 \mathrm{um}$ syringe filter unto the end of the syringe and dispense (Fitered) the remaining portion of the sample in the syringe $(* 7 \mathrm{~mL})$ into a tared beaker for pH analysis: Reweigh the beaker to determine the volume of the sampic (assuming that the solids fraction is negigible). Measure and record the pH of the samole as done in Steo **

\section{4. $\mathrm{MnO}_{4}^{-}$Analysis of the 30 Minute Sample}

Use a portion of the filtered pH sample to perform a $\mathrm{MnO}_{4}^{-}$analysis. The sample may thave to be diluted so that its spectrophotometric absorbance (at $\lambda=525 \mathrm{~nm}$ ) is less than that of the highest standard to be prepared ( $50 \mathrm{mg} / \mathrm{LnO4}$ ). Check standards (10 and $50 \mathrm{mg} / \mathrm{L} \mathrm{MnO4}$ ) will be prepared with reagent grade $\mathrm{KMnO}_{4}$ and measured each analysis day. A new 5 poith calibration curve will be prepared if the absorbance of these check standands differs from the expected value by $>15 \%$.

25. Collection and Analysis of Additional Aliquot Samples

Collect and analyze aliquots from each rexetor for TCE, pH. and $\mathrm{KMnO}_{4}$ (Steps 21-24) at the following ADDIIONAL time periods: If hs, 4 hrs, $\$$ hrs, 20 hrs, and 24 hrs.

IMPORTANT - For each reactor collect and extract a duplicate sample (Steps 21-24) from one of the 6 time intervals being evalwated.

26. Extraction of Charcoal Desorption Tubes

After the final aliquot samples are collected, remove the charcoal desorption tube(s) from each reactor. Each charcoal bed contained in the tube(s) will be placed into pre-filled and pre-weighed vials containing a known volume of hexane $(\approx 5 \mathrm{~mL})$. These extracts will be processed and analyzed in the same manner as the aqueous aliquots for TCE

\section{Clean up}

Clean up the reactors for re-use in the next run of the experiment. Also place any waste materials generated from the experiment in the appropriate satellite accumulation area.

28. GC ANALYSIS of VOCs

All VOC analyses for this experiment will be conducted using a G.C.SECD detector. The instrument will calibrated for TCE (and also for cis-1,2 DCE. trans-1,2 DCE. and vinyl chloride for the co-contaminants experiment), using a 5 point calibration curve with standard concentrations ranging from $5-1000 \mu g / \mathrm{L}$ (pp)

Kuscacten

Recorded by

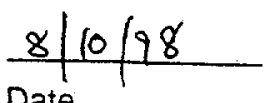

Date

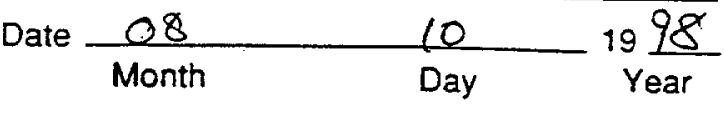

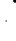
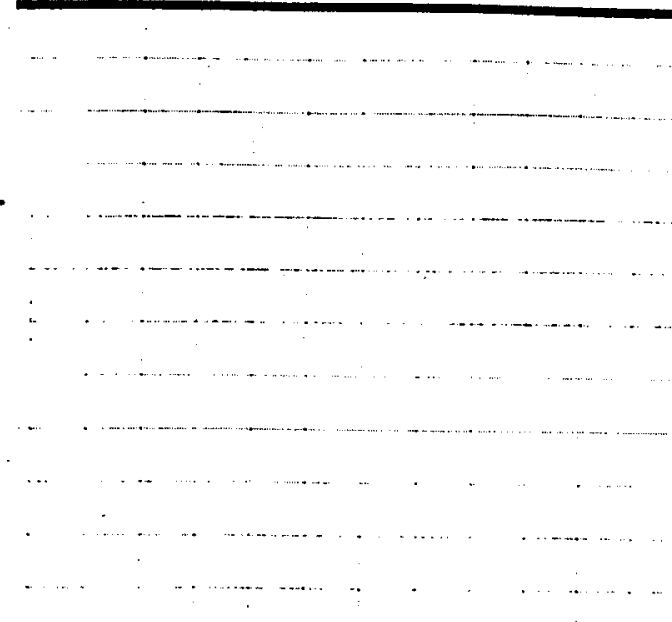
Subject Exp. $4 b-k 1$

Date $\begin{array}{cc}08 & 11 \\ \text { Month } & \text { Day }\end{array}$

\begin{tabular}{|c|c|c|c|c|c|c|}
\hline & Media & $\begin{array}{l}\text { Basait } \\
\text { Form } \\
\end{array}$ & $\begin{array}{c}\text { Liquid:Solid } \\
\text { Ratio }\end{array}$ & $\begin{array}{c}\text { Initial TCE } \\
\text { Concentration } \\
(\mathrm{mg} / \mathrm{L})\end{array}$ & $\begin{array}{c}\text { Initial Organic } \\
\text { Co-Contaminant } \\
\text { Concentration } \\
(\mathrm{mg} / \mathrm{L})\end{array}$ & $\begin{array}{c}\text { Initial } \\
\text { Permanganate } \\
\text { Concentration } \\
(\%) \\
\end{array}$ \\
\hline \multirow{6}{*}{$\begin{array}{l}\text { EXP 4b } \\
\text { RUN } 1\end{array}$} & CONTROL-Groundwater & NA & NA & 10 & 0 & 0 \\
\hline & CONTROL-Groundwater & NA & NA & 10 & 0 & 0 \\
\hline & Groundwater & NA & NA & 10 & 0 & 0.01 \\
\hline & Groundwater & NA & NA & 10 & 0 & 0.01 \\
\hline & Groundwater & NA & NA & 10 & 0 & 0.10 \\
\hline & Groundwater & NA & 8 NAigX & 10 & 0 & 0.10 \\
\hline
\end{tabular}

Tedlar bas wt. 52.117

Tedlarbagt $G W 3104.1$

sonTCEStock added $31.0 \mathrm{ml}$

Calib. $\times 177440$

50 $\quad 49.98$

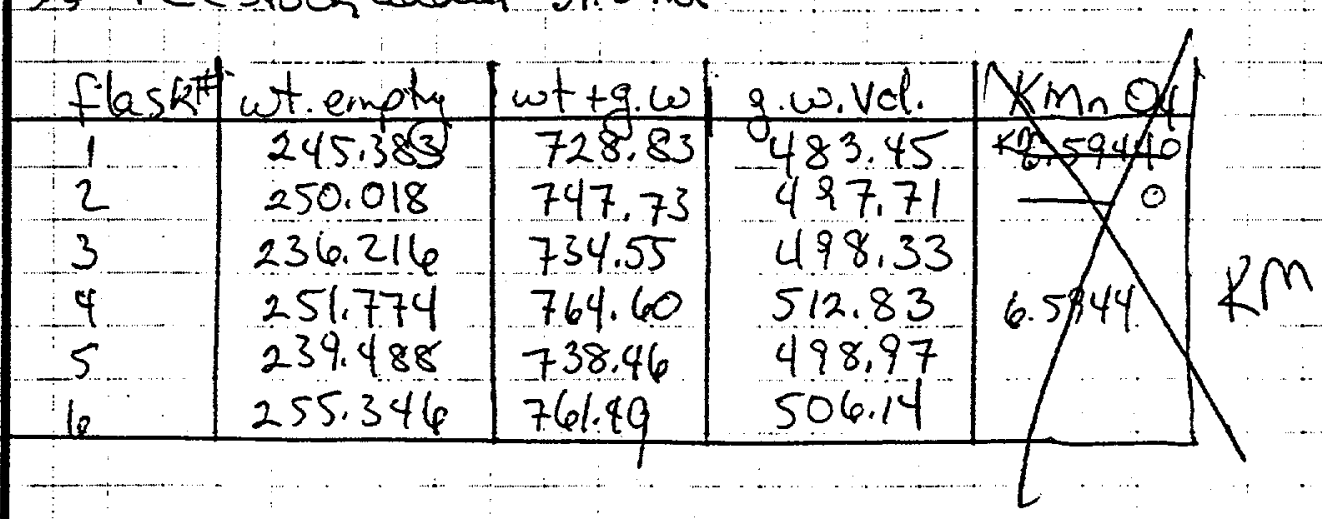

$\frac{K M C C l a c k e n}{\text { Recorded by }} \frac{08 / 11 / 98}{\text { Date }}$

$\underset{\text { Read and understood by }}{C\left(2 C e^{\text {Continued on page }} \frac{99}{(17)}\right.} \frac{(9)}{\text { Date }}$ 
Subject Ex $\varepsilon_{1} \cdot 4 b-R_{1}$

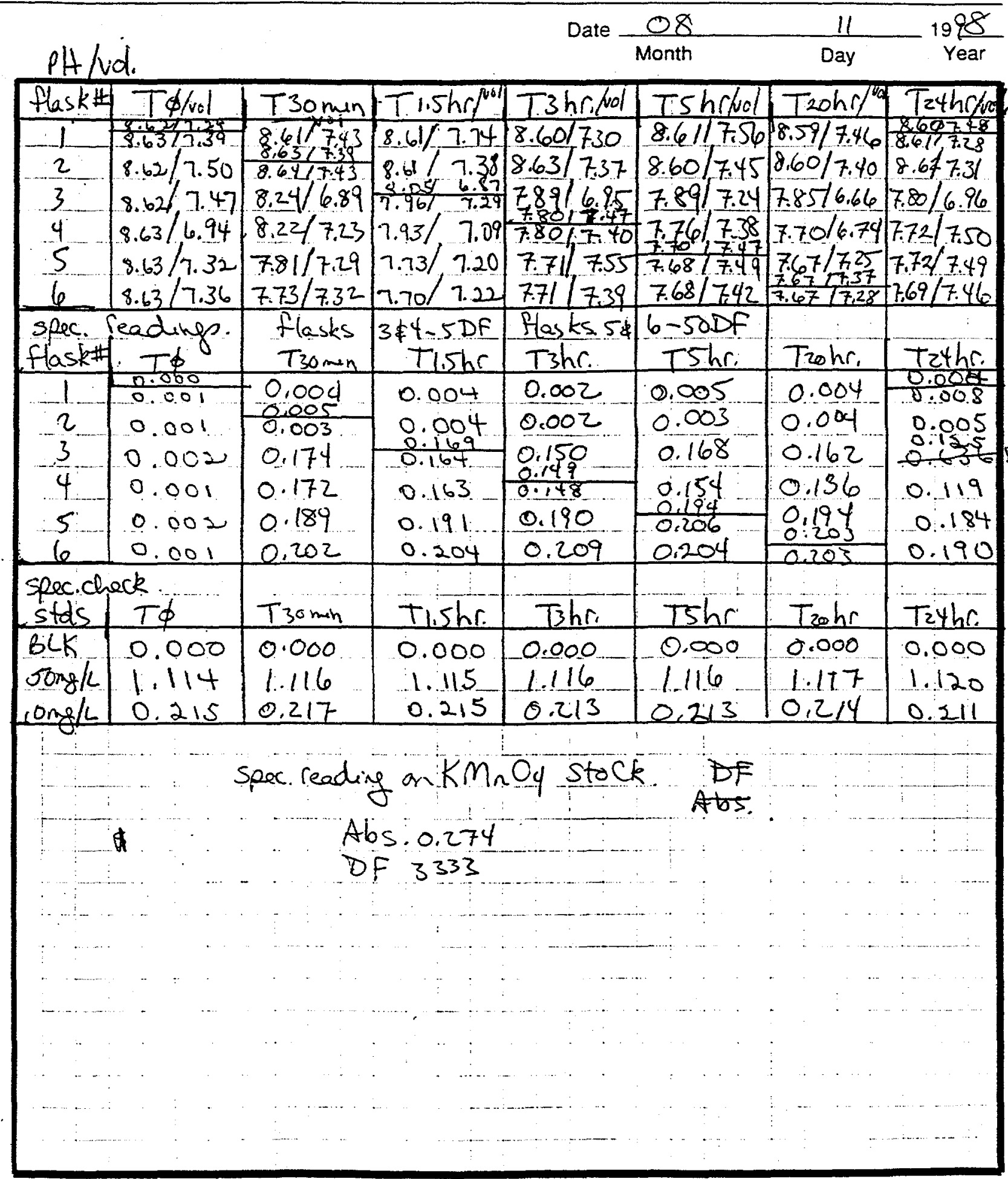

$\frac{\text { KMCClacken }}{\text { Recorded by }} \frac{8 / 11 / 98}{\text { Date }}$

Continued on page 100

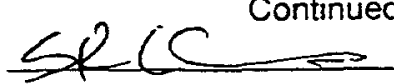

Read and understood by

Date 
Subject Eyp $4 b-R 1$

Date

Month

11

$19 \frac{98}{\text { Year }}$

\begin{tabular}{|c|c|c|c|c|c|c|}
\hline sampletine & GCH & wt.emply & wt then & $\omega+t g . \omega$ & Sample 1.D. & $D F$ \\
\hline 16125 & 1404 in & 10.968 & $\frac{198}{12}=0$ & 16.001 & $4 b-R 1-5 h r-4$ & 1 \\
\hline $16: 26$ & 1495 & 11.017 & $4.196 \mathrm{k}$ & 16.068 & $\ldots a$ & 1 \\
\hline 16.27 & 1496 & 10.983 & $12.89 x_{r}$ & 15,887 & 56 & 1 \\
\hline $16: 28$ & 1497 & 10.990 & $15: 840$ & 15,962 & $\ldots 6$ & ! \\
\hline $128: 19$ & 1498 & 11.060 & $12.967 \mathrm{sin}$ & 15,829 & $4 b-R_{1}-20 h r-1$ & 20 \\
\hline $08: 20$ & 1499 & 10.912 & $12 . \frac{895}{95 m}$ & 16.175 & 2 & 20 \\
\hline $08: 4$ & 1500 & 11.029 & 12.856 & 16.186 & 3 & 1 \\
\hline $08: 22$ & 1501 & 10.961 & $12.865 \mathrm{~km}$ & 16,070 & 4 & 1 \\
\hline $08: 23$ & 1502 & 16.881 & $12.880^{2} \mathrm{~m}$ & 16.072 & 54 & 1 \\
\hline $08: 24$ & 1503 & 10.927 & $12.88^{14}=$ & 15,766 & $k^{k}$ & 1 \\
\hline $08: 25$ & 1504 & 11.071 & $12.898 \mathrm{~km}$ & 16.063 & 66 & $!$ \\
\hline $11: 34$ & 1505 & 10.977 & $+3.050 \mathrm{~mm}$ & 16.135 & $h r-1 a$ & 20 \\
\hline $11: 35$ & 1506 & 11.066 & 12.943 & 16,246 & 16 & 20 \\
\hline $11: 35$ & 1507 & 10.893 & 12.768 & 15,906 & 2 & 20 \\
\hline$-11: 36$ & 1508 & 11.029 & 12.890 & 16.028 & & 1 \\
\hline $11: 38$ & 1509. & 10.945 & 12.829 & 15,874 & 4 & 1 \\
\hline $11: 39$ & 1510 & 10.820 & 12.653 & 15.784 & 5 & 1 \\
\hline $11: 40$ & 150. & 11.076 & 12.966 & 15.990 & $\ldots 6$ & 1 \\
\hline $11: 46$ & 1512 & 10.913 & 12.835 & $=13.0$ & 46-Richar la & 1 \\
\hline $11: 47$ & 1513 & 10.965 & 12.872 & 12.922 & 16 & 1 \\
\hline$-11: 49$ & 1514 & 10.923 & 12.768 & 12869 & $2 a$ & $l$ \\
\hline $11: 48$ & 1515 & 10.912 & 12,788 & 12837 & 26 & 1 \\
\hline $11: 49$ & 1516 & 11.010 & 12.894 & 13,000 & $3 a$ & 1 \\
\hline $11: 50$ & 1517 & 10.991 & 12.863 & 12.914 & $3 b$ & 1 \\
\hline $11: 51$ & 1518 & 10.841 & 12.729 & 12,819 & $4 a^{\circ}$ & $i$ \\
\hline $11: 52$ & 1519 & 10.970 & 12.854 & 12.900 & 46 & 1 \\
\hline $11: 55$ & 1520 & 11.123 & 12.936 & 13.025 & $5 a$ & 1 \\
\hline $11: 54$ & 1521 & 11.011 & 12.810 & 12,908 & $5 b$. & 1 \\
\hline $11: 45$ & 1522 & 10.915 & 12.787 & 12.900 & $6 a$ & 11 \\
\hline $11: 45$ & 1523 & 10.929 & 12.777 & 12.832 & 66 & $i v$ \\
\hline & & & & $\ldots .$. & & \\
\hline
\end{tabular}

R

Continued on page 101

Recorded by

Date

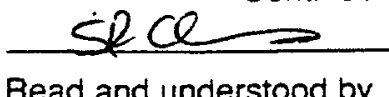

$8 / 17198$

Read and understood by Date 
Exo.4b.R1

Date $\frac{08}{\text { Month }} \quad \frac{11}{19 \frac{98}{\text { Year }}}$

\begin{tabular}{|c|c|c|c|c|c|c|}
\hline Somple time & GC\# & wt.empty & wt thexaes & $\omega t+g . \omega$ & Sample ID. & $D F$. \\
\hline $30: 5 x$ & 1461 & 10.908 & 14102 & 19.323 & $4 b . R 1-T B B a$ & 20 \\
\hline $10: 58$ & 1462 & 10.931 & 14.149 & 19.339 & $4 b-R_{1}-T B b$ & का \\
\hline $11: 20$ & 1463 & 10.883 & 12.828 & 16.182 & $4 \phi-R_{1}-T \phi-1 a$ & $z_{8}$ \\
\hline $11: 20$ & 1464 & 11.078 & 13,040 & 16.405 & $\ldots$ & 28 \\
\hline $11: 21$ & 1465 & 10823 & 12.767 & 16.018 & 2 & 20 \\
\hline $11: 22$ & 1466 & 10.992 & 12.946 & 16.679 & $3 \pitchfork$ & 20) \\
\hline $11: 23$ & 1467 & 10.945 & 12,886 & 16.106 & $4 k$ & 20 \\
\hline $11: 23$ & 1468 & 10.864 & 12,800 & $15 \cdot 914$ & & 61 \\
\hline $11: 24$ & 1469 & 10.858 & 12.820 & 15.886 & & 20 \\
\hline 12:00. & 1470 & 10885 & 12.833. & 16.006 & $4 b-R_{1}-T_{30 \text { min }}-1$ & 201 \\
\hline $12: 01$ & 1471 & 10.929 & 12.881 & 16.031 & $\ldots 2 a$ & 201 \\
\hline $12: 02$ & 1472 & $11.110^{\circ}$ & 13.050 & 16.090 & $2 b$ & 20 \\
\hline $12: 03$ & 1473 & 11.050 & 12.989 & 16.201 & $3 \ldots$ & 1. \\
\hline $12: 04$ & 1474 & 10.945 & 12.880 & 16.133 & 4 & 1 \\
\hline :05 & 1475 & 10.928 & 12.854 & 15.908 & 5 & $i$ \\
\hline $12: 06$ & 1476 & 10.944 & 12.888 & 16.005 & 6 & 1 \\
\hline $13: 05$ & 1477 & 10.911 & 12,835 & 15.723 & 4b-Rl-T1.5hr-1 & 2 \\
\hline $13: 05$ & 1478 & 10.947 & 12.867 & 16,121 & 2 & 20 \\
\hline $13: 06$ & 1479 & 11.000 & 12.920 & 16.073 & $3 a$ & 1). \\
\hline $13: 07$ & 1480 & 10.923 & 12.835 & 15.834 & $3 b$ & 1 \\
\hline $13: 08$ & 1481 & 10.984 & 12.901 & 16.068 & 4 & 1 \\
\hline $13: 09$ & 1482 & 11.045 & 12.935 & 16.018 & 5 & 11 \\
\hline $13: 10$ & 1483 & 11,081 & 13.013 & 16.120 & -6 & $1)$ \\
\hline $14: 30$ & 1484 & 10.914 & 12.825 & 16.021 & $4 b_{b}-R_{1}-T_{3} h r-1$. & 20 \\
\hline 14:31. & 1485 & 10.995 & 12.913 & 16.639 & 2 & \\
\hline $14: 32$ & 1486 & 10.947 & 12.859 & 15.856 & 3. & 1) \\
\hline$: 33$ & 1487 & 10.973 & $12: 892$ & 15.878 & $4 a$ & 1 \\
\hline $14: 34$ & 1488 & 10.980 & 12.398 & 15.774 & $4 b$ & 1 \\
\hline $14: 35$ & 1489 & 10.935 & 12.857 & 16.024 & 5 & 1 \\
\hline $14: 36$ & 1490 & 11.022 & 12.938 & 16.025 & 6 & 1 \\
\hline $16: 22$ & 1491 & 10.853 & 12.755 & 15,940 & $46-R_{1}-T_{5} h r-1$ & \\
\hline $16: 23$ & 1492 & 10.965 & 12.894 & 16,045 & 2 & \\
\hline $16 i 24$ & & 10.891 & 12.800 & & 3 & 10 \\
\hline
\end{tabular}


$F-101$ 
Subject $2 \times 0.4 b . R 2$

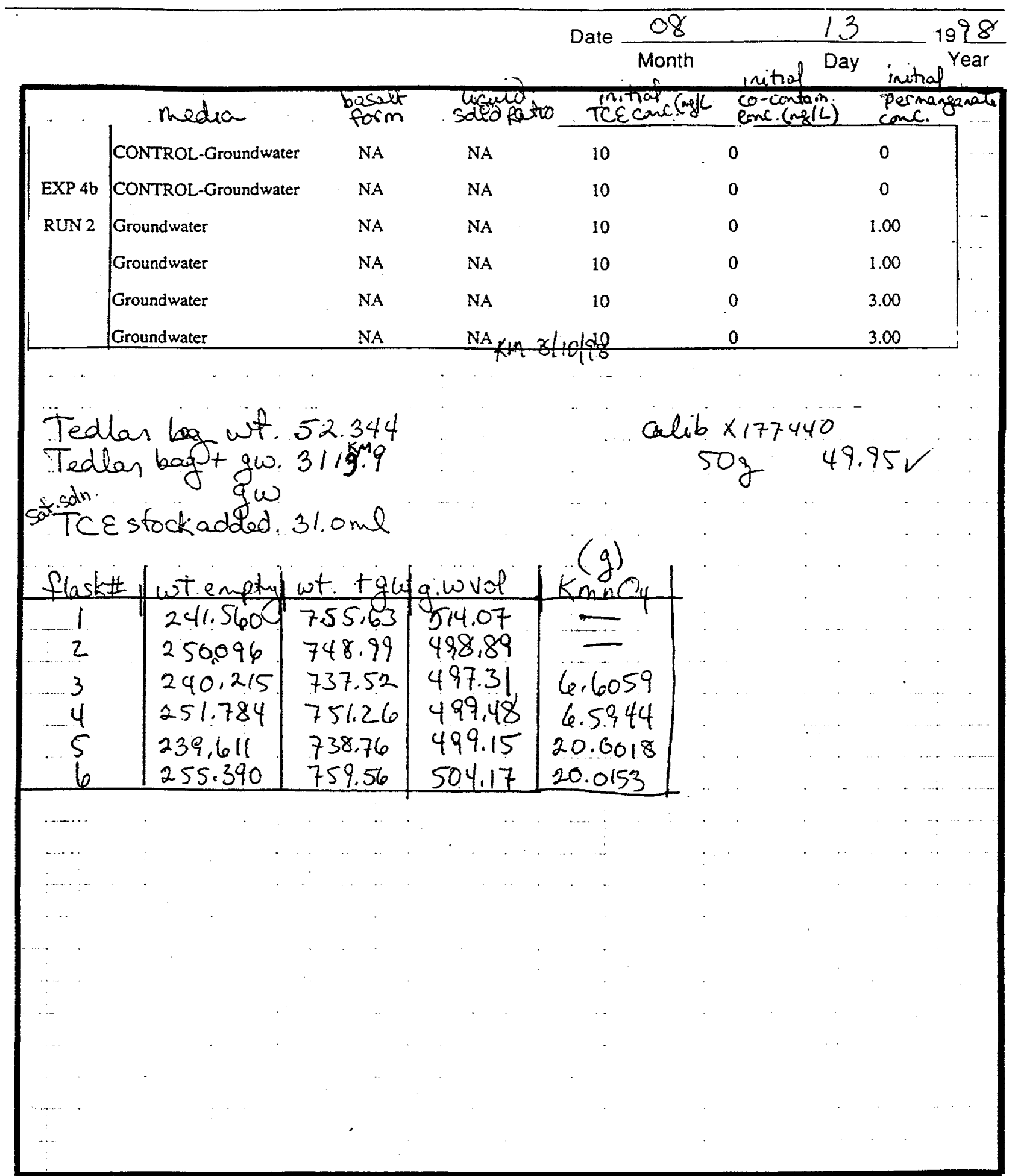

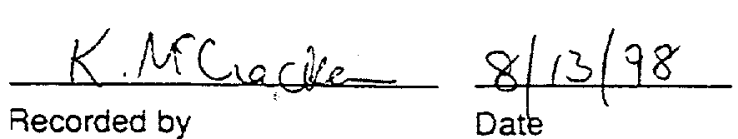

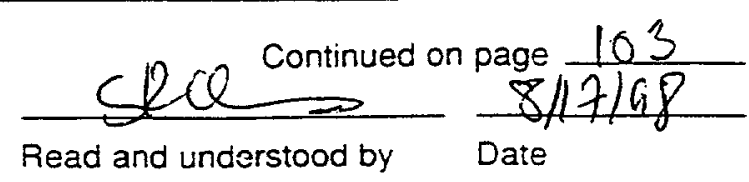


Subject $\sum x p-4 b .-R_{2}$

$$
\text { Date } \frac{08}{\text { Month }} \quad \frac{13}{\text { Day }} 19 \frac{98}{\text { Year }}
$$

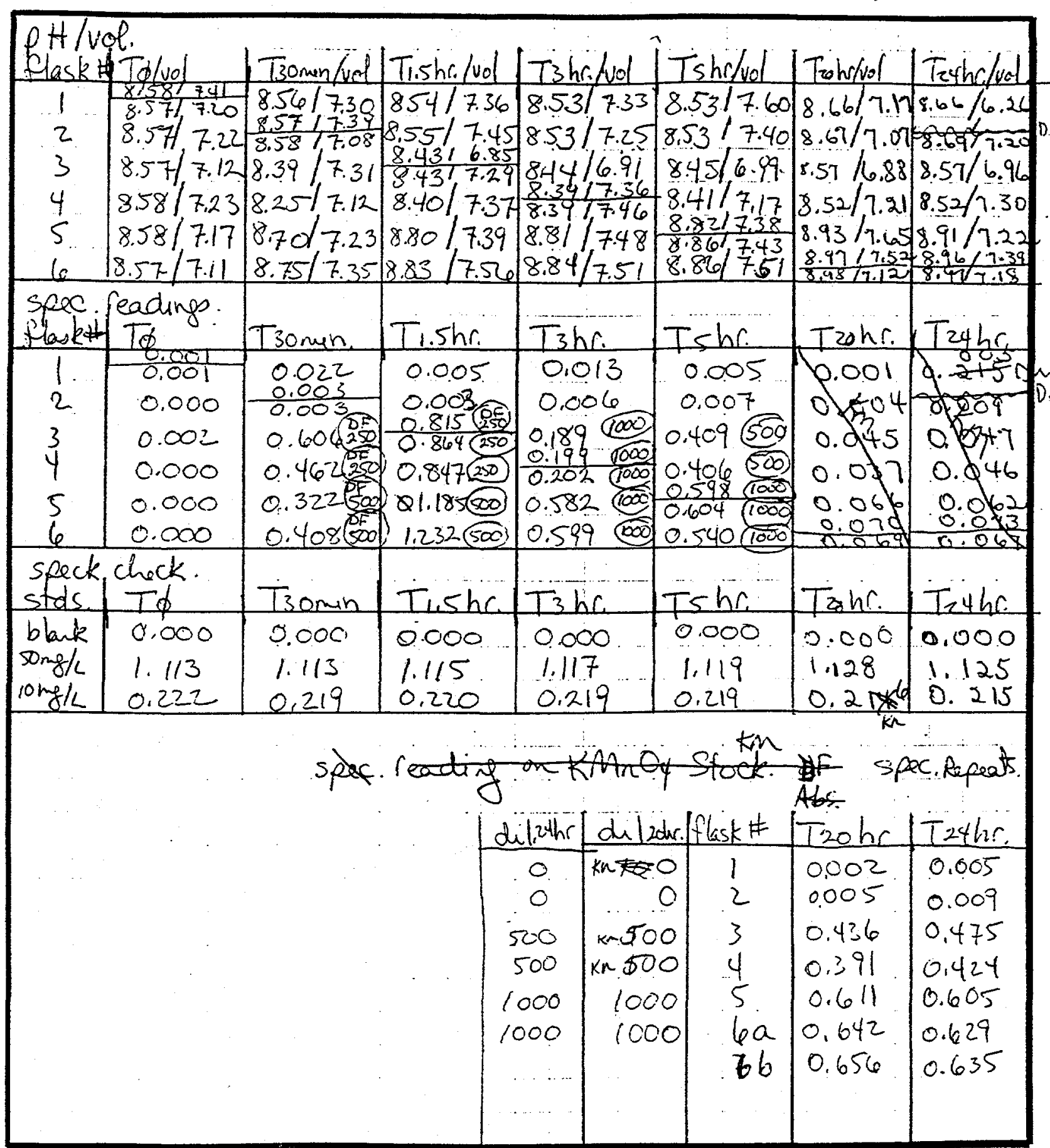

$\frac{K \cdot M C_{\text {iacke }}}{\text { Recorded by }} \frac{8 / 13 / 78}{\text { Date }}$

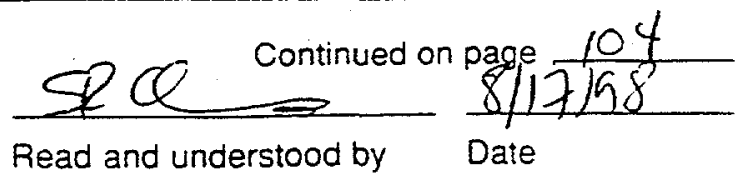


Date

13

$19 \frac{98}{\text { Year }}$

\begin{tabular}{|c|c|c|c|c|c|c|}
\hline Sanplotine & GC\# & wt.emply & wt. thexae & $\omega t+g \omega_{1}$ & Sample $1 D_{1}$ & $D F$ \\
\hline $811311 ; 30$ & 1660 & 11.020 & 14.292 & 19.223 & $4 b-R_{2}-7 B a$ & 20 \\
\hline 113 & 1661 & 10.926 & 14.201 & 18.980 & $4 b-R_{2}-T b b$ & \\
\hline $11: 36$ & 1662 & 10,906 & 12.853 & 16.142 & $40-R_{2}-T_{\phi}-1 a$ & \\
\hline $11: 31$ & 1663 & 10.886 & 12.842 & 16.148 & 16 & \\
\hline 10.32 & 1664 & 10.909 & 12.869 & 16.092 & 2 & \\
\hline $11: 33$ & 1645 & 10.948 & 12.917 & 16.169 & 3 & \\
\hline $10: 34$ & 1666 & 10.851 & 12.809 & 15.928 & 4 & \\
\hline $10: 35$ & 1667 & 10.989 & 12.951 & 16.108 & 50 & \\
\hline $11: 36$ & 1668 & 11.013 & 12.954 & 16.084 & 6 & \\
\hline $12: 10$ & 1669 & 10.945 & 12.897 & 16.096 & $46 \cdot R_{2}-T_{3}$ omen -1 & \\
\hline $12: 11$ & 1670 & 10.989 & 12.940 & 16.027 & $\ldots 2 a$ & \\
\hline $12: 12$ & 1671 & 10.908 & 12,856 & 16.036 & 26 & \\
\hline $12 \div 3$ & 1672 & 10.983 & 12.933 & 16.193 & 3 & \\
\hline $12: 14$ & 1673 & 10.888 & 12.832 & 15.907 & 4 & \\
\hline $12: 15$ & 1674 & $10.80 f$ & 12.746 & 15.955 & 5 & l. \\
\hline $12: 16$ & 1675 & 10.899 & 12.841 & 15,984 & 6 & $\|$ \\
\hline $13: 20$ & 1676 & 10.912 & 12.851 & 16.117 & $46 k_{2}-T 1.5 h_{r_{1}}-1$ & 20 \\
\hline $13: 21$ & 1677 & 10.950 & 12.889 & 15.997 & 2 & 20 \\
\hline 13122 & 1678 & 10.916 & 12,850 & 16.159 & $3 a$ & 1 \\
\hline $13: 23$ & 1679 & 11.066 & 13.006 & 16.047 & 繁b & 1 \\
\hline $.13: 24$ & 1680 & 11.021 & 12.964 & 16.095 & 4 & l \\
\hline $13: 25$ & 1681 & 11.138 & 13.073 & $16.3 / 7$ & 5 & $\ell$ \\
\hline$\ldots 13: 26$ & 1682 & 11.052 & 12999 & $16,07.5$ & 6 & l \\
\hline 14.45 & 1683 & 11.059 & 12.990 & 16.008 & $4 b R_{2}-T_{3} h c_{0}-1$ & 20 \\
\hline $14: 46$ & 1684 & 11.082 & 13,005 & 16.037 & 2 & 20 \\
\hline $14: 47$ & 1685 & 10.976 & 12.908 & 16.161 & 3 & 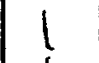 \\
\hline $14: 48$ & 1684 & 10.910 & 12.848 & 16.033 & $4 a$ & \\
\hline $14: 49$ & 1687 & 10.965 & 12.905 & 16.032 & 46 & ( \\
\hline $14: 50$ & 1688 & 11.113 & 13.048 & 16.240 & 5 & ( \\
\hline $14: 51$ & 1689 & 10.925 & 12.863 & 16.096 & 6 & 1 \\
\hline $1: 50$ & 1690 & 10.956 & 12.892 & 15.936 & $46 R_{2}-T 5 h c-1$ & 20 \\
\hline $6: 51$ & 1691 & 11.052 & 12.980 & 16.060 & 2 & 20 \\
\hline $16: 52$ & 1682 & 10.952 & 12.858 & 15.940 & 3 & \\
\hline
\end{tabular}
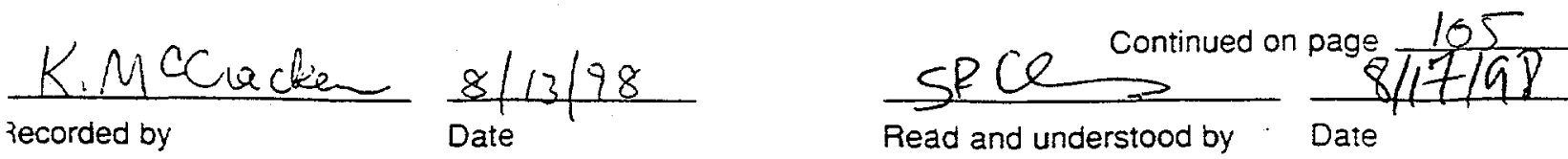


Date $\frac{08}{13} \frac{13}{\text { Month }} \quad$ Day 198

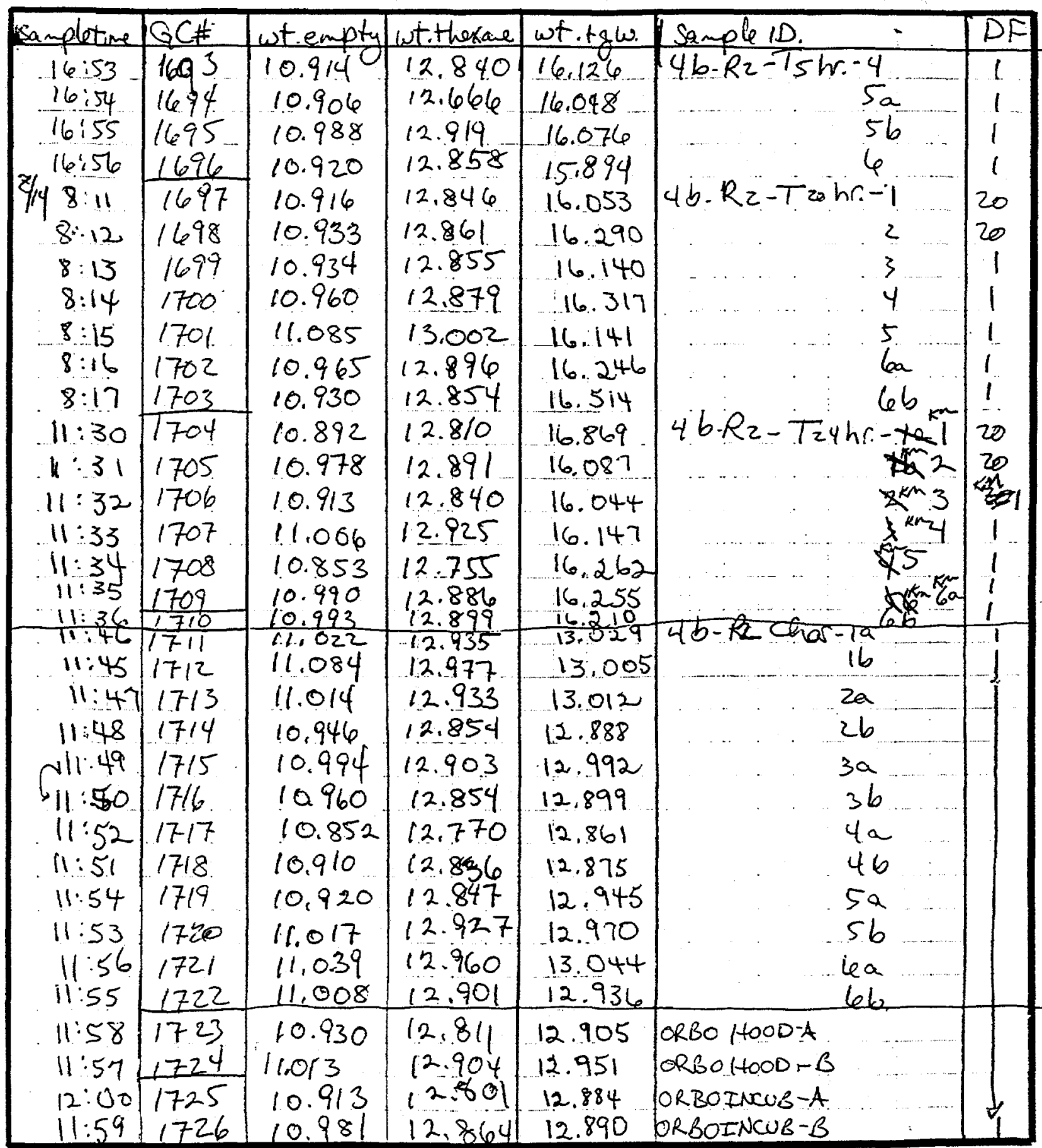

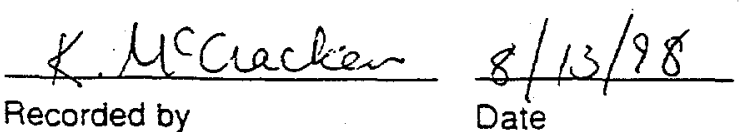

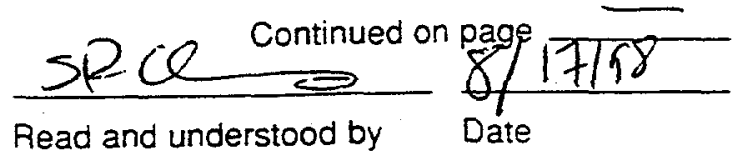


Subject $\quad \sum x_{0} \cdot 4 a-26$

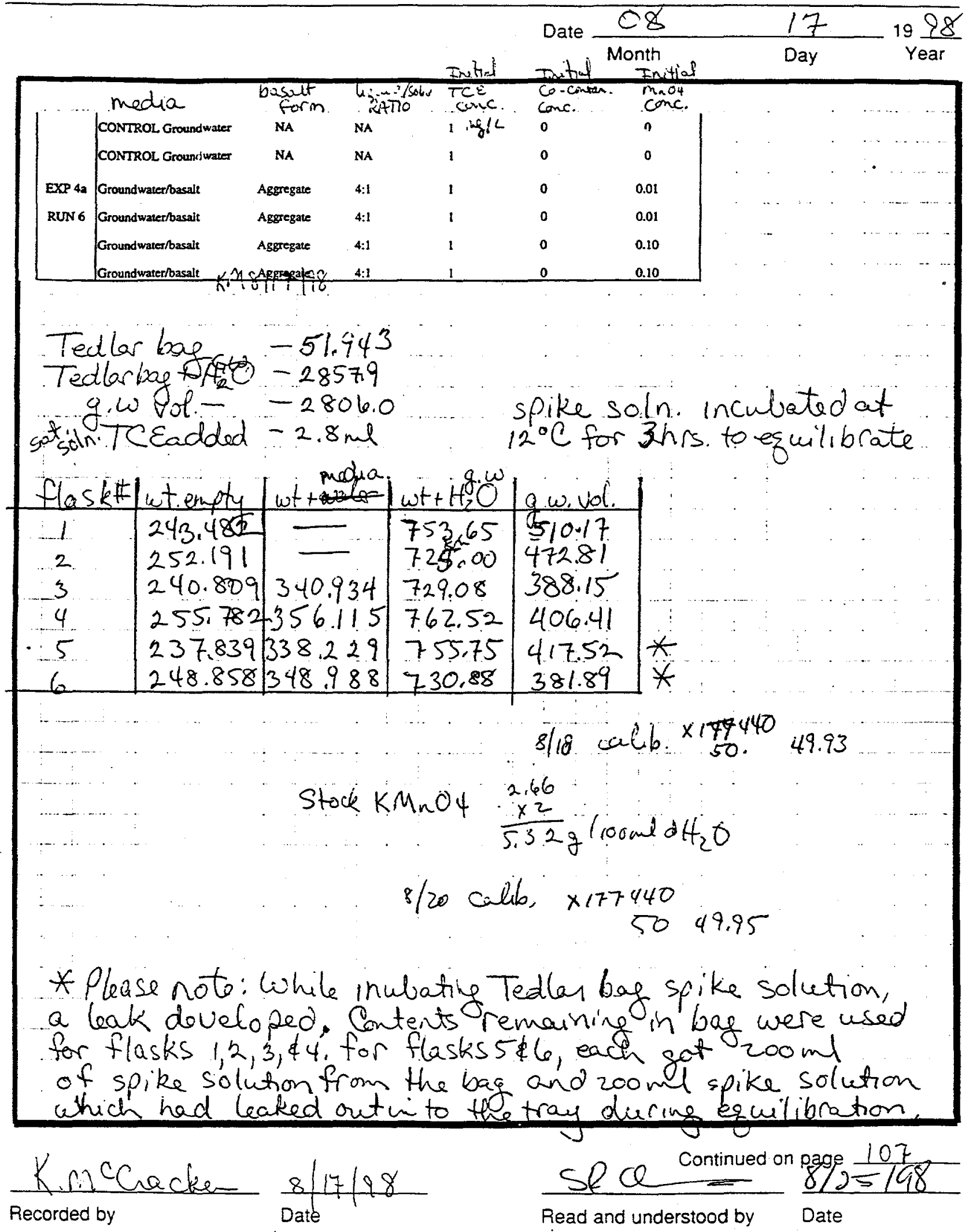


Subject

$E \times 0.4 a-R b$

\begin{tabular}{|c|c|c|c|c|c|c|c|}
\hline & & & & Date & 08 & 17 & -1998 \\
\hline vol. & & & & & Month & Day & Year \\
\hline flask\# & $T_{\phi}$ & T30 man & T1.5hr & T3he & Tshr. & Trohr & Tetho. \\
\hline 1 & 7.54 & 7,34 & 7.41 & 7.62 & 7.43 & 7.66 & $7: 60$ \\
\hline 2 & 7.20 & $\frac{7.20}{-7.18}$ & 7.33 & 7.48 & 7.26 & 7.34 & 7.35 \\
\hline 3 & 7.37 & 6.88 & $\frac{6.95}{6.99}$ & 6.98 & 7.22 & 7.10 & $\frac{6.58}{7.34}$ \\
\hline 4 & 7.32 & 7.00 & 7.40 & $\frac{7.31}{6.96}$ & 7.69 & 7.32 & 7.26 \\
\hline 5 & 7.23 & 7.18 & 7.43 & 7.56 & $\frac{7.7}{7.43}$ & 7.32 & 7.26 \\
\hline 6 & 6.85 & 7.19 & 7.47 & 7.22 & 7.17 & 7.38 & 7.32 \\
\hline ptrea & dings. & & & & & & \\
\hline flask & 78 & Izamin & T1.5hr & T3he & Tshr & Trohr & T2thr \\
\hline 1 & $\frac{8.40}{8.41}$ & 8.37 & 8.42 & 8.38 & 8.38 & 8.28 & 8.26 \\
\hline 2 & 8.41 & $\frac{8: 4 \frac{1}{3}}{8.43}$ & 8.41 & 8.38 & 8,38 & 8.24 & 8.24 \\
\hline 3 & 8.38 & 8.27 & $\frac{8.25}{8.2 .3}$ & 8.24 & 8.24 & 8.19 & $\frac{8.22}{8,21}$ \\
\hline 4 & 8.37 & 8,27 & 8,22 & $\frac{0.22}{8.22}$ & 823 & $8.18^{\circ}$ & 8.21 \\
\hline 5 & 8.35. & 8.39 & 8.37 & 8.36 & $\frac{8,36}{8,36}$ & 729 & 8.30 \\
\hline 6 & 8.34 & 8.39 & 8.37 & 8.35 & 1836 & 29 & 3.30 \\
\hline spec. 1 & eadias $* 4$ & laoks 18. & $N D F ; 3 E 4$ & $D F=5 ; 5$ & $16 D F=50$ & & \\
\hline flask & $T \phi^{\prime}$ & $T 30 \mathrm{~min}$ & T1.5hr & T3hr & Tsher & Trohr & Tzthr \\
\hline $1 \ldots$ & $\frac{0.004}{0.004}$ & 0.005 & 0.006 & 0.004 & 0.006 & 0.004 & 0.009 \\
\hline 2 & 0.004 & $\frac{0.004}{0.003}$ & 0.005 & 0.004 & 0.005 & 0.005 & 0.005 \\
\hline 3 & 0.009 & 0.508 & 0.4758 & 0.495 & 0.494 & 0.480 & $\frac{0.483}{0.550}$ \\
\hline 4 & 0.003 & 0.494 & 0.483 & $\frac{0.491}{0.490}$ & 0.487 & 0.476 & 0.552 \\
\hline 5 & 0.002 & 0.491 & 0.480 & 0.492 & $\frac{0.490}{0.525}$ & $\begin{array}{l}0.497 \\
0.571\end{array}$ & 0.507 \\
\hline 6 & 0.001 & 0.579 & 0.5055 & 0.554 & 0.565 & $\frac{0.571}{0.581}$ & 0.564 \\
\hline spec.s & ds. chack & & & & & & \\
\hline steds & I申. & Tsomin & T1.5hr & T3hr & Tshr & Trohe & Tethe \\
\hline Blonk & 0.000 & 0.000 & 0.000 & 0.000 & 0.000 & 0.000 & 0.000 \\
\hline $50 \mathrm{~m} / \mathrm{h}$ & 1.120 & 1.120 & 1.116 & 1.16 & 1.118 & 1.121 & 1.121 \\
\hline $10 \mathrm{ng} / \mathrm{L}$ & 0.214 & 0.214 & 0.212 & 0.211 & 0.209 & 0.206 & 0.206 \\
\hline & & & 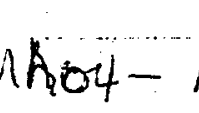 & $\cdots$ & & 0 & \\
\hline & & & $D F=16$ & - Abs. & 0,539 & & \\
\hline & & & & & & & \\
\hline
\end{tabular}

$\frac{K M C c r a c k e r}{\text { Recorded by }} \frac{8 / 20 / 98}{\text { Date }}$

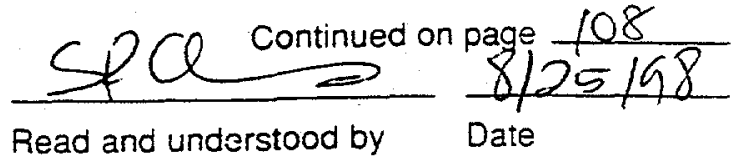


Subject

$E \times 0.4 a-R 6$

Date

$\frac{O S}{\text { Month }}$

18

$19 \frac{98}{\text { Year }}$

\begin{tabular}{|c|c|c|c|c|c|c|}
\hline 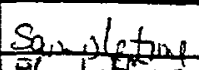 & $G C \#$ & wt.empty & $w t . t$ herous & wt.tsample & sanple, $D$. & $D F$ \\
\hline 918.8 .45 & 172.7 & $11.224^{\circ}$ & 14.471 & 19.722 & $42-R 6-T B a$ & 2 \\
\hline $13: 45$ & 1728 & 10.968 & 14.181 & 19.101 & $4 a-R_{6}-T B b$ & 1 \\
\hline $81 / 9 \quad 11: 00$ & 1729 & 11.219 & 13.106 & 16,337 & $4 a-R_{6}-T_{\phi}-1 a$ & \\
\hline $11: 01$ & 1730 & 10.969 & 12.854 & 16.011 & 16 & \\
\hline $11: 02$ & 1731 & 11.150 & 13.047 & 16.073 & 2 & \\
\hline $11: 03$ & 1732 & 11.053 & 12.940 & 16.139 & 3 & \\
\hline $11: 04$ & 1733 & 11.090 & 13.011 & 16.133 & 4 & \\
\hline$k: 05$ & 1734 & 11.085 & 13.000 & 16.220 & 5 & \\
\hline $11: 06$ & 1735 & 10.916 & 12.793 & 15.826 & 6 & \\
\hline $11: 30$ & 1736 & 10.921 & 12.805 & 15.859 & $4 a-R b_{2}-T_{30 \text { min }}-1$ & \\
\hline $11: 31$ & 1737 & 10.975 & 12.860 & 16.042 & $2 a$ & U \\
\hline $10: 32$ & 1738 & 101028 & 12.921 & 16.105 & 26 & 2 \\
\hline $16 i 33$ & 1739 & 11.202 & 13.068 & 16.175 & 3 & 1 \\
\hline $11: 34$ & 1740 & 11.049 & 12.921 & 15.963 & 4 & 1 \\
\hline $11: 35$ & 1741 & 11.020 & 12.909 & 16,004 & 5 & 1 \\
\hline $11: 36$ & 1742 & 11.031 & 12.916 & 16.030 & $\ldots$ & 1 \\
\hline $12: 36$ & 7743 & 11.145 & 13.034 & 16.210 & $4 a-R 6-T 1.5 h r_{1}-1$ & 2 \\
\hline $12: 37$ & 1744 & 11.134 & 13.018 & 16.223 & 2 & 2 \\
\hline $12: 38$ & 1745 & 11.098 & 13.029 & 16.174 & $3 a$ & 1 \\
\hline $12: 39$ & 1746 & 11.076 & 12.961 & 16.283 & 96 & 1. \\
\hline $12: 40$ & 1747 & 11.214 & 13.097 & 16.194 & 4 & 1 \\
\hline $12: 41$ & 1748 & 16.919 & 12.813 & 15.864 & 5 & $i$ \\
\hline $12: 42$ & 1749 & 10.997 & 12.895 & 15.940 & 6 & $i$ \\
\hline $14: 05$ & 1750 & 11.001 & 12.898 & 15.946 & $4 a-R 6-T_{3} h r-1$ & 2 \\
\hline $14: 06$ & 1751 & 11.169 & 13,040 & 16.148 & 2 & 2 \\
\hline $14: 07$ & 1752 & 11.155 & 13.017 & 16.010 & 3 & 1 \\
\hline $14: 08$ & 1753 & 11.078 & 12.941 & 15.957 & $4 a$ & i \\
\hline $14: 09$ & 1754 & 11.063 & 12.953 & 16.194 & 46 & \\
\hline $14: 10$ & 1755 & 11.135 & 13.031 & 16.095 & 5 & 1 \\
\hline $14: 11$ & 1756 & 11,070 & 12.962 & 16.210 & 6 & \\
\hline $16: 04$ & 1757 & 11,106 & 13.028 & 16.112 & $4 a-R_{6}-T 5 h r-1$ & 2 \\
\hline 16.05 & 1758 & 11.121 & 13,014 & 16.294 & 2 & 2 \\
\hline $16: 06$ & 1759 & 11.186 & 13.074 & 16.404 & 3 & \\
\hline
\end{tabular}

$\frac{\mathrm{KunCC}}{\text { Recorded by }} \frac{8}{\text { Date }}$

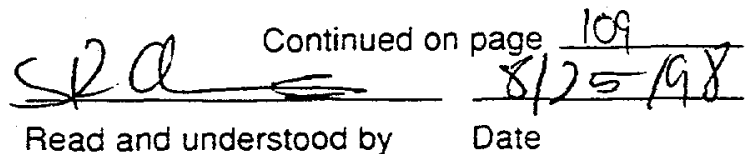




Date \begin{tabular}{ccc}
08 & 19 & \\
\cline { 1 - 2 } & ${ }_{\text {Month }} 998$ \\
Year
\end{tabular}

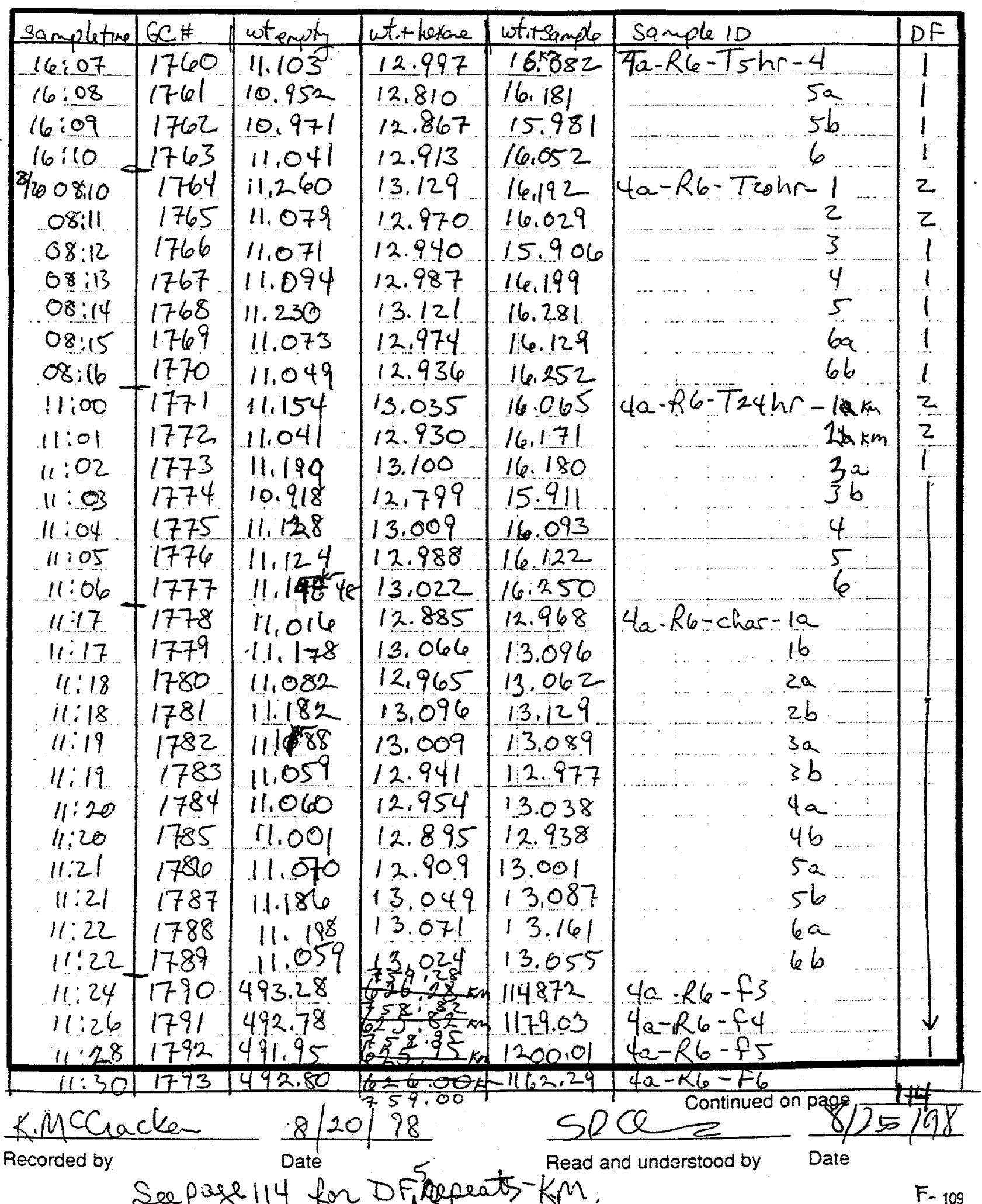


Subject Exp te-Ri repeat dilutions

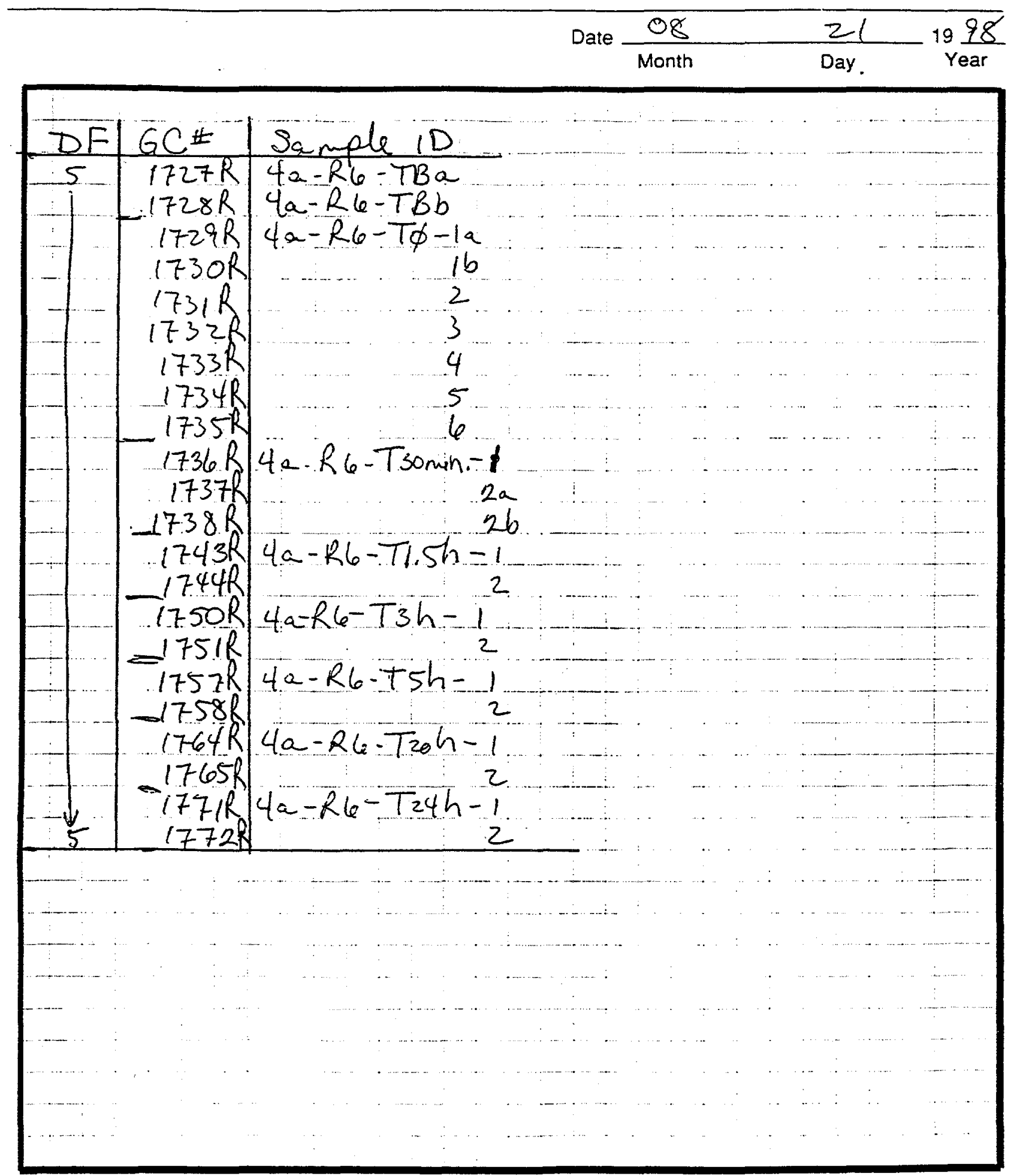

$\frac{\text { K.MCCacher }}{\text { Recorded by }} \frac{08 / 21 / 98}{\text { Date }}$

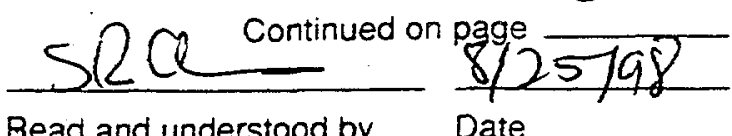

Read and understood by Date 
Subject $\quad \varepsilon_{x p} \cdot 4_{2} \cdot R \phi$

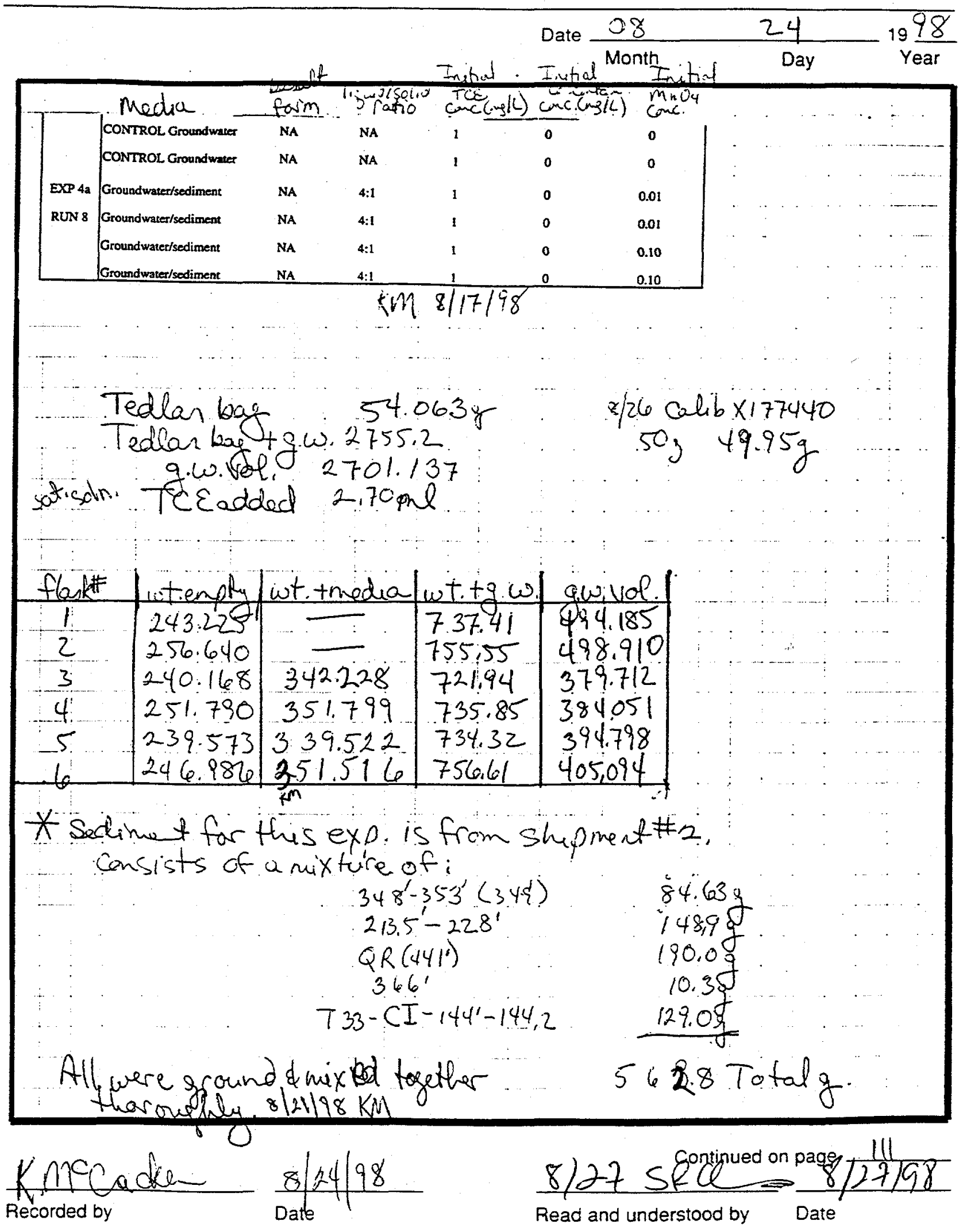


Subject

Exp.ta-R8

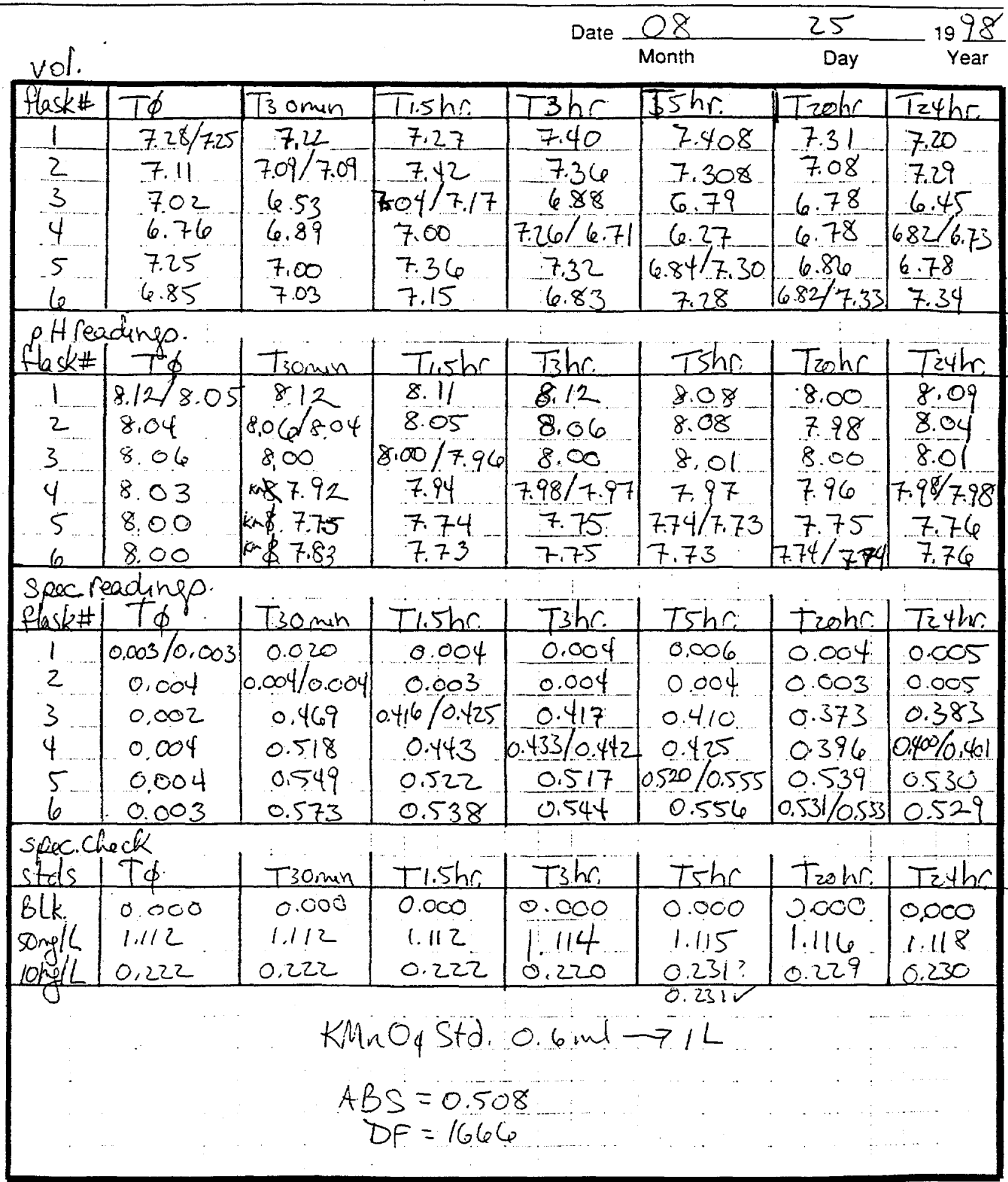

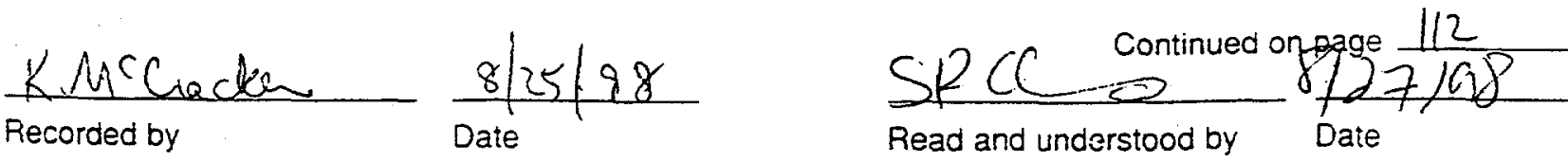


Subject Exp ya-Rs

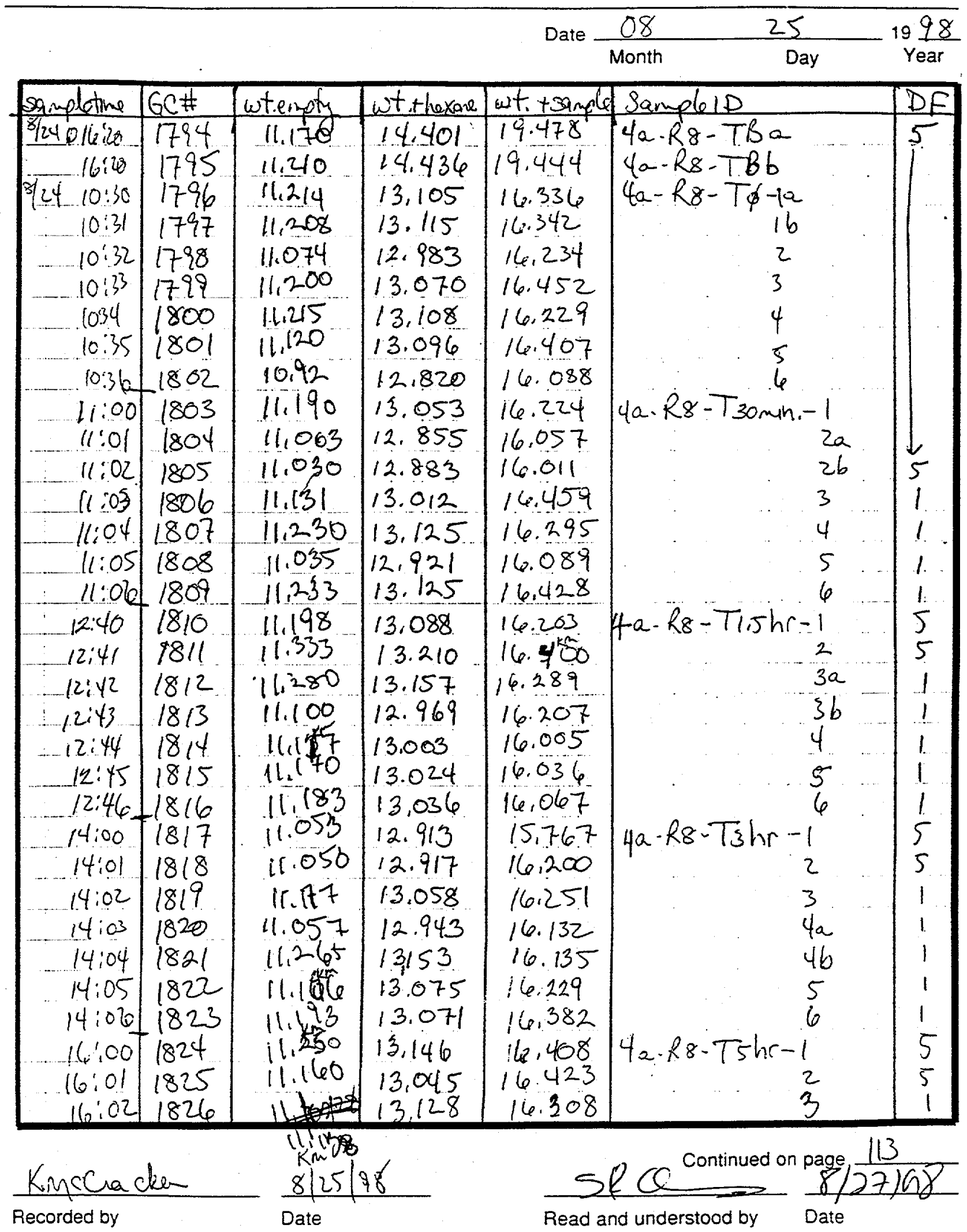


Subject Exp.4a-R8

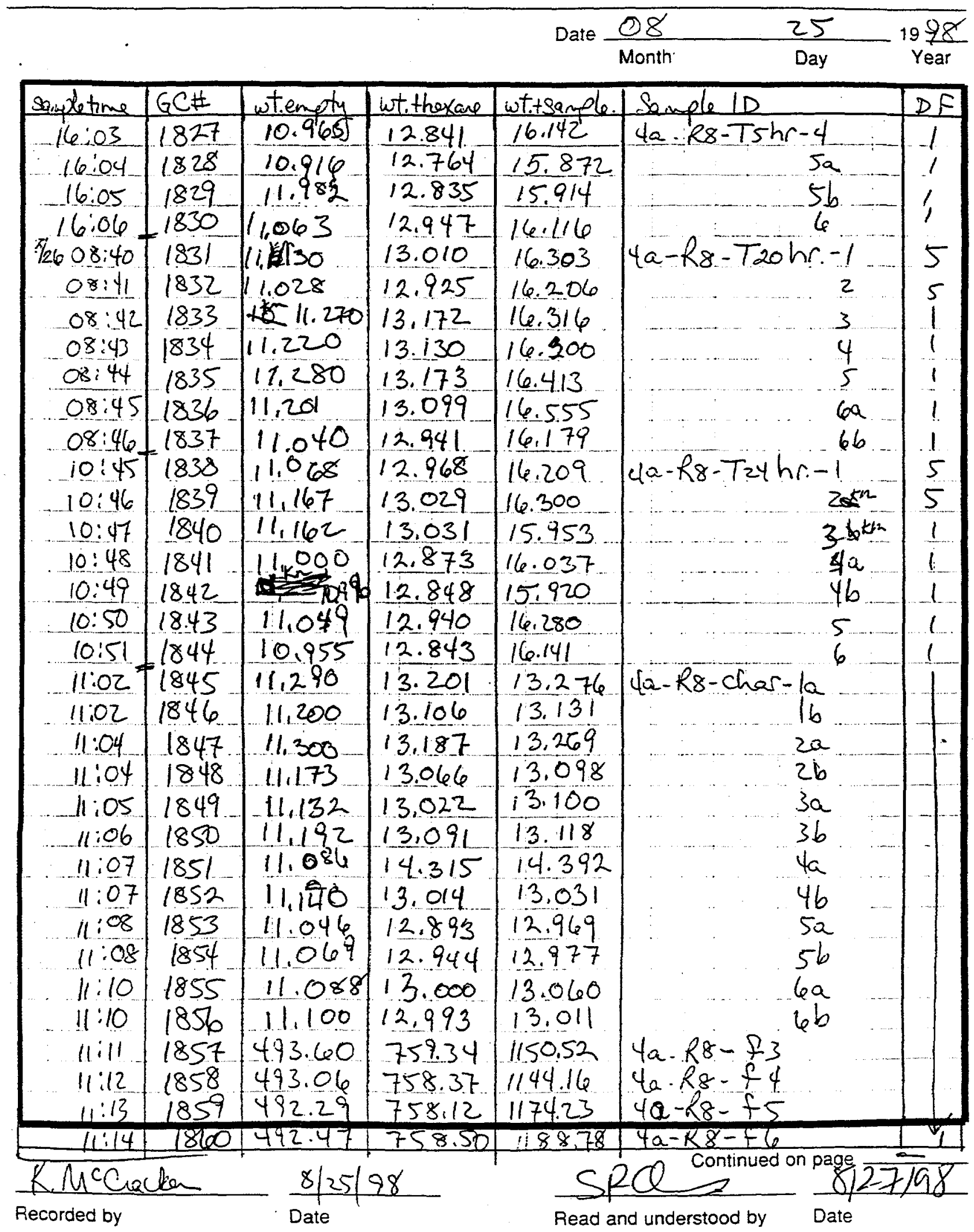


Subject $\varepsilon_{x p} 46-R \delta$

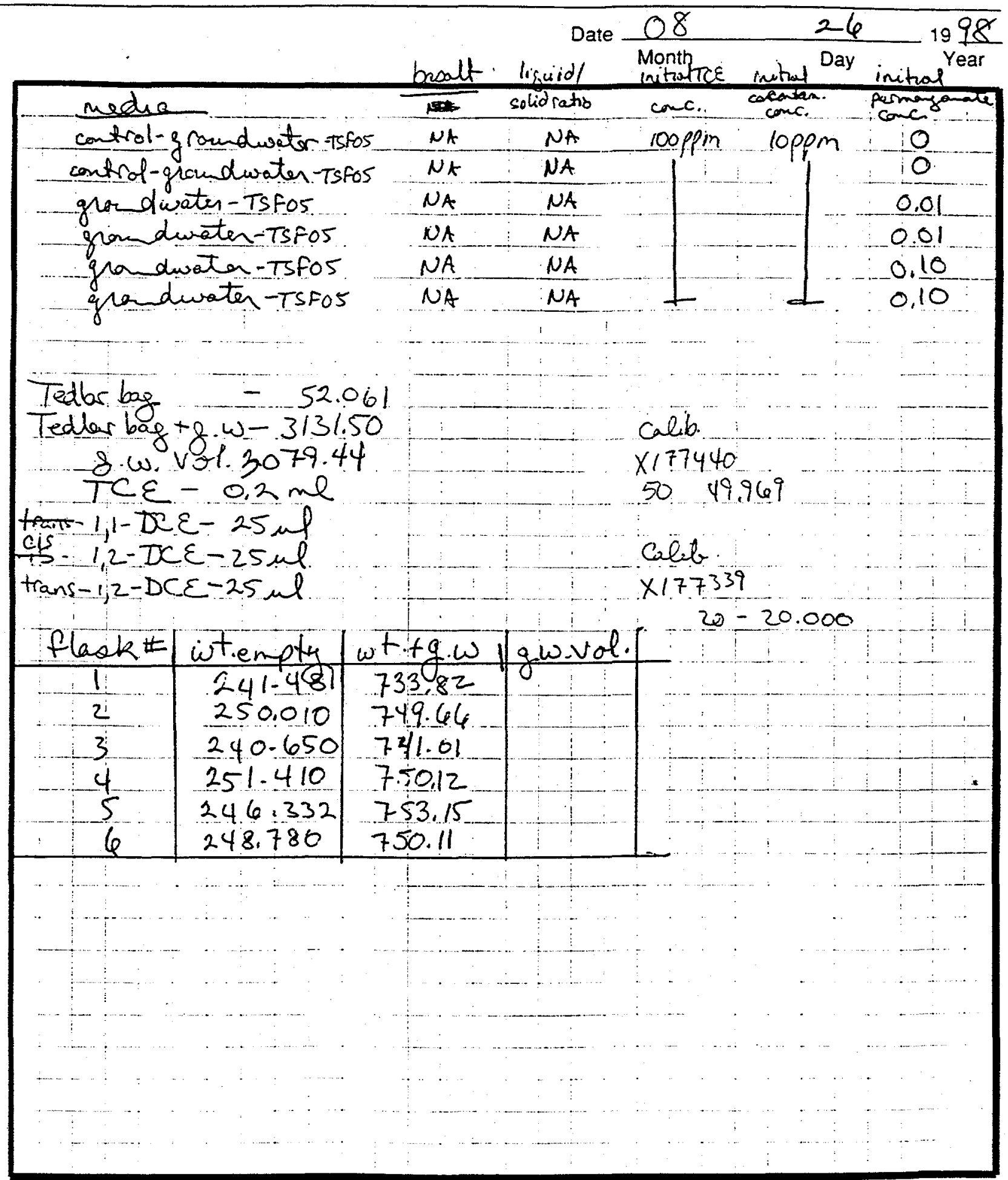

K.Mccacken

Recorded by

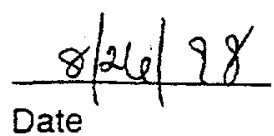

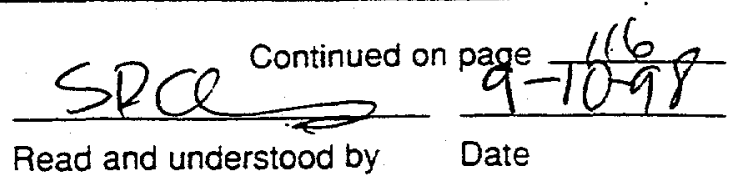




Date $\begin{array}{ccc}08 & 2.7 & 19 \frac{98}{\text { Mear }}\end{array}$

\begin{tabular}{|c|c|c|c|c|c|c|}
\hline saple & GC\# & wtenply & wot.thexane & int.tsample & Sample ID & $D F$ \\
\hline $8 / 27.11: 00$ & 1861 & 11.0990 & 14363 & 19,893 & $4 b-R 5-T B a$ & \\
\hline $11: 00$ & 1862 & 11.173 & 14.463 & 19.549 & $46-R_{5}-\pi B b$ & \\
\hline $11: 01$ & 1863 & 11.080 & 13.021 & 16.419 & $4 b-R 5-T \phi-1 a$ & \\
\hline $11: 02$ & 1864 & 11.032 & 13.002 & 16.252 & 16 & \\
\hline $11: 03$ & 1865 & 11,109 & 13.081 & 16.510 & 2 & \\
\hline $11: 04$ & 1866 & 11.092 & 13.060 & 16.339 & 3 & \\
\hline $11: 05$ & 1827 & 11.043 & 13.011 & 16,316 & 4 & \\
\hline $11: \infty$ & 1868 & 10.965 & 12.933 & 16.282 & 5 & \\
\hline $11: 0 \mathrm{E}$ & 1889 & 11.152 & 13.113 & 16.322 & 6 & \\
\hline 1136 & 1870 & 11.065 & 13.047 & 16,363 & $46-R_{5}-T_{30 m}-1$ & \\
\hline $11: 37$ & 1871 & 10.956 & 12.937 & 16,115 & $\ldots 2 a$ & \\
\hline $16: 38$ & 1872 & 11.161 & 13.139 & 16.464 & $2 b$ & \\
\hline $16: 39$ & 1873 & 10.844 & 12.814 & 16.000 & 3. & 1 \\
\hline $11: 40$ & 1874 & 10.891 & 12.867 & 16.156 & 4 & 1 \\
\hline $11: 41$ & 1875 & 10.939 & 12.918 & $16 \cdot 174$ & 5 & 1 \\
\hline $11: 42$ & 1876 & 10.950 & 12.925 & 16.130 & 6 & \\
\hline $12 ; 30$ & 1877 & 10.870 & 12.721 & 15.943 & $4 b-R_{5}-T 1.5 h-1$ & \\
\hline $12: 31$ & 1878 & 10.913 & 12.882 & 16.039 & 2 & \\
\hline $12: 32$ & 1879 & 10.958 & 12.908 & 16.162 & $3 a$ & 1 \\
\hline $12: 33$ & 1880 & 11.012 & 12.965 & 16.027 & 46 & 1 \\
\hline $12: 34$ & 1881 & 11.149 & 13.118 & 16.238 & 4 & 1 \\
\hline $12: 35$ & 1882 & 11.024 & 12.980 & 16.265 & 5 & 1 \\
\hline 1236 & 1883 & 11.038 & 12.905 & $14: 235$ & 6 & 1 \\
\hline $14: 02$ & 1884 & 11.292 & 13.252 & 16.0334 & $4 b-25-T_{3} h-1$ & $100 ; 2$ \\
\hline $14 ; 03$ & 1885 & 11.106 & 13.080 & 16,341 & 2 & \\
\hline $14: 04$ & 1886 & 11.147 & 13.122 & 16.412 & 3. & 1 \\
\hline $14: 05$ & 1887 & 11.233 & 13.202 & 16.488 & $4 a$ & 1 \\
\hline $14: 06$ & 1.888 & 11.004 & 12.978 & 16.096 & 46 & 1 \\
\hline $14: 07$ & 1889 & 10.971 & 12.937 & 16.295 & 5 & 1 \\
\hline $14 i 0 x^{x}$ & 1830 & 10.903 & 12.870 & 16.258 & 6 & 1 \\
\hline $16: 00$ & 1891 & 11.152 & 13.120 & 16.193 & $46-R_{5}-T_{5} h-1$ & $100 j$ \\
\hline 16.01 & 1892 & 11.103 & $\{3,06\}$ & 16.247 & 2 & $100 ; \approx 0$ \\
\hline $16: 02$ & 1893 & 11,148 & 13,115 & 16.223 & 3 & 1 \\
\hline
\end{tabular}

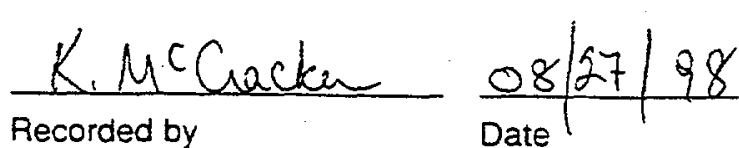

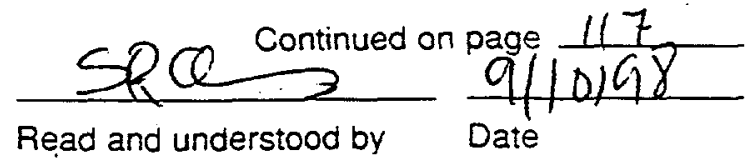




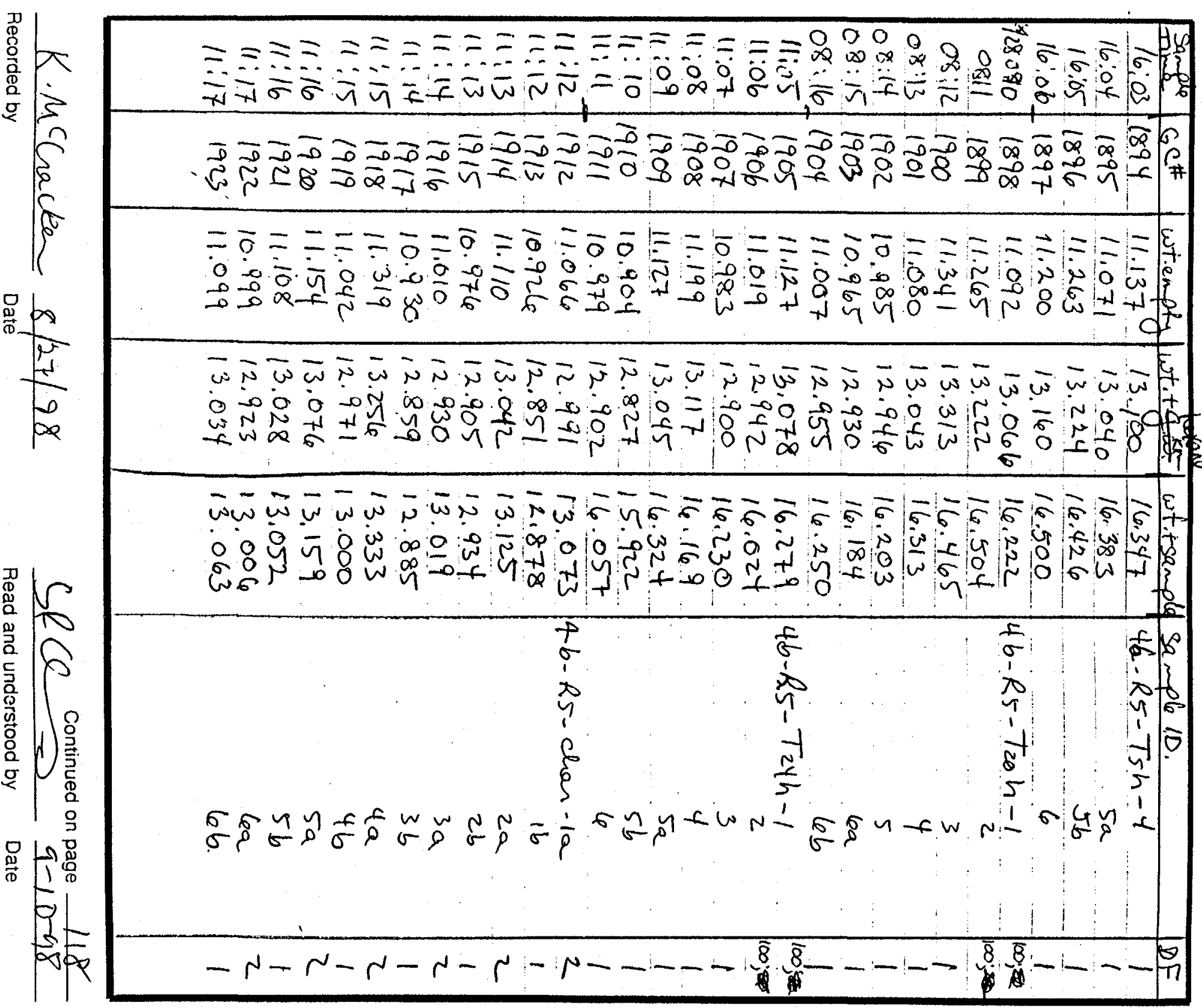

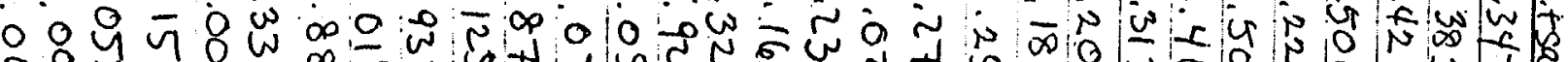

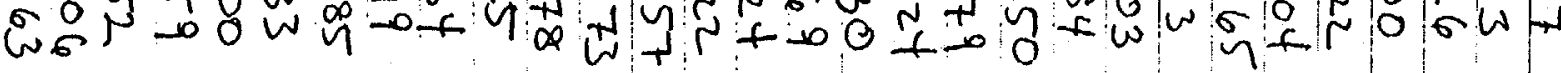

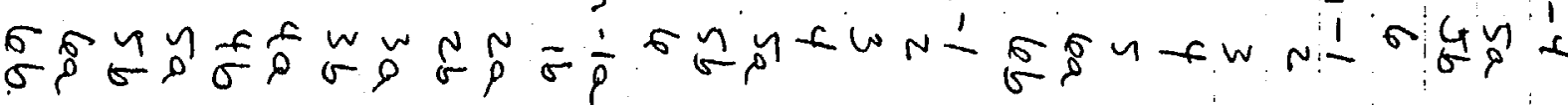


Subject $\quad \varepsilon_{x \rho}+b_{-}-R_{5}$

\begin{tabular}{|c|c|c|c|c|c|c|c|}
\hline 10 & & & & & Month & Day & Year \\
\hline Hlaske\# & $1 \bar{\phi}$ & T30min & T1.5h & $T_{3} h$ & T5h & Troh & T24h. \\
\hline 1 & $7.32 / 7.28$ & 7.20 & 7.32 & 7.35 & 7.48 & 740 & 7.45 \\
\hline 2 & 7.08 & $7.22 / 7.18$ & 7.31 & 7.14 & 7.39 & 7.29 & $7.3 i$ \\
\hline 3 & 7.15 & 6.90 & $6.75 / 7.38$ & 6.93 & 6.85 & 6.59 & 6.67 \\
\hline 4. & 7.21 & 7.17 & 7,45 & $7.38 / 7.32$ & 7.40 & 7.62 & 744 \\
\hline 5 & 6.99 & 7.28 & 7.23 & 7.25 & $7.30 / 7.38$ & 7.11 & $7720 \% 7,17$ \\
\hline 6 & 7.18 & 7.09 & 7.43 & 7.38 & $7.49^{\circ}$ & $7.10 / 7,12$ & $7.31^{11}$ \\
\hline $\mathrm{H}$ & odings & T1 & $T, 5 h$ & $T=1$ & Thh & Tizh & $T=1$ \\
\hline 1 & 8.658 .51 & 8.48 & 8.46 & 8.44 & 8.46 & 8.44 & 8.46 \\
\hline 2 & 8,50 & $8.50 / \times .51$ & 846. & 8.45 & 8,46 & 8.44 & 8.46 \\
\hline 3 & $\$ 51$ & 7.63 & $7.57 / 7.43$ & 7.47 & 7,54 & 7.49 & 7.53 \\
\hline 4 & 8.50 & 7.50 & 7.35 & $7.30 / 7.25$ & 7.38 & 7.33 & 7.36 \\
\hline 5 & 8.50 & 7.20 & 7.22 & 7.17 & $7.13 / 7.10$ & 7.20 & 7.277 .18 \\
\hline 6 & 8,50 & 7.09 & 7.14 & 7.08 & 7.07 & 17. $12 / 7,10$ & 7.13 \\
\hline specired & dinks & $\overline{D F} .182-$ & $1 \times 3 \$ 4$ & $45 ; 566$ & -50 & & \\
\hline Hask & $T 6$ & T3omin & $T 1.5 h$ & $T^{k-} \mathrm{T} h$ & Tsh & Iroh & T24h \\
\hline 1 & $0,004 / 0,003$ & 0.003 & 0.004 & 0.004 & 0,005 & 0.003 & 0.003 \\
\hline 2 & 0.003 & $0.004 / 0.007$ & 0.003 & 0.003 & 0.005 & 0.004 & 0.004 \\
\hline 3 & 0.003 & 0.307 & $0.246 / 0.256$ & 0.218 & 0.190 & $0,4 0 4 \longdiv { D F z }$ & 0.406 \\
\hline .7 & 0.003 & 0.323 & 0.260 & $0,218 / 0,220$ & 0.199 & 0.426007 & 0.430 \\
\hline 5 & 0.004 & 0.368 & 0.373 & 0.370 & $0.36 / 0.397$ & 0,373 & 9.37260 .392 \\
\hline 10 & 0,004 & 0.390 & 0.404 & 0.400 & 0.399 & $0,395 / 0,398$ & 0.397 \\
\hline spec. St & \&S.T申 & T3omin & $T 1.5 \mathrm{~h}$ & $T 3 h$ & Tsh & Troh & Th4h \\
\hline Blank & 0.000 & 0.000 & 0.000 & 0.000 & 0.000 & 0.000 & 0.000 \\
\hline somelh & 1.119 & 1.119 & 1.120 & 1.113 & 0,114 & 1.119 & 1.116 \\
\hline $10 \mathrm{me} / \mathrm{L}$ & 0.226 & 0.226 & 0,8226 & 0.216 & 0.212 & 0.222 & 0.222 \\
\hline 0 & & & 1 & & & & \\
\hline & & & stock KM & $0 \%$ - Abs. & & & \\
\hline & & & & & & & \\
\hline & & & & & & & \\
\hline & & & & & & & \\
\hline
\end{tabular}

$\frac{\text { K.MClacker }}{\text { Recorded by }} \frac{8}{\text { Date }} / 98$ $\underset{\text { Read and understood by }}{\text { SRCe continued on page }} \frac{119}{\text { Date }}$ 
Subject Exp.4b-Rs

Date $\frac{08}{\text { Month }} \quad \frac{28}{\text { Day }} 19 \frac{98}{\text { Year }}$

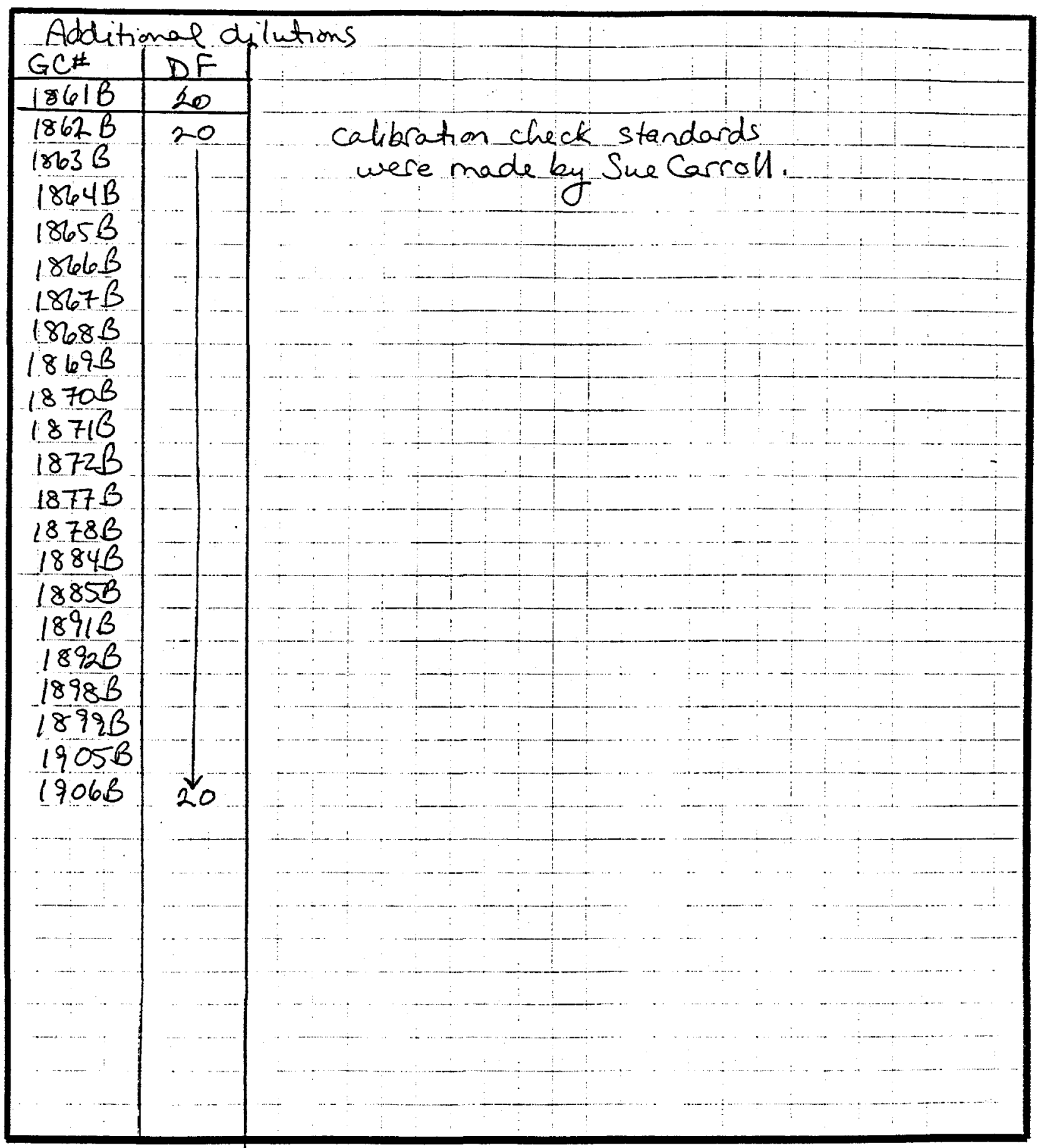

$\frac{K M^{C} \mathrm{CaCke}}{\text { Recorded by }} \frac{8 / 28 / 98}{\text { Date }}$

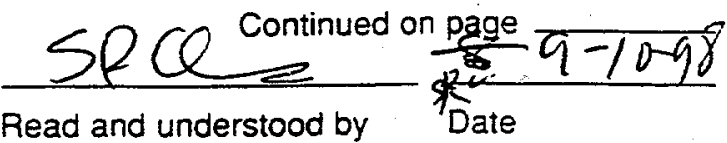


Subject Exp.4b-RT Repeat/dicutions.

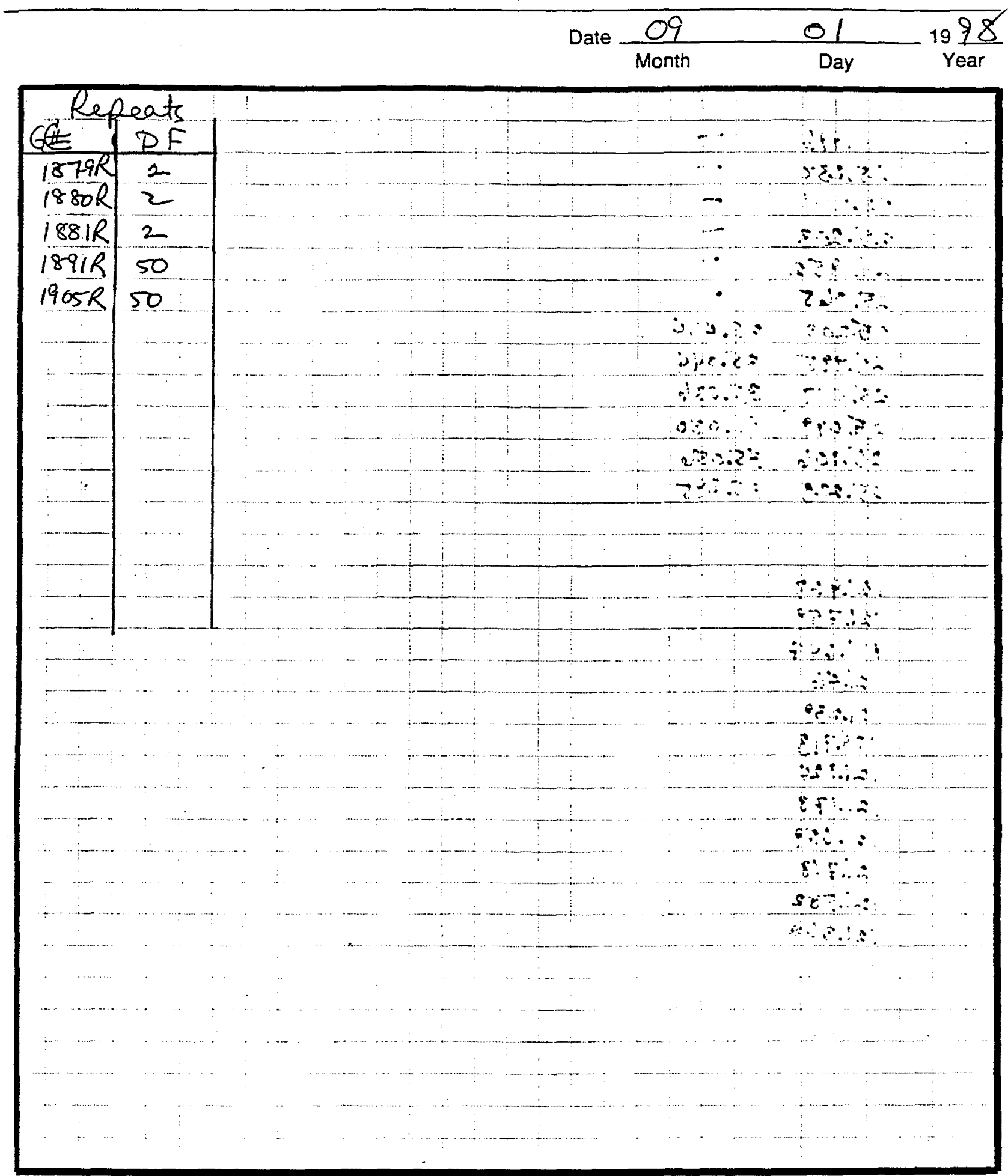

KMc Cracker

Recorded by

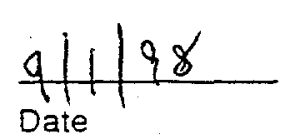

$\frac{911 / 98}{\text { Date }}$ $\underset{\text { Read and understood by }}{\mathrm{SRCl} \text { Continued on page } \overline{91498}} \frac{\overline{\text { Date }}}{2}$ 

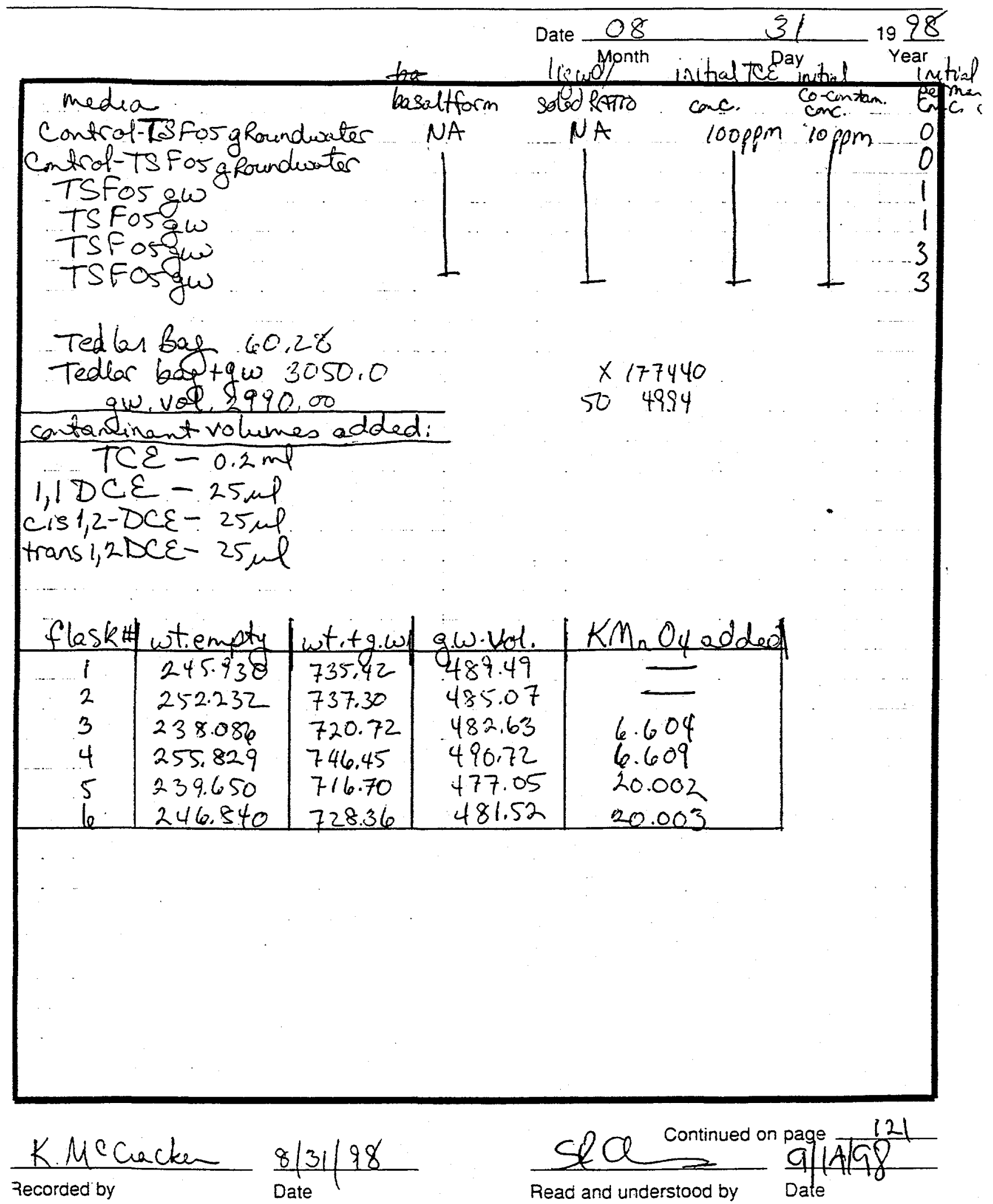
Subject

Exp.4b-R6

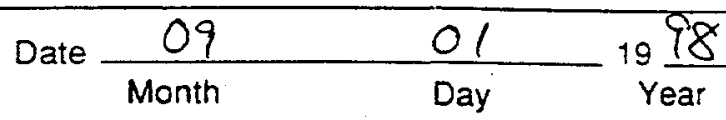

\begin{tabular}{|c|c|c|c|c|c|c|c|}
\hline flaskt & $T \phi$ & T30mn & Ti.5hr & T3hr & Tshr & Trohs & $T_{24} h^{\prime}$ \\
\hline 1 & $7.10 / 6.97$ & 7.04 & 7.09 & 7.03 & 7.10 & 7.11 & 6.96 \\
\hline 2 & 7.22 & $6.98 / 6.99$ & 7.13 & 7.07 & 7.07 & 7.18 & $z_{1} 12$ \\
\hline 3 & 7.21 & .7 .10 & $16.71 / 7.16$ & 6.64 & 6.57 & 6.43 & 6.77 \\
\hline 4 & 7.00 & 6.46 & 7.33 & $6.97 / 7.12$ & 7.08 & 6.91 & $\pi_{1} 12$ \\
\hline 5 & 7.05 & 7.01 & 7.05 & 6.95 & $6.76 / 7.18$ & 6.65 & 6.75 \\
\hline 6 & 7.11 & 6.99 & 7.46 & 7.19 & 7.19 & $7.09 / 7.20$ & $z, 12 / 7,21$ \\
\hline $\mathrm{QH}$ & & & & & & & \\
\hline pckt & $I \phi$ & Tzomin. & T1.5hr & T3hr & Tshe & Tzohr & $T_{2} 4 \mathrm{hr}$ \\
\hline 1 & 8.4218 .42 & 8.43 & 8.37 & 8.37 & 8.37 & 8.42 & 840 \\
\hline 2 & 8,42 & $8.42 / 5.42$ & 8.39 & 8.39 & 8.38 & 8.42 & 8.40 \\
\hline 3 & 843 & 7.40 & $744 / 7.29$ & $7.47^{\circ}$ & 7.48 & 7.38 & 7,34 \\
\hline 4 & 843 & 7.16 & 721 & 7.307 .23 & 7.33 & 7.24 & 7,23 \\
\hline 5 & 842 & 7.10 & 7.26 & 7.30 & $7.32 / 729$ & 7.27 & 726 \\
\hline 6 & 843 & 7.16 & 7.32 & 7.38 & 7.36 & $7.62 / 7.60$ & $7.62 / 60$ \\
\hline Spec Re & dines & $D F: 1,2$ & 38 & $=500$ & $5 \notin 6=1002$ & & \\
\hline flast4 & Td & T30min. & T.5 hr & T3 hr & TShr & Tzohs & T24h \\
\hline & $0.603 / 00^{3}$ & 0.002 & 0.002 & 0,004 & 0.003 & 0.003 & 0.004 \\
\hline 2 & 0.002 & $0.009 / 0.003$ & 0.002 & 0.003 & 0.003 & 0.002 & 0.005 \\
\hline 3 & 0.001 & 0.195 & $0.443 \% .453$ & 0.462 & 0.451 & 0.449 & 0.447 \\
\hline 4 & 0.001 & 0.217 & 0.439 & b.457\%. 468 & 0.435 & 0.452 & 0.451 \\
\hline 5 & 0.003 & 0.240 & 0.487 & 0.553 & $0.547 / 0.579$ & 0.591 & 0.540 \\
\hline 6 & 0.002 & 0.323 & 0.440 & 0.559 & 0,592 & 0.57310 .56 & $0.55 \% 55$ \\
\hline specste & $5 .+6$ & T3omin & Ti.5hr & T3ho & Tshr & Tzohr & Tzaho \\
\hline Blank & 0.000 & 0.000 & 0.000 & 0.000 & 0.000 & 0.000 & 0.000 \\
\hline $50 \mathrm{mg} / \mathrm{h}$ & 01.120 & 1.120 & 1.120 & 1.115 & 1,117 & 1.114 & 1.114 \\
\hline $10 \mathrm{mg} / \mathrm{L}$ & 0.222 & 0.222 & 0.222 & 0.225 & 0.225 & 0.224 & 0.223 \\
\hline & & & & & & & \\
\hline-7 & & & & & & & $\ldots . .$. \\
\hline & & & & & & & 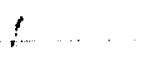 \\
\hline & & & & & & & \\
\hline
\end{tabular}

$\frac{k M M^{C} \text { racke }}{\text { Recorded by }} \frac{09 / 01 / 96}{\text { Date }}$ $\frac{S R Q \text { Continued on page } \frac{122}{9 / 98}}{\text { Read and understood by }}$ 
Subject

Exp. $46 \cdot R 6$

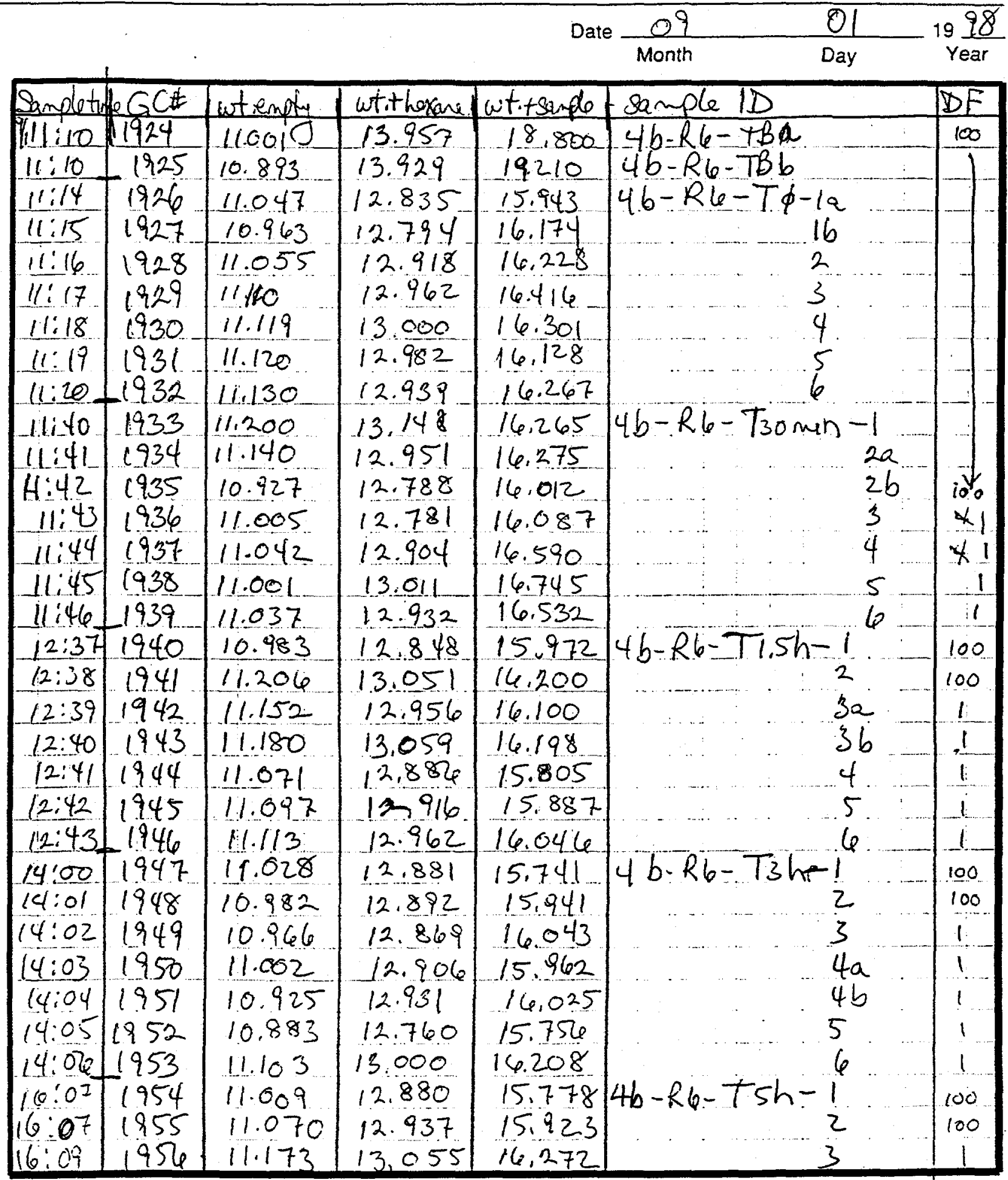

KiMccuacke-

Recorded by
$09-01-98$

Date

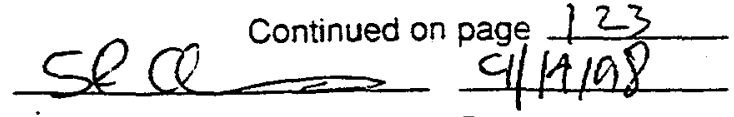

Read and understood by Date 
Subject Exp. $4 b . R 6$

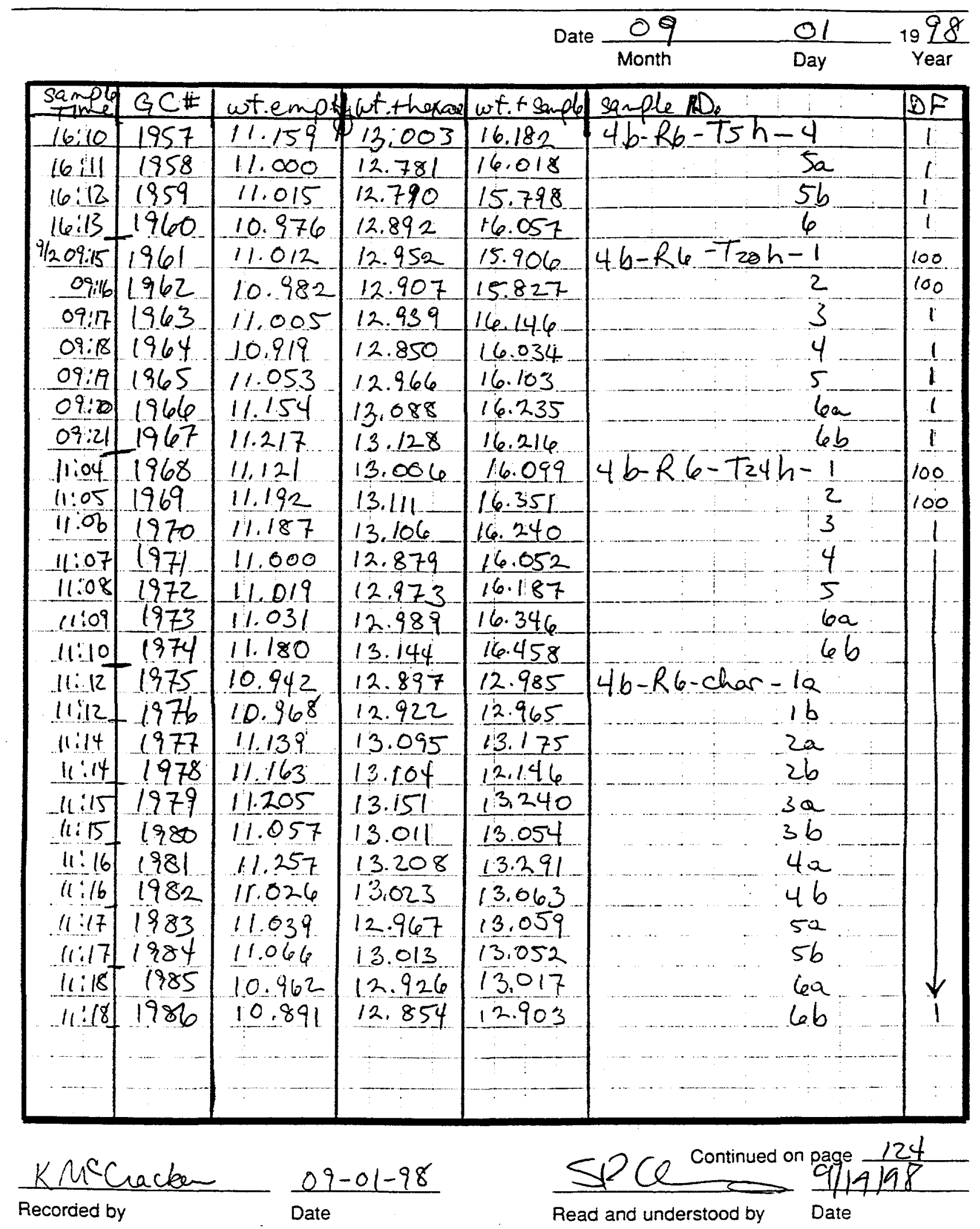

F-124 

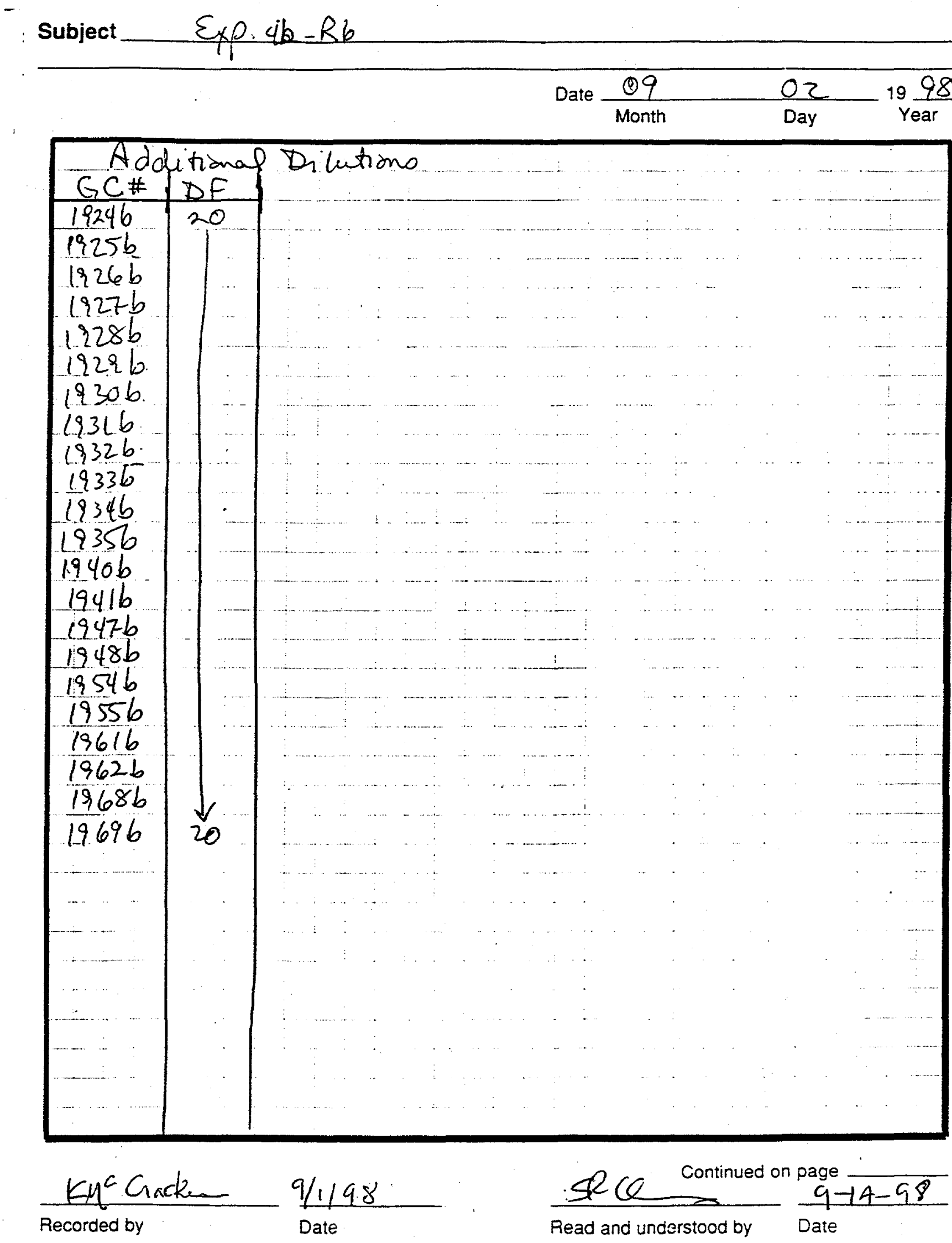


$\begin{array}{lll}\text { Matrix Soike Study } & \\ \text { start } & \text { Date } \frac{09}{\text { Month }} & 08 \\ & 1989 & \text { Day end }\end{array}$

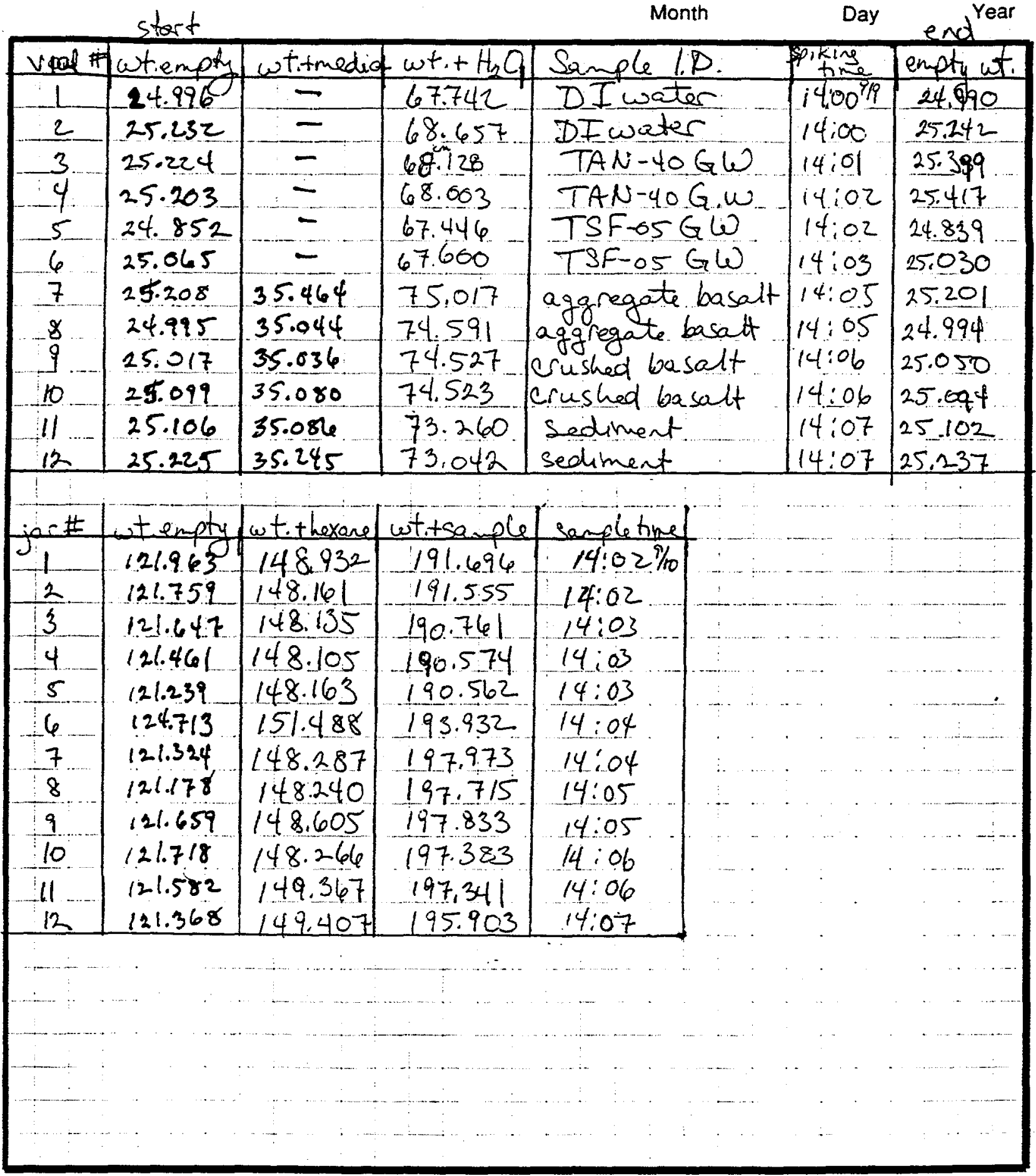

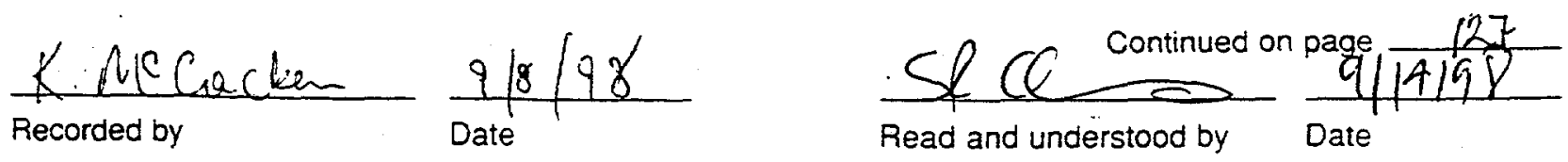




Date $\begin{array}{lll}09 & 09 & 1998 \\ \text { Month } & \text { Day } & \text { Year }\end{array}$

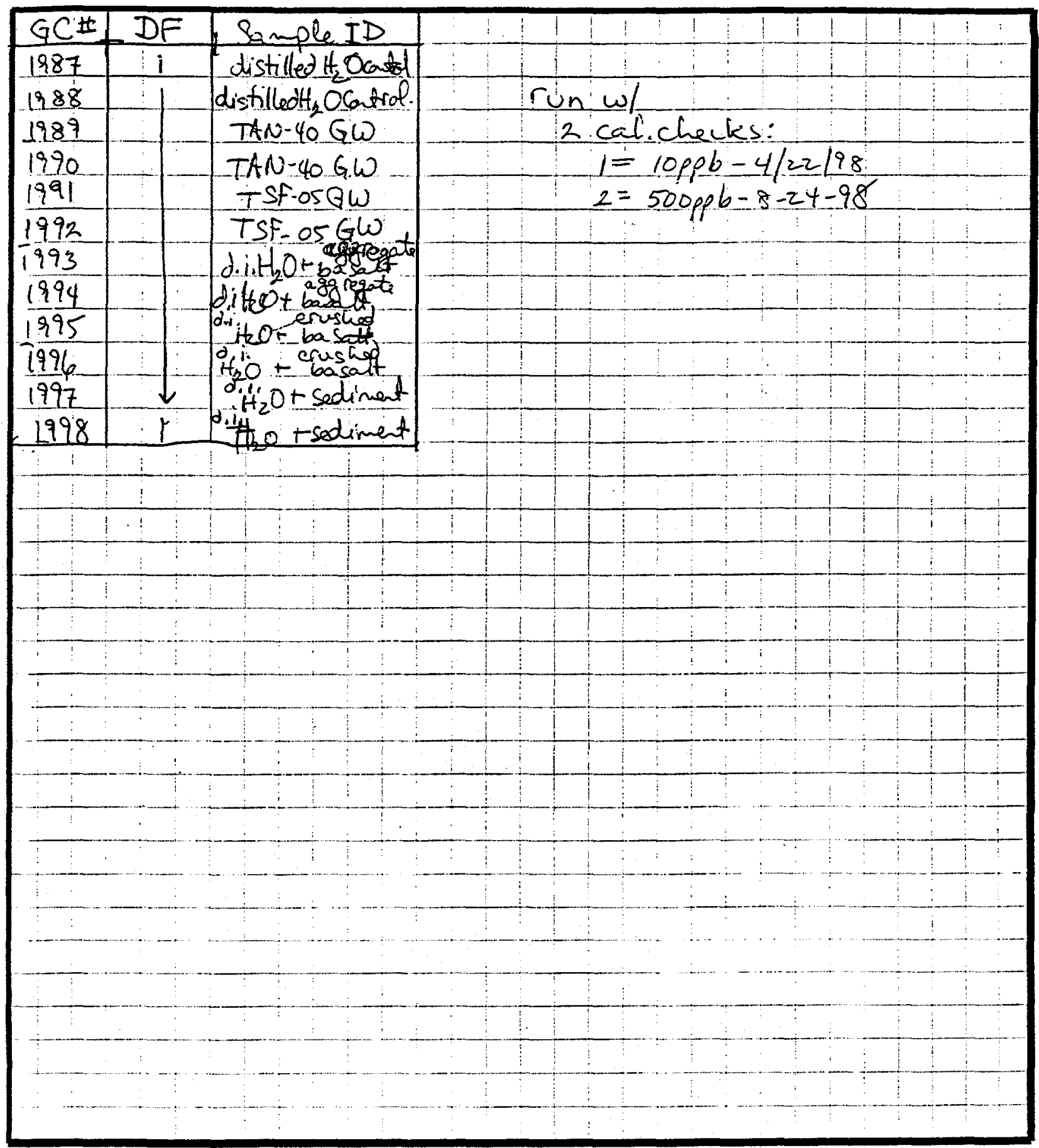

$\frac{K M^{C} \mathrm{Cracke}}{\text { Recorded by }} \frac{918 / 98}{\text { Date }}$ $\underset{\text { Read and understood by }}{\operatorname{SPCC}} \frac{\text { Continued on page }}{\text { Date }}$ 
Subject 082698 Gel cueve Ioformation

Date

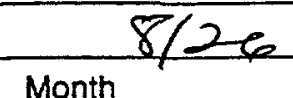

Day 1998

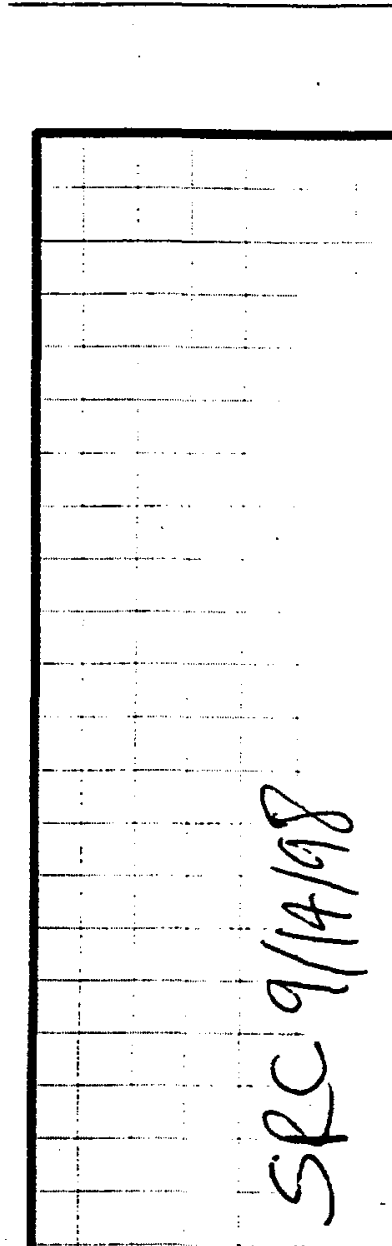

New Galbention Sads $8-26-48$ papention.

secline

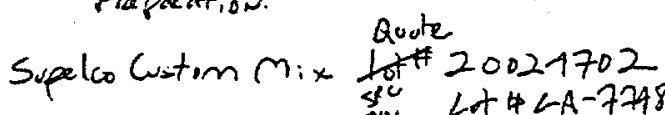

स24 LA+4 $\angle A-77488$ sing Empty

syinge full $=18.9070 \mathrm{~g} 5 \mathrm{sin}^{2}, 18.5654 \mathrm{~g}$

copem "stock" sout.w? addel $0.5776 \mathrm{~mL}$ of costom $m_{0 x}$

(Assuming seg of catimnia $=0.66$ )

to $10 \mathrm{~mL}$ Flask (Vdunotf.e) t filke to vdone

Resulting Stock Concis

$$
\begin{aligned}
T C E & (200.3)(.5176 \mathrm{~mL})=(x)(10 \mathrm{~mL}) \\
x & =10.37 \mathrm{mg} / \mathrm{L}
\end{aligned}
$$

Similasly

$$
\begin{aligned}
& V C=10.36 \mathrm{mg} / \mathrm{L} \\
& \text { Cis } 1.2 \text { OCE }=10.36 \mathrm{mg} / \mathrm{L} \\
& \text { TLO. } 1.2 \text { OCE }=10.37 \mathrm{gg} / \mathrm{L} \\
& 1.100 E=10.35 \mathrm{mg} / \mathrm{L}
\end{aligned}
$$

STP: PREP

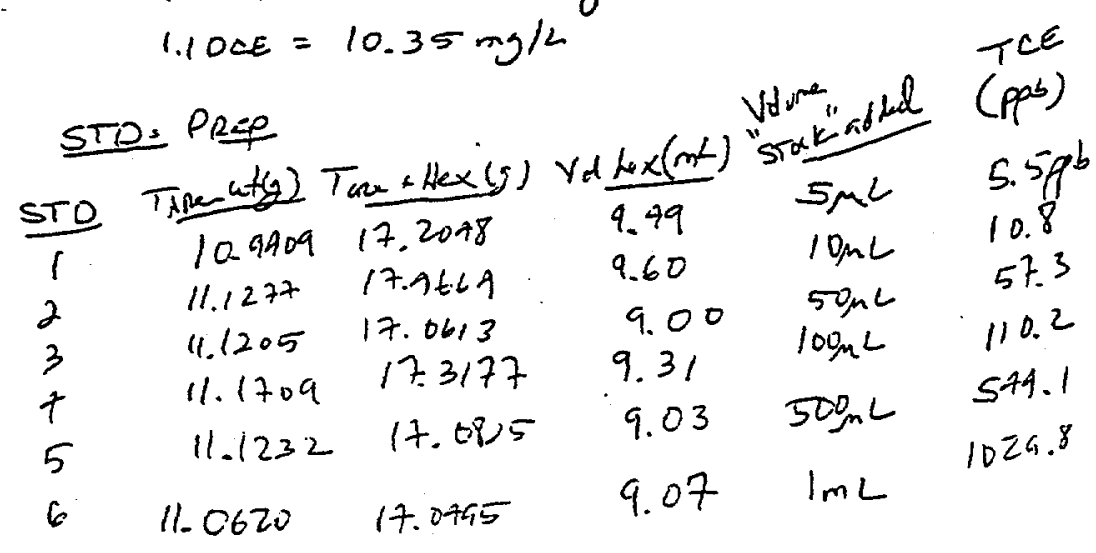

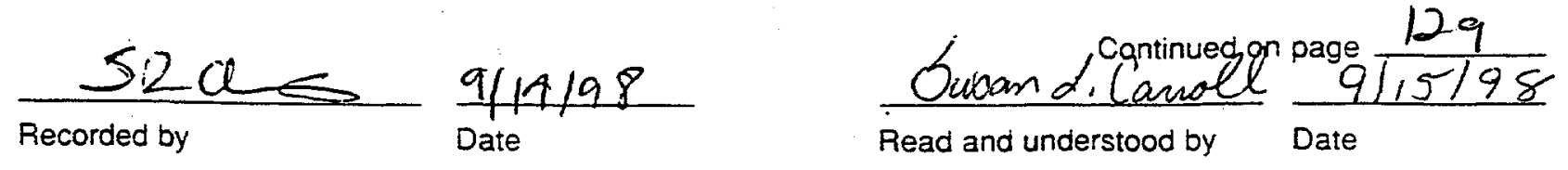

F -128 
$\frac{\text { Subject Cal Cucter Info Continved }}{\text { Date } \frac{8 / 26}{\text { Month }_{\text {Day }}{ }_{\text {Year }}^{1998}}}$

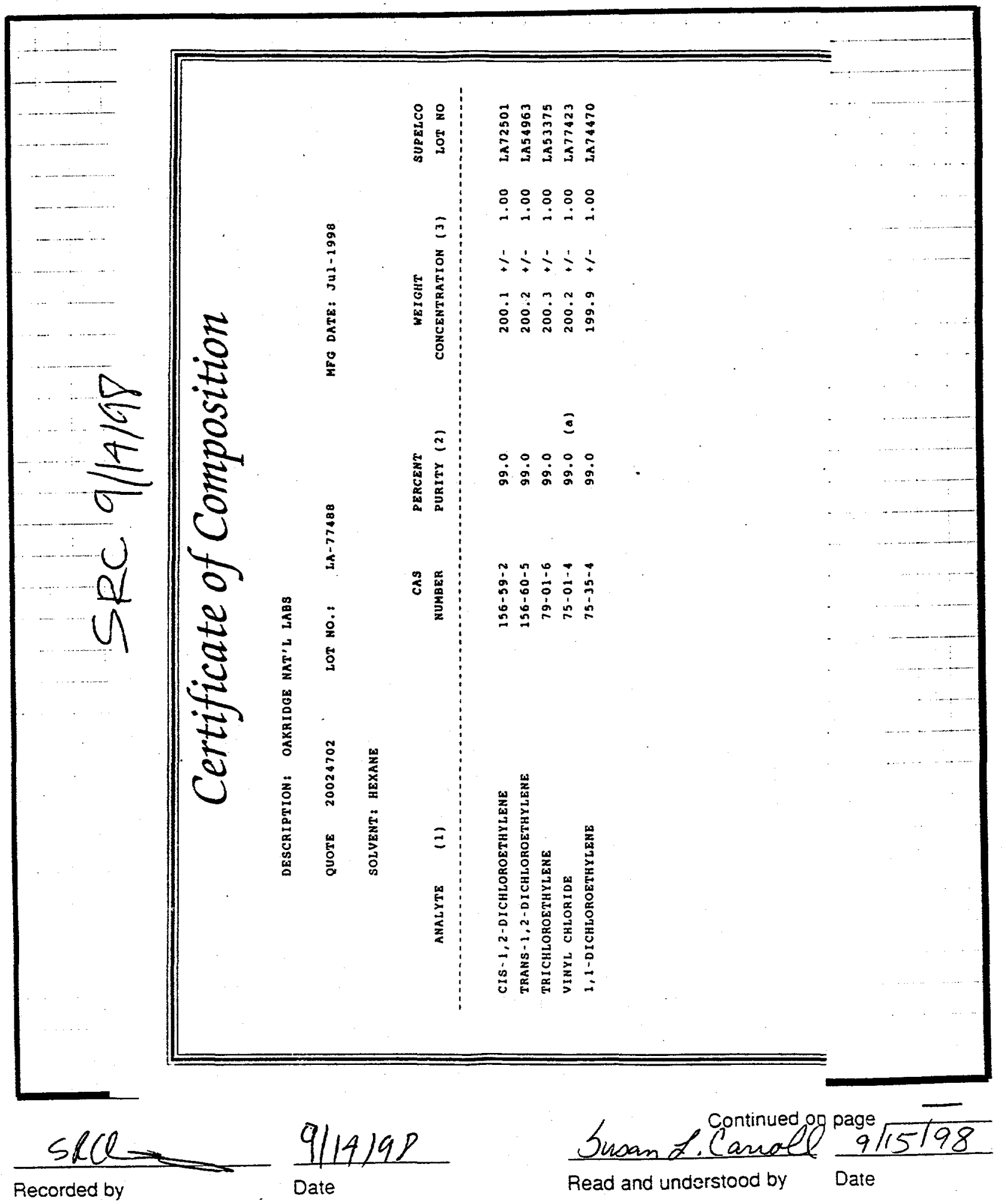




\section{Laboratory Evaluation of In}

Situ Chemical Oxidation as a Technology for Groundwater Remediation at the INEEL

\section{TAN Site}

Laboratory Notebook

ORNL-CASD 
3

3/9/98 5Tart of project notebook.

Pesformed dersity -eassements on Two single portions widh Minibens analyeder. Resntis Filed with Daily tample activity log.

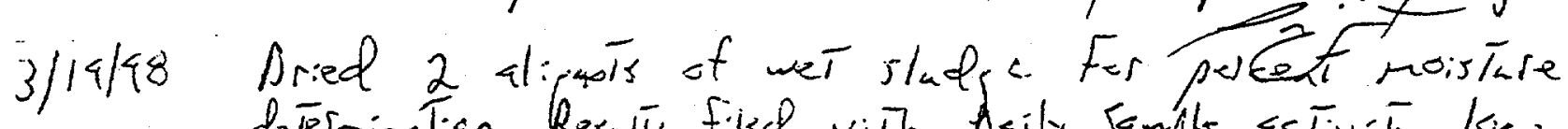
dater-ination. Rernlis filed with Aaily sangle activity kig.

$3 / 20148$ Perfoined ToC analysis of wat and difed aliphers of sludger. Rerulis filled with beily Semple acivity Loy.

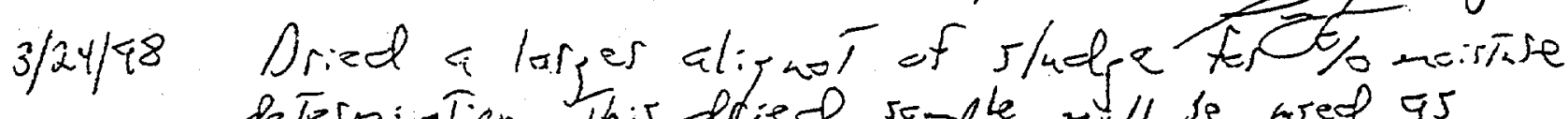
determination. This ditied sa-ple wll se ased as

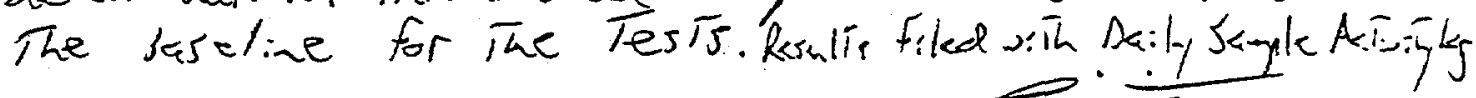

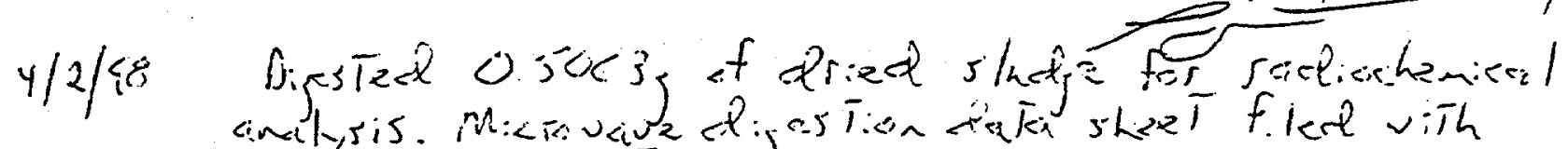

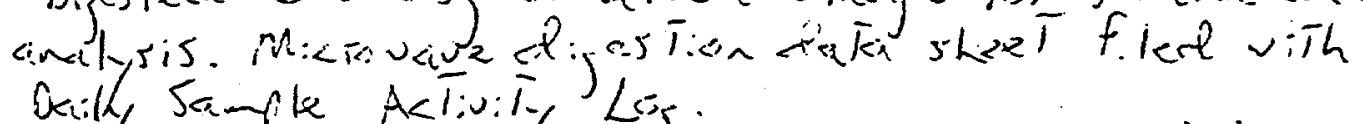
beily sangle A<ivity Lug.

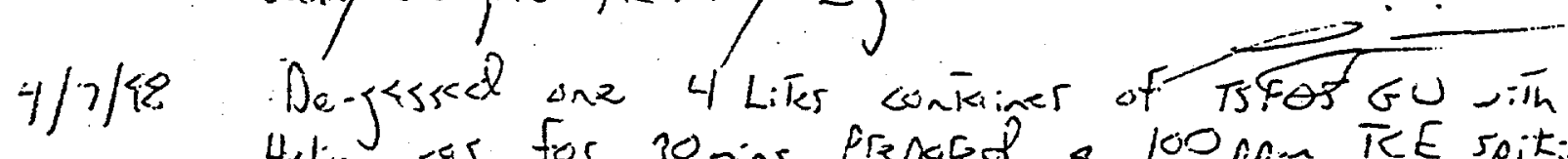
Helium jas for 30 nins. Prapated a $100 \mathrm{fg}$ m TLE spitin

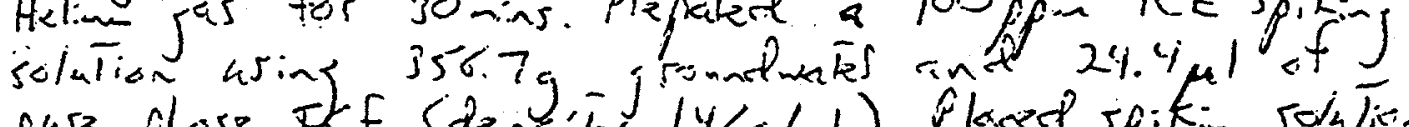

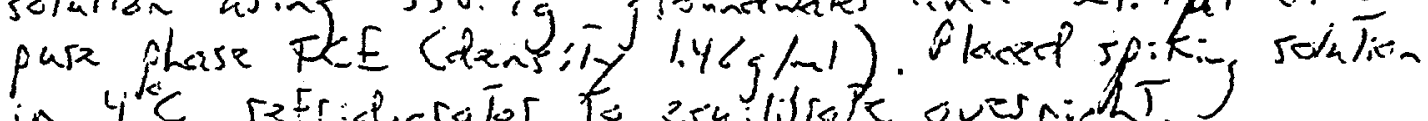
in 4 c C refristyciatos to ejuilisrate ovesnight.

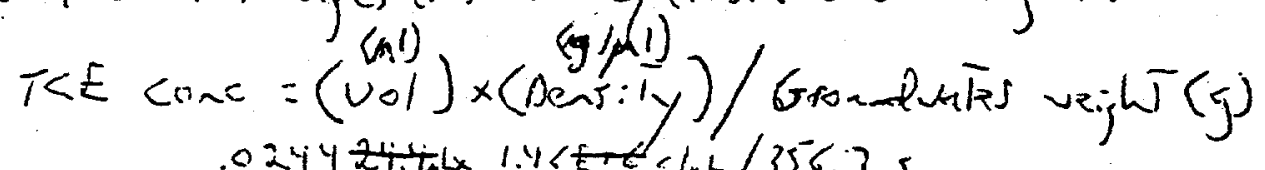

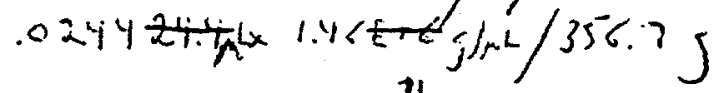

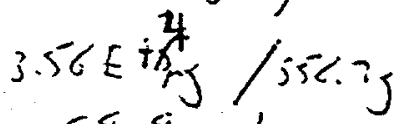

$$
\begin{aligned}
& \text { क्ष. ing/g }
\end{aligned}
$$

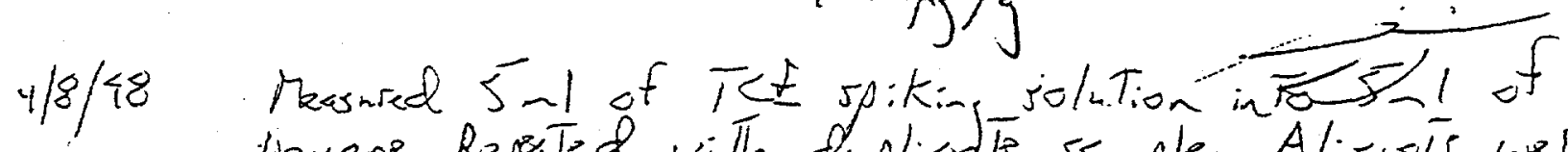
Hexane. Repseted with duplicdte sample. Alignols were shaten at 300 ppo for 2 hours. After extration $0.01 \mathrm{~mL}$ of the extracis wase pat in To 0 . 9 a $\mathrm{mL}$ Hexane for $a$ 100 fold dilution. These sayles will be analyzed by

F-131 
4

4/8/98 (conT) Apposinate TCE concentisation in dilntions shouth je lifin.

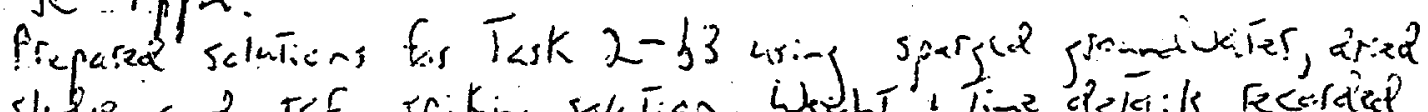

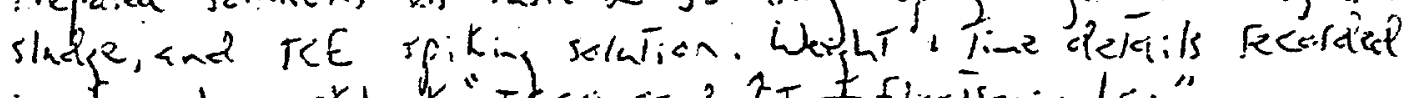
in Exeal warkjoork "Istece sindy test Eikeisenic Lej":

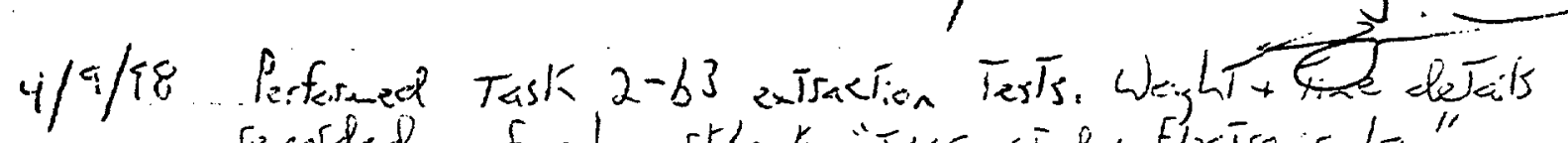
recorded ; Exal wirksook "Isec sindy Elecisonic Los"."

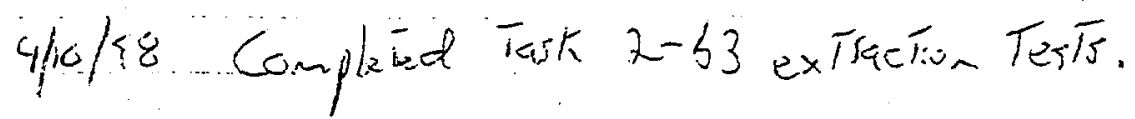

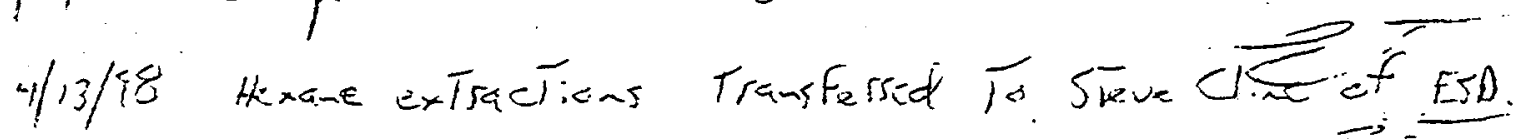

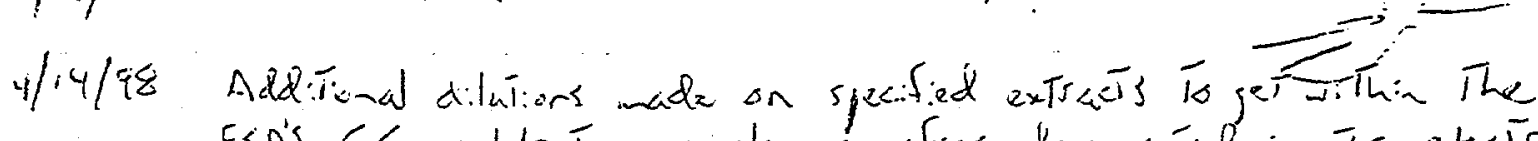

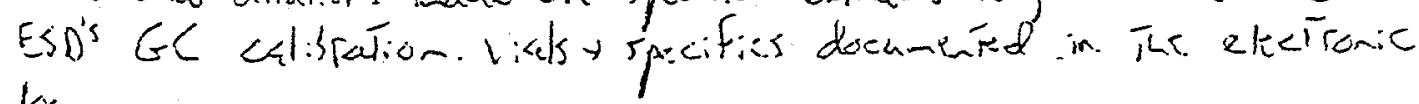
$\mathrm{kg}$.

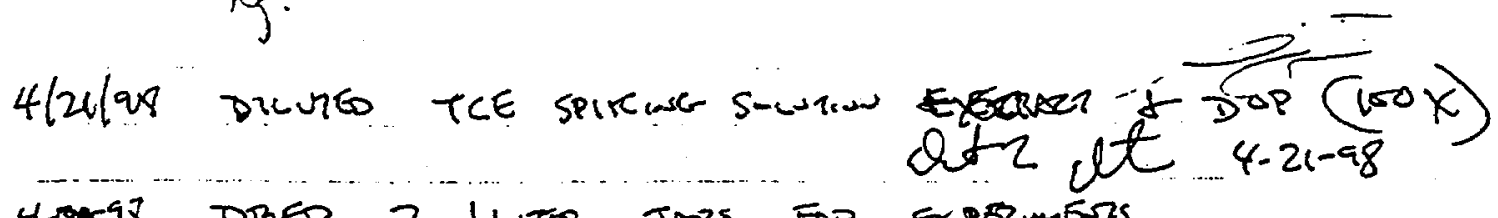

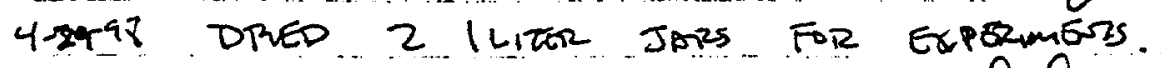

QD $2.2 \operatorname{te} 4-29-48$

$5 / 4 / 48$. Dried 2 llizer jars for experinen is... Alse weigled ow

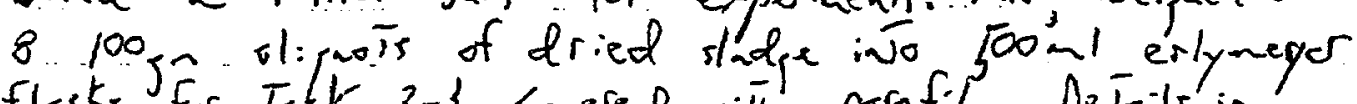
flasks For Talk 3-3. Lovesed with fasafilm. Derails in eketion:c log.

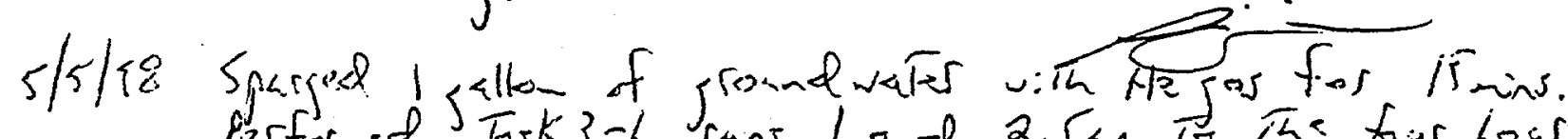

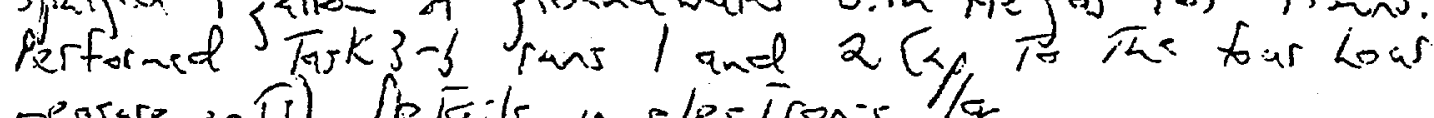

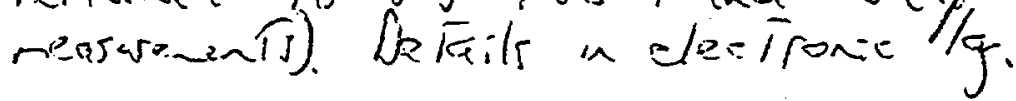

$516 / 98$ Compked Task 3-3 rans 1.2. Renova portions of

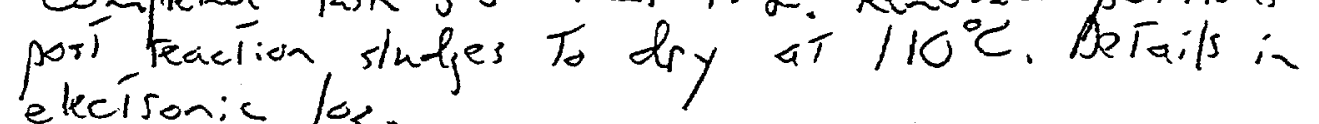
elecísonic log.

F-132 
5 $5 / 2 / 48$ sparged 1 jollon of joundwater with He jas (up to four hour measwemenis). Details in electronic 16.

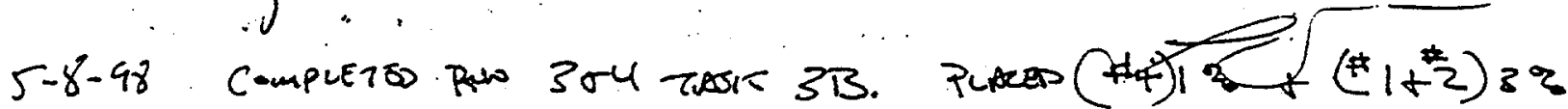

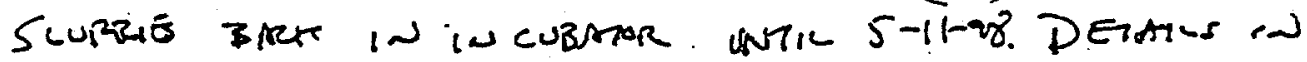

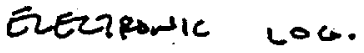

lA? et $5=8-9$

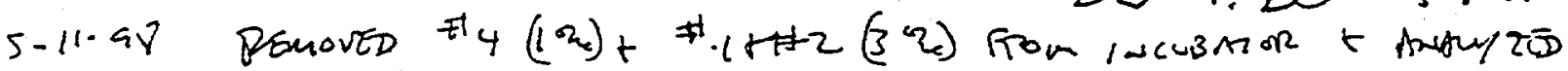

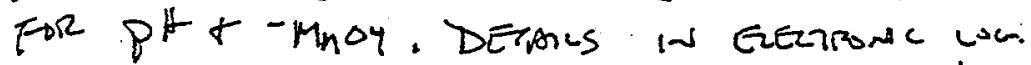

Qt?. Qt 5-11-ar

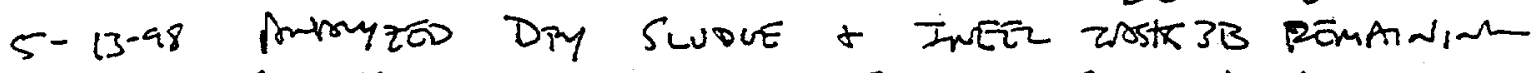

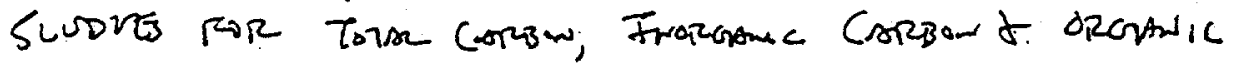

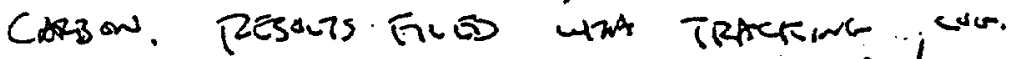

eft. $b t=5-13-97$

5-26-99. DRHE 2 luTER JARS OF SLUDGE POR TASK $Y_{b}$ CXP.

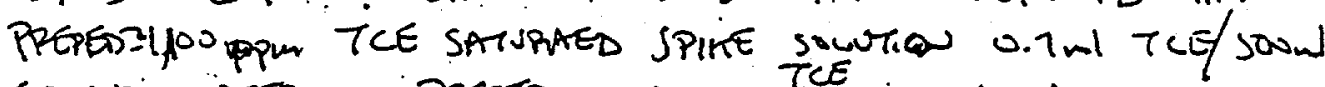

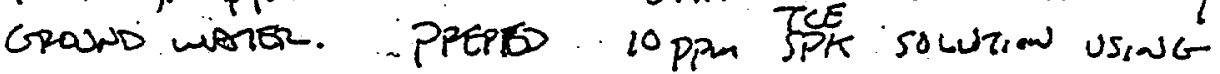

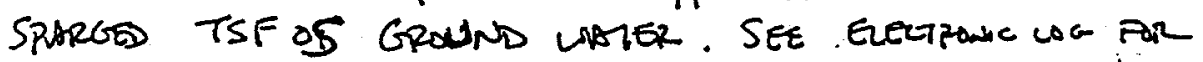

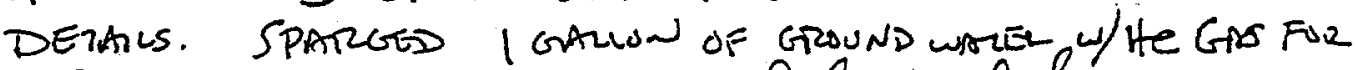
15 mis. 202 . Q $5-26-48$

$5 / 27 / 48$

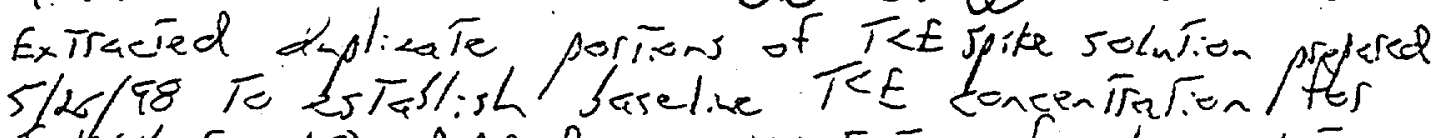
tak 4 r ran 10. Added a $4: 1$ ratio of $5 \mathrm{pki}$ solution To dried slindge ino leacers. Placed slatriest Twe contsd solutions into incalator set $q \bar{T} 12^{\circ}<$ and rhaking aT 200 rpm for a 24 hr. equilibration period. Do kails in electsonic log.

$5 / 28 / 48$

$5 / 2 i / 18$

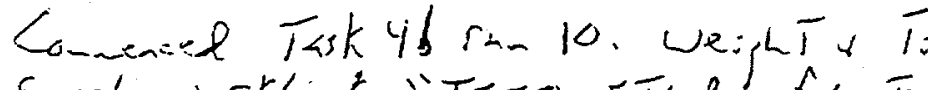
Exeel worktoot "Isce stidy Electronic Lg.

Completed Taskys ran 10. weighis Tire tetails in "IsCo sindy tlecironic Lo". Belizured GC' extracis

F-133 
6

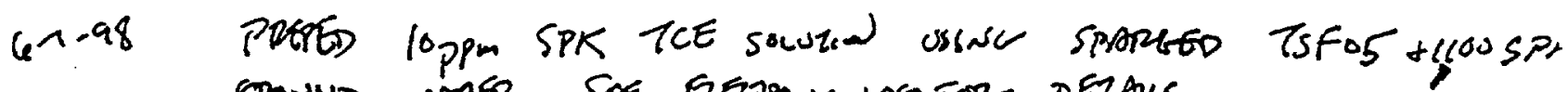

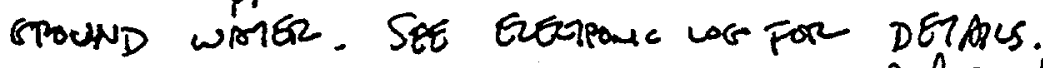

detzdt $a-1.98$

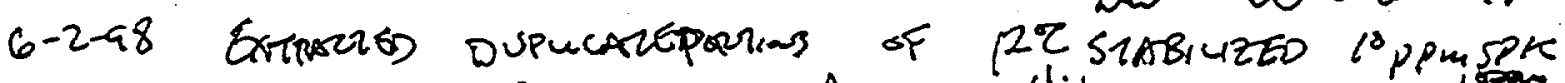

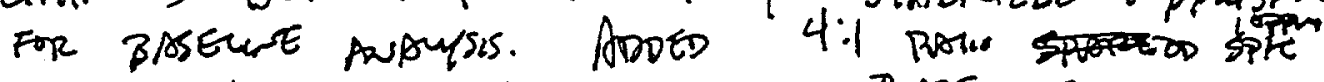

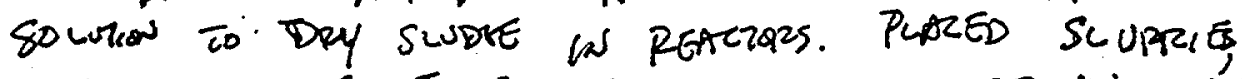

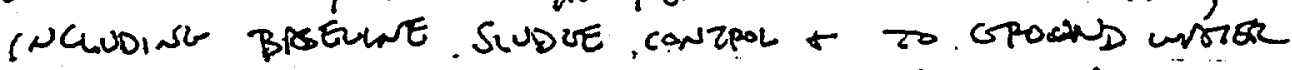

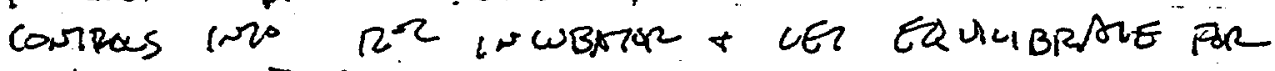

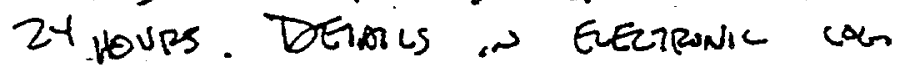

Qutz at $6-2-98$

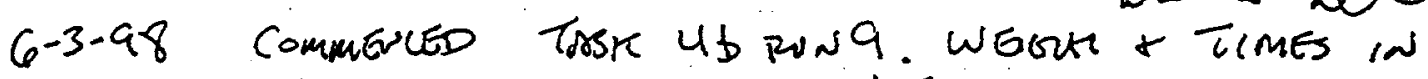

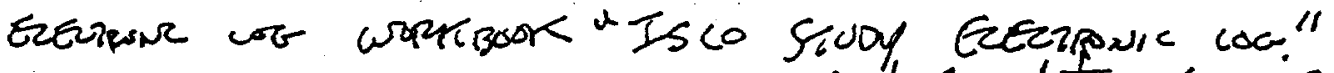
ant 2. de 6-3-98

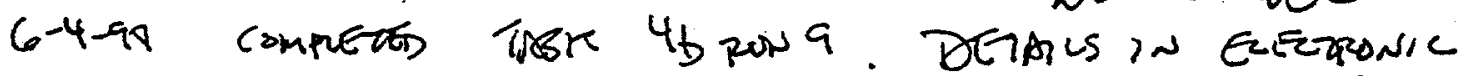

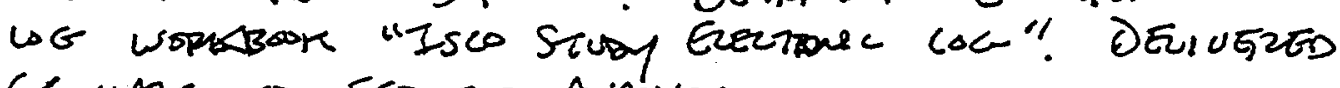

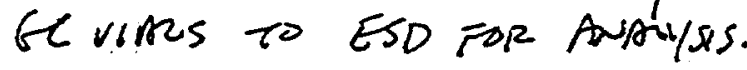

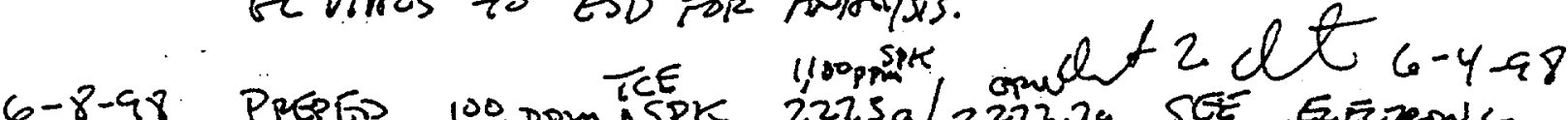

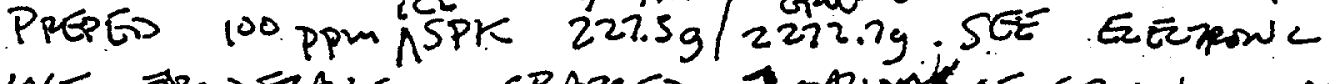

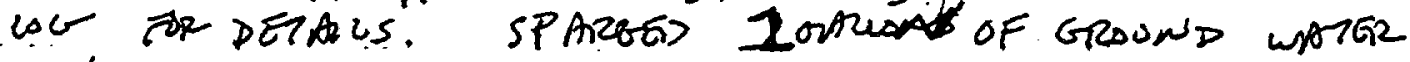
if lite एur 15 min.

$$
\theta+2 d t 6-8-98
$$

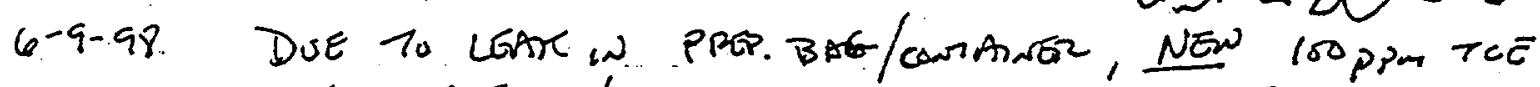

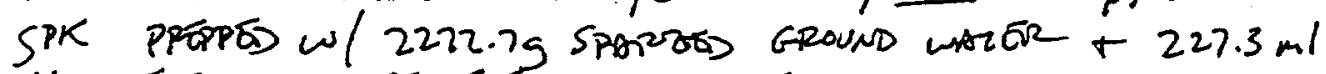

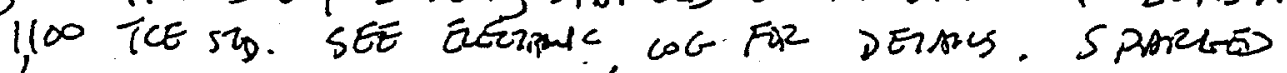
lonion Grousd water w/lte For 15 mid.

alt 2 et $6-9-98$

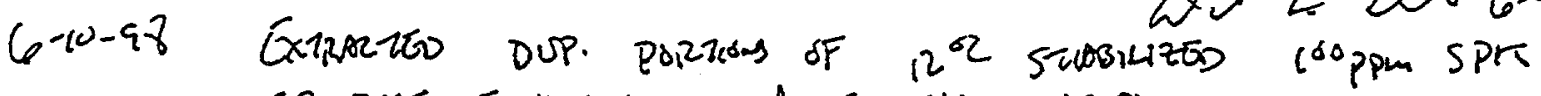

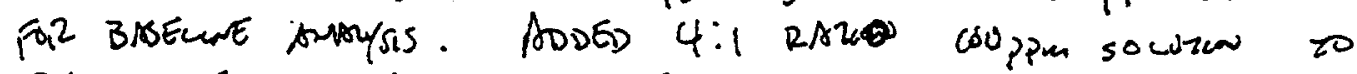

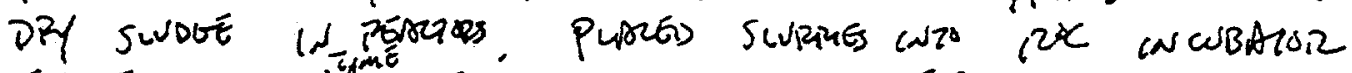

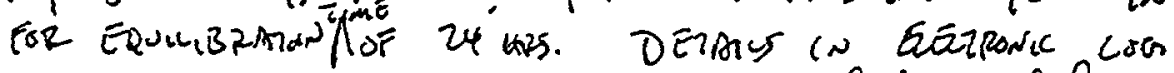

$6-41-98$ Q 2 . 2 t 6-10-98

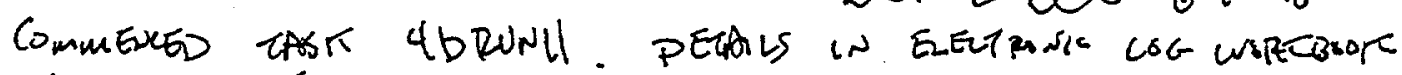
"Isco sujon fáchionic log:"

Qt 2 et $6-61-98$

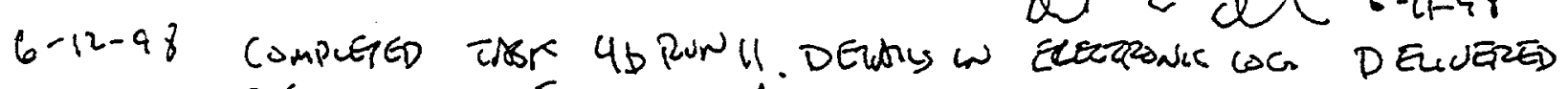

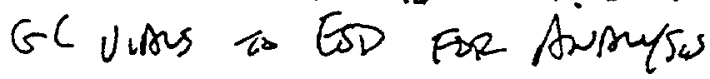

at 2. et $6 t_{6-2.97}$

$\mathrm{F}-134$ 
7

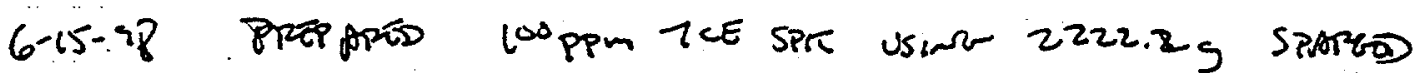

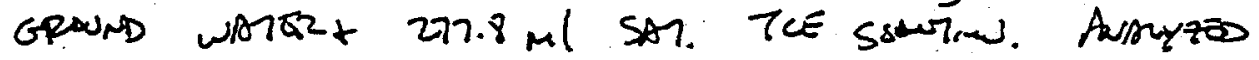

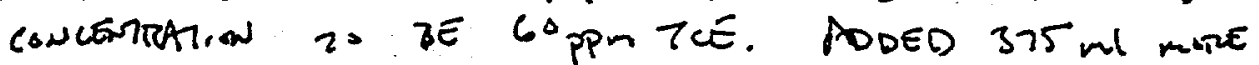

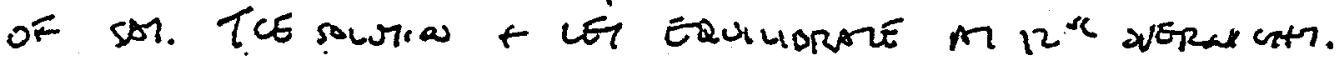
SEE ELETPUAC WO FOR PETALS.

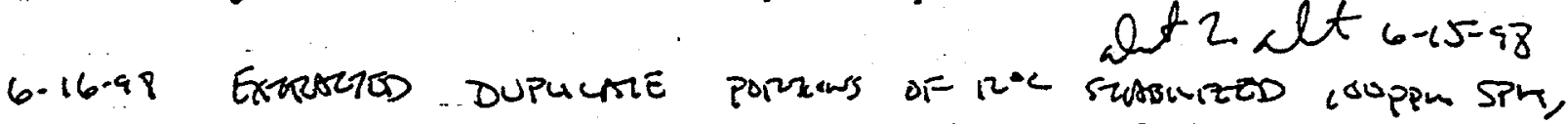

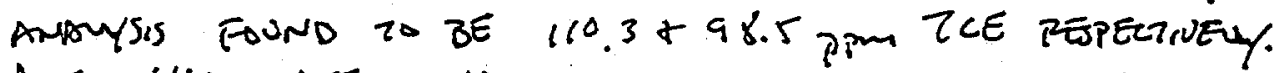

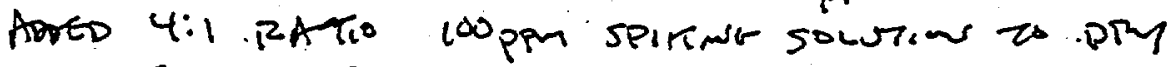

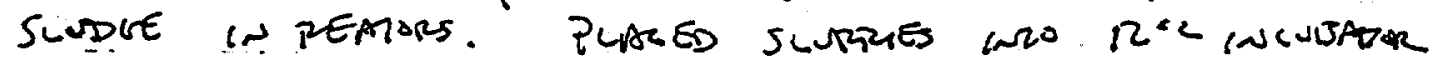

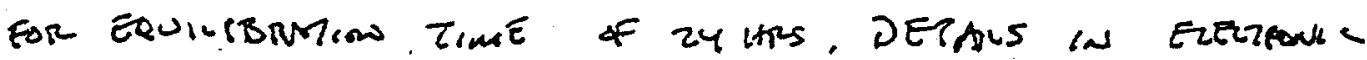
LAG.

ant 2. $l$ t $6-16-98$

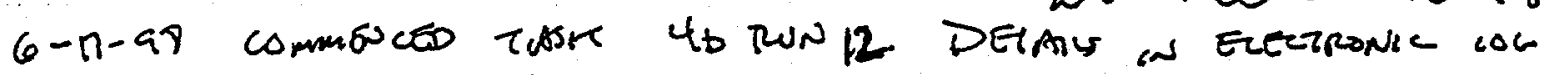
wORK BOSK "I SCO SCUDY ELEZTROASC LoG"

Qt 2. el $6-1298$

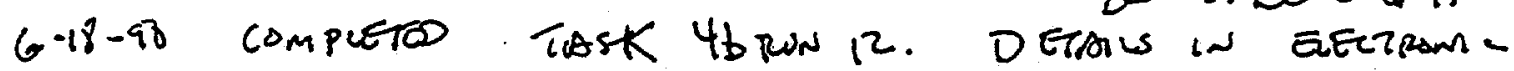

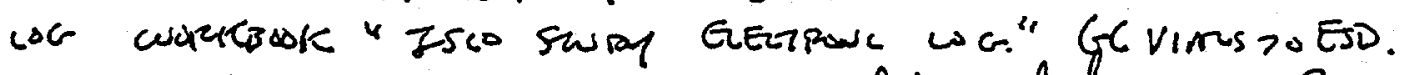

alt i. elf $6-18-4,8$

GIa-GT RE-DIUTLAUS PERFORMED ON SEE CT EXTRACTS

$$
\text { Qt. Let } 6-19-98
$$

6/19/48 Ran 10 and 11 of Task 43 must be redone due To low TCE concentrations in spike solution. Nev ran numbers will be Ran 15 and 16 respectively. The run II data will be used as the ruhR 9 data likE concentration was wYopan) which also had tow TeE. concentration in The spiking solution ( h pm vs $10 \mathrm{pm}$ ).

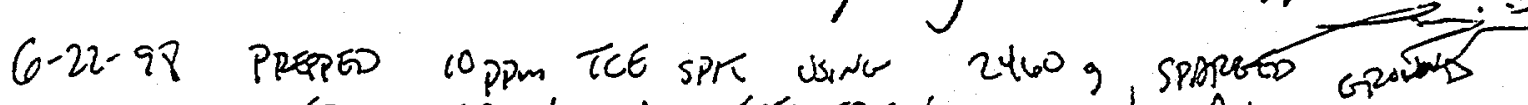

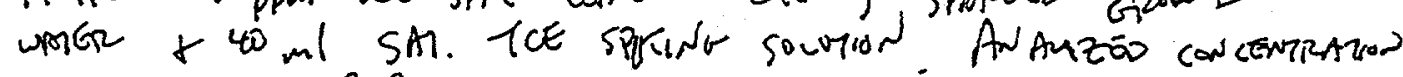

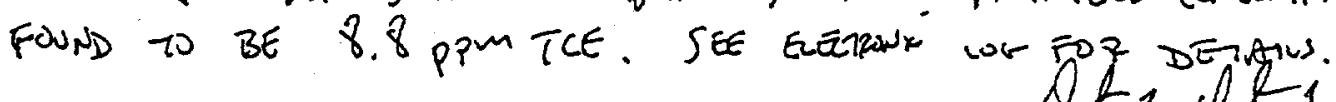

Detrition

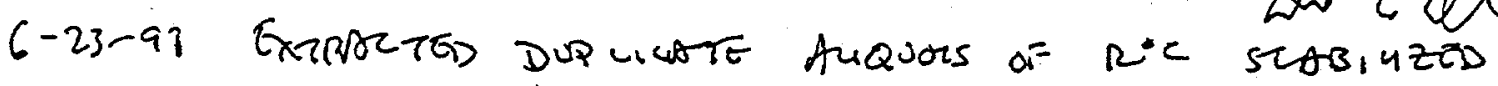

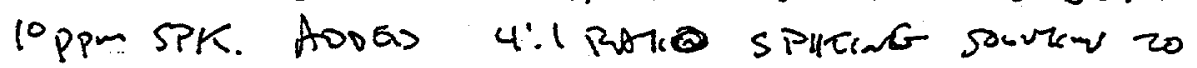

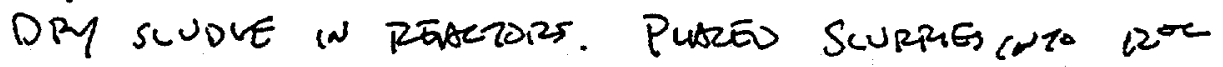
incubator for visit equinballan. SEe aetromic lox.

$$
\text { aletzid } x^{4-23 a 1}
$$

$\mathrm{F}-135$ 
8

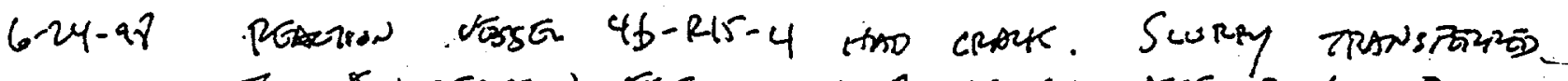

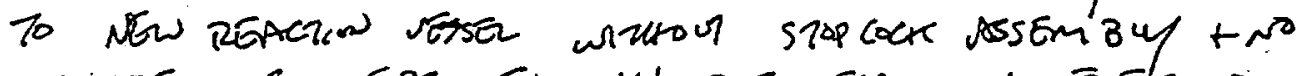

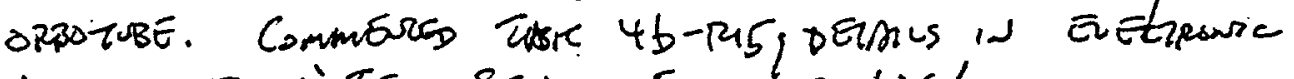

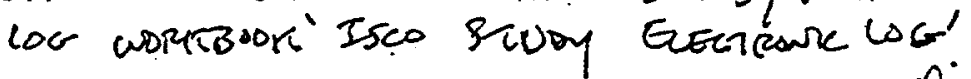

Qitzal $6-24-98$

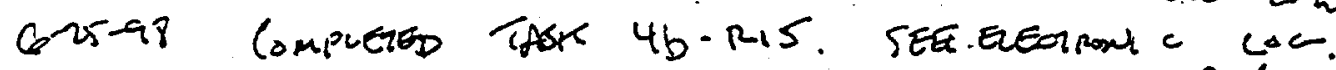

det 2 et $6-2 r-9 \nabla$

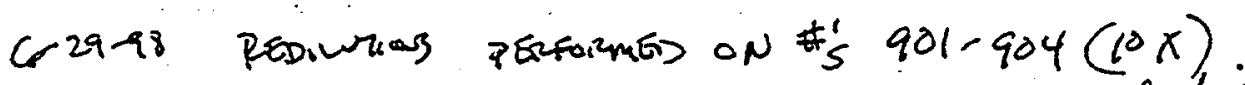

altis at $6-29-98$

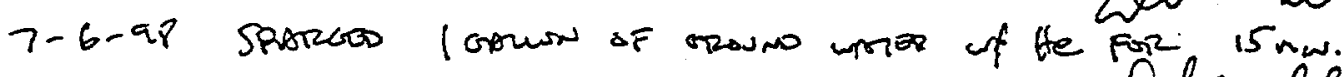

Qhe.elt 7-6-98

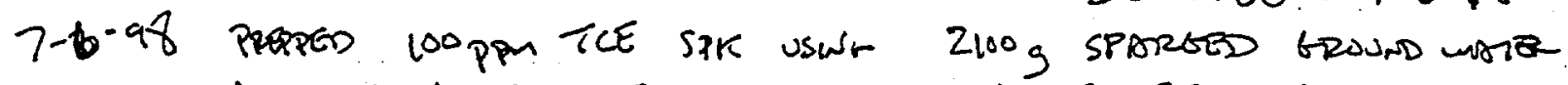

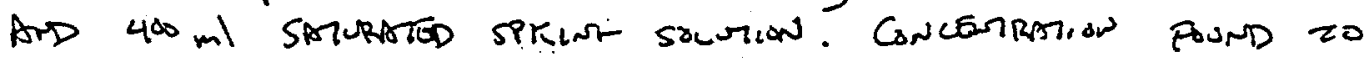

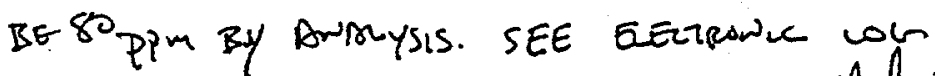

lif 2 it $7-6-98$

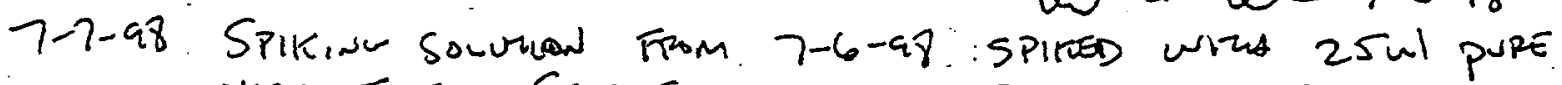

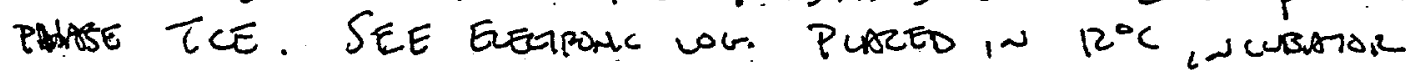
OVERMONA.

lif2 $d t_{7-7-98}$

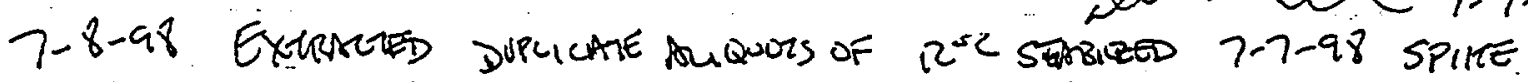

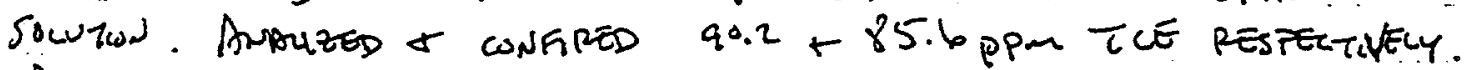

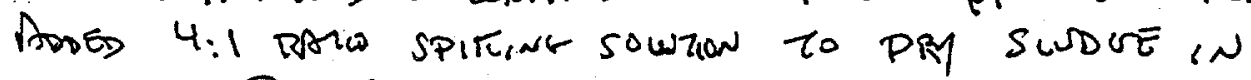

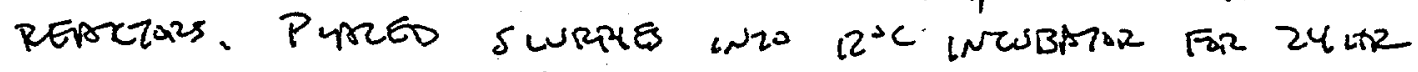

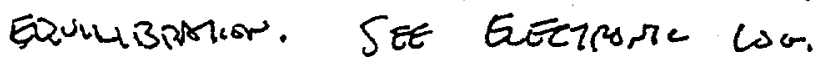

dt2 dt $2-8-28$

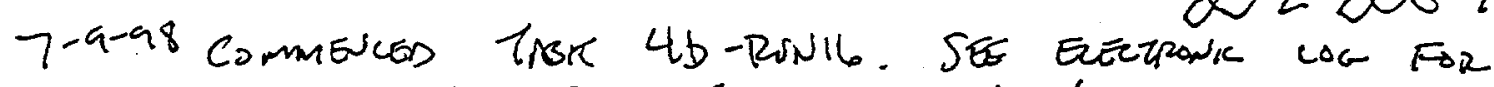

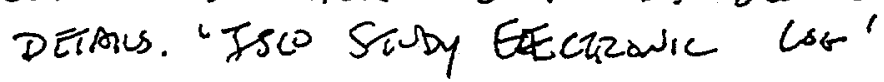

Q42. elt $1-9-96$

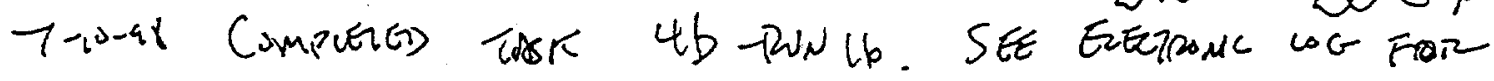
pentics.

7-B-98 DREO 500 s sudtue ( isforos).

Qite dt7-10-28

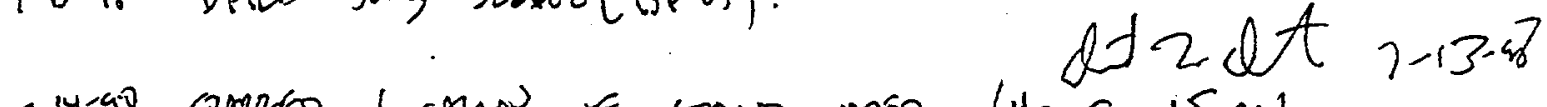

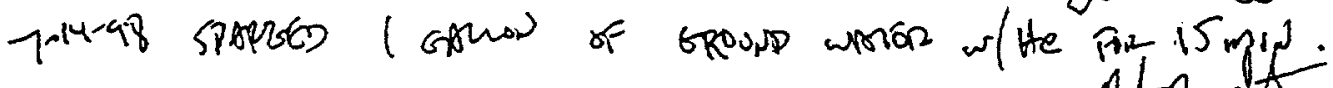

Qted de $7-14,8$

F-136 
9

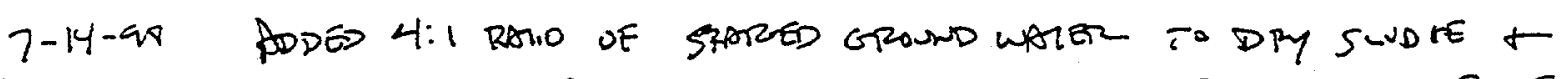

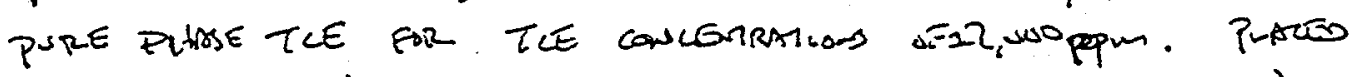

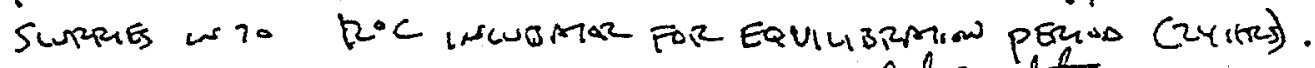
Qf 2. de 7-is-a.8

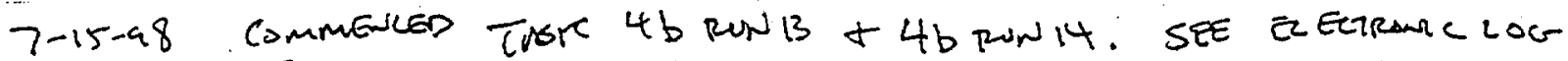

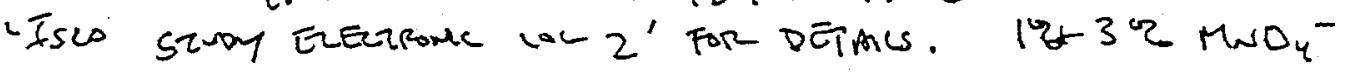

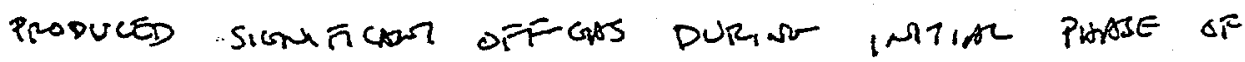
story.

det 2.d $7-15-48$

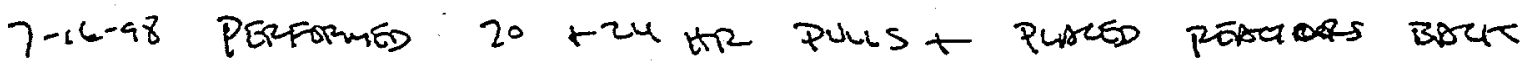
in to $12^{\text {IC }}$ LNCUBMOR. .

Qut2. Dt 7-16-48

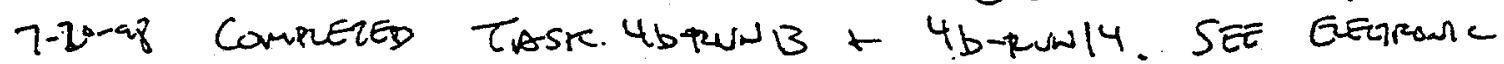

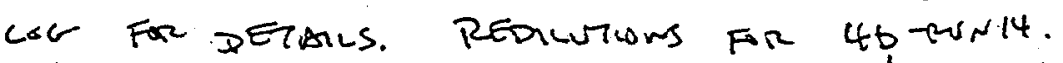

Q 12 d et $7-20-88$ w/ He For 15 min.

ditz et 7-24-68

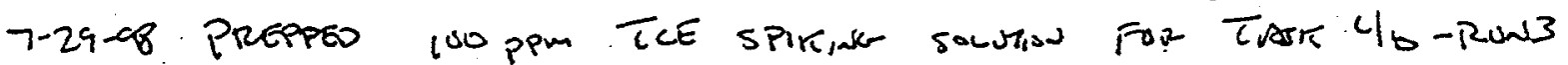

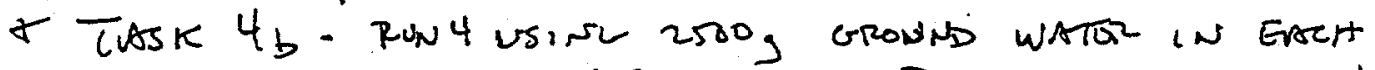
$\& 280$ ul pure phase tele in earh. Placed botit $2500 \mathrm{ml}$ teduar bros in incubarar al $12^{\circ} \mathrm{C}$ arfirninti. Bod

let 2. $d t 7-29-98$

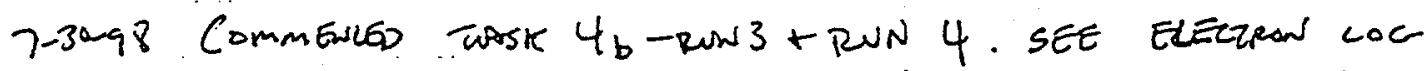

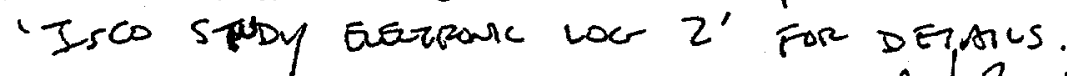

Qut 2 idt $730-98$

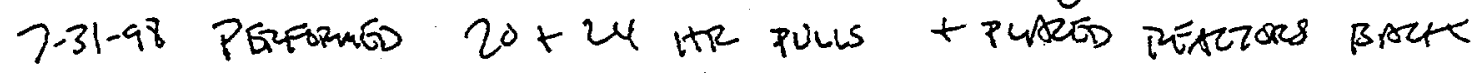

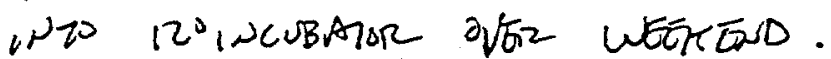

ilt 2 \& $7-31-98$

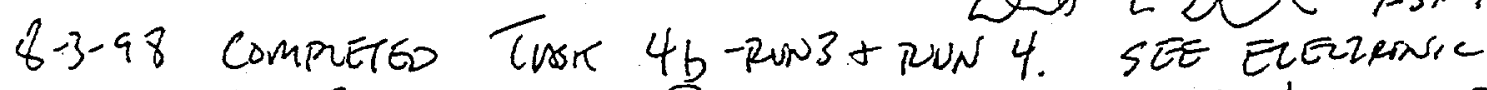

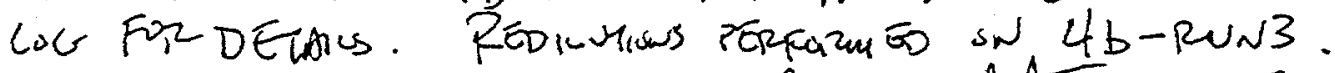

QA 2 \& $8-3-98$

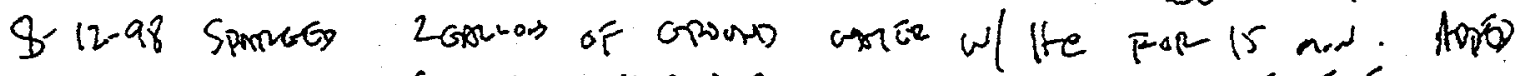

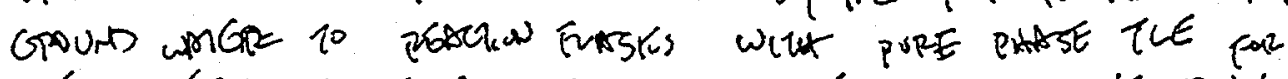

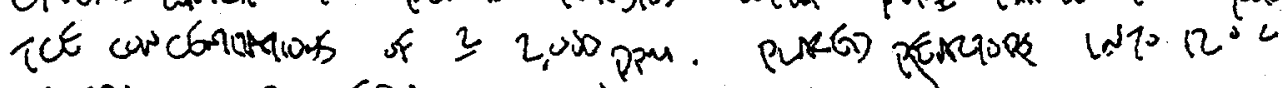

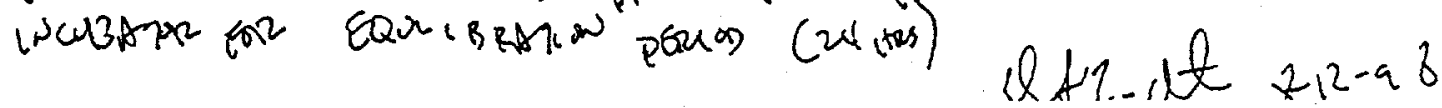

F-137 
10

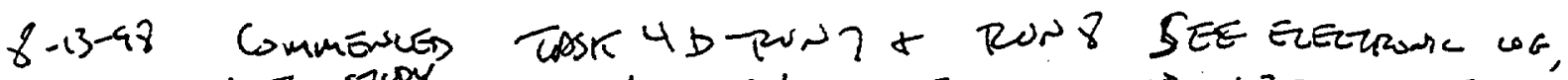

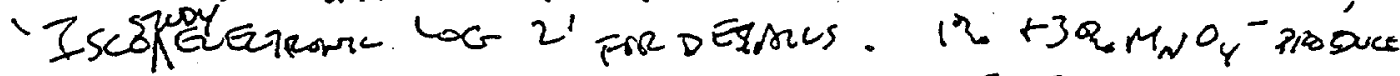

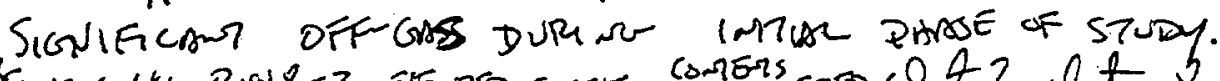

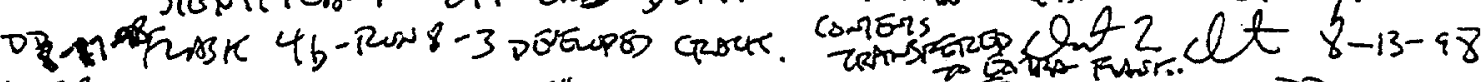

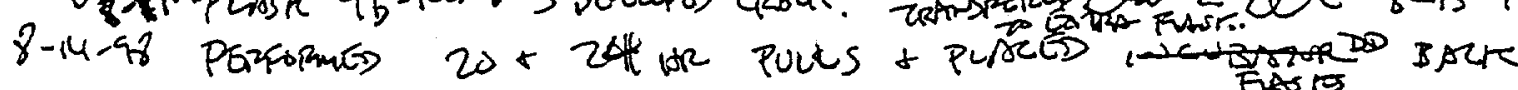

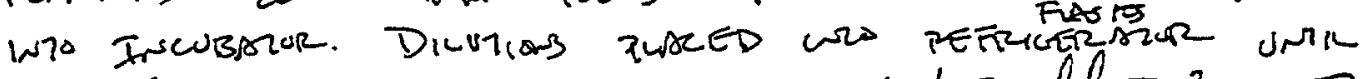
$8-17-98$

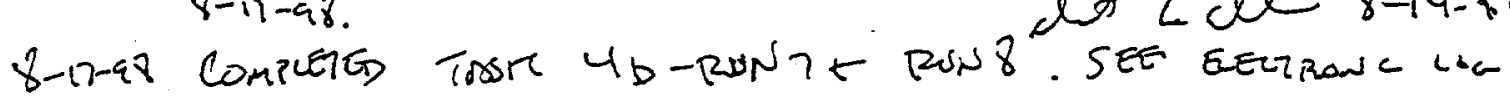
Far DECANGS.

dut 2. de 8-17-48

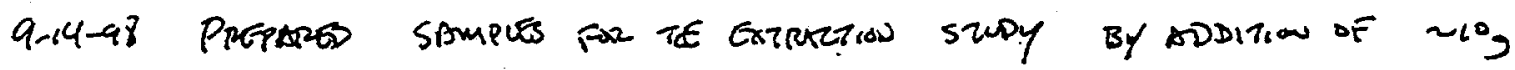

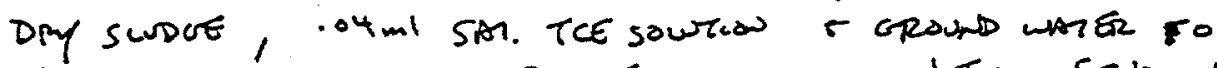

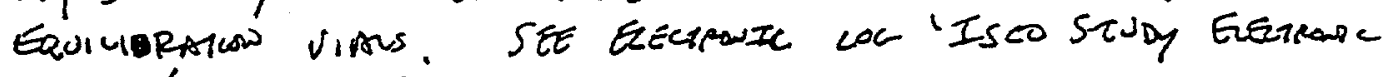
LOE $2^{\prime}$ EOR DETAIUS.

chtzel $q-14-c 8$

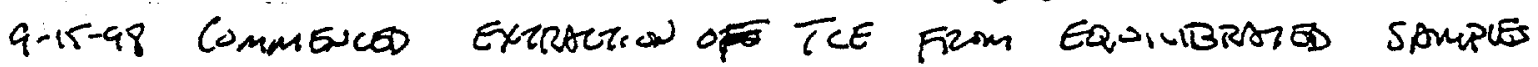

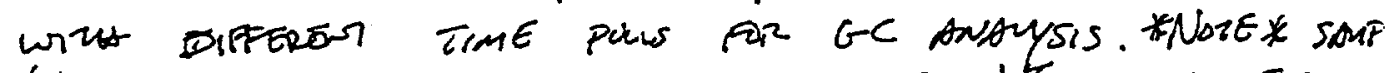

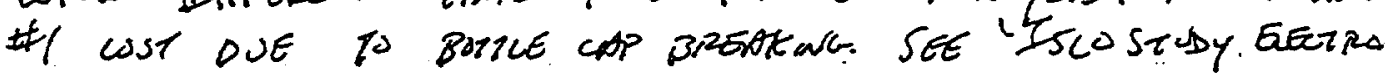
lá 2" For DeTAlus.

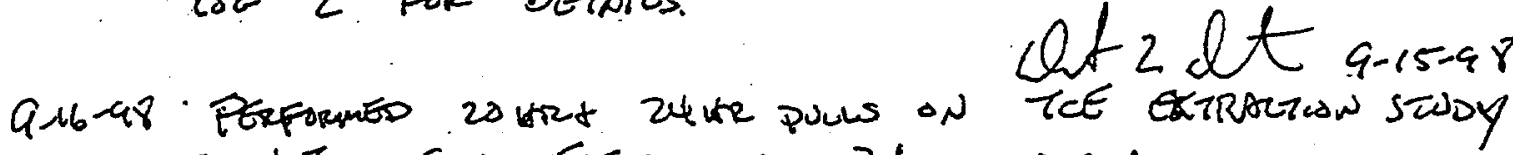
SEE 'ISCO Suby ELETPAalc LOW 2 ' ER DETAUS

out2 elt $9-16-8$

$F-138$ 
2

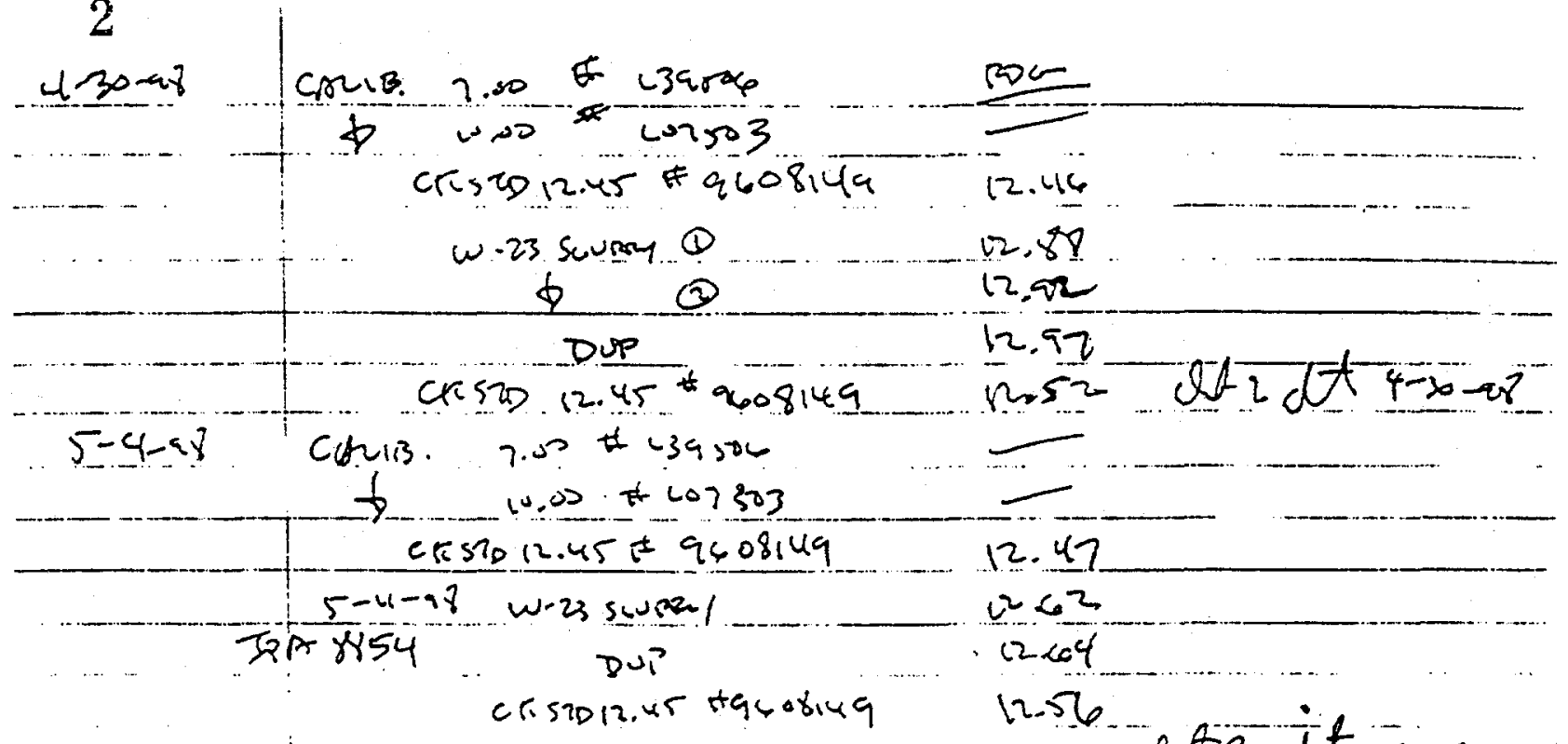

$$
\text { CrSIDizur tagobiug } 1256
$$

$2 t_{2} d t_{54-98}$

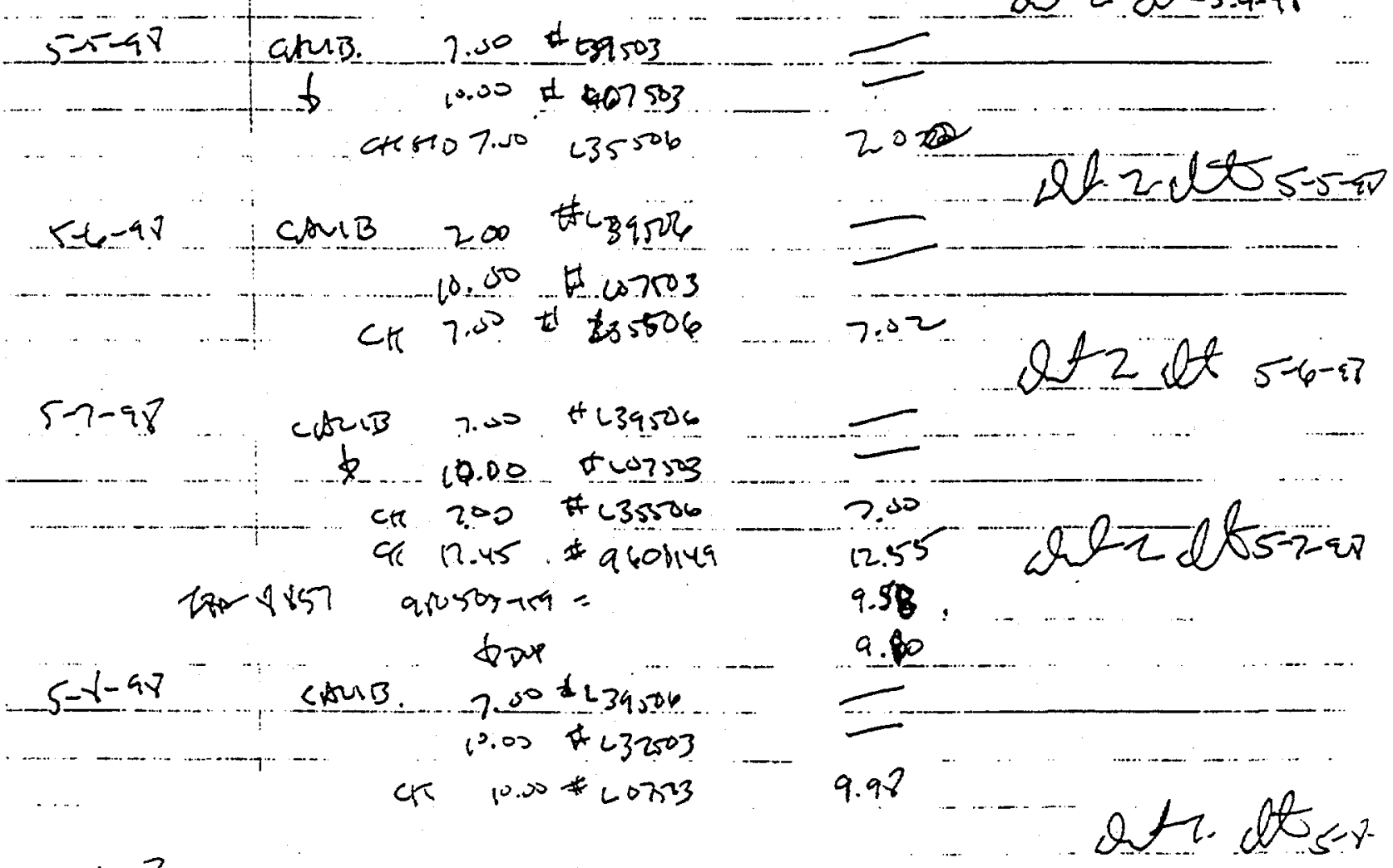

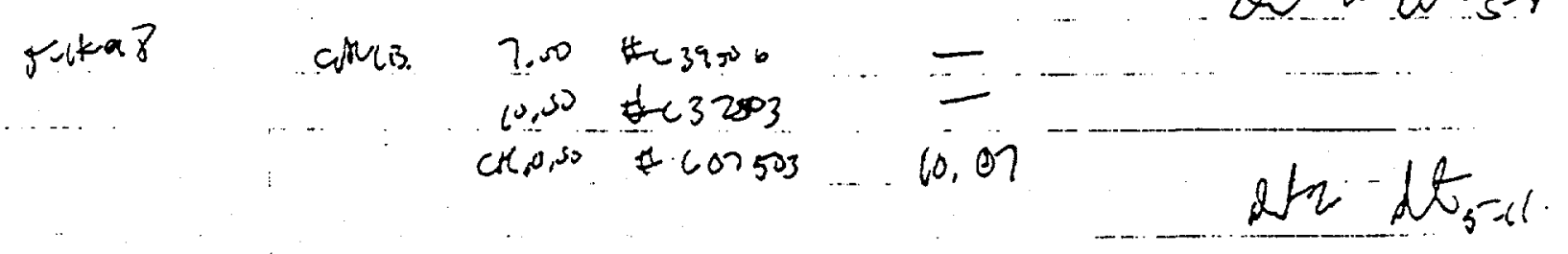

F-139 
3

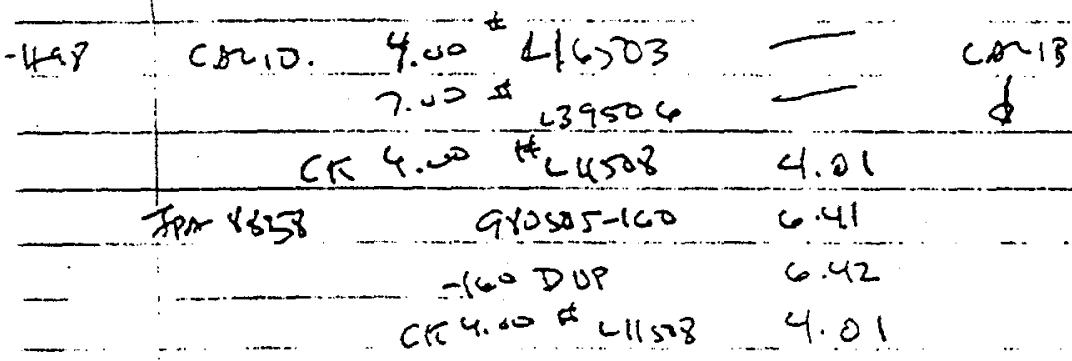

Qtz et $5-11-98$

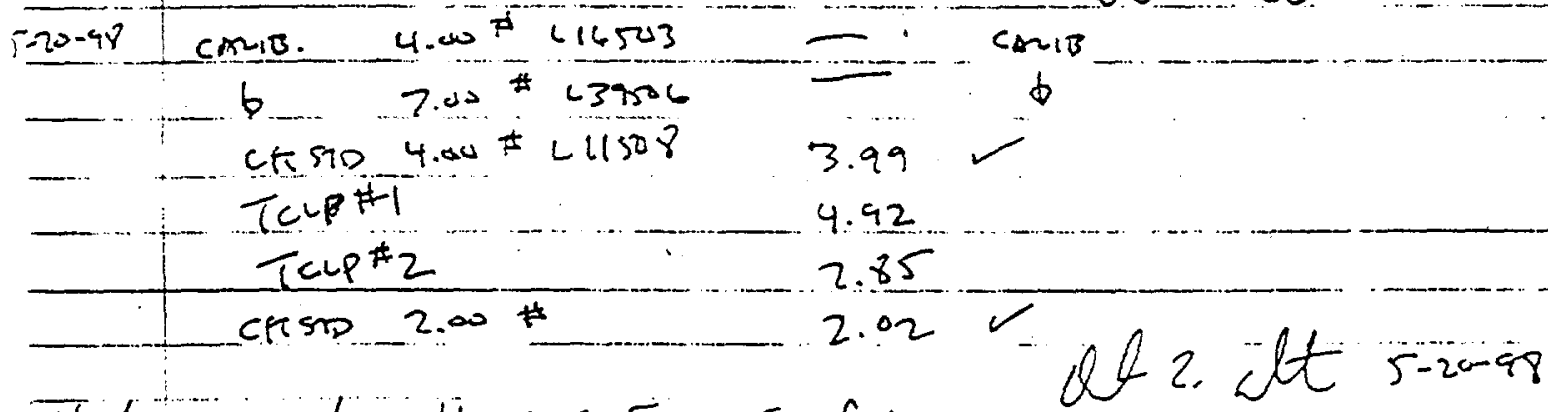

5/21/28 sa-ple pH TosT For TCLP 12

Rerin Cairis -1.37

Resin Anon 2.67

Adeded apropriate volume of IN HCL To each

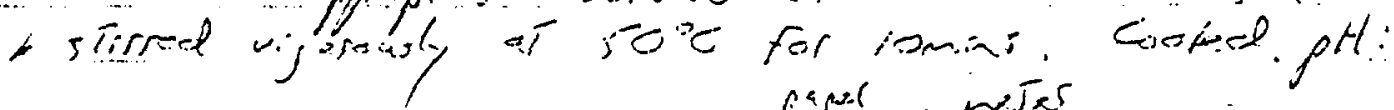

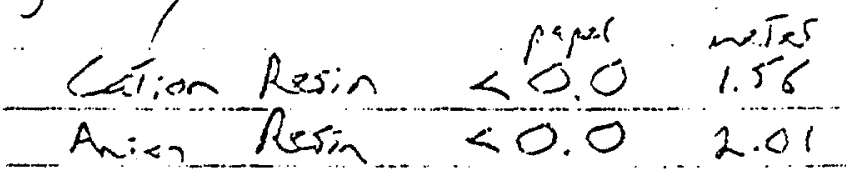

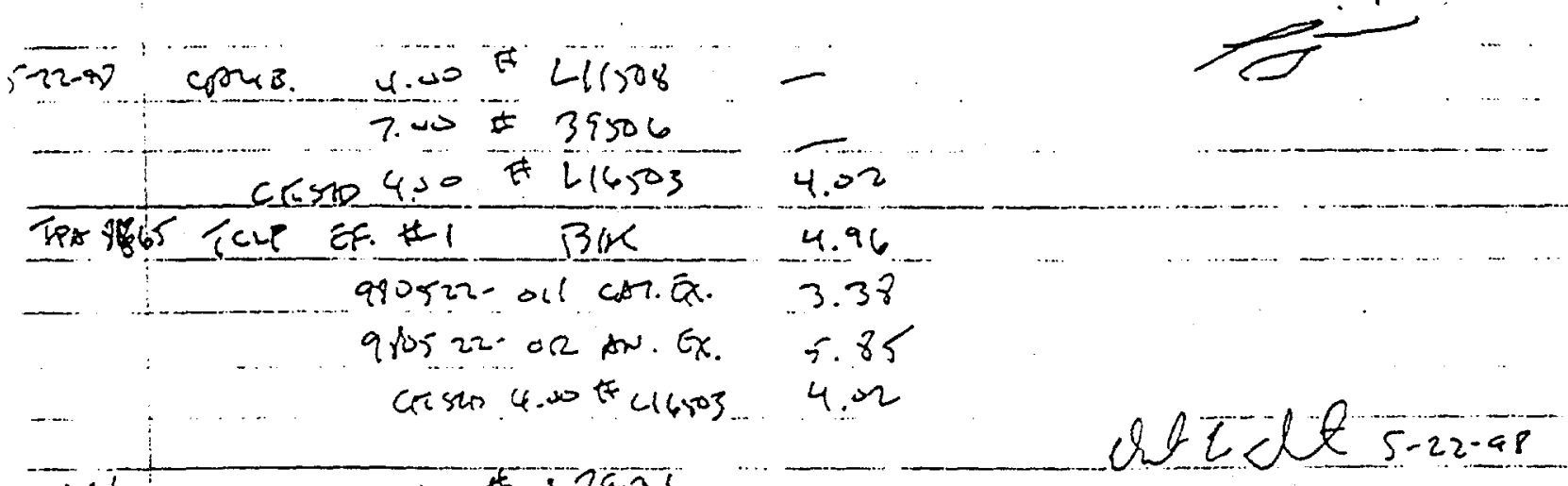

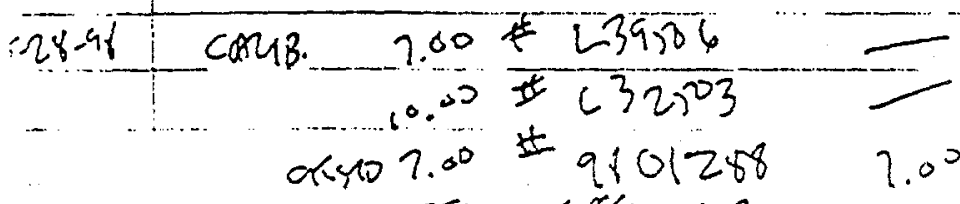

chro 7 .

F-140 


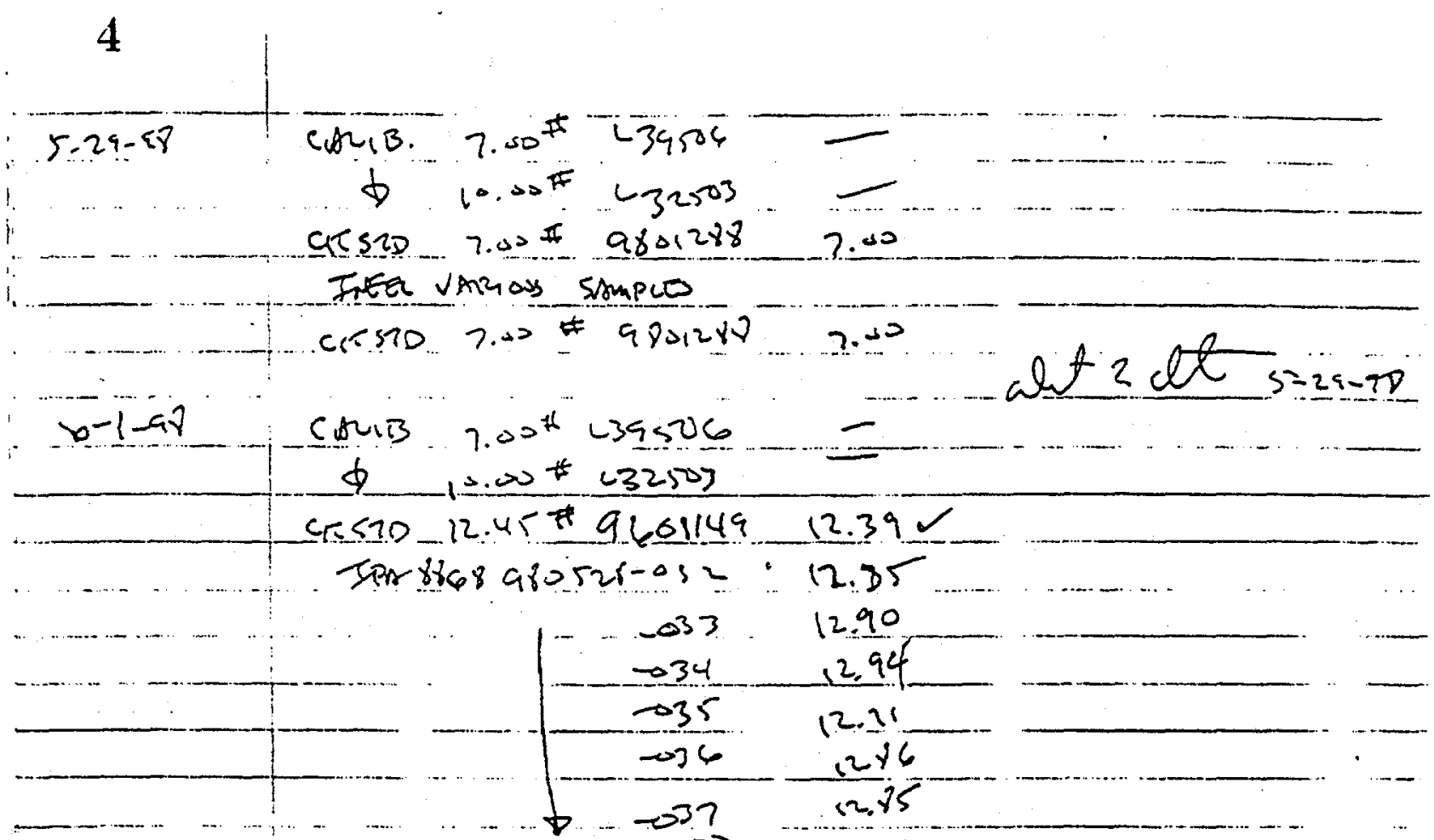

$57 \times 470480524-029$-28 10.37

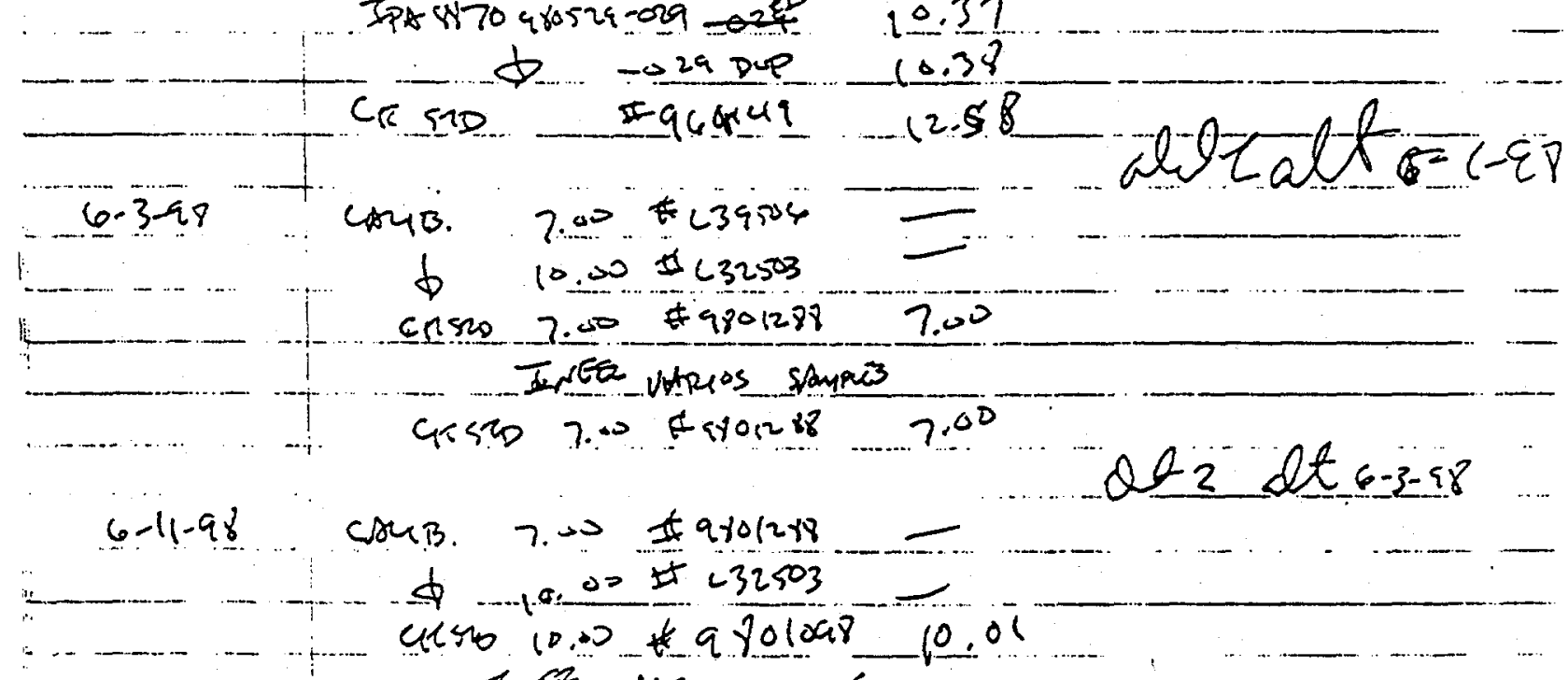

IreEr jaros smaras

cresos lo.os ardogr 10.02

$2 h_{2} d t$ 6.11-9.7

$6-12 ; 2$

$\begin{array}{ll}\text { cpis } & 2.00 \neq 9801288 \\ \phi & 0.00 \neq 032503\end{array}$

o (INEE varioss ssmples)

$10.00+201001.03$

onte et $6-12-48$

F-141 
5

$6-15-48$

Conis 4.00 -1158 -

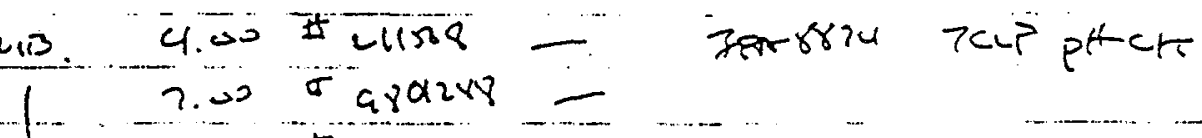

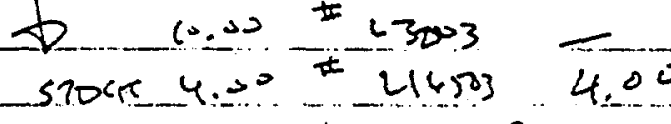

SiDC

$\begin{array}{ll}10.0801098 & 10.02 \\ 980615-0.1 & 8.37\end{array}$

$-1 \frac{32}{-0.3} \quad \frac{8.45}{8.18}$

CKs10 4.00 5ul6o3 4.31

$6-6-490$

$4.00 \div 411508$

$-7.00 \div 880128$

$\operatorname{crs30} 4.00 \# 4165834.00$

Tup Jprsine

$$
980615-1 \ldots .4 .93
$$

Extracis

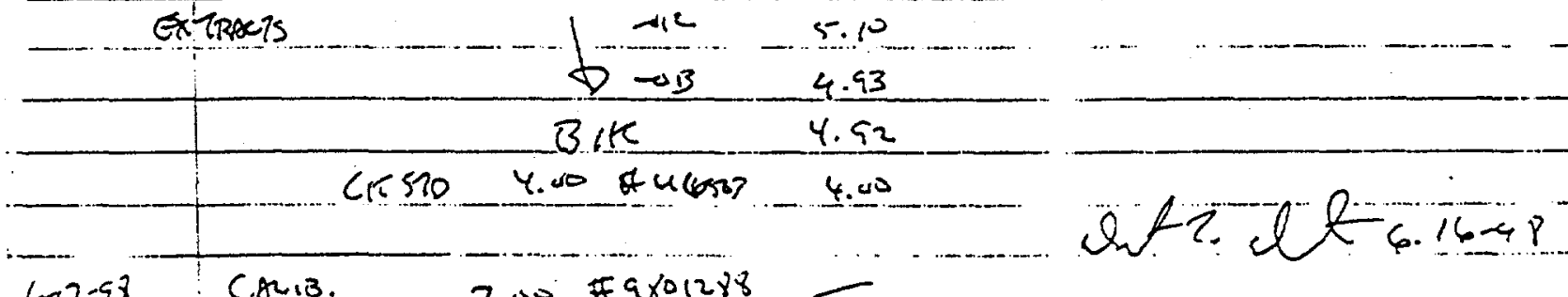

60798 caris.

7. $00 \$ 9801288$

$10.0 \neq 43253$

Crsio10.0) $9801098 \quad 10.00$

(InEe varass simpio).

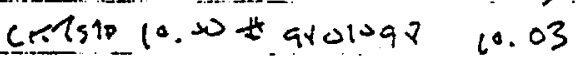

Ql 2: det $61=97$

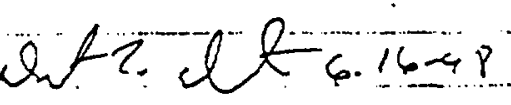

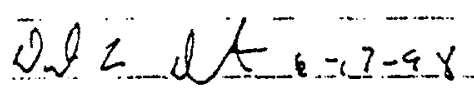

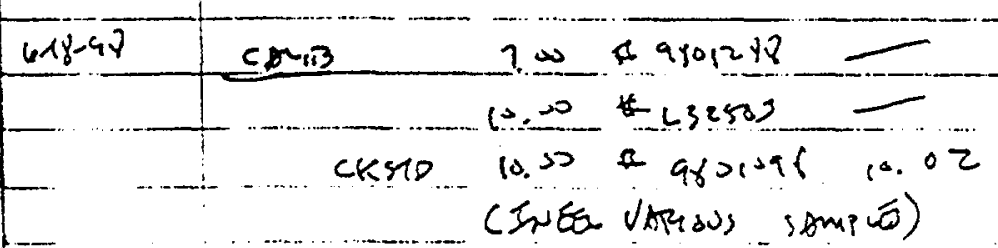

crro $10.00+201099$ 1 03

4.25.98 cBuis

$$
\begin{aligned}
& 1.00+9801287 \\
& 10.00+632983= \\
& 100 * 0101096-10.05
\end{aligned}
$$

at $2 \cdot \operatorname{let} 6-8 \cdot a r$

(UNEC SAMPCE)

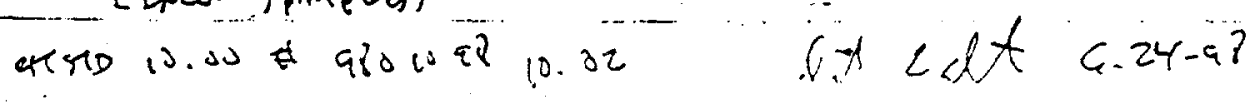

F-142 
6

$$
\begin{aligned}
& \text { d } 10.00^{2}-32503 \\
& \text { crsto 10.05 9801098 10.06 }
\end{aligned}
$$

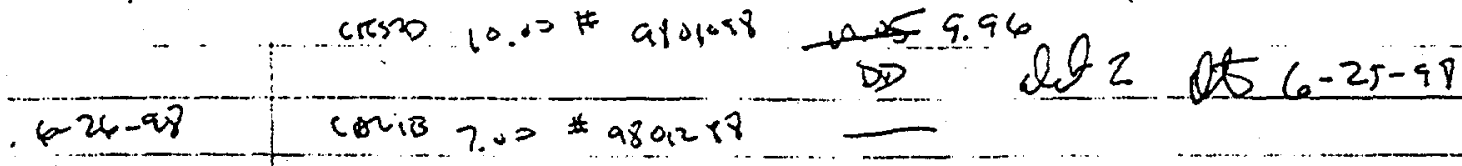

$$
\begin{aligned}
& \$ 10.00 \neq 42503 \\
& 452010.00 \pm 9801098 \quad 10001
\end{aligned}
$$

$980625.011 \quad 12.90$

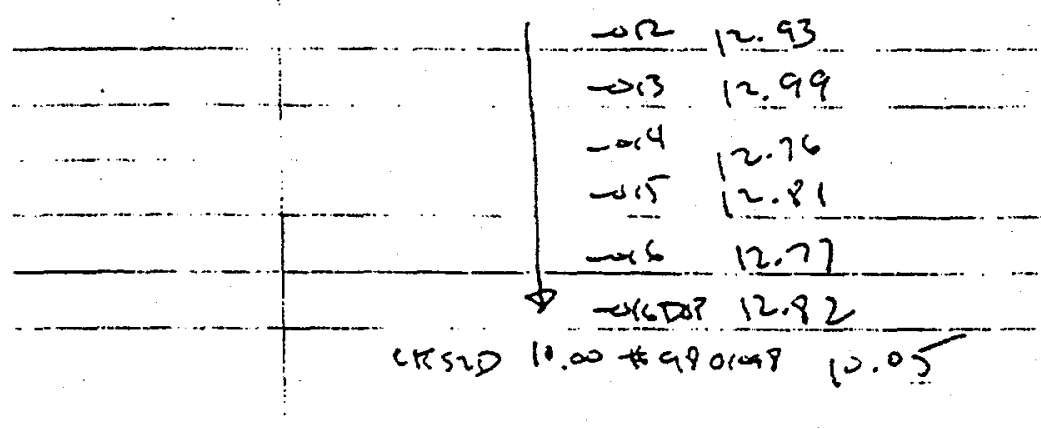

$7-6-a p$

$$
\begin{aligned}
& \text { dfret } 6-2548
\end{aligned}
$$

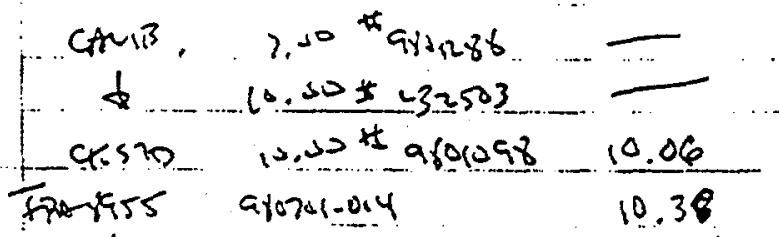$$
\& \quad \text { DOP } 10.07008-10.44
$$$$
\text { CKsid } 10.0 * 97900-10.10
$$

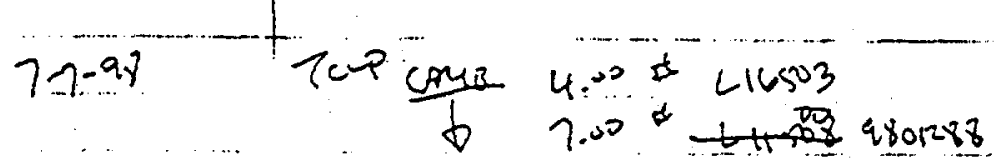

$$
\text { ese ett 7-6-98 }
$$

ceso 4.00465014 .01

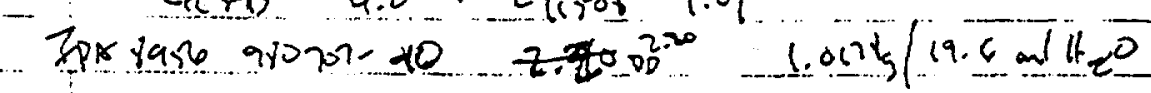
DUP $\quad 2.13$

a.kn $4.00 \mathrm{~F}, 211008 \quad 3.98$

Qf 2 wt 7 ing

$.7 x-4$

$$
\begin{aligned}
& \text { crus } 400 \text { * } 4605 \\
& \text { 6 } 7.00 \div 960248
\end{aligned}
$$

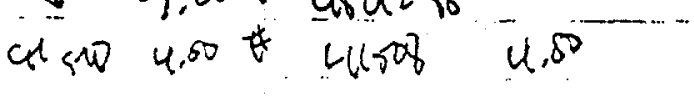

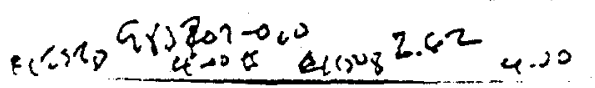

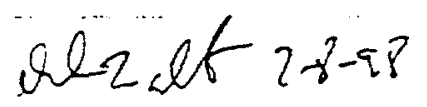

$F-143$ 
7

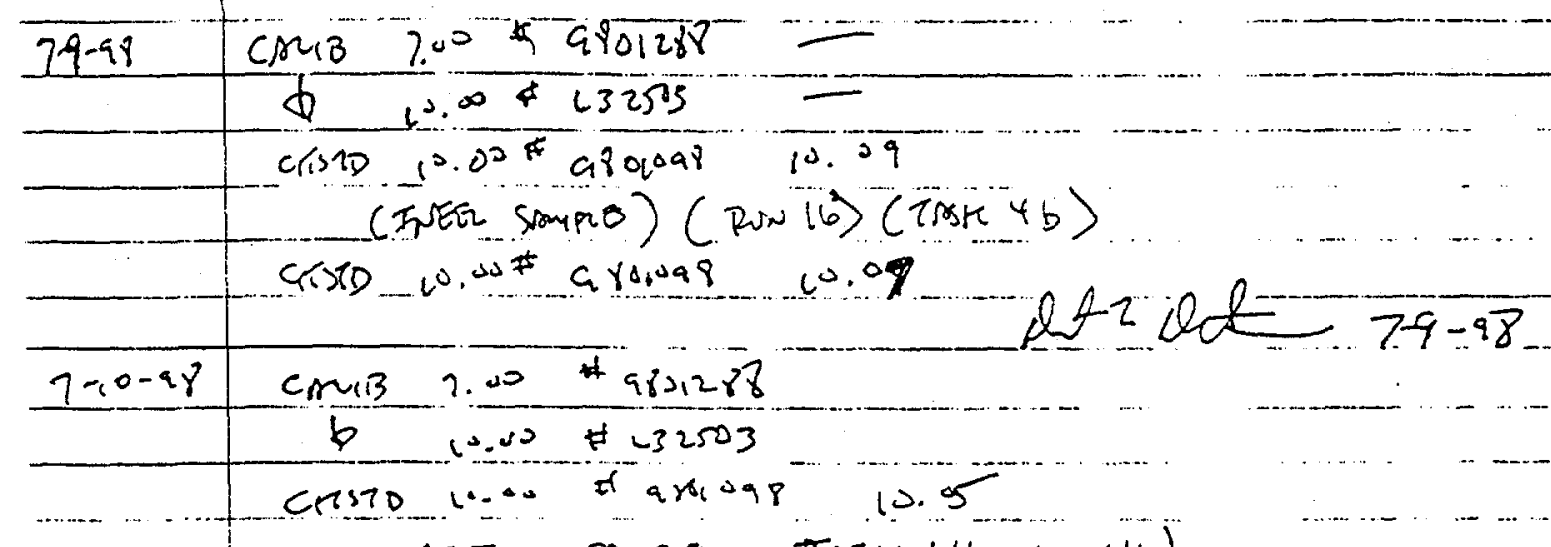

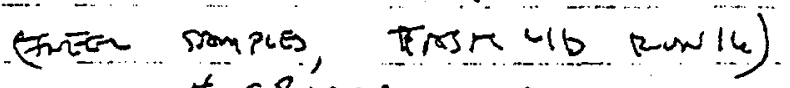

CKistD 10.00 t a a d 0al 10.00

ob zelt $7=0-99$

$7=1548 \quad \cos 13-0.00 \times 980288$

$$
\begin{aligned}
& \text { b... } 10.0 \quad 132533 .
\end{aligned}
$$

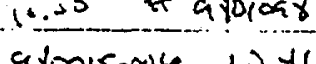

cessin

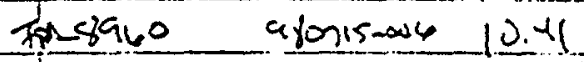

$\int_{-\infty 0729.1048007}^{-\infty}$

(Jren simpus 2,000106 )

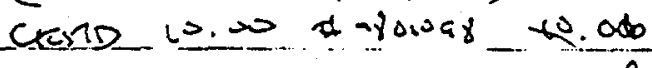

$$
\frac{d x}{d t} d t=7-98
$$

$7=1640$ cons $7.00+480268$

$$
6=-[00 * 0.0603
$$

46320 10.0 \& a9010al (10.0?

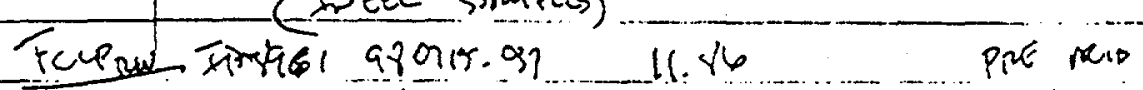

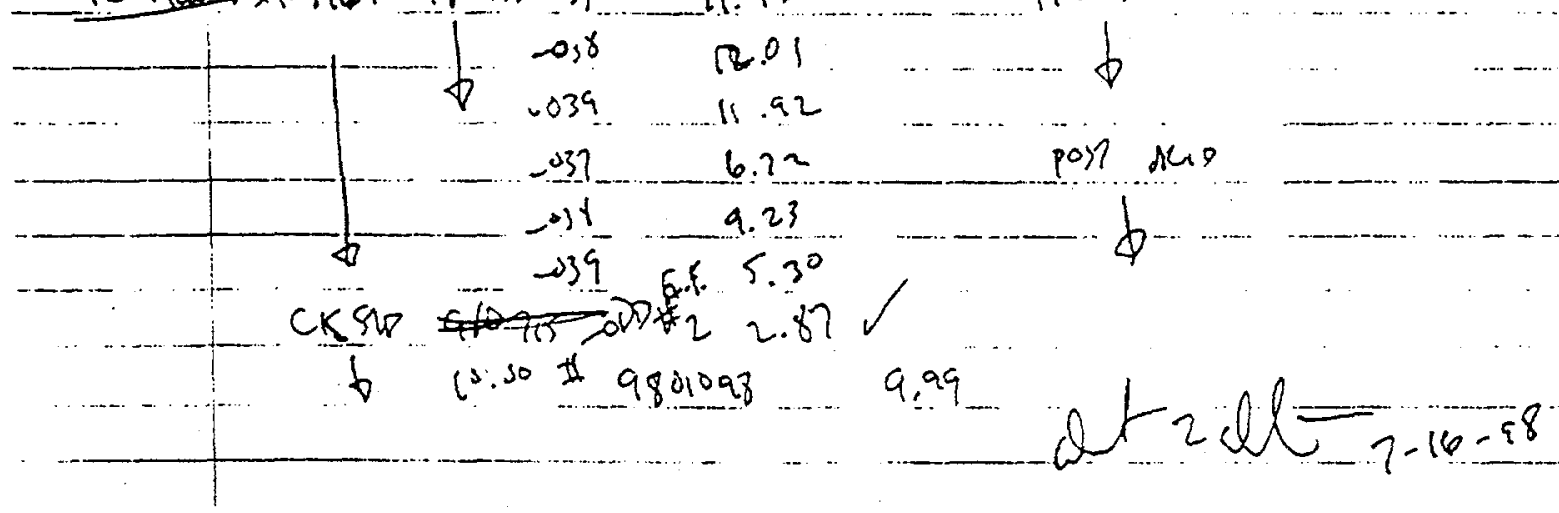

F-144 


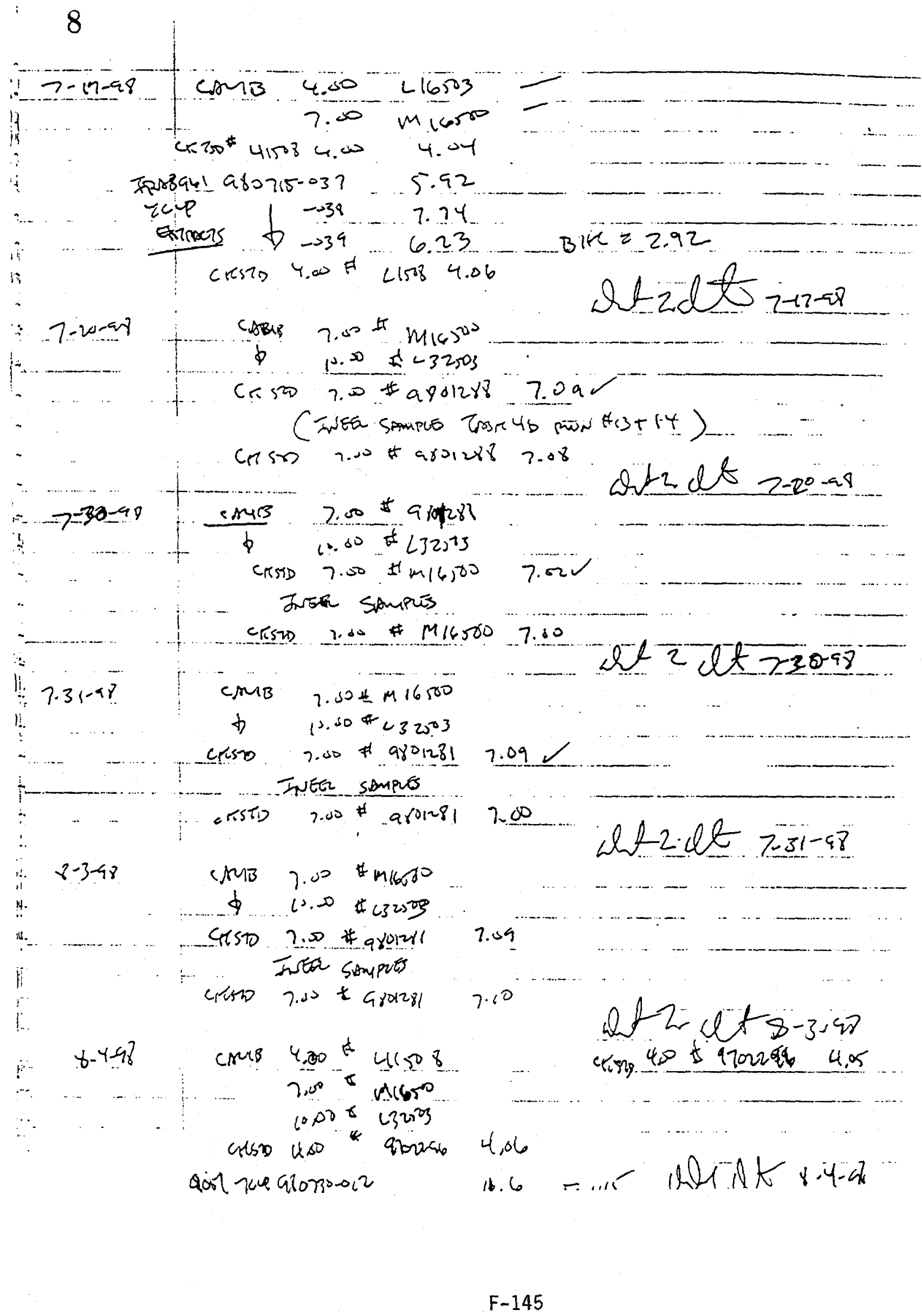


9

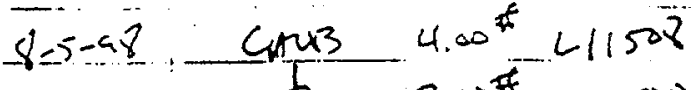

$$
\begin{aligned}
& \text { - } \frac{\Phi}{\cos 10} 4.00 \pi^{m} \operatorname{mos} 00
\end{aligned}
$$

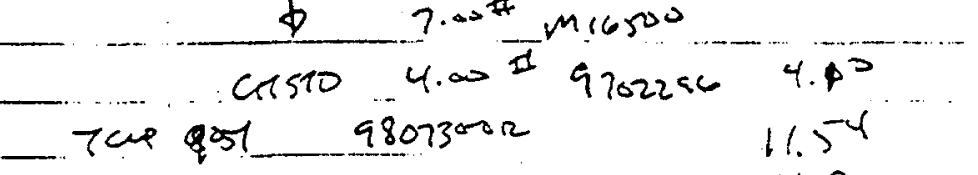

$$
\begin{aligned}
& 11.5^{-4}
\end{aligned}
$$

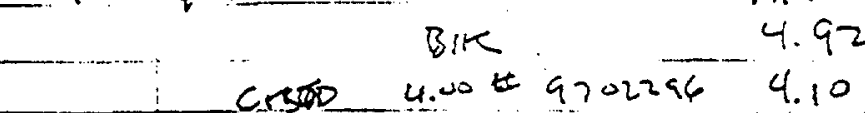

$$
\begin{aligned}
& \text { cisig } 7.0^{4} \operatorname{mis}, 00 \\
& \text { b } 0.00 \text { F } 132503
\end{aligned}
$$

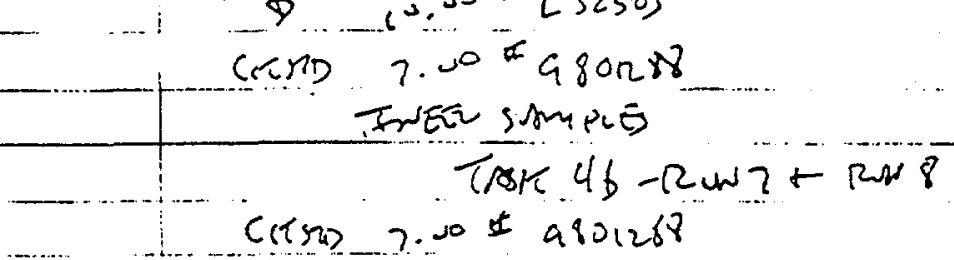

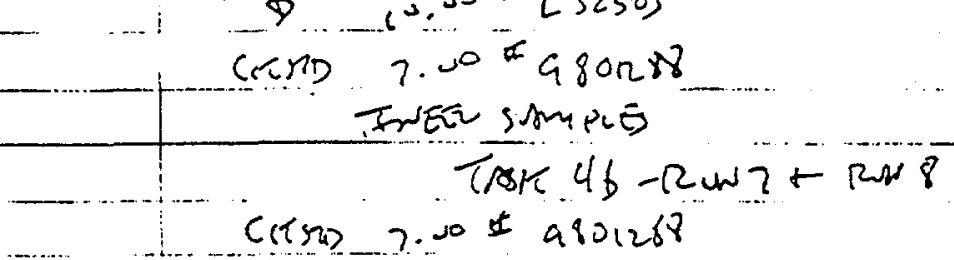

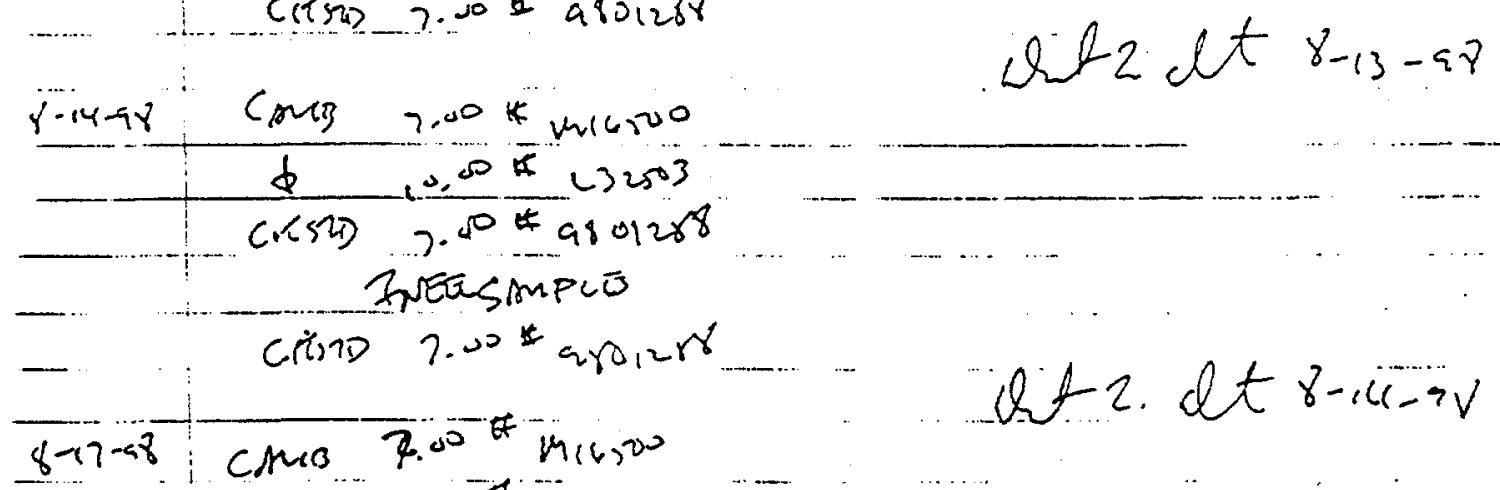

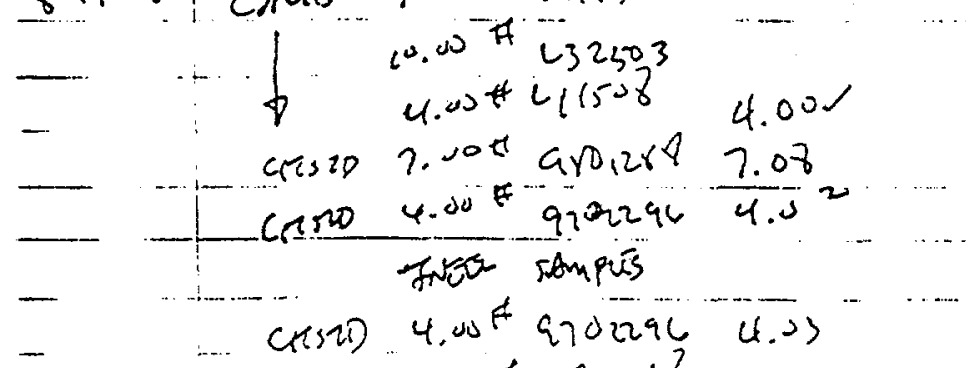

C(rin) 20004 ab1288 7.09

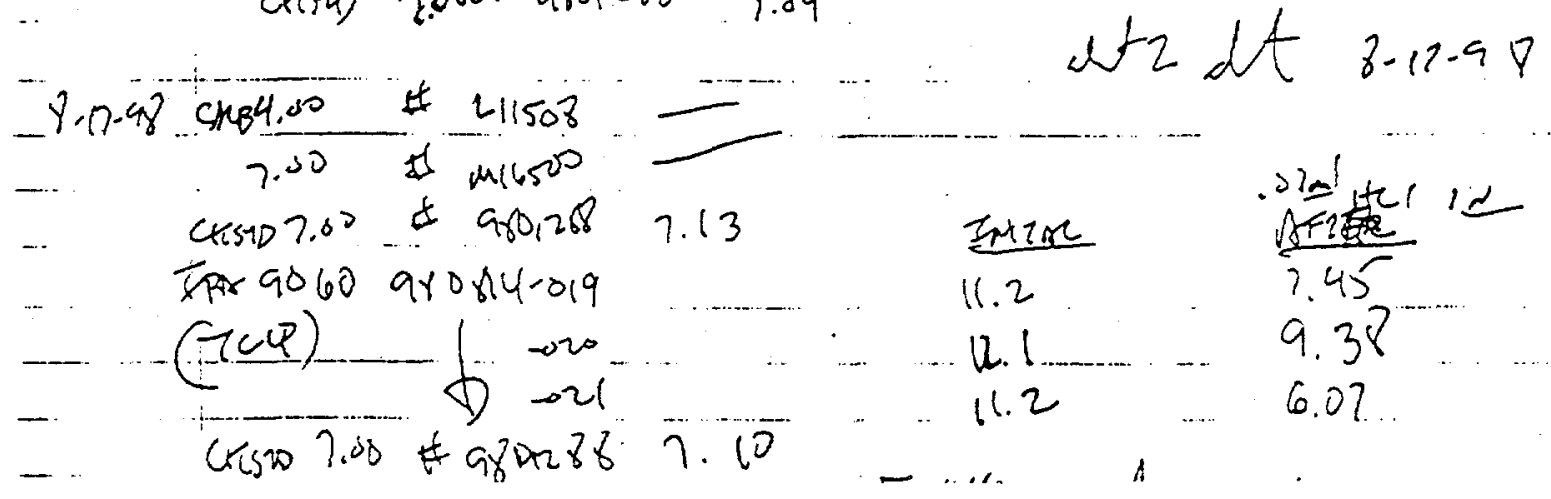

F-146 


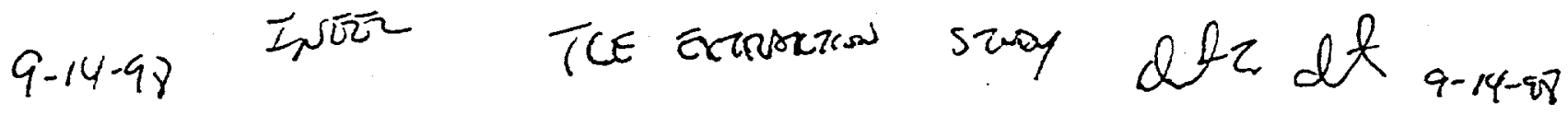

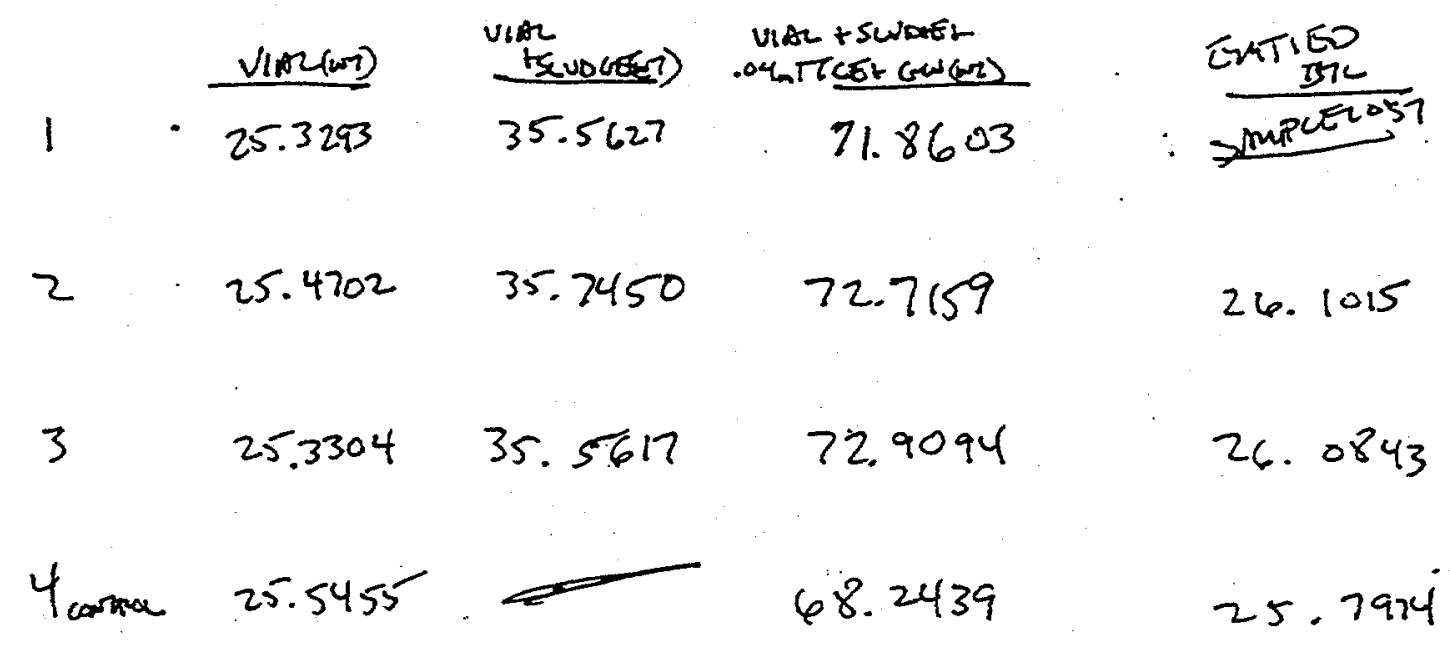

$9-15-98$ Extrsection

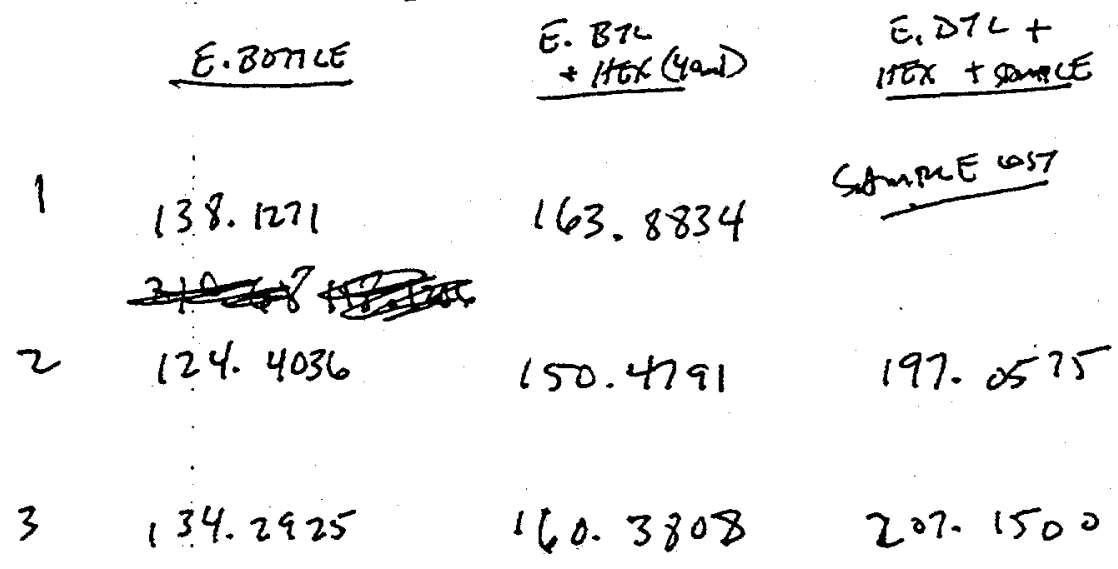

4 coner B.8. $1266 \quad 164.2141 \quad 2.66 .6300$

$F-147$ 


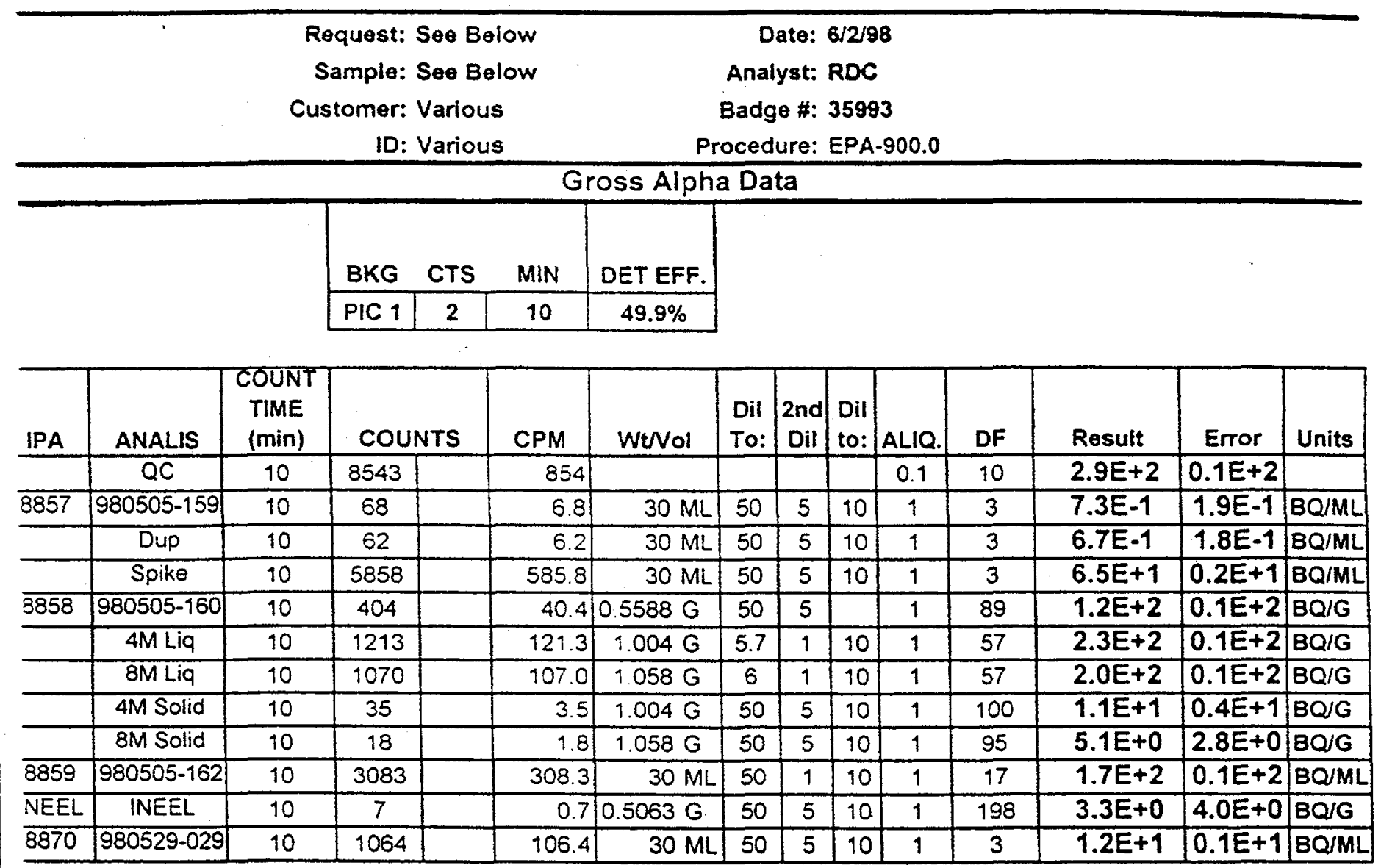

COPY

\begin{tabular}{c|c|c|c|c|c|}
\hline $\begin{array}{c}\text { Ontrol } \\
\text { ID }\end{array}$ & $\begin{array}{c}\text { Measured } \\
\text { Value }\end{array}$ & $\begin{array}{c}\text { Known } \\
\text { Value }\end{array}$ & $\%$ Diff & Units & Instrument ID \\
\hline 1897 & $2.9 \mathrm{E}+2$ & $2.74 \mathrm{E}+2$ & 5.8 & $\mathrm{~Bq} / \mathrm{ml}$ & PIC 9400 \\
\hline
\end{tabular}

Orginal Fred With IPA 885 ?

Reviewed by:

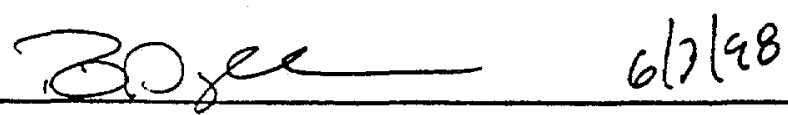

Approved by:

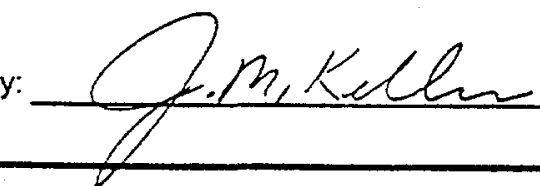


Radioactive Materials Analytical Laboratory

Inorganic Chemistry Worksheet

Request: IPA8858; INEEL

Sample: 980505-160; See Below

Customer: Sears; INEEL

ID: W-16-S1; INEELTask 3B
Date: $5 / 13 / 98$

Analyst: DD

8adge \#: 33952

Procedure:

Carbon Data

\begin{tabular}{|c|c|c|}
\hline tion & ges & STD $\% C$ \\
\hline TC & $\mathrm{J12782}$ & \\
\hline & & 36.33 \\
\hline IC & M5G9187 & 11.32 \\
\hline
\end{tabular}

\begin{tabular}{|c|c|c|c|c|c|c|c|c|}
\hline \multirow[b]{2}{*}{ IPA } & & \multicolumn{2}{|c|}{ Total Carbon \% } & \multicolumn{2}{|c|}{ Inorganic Carbon \% } & \multicolumn{2}{|c|}{ TOC $\%$} & \multirow{2}{*}{$\begin{array}{c}\text { STD } \\
\% \text { Rec. } \\
\end{array}$} \\
\hline & Sample & Result & Error & Result & Error & Result & Error & \\
\hline TC Sid & $\sqrt{12782}$ & 36.05 & 3.605 & & & $2 \ldots$ & 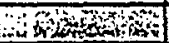 & $99 \%$ \\
\hline IC Std & M5G9187 & 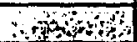 & 6row & 10.79 & 1.079 & $2+3$ & byan & $95 \%$ \\
\hline 8858 & $980505-160$ & 0.95 & 0.095 & 0.443 & 0.0443 & 0.507 & 0.0507 & \\
\hline & INEEL Dry & 8.11 & 0.811 & 1.44 & 0.144 & 6.67 & 0.667 & \\
\hline & $3 b-R 1-3$ & 4.89 & 0.489 & 1.47 & 0.147 & 3.42 & 0.342 & \\
\hline & $3 b-R 1-4$ & 3.83 & 0.383 & 1.19 & 0.119 & 2.64 & 0.264 & \\
\hline & $3 b-R 2-3$ & 3.04 & 0.304 & 0.673 & 0.0673 & 2.367 & 0.2367 & \\
\hline & $3 b-R 2-4$ & 2.42 & 0.242 & 1.12 & 0.112 & 1.3 & 0.13 & \\
\hline & $3 b-R \cdot 3-3$ & 1.75 & 0.175 & 0.835 & 0.0835 & 0.915 & 0.0915 & \\
\hline & $3 b-R 3-4$ & 2.29 & 0.229 & 2.26 & 0.226 & 0.03 & 0.003 & \\
\hline & $3 b-R 4-3$ & 1.35 & 0.135 & 0.474 & 0.0474 & 0.876 & 0.0876 & \\
\hline & $3 b-R 4-4$ & 1.51 & 0.151 & 0.406 & 0.0406 & 1.104 & 0.1104 & \\
\hline IC Std & M5G9187 & 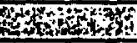 & Henky & 9.73 & 0.973 & 20 & Wostomistis & $86 \%$ \\
\hline TC Std & $\sqrt{12782}$ & 31.39 & 3.139 & 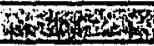 & - & 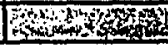 & 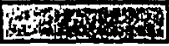 & $86 \%$ \\
\hline
\end{tabular}

Comments:

\section{COPY}
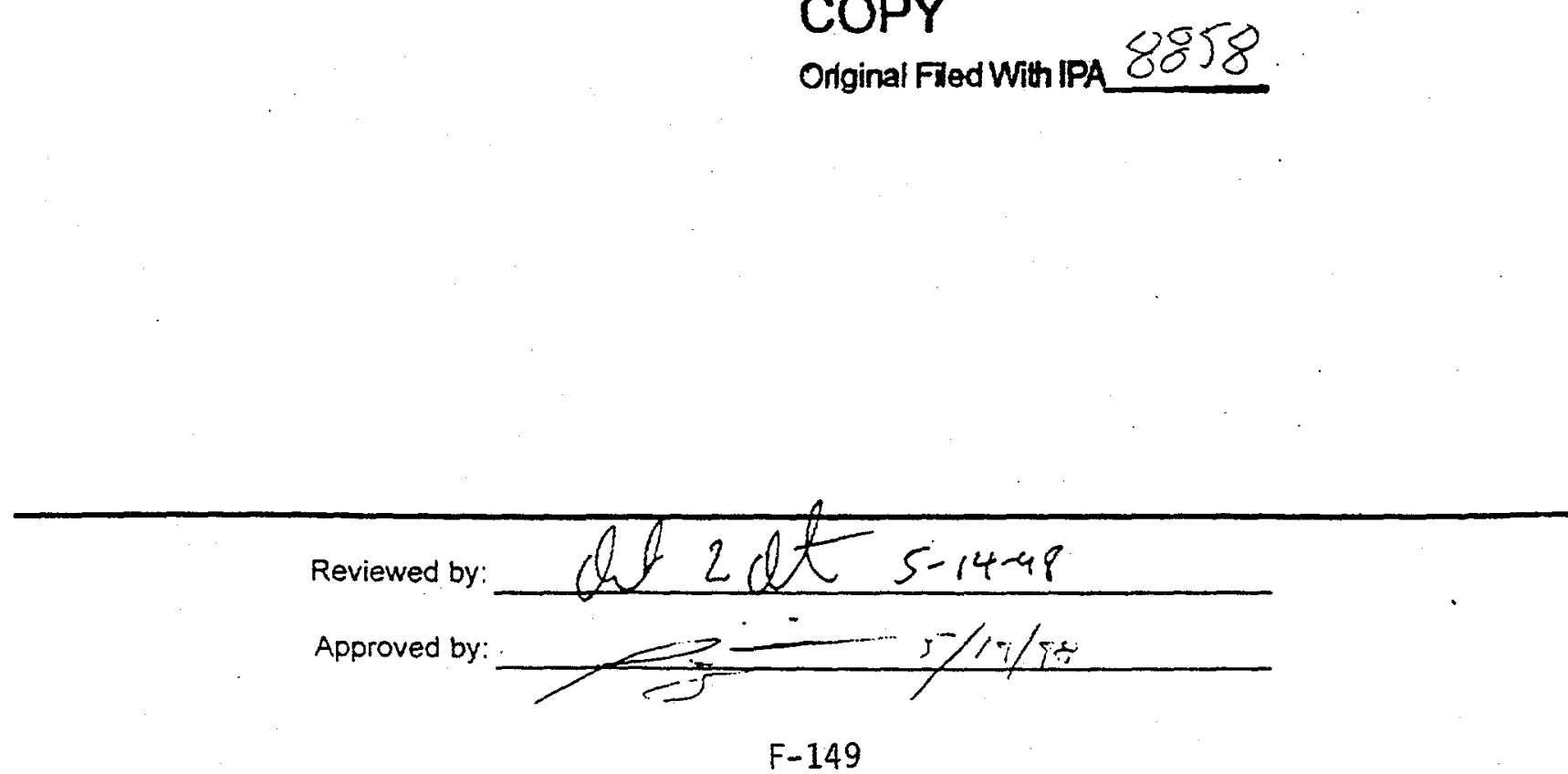


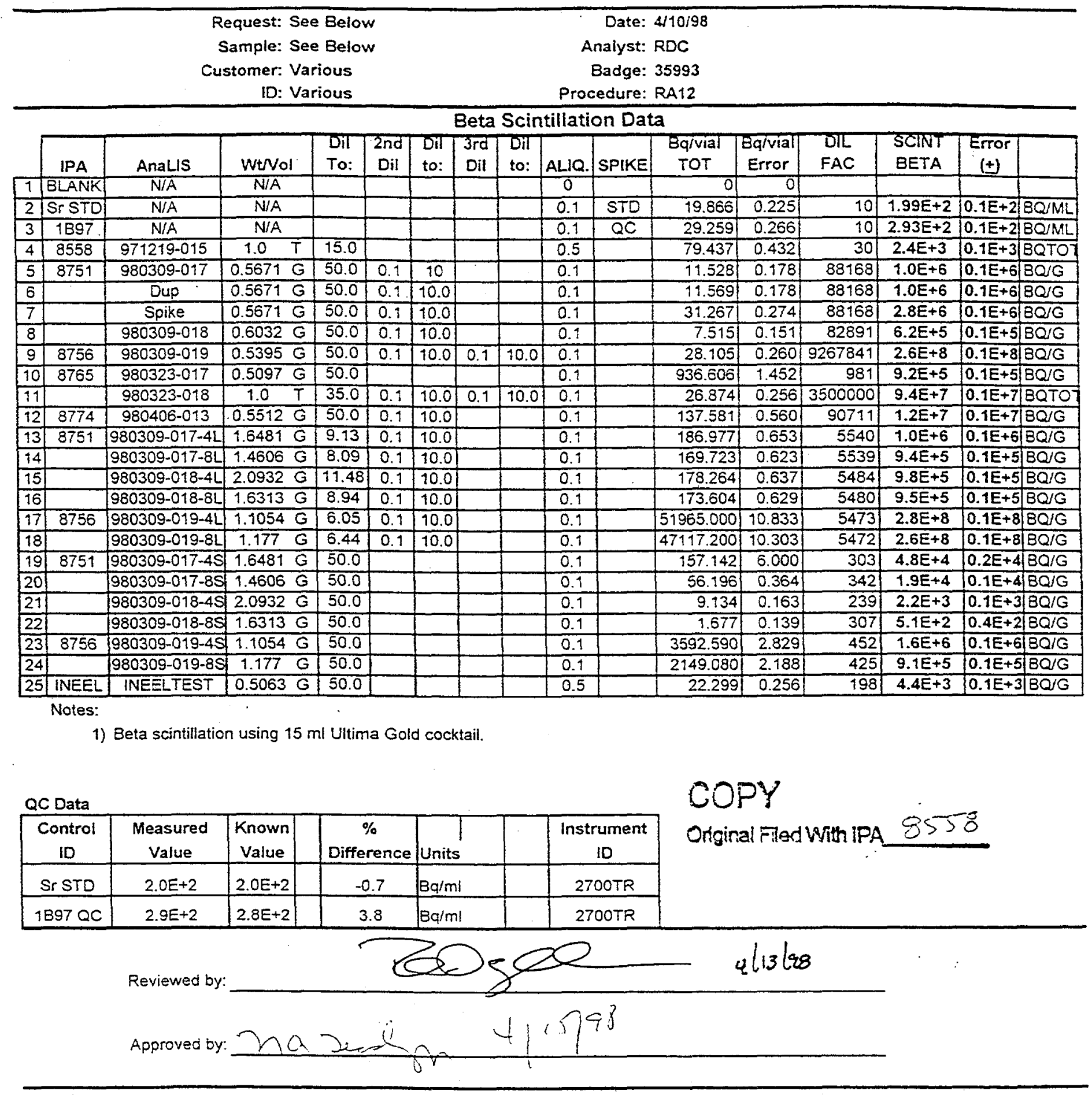




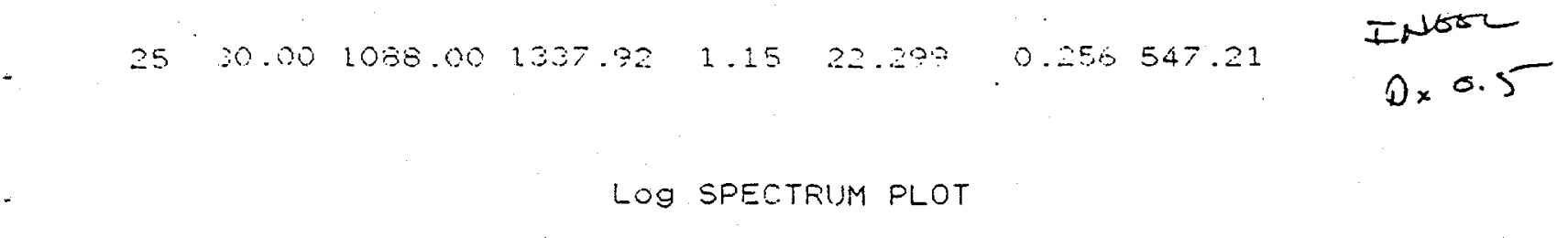

$\because 71.5$ Y Log maximum Protocol No. 60 Sample No. 25 Repeat 1

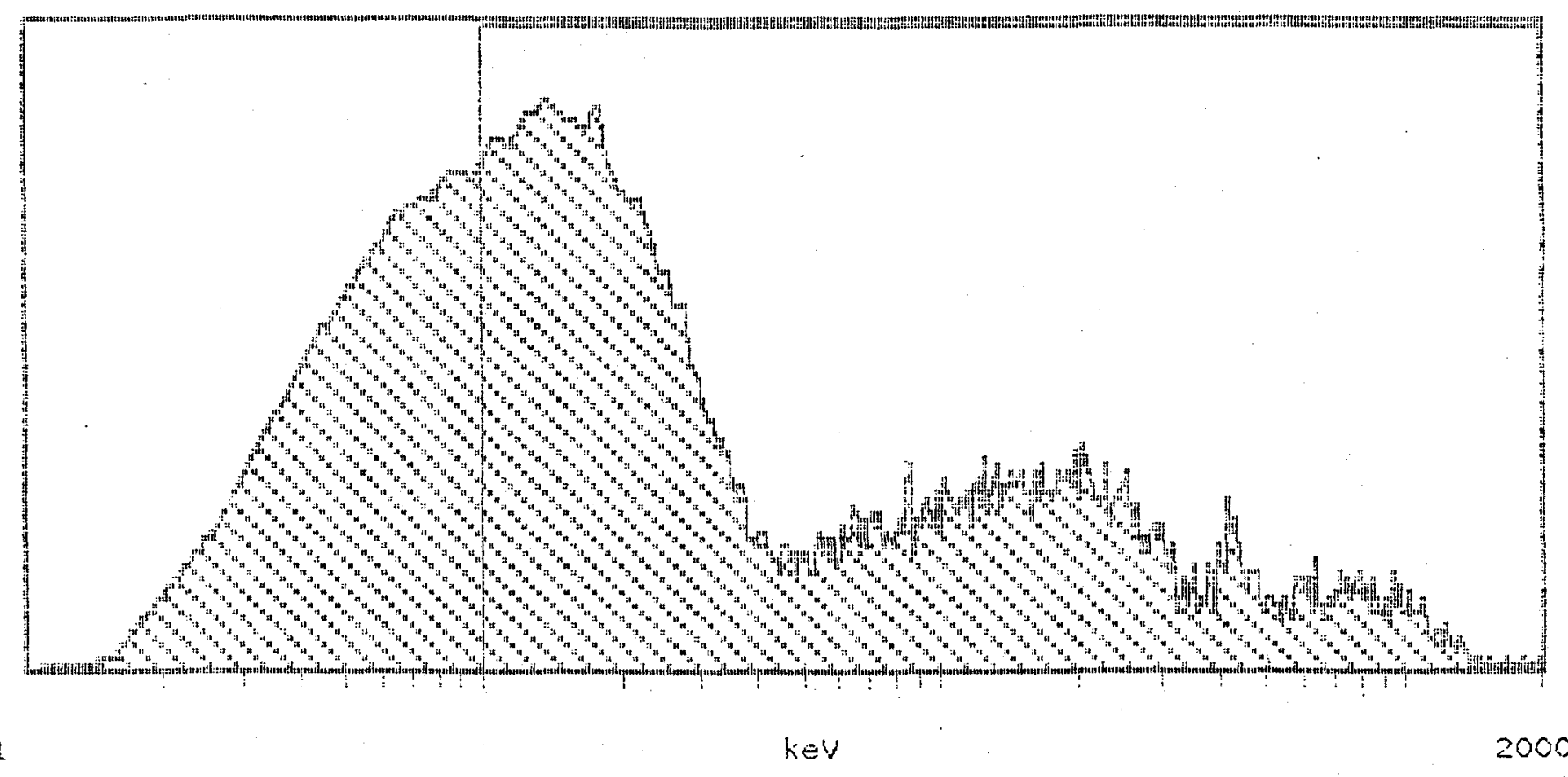

\begin{tabular}{cccc} 
Begion & LL & \multicolumn{1}{c}{ UL } & \multicolumn{1}{c}{ CPM } \\
$A:$ & 0.0 & 2000 & 1130.4 \\
$B:$ & 0.0 & 0.0 & 0.0 \\
C: & 0.0 & 0.0 & 0.0
\end{tabular}




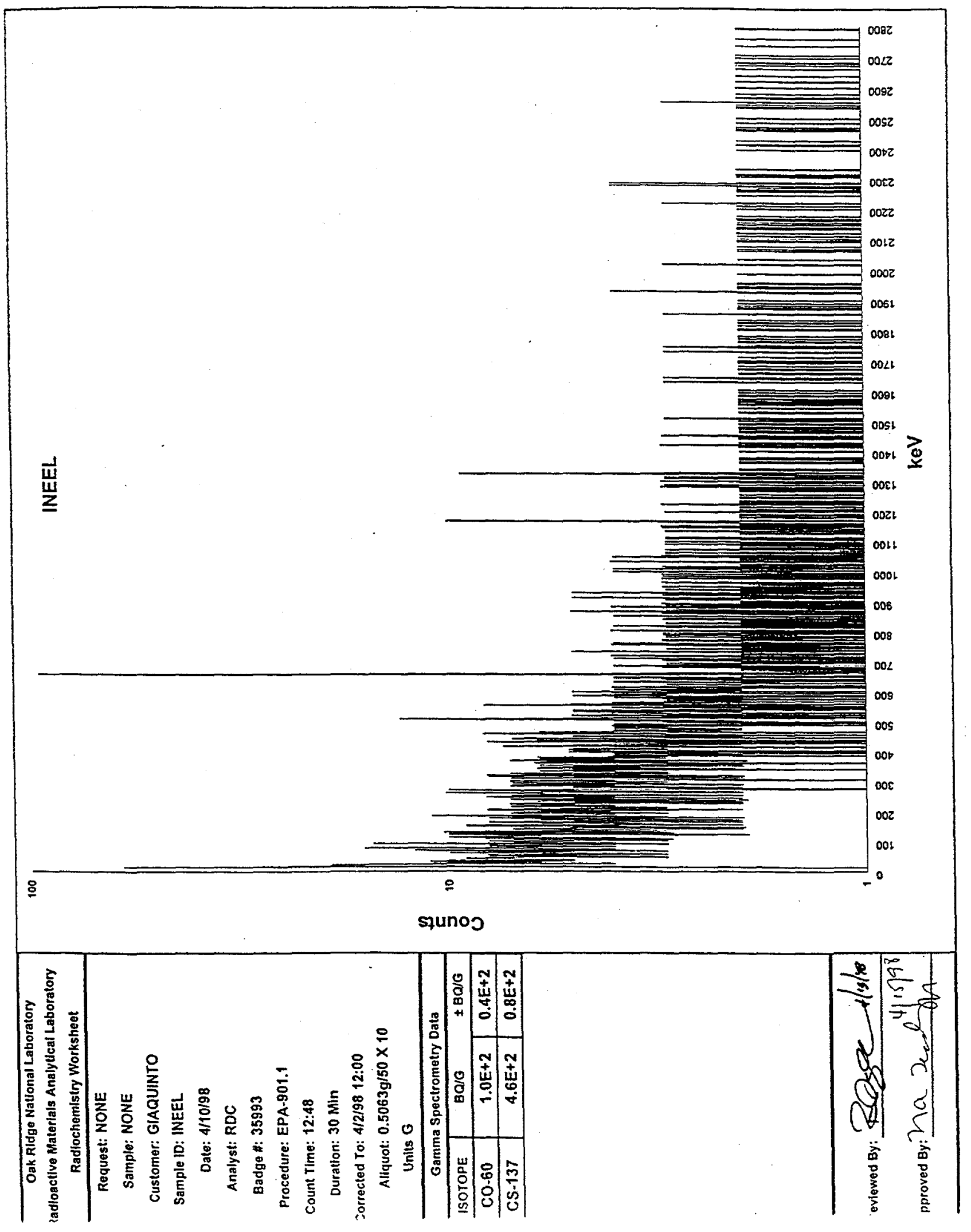


Initials: $M$

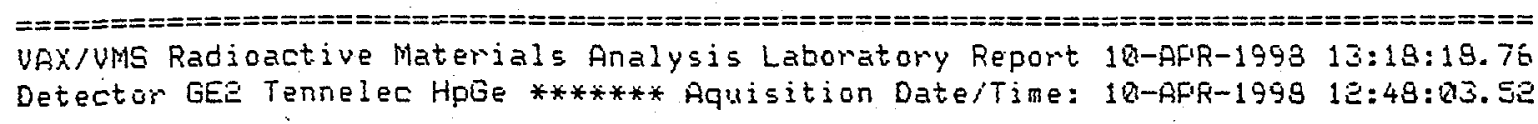

Request No, Customer, Cussim: INEEL DIGEST

\begin{tabular}{|c|c|}
\hline Samole io & : EINEELTEST \\
\hline Semple & $:$ VIAL $9 \mathrm{~cm}$ \\
\hline Quantity & 1.01E6QE-O1 \\
\hline Start Channel & $=10$ \\
\hline End Channel & 4396 \\
\hline
\end{tabular}

End Channel:4296

\author{
Corme : E-AFR-1998 1E:001:Q0र. Qिए \\ Geometry : GEQVSugQ197 \\ EKGEILE : ESBOJE1-EKG \\ Real Time: 0 00:30:00.15 \\ Live time: a ou: $30: 000$. 010
}

\begin{tabular}{|c|c|c|c|c|c|c|c|c|c|}
\hline Ph & It & Energy & Area & Bkgnd & FWH & Channel & *EFf & Cts/sec \%Err & Fit \\
\hline 1 & 8 & 435.49 & 9 & 11 & 1.51 & 539.41 & $3.25 E-01$ & $5.11 E-0369.0$ & \\
\hline$\Xi$ & 0 & $440.19 *$ & 11 & 1 & E. EQ & $544 . \pm 0$ & 3. $E e E-Q_{1}$ & $5.99 E-11335.8$ & \\
\hline 3 & 0 & 465.84 & 7 & $\Xi 4$ & 3.42 & $575.8 \Xi$ & 3. $\operatorname{QBSE}-41$ & 4. $17 E-013127.5$ & \\
\hline 4 & Q & $681.56 *$ & 158 & 7 & 1.38 & 817.05 & E. $23 E-Q 1$ & $9.8 Q E-k=8.7$ & 1. GEE+QDQ \\
\hline 5 & a & 1173.30 & 30 & 0 & $E .31$ & 1447.77 & $1.41 E-01$ & $1.67 E-6218.3$ & \\
\hline 6 & 0 & $133=.41$ & 24 & 8 & 2.36 & 1643.89 & 1. $27 E-91$ & 1. उउE-QDE $\Xi 0.4$ & \\
\hline
\end{tabular}

Flag: "*" = Feak area was modified by background subtraction 
Nuclide Line Activity Report

Nuclide Type: activation

\begin{tabular}{|c|c|c|c|c|c|c|c|}
\hline & & & & & Uncorrected & Decay Corn & $=-5 i g n a$ \\
\hline $\begin{array}{l}\text { Nuctioe } \\
c 0-60\end{array}$ & $\begin{array}{r}\text { Energy } \\
173,=4\end{array}$ & $\begin{array}{r}\text { Area } \\
-70\end{array}$ & $\begin{array}{l}\text { XABn } \\
\text { ge } 90\end{array}$ & $\begin{array}{l}\% E T t \\
4 n 9 E-a !\end{array}$ & $\begin{array}{l}82 / 6 \\
1695+0 \%\end{array}$ & $\begin{array}{l}\mathrm{BQ} / \mathrm{G} \\
+17-3=0\end{array}$ & Herror \\
\hline & 1332.50 & 24 & $99.98 *$ & 1. $E T 4 E-Q 1$ & 1. $034 E+02 E$ & 1. $037 E+w=$ & 40.92 \\
\hline
\end{tabular}

Nuclide Type: fission

\begin{tabular}{|c|c|c|c|c|c|c|c|}
\hline & & & & & Uncomrected & Decayy Cory & e-Sigma \\
\hline $\begin{array}{l}\text { uc } \\
\text { S- }\end{array}$ & $\begin{array}{l}\text { Energy } \\
661.86\end{array}$ & $\begin{array}{r}\text { Area } \\
158\end{array}$ & $\begin{array}{c}\% A b n \\
85 . \Xi 1 *\end{array}$ & $\begin{array}{c}\text { XEff } \\
\text { E. } 2 E \theta E-01\end{array}$ & $\begin{array}{c}B Q / G \\
\text { 4. } 581 E+a E\end{array}$ & $\begin{array}{c}B Q / G \\
\text { 4. } 583 E+Q 1=\end{array}$ & $\begin{array}{l}\text { \%Error } \\
17.34\end{array}$ \\
\hline
\end{tabular}

Flag: "*" = Keyline 
Sumary of Nuclide Activity Sample ID : EINEELTEST

Total number of lines in spectrum

Number of unideritified lines

Number of lines tentatively identified by NID

Nuclide Type : activation

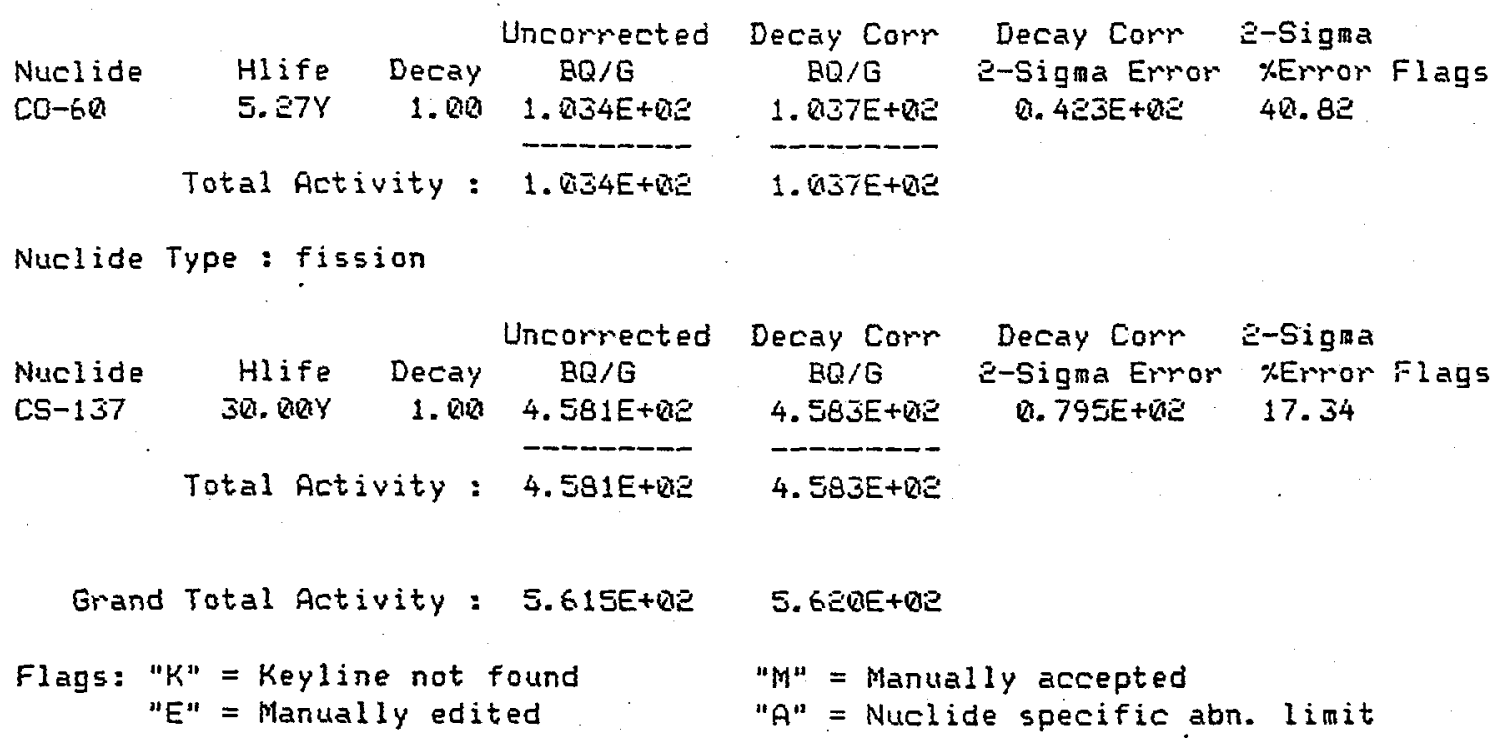

Fiage: 2

Acquisition date: $10-A P R-1998$ 10:48:83
6

2

4 GE. $67 \%$ 
Unidentified Energy Lines

Sample ID: EINEELTEST
Fage : 3

Acquisition date : 10-AFR-1998 $1 E: 48: \bar{a}$

\begin{tabular}{|c|c|c|c|c|c|c|c|c|c|c|c|}
\hline It & Energy & Area & Bkgnd & FWHM & Channel & Left & $F w$ & Ct $5 / \mathrm{sec}$ & xErr & $x \in f f$ & lat \\
\hline$a$ & 435.49 & 9 & 11 & 1.51 & & 534 & 9 & & $* * * *$ & 3. $25 E-Q 13$ & \\
\hline 0 & 440.18 & 11 & 1 & 2. 20 & 544.20 & 542 & 5 & $5.98 E-123$ & 71.7 & $=-\infty 1$ & \\
\hline 0 & 465.84 & 7 & 84 & 3.42 & 575.83 & 570 & 11 & 4. $17 E-43$ & $* * * *$ & $3.05 E-01$ & \\
\hline
\end{tabular}

Flags: "T" = Tentatively associated 
Minimum Detectable Activity Report

\begin{tabular}{|c|c|c|c|}
\hline Nuclide & $\begin{array}{c}\text { Bckgnd } \\
\text { Sum }\end{array}$ & $\begin{array}{l}\text { Energy } \\
\text { (keV) }\end{array}$ & $\begin{array}{c}M D A \\
(B Q / G)\end{array}$ \\
\hline $\mathrm{BE}-7$ & 7. & 477.61 & $2.9078 E+a z$ \\
\hline NA-QE & 1. & 1274.53 & $3.0754 E+01$ \\
\hline$k-4 a$ & 6. & 1460.83 & $6.1359 E+12 E$ \\
\hline CR-51 & 13. & 320.08 & 3. 08Q9E+Q2 \\
\hline$M N-54$ & 7. & 834.83 & 4. $4593 E+01$ \\
\hline $20-57$ & 18. & 1 1ㄹ. $06^{\circ}$ & 2. $0559 E+01$ \\
\hline $5 E-75$ & 18. & 264.66 & 4. $1599 E+01$ \\
\hline$N B-94$ & 6. & 871.10 & 4.3702E+at \\
\hline$N B-95$ & 5. & 765.79 & 4. $2857 E+81$ \\
\hline $2 R-95$ & 3. & 756.72 & 5. $9353 E+01$ \\
\hline$R U-183$ & 4. & 497.05 & $=.9217 E+81$ \\
\hline$R U-106$ & 4. & 621.92 & ¿. $9574 E+82$ \\
\hline$C D-109$ & 9. & 88.013 & 4. $5785 E+02$ \\
\hline$A G-110 M$ & 6. & 657.76 & $3.7071 E+01$ \\
\hline$T E-121$ & 5. & 573.13 & $4.9961 E+01$ \\
\hline$T E-1 \geq 1 M$ & 12. & ㄴ..ㄹ & 2. 1486E+Q1 \\
\hline$T E-1 \geq 3 M$ & 9. & 158.99 & $1.6111 E+01$ \\
\hline$I-125$ & 18. & 27.40 & 4.867בE+Q3 \\
\hline $5 B-1 \geq 5$ & 9. & 427.88 & $9.4621 E+01$ \\
\hline TE-127 & a. & 417.93 & Half-Life too short \\
\hline $1-129$ & 11. & 39.60 & $3.5448 E+03$ \\
\hline $1-131$ & 12 & 364.48 & $6.5 E 63 E+01$ \\
\hline $1-132$ & a. & 667.73 & Half-Life too short \\
\hline $1-133$ & 7. & 529.85 & 2. $1935 E+Q 4$ \\
\hline$c s-134$ & 8. & 604.71 & 3. $7827 E+01$ \\
\hline$I-135$ & 0 & 1260.42 & Half-Life too short \\
\hline CE-144 & 17. & 133.54 & 1.5129E+az \\
\hline$F M-147$ & 19. & 121.26 & $6.1660 E+Q 5$ \\
\hline$E U-15 z$ & 2 & 1409.00 & E. Q119E+QE \\
\hline$E U-154$ & 1. & 1274.54 & 8. $6221 E+01$ \\
\hline$E U-155$ & 14. & B6. 54 & $5.9950 E+01$ \\
\hline$H G-203$ & G. & 279.19 & 2. $0957 E+01$ \\
\hline$F \mathrm{~B}-E 12$ & a. & 239.58 & Half-Life too short \\
\hline$R A-224$ & 11. & 240.76 & 2. $0594 E+13$ \\
\hline KA-E:ES & 13. & 40.34 & 1. $27375+a 3$ \\
\hline$R A-Z E G$ & 8. & 609.31 & $7.7164 E+1$ \\
\hline$A C-E=7 D$ & 9. & 235.97 & $1.4468 E+22 E$ \\
\hline TH-2E8 & 17. & 84.26 & 1. $8780 E+03$ \\
\hline TH-EZG & 15. & - 193.59 & $3.758 \mathrm{eE}+0 \mathrm{e}$ \\
\hline$u-235$ & 12. & 143.79 & 1. $3506 E+00$ \\
\hline$u-238$ & 1. & $10 a 1.0 a$ & 4. $1533 E+133$ \\
\hline$A M-241$ & 9. & 59.54 & 1. $1005 E+40$ \\
\hline$C M-243$ & 4. & 277.62 & $9.5989 E+013$ \\
\hline
\end{tabular}


RADIOACTIUE MATERIALS ANALYSIS LAB

Detector GEE

URLUES WHICH ARE LESS THAN MDA

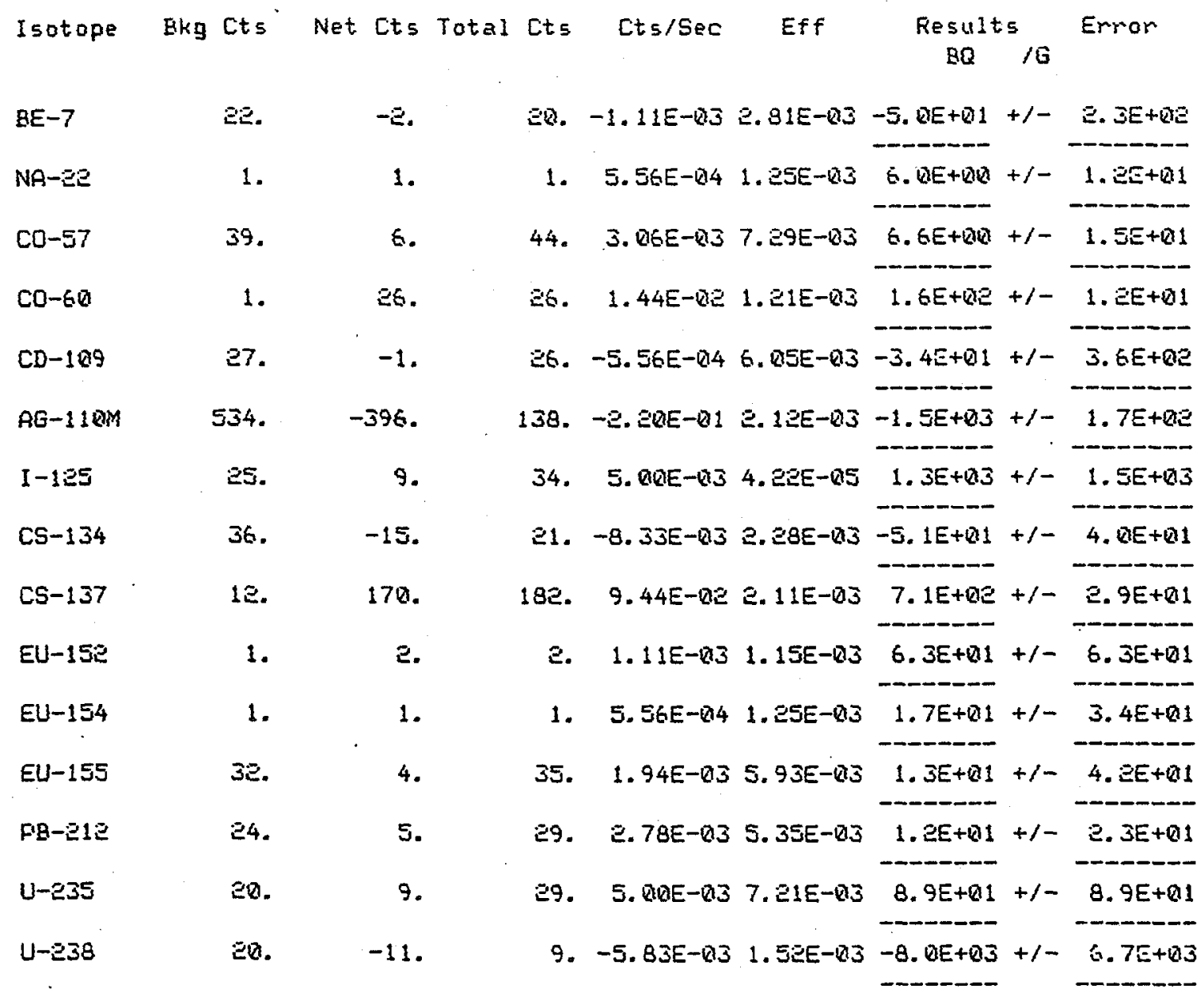


Radioactive Materials Analytical Laboratory Inorganic Chemistry Worksheet

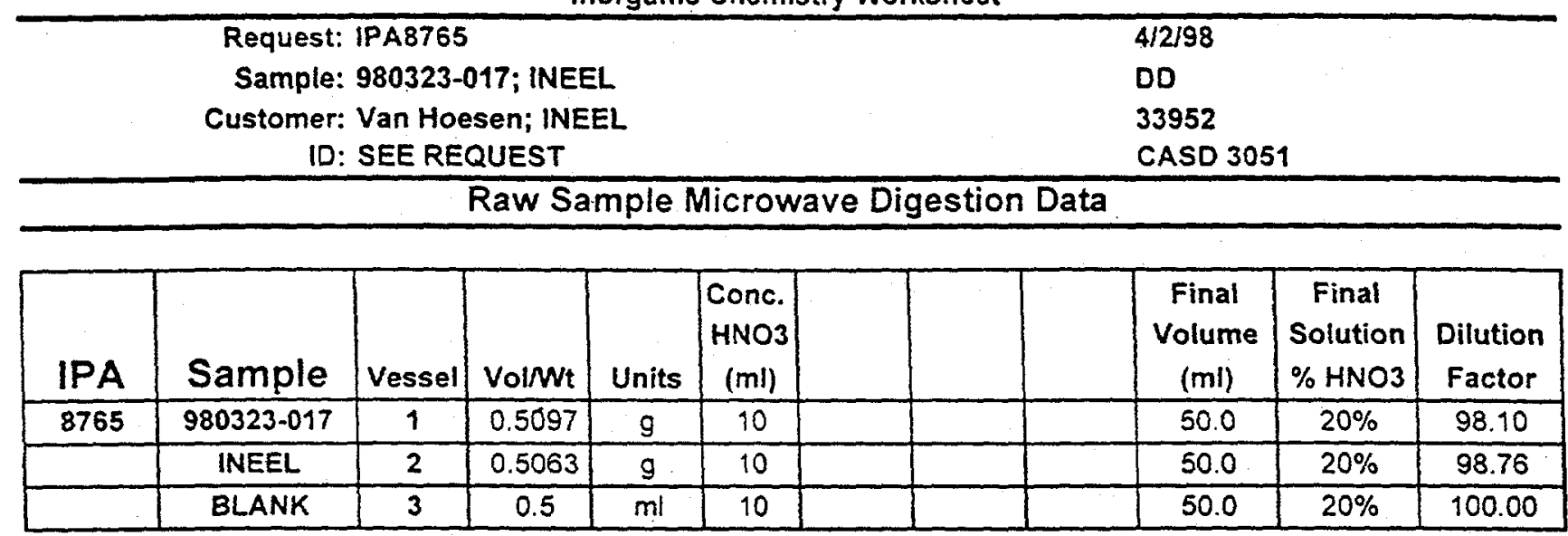

\section{COPY \\ Original Fred Wth IPA 8765}

Digestion Comments:

\begin{tabular}{|c|c|c|}
\hline Time $(M)$ & Power(W) & Temp $\left.^{\circ} \mathrm{C}\right)$ \\
\hline 1 & 250 & 100 \\
\hline 1 & 0 & 100 \\
\hline 1 & 250 & 140 \\
\hline 1 & 0 & 140 \\
\hline 10 & 550 & 175 \\
\hline
\end{tabular}

Homogenization: 980323-017 asd INEEL samples were mixed to homogenize.

Reaction/Off-Gassing: 980323-017 produced a reaction and off-gassing upon nitric addition.

The INEEL sample also produced a small reaction and off-gassing upon nitric addition.

Dissolution Observations: 980320-015 formed a very light tan digest with no observable solids.

(>99\% in solution)

The INEEL sample produced a cloudy-tan digest with tan, black and gray solids

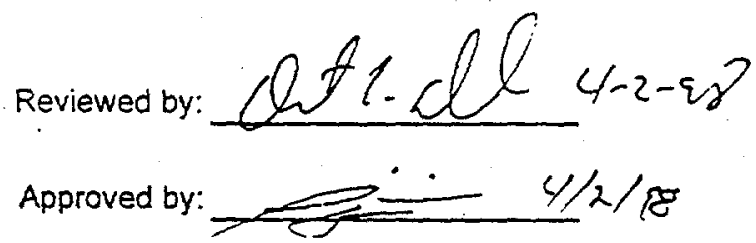


Request: IPA8663; 8678; INEEL

Sample: 980212-013; 980223-058

Customer: Sears; Mattus; INEEL

ID: See Request
Date: 3-19-98/3-20-98

Analyst: $D D$

Badge \#: 33952

Procedure: SW-846-9060

\section{Carbon Data}

Calibration Ranges STD\%C

\begin{tabular}{|c|c|c|c|}
\hline TC & 37002731 & & \\
\hline & & & 39.96 \\
\hline IC & B26346 & & 143 \\
\hline
\end{tabular}

\begin{tabular}{|c|c|c|c|c|c|c|c|c|}
\hline \multirow[b]{2}{*}{ IPA } & \multirow[b]{2}{*}{ Sample } & \multicolumn{2}{|c|}{ Total Carbon $\%$} & \multicolumn{2}{|c|}{ Inorganic Carbon \% } & \multicolumn{2}{|c|}{ TOC \% } & \multirow{2}{*}{$\begin{array}{c}\text { STD } \\
\% \text { Rec. }\end{array}$} \\
\hline & & Result & Error & Result & Error & Result & Error & \\
\hline TC Std & 37002731 & 38.1 & 3.81 & & & & & $95 \%$ \\
\hline $1 \mathrm{C} \mathrm{Std}$ & $B 26346$ & & & 14.33 & 1.433 & $\cdots$ & & $100 \%$ \\
\hline 8663 & $980212-013$ & 8.49 & 0.849 & 0 & 0 & 8.49 & 0.849 & \\
\hline 8678 & $980223-058$ & 2.87 & 0.287 & 1.32 & 0.132 & 1.55 & 0.155 & \\
\hline INEELI & WET & 2.72 & 0.272 & 0 & 0 & 2.72 & 0.272 & \\
\hline INEEL2 & WET & 3.103 & 0.3103 & 0 & 0 & 3.103 & 0.3103 & \\
\hline INEELI & DRY & 5.56 & 0.556 & 0 & 0 & 5.56 & 0.556 & \\
\hline INEEL2 & DRY & 9.17 & 0.917 & 0 & 0 & 9.17 & 0.917 & \\
\hline IC Std & 826346 & 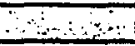 & $\therefore-\therefore$ & 14.63 & 1.463 & $\therefore \therefore$ & $\therefore \quad$ & $102 \%$ \\
\hline TC Std & 37002731 & 35.33 & 3.533 & 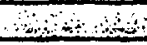 & 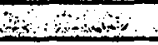 & 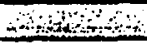 & $\therefore$ & $88 \%$ \\
\hline
\end{tabular}

Comments:

"Sample results of $0 \%$ are reported as $<0.1 \%$ on the final report.

\section{COPY}

Original Fled With IPA

Reviewed by:

et 2 dt $3 \cdot 4-98$

Approved by: 
Radioactive Materials Analytical Laboratory

Inorganic Chemistry Worksheet

\begin{tabular}{|c|c|c|c|c|c|}
\hline $\begin{array}{r}\text { Request: } \\
\text { Sample: } \\
\text { Customer: } \\
\text { ID: }\end{array}$ & $\begin{array}{l}\text { IPA8751; 8756; } \\
980309-017,-018 \\
\text { Sears; INEEL } \\
\text { See Requests }\end{array}$ & $\begin{array}{l}\text { INEEL } \\
3 ; 980309-019 ; 11\end{array}$ & EEL & $\begin{array}{r}\text { Date: } \\
\text { Analyst: } \\
\text { Badge \#: } \\
\text { Procedure: }\end{array}$ & $\begin{array}{l}24-98 / 3-25-98 \\
0 \\
952 \\
\text { MAL }\end{array}$ \\
\hline \multicolumn{6}{|c|}{ PERCENT MOISTURE / SOLIDS DATA } \\
\hline $\begin{array}{c}\text { SAMPLE } \\
\text { NO. } \\
980309-017 \\
980309-018 \\
980309-019 \\
\text { INEEL }\end{array}$ & \begin{tabular}{|c|}
$\begin{array}{c}\text { CONTAINER } \\
\text { WEIGHT } \\
(\mathrm{g})\end{array}$ \\
1.1002 \\
1.0991 \\
1.0927 \\
189.7200 \\
\end{tabular} & \begin{tabular}{|c|}
$\begin{array}{c}\text { CONTAINER } \\
\text { \& WET WT. } \\
\text { (g) }\end{array}$ \\
2.9880 \\
2.6945 \\
2.8554 \\
441.2600 \\
\end{tabular} & $\begin{array}{c}\text { WET } \\
\text { WEIGHT } \\
(\mathrm{g}) \\
1.8878 \\
1.5954 \\
1.7627 \\
251.5400\end{array}$ & \begin{tabular}{|c|}
$\begin{array}{c}\text { CONTAINER } \\
\& \text { DRY WT. } \\
\text { (g) }\end{array}$ \\
2.1009 \\
2.1864 \\
2.4754 \\
294.3800 \\
\end{tabular} & $\begin{array}{c}\begin{array}{c}\text { DRY } \\
\text { WEIGHT } \\
(\mathrm{g})\end{array} \\
1.0007 \\
1.0873 \\
1.3827 \\
104.6600 \\
\end{array}$ \\
\hline $\begin{array}{c}\text { SAMPLE } \\
\text { NO. } \\
980309-017 \\
980309-018 \\
980309-019 \\
\text { INEEL }\end{array}$ & $\begin{array}{c}\text { PERCENT } \\
\text { SOLIDS } \\
\% \\
53.0 \\
68.2 \\
78.4 \\
41.6\end{array}$ & $\begin{array}{c}\begin{array}{c}\text { PERCENT } \\
\text { MOISTURE } \\
\%\end{array} \\
47.0 \\
31.8 \\
21.6 \\
58.4\end{array}$ & & & \\
\hline
\end{tabular}

\section{COPY
Original Fled With IPA 8751}

NOTES:

1) Samples dried at an average oven temperature of $105^{\circ} \mathrm{C}$, cooled in a dessicator and weighed.

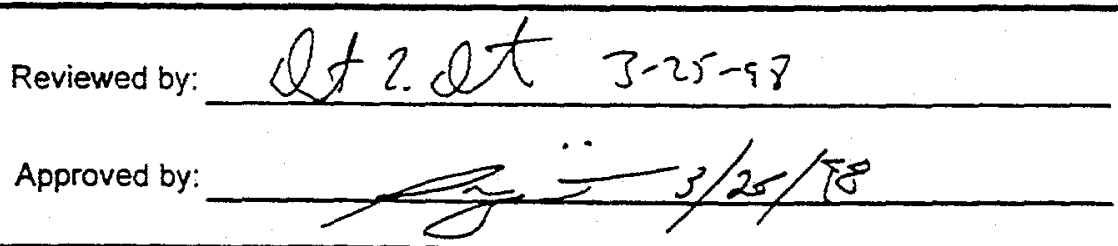


Radioactive Materials Analytical Laboratory

Inorganic Chemistry Worksheet

Request: INEEL

Sample: $1 \& 2$

Customer:

ID:
Date: $3-19-98 / 3-20-98$

Analyst: DD

Badge \#: 33952

Procedure: RMAL

PERCENT MOISTURE / SOLIDS DATA

\begin{tabular}{|c|c|c|c|c|c|}
\hline $\begin{array}{c}\text { SAMPLE } \\
\text { NO. }\end{array}$ & $\begin{array}{c}\text { CONTAINER } \\
\text { WEIGHT } \\
(\mathbf{g})\end{array}$ & $\begin{array}{c}\text { CONTAINER } \\
\& \text { WET WT. } \\
(\mathbf{g})\end{array}$ & $\begin{array}{c}\text { WET } \\
\text { WEIGHT } \\
(\mathbf{g})\end{array}$ & $\begin{array}{c}\text { CONTAINER } \\
\& \text { DRY WT. } \\
(\mathbf{g})\end{array}$ & $\begin{array}{c}\text { DRY } \\
\text { WEIGHT } \\
(\mathbf{g})\end{array}$ \\
\hline 1 & 1.0895 & 3.1880 & 2.0985 & 2.2709 & 1.1814 \\
\hline 2 & 1.0989 & 3.3453 & 2.2464 & 1.7306 & 0.6317 \\
\hline
\end{tabular}

\begin{tabular}{|c|c|c|}
\hline $\begin{array}{c}\text { SAMPLE } \\
\text { NO. }\end{array}$ & $\begin{array}{c}\text { PERCENT } \\
\text { SOLIDS } \\
\%\end{array}$ & $\begin{array}{c}\text { PERCENT } \\
\text { MOISTURE } \\
\%\end{array}$ \\
\hline 1 & 56.3 & 43.7 \\
\hline 2 & 28.1 & 71.9 \\
\hline
\end{tabular}

NOTES:

1) Samples dried at an average oven temperature of $110^{\circ} \mathrm{F}$, placed in desiccator, weighed, and the process repeated until stable weight achieved.

Reviewed by:

Approved by: 


\section{Radioactive Materials Analytical Laboratory Inorganic Chemistry Workshee}

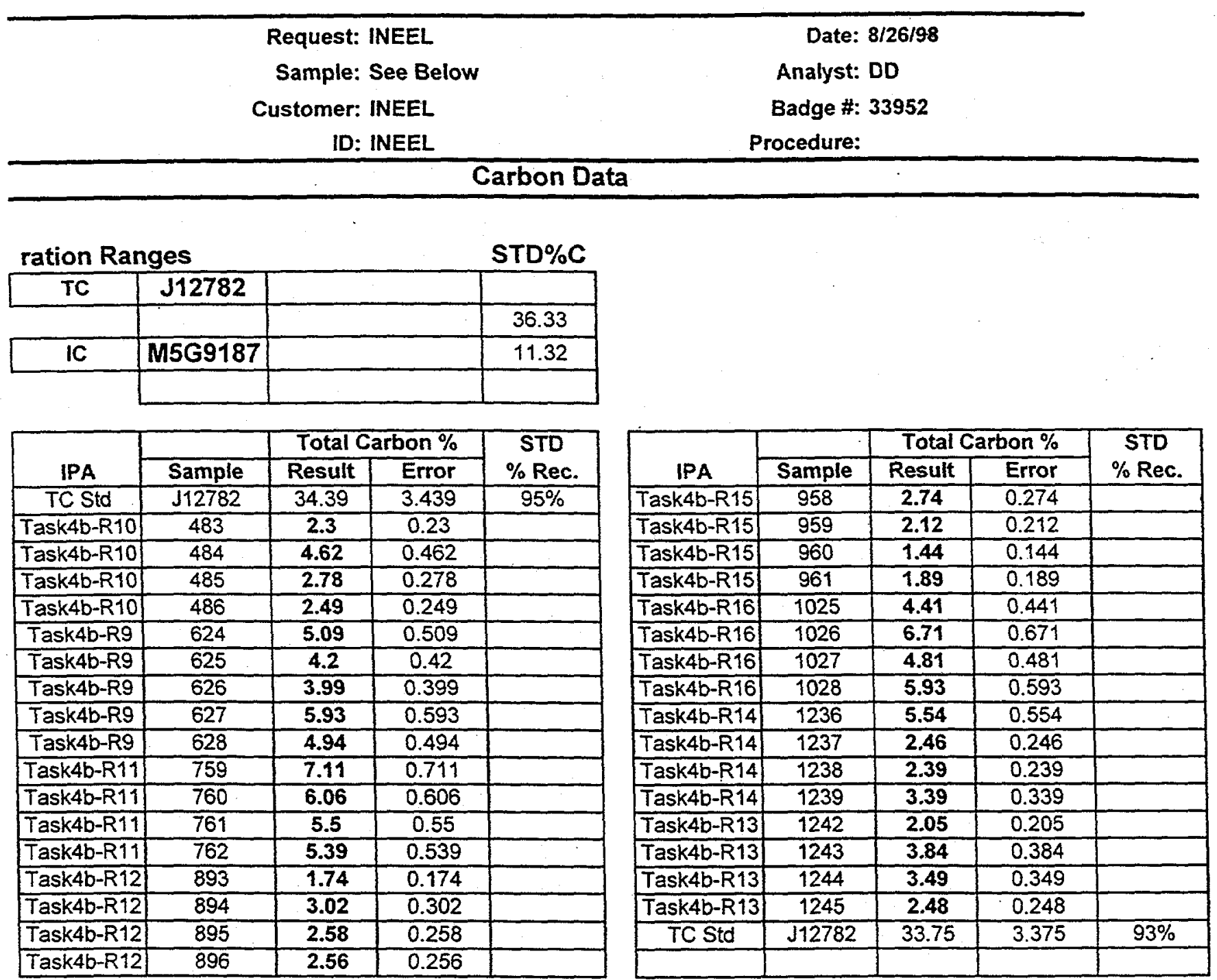

Comments: *Sludge dried at $105^{\circ} \mathrm{C}$ for $-48 \mathrm{hrs}$ and placed in dessicator until analyzed.

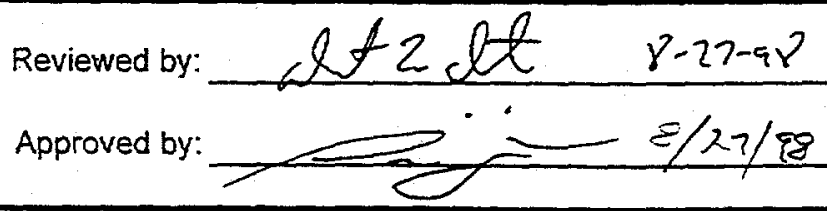




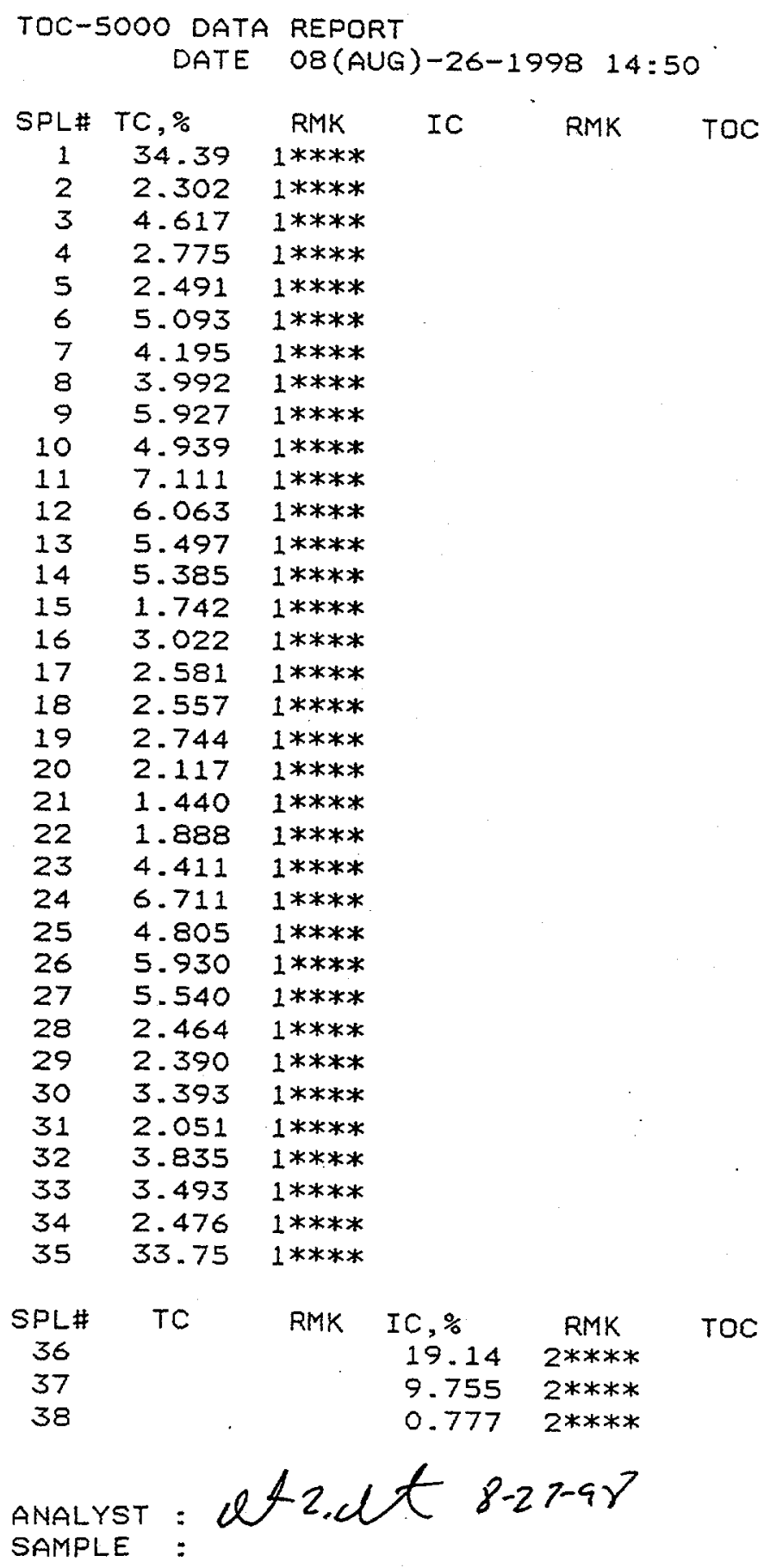




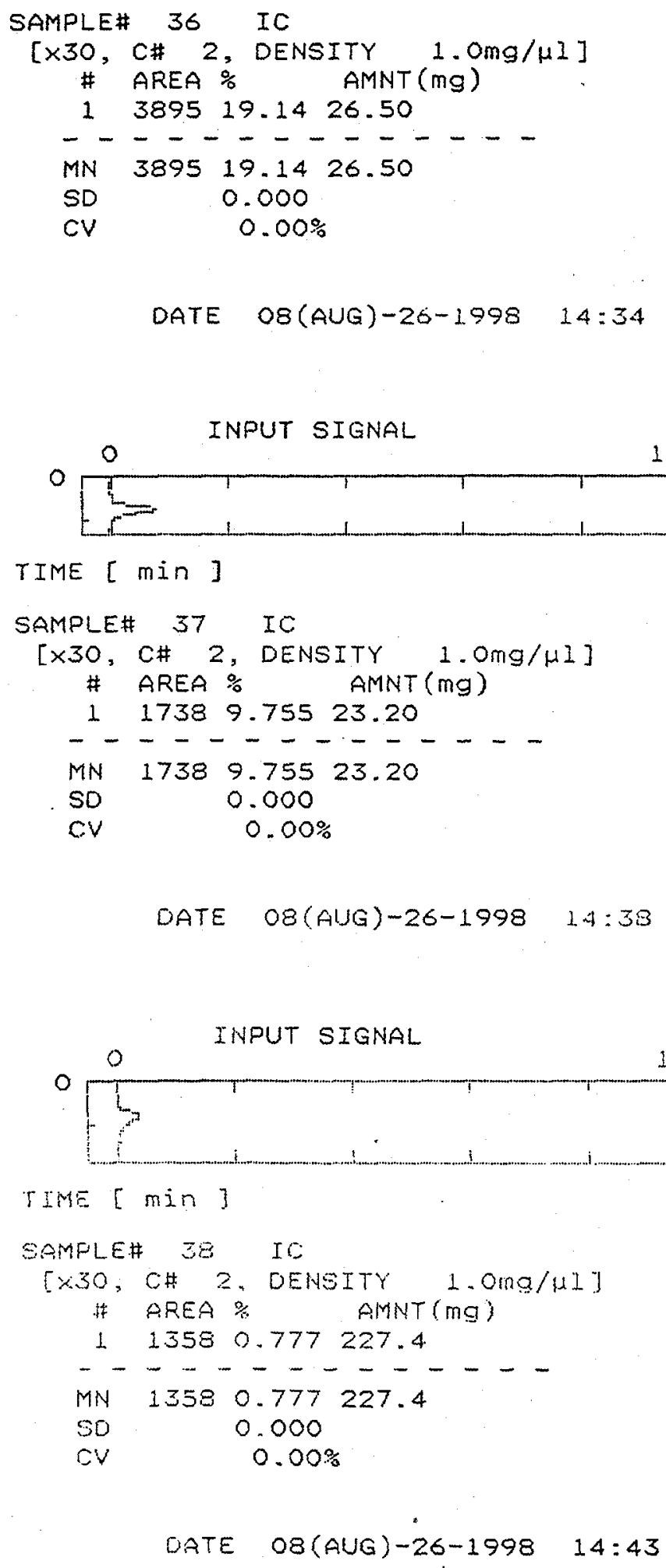

TIME [ min ]

TIME $[\min ]$

SAMPLE\# 38 IO

[X30, CH 2, DENSITY 1.OMg/HI]

样 AREA \% AMNT(mg)

$1 \quad 1358 \quad 0.777 \quad 227.4$

- - . . . . . . . . .

MN $1358 \quad 0.777 \quad 227.4$

So $\quad 0.000$

CV $\quad 0.00 \%$

date o8(AUG)-26-1998 14:43 


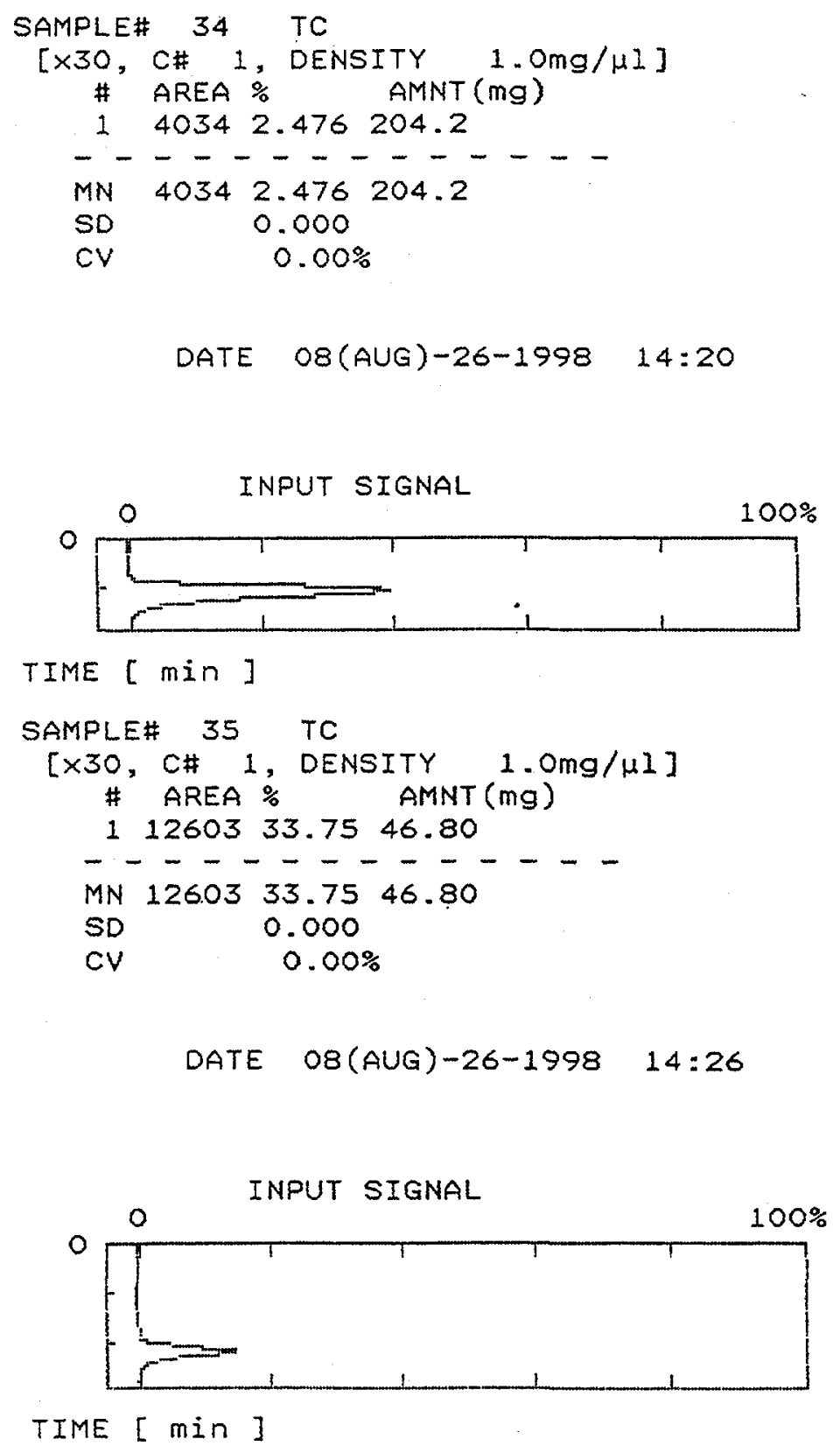

TIME [ min ] 

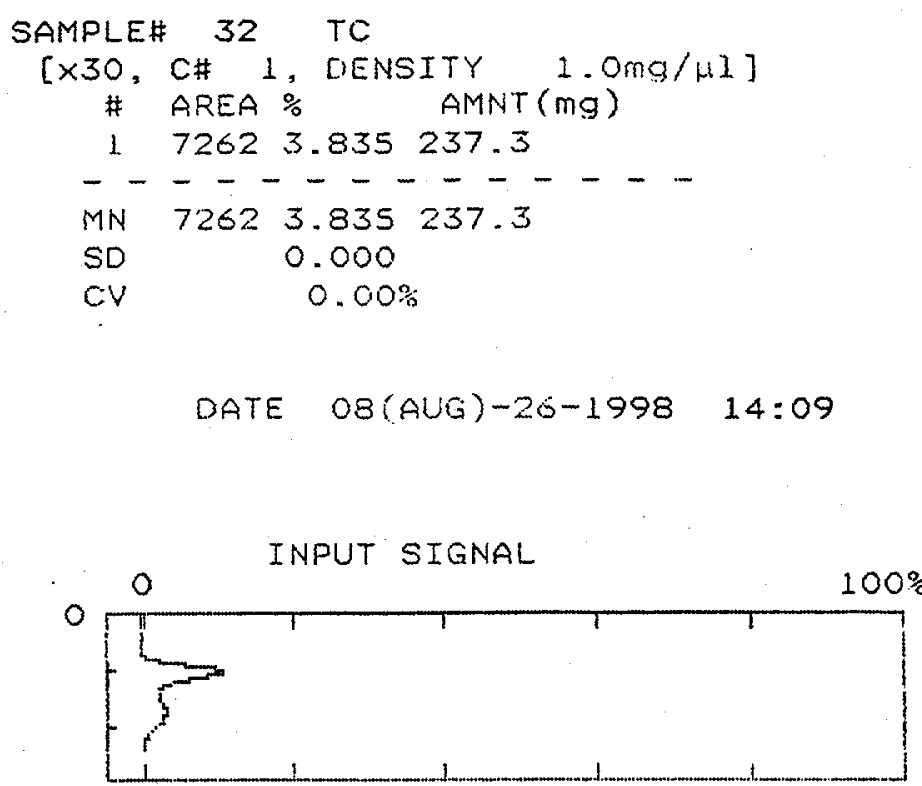

TIME [ min]

SAMPLE\# 33 TC

[ $\times 30, C \# 1$, DENSITY $1.0 \mathrm{mg} / \mu \mathrm{I}]$

\# AREA \% AMNT $(\mathrm{mg})$

$15578 \quad 3.493 \quad 200.1$

- $-\ldots \ldots+\ldots-\ldots$

MN $5578 \quad 3.493 \quad 200.1$

SO $\quad 0.000$

cV $\quad 0.00 \%$

DATE O8(AUG)-26-1998 14:15

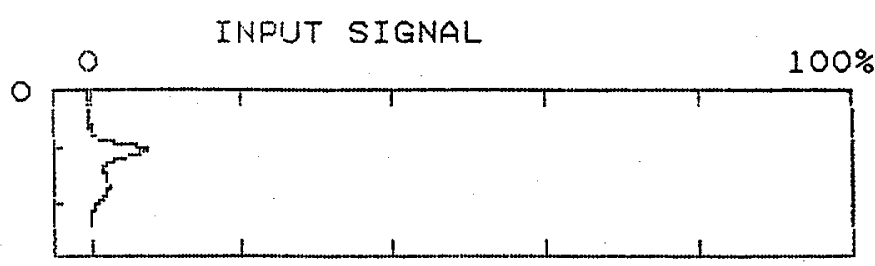

TIME [ min] 


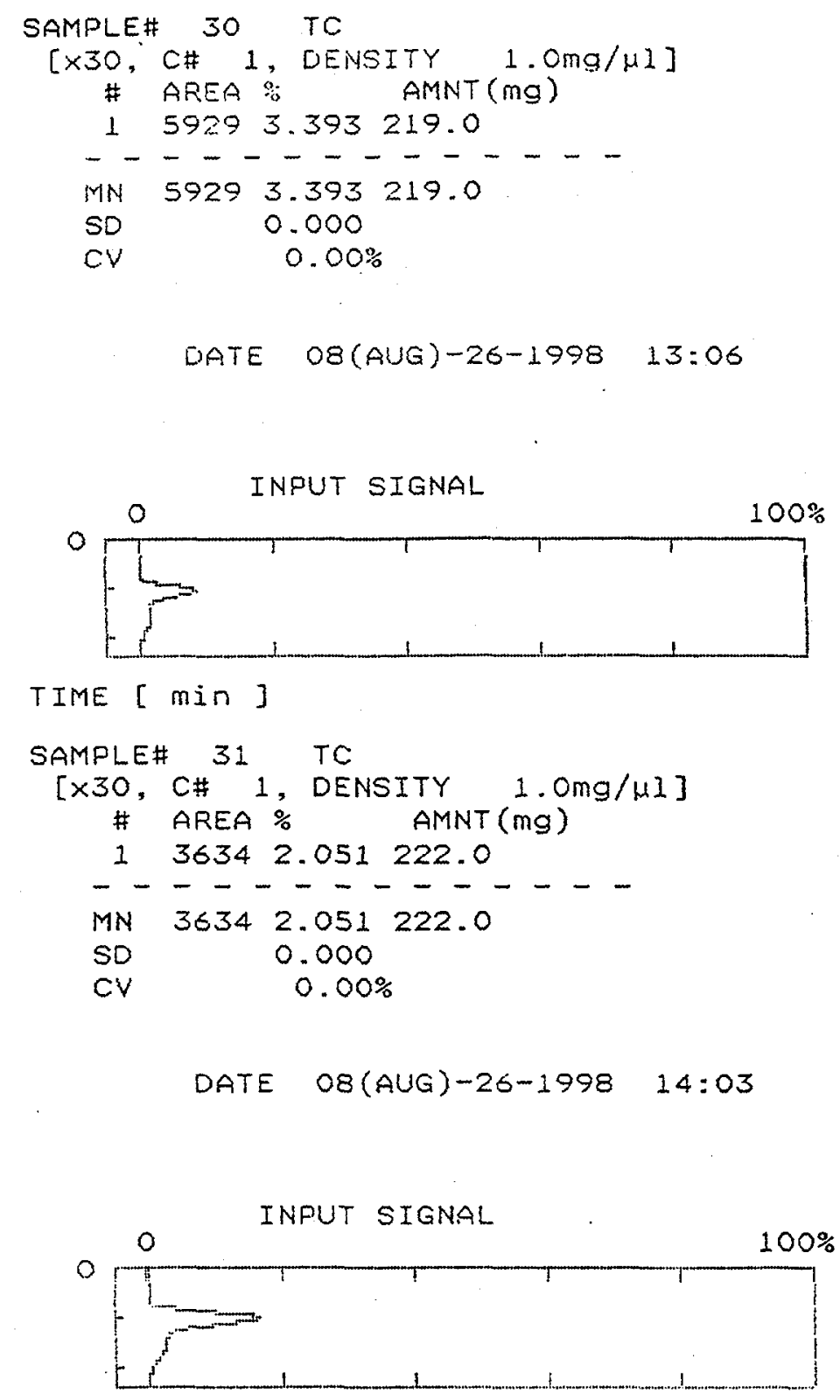

TIME [ min ] 


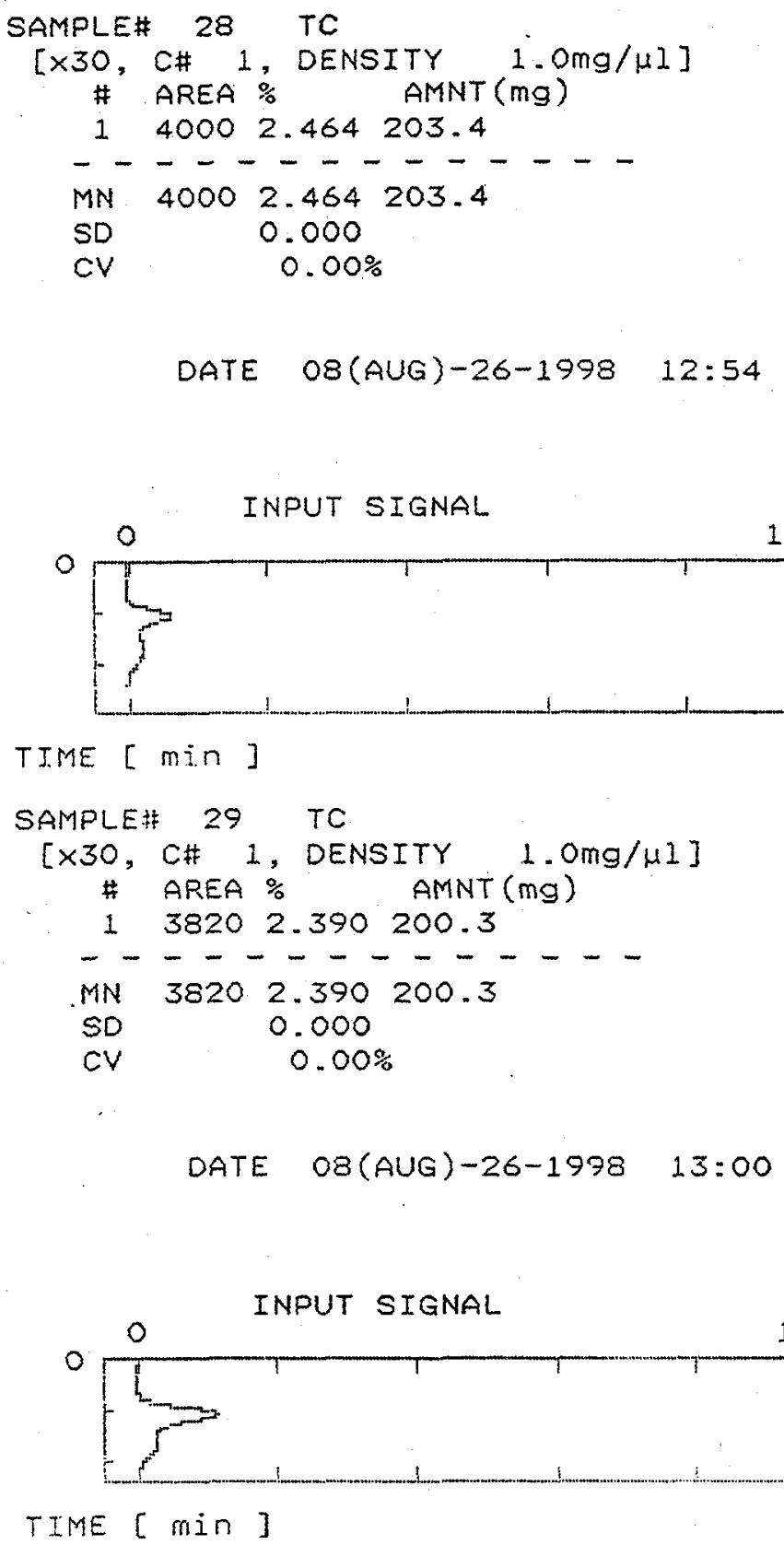

TIME [ min ]

SAMPLE\# 29 TC

[×30, C\# 1, DENSITY $1.0 \mathrm{mg} / \mu 1]$

\# AREA \% AMNT (mg)

138202.390200 .3

$-----------\ldots$

MN 38202.390200 .3

SD $\quad 0.000$

CV $\quad 0.00 \%$

DATE O8(AUG)-26-1978 13:00

TIME [ min] 


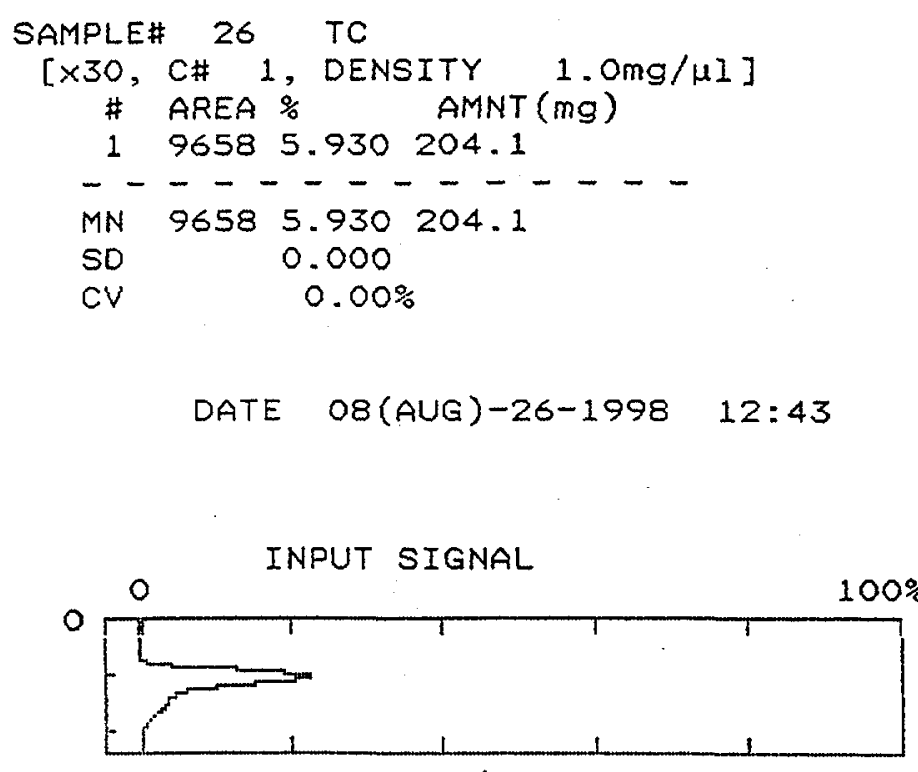

TIME [ $\min ]$

SAMPLE\# 27 TC

[ $\times 30$, C\# 1 , DENSITY $1.0 \mathrm{mg} / M \mathrm{I}]$

\# AREA \% AMNT (mg)

$19673 \quad 5.540218 .8$

- - - - - - - - - -

MN $9673 \quad 5.540 \quad 218.8$

SD $\quad 0.000$

CV $\quad 0.00 \%$

DATE O8(AUG) $-26-1998 \quad 12: 49$

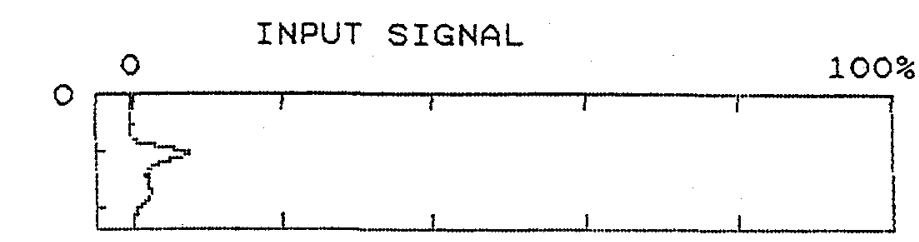

TIME [ $\mathrm{min}]$ 


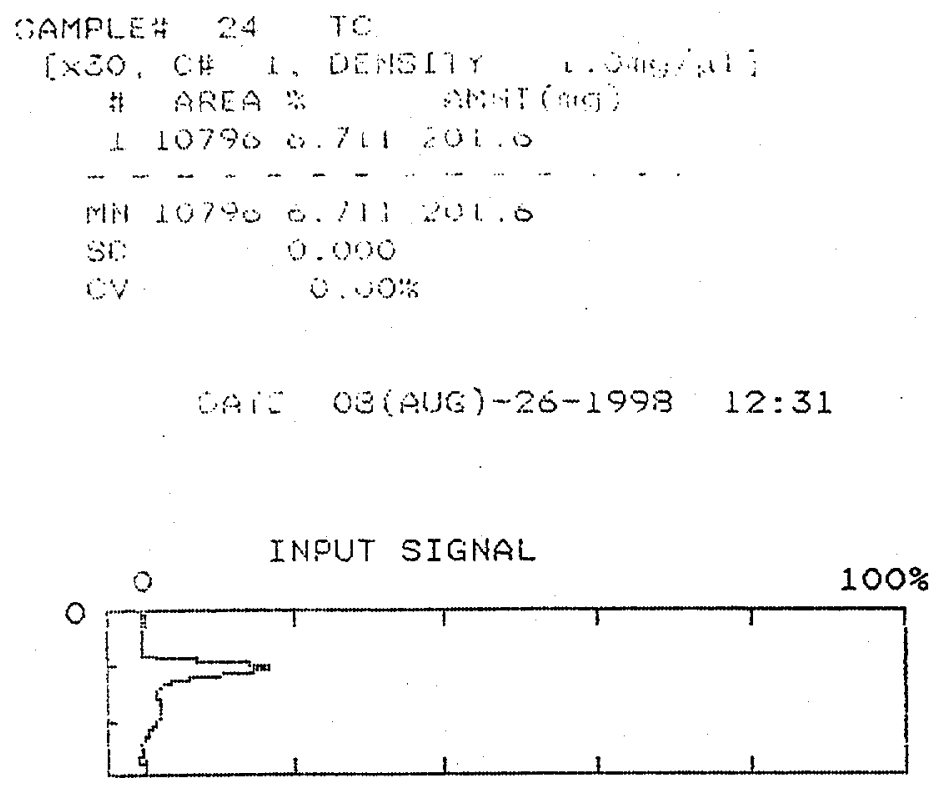

TIME [min]

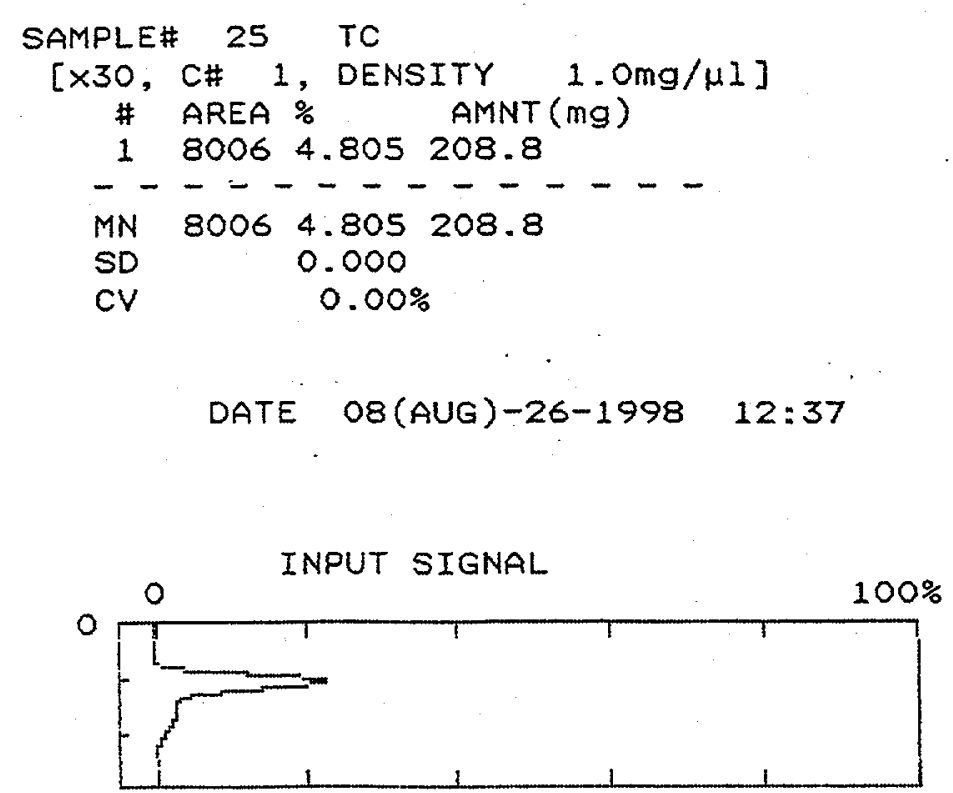

TIME [min ] 


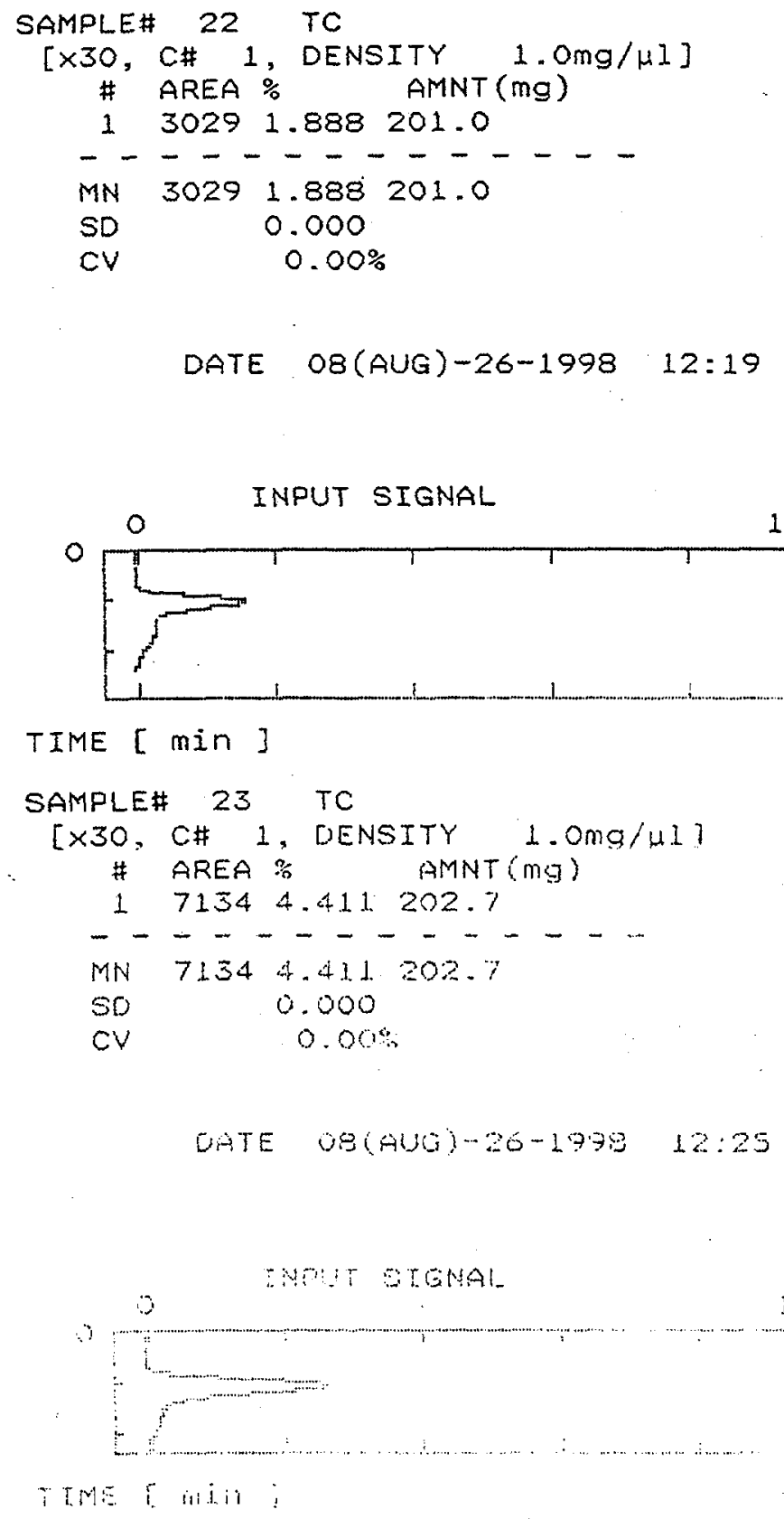

TIME [min]

SAMPLE\# 23 TC

[ $\times 30$, C\# 1, DENSITY 1.OMG/UI]

\# AREA \% AMNT (mg)

171344.411 .202 .7

- - - - - - - _ _ - .

MN $7134+4.11 .202 \%$

$50 \quad 0.000$

CV $\quad 0.00 \%$

DATE OQ(AUG)-20-199\% $12: 25$

iTMS S initi : 

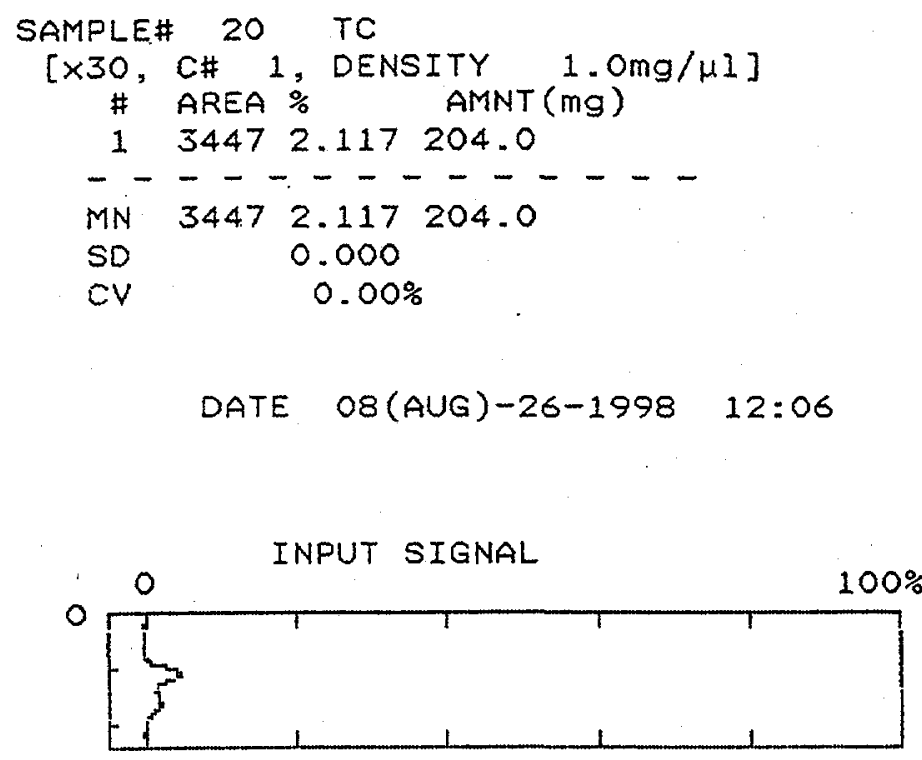

TIME [ min ]

SAMPLE\# 21 TC

$[\times 30, C \# 1$, DENSITY $1.0 \mathrm{mg} / \mu 1]$

\# AREA \% AMNT (mg)

$12550 \quad 1.440 \quad 221.9$

- - - - - _ - _ - . -

MN 25501.440221 .9

SD $\quad 0.000$

CV $\quad 0.00 \%$

DATE O8(AUG)-26-1998 12:13

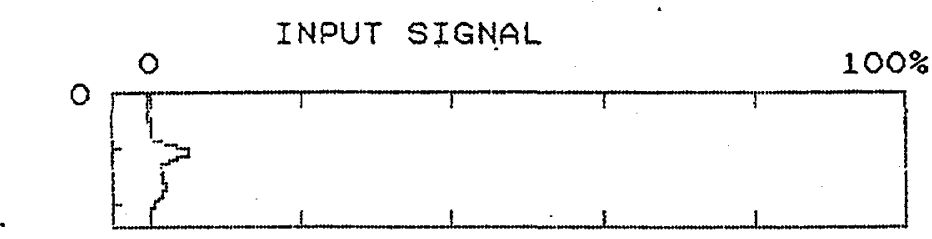

TIME [ min] 


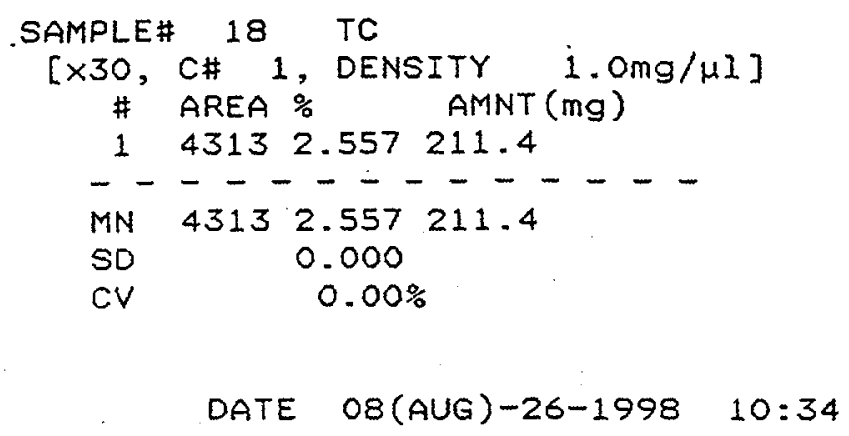

TIME [min ]
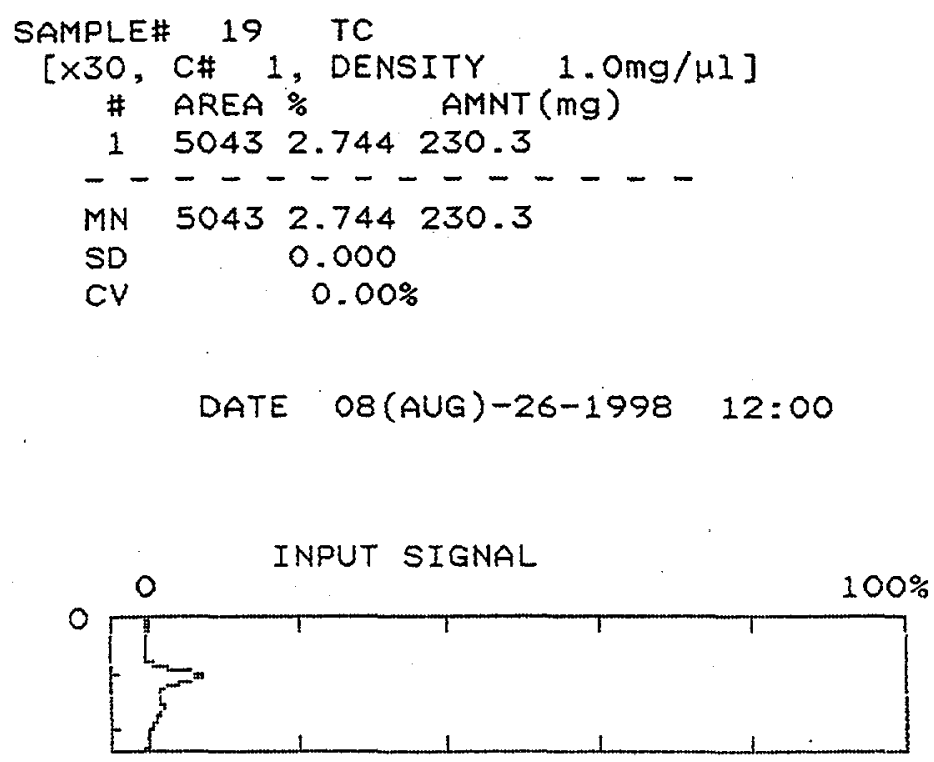

$\operatorname{TIME}[\min ]$ 


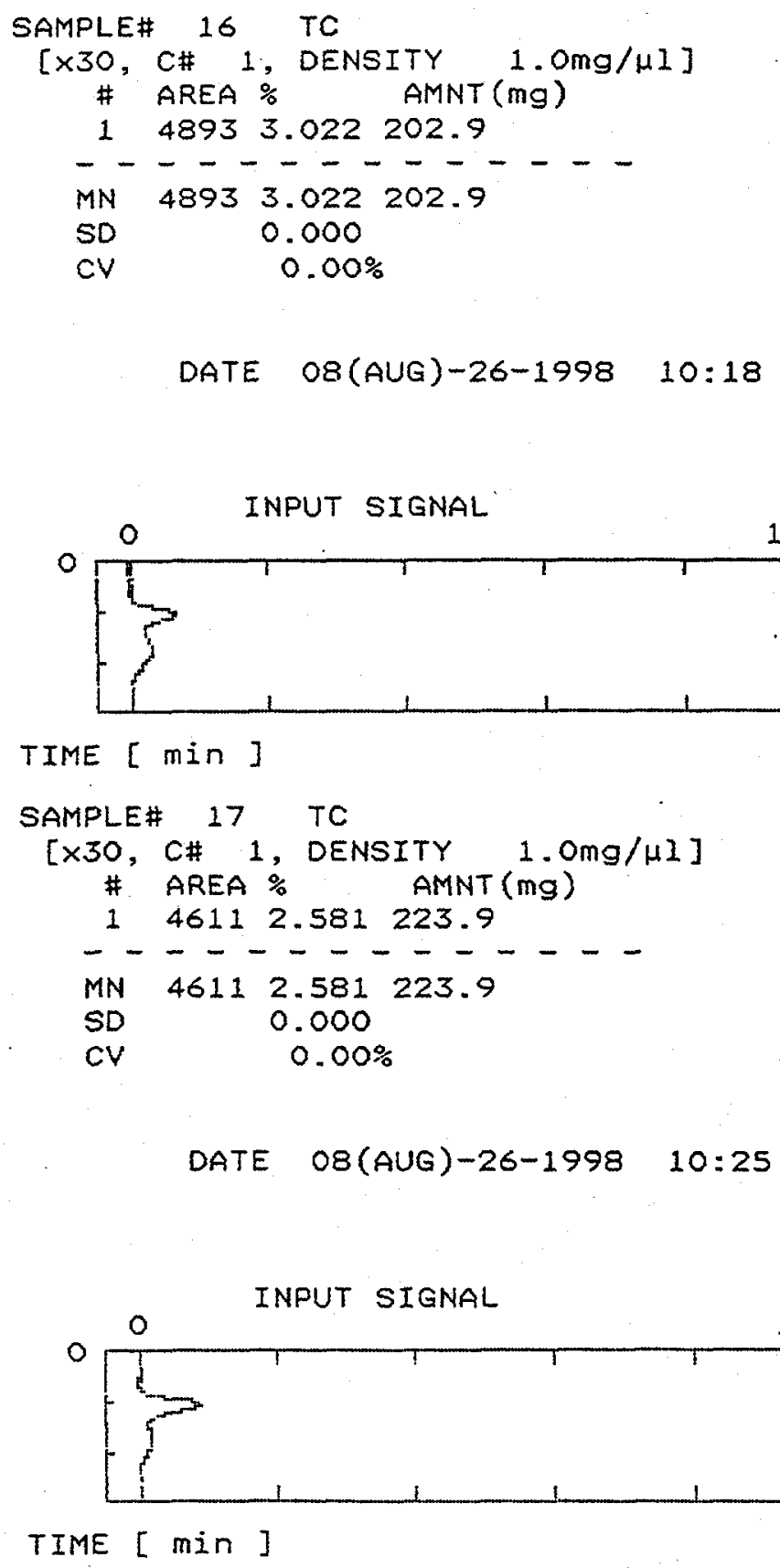

TIME [min ]

SAMPLE\# 17 TC

[X30, C\# 1, DENSITY 1.0mg/HI]

\# AREA \% AMNT $(\mathrm{mg})$

146112.581223 .9

TIME [ min ] 


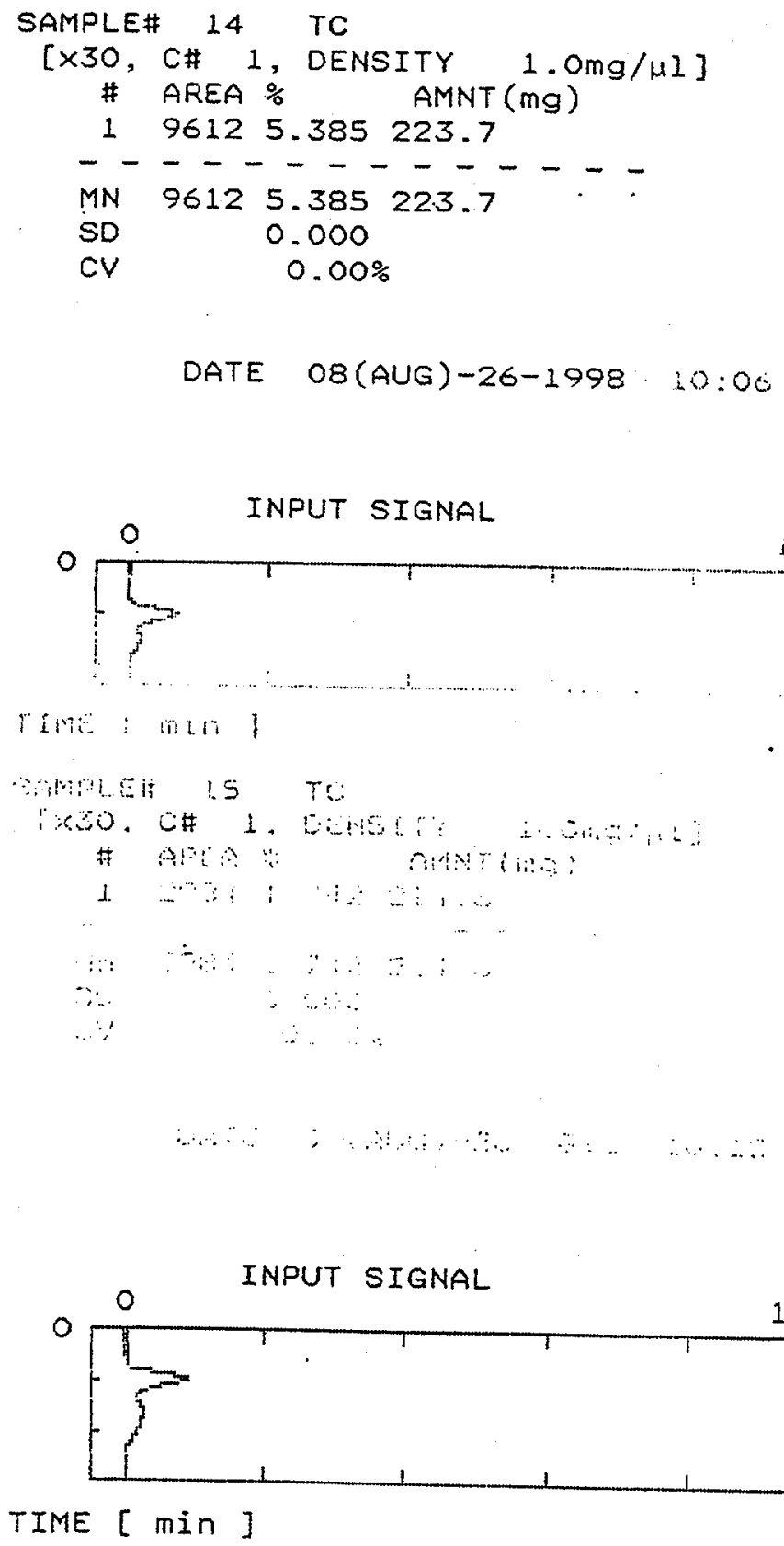

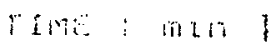

Ginteis IS TS

TIME [ min] 


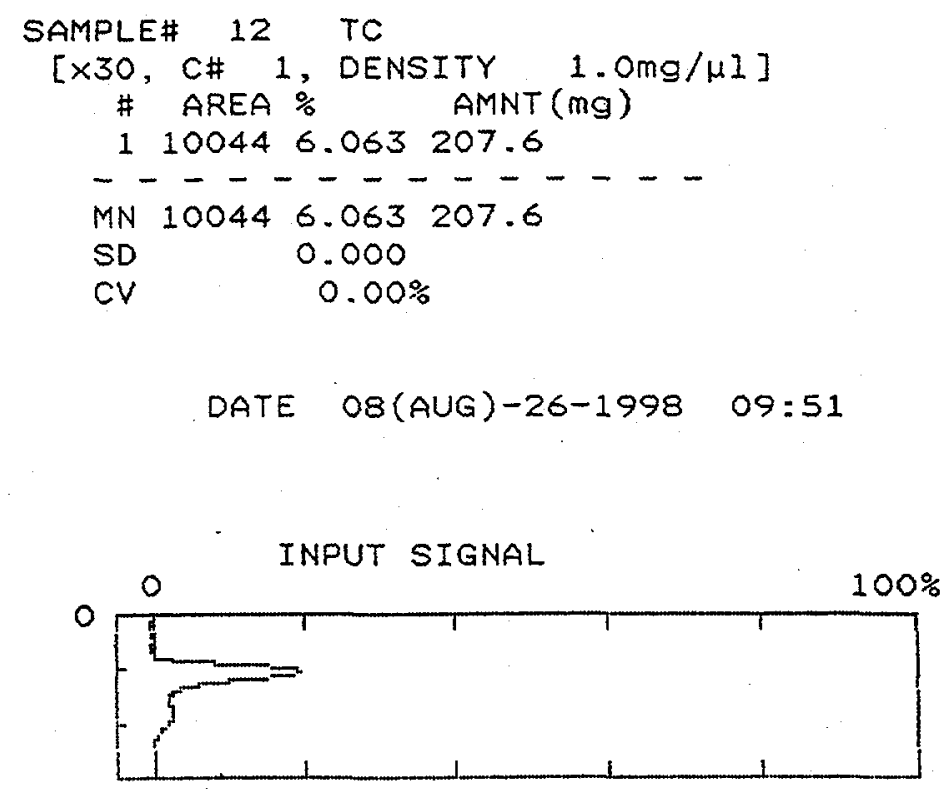

TIME [ min ]

SAMPLE\# 13 TC

[ $\times 30$, C\# 1, DENSITY $1.0 \mathrm{mg} / \mu \mathrm{l}]$

\# AREA \% AMNT (mg)

191855.497209 .4

- - - - - - - - - - -

MN $9185 \quad 5.497 \quad 209.4$

SD $\quad 0.000$

CV $\quad 0.00 \%$

DATE 08(AUG)-26-1998 10:00

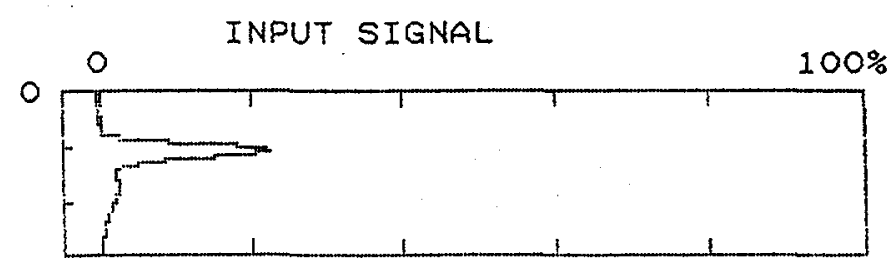

TIME [ min ] 


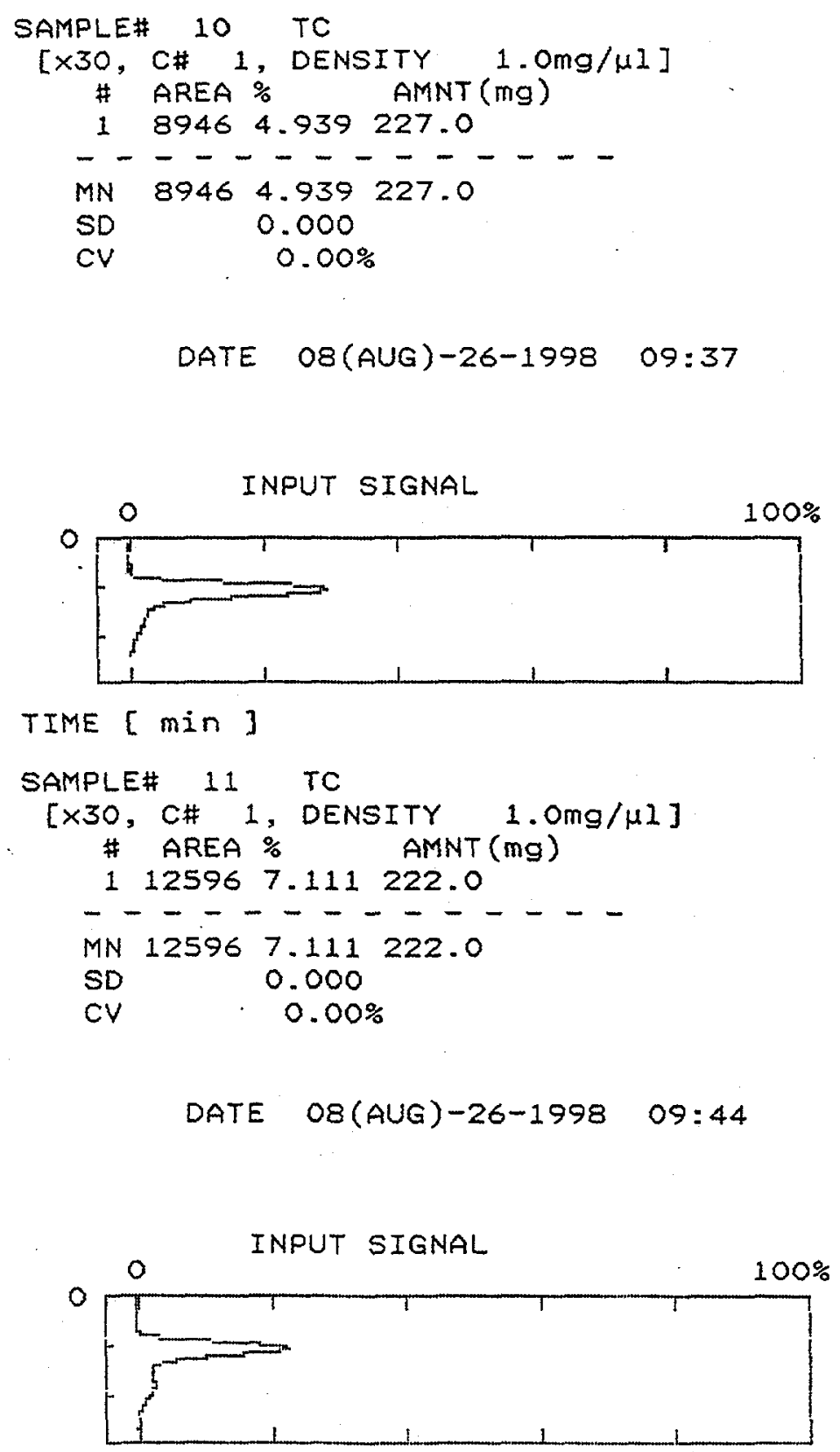

TIME [min] 


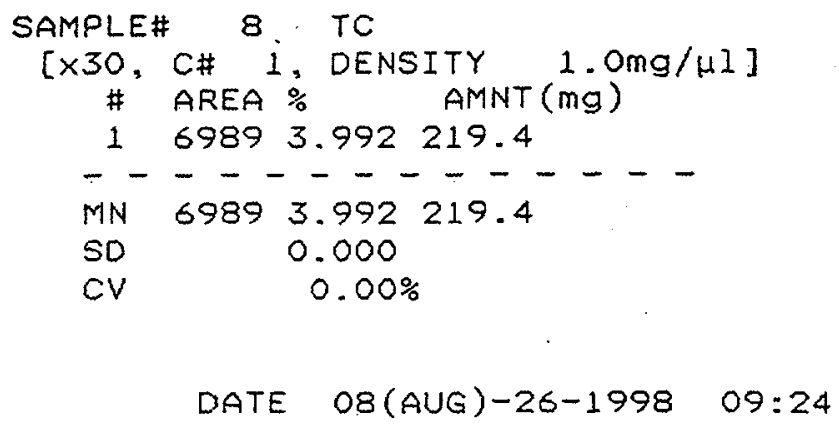

TIME [ min ]
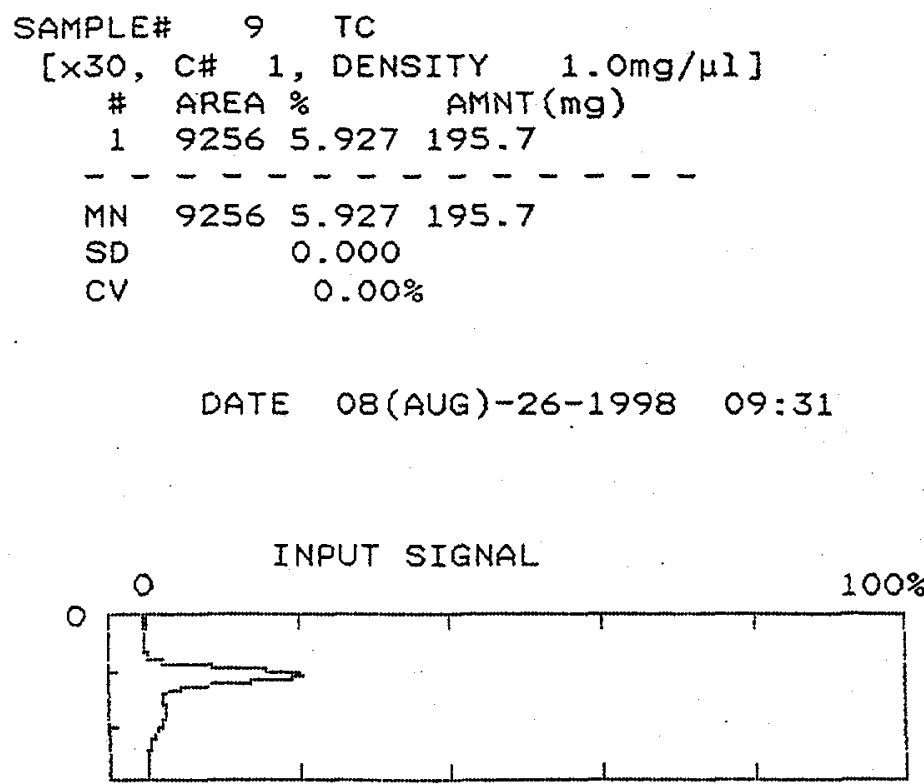

TIME [ $\mathrm{min}]$ 


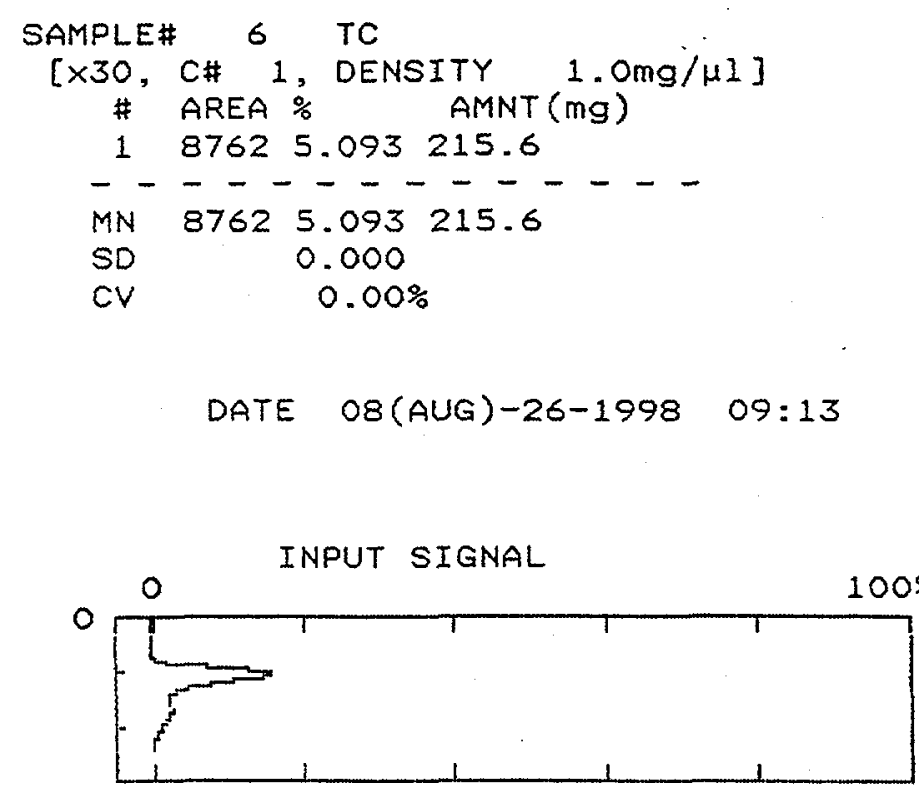

TIME [min]

SAMPLE\# 7 TC

[ $\times 30, C \# 1$, DENSITY $1.0 \mathrm{mg} / \mu \mathrm{I}]$

\# AREA \% AMNT (mg)

$17103 \quad 4.195 \quad 212.2$

- - - - - - - - - - -

MN $7103 \quad 4.195 \quad 212.2$

$\begin{array}{ll}\text { SD } & 0.000 \\ \text { CV } & 0.00 \%\end{array}$

DATE OB(AUG)-26-1998 09:19

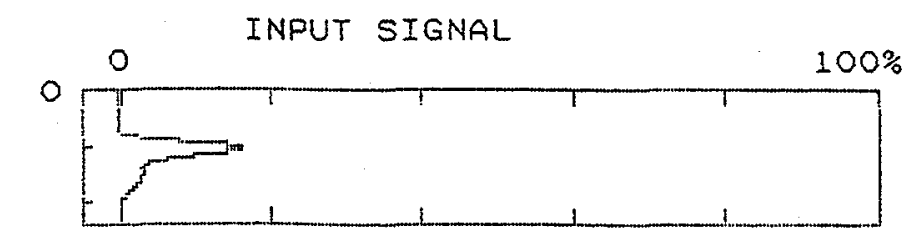

TIME [ min] 


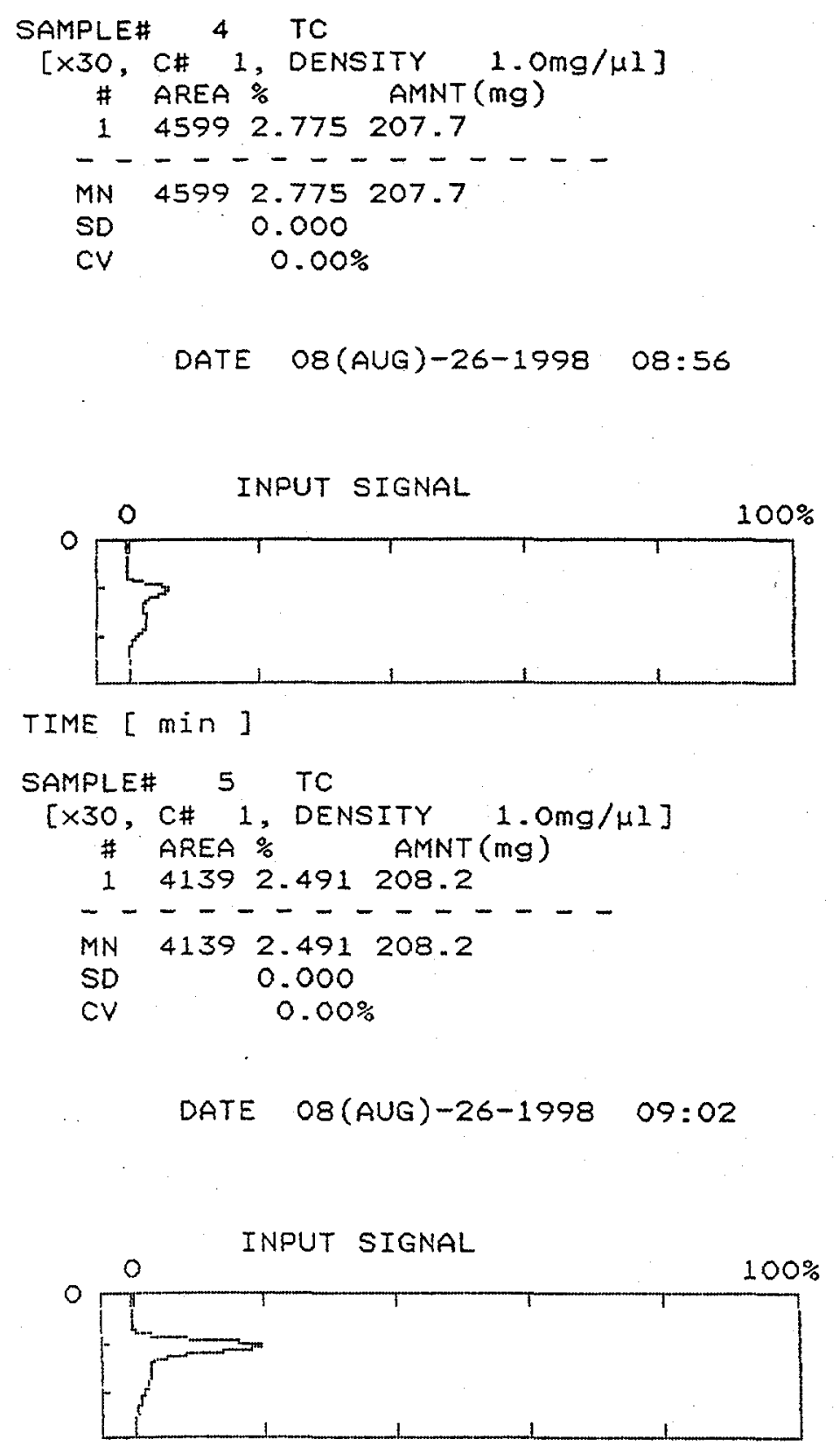

TIME [ min] 


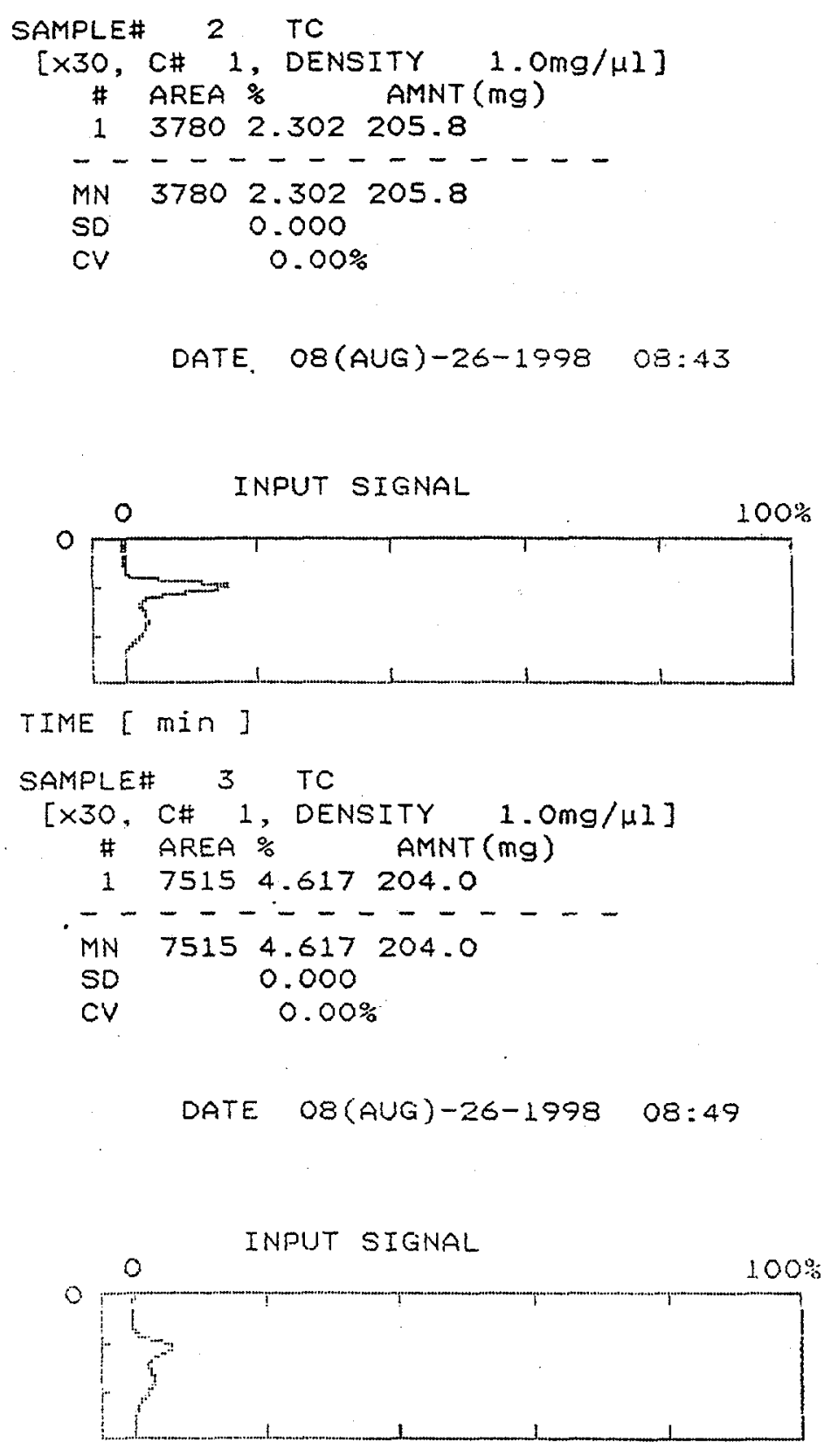

TIME [ min] 


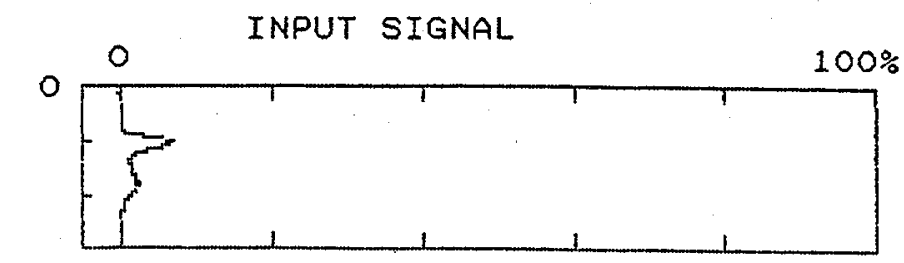

$\operatorname{TIME}[\min ]$ 


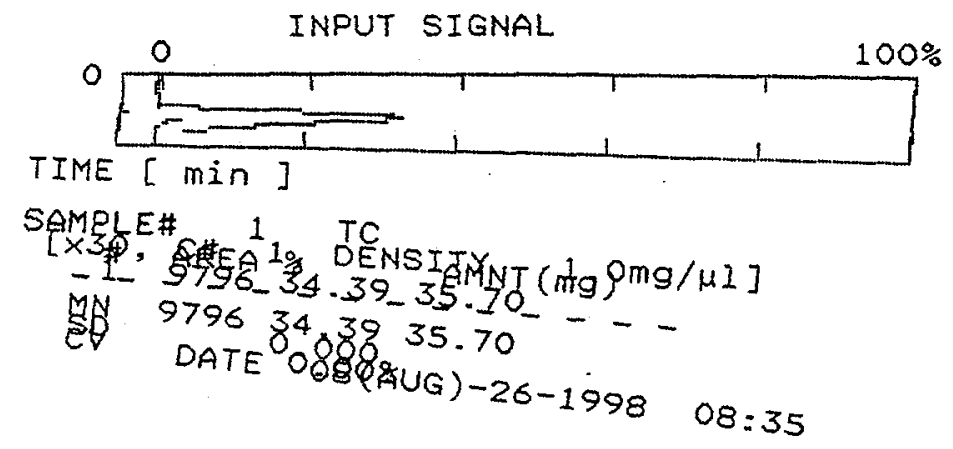




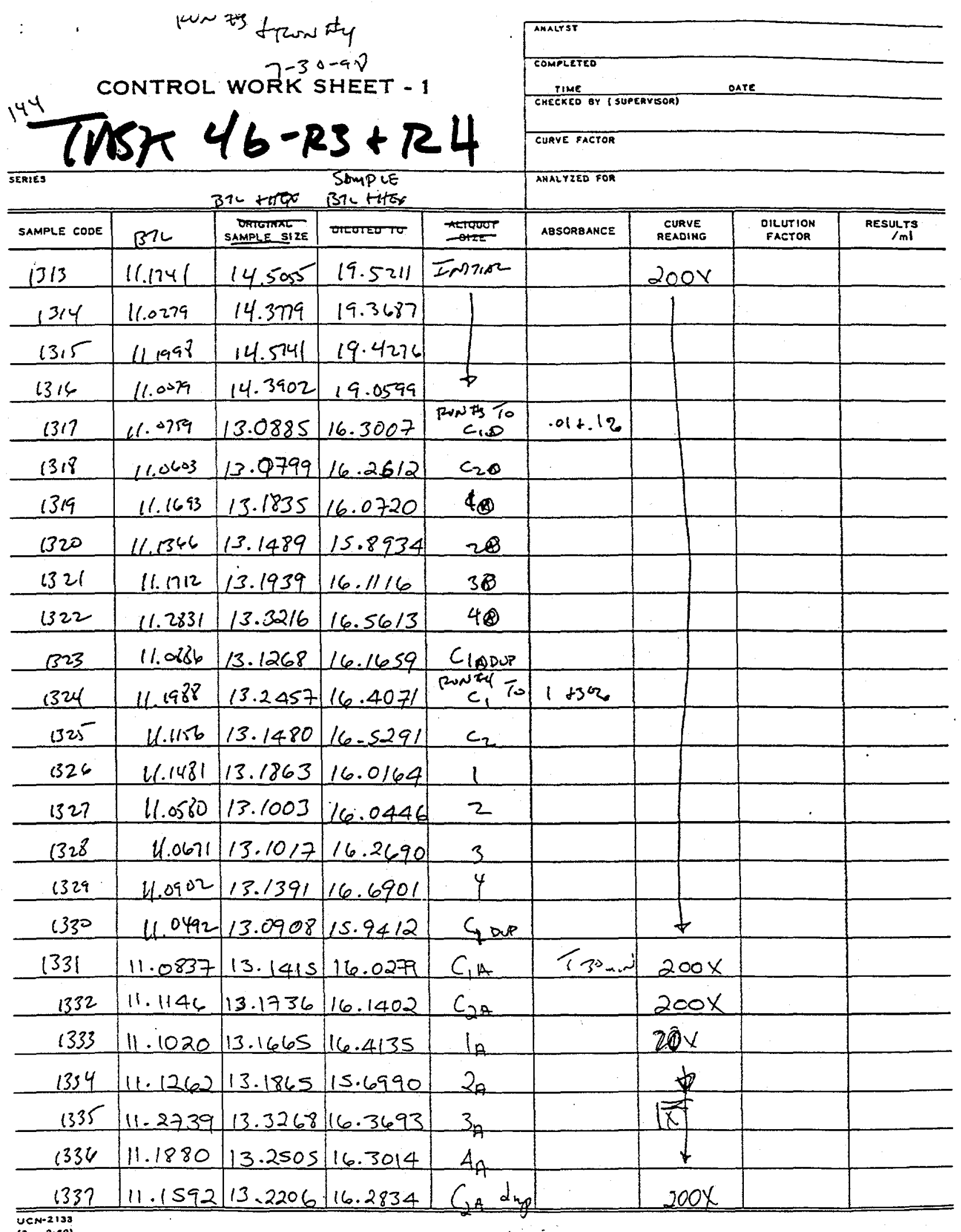

F-185 
CONTROL WORK SHEET - 1

\begin{tabular}{|l|}
\hline ANALYST \\
SOMPLETEO \\
TIME \\
CHECKEO BY (SUPEAYSORI OATE \\
\hline CURYE FACTOR
\end{tabular}

\begin{tabular}{|c|c|c|c|c|c|c|c|c|}
\hline \multicolumn{5}{|l|}{$\overline{\text { SERISS }}$} & \multicolumn{4}{|l|}{ AMALYZEO FOA } \\
\hline SAMPLE CODE & & $\begin{array}{l}\text { ORIGINAL } \\
\text { SAMPLE SIEE } \\
\end{array}$ & DILUTED TO & $\begin{array}{c}\text { ALIQUOT } \\
\text { SIIEE }\end{array}$ & ABSORA ANCE & $\begin{array}{c}\text { CURVE } \\
\text { REAOING }\end{array}$ & $\begin{array}{l}\text { DLLUTION } \\
\text { FACTOA }\end{array}$ & $\begin{array}{c}\text { RESULTS } \\
/ / \mathrm{mI}\end{array}$ \\
\hline 1338 & 10.9526 & 13.0190 & 16.4352 & $\because$ & $(3 \times-)$ & $200 x$ & & \\
\hline 1339 & 11.1001 & 13.1679 & 16.1394 & & $C$ & $200 x$ & & \\
\hline 1340 & 11.0957 & 13.1746 & 16.4797 & & 1 & $1 x$ & & \\
\hline 1341 & 11.1266 & 13.1965 & 16.6931 & & 2 & 1 & & \\
\hline 1342 & 11.1436 & 13.2042 & 16.4330 & & 3 & & & \\
\hline 1343 & 11.0701 & 13.1280 & 16.4872 & & 4 & $\forall$ & & \\
\hline 1344 & 11.0205 & 13.0841 & 16.0091 & $\therefore$ & & $200 x$ & & \\
\hline 1345 & $\begin{array}{r}11.1986 \\
H .19+11 \\
\end{array}$ & 13.2659 & 16.3448 & & & $200 x$ & & \\
\hline 1346 & 11.1911 & 13.2605 & 16.6283 & & & $200 x$ & & \\
\hline 1347 & 11.2067 & 13.2758 & 16.7230 & & & $20 x$ & & \\
\hline 1348 & 11.1994 & 13.2544 & 16.4710 & & & $t$ & & \\
\hline 1349 & 11.2644 & 13.3263 & 16.1659 & & & L $1 x$ & & \\
\hline 1350 & 11.1564 & 13.2095 & 16.7823 & & $4 A$ & $+1 x$ & & \\
\hline 1351 & 11.1790 & 13.2295 & 16.3171 & & & $20 x$ & & \\
\hline 1352 & 11.1498 & 13.1883 & 16.0310 & & & $200 x$ & & \\
\hline 1353 & 11.2235 & 13.2715 & 16.2055 & & $C$ & $200 x$ & & \\
\hline 1354 & 11.1850 & 13.2135 & 16.2806 & & 1 & Q & & \\
\hline 1355 & 11.1399 & 13.1972 & 16.2888 & & 2 & 1 & & \\
\hline 1356 & 11.2940 & 13.3478 & 16.6201 & & 3 & & & \\
\hline 1357 & 11.2731 & 13.3269 & 16.6295 & & 4 & & & \\
\hline 1358 & 11.0851 & 13.1428 & 16.0862 & & $1 d x$ & 6 & & \\
\hline 1359 & 11.1447 & 13.1158 & 16.5637 & & $C A$ & $260 x$ & T4ums & \\
\hline 1360 & 11.0996 & 13.0895 & 16.5976 & & C. & $200 \times$ & & \\
\hline 1361 & 11.1443 & 13.1419 & 16.2157 & & In & $20 x$ & & \\
\hline 1362 & 11.0956 & 13.0888 & 16.2714 & & $2 n$ & $20 x$ & & \\
\hline
\end{tabular}
ueN-2133 
CONTROL WORK SHEET - 1

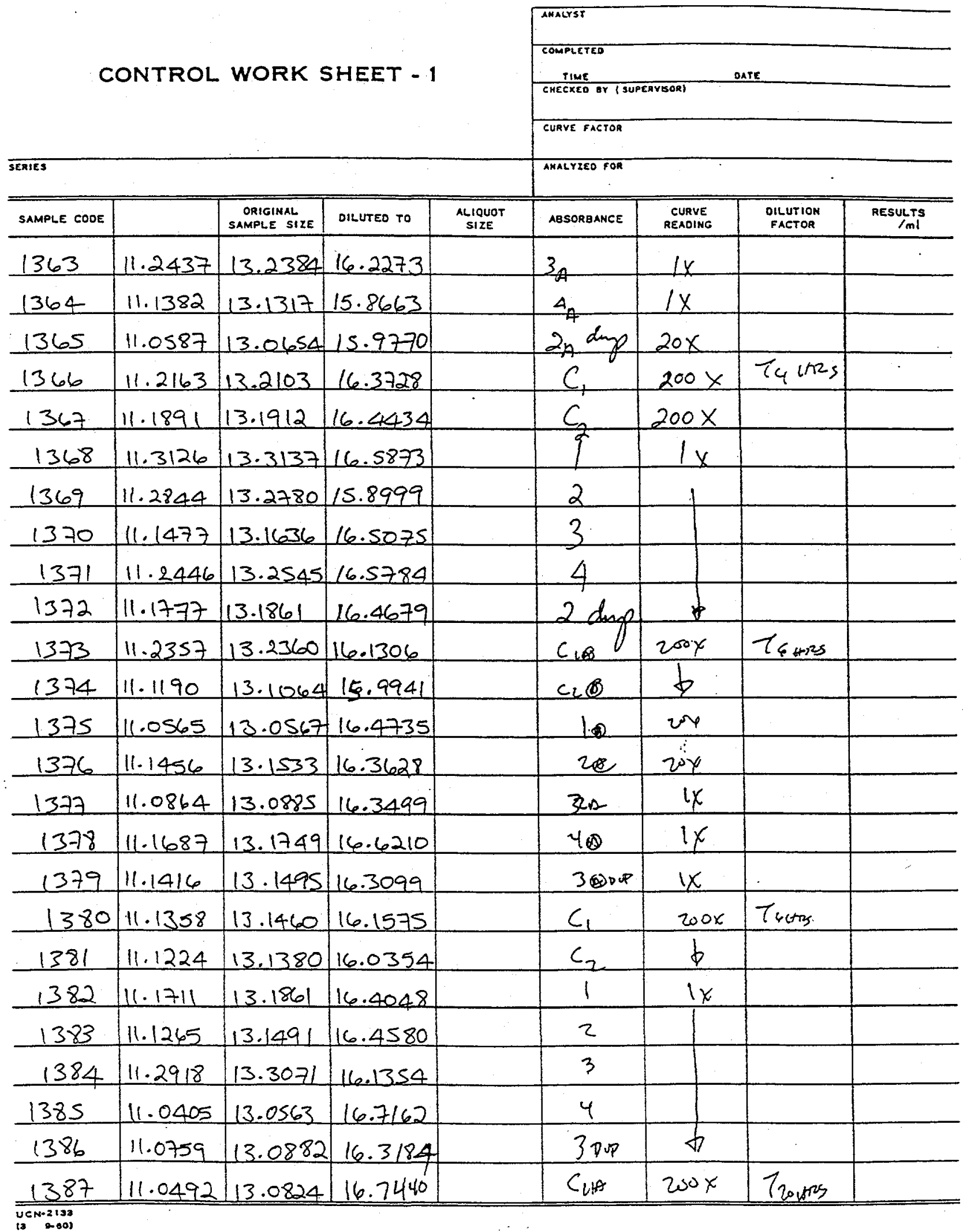


CONTROL WORK SHEET - 1

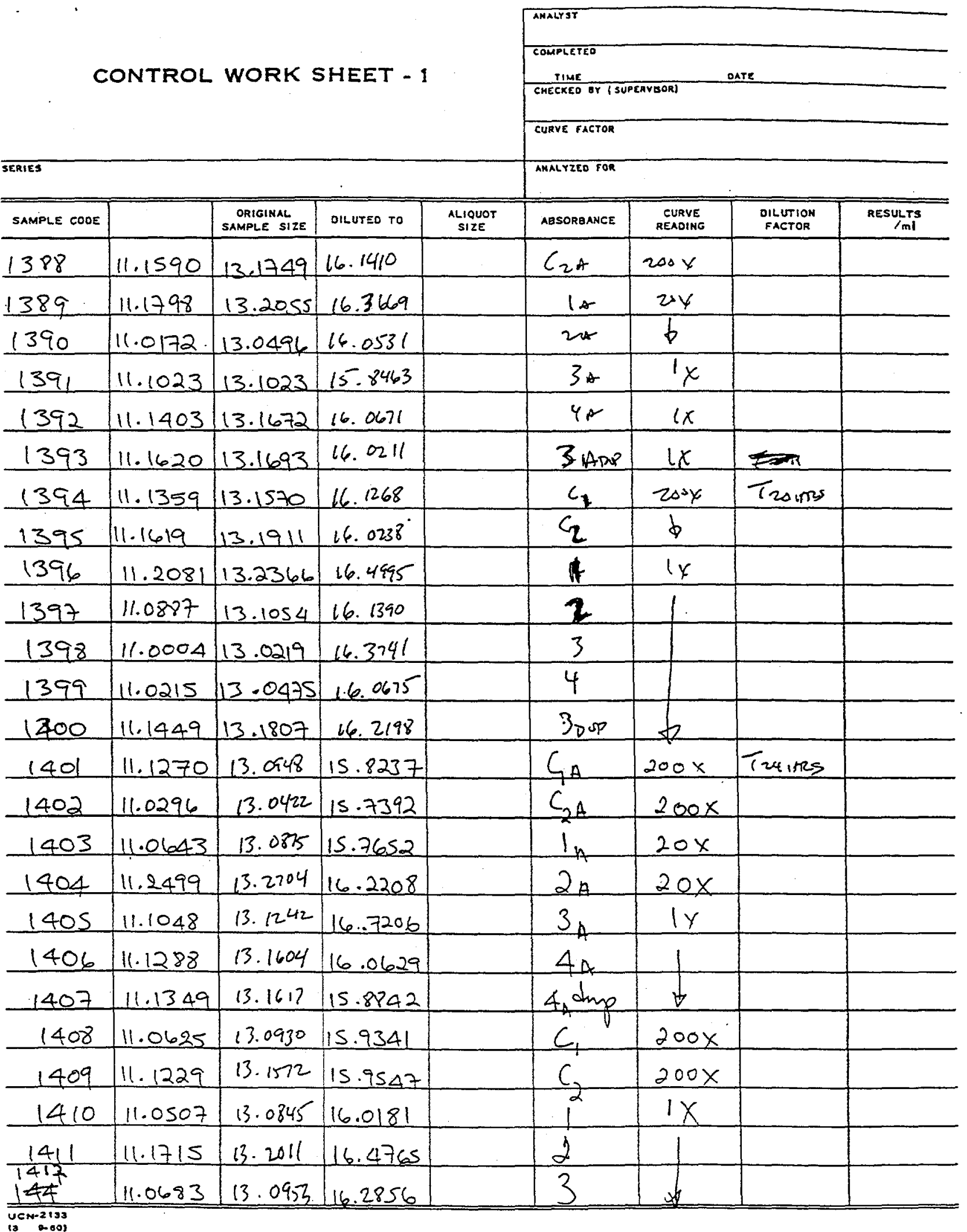


CONTROL WORK SHEET - 1

\begin{tabular}{|l|}
\hline ANALYST \\
\hline COMPLETEO \\
TIME \\
\hline CMECKEO OY (SUPEAYISOR) OATE \\
\hline CURYE FACTOR \\
\hline ANALYZEO FOR \\
\hline
\end{tabular}

\begin{tabular}{|c|c|c|c|c|c|c|c|c|}
\hline \multicolumn{5}{|l|}{ SERIES } & \multicolumn{4}{|l|}{ ANALYZEO SOR } \\
\hline SAMPLE CODE & & $\begin{array}{c}\text { ORIGIMAL } \\
\text { SAMPLE SIZE }\end{array}$ & DILUTED TO & $\begin{array}{c}\text { AllQuot } \\
\text { SIZE }\end{array}$ & ABSORBANCE & $\begin{array}{c}\text { CURVE } \\
\text { REAOING }\end{array}$ & $\begin{array}{l}\text { DLLUTION } \\
\text { FACTOR }\end{array}$ & $\begin{array}{r}\text { RESULTS } \\
1 \mathrm{mI}\end{array}$ \\
\hline 1413 & 11.1692 & 13.1889 & 16.4694 & 4 & $1 x$ & & & \\
\hline 1414 & 11.1209 & 13.1683 & 150.9529 & $\Delta d$ & $1 x$ & & & \\
\hline 1415 & 11.1370 & 13.1582 & 16.2060 & & $C_{1}^{96+12}$ & $200 x$ & & \\
\hline 1416 & 11.2364 & 13.2672 & 16.0098 & & $c_{2}$ & 6 & & \\
\hline 1417 & 11.1068 & 13.1465 & 16.3239 & & 18 & $40 x$ & & \\
\hline 1418 & 11.0680 & 13.1045 & 16.3845 & & 20 & $4 \times x$ & & \\
\hline 1419 & 11.1619 & 13.2002 & 16.4585 & & 36 & $1 x$ & & \\
\hline 1420 & 11.2784 & 13.3168 & 17.0012 & & 4 (20) & $1 x$ & & \\
\hline 1421 & 11.1597 & 13.2049 & 16.0246 & & $C_{20}$ Dur & $200 x$ & & \\
\hline 1422 & 11.1156 & 13.1655 & 15.9315 & & $e_{1}$ & $200 x$ & & \\
\hline 1423 & 11.1151 & 13. 16.68 & 15.9345 & & $c_{2}$ & $\phi$ & . & \\
\hline 1424 & 11.0708 & 13.1295 & 16.0589 & & 1 & 16 & & \\
\hline 1425 & 11.0939 & 13.1559 & 16.4611 & & 2 & 1 & & \\
\hline 1426 & 11.0814 & 13.1262 & 16.1722 & & 3 & & & \\
\hline 1427 & 11.1746 & 13.2202 & 16.9189 & & 4 & $\phi$ & & \\
\hline 1428 & 11.2564 & 13.3090 & 116.1721 & & $C_{2 p \beta}$ & zor & & \\
\hline 1429 & 11.1543 & 14.5244 & 14.6192 & & $\left.\operatorname{lop}_{B}=d\right\}$ & $1 x$ & & \\
\hline 1430 & 11.1111 & 14.4896 & 14.5311 & & 1 & & & \\
\hline 1431 & 11.1913 & 14.6074 & 14.6900 & & & & & \\
\hline 1432 & 11.1505 & 14. 5154 & 14.6144 & & & & & \\
\hline 1433 & 11.1848 & 14.6067 & 14.7006 & & & & & \\
\hline 1434 & 11.1982 & 14.6169 & $44.65-37$ & & & & & \\
\hline 1435 & 11.1020 & 14.5280 & 14. 6209 & & & & & \\
\hline 1436 & 11.1536 & 14.5817 & 14.6239 & & & & & \\
\hline 1437 & 11.1578 & 14.6034 & 14.6991 & & 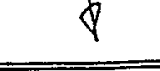 & 8 & & \\
\hline
\end{tabular}
uen-2is3 t3 2001 
CONTROL WORK SHEET - 1

\begin{tabular}{|l|}
\hline AMALYST \\
\hline COMPLETEO \\
TIME \\
\hline CMECKED BY (SUPERYISOR) DATE \\
\hline CURYE FACTQR \\
\hline AMALYZED FOR
\end{tabular}

\begin{tabular}{|c|c|c|c|c|c|c|c|c|}
\hline SAMPLE CODE & & $\begin{array}{c}\text { OAIGINAL } \\
\text { SAMPLE SIZE }\end{array}$ & OLLUTED TO & $\begin{array}{c}\text { ALIOUOT } \\
\text { SIZE }\end{array}$ & ABSORBANEE & $\begin{array}{c}\text { CURVE } \\
\text { READING }\end{array}$ & $\begin{array}{l}\text { DILUTION } \\
\text { EACTOR } \\
\end{array}$ & $\begin{array}{l}\text { RESULTS } \\
/ \mathrm{ml}\end{array}$ \\
\hline 1438 & 11.1360 & 14.5553 & 14.5969 & $\begin{array}{l}\operatorname{pur}_{10} 3 \\
0 \min 3\end{array}$ & $1 x$ & $a^{4}$ & $\therefore$ & \\
\hline 1439 & 11.1251 & 14.5317 & 14. 6273 & & 1 & & $\vdots$ & \\
\hline 1446 & 11.1080 & 14.5031 & 14.5418 & $\phi$ & & & $\therefore r$ & \\
\hline 1441 & $11 \cdot 1573$ & 14.5596 & 19.6287 & $\begin{array}{l}\text { Puns \#4 } \\
\text { OR3? }\end{array}$ & & & $\cdot 1$ & \\
\hline 1442 & 11.2408 & 14.6816 & 14.7241 & 1 & & & & \\
\hline 1443 & 11.0839 & 14.5204 & 14.6193 & & & & & \\
\hline 1444 & 11.0265 & 14.4606 & 64.5041 & & & & & \\
\hline 1445 & 11.1305 & 14.5609 & 14.6550 & & & & & \\
\hline 1446 & 11.0727 & 14.5029 & 14.5409 & & & & & \\
\hline 1447 & 11.1110 & 14.5349 & 14.6346 & & & & & \\
\hline 1448 & 11.0398 & 14.4719 & 14.5104 & & & & & \\
\hline 1449 & 11.1386 & 14.5778 & $14.680^{\circ}$ & & & & & \\
\hline 1450 & 11.0791 & 14.5050 & 14.5462 & & & & & \\
\hline 1451 & 11.1221 & 14.5586 & $14.6 \cos$ & & & & & \\
\hline 1452 & 11.0953 & 14.5290 & 14.5757 & $\varnothing$ & & & & \\
\hline$\sum 1453$ & $\begin{array}{r}488.39 \\
+1.0352 \\
\end{array}$ & 271.66 & 1074.73 & $18 / 4$ & (1) & & & \\
\hline 1454 & $\begin{array}{r}489.50 \\
+1.0745 \\
488.96\end{array}$ & 281.94 & 1085.10 & 20 & 2 & & & \\
\hline 1455 & $\begin{array}{r}488.96 \\
11+841 \\
\end{array}$ & 287.70 & 1098.16 & $\sec$ & (3) & & & \\
\hline$\$ 1456$ & $\begin{array}{r}489.37 \\
+1.0831 \\
49.24\end{array}$ & 290.14 & 1100.77 & $f(x)$ & (4) & & & \\
\hline 1457 & $\frac{4.04}{11013}$ & 293.89 & 1094.56 & $\| \varepsilon$ & 14 & & & \\
\hline 1458 & 17.0944 & 281.08 & 1085.12 & $z \varepsilon$ & $2 A$ & & & \\
\hline 1559 & 485.28 & 280.00 & 1084.80 & $\beta<$ & $3 p$ & & & \\
\hline 1460 & 491.36 & 289.80 & 1090.76 & $\varepsilon$ & $A_{4}$ & & & \\
\hline & & & & & & & & \\
\hline
\end{tabular}


7-30-98 pents 016.12

$\frac{400-15 \times 900}{0830} 11.2 .249000930$

2100

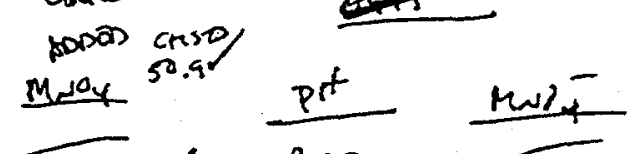

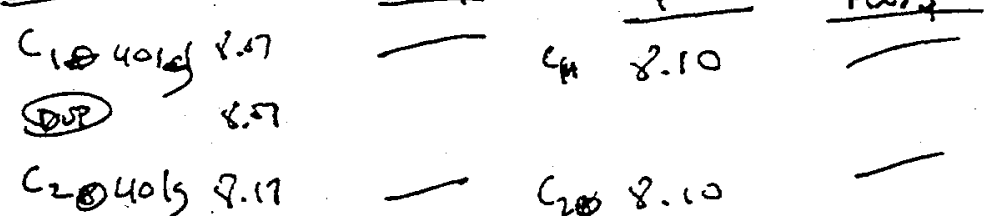

$c_{10} \frac{p^{6}}{8.04} \quad$ mosy

$c_{2089}$

10458.17

(20) 8.10

$2840 l_{3} 8.18$

(ब) 6.78

29.5

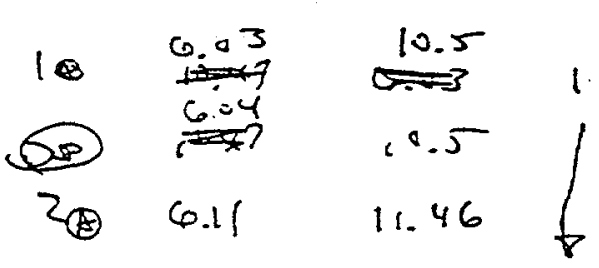

$301009.8 .23 \quad 10$ al $306.26 \quad 49.8 \quad 0.5 / 1.530 \quad 5.93 \quad 49.6 \quad 0.5 / 8$

$4.40 \%, 8.23$

praser 10, 1020

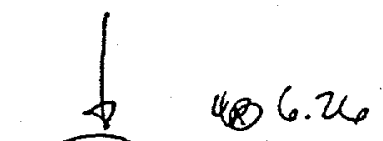

$48.9 \downarrow$

(293)

480049.4

$c_{1} 40,8.37$

42.29

C. 8.25

(008)

$c_{2} 400,8.35-c_{2} 8.38$

$c_{2} 8.26$

$1400,8.36 \quad\left(5.2333_{5}\right) 008.38$

$12.4 \quad 0.01 / 8.11 \quad 6.38$

$2^{2009}+36 \quad(5.28150) 2_{16-61}$

(49) 6.38

26.32

$25.40 .02 / \%$

$\left.340056.39 \quad \frac{(16.00129)}{16.9}\right] 7.00$

12.4

25.3

25.1

$440057.100^{\text {6o.par }} 47.03$

35.4

$365^{-}$

$37.60 .1 / 8.0$

$4 \quad 6.92 \quad 3 ? 7$

F-191 
$7-3-48$

208.26

6.31

(20) C.M

6.39
Ch $\frac{1300}{209}=$

20.41

30 .

$7 / 3 / / 98$

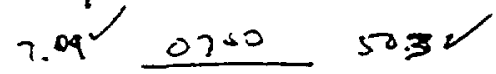
$\mathrm{ett}^{\mathrm{e}}$

C. 7.93

mony

(20) 7.99

(24) $\quad 6.2$

2.56 क

$48.8 \quad .518 .5$

उत) 6.11

(10.8) 0.4

(ब) 6.13

\#4 p.0.5 m-10y

c. 8.38 .

$$
\begin{aligned}
& c_{1} 8.32 \\
& c_{2} 8.36
\end{aligned}
$$

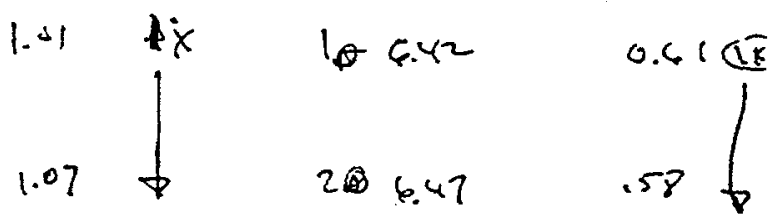

$.5 / 8.5$

49.4

$c_{2} 8.40$

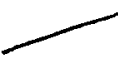

16.91

26.26

(20) 6.76

32.19

$\left.25.2\right|_{25.2} ^{24.7} 26.60$

47.22

37.7 .0

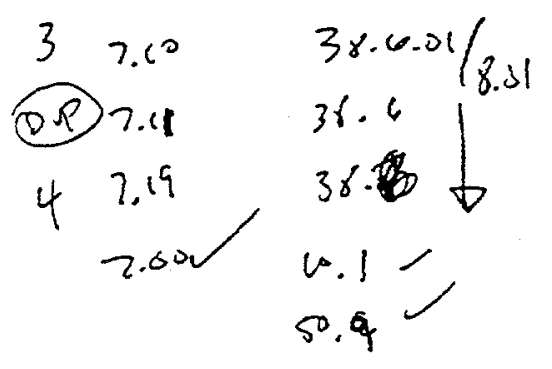

49.3

$49.5+$

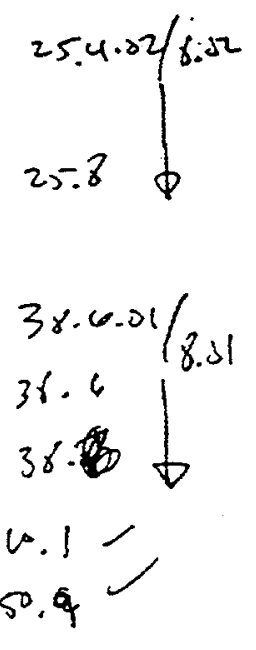

$\mathrm{C}_{2} 8.09$

16.73

28.72

$47.7 .5 / 8$.

48.2648 .0

(D) 6.21

$48.0 D$

$3 \quad 7.30 \quad 32.0 \%$

(2.8) 7.32

36.0
38.18 c. 8.08

F-192 


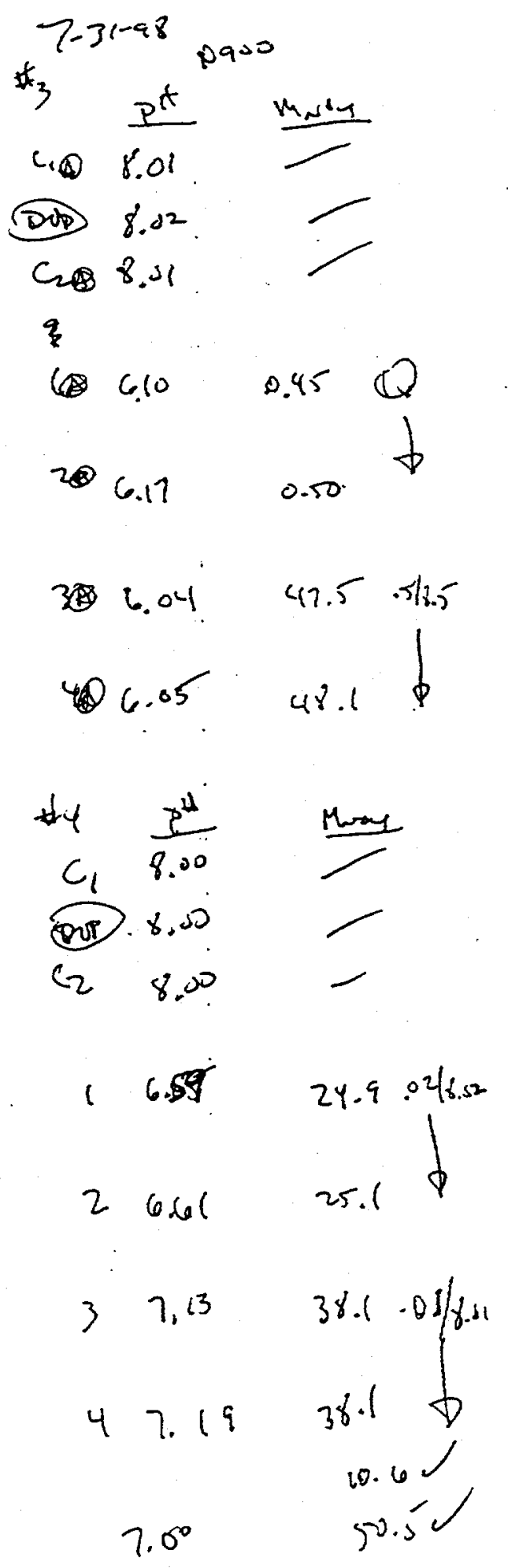

F-193 


$$
\begin{aligned}
& \text { sonts }+ \text { ond }
\end{aligned}
$$

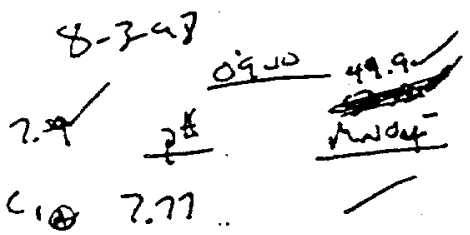

$$
\begin{aligned}
& \text { (6) } 28.84 \\
& \text { (1) } 6.67 \ldots \\
& 286.71 \ldots \\
& 306.4 y^{\circ} \quad 47.2 \% .5 \\
& 406.4 i^{\circ} 47.4 \text { b }
\end{aligned}
$$

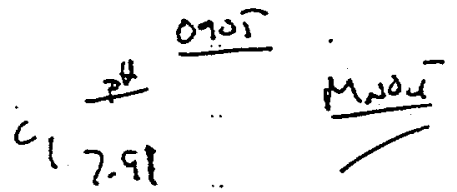

$$
\begin{aligned}
& \int_{2 \pi}^{c_{2}} 2.92 \\
& 16.86 \text { 25.4.02/8.2 } \\
& 20.73^{2} 25.2 \phi \\
& 32.35^{\circ} \quad 32.4 .01 / 6.01 \\
& +7.4639 .9 \text { b } \\
& 7.10^{\circ} \quad \begin{array}{ll}
10.3 \\
50.1
\end{array}
\end{aligned}
$$


$8-12-98$

TAss $4 b$ - Rna $7+$ Ran 8

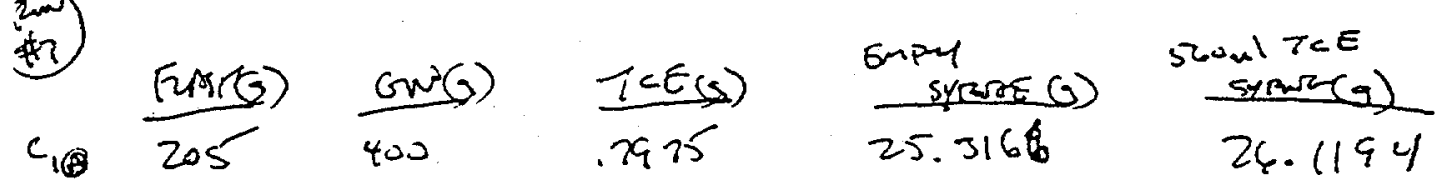

$\begin{array}{llllll}c_{2} & 213 & 400 & 0.815 & 25.3219 & 26.1373\end{array}$

$10 \quad 2.2 \quad 400 \quad 0.8072 \quad 25.3222 \quad 26.128^{2}$

$20 \quad 400.8 \quad 0.7945 \quad 25.3210 \quad 26.1301$

3 (8) $400 \quad 0.8055 \quad 25.3356 \quad 26.1400$

$4205 \quad 400 \quad 0.8077 \quad 25.3345 \quad 26.1415$

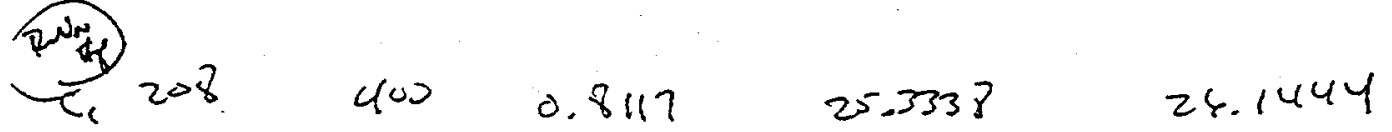

$\begin{array}{lllll}c_{2} 221 & 400 \quad 0.8058 & 25.3327 & 26.1385\end{array}$

$\begin{array}{lllll}1209 & 400 & 0.8095 & 25.3327 & 26.1422\end{array}$

$\begin{array}{lllll}207 & 400 & 0.8171 & 25.3327 & 26.1484\end{array}$

$\begin{array}{lllll}3206 & 400 & 0.8259 & 25.3313 & 26.1327\end{array}$

$\begin{array}{lllll}4009 & 400 & 0.6092 & 25.3318 & 26.1400\end{array}$

25.3308

F-195 


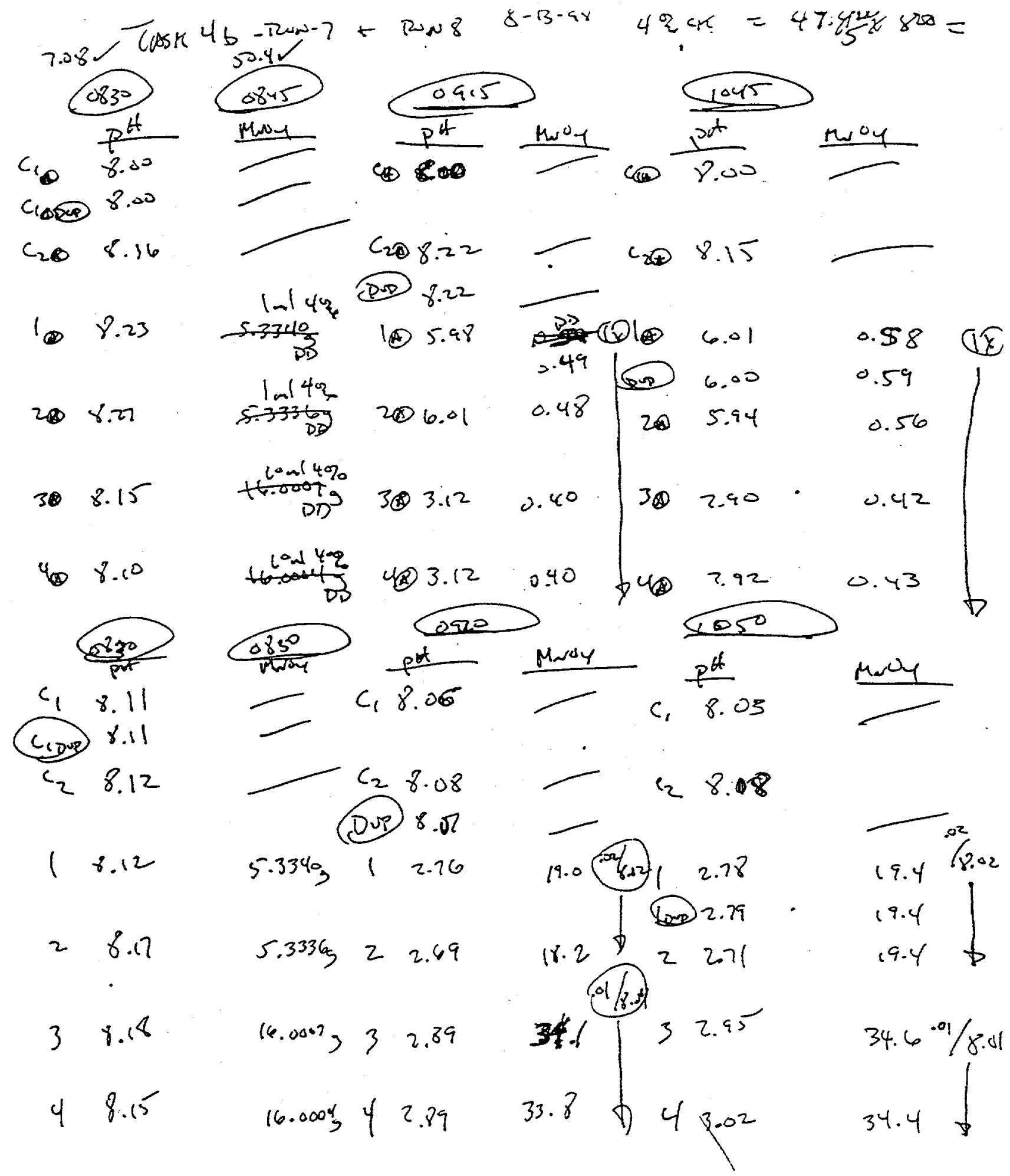


$8-13-92$

1245

$c_{0} \frac{p^{4}}{8.00}=$

$\begin{array}{lll}10 & 5.69 & 0.30 \\ 20 & 5.81 & 0.22 \\ 20000 & 5.81 & 0.22 \\ 3 \oplus & 2.79 & 0.33 \\ 4 \otimes & 2.78 & 0.346\end{array}$

1250

c. 7.82

$c_{2} 7.85$

$\begin{array}{ll}1 & 2.65 \\ 2 & 2.58 \\ 2000 & 2.58 \\ 3 & 2.84\end{array}$

42.93

19.0

6.0 b
445

c. $\frac{\mathrm{pr}^{+}}{7.74}=\mathrm{MNO}_{4}^{-}$

$C_{2} 7.80$

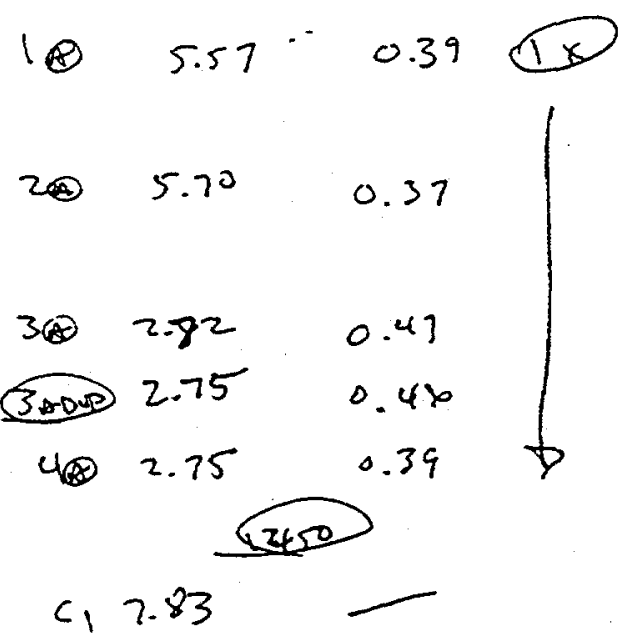

$c_{2} 7.84$

$18.8 .02 / 2.2$

$34.3 .01 / 8.01$

32.86
$4 \quad 2.93$
$\begin{array}{ll}3007 \\ 2.16\end{array}$

4.02
$0.8 .02 / 8.02 .1$

6.5

$34.2 \cdot 0 / 8.0121$

34.1

34.3

10.5

50,4

F-197 


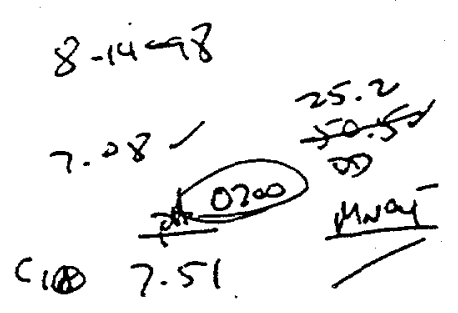

0207.45
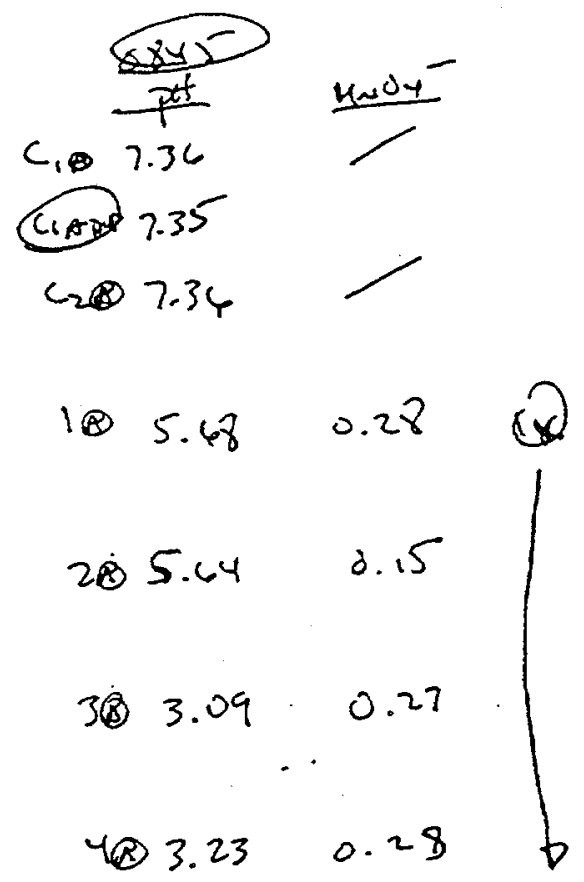

$\begin{array}{ll}3.20 & 0.29 \\ 3.20 & 0.28\end{array}$

025

c) 7.32

$c_{2} 7.31+\frac{c_{2}}{c_{2}} 7.35$

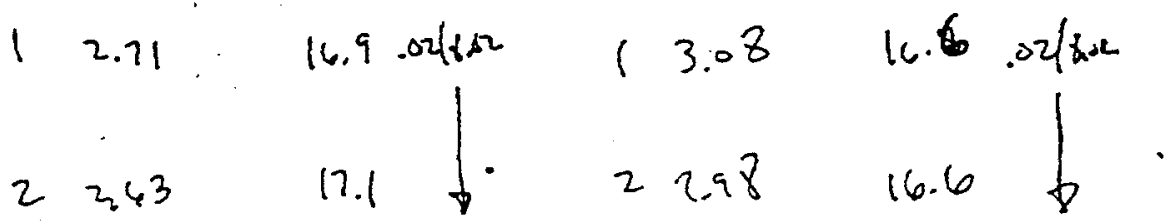

$\begin{array}{lllllll}3.95 & 33.3 .01(6.01 & 3 & 3.36 & 33.3 & 0.048 .41\end{array}$

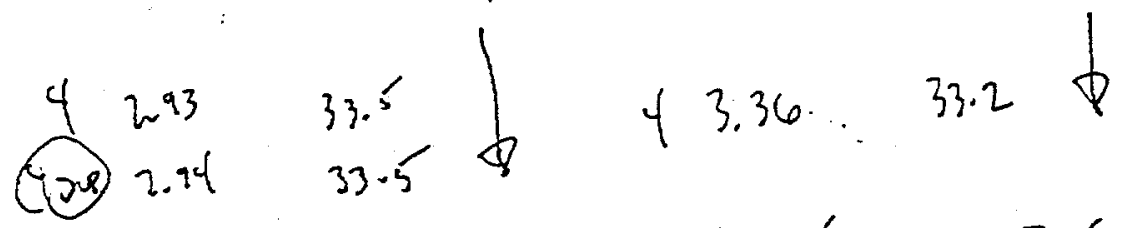

$4.02 J$

10.3

$F=198$ 


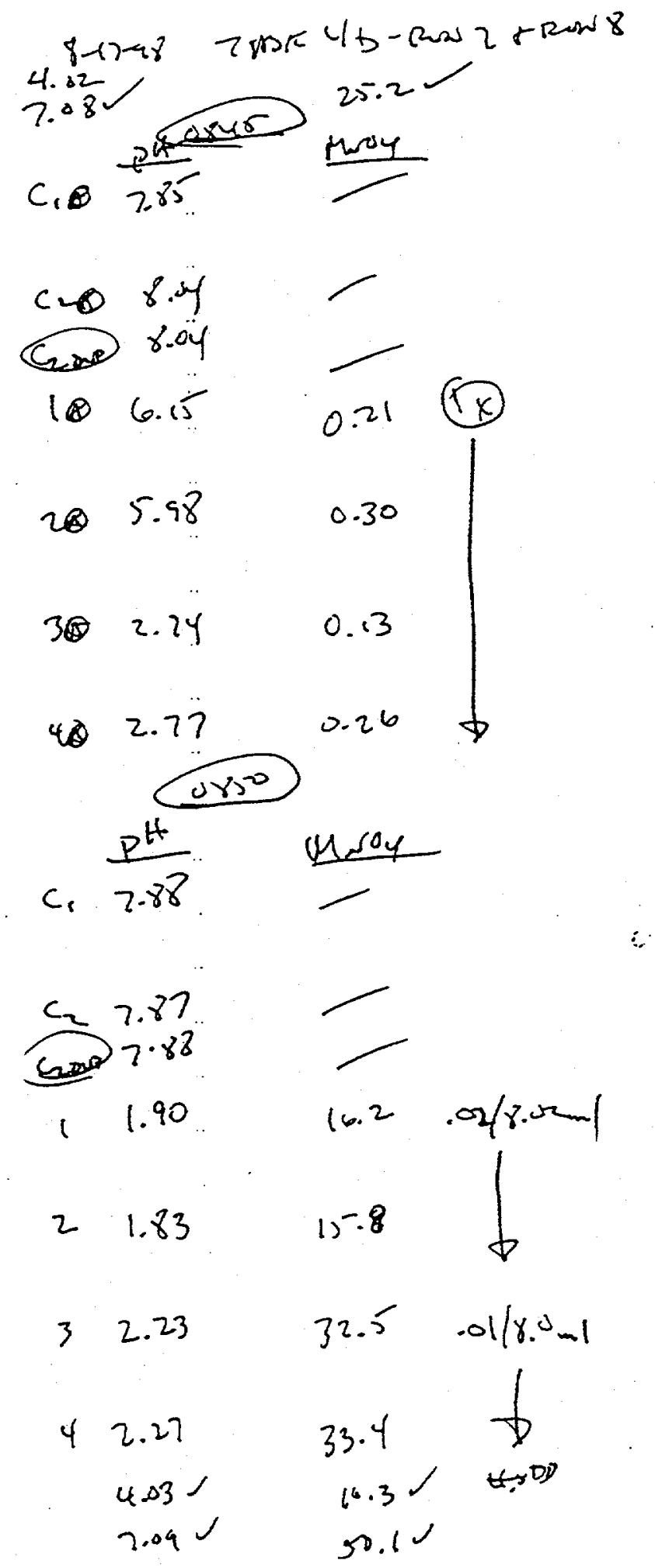


CONTROL WORK SHEET - 1

AMALYST
COMPLETEO
TIME ONECXEO OY (SUPERVISOA) OATE
CURVE FACTOR
ANALYZEO FOR

\begin{tabular}{|c|c|c|c|c|c|c|c|c|}
\hline \multicolumn{5}{|l|}{$\overline{\text { SERIES }}$} & \multicolumn{4}{|l|}{ AMALYZEO FOR } \\
\hline SAMPLE CODE & & $\begin{array}{c}\text { ORIGINAL } \\
\text { SAMPLE SIZE } \\
\end{array}$ & DILUTEO TO & $\begin{array}{c}\text { ALIQUOT } \\
\text { SIZE } \\
\end{array}$ & ABSOREANCE & $\begin{array}{c}\text { CURVE } \\
\text { REAOING }\end{array}$ & $\begin{array}{c}\text { OLLUTION } \\
\text { FACTOR } \\
\end{array}$ & $\begin{array}{c}\mathrm{RESULTS} \\
/ \mathrm{mI} \\
\end{array}$ \\
\hline 1524 & 11.0322 & 13.0310 & 15.8988 & $\operatorname{cis}$ & $2000 x$ & & senos & \\
\hline 1525 & 11.0725 & 12.9330 & 16.0034 & $C_{20}$ & $\phi$ & & 1 & \\
\hline 1526 & 11.1811 & 12.9839 & 15.7173 & 10 & & & & $\cdot$ \\
\hline 1527 & 11.0795 & 12.9434 & 15.6728 & 20 & & & & \\
\hline 1528 & 11.0981 & 12.9533 & 15.5695 & 30 & & & & \\
\hline 1529 & 11.0910 & 12.9500 & 16.3196 & 40 & & & & \\
\hline 1530 & 11.0398 & 12.8996 & 15.7950 & Cuppar & $2 \frac{1}{x}$ & & & \\
\hline 1531 & 11.1416 & 12.9808 & 16.0847 & $c_{1}$ & -200 & $20>2 x$ & & \\
\hline 1532 & 11.1812 & 12.9795 & 15.9446 & $c_{2}$ & & & & \\
\hline 1533 & 11.2231 & 12.9529 & 15.7634 & 1 & $\operatorname{sen} x$ & & & \\
\hline 1534 & 11.0072 & 12.7371 & 15.5219 & 2 & 20 & & & \\
\hline 1535 & 11.0748 & 12.8738 & 15.5257 & 3 & if & & & \\
\hline 1536 & 11.0851 & 12.9510 & 16.0496 & 4 & & & & \\
\hline 1537 & 11.0033 & 12.8412 & 15.7421 & $c_{1 \text { our }}$ & & $\phi$ & $\sqrt{1}$ & \\
\hline 1538 & 11.1507 & 13.1605 & $15.7 / 22$ & $\mathrm{C} *$ & $2000 x$ & & $T_{30 m+2}$ & \\
\hline 1539 & 11.0464 & 13.0144 & 15.8194 & $\cos \theta$ & $b$ & & & \\
\hline 1540 & 11.0302 & 13.0177 & 15.7964 & 10 & & & & \\
\hline 1541 & 11.1262 & 13.1166 & 15.9530 & $2 \theta$ & & & & \\
\hline 1542 & 11.2401 & 13.2233 & 16.2601 & $3 \theta$ & & & & \\
\hline 1543 & 10.9575 & 12.9598 & 16.0252 & 40 & $\phi$ & & & \\
\hline 1544 & 11.1362 & $13.10 / 6$ & 15.8733 & $C_{\text {zear }}$ & $2000 x$ & & & \\
\hline 1545 & 11.1245 & 13.1174 & 15.9071 & $c_{1}$ & $20=0 x$ & & & \\
\hline 1546 & 11.0421 & 13.0450 & 15.8270 & $C_{2}$ & 6 & & & \\
\hline 1547 & 11.0892 & 13.0972 & 16.2875 & 1 & $100 \times$ & & & \\
\hline 1548 & 11.0818 & 13.0787 & 16.0597 & 2 & $\varnothing$ & & $D$ & \\
\hline
\end{tabular}




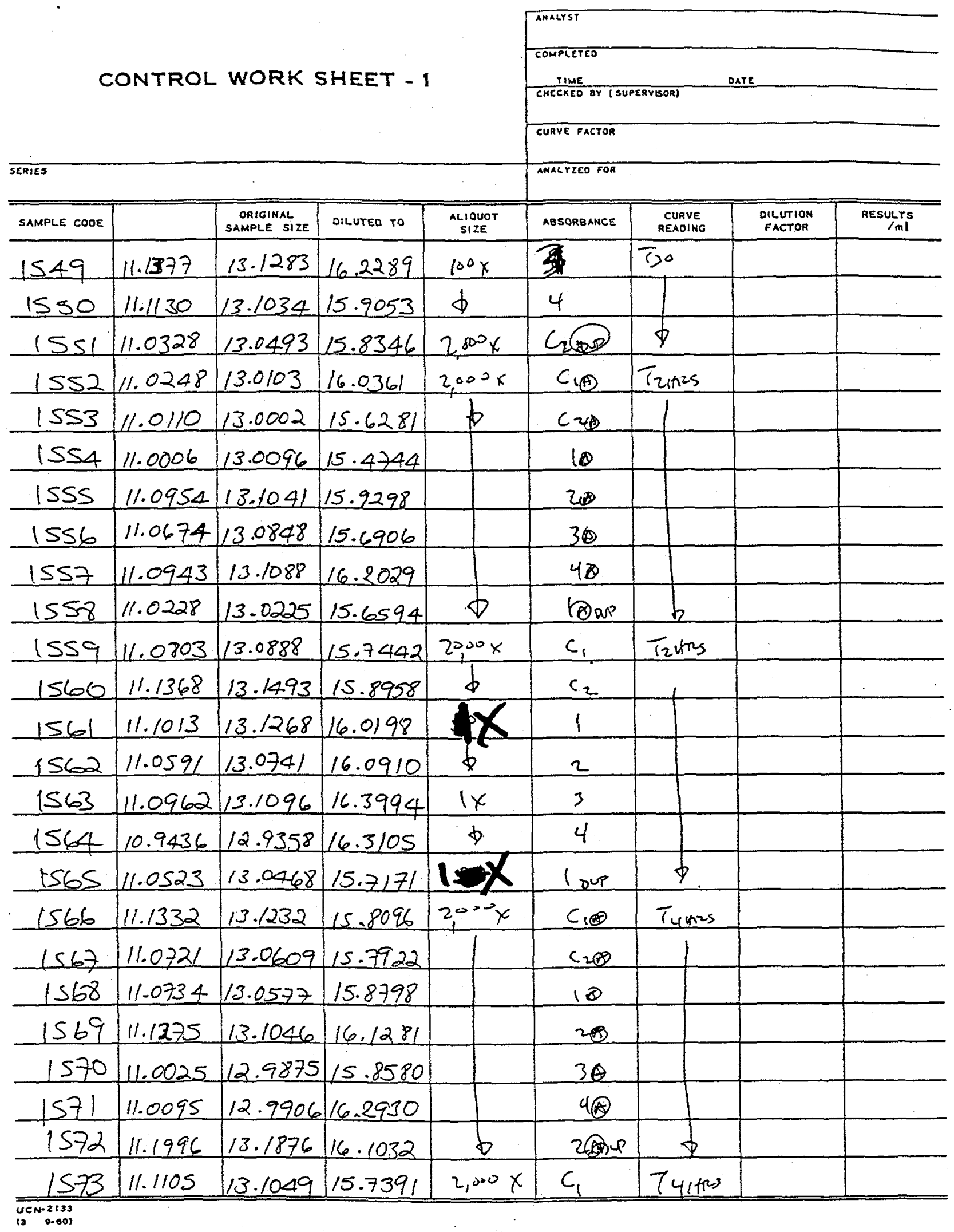

$F-201$ 
CONTROL WORK SHEET - 1

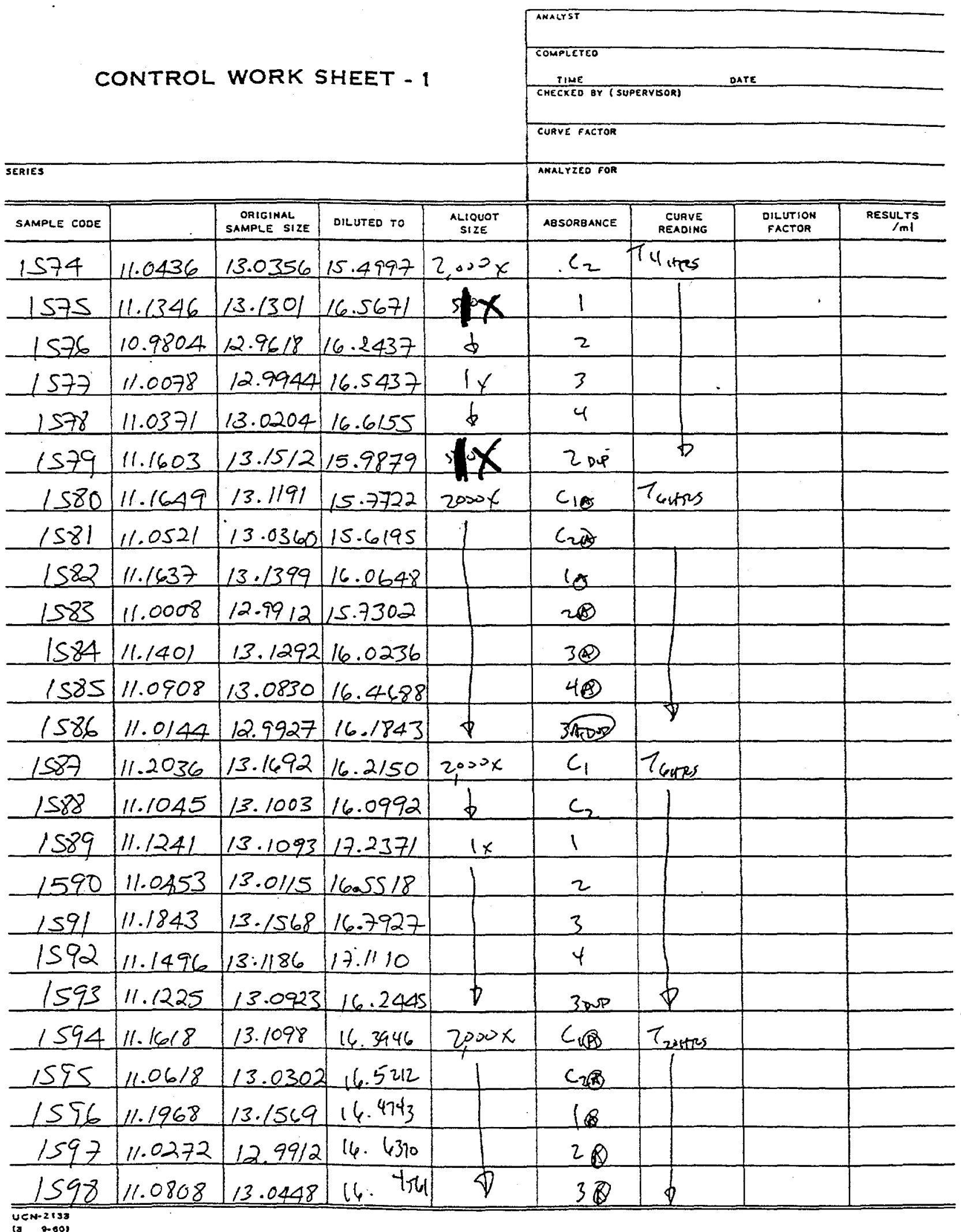


CONTROL WORK SHEET - 1

\begin{tabular}{|l}
\hline AMALYST \\
\hline COMPLETEO \\
\hline CHMEKE OY (SUPERYSOR) ORTE \\
\hline CURYE FACTOR \\
\hline AMALYZEO FOR
\end{tabular}

\begin{tabular}{|c|c|c|c|c|c|c|c|c|}
\hline SAMPLE CODE & & $\begin{array}{c}\text { ORIGINAL } \\
\text { SAMPLE SIZE } \\
\end{array}$ & DILUTED TO & $\begin{array}{c}\text { ALIOUOT } \\
\text { SIZE } \\
\end{array}$ & AESORBANCE & $\begin{array}{c}\text { CURVE } \\
\text { READING }\end{array}$ & $\begin{array}{l}\text { ORLUTION } \\
\text { FACTOR }\end{array}$ & $\begin{array}{r}\text { RESULTS } \\
/ \mathrm{ml} \\
\end{array}$ \\
\hline 1599 & 11.1240 & 13.0851 & 16.2475 & $2,00>x$ & 40 & Travtes & & \\
\hline 1600 & 11.1273 & 13.0905 & 16.9562 & 6 & $(4 \times 0)$ & $b$ & & \\
\hline 1601 & 11.0837 & 13.0413 & 16.7470 & $2000 x$ & $C_{1}$ & $T_{2 \times n^{2} s}$ & & \\
\hline 1602 & 11.0785 & 13.0453 & 16.5227 & $\phi$ & $c_{2}$ & 1 & & \\
\hline 1603 & 11.0881 & 13.0519 & 16.5113 & $1 x$ & 1 & & & \\
\hline 1604 & 11.0349 & 12.9927 & 16.4213 & & 2 & & & \\
\hline 1605 & 11.0347 & 12.9864 & 16.5451 & & 3 & & & \\
\hline 1604 & 11.0286 & 12.9673 & 158678 & & 4 & & & \\
\hline 1607 & 11.1679 & 13.1020 & 17.4522 & $\phi$ & YDor & $\varnothing$ & & \\
\hline 1608 & 11.1082 & 13.0842 & 16.1450 & $2000 x$ & $\cos$ & Twins & & \\
\hline 1609 & 11.0398 & 13.0603 & 15.8910 & & $C_{20}$ & & & \\
\hline 1610 & 11.1438 & 13.1787 & 16.4283 & & 10 & & & \\
\hline 1611 & 11.0621 & 13.1016 & $16 .+220$ & & 20 & & & \\
\hline 1612 & 11.1134 & 13.1576 & 16.1571 & & 30 & & & \\
\hline 1613 & 10.9296 & 12.9696 & 15.8009 & & $4 \theta$ & & & \\
\hline 1614 & 10.9888 & 13.0284 & 15.9754 & $\phi$ & $C_{1 \otimes P J P}$ & $\phi$ & & \\
\hline 1615 & 11.1229 & 13.1590 & 16.1332 & $2800 x$ & $c_{1}$ & $T_{240+25}$ & & \\
\hline 1616 & 11.0567 & 13.1376 & 16.5414 & 6 & $S$ & & & \\
\hline 1617 & 11.0094 & 13.0952 & 16.0237 & $1 x$ & 1 & & & \\
\hline 1618 & 11.0037 & 13.0788 & 116.1400 & 1 & 2 & & & \\
\hline 1619 & 11.1325 & 13.2069 & 16.5726 & & 3 & & & \\
\hline 1620 & 11.1191 & 13.1935 & 16.4130 & $\phi$ & 4 & & & \\
\hline 1621 & 10.9702 & 13.0382 & 16.0380 & $2000 x$ & $C(0,0)$ & $\varnothing$ & & \\
\hline 1622 & 11.0739 & 13.0568 & 16.3349 & $2006 x$ & 10 & Tactos & & \\
\hline 1623 & 11.0279 & 13.0076 & 16.5358 & $b$ & $C_{2}$ & $\phi$ & & \\
\hline
\end{tabular}


CONTROL WORK SHEET - 1

\begin{tabular}{l} 
AMALYST \\
\hline SOMPLETED \\
TIME \\
\hline CHECKEO QY (SUPEAVBSOR) \\
\hline
\end{tabular}

SERIES

\begin{tabular}{|c|c|c|c|c|c|c|c|c|}
\hline SAMPLE CODE & & $\begin{array}{c}\text { ORIGINAL } \\
\text { SAMPLE SIZE }\end{array}$ & DILUTED TO & $\begin{array}{c}\text { ALIQUOT } \\
\text { SIZE } \\
\end{array}$ & ABSORBANCE & $\begin{array}{c}\text { CURVE } \\
\text { REAOING }\end{array}$ & $\begin{array}{l}\text { DLLUTION } \\
\text { FACTOR }\end{array}$ & $\begin{array}{r}\text { RESULTS } \\
/ \mathrm{mI} \\
\end{array}$ \\
\hline 1624 & 11.1562 & 13.1490 & 16.4955 & 20004 & 18 & Ta6urs & & \\
\hline 1625 & 11.0839 & 13.0790 & 16.5310 & & 20 & & & \\
\hline 1626 & 11.1167 & 13.1154 & 16.5875 & & 300 & & & \\
\hline 1627 & 11.1041 & 13.1090 & 16.6073 & & $4 \theta$ & & & \\
\hline 1628 & 11.1597 & 13.1673 & 16.3839 & $\rightarrow$ & $C_{20}$ & $\phi$ & & \\
\hline 1629 & 11.0890 & 13.0931 & 16.7285 & $2009 x$ & $c_{1}$ & Taces & & \\
\hline 1630 & 11.1328 & 13.1543 & 16.5598 & $\$$ & $c_{2}$ & & & \\
\hline 1631 & 11.1062 & 13.1274 & 16.6325 & $1 x$ & 1 & & & \\
\hline 1632 & 11.0003 & 13.0107 & 16.3971 & & 2 & & & \\
\hline 1633 & 11.0522 & 13.0592 & 16.5154 & & 3 & & & \\
\hline 1634 & 11.2222 & 13.2406 & 16.9492 & $\phi$ & 4 & & & \\
\hline 1635 & 11.0910 & 13.1020 & 16.2317 & $2,000 x$ & $C_{202}$ & $\nabla$ & & \\
\hline 1636 & 11.0419 & 14.3830 & 14.3838 & soox & $C_{108 S 00}$ & $0,2(30)(3,3)$ & & \\
\hline 1637 & 11.1110 & 14.4641 & 14.5067 & $c^{3} x$ & $C_{1} \in B \sin$ & 1 & & \\
\hline 1638 & 11.0384 & 14.4024 & 14.5908 & $\sin x$ & $\left.G_{20}\right) \mathrm{se}$ & & & \\
\hline 1639 & 11.0458 & 14.3904 & 14.4383 & $c^{2} x$ & $\angle 2 B D$ & & & \\
\hline 1640 & 11.0853 & 14.4339 & 14.5303 & $3^{30} x$ & 1000 & & & \\
\hline 1641 & 11.0870 & 14.4377 & 14.4804 & $c^{2} x$ & 1000 & & & \\
\hline 1642 & 11.1543 & 14.5093 & 14.6110 & $500 x$ & 20000 & & & \\
\hline 1443 & 11.0761 & 14.4540 & 14. 4948 & $10 x$ & 200 100 & . & & \\
\hline 1644 & 11.0579 & 14.4277 & 14.4977 & $5200 x$ & 3030 & & & \\
\hline 1645 & 11.1248 & 14.4589 & 14.5058 & $c^{3} x$ & 3030 & & & \\
\hline 1646 & 10.9777 & 14.3193 & 14.4227 & $500 x$ & $4(8) 3(9)$ & & & \\
\hline 1647 & 11.0516 & 14.3876 & 14.9301 & $c^{2} x$ & $40 \quad 50$ & $\nabla$ & & \\
\hline & & & & & $=$ & & & \\
\hline
\end{tabular}


CONTROL WORK SHEET - 1

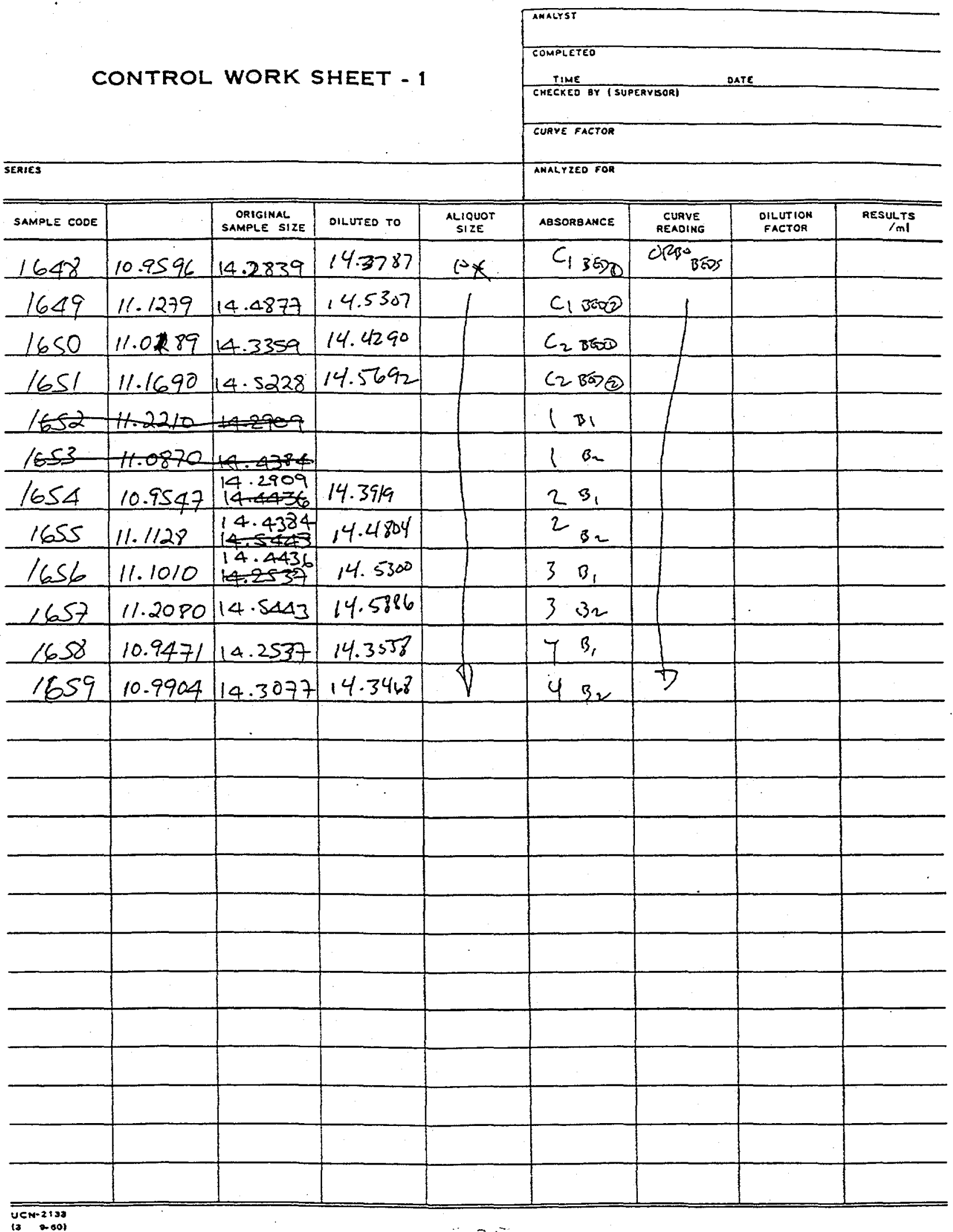




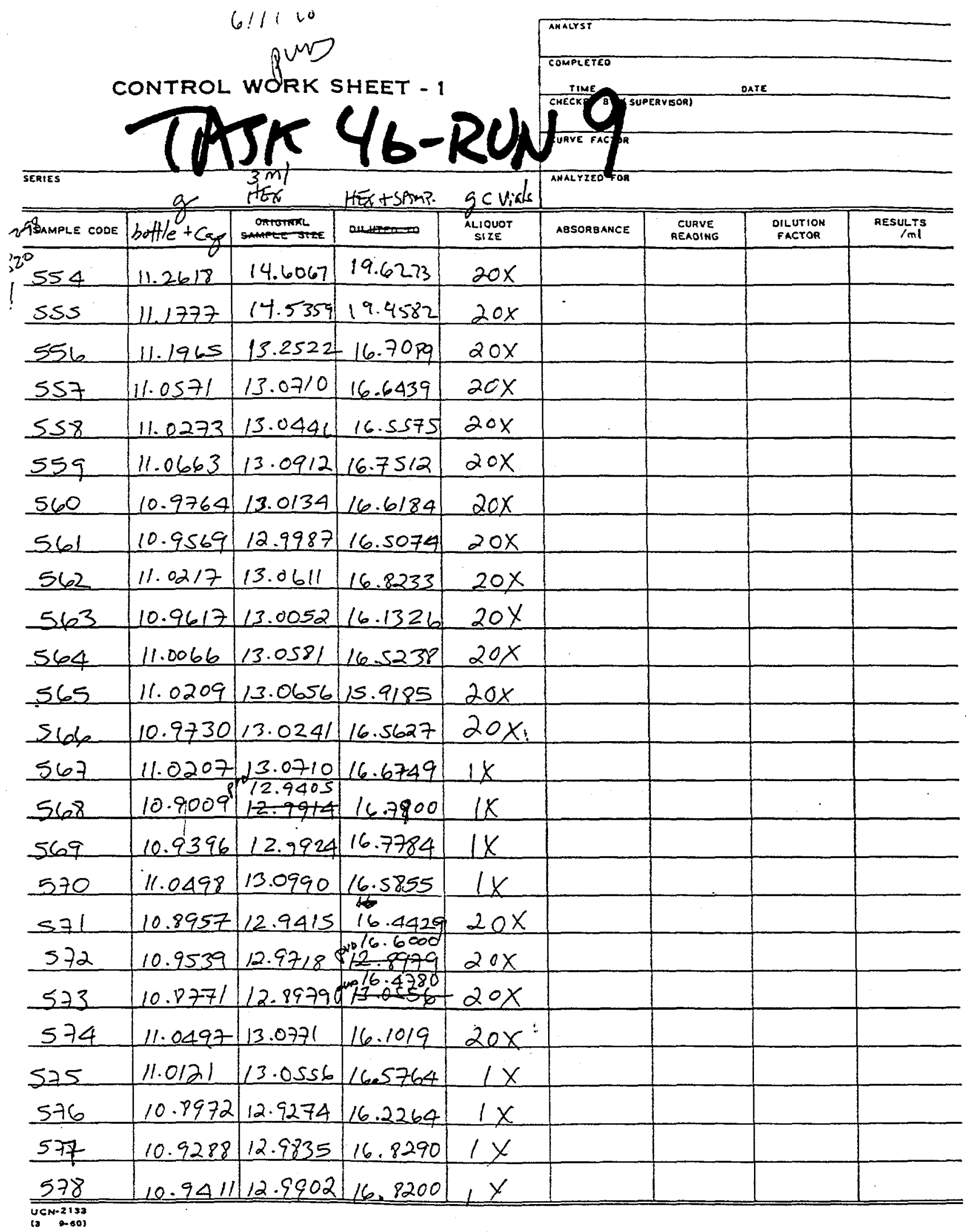

F-206 
CONTROL WORK SHEET - 1

ANALTST

COMPLETEO

TIME OATE

CHECXEO OY (SUPERTEOA)

CUAYE FACTOR

$\rightarrow$

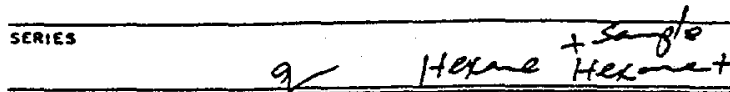
AMALYZEO FOR

\begin{tabular}{|c|c|c|c|c|c|c|c|c|}
\hline SAMPLE CODE & $\operatorname{bot} 11_{e}^{0}+\cos \theta$ & $\begin{array}{l}\text { ORIGINAL } \\
\text { SAMPLE SIZE }\end{array}$ & DILUTED TO & $\begin{array}{l}\text { ALIQUOT } \\
\text { SIZE }\end{array}$ & ABSORBANCE & $\begin{array}{c}\text { CURVE } \\
\text { REAOING }\end{array}$ & $\begin{array}{l}\text { DILUTION } \\
\text { FACTOR }\end{array}$ & RESULTS \\
\hline 579 & 10.9189 & 12.9664 & 16.443 & $20 x$ & & & & \\
\hline
\end{tabular}

\begin{tabular}{l|l|l|l|l|l|l|}
580 & 10.8781 & 12.8912 & 16.7149 & $20 \times$
\end{tabular}

\begin{tabular}{l|l|l|l|l|l|l|l}
581 & 10.9688 & 12.9731 & 16.7304 & $20 \mathrm{X}$
\end{tabular}

\begin{tabular}{l|l|l|l|l|l|l|}
582 & 10.9284 & 12.9436 & 16.6823 & $20 x$
\end{tabular}

\begin{tabular}{l|l|l|l|l|l|}
583 & 10.8970 & $12.9 / 70$ & 15.7366 & $\mid X$
\end{tabular}

\begin{tabular}{l|l|l|l|l|l|l|}
584 & 10.9041 & 12.9399 & 16.4127 & $1 X$
\end{tabular}

\begin{tabular}{l|l|l|l|l|l}
585 & 10.9694 & 12.9990 & 16.8080 & Ix
\end{tabular}

\begin{tabular}{l|l|l|l|l|l|l|}
586 & 10.8463 & 12.8734 & 16.3652 & $\mid x$
\end{tabular}

\begin{tabular}{l|l|l|l|l|l|}
587 & 10.8541 & 12.8985 & 16.5819 & $1 X$ \\
\hline
\end{tabular}

\begin{tabular}{l|lll}
588 & 10.9797 & 12.9622 & 1299 \\
\hline
\end{tabular}

\begin{tabular}{l|l|l|l|l}
589 & 10.9023 & 12.9281 & 16.6582 & $20 x$ \\
\hline
\end{tabular}

\begin{tabular}{l|l|l|l|l|l|l|l}
590 & 10.9623 & 12.9912 & 16.3607 & $20 x$
\end{tabular}

\begin{tabular}{l|l|l|l|l|l}
591 & 10.9734 & 13.0159 & 16.6906 & $1 x$
\end{tabular}

\begin{tabular}{l|l|l|l|l|l}
592 & 10.9872 & 13.0313 & 16.2045 & $1 x$ \\
\hline
\end{tabular}

\begin{tabular}{l|l|l|l|l}
593 & 10.9575 & 12.9970 & 16.9021 & $1 X$
\end{tabular}

\begin{tabular}{l|l|l|l|l|l|}
594 & 10.9242 & 12.9753 & $16.680 L$ & $1 X$
\end{tabular}

\begin{tabular}{l|l|l|l|l|l|}
595 & 10.9388 & 12.9931 & 16.8545 & $1 X$
\end{tabular}

\begin{tabular}{l|l|l|l|l|l}
596 & 10.9737 & 13.0007 & 16.4667 & $20 x$ \\
\hline
\end{tabular}

\begin{tabular}{l|l|l|l|l}
597 & 10.9894 & 13.0059 & 16.6537 & $20 \times$
\end{tabular}

\begin{tabular}{l|l|l|l|l|l}
598 & 10.9155 & 12.9335 & 16.6990 & $20 X$ \\
\hline
\end{tabular}

\begin{tabular}{l|l|l|l|l|l|l|}
599 & 10.9655 & 12.9878 & 16.7797 & $1 \times$
\end{tabular}

\begin{tabular}{l|l|l|l}
100 & 10.9118 & 12.9390 & 16.4149
\end{tabular}

\begin{tabular}{l|l|l|l|l}
601 & 11.9822 & 13.0059 & 15.89 \\
\hline
\end{tabular}

\begin{tabular}{l|l|l|l}
602 & 10.9290 & $(4.9746$ & $(6.293)$ \\
\hline
\end{tabular}

\begin{tabular}{l|l|l|l}
603 & 10.8623 & 12.9043 & 16.7882
\end{tabular}

UCN-2133

$(3,0-60)$ 
CONTROL WORK SHEET - 1

\begin{tabular}{|c|c|c|c|}
\hline \multicolumn{4}{|l|}{ ANALYST } \\
\hline \multicolumn{4}{|c|}{$\begin{array}{l}\text { COMPLETEO } \\
\text { TIME } \\
\text { CHECKEO OT (SUPCAYSORI }\end{array}$} \\
\hline \multicolumn{4}{|c|}{ CHECKED Or (SUPEAVESOR) } \\
\hline \multicolumn{4}{|l|}{ CUAVE FACTOR } \\
\hline \multicolumn{4}{|l|}{ AMALYZEO FOR } \\
\hline ABSORBAMCE & $\begin{array}{c}\text { CURVE } \\
\text { READING }\end{array}$ & $\begin{array}{l}\text { OLLUTION } \\
\text { FACTOR }\end{array}$ & $\begin{array}{c}\text { RESULTS } \\
/ \mathrm{mI} \\
\end{array}$ \\
\hline$\cdot$ & & & \\
\hline & & & \\
\hline & & & \\
\hline
\end{tabular}

\begin{tabular}{|c|c|c|c|c|c|c|c|c|}
\hline SERIES & 21 & $1+E x+B \pi$ & 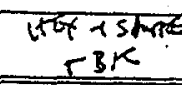 & & AHALYZEO FOR & & & \\
\hline SAMPLE CODE & bottle +Coga & $\begin{array}{c}\text { ORIGINAL } \\
\text { SAMPLE SIZE } \\
\end{array}$ & DILUTED TO & $\begin{array}{c}\text { ALLOUDT } \\
\text { SIZE }\end{array}$ & ABSORBANCE & $\begin{array}{c}\text { CURVE } \\
\text { READING }\end{array}$ & $\begin{array}{l}\text { OLLUTION } \\
\text { FACTOA }\end{array}$ & $\begin{array}{c}\text { RESULTS } \\
/ \mathrm{ml}\end{array}$ \\
\hline 604 & 10.9221 & 12.9539 & 16.7670 & $20 x$ & . & & & \\
\hline 605 & 10.9806 & 13.0126 & 16.9193 & $20 x$ & & & & \\
\hline 606 & 10.9751 & 13.0172 & 16.8882 & $20 x$ & & & & \\
\hline 607 & 10.9819 & 13.0261 & 16.7745 & $1 x$ & & & & \\
\hline 608 & 10.9822 & 13.0281 & 16.6708 & $1 x$ & & & & \\
\hline 609 & 10.9735 & 13.0397 & 16.6400 & $1 x$ & & & & \\
\hline 610 & 10.8657 & 12.9257 & 16.6770 & $1 x$ & & & & \\
\hline 611 & 10.9980 & 13.0570 & 16.0013 & $1 x$ & & & & \\
\hline $6 / 2$ & 10.9648 & 12.9844 & 13.0781 & $\left\langle c_{1}-1\right| x$ & & & . & \\
\hline 613 & 10.9726 & 13.0131 & 13.0607 & $s c_{1}-2$ & & & . & \\
\hline 614 & 10.9378 & 12.9859 & 13.2849 & $1-1$ & & & & \\
\hline $6 / 5$ & 10.9363 & 12.9793 & 13.0257 & $4-2$ & & & & \\
\hline 616 & 11.0015 & 13.0369 & B. 1242 & $\# 2-1$ & & & & \\
\hline $6 A$ & 10.9452 & 12.9950 & 13.0367 & $F_{2-2}$ & & & & \\
\hline 618 & 10.8596 & 12.8956 & 12.9903 & $+3-1$ & & & & \\
\hline 619 & 10.8880 & 12. 9259 & 12.9680 & $\# 3.2$ & & & & \\
\hline 620 & 10.9560 & 13.0077 & 13.1034 & $\pm 4-1$ & & & & \\
\hline 621 & 10.9826 & 13.0267 & 13.0660 & $* 4-2$ & & & & \\
\hline 622 & 10.9493 & 12.9939 & 13.0929 & $c 2-1$ & & & & \\
\hline $5=623$ & 11.0094 & 13.0537 & 19.0985 & $C_{2}-2$ & & & & \\
\hline 624 & 492.8 & $\begin{array}{l}\text { that andy } \\
268.01\end{array}$ & $\frac{1152.55}{6.69}$ & & & & & \\
\hline 625 & 491.8 & 272.49 & 1132.55 & & & & & \\
\hline 626 & 492.4 & 262.07 & $\begin{array}{r}1,51.24 \\
\square\end{array}$ & & & & & \\
\hline 627 & 492.4 & 283.00 & 1141.85 & & & & & \\
\hline $4 \quad 628$ & 492.8 & 284.42 & 1179.68 & $\phi$ & & & & \\
\hline
\end{tabular}


$C-1-2)$

Forre pried

$$
\sec \frac{\text { Fosse }}{206.6}
$$

$c_{1} 224.7-(360) 361$

$c_{2} 220.2-(360) 380$

$\begin{array}{lllll}0.061 & 208.5 & 92.6 & (368) & 368\end{array}$

$\phi 2 \quad 214.6 \quad 97.2$ (389) 389

$0.123 \quad 206.1 \quad 89.9 \quad(360) 363$

\$ $4207.996 .6 \mathrm{~J}$
$6-2-98$

1)

800 क

rover

$-$

$0.92 \times 1$

$(386) 387$
$0.973-1$
$9.5-1$
$10 \mathrm{~m} 1$

F-209 


$$
6-3-48 \text { (0.5?- }
$$

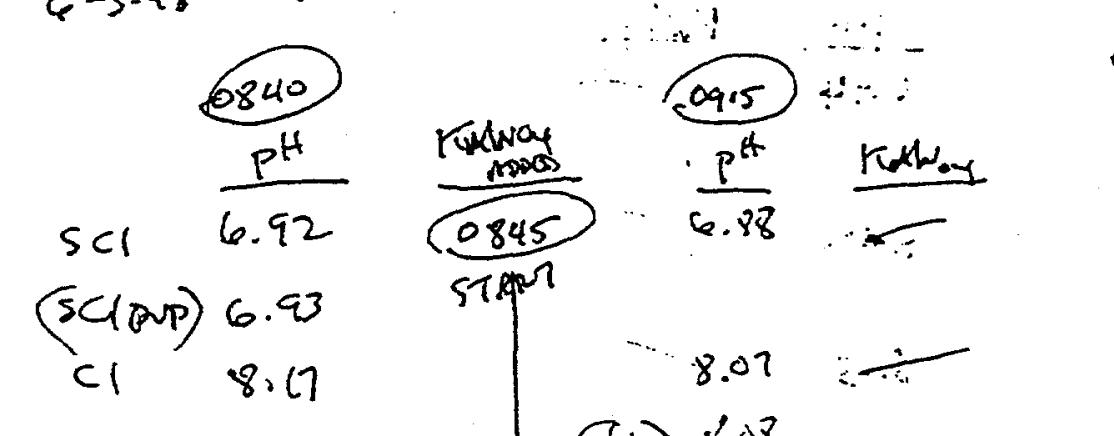

128.22

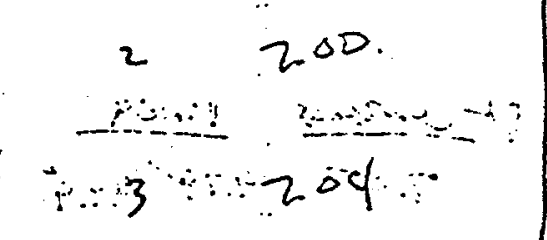

$4 \quad 2.23$

ת..04
(10.) 8.08

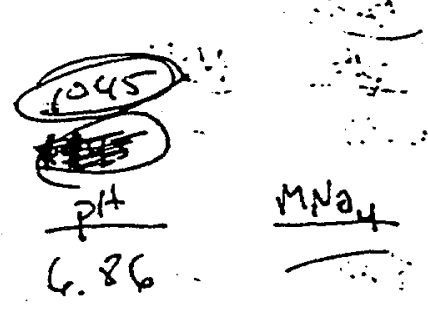

8. $13 \cdots$

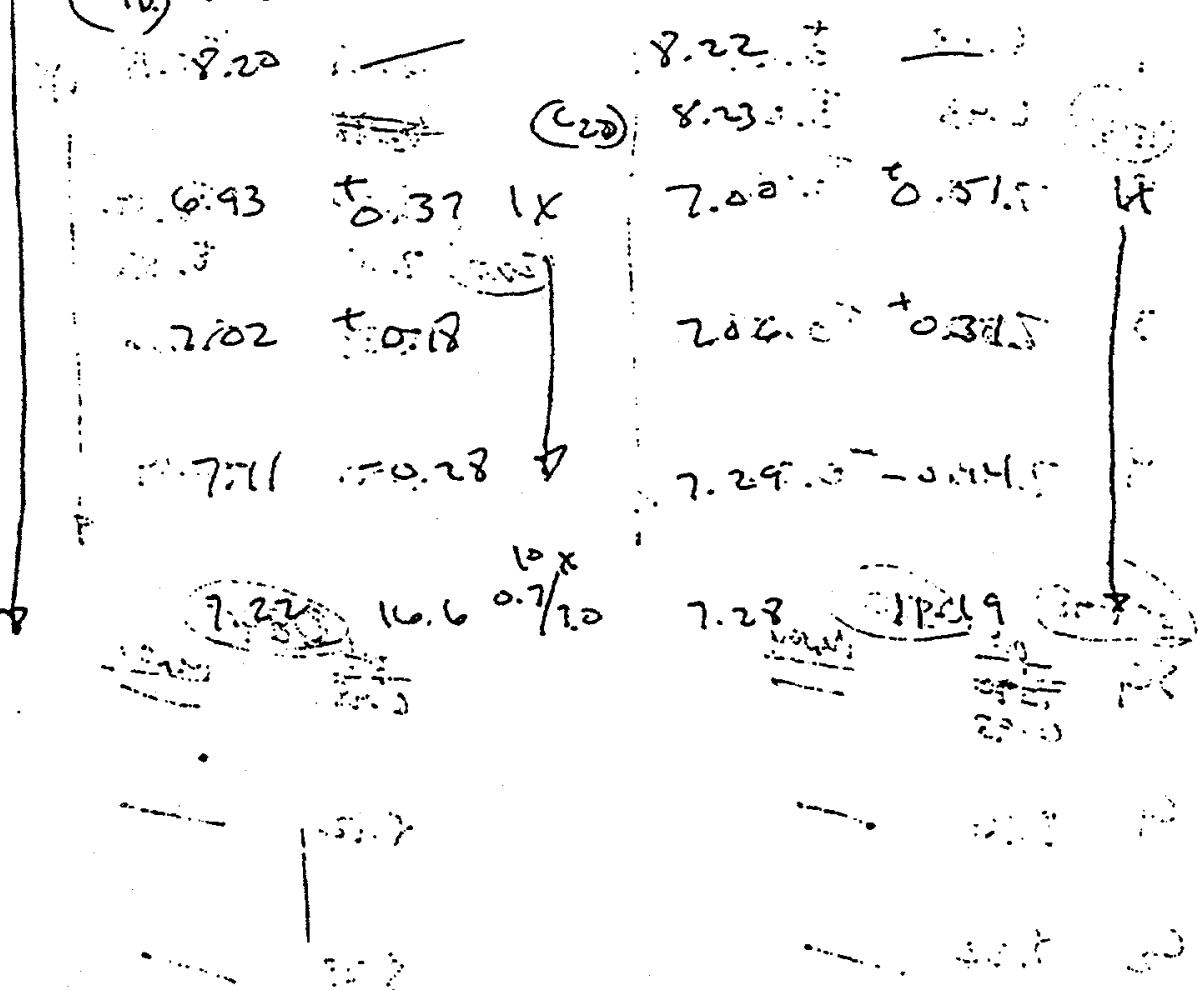
$\therefore$ 


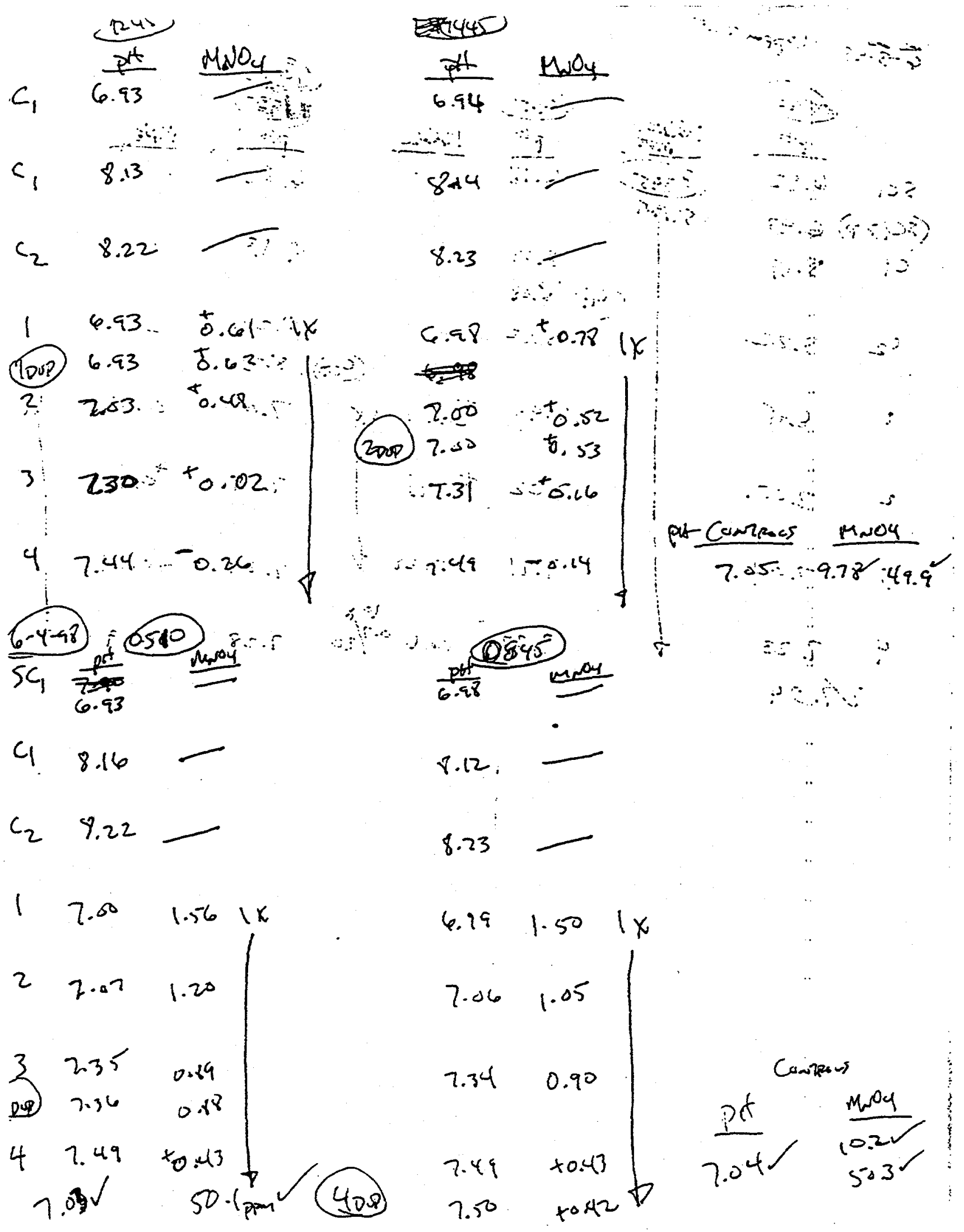

$F-211$ 


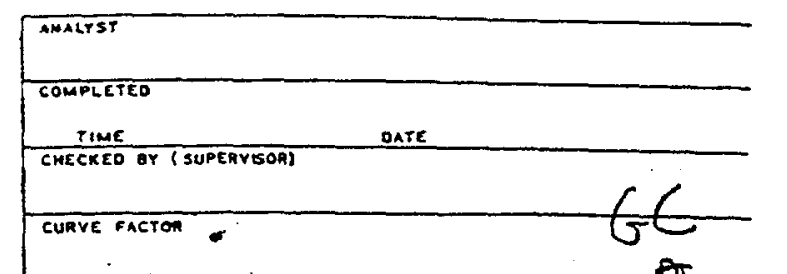

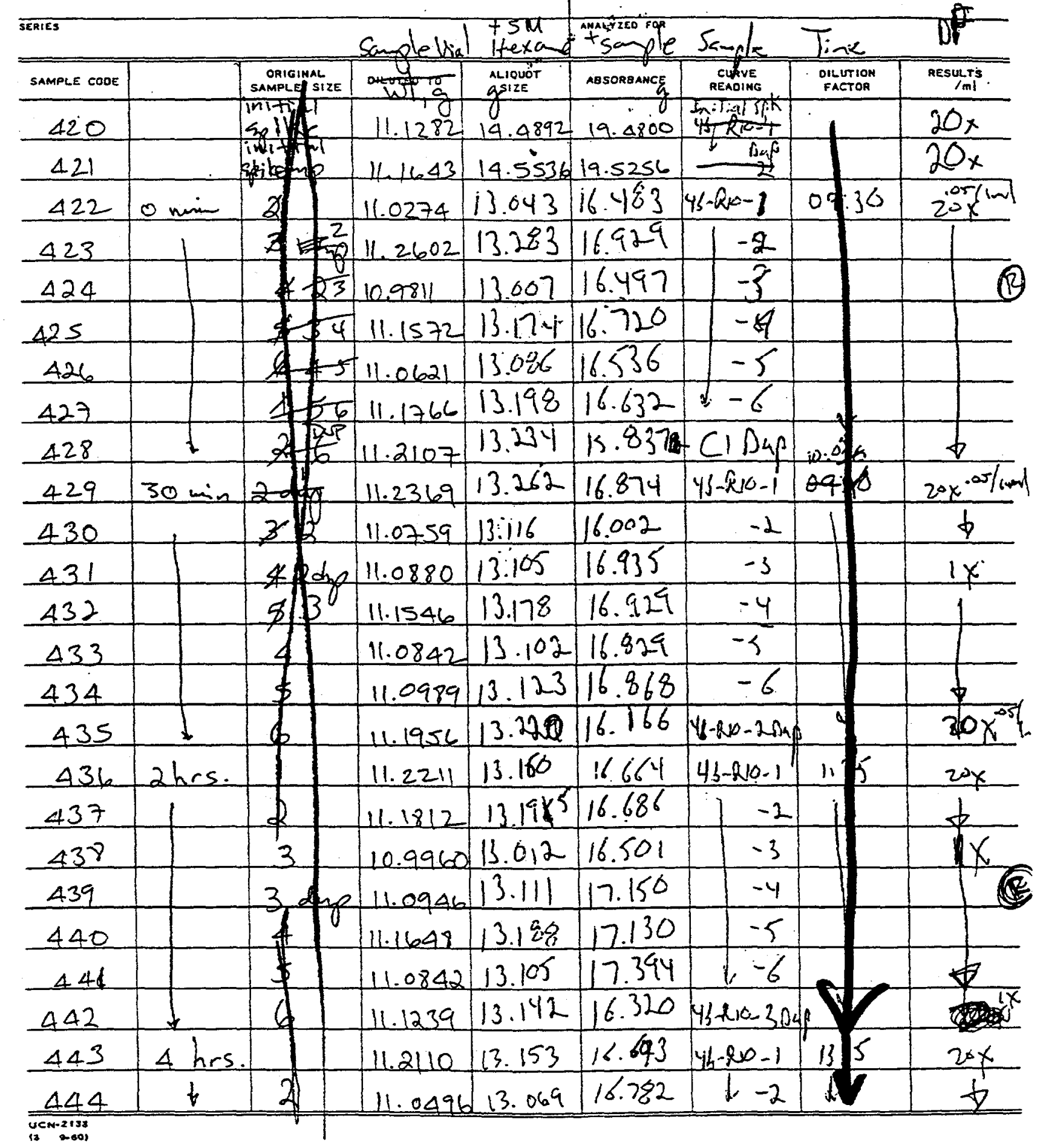




\begin{tabular}{|c|c|c|c|c|c|c|c|c|}
\hline SERtEs & & & Vial & tHexhine & $\begin{array}{l}\text { AMACYZEO foR } \\
\text { tSk-nke }\end{array}$ & $5<-012$ & Tine & DF \\
\hline SAMPLE CODE & & $\begin{array}{c}\text { ORIGINAL } \\
\text { SAMPLE SIZE }\end{array}$ & Wtar & $\begin{array}{c}\text { ALIOUOT } \\
\text { SIZE }\end{array}$ & ABSORDANCE & $\begin{array}{c}\text { CPSUVE } \\
\text { REABING }\end{array}$ & 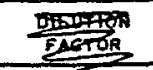 & $\begin{array}{r}\text { RESULTS } \\
/ m i \\
\end{array}$ \\
\hline 445 & 94 hrs. & 31 & 11.1182 & 13.139 & 17.000 & $43-2 k-3$ & & $1 x$ \\
\hline 446 & & 4 & 11.1786 & 13.202 & 17.092 & -4 & & 1 \\
\hline 447 & & $4 \operatorname{lng}$ & 11.1380 & 13.157 & 16.912 & -5 & & \\
\hline 448 & & & 11.2186 & 13.239 & 17.248 & -6 & & \\
\hline 149 & & 4 & 11.21070 & 13.291 & 16.050 & $-4 x$ & 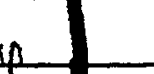 & $\$$ \\
\hline 450 & tohrs. & & 11.1807 & 13.204 & $1=.835$ & $4 \angle R L-4=0$ & $\partial$ & $20 x$ \\
\hline 451 & & & 11.11689 & 13.204 & 16.904 & $1-2$ & & b \\
\hline 452 & & & 11.0750 & 13.109 & 17.216 & -3 & & $1 x$ \\
\hline 453 & & & 11.0821 & 13.115 & 16.932 & $-y$ & & 1 \\
\hline 454 & & +- & 11.0314 & 13.069 & 17.076 & -5 & & \\
\hline 455 & & Ithe & 11.2438 & 13.275 & 17.253 & $1-6$ & & \\
\hline $4 \leq 6$ & $\rightarrow$ & & 11.1091 & 13.144 & 16.454 & $\checkmark D_{4}$ & & $s$ \\
\hline 457 & 30 hrs. & & 11.2086 & 13.163 & 16.576 & $43210-1$ & & \\
\hline 458 & & & 11.1875 & $13.20 \% 7$ & 16.788 & 2 & & \\
\hline 459 & & D1 & 11.1586 & 13.169 & 16.942 & 3 & & \\
\hline 460 & - & 4 & 11.1154 & 13.124 & 16.927 & 4 & & \\
\hline 461 & & $H$ & 11.2497 & 13.256 & 17.213 & 5 & & \\
\hline 462 & & (1) & 11.0256 & 13.043 & 16.104 & 6 & & \\
\hline 463 & & $6 . x$ & 11.0733 & 13.075 & 16.292 & $1-604$ & & \\
\hline 464 & $24 \mathrm{kr}$ & & 11.2040 & 13.209 & 16.802 & $4 B-210-1$ & & \\
\hline 465 & 1 & & 11.1138 & 13.114 & 16.336 & -2 & & \\
\hline 466 & & & 11.1687 & 13.170 & 17.005 & -3 & & \\
\hline 467 & & & 11.1839 & 13.178 & 16920 & -4 & & \\
\hline 468 & & & 11.1593 & 13.146 & 17.034 & -5 & & \\
\hline 469 & $v$ & & 11.1139 & 13.117 & 17.275 & $17 \quad-6$ & & \\
\hline
\end{tabular}


CONTROL WORK SHEET - 1

\begin{tabular}{|} 
AMALYST \\
COMPLETEO \\
TINE \\
\hline CMECKEO OY (SUPERYISOA) \\
\hline CURYE FACTOR
\end{tabular}

\begin{tabular}{|c|c|c|c|c|c|c|c|c|}
\hline SERIES & & & vial & 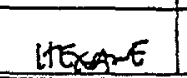 & 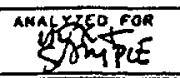 & Sonpes & & \\
\hline SAMPLE COOE & & $\begin{array}{c}\text { ORIGINAL } \\
\text { SAMPLE SIZE }\end{array}$ & $w \mid$ & W & A ABgance & $\begin{array}{c}\text { EOTVE } \\
\text { REAOUAG }\end{array}$ & $\begin{array}{l}\text { DiLUTION } \\
\text { FACTOR }\end{array}$ & $\begin{array}{c}\text { RESULTS } \\
/ \mathrm{ml} \\
\end{array}$ \\
\hline$\Delta 70$ & $2^{4} / \mathrm{hr}$ & & 11.1090 & 13,121 & 15.457 & $4 B-21^{80}$ & & \\
\hline 471 & & & 11.1826 & 14.397 & 14.485 & 10,2301 & & \\
\hline 472 & & & 11.1264 & 14.443 & $14.5-02$ & 108302 & & \\
\hline 473 & & & 11.0593 & 14.402 & 14.493 & $2 \times 2001$ & & \\
\hline 474 & & & 11.0464 & 14.396 & 14.361 & 2012002 & & \\
\hline 475 & & & 11.1426 & 14.482 & 14.576 & 300001 & & \\
\hline 476 & & & 11.1836 & 14.540 & 14.580 & 30852 & & \\
\hline 477 & & & 11.1640 & 14.515 & 14.612 & 4 orsol & & \\
\hline 478 & & & 11.0961 & 14.454 & 14.496 & 4482.2 & & \\
\hline 479 & & & 11.0693 & 14.415 & 14.508 & $5+2801$ & & \\
\hline 480 & & & 11.0940 & 14.441 & 14.484 & 5 Sigs 2 & & \\
\hline 481 & & & 11.1897 & 14.540 & 14.635 & cuesil & & \\
\hline 482 & & & 11.1737 & 14.525 & 14.563 & 600802 & & \\
\hline 483 & & & $\begin{array}{r}492.3 \\
+1.0995 \\
\end{array}$ & $8 / 7.0$ & 1698.2 & $\begin{array}{r}4 B-210-3 \\
\text { pos } 7\end{array}$ & & \\
\hline 484 & & & $\begin{array}{r}492.6 \\
H .003\end{array}$ & 849.6 & 1074.3 & $4 B-150-y$ & & \\
\hline 485 & & & $\begin{array}{r}4 g^{2}-4 \\
\\
\end{array}$ & $\begin{array}{l}M . x \times \text { a.dy } \\
281 .{ }^{2}\end{array}$ & 1147.8 & $\begin{array}{r}43-2010-5 \\
P 037\end{array}$ & & \\
\hline 486 & & & $\begin{array}{r}491.7 \\
11.2\end{array}$ & $\begin{array}{l}15 \pi k k \\
870.8\end{array}$ & 1098.8 & $40-\sqrt[3]{300-6}$ & & \\
\hline & & & & & & & & \\
\hline & & & & & & & & \\
\hline & & & & 5 & & & & \\
\hline & & & & & & & & \\
\hline & & & & & & & & \\
\hline & & & & & & & & \\
\hline & & & & & & & & \\
\hline
\end{tabular}




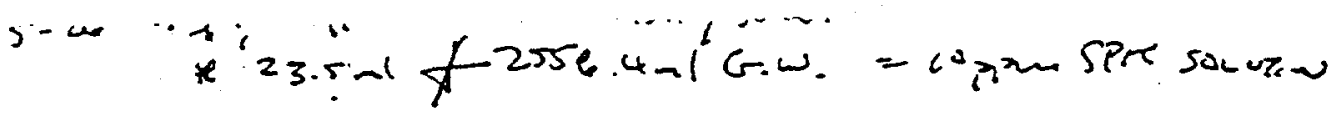

$5-27-98$

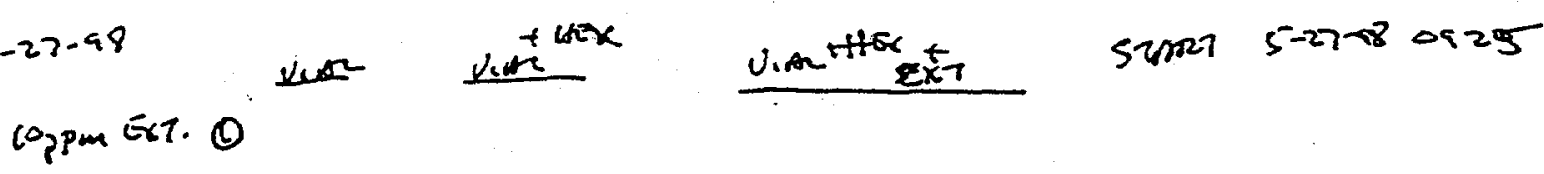
(10)

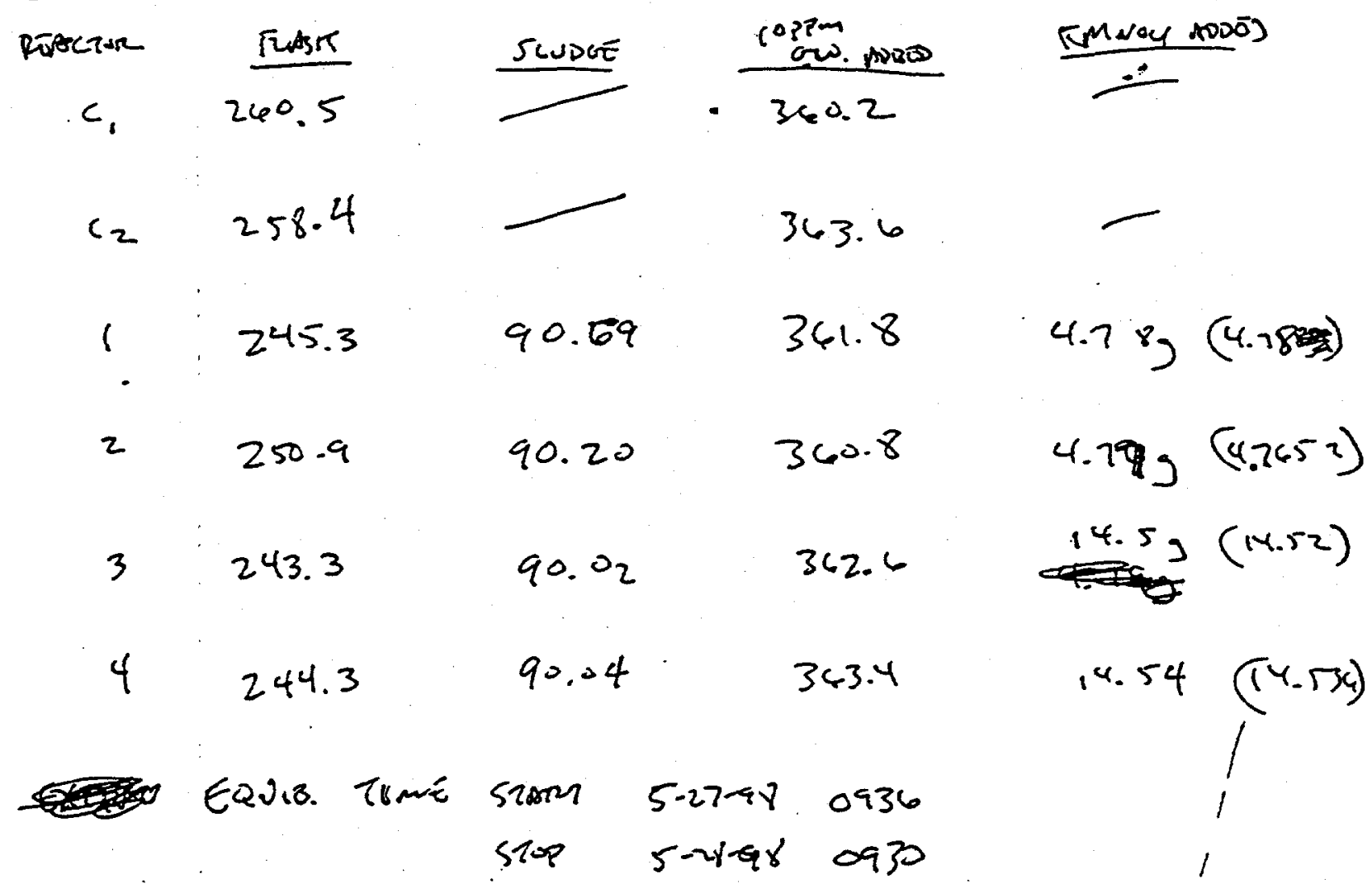

$\mathrm{F}-215$ 
$S=28-48$

PPE लिखिय

T(mE PH O930

1(91) 8.13

(C) DUP 8.14

2 (2) 8.14

if 3 (1) 7.11

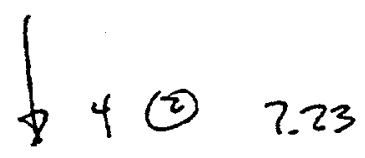

$3350 \quad 7.32$

$\left.\right|_{6}(4) 7.8$

$$
\tau=1335
$$

1 c. $\frac{p^{15}}{8.06}=$

$$
\begin{array}{lll}
2 & c_{2} & 8.07
\end{array}
$$

$317.74 \quad 17.00 .04 / 30^{\circ}+1$

$4=7.70 \quad 14.3$

$(208) 7.69$

$53 \quad 1.7714 .4$

647.775 .4

$$
T_{0}=0433 \quad \text { in ... }
$$

$T_{30}=000 \quad T_{2 \text { ins }} 1135 \quad T_{z_{\text {thes }}} \quad 1135$
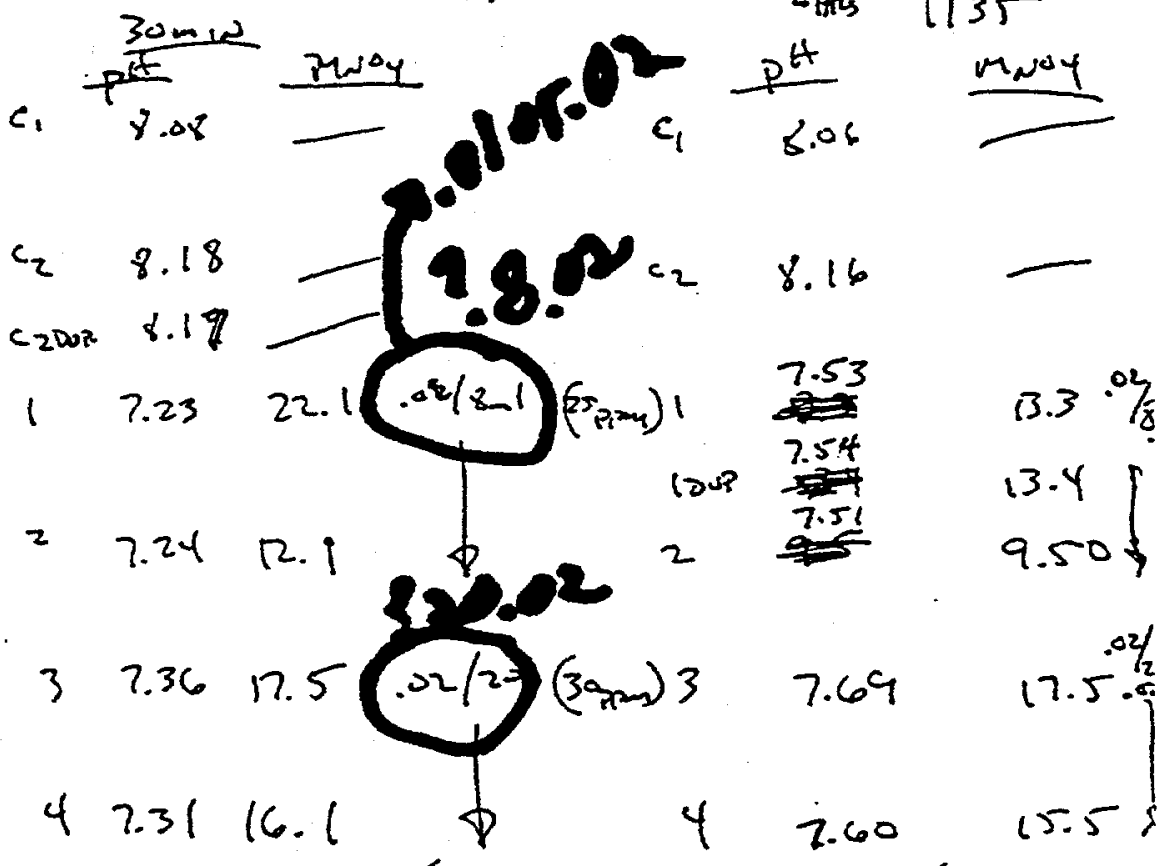
ar 7.40

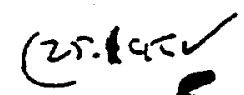

$T=$ ams

c. $\frac{p+}{8.08}$ mor

$c_{2} \quad 8.16$

$14.5 .02 / 20 \mathrm{~m} \quad 3 \quad 7.81 \quad 16.50002 / 20.0201$

$7.79 \quad 12.9(0.4 / 80 x-1)$

$2.80 \quad 11.0$

(3008)

4

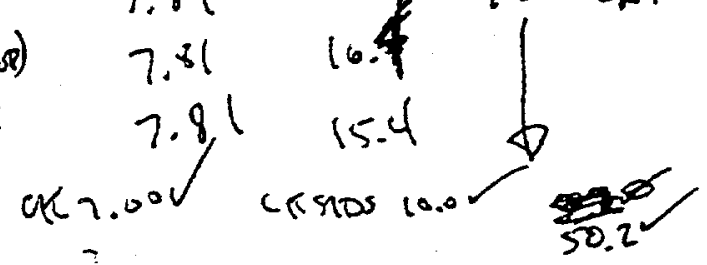

$F-216$ 
$5-29-48$

0210

0935

$c_{1} \quad \frac{p^{4}}{8.04}=$
$c_{2} \quad 8.15=$

Monoy

c. 8.06

$c_{100} 8.06$

$\mathrm{C}_{2} 8.14$

$1 \quad 2.84-176 x$

$1 \quad 7.85-0.27 x$

$=2.86-0.214 x \quad 2.9 .85-0.21 \quad 1 x$

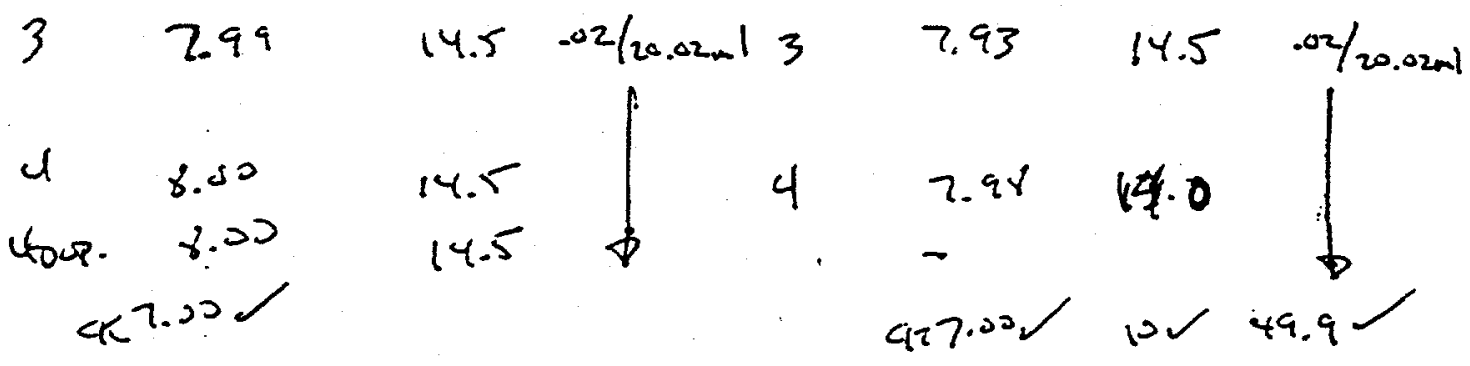

$\because$

$\mathrm{F}-217$ 
$6-150895$

7.98
$C_{2}$
$C_{2}$
8.99

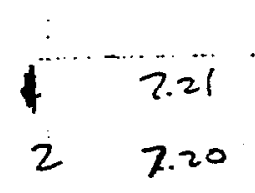

a $\frac{P H}{8.00}$ Mar

$c_{2}^{8.10}{ }_{8.09}^{8.10} c_{2} 8.0$
C. $\frac{p+4}{8.01}$ MNOY

0.04

$0.27 \rightarrow \frac{1000}{2} 7.10$

45.4 (2x) 325

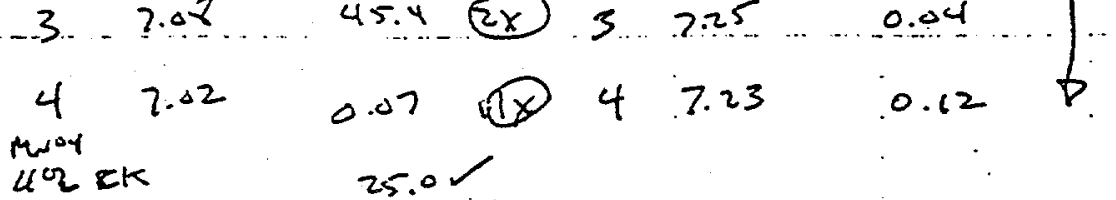

$25.0 /$

c1570 10.01)

1480

1245

$50.1(800 x)$

$\cdot$

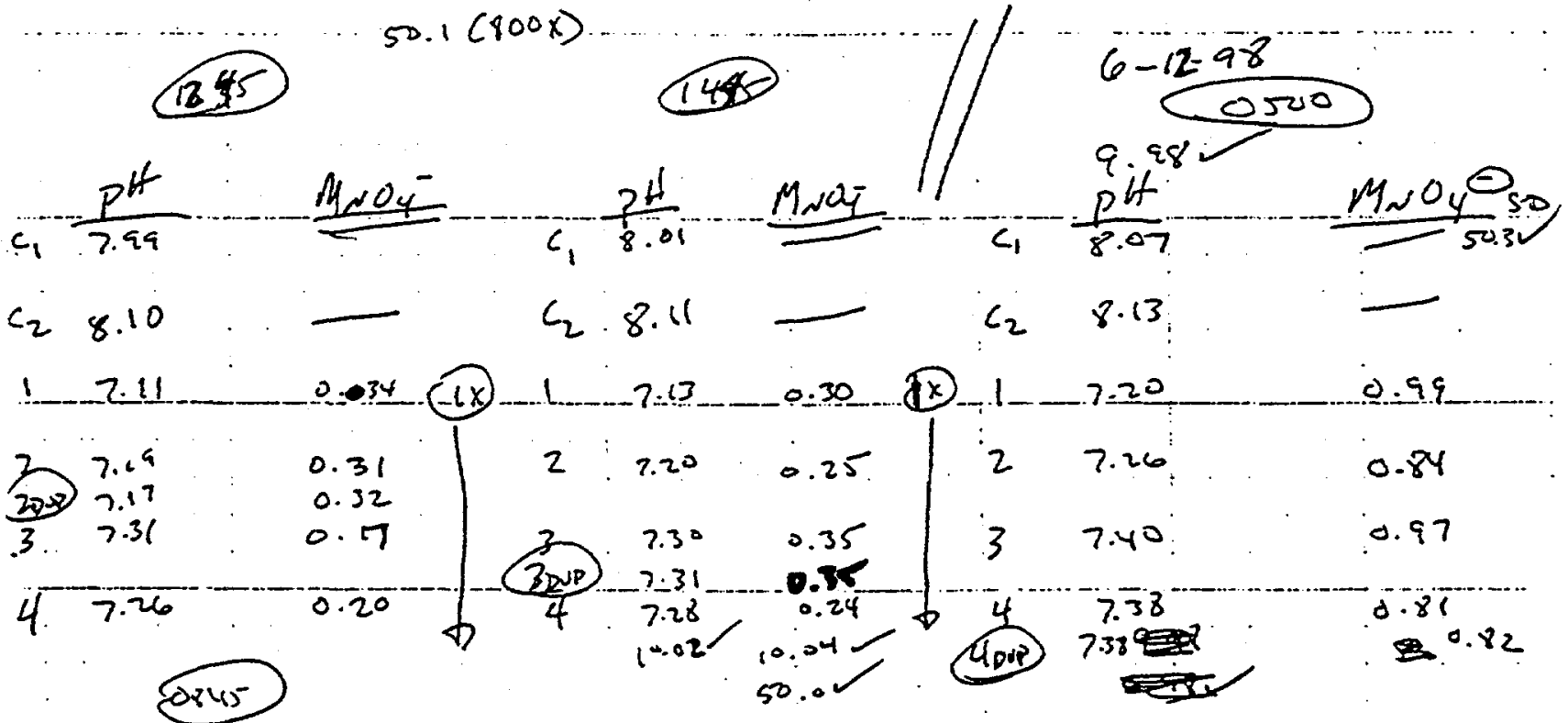

$c_{1} \frac{2 H}{8.13}+12$
$c_{2}$
8.19

$1 \ldots 7.32 \ldots .97$

i $\quad 2.39 \quad 1.03$

$37.52 \quad 0.98$

$4 \quad 1.55 \quad 1.14$

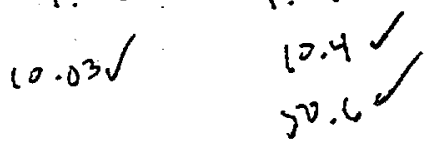

$F-218$ 


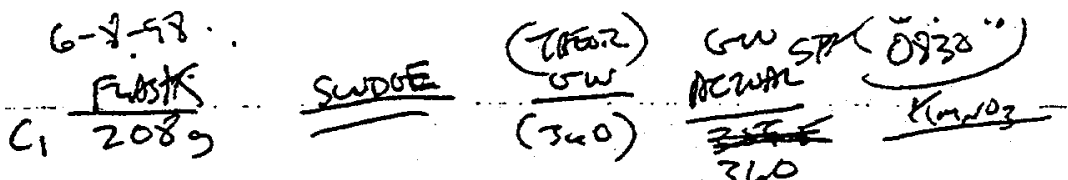

$$
\begin{aligned}
& c_{2} 221.4,-(360) \quad 363 \\
& 1210, \quad 942, \quad(327) \quad 379 \quad 0.948 \mathrm{ml} \\
& 2215.7,95.2 \quad(381) \quad 381 \quad 0.95341 \\
& 3206.5,93.7 \quad(375) 326 \quad 0.65 \mathrm{ml} \\
& 4.208 .4990 .6 \text { (302) } 365 \text { 9.4 }
\end{aligned}
$$

$F-219$ 
CONTROL WORK SHEET - 1

\begin{tabular}{|c|c|c|c|}
\hline \multicolumn{4}{|l|}{ AMALYST } \\
\hline \multicolumn{4}{|c|}{$\begin{array}{l}\text { COMPLETEO } \\
\text { TIME }\end{array}$} \\
\hline \multicolumn{4}{|c|}{ CHECKED AY (SUPERVBOAT) } \\
\hline \multicolumn{3}{|l|}{ CURYE FACTOR } & \\
\hline \multicolumn{4}{|l|}{ ANALYYZED FOA } \\
\hline ABSORBANCE & $\begin{array}{l}\text { CURVE } \\
\text { REAOINC }\end{array}$ & $\begin{array}{l}\text { OLLUTION } \\
\text { FACTOR }\end{array}$ & $\begin{array}{c}\text { RESULTS } \\
/ \mathrm{ml}\end{array}$ \\
\hline & & & \\
\hline
\end{tabular}

\begin{tabular}{|c|c|c|c|c|c|c|c|c|}
\hline \multirow{2}{*}{$\begin{array}{l}\text { SERIES } \\
\text { SAMPLE CODE }\end{array}$} & \multirow[t]{2}{*}{$B T L$} & \multirow{2}{*}{ 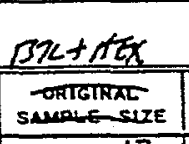 } & \multirow{2}{*}{ 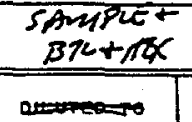 } & \multirow{2}{*}{$\frac{\text { DIL. }}{\substack{\text { RCTOUOT } \\
\text { STLE }}}$} & \multicolumn{4}{|c|}{ ANALYZEO Fon } \\
\hline & & & & & ABSOREANCE & $\begin{array}{c}\text { CURVE } \\
\text { REAOING }\end{array}$ & $\begin{array}{l}\text { DILUTION } \\
\text { FACTOR }\end{array}$ & $\begin{array}{c}\text { RESULTS } \\
/ \mathrm{mI} \\
\end{array}$ \\
\hline 696 & 10.9963 & 14.325 & 19.3207 & $200 x$ & & & & \\
\hline 697 & 10.8979 & 14.245 & 19.2450 & $200 x$ & & & & \\
\hline 698 & 11.0422 & 13.0580 & 15.9510 & $20-x$ & & & & \\
\hline 699 & 11.0783 & 13.0944 & 16.8382 & $\phi$ & & & & \\
\hline$\$ 00$ & 10.9558 & 12.9719 & 16.4581 & 206 & & & & \\
\hline 701 & 10.9820 & 13.0032 & 16.2211 & & & & & \\
\hline 702 & 11.0121 & 13.0180 & 16.7482 & & & & & \\
\hline 703 & 10.9276 & 12.9477 & 16.7017 & 6 & & & & \\
\hline 704 & 10.8960 & 12.9190 & 16.5352 & $200 x$ & & & & \\
\hline 705 & 10.9743 & 12.9931 & $16.65 / 5$ & $200 x$ & & & & \\
\hline 706 & 10.9544 & 12.9781 & 15.9370 & $2+0 x$ & & & & \\
\hline 707 & 10.9287 & 12.9506 & 16.3368 & $2-x$ & & & & \\
\hline 708 & 11.0264 & 13.0456 & 16.5151 & & & & & \\
\hline 709 & 10.9823 & 13.0051 & 16.7274 & & & & & \\
\hline 710 & 10.8722 & 12.9014 & 16.4048 & $\phi$ & & & & \\
\hline 711 & 10.9635 & 12.9918 & 16.6573 & $2 \operatorname{ser}$ & & & & \\
\hline 712 & 11.0077 & 13.0234 & 16.4409 & $200 x$ & & & & \\
\hline 713 & 10.9567 & $12.96<0$ & 164762 & $200 x$ & & & & . \\
\hline 714 & 10.9627 & 12.9646 & 16.6199 & $2 x$ & & & & \\
\hline $7 / 5$ & 10.9892 & 13.0127 & 16.7415 & 1 & & & & \\
\hline 716 & 10.9697 & 12.5979 & 16.5563 & & & & & \\
\hline 717 & 10.908 & 12.9354 & 16.3907 & 8 & & & & \\
\hline $7 / 8$ & 10.9302 & 12.9571 & 15.9703 & $20 x$ & & & & \\
\hline 719 & 11.0133 & 13.0412 & $(c .615)$ & 2004 & & & & \\
\hline 320 & 10.9046 & 12.9275 & 16.4863 & $\phi$ & & & & \\
\hline
\end{tabular}


CONTROL WORK SHEET - 1

ANALYST

COMPLETEO

TIME

GUAYE FACTOR

SERIES

AlALTYZO FOA

\begin{tabular}{|c|c|c|c|c|c|c|c|c|}
\hline SAMPLE COOE & 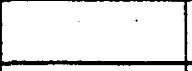 & $\begin{array}{c}\text { ORtGINAL } \\
\text { SAMPLE SIZE }\end{array}$ & DIL UTEO TO & $\begin{array}{c}\text { ALIQUOT } \\
\text { SIZEE } \\
\end{array}$ & ABSORBANCE & $\begin{array}{c}\text { CURVE } \\
\text { READING }\end{array}$ & $\begin{array}{l}\text { DLLUTION } \\
\text { FACTOPR }\end{array}$ & $\begin{array}{r}\text { RESULTS } \\
/ \mathrm{mI}\end{array}$ \\
\hline 721 & 10.9048 & 12.9358 & 16.4556 & $20 x$ & & & . & . \\
\hline 722 & 10.9703 & 13.0004 & 15.9719 & 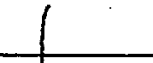 & & & $\therefore$ & $\therefore$ \\
\hline 723 & 10.9310 & 12.9658 & 16.5502 & & & & & $\therefore$ \\
\hline 724 & 10.9659 & 13.0042 & 16.3987 & & & & & \\
\hline 725 & 10.9879 & 13.0241 & 16.4455 & $\phi$ & & & & \\
\hline 726 & 10.9021 & $\begin{array}{r}12.8522 \\
15.9719 \\
\end{array}$ & 16.5334 & $200 x$ & & & & \\
\hline 727 & 10.9167 & 12.9280 & 16.5410 & $200 x$ & & & & \\
\hline 728 & 10.9387 & 12.9611 & 16.5739 & 20 & & & & $\vdots$ \\
\hline 729 & $10: 9874$ & 13.0200 & 16.8709 & & & & & \\
\hline 730 & 10.8692 & 12.9001 & 16.1821 & & - & & & \\
\hline 731 & 10.8988 & 12.9343 & 15.8348 & & & & & \\
\hline 732 & 10.9061 & 12.9398 & 16.2302 & $\downarrow$ & & & & \\
\hline 733 & 10.7589 & 12.7780 & 16.2775 & $200 x$ & & & & \\
\hline 734 & 11.0050 & 13.0167 & 16.6139 & $200 x$ & & & & \\
\hline 735 & 10.8926 & 12.9019 & 16.3837 & $20 x$ & & & & \\
\hline 736 & 10.9118 & 12.5370 & 16.3664 & 1 & & & & \\
\hline 737 & 10.9662 & 12.9890 & 16.1220 & & & & & \\
\hline 738 & 10.9897 & 13.0172 & 16.1672 & & & & & \\
\hline 739 & 10.9138 & 12.9415 & 15.6965 & $t$ & & & & \\
\hline 740 & 10.9580 & 12.9665 & 16.3624 & $200 x$ & & & & \\
\hline 741 & 10.9864 & 12.9905 & 16.6041 & $200 x$ & & & & \\
\hline 742 & 10.9785 & 13.0031 & 16.1987 & $20 x$ & & & & \\
\hline 743 & 10.8769 & 12.9077 & 15.8403 & 1 & & & & \\
\hline 744 & 10.8671 & 12.8981 & 16.2021 & & & & & \\
\hline 745 & 11.0593 & 13.0887 & 16.3354 & $t$ & & & & \\
\hline
\end{tabular}


CONTROL WORK SHEET - 1

\begin{tabular}{|l|}
\hline AMALYST \\
COMPLETEO \\
TIME \\
\hline CMECKED OY ( SUPERVEOR) \\
\hline AMALYZEO FOR \\
\hline
\end{tabular}

\begin{tabular}{|c|c|c|c|c|c|c|c|c|}
\hline SAMPLE CODE & & $\begin{array}{l}\text { ORIGIMAL } \\
\text { SAMPLE SIZE }\end{array}$ & DILUTEO TO & $\begin{array}{l}\text { ALLQUOT } \\
\text { SIIEE }\end{array}$ & ABSORBANCE & $\begin{array}{c}\text { CURVE } \\
\text { REAOING }\end{array}$ & $\begin{array}{l}\text { DHLUTION } \\
\text { FACTOR }\end{array}$ & $\begin{array}{l}\text { RESULTS } \\
\text { /mi }\end{array}$ \\
\hline 746 & 10.8167 & 12.8245 & 15.9914 & $200 x$ & & & & \\
\hline 747 & 10.9961 & 14.4247 & -14.5258 & $1 x$ & & & & \\
\hline 748 & 10.9529 & 14.3839 & 14.4290 & & & & & \\
\hline 749 & 10.9716 & 19.4117 & 14.5088 & & & & & \\
\hline 750 & 10.9671 & 14.4017 & 14.4404 & & & & & \\
\hline 751 & 11.0107 & 14.4394 & 14.5320 & & & & & \\
\hline 752 & 10.9900 & 14.4219 & 14.4691 & & & & & \\
\hline 753 & 10.7970 & 14.1530 & 14.2431 & & & & & \\
\hline 354 & 10.9886 & 14.4097 & 14.4334 & & & & & \\
\hline 755 & 10.9526 & 14.3750 & $14.443^{\circ}$ & & & & & \\
\hline 756 & 11.0068 & 14.4244 & 14.4660 & & & & & \\
\hline 357 & 10.9988 & 14.3529 & 14.4481 & & & & & \\
\hline 758 & 10.8824 & 14.3022 & 14.3455 & $b$ & & & & \\
\hline 1759 & 492.68 & 276.42 & 1142.33 & . & & & & \\
\hline 2760 & 492.99 & 278.90 & 1151.58 & & & & & \\
\hline 761 & 492.99 & 276.36 & 1163.00 & & & & & \\
\hline 362 & 437.31 & 254.85 & 1067.99 & & & & & \\
\hline & & & & & & & & \\
\hline & & & & & & & & \\
\hline & & & & & & & & \\
\hline & & & & & & & & \\
\hline & & & & & & & & \\
\hline & & & & & & & & \\
\hline
\end{tabular}




\section{6 row 11}

12 Jun $98 \quad 13: 10$
Protocol \#:60

Quench Indicator: tsIE

Ext std Terainator: Count Error $=$ ierror $/ 100 *$ BQ/VIAL

Coincidence lime(as): 18

Delay Before Burst(ns): Normal

Protocol Data Filenase: C:ISPECTRATPROT.DAT

Count Data Filenane: C:ISPECTRALSOATA6O.OAT

Spectrun Data Orive \& Path: C:ISPECTRA

S\# TIME CPMA DPMI A:25\% BO/VIAL ERROR TSIE FLAG

WARNING: USER HAS MOOIFIED COUNT CONDITIONS
130.00
40.10
$5.77 \quad 0.000$
0.000625 .70
8

LOG SPECTRUM PLOT

369.1 Y Log maximum Protocol No. 60 Sample No. 1 Repeat 1

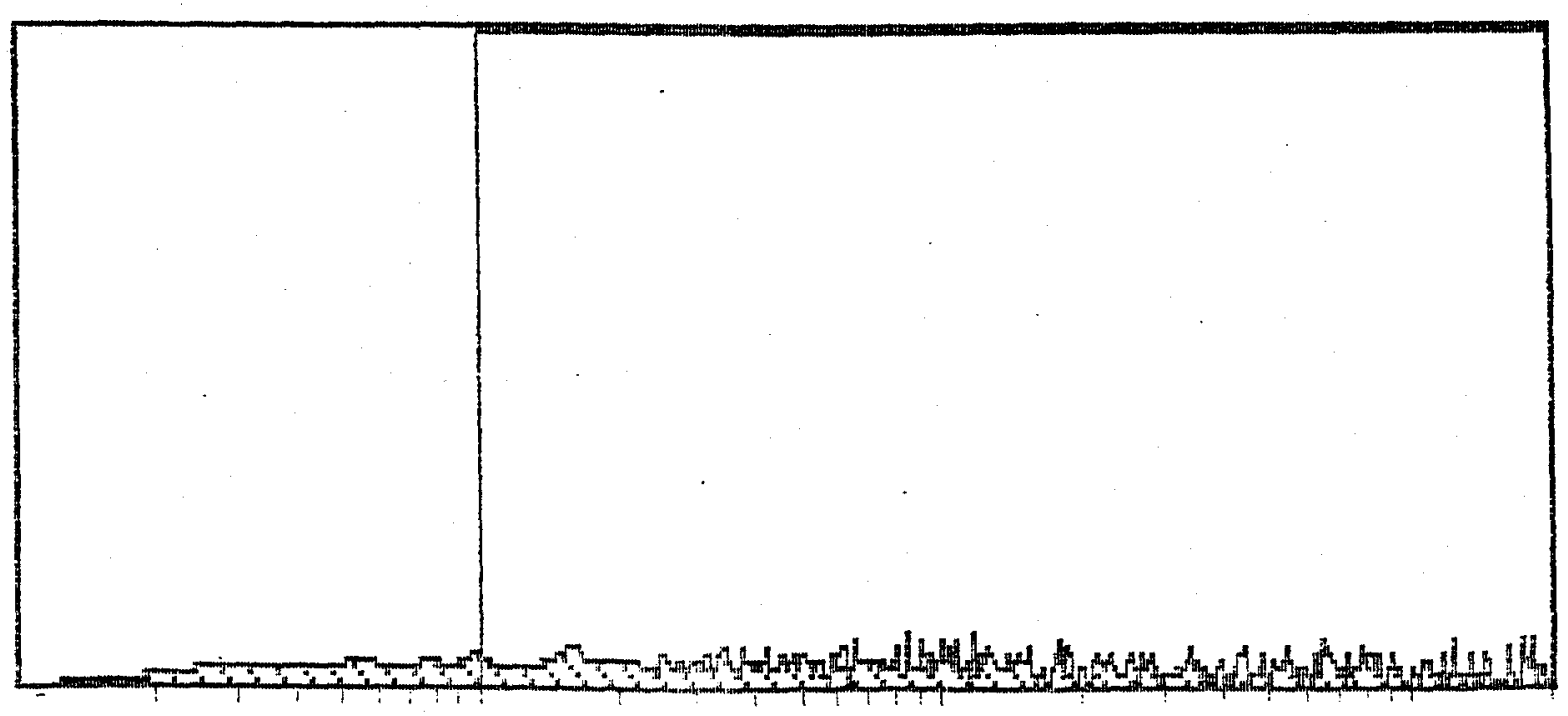




$\begin{array}{cccc}\text { Region } & \text { LL } & \text { UL } & \text { CPM } \\ \text { A: } & 0.0 & 2000 & 40.1 \\ \text { B: } & 0.0 & 0.0 & 0.0 \\ \text { C: } & 0.0 & 0.0 & 0.0\end{array}$

$2 \quad 30.00 \quad 1095.97 \quad 1157.56 \quad 1.14 \quad 19.293 \quad 0.220 \quad 241.05$

\section{LOg SPECTRUM PLOT}

1424.8 Y Log maximum Protocol No.60 Sample No. 2 Repeat. 1

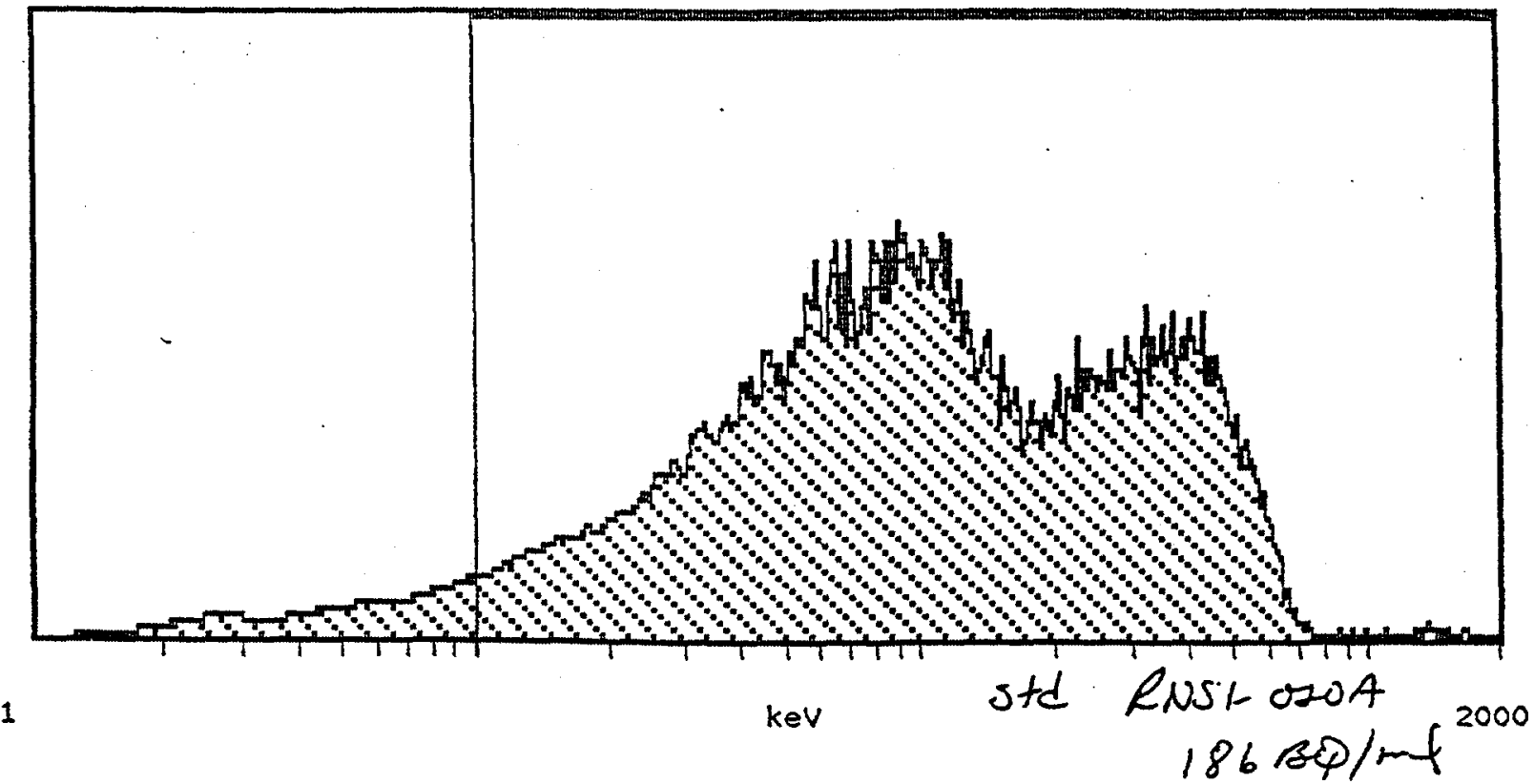

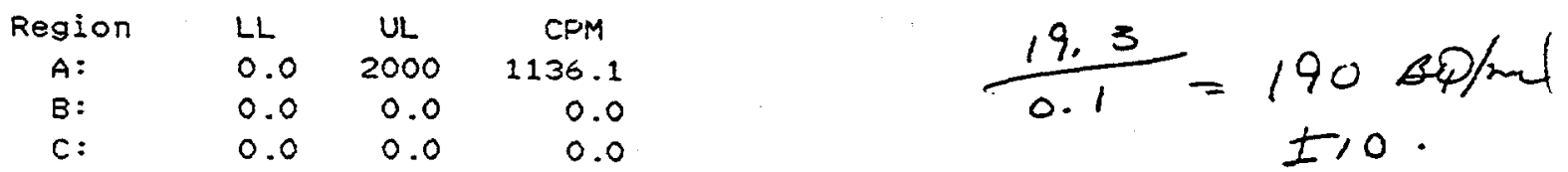


$\begin{array}{llllllll}3 & 30.00 & 1682.83 & 1738.74 & 0.91 & 28.979 & 0.264 & 604.82\end{array}$

\section{LOG SPECTRUM PLOT}

2524.2 Y Log maximum Protocol No. 60 sample No. 3 Repeat 1

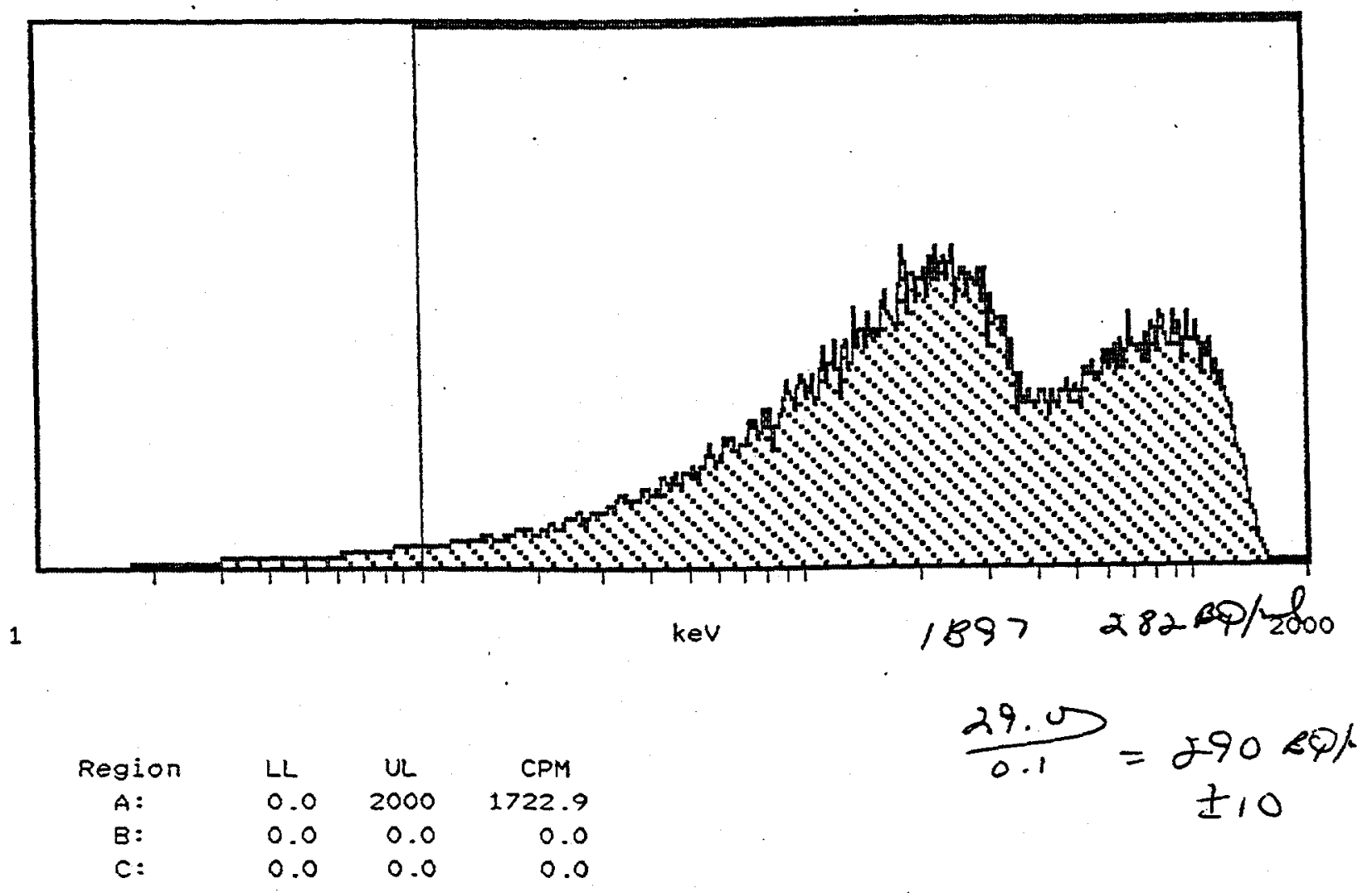


$\begin{array}{llllllll}3 & 30.00 & 1682.83 & 1738.74 & 0.91 & 28.979 & 0.264 & 604.82\end{array}$

LOS SPECTRUM PLOT
2524.2 Y Log maximum Protocol No. 60 Sample No. 3 Repeat 1

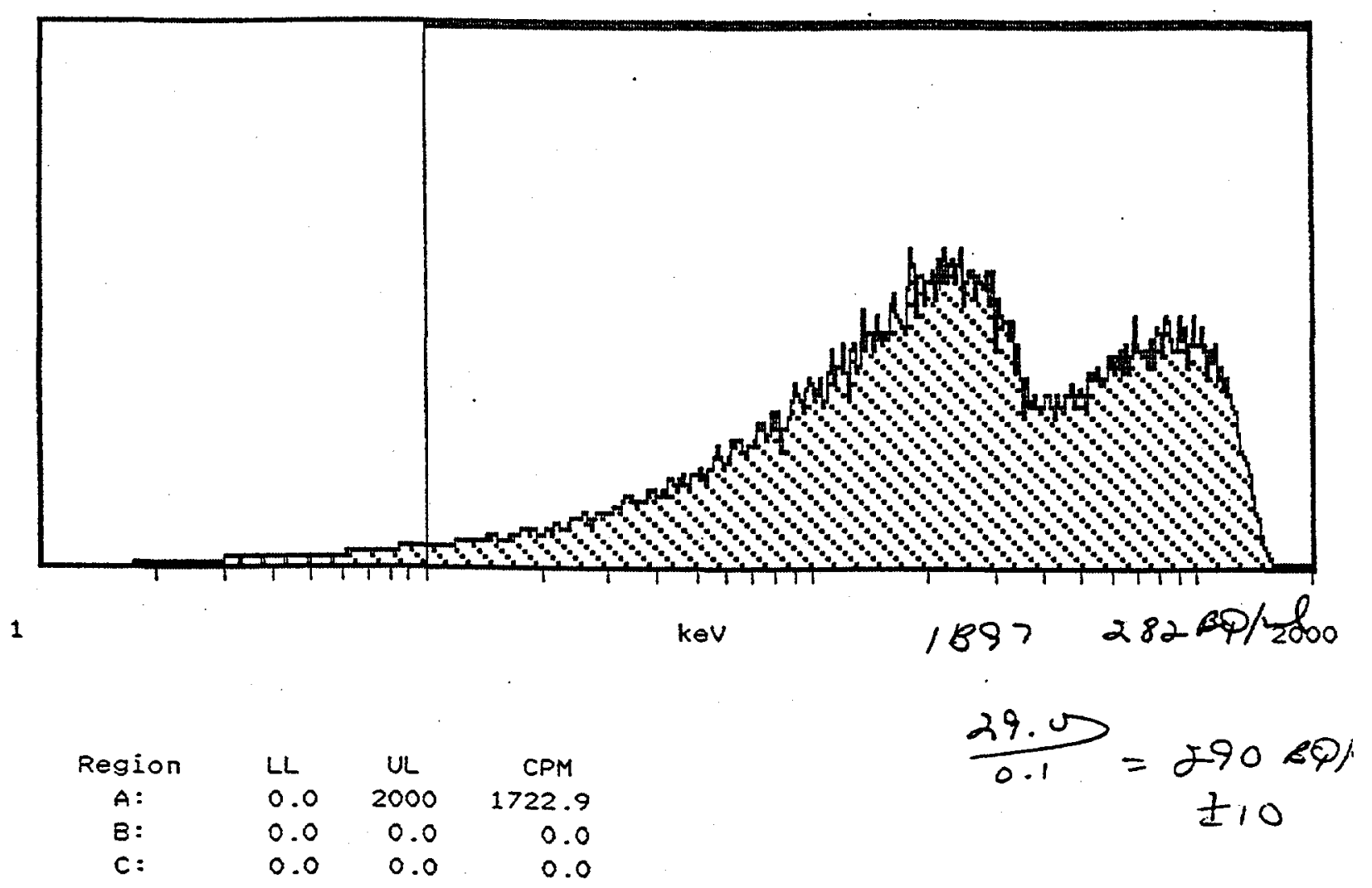



430.00
0.00
43.42
0.00
0.724
0.000633 .19

LOg SPECTRUM PLOT

324.6

Y Log maximum

Protocol No. 60 Sample No.

4 Repeat

1

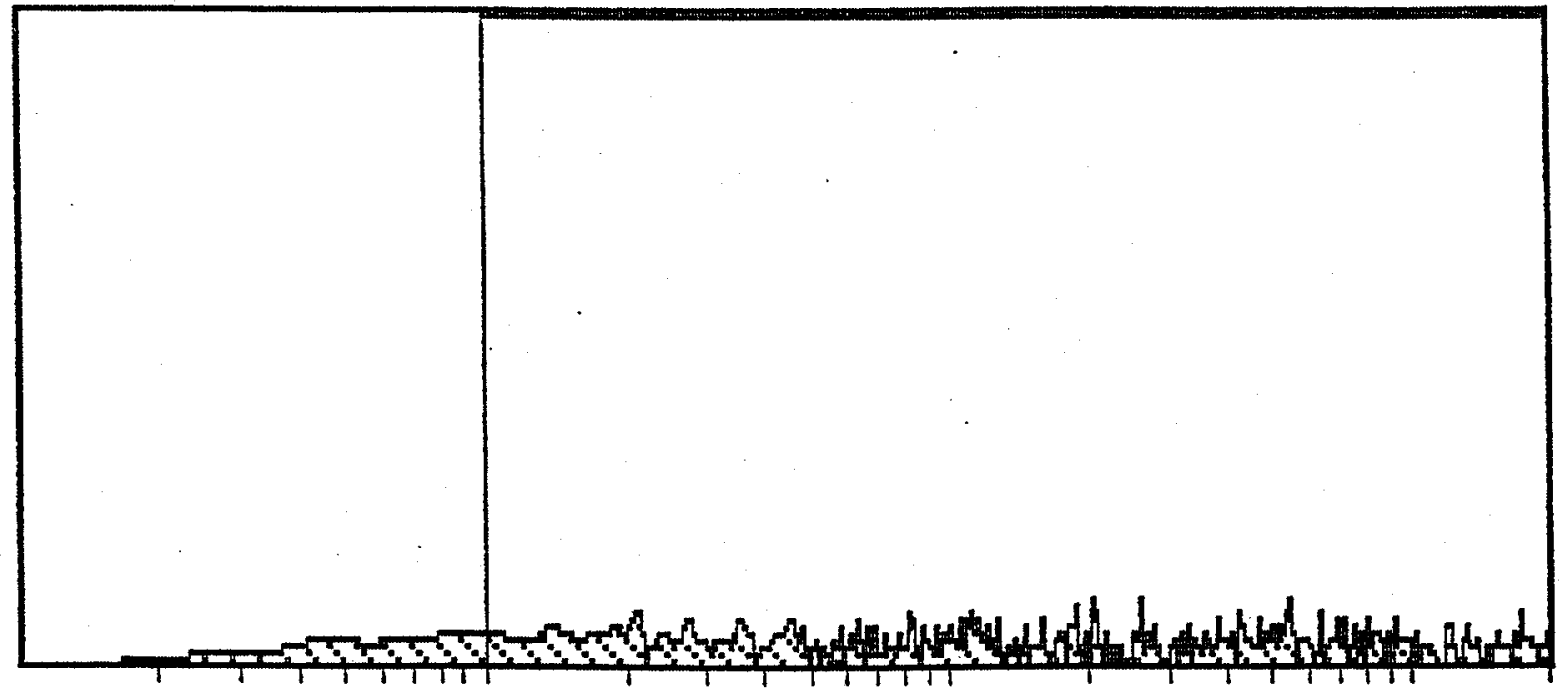

1

kev

2000

$\begin{array}{cccc}\text { Region } & \text { LL } & \text { UL } & \text { CPM } \\ \text { A: } & 0.0 & 2000 & 39.8 \\ \text { B: } & 0.0 & 0.0 & 0.0 \\ \text { C: } & 0.0 & 0.0 & 0.0\end{array}$




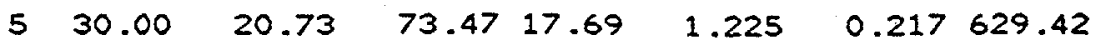

\section{LOg SPECTRUM PLOT}

515.4 Y Log maximum Protocol No. 60 Sample No. 5 Repeat 1

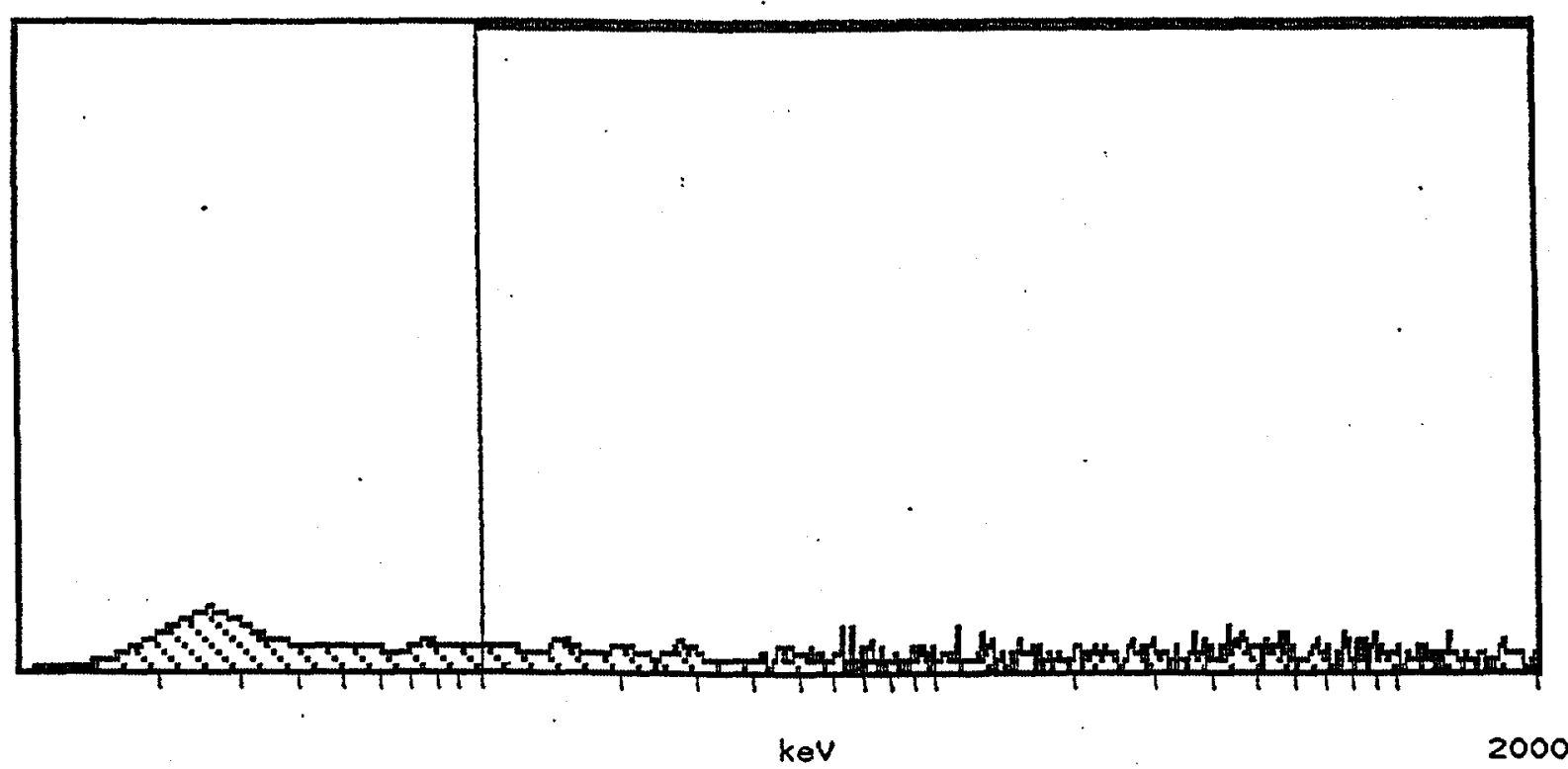

\begin{tabular}{clrl} 
Region & LL & UL & \multicolumn{1}{c}{ CPM } \\
A: & 0.0 & 2000 & 60.8 \\
B: & 0.0 & 0.0 & 0.0 \\
C: & 0.0 & 0.0 & 0.0
\end{tabular}


$\begin{array}{lllllll}6 & 30.00 & 12.20 & 60.79 & 28.77 & 1.013 & 0.291636 .63\end{array}$

Log SPECTRUM PLOT
$367.0 \quad$ Y Log maximum Protocol No. 60 Sample No. 6 Repeat 1

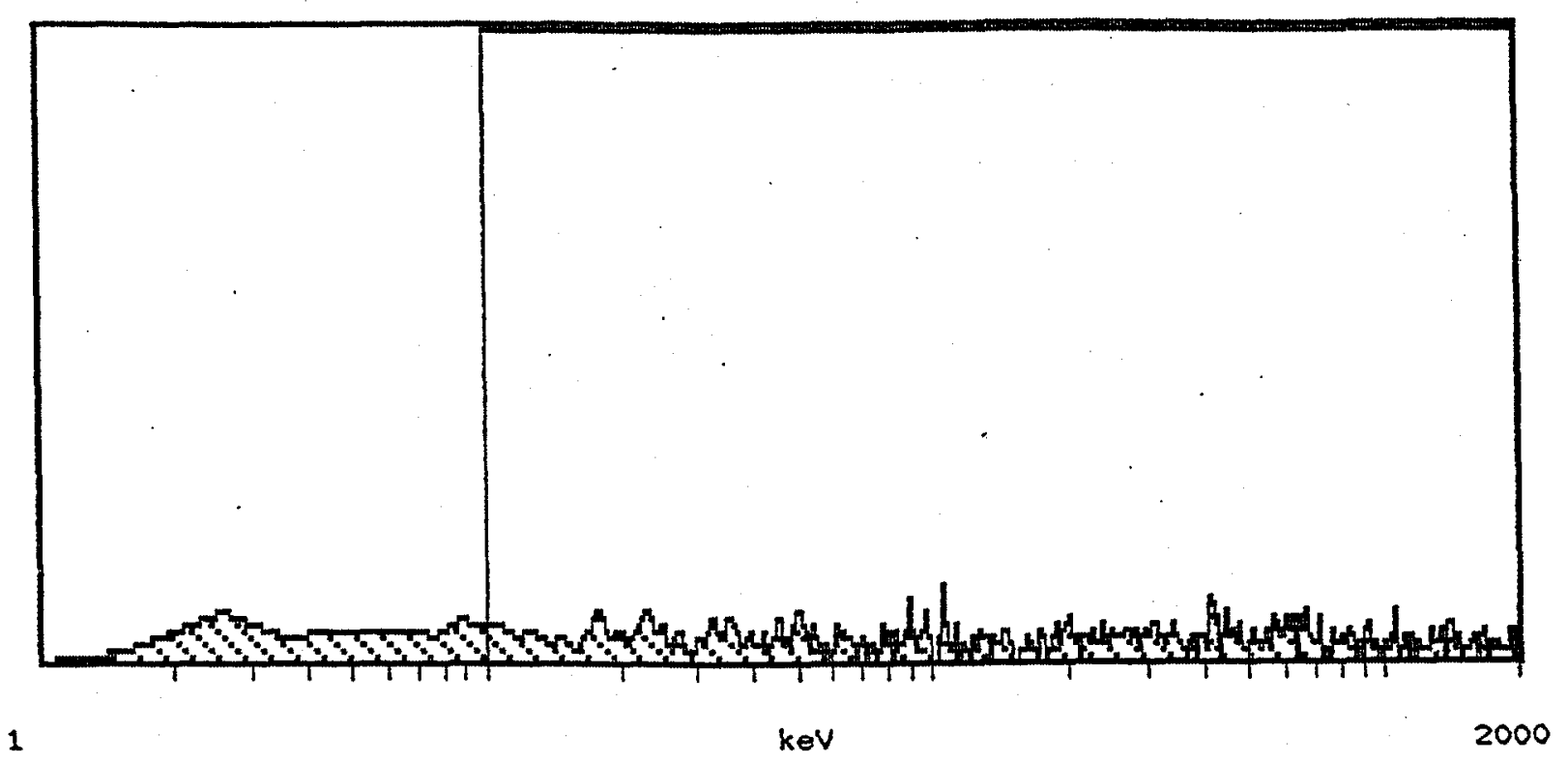

\begin{tabular}{cccc} 
Region & LL & UL & \multicolumn{1}{c}{ CPM } \\
A: & 0.0 & 2000 & 52.3 \\
B: & 0.0 & 0.0 & 0.0 \\
C: & 0.0 & 0.0 & 0.0
\end{tabular}




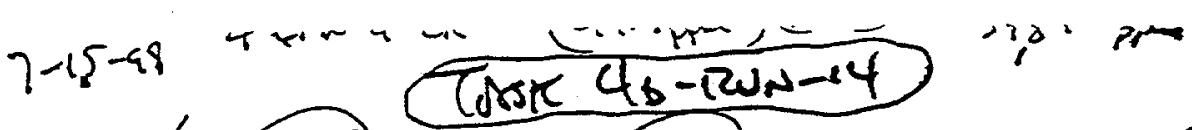

$[0.0]^{2}$

2845

(x+2005)-

(cos)

2502

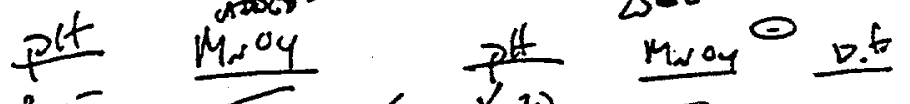

C1 8.05

(4) 8.25

C. 8.21

T

C. $8.20=$

C2 8.21 -

(2.) $8.2^{\circ}-$

$26.7^{\circ} \cdot 4.8447,=5.98$

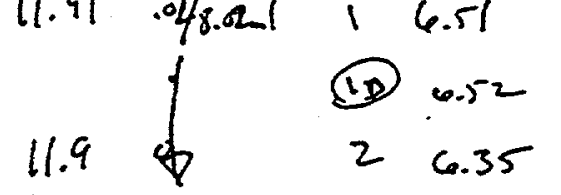

$36.73: 14.6416 \mathrm{~g} 36.24 \quad 0.1 / 8.01 \mathrm{ml} 36.6$

$4^{6.63} 14.6020^{\circ}$,

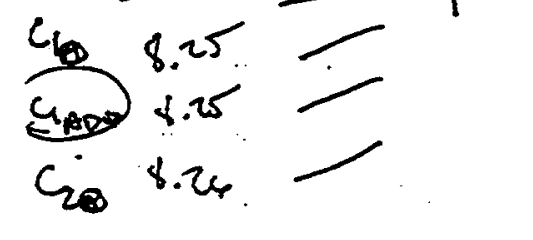

(3) $6.58 \quad .98 \mathrm{ml}$

$6.16=$

c. $8.6^{\circ}-$

$4 \quad 6.47 \quad 53.3$

$\frac{16.4}{16.4} ?^{2.04 / \% 8}$

2

$35.8 \quad 0 / 5$

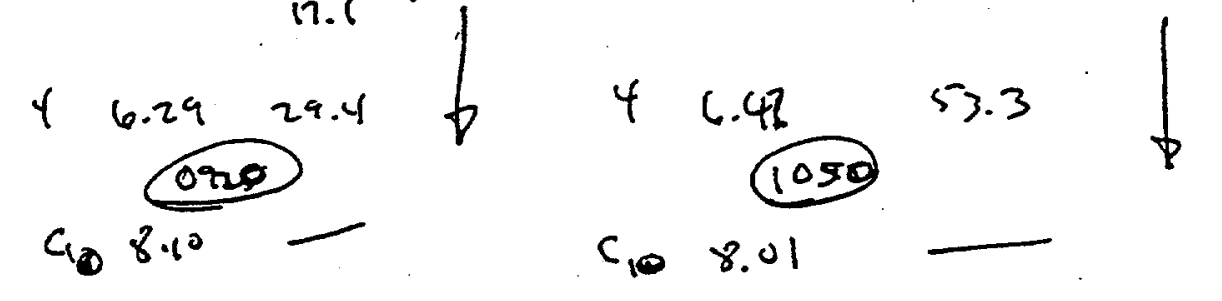

$206.62 \quad .905,1$

106.531 .90

$3_{0} 6.51 \quad 9.2 \mathrm{ml}$

$20 \quad 6.66 \quad 1.70$

7.35 and 4 (3) $6.48 \quad 0.58$

$30 \quad 6.44 \quad 0.97$

To3k 4 b-213

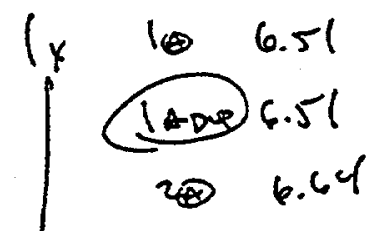

2.10 .18

1.88

304.51

1.44

(18) $6.8^{\circ}$

0.56
C.8 8.13

2.10

$F-230$ 


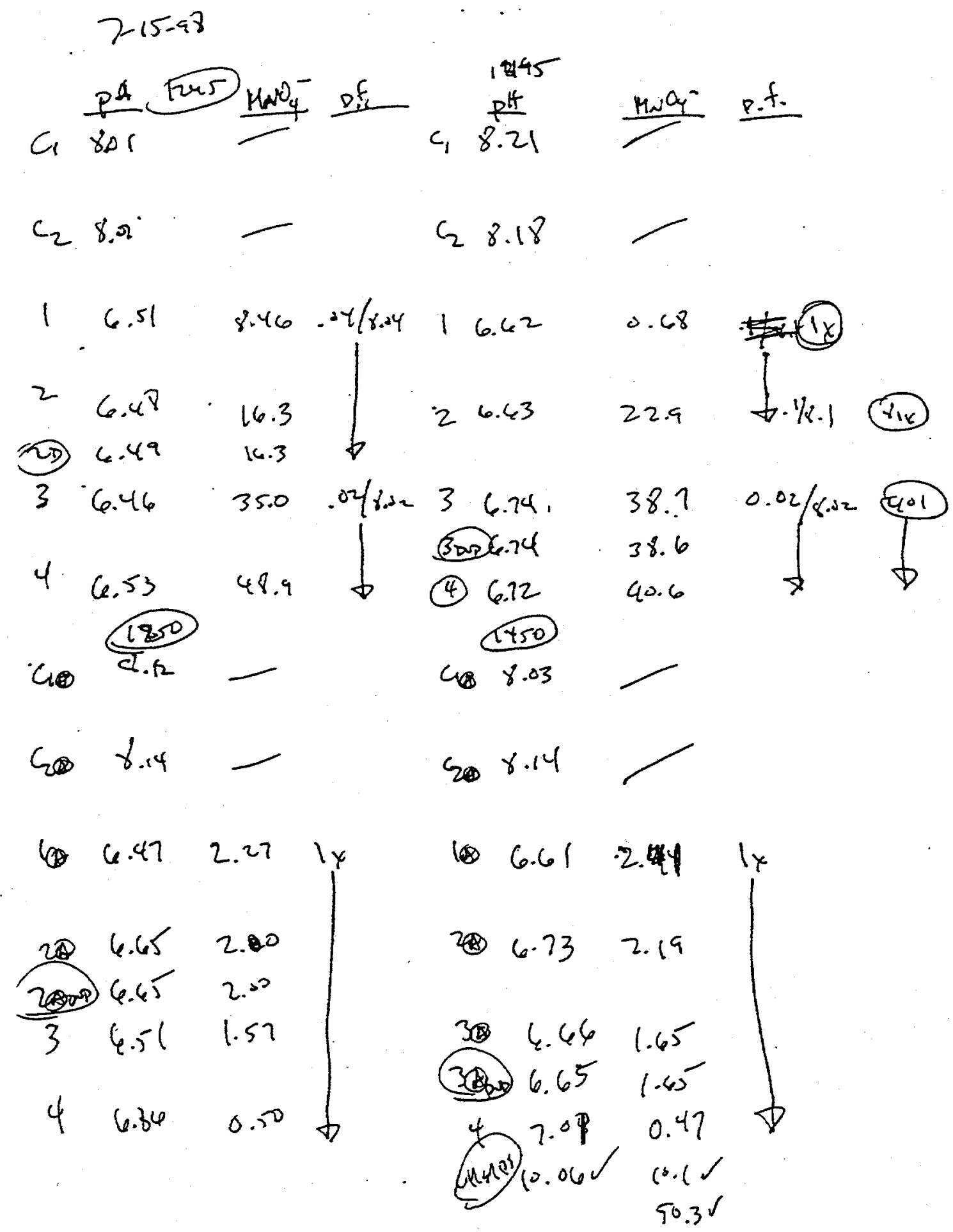




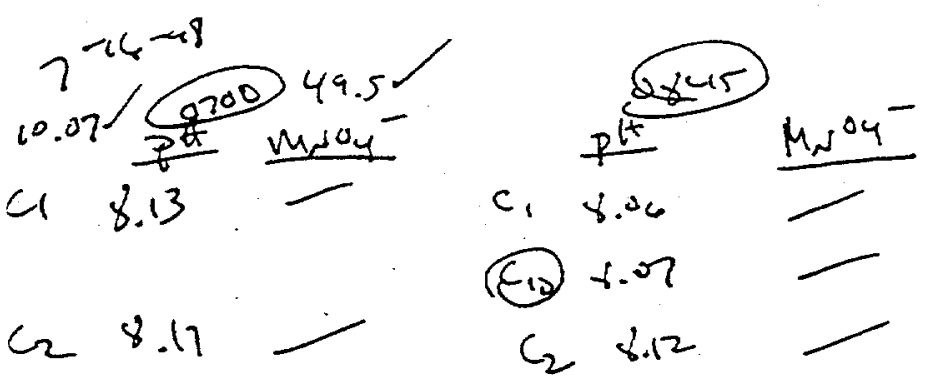

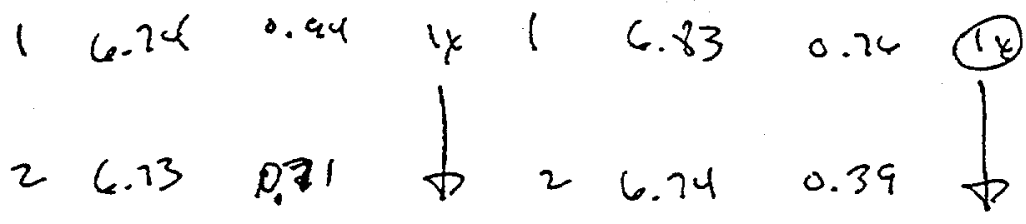

$\begin{array}{lllllll}36.82 & 31.9 & .02 / 2.32 & 0.83 & 37.1 & .02 / 8.32\end{array}$ $46.13 \quad 28.7$ $0_{0.050} 6.8328 .6$ o $4.8425 .6 \phi$

60800

$C .8 .13$

(1.) 6.81

$2.12 \quad 1 x$

$280.85 \quad 2.00$

$30 \quad 6.80 \quad 2.07$

$40.17 \quad 0.68$

40. 7.670 .67

(18) 6.81

$2.74(1)$

$206.77 \quad 2.43$
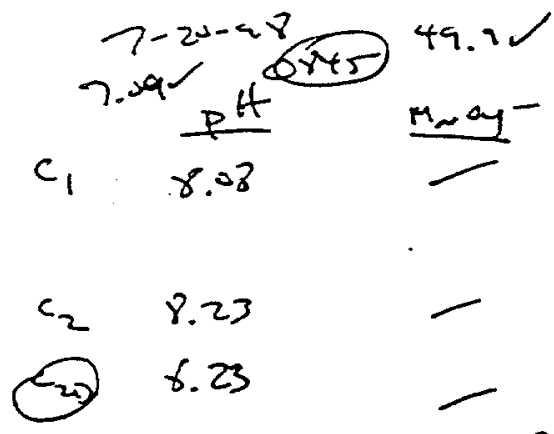

$2.00 \quad 5.87$ (1)

27.00

3.36

47.15 $18.3^{\circ} \$$

8285

$c 827$

$\begin{array}{lll}C_{20} & 8.29\end{array}$

8.27

28) $7.13 \quad-4.82$

38) $1.08 \quad 4.76$

4(5) 268

$1.1+7$

$\mathcal{M} .08$

$50.1 /$

$F-232$ 
7-14-4P

$$
1 \sigma_{0}+32
$$

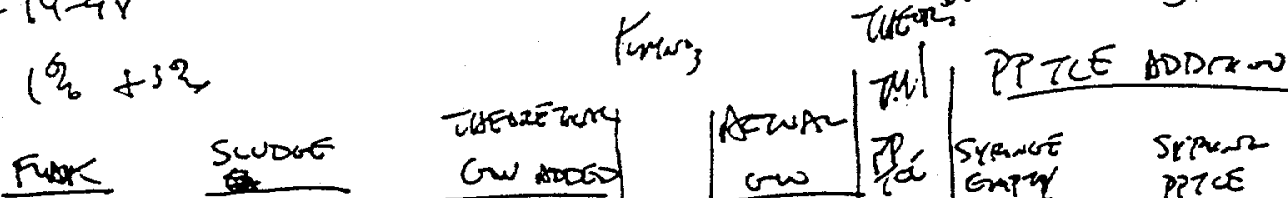

$c_{1} 209$

$c_{2} 221$

$1211 \quad 90.4(4.7929) 362$

2209

3209

4208

$.01 q+.1 q_{0}$

C. 204

Cos 212

la 212 91.2

2420590.4

$3 A \quad 210 \quad 91.8$

4 a 205 90.1
Enpty stpres

TrPun $\frac{P P}{C E E}$ PODSOS

.506

$\begin{array}{ll}40.344 & 41.0807\end{array}$

37. 1089

$36.8707 \quad 37.606$

$36.8698 \quad 37.5876$

36.869037 .5886

36.867937 .6019

36.855237 .6058

$36.86663 \quad 37.5929$

36.866237 .6026

$36.8658 \quad 37.5871$

$36.8648 \quad 37.5924$

36.864837 .5901

$F-233$ 


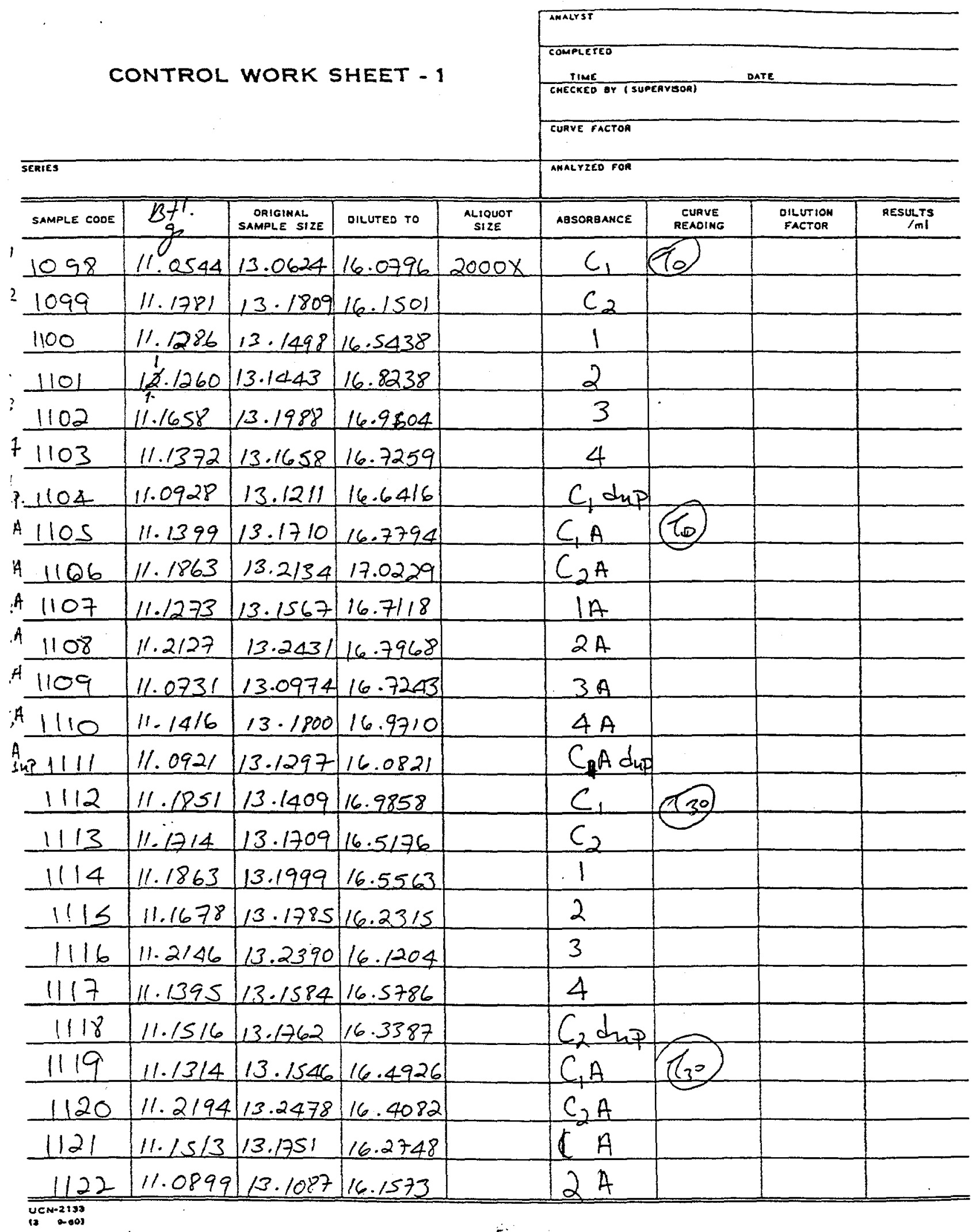

F-234 
CONTROL WORK SHEET - 1

ANALYST
COMPLET
TIME
CAECXEO 
CONTROL WORK SHEET - 1

\begin{tabular}{|l|}
\hline AMALYST \\
COMPLETEO \\
TIME \\
\hline CMECKEO BY (SUPERYSOR) \\
\hline CURYE FACTOR \\
\hline AMALYZEO FOR
\end{tabular}

\begin{tabular}{|c|c|c|c|c|c|c|c|c|}
\hline SAMPLE CODE & & $\begin{array}{c}\text { ORIGINAL } \\
\text { SAMPLE SIIE }\end{array}$ & DILUTED TO & $\begin{array}{l}\text { ALLQUOTT } \\
\text { SIZE }\end{array}$ & ABSORBANCE & $\begin{array}{c}\text { CURVE } \\
\text { READING }\end{array}$ & $\begin{array}{l}\text { DELUTION } \\
\text { FACTOR } \\
\end{array}$ & $\begin{array}{c}\text { RESULTS } \\
/ \mathrm{mi} \\
\end{array}$ \\
\hline 1148 & 11.0297 & 13.0877 & 16.1463 & & $\mathrm{C}_{2} \mathrm{~A}$ & & & \\
\hline 1149 & 11.0532 & 13.1138 & 16.7562 & & $1 A$ & & & \\
\hline 1150 & 11.1567 & 13.2185 & 16.0731 & & $2 A$ & & . & \\
\hline 1151 & 11.1988 & 13.2652 & 16.9933 & & $3 A$ & & & \\
\hline 1152 & 11.0868 & 13.1553 & 16.8067 & $\cdots$ & $4 A$ & & & \\
\hline 1153 & 11.1023 & 13.1702 & 16.9347 & & $2 A d i p$ & & & \\
\hline 1154 & 11.1438 & 13.1658 & 16.3577 & & $C_{1}$ & & & \\
\hline 1155 & 11.1986 & 13.2146 & 16.3165 & & $C_{2}$ & & & \\
\hline 1156 & 11.1415 & 13.1732 & 16.4694 & & 1 & & & \\
\hline 1157 & 11.1168 & 13.1541 & 16.1889 & & 2 & & & \\
\hline 1158 & 11.1756 & 13.2288 & 16.4935 & & 3 & & & \\
\hline 1159 & 11.1431 & 13.2106 & 16.4911 & & 4 & & & \\
\hline 1160 & 11.1562 & 13.2238 & 16.2189 & & 3 dup & & & \\
\hline $1|6|$ & 11.1624 & 13.2154 & 16.2980 & & $C A$ & & & \\
\hline 1162 & 11.1732 & 13.2414 & 16.1994 & & $C_{2} A$ & & & \\
\hline 1163 & 11.1671 & 13.2313 & 16.6064 & & 14 & & & \\
\hline 1164 & 11.1317 & 13.1771 & 16.4494 & & $2 A$ & & & \\
\hline 1165 & 11.1042 & 13.1704 & 16.1450 & & $3 A$ & & & \\
\hline 1166 & 11.0748 & $13.13+4$ & 16.5581 & & $\triangle A$ & & & \\
\hline 1167 & 11.1069 & 13.1715 & 16.7962 & & $3 A d_{4 P}$ & & & \\
\hline 1168 & 11.1929 & 13.2253 & 16.2485 & & $C_{1}$ & & & \\
\hline 1169 & 11.1569 & 13.1934 & 16.2826 & & $C_{2}$ & & & \\
\hline 1170 & 11.1261 & 13.1707 & 16.5542 & & 1 & & & \\
\hline 1171 & 11.0987 & 13.1416 & 16.4487 & & 2 & & & \\
\hline 1172 & 11.1448 & 13.1864 & 16.5064 & & 3 & & & \\
\hline
\end{tabular}


CONTROL WORK SHEET - 1

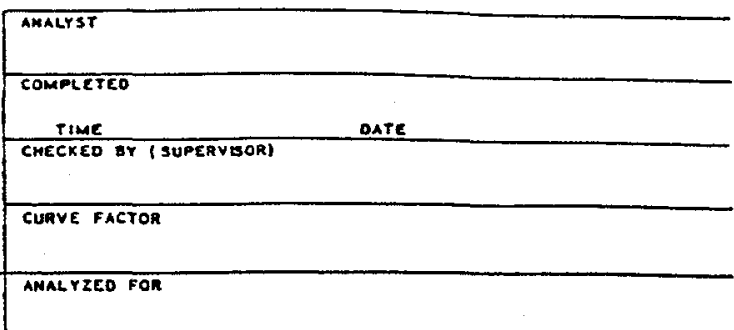

\begin{tabular}{|c|c|c|c|c|c|c|c|c|}
\hline SAMPLE CODE & & $\begin{array}{c}\text { ORIGINAL } \\
\text { SAMPLE SIZE }\end{array}$ & DILUTED TO & $\begin{array}{l}\text { ALLOUOT } \\
\text { SIZE }\end{array}$ & ABSORBANCE & $\begin{array}{c}\text { CURVE } \\
\text { REAOING }\end{array}$ & $\begin{array}{c}\text { DILUTION } \\
\text { FACTOR }\end{array}$ & $\begin{array}{r}\text { RESULTS } \\
/ \mathrm{ml} \\
\end{array}$ \\
\hline 1173 & 11.1209 & 13.1679 & 16.7607 & & 4 & & & \\
\hline 1174 & 11.1375 & 13.1886 & 16.2199 & & $4 d_{4 F}$ & & & \\
\hline 1175 & 11.1959 & 13.2398 & 16.7869 & & $C, A B$ & & & \\
\hline 1176 & 11.1075 & 13.1587 & 16.2300 & & $C_{2} A$ & & & \\
\hline 1177 & 11.1433 & 13.1880 & 16.5789 & & $1 A$ & & & \\
\hline $11-18$ & 11.1782 & 13.2232 & 16.6262 & & $2 A$ & & & \\
\hline 1179 & 11.1501 & 13.1952 & $16.316 \mathrm{C}$ & & $3 A$ & & & \\
\hline 1180 & 11.1077 & 13.1521 & 16.5210 & & $4 A$ & & & \\
\hline 1181 & 11.2269 & 13.2787 & $16.4 \times 96$ & & $A A d_{2}$ & & & \\
\hline 1182 & 11.2081 & 13.2417 & 16.3739 & & $C_{1}$ & & & \\
\hline 1183 & 11.2105 & 13.2348 & 16.6416 & & $c_{2}$ & & & \\
\hline 1184 & 11.0927 & 13.1119 & 16.1435 & & 1 & & & \\
\hline 1185 & 11.1732 & 13.2049 & 16.2097 & & 2 & & & \\
\hline 1186 & 11.2331 & 13.2636 & 16.2757 & & 3 & & & \\
\hline 1187 & 11.1759 & 13.2175 & 16.5525 & & 4 & & & \\
\hline 1188 & 11.1045 & 13.1394 & 16.2779 & & & & & \\
\hline 1189 & 11.1811 & 13.2179 & 16.4381 & & $C, A$ & & 亡 & \\
\hline 1190 & 11.2015 & 13.2369 & 16.4353 & & $\mathrm{C}_{2} \mathrm{~A}$ & & & \\
\hline 1190 & 11.1229 & 13.1601 & 16.2032 & & $1 A$ & & & \\
\hline 1192 & 11.1469 & 13.1826 & 16.2243 & & $2 A$ & & & \\
\hline 1193 & 11.2316 & 13.2714 & 16.2968 & & $3 A$ & & . & \\
\hline 1194 & 11.1102 & 13.1545 & 16.4699 & & $\Delta A$ & & & \\
\hline 1195 & 11.1167 & 13.1605 & 16.1315 & & $C_{1} A d_{4}$ & & & \\
\hline 1196 & 11.2027 & 13.1896 & 16.6202 & & & & & \\
\hline 1197 & 11.1978 & 13.2102 & 16.4617 & & & & & \\
\hline
\end{tabular}


CONTROL WORK SHEET - 1

ANALYST

COMPLETED

Time CHECKED OT (SUPERVISOR)

Dase CUAVE FACTOR

SERIES AMALYZEO FOR

\begin{tabular}{|c|c|c|c|c|c|c|c|c|}
\hline SAMPLE CODE & & $\begin{array}{c}\text { ORIGINAL } \\
\text { SAMPLE SIZE }\end{array}$ & DILUTED TO & $\begin{array}{c}\text { ALLQuOT } \\
\text { SIZE }\end{array}$ & ABSORBANCE & $\begin{array}{c}\text { CURVE } \\
\text { READING }\end{array}$ & $\begin{array}{l}\text { DHLUTION } \\
\text { FACTOR }\end{array}$ & $\begin{array}{c}\text { RESULTS } \\
/ \mathrm{ml}\end{array}$ \\
\hline 1198 & 11.1905 & 13.2127 & 16.3538 & & & & & \\
\hline 1199 & 11.1599 & 13.1799 & 17.6384 & & & & & \\
\hline 1200 & 11.0814 & 13.0991 & 17.4425 & & & & & \\
\hline 1201 & 11.1846 & 13.2176 & 13.7722 & & & & & \\
\hline 1202 & 11.1444 & 13.1490 & 16.2809 & & & & & \\
\hline 1203 & $11.15 / 5$ & 13.1844 & $16.47 / 5$ & & & & & \\
\hline 1204 & 11.1389 & 13.1880 & 16.1138 & & & & & \\
\hline 1205 & 11.1938 & 13.2187 & 16.6301 & & & & & \\
\hline 1206 & 11.1912 & 13.2280 & 16.4899 & & & & & \\
\hline 1207 & 11.1987 & 13.2444 & 16.8252 & & & & & \\
\hline 1208 & 11.1055 & 13.1462 & 16.4059 & & & & & \\
\hline 1209 & 11.1454 & 13.1837 & 16.1846 & & & & & \\
\hline 1210 & 11.1953 & 14.5782 & 14.6813 & & & & & \\
\hline 1211 & 11.1117 & 14.5180 & 145606 & & & & & \\
\hline 1212 & 11.1182 & $14 . \$ 320$ & $\$ 9.5326$ & & & & & \\
\hline $12 / 3$ & 11.0677 & 14.4739 & 14.520 & & & & & \\
\hline 1214 & 11.2030 & 14.6144 & 14.7176 & & & & & . \\
\hline 1215 & 11.1647 & 14.5782 & 14.6148 & & & & & \\
\hline $12 / 6$ & 11.1417 & 14.5598 & 14.6531 & & & & & \\
\hline 1217 & 11.1728 & 14.5795 & 14.6165 & & & & & \\
\hline 1218 & 11.1298 & 14.5472 & 14.6513 & & & & & \\
\hline 1219 & 11.0886 & 14.5000 & 14.5444 & & & & & \\
\hline 1220 & 11.1184 & 14.5593 & 14.6568 & & & & & \\
\hline 1221 & 11.1614 & 14.5777 & 14.6257 & & & & & \\
\hline 1222 & 11.1315 & 14.5275 & 14.6226 & & & & & \\
\hline
\end{tabular}
Uen.2133 
CONTROL WORK SHEET - 1

AMALYST

COMPLETEO

TIME

CURVE FACTOR

sentes

ANAL TIED FON

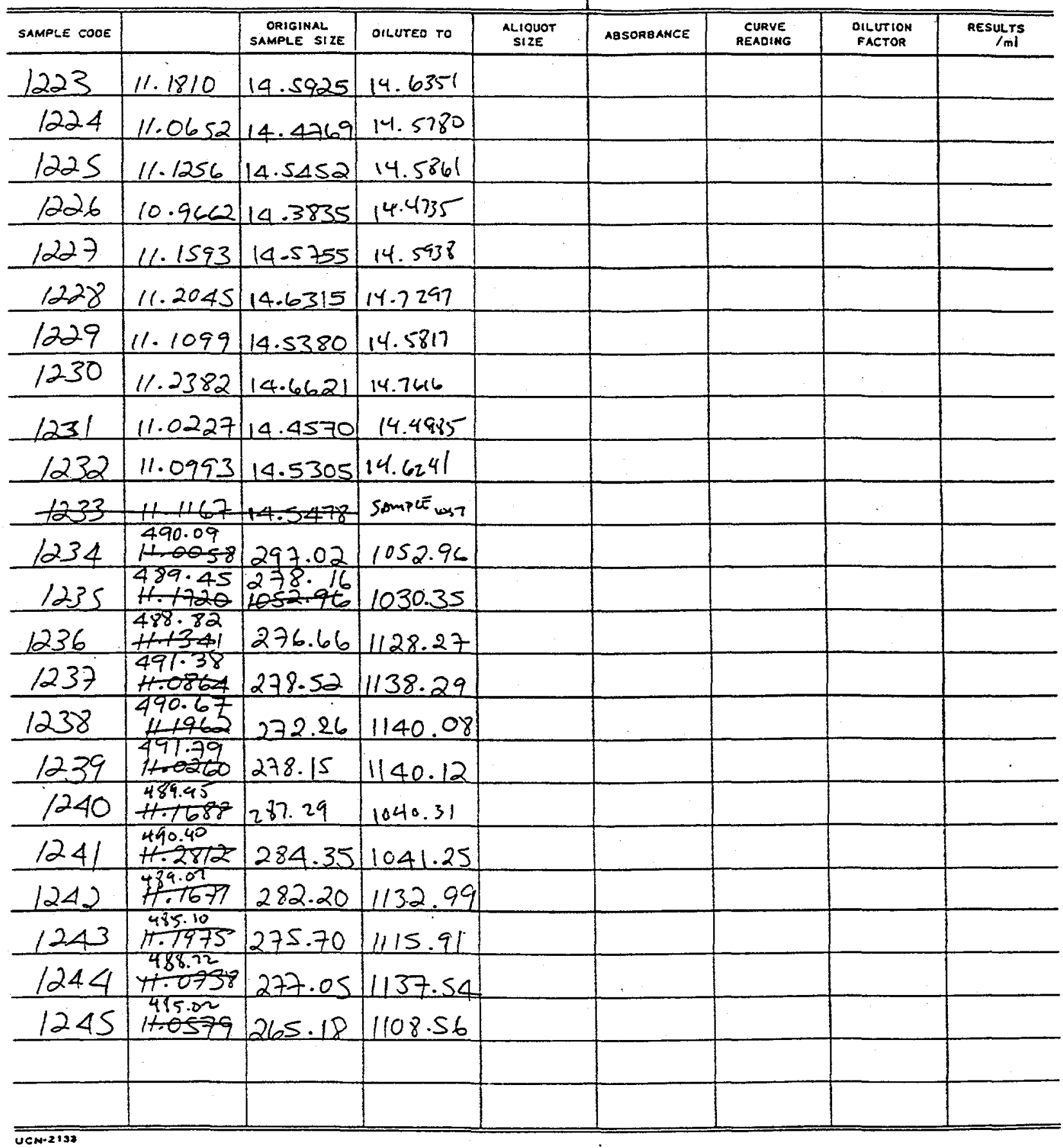




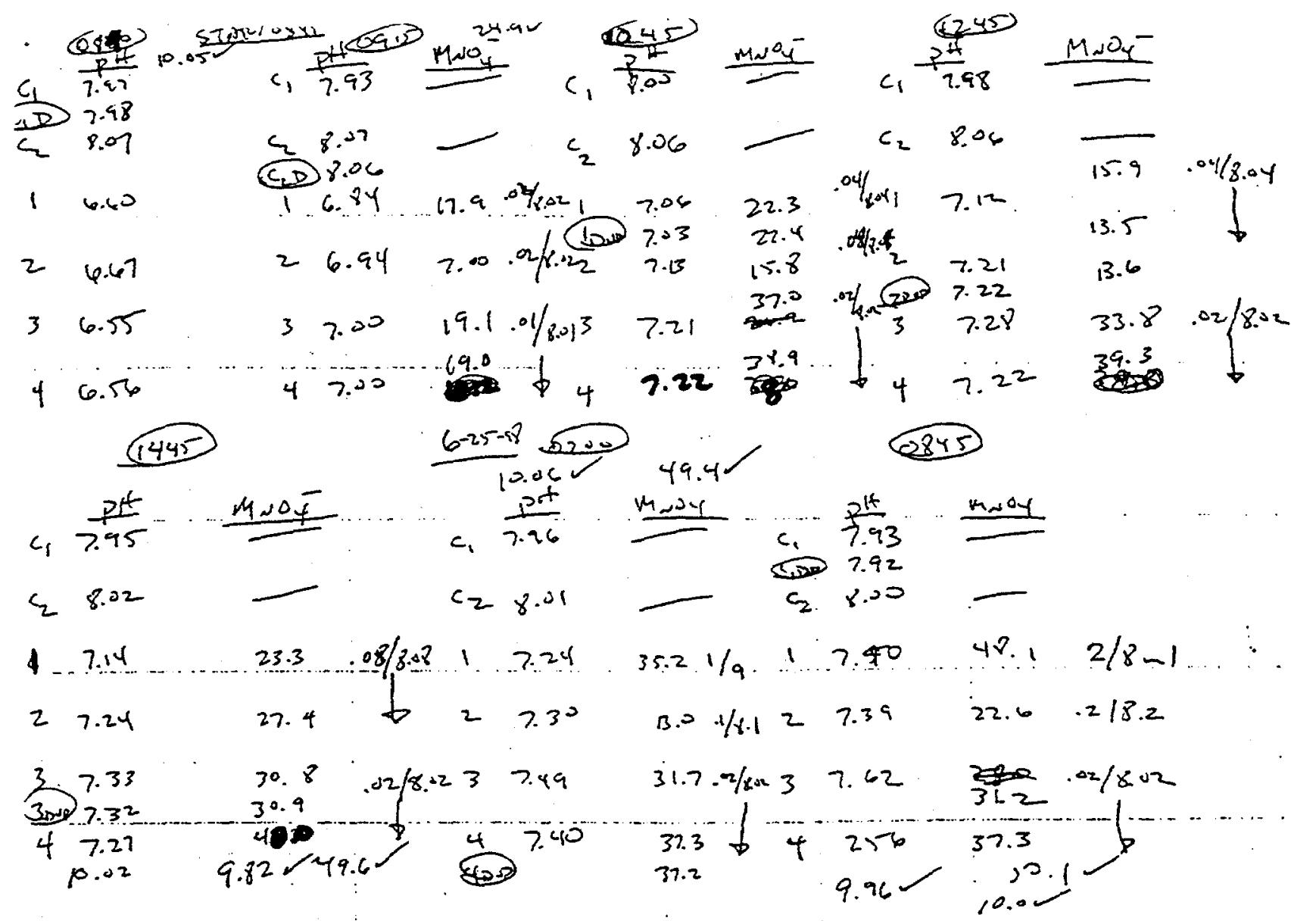

$$
\begin{gathered}
\text { TASK 4b-R15 } \\
\text { 10pPM 1CE } \\
1.0 \% \mathrm{MNOY}^{-} \\
3.0 \% \text { MNOY }
\end{gathered}
$$

$F-240$ 


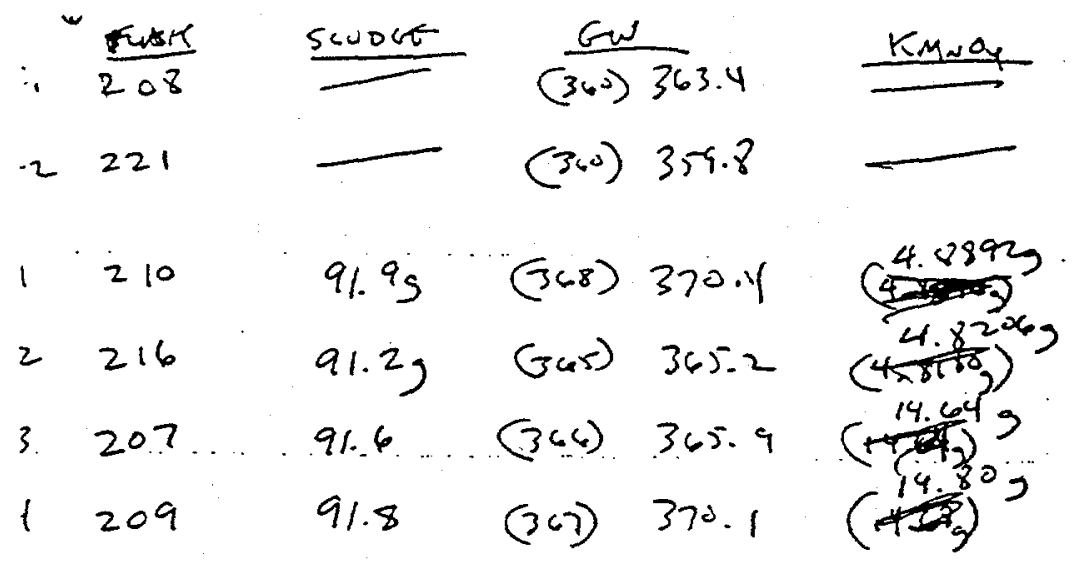


$6 / 23 / 98$

CONTROL WORK SHEET - 1

AKACYST

COMPLETEO

TIME

CURVE FACTOR

ANALYZEO FOR

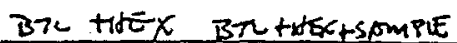

\begin{tabular}{|c|c|c|c|c|c|c|c|c|}
\hline SAMPLE CODE & BTL & 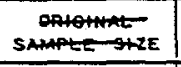 & 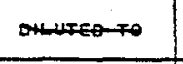 & $\begin{array}{l}\text { ALIQUOT } \\
\text { SIZE }\end{array}$ & AESORBAMCE & $\begin{array}{c}\text { CURVE } \\
\text { READING }\end{array}$ & $\begin{array}{l}\text { DIL UTION } \\
\text { FACTOR }\end{array}$ & RESULTS \\
\hline 897 & 11. 1041 & 14.4865 & $19-3747$ & $20 x$ & & & & \\
\hline 898 & $11.05 / 9$ & 14.4206 & 15.32 & & & & & \\
\hline 899 & 11.0311 & $13.0 \leq 40$ & 16.9724 & & & & & \\
\hline 900 & 11.0329 & 13.0310 & 16.9 & $\Phi$ & & & & \\
\hline 901 & 10.8965 & 12.9032 & 16.35 & $1 x$ & & & & \\
\hline 902 & 11.0154 & 13.0364 & $16.7 P 70$ & & & & . & \\
\hline 903 & 10.9872 & 13.0121 & 16.7616 & & & & & \\
\hline 904 & 11.0045 & 13.0356 & 16.3847 & $\phi$ & & & & \\
\hline 905 & 11.0087 & 13.0253 & 15.9826 & & & & & \\
\hline 906 & 11.0320 & 13.0108 & 16.7383 & & & & & \\
\hline 907 & 10.9248 & 12.98 & 16.8752 & $\phi$ & & & & \\
\hline 908 & 10.9758 & 12.9873 & 16.7544 & & & & & \\
\hline 90 & 11.0045 & 13.0219 & 17.1856 & & & & & \\
\hline 910 & 11.1422 & 13.1788 & 17.5095 & & & & & \\
\hline 911 & 10.9822 & 13.0197 & 17.0375 & & & & & \\
\hline 12 & 11.0140 & 13.0525 & 16.8 & & & * & & \\
\hline 13 & 10.9803 & 12.9850 & 16.7006 & $20 x$ & & & & \\
\hline 914 & 11.0813 & 13.08 & 16.7328 & $20 \times$ & & & & \\
\hline 915 & 11.0080 & 13.0257 & 16.8458 & $3 x$ & & & & \\
\hline 9 & 10.9793 & $13.00 / 6$ & 16.8565 & & & & & \\
\hline 917 & $10.9-992$ & 13.0071 & 17.0729 & & & & & \\
\hline 918 & 10.9466 & 12.9729 & 17.0102 & & & & & \\
\hline 919 & 11.1284 & 13.1455 & 16.6011 & 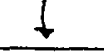 & & & & \\
\hline 920 & 10.9013 & 12.8788 & 16.4157 & $20 x$ & & & & \\
\hline 921 & 10.9951 & 13.0111 & 16.5590 & & & & & \\
\hline
\end{tabular}
$\overline{U C N-2+33}$ 
CONTROL WORK SHEET - 1 \begin{tabular}{|l|}
\hline AMACYST \\
\hline COMPLETES \\
TIME \\
\hline CHECXEO OY (SUPEAVISOR) OATE \\
\hline GURYE FACTOR \\
\hline AMALYZEO FOR \\
\hline
\end{tabular}

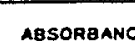

\begin{tabular}{|c|c|c|c|c|c|c|c|c|}
\hline$\overline{\text { SERIES }}$ & & & & & AHALYZEO FOR & & & \\
\hline SAMPLE CODE & & $\begin{array}{l}\text { ORIGINAL } \\
\text { SAMPLE SIZE } \\
\end{array}$ & DILUTED TO & $\begin{array}{c}\text { ALLQUOT } \\
\text { SIZE }\end{array}$ & ABSOREANCE & $\begin{array}{c}\text { CURVE } \\
\text { READING }\end{array}$ & $\begin{array}{l}\text { OLLUTION } \\
\text { FACTOR }\end{array}$ & $\begin{array}{r}\text { RESULTS } \\
/ \mathrm{mI} \\
\end{array}$ \\
\hline 922 & 11.0330 & 13.0623 & 16.4571 & $1 x$ & & . & & \\
\hline 923 & 11.0016 & 13.0346 & 15.9015 & 1 & & & & \\
\hline 924 & 10.9722 & 13.0147 & 16.8153 & & & & & \\
\hline 925 & 11.0777 & 13.1145 & 16.9618 & & & & & - \\
\hline 926 & 10.9687 & 13.0151 & 16.1687 & $\downarrow$ & & & & \\
\hline 927 & 11.0251 & 13.0393 & 16.6428 & & & & & \\
\hline 918 & 11.1107 & 13.1150 & 16.6710 & - & & & & \\
\hline 929 & 11.0339 & 13.0507 & 16.6811 & & & & & \\
\hline 930 & 10.9365 & 12.9531 & 16.8241 & & & & & \\
\hline 931 & 10.9482 & 12.9791 & 16.7922 & & & & & \\
\hline 932 & 11.0006 & 13.0175 & 16.9218 & & & & & \\
\hline 933 & 11.0667 & 13.0943 & 16.0883 & & & & & \\
\hline 934 & 11.0475 & 13.0715 & 16.2880 & & & & & \\
\hline 935 & 10.9658 & 12.9991 & 16.4546 & & & & & \\
\hline 936 & 11.1824 & 13.2163 & 17.0871 & & & & & \\
\hline 937 & 11.0093 & 13.0419 & 16.4108 & . & & & & \\
\hline 938 & 10.9052 & 12.9412 & 16.3751 & & & & & \\
\hline 939 & 11.0618 & 13.1016 & 16.6002 & & & & & \\
\hline 940 & 11.0026 & 13.0417 & 16.2035 & & & & & \\
\hline 941 & 11.0025 & 13.0329 & 16.3010 & & & & & \\
\hline 942 & 11.1231 & 13.1234 & 16.7042 & & & & & \\
\hline 943 & 11.0869 & 13.0921 & 16.4346 & & & & & \\
\hline 944 & 11.0770 & 13.1010 & 16.8089 & & & & & \\
\hline 945 & 11.0019 & 13.0515 & 16.8103 & & & & & \\
\hline 946 & 11.0827 & 13.1460 & 17.1248 & & & & & \\
\hline
\end{tabular}


CONTROL WORK SHEET - 1

\begin{tabular}{|l|}
\hline AMALYST \\
COMPLETEO \\
THME \\
\hline CUECKEO OY (SUPERVISOA) OATE \\
\hline AMALYIEO FOR \\
\hline
\end{tabular}

\begin{tabular}{|c|c|c|c|c|c|c|c|c|}
\hline \multicolumn{5}{|l|}{$\overline{s E R I E S}$} & \multicolumn{4}{|l|}{ ANALYZEO FOR } \\
\hline SAMPLE CODE & & $\begin{array}{l}\text { ORIGINAL } \\
\text { SAMPLE SIZE } \\
\end{array}$ & DILUTED TO & $\begin{array}{c}\text { ALIQUOT } \\
\text { SIZE } \\
\end{array}$ & ABSORGANCE & $\begin{array}{c}\text { CURVE } \\
\text { READING }\end{array}$ & $\begin{array}{l}\text { OILUTION } \\
\text { FACTOR }\end{array}$ & $\begin{array}{r}\text { RESULTS } \\
/ \mathrm{mi} \\
\end{array}$ \\
\hline 947 & 11.1097 & 13.1564 & 16.3142 & & & & & \\
\hline 948 & 11.1259 & $\begin{array}{r}4.5015 \\
3.7894 \\
\end{array}$ & 14.5965 & & & & & \\
\hline 949 & 11.1700 & $\begin{array}{l}14.5722 \\
13.2301 \\
\end{array}$ & 14.6180 & & & & & \\
\hline 950 & 10.9709 & $\begin{array}{l}4.3880 \\
13.0353\end{array}$ & 14.4860 & & & & & \\
\hline 951 & 11.0094 & $\begin{array}{r}14.4344 \\
5.0851 \\
\end{array}$ & 14.4792 & & & & & \\
\hline 952 & 10.9591 & $\begin{array}{r}14.3814 \\
+30311 \\
\end{array}$ & 14.4709 & & & & & \\
\hline 953 & 11.0916 & $\begin{array}{r}4.5045 \\
3 .+527 \\
4.207\end{array}$ & 14.5486 & & & & & \\
\hline 954 & 10.8610 & $\frac{14.2807}{12278}$ & $14.37 / 3$ & & & & & \\
\hline 955 & 11.0033 & 13.024 & 14.4643 & & & & & \\
\hline 956 & 11.0434 & $\begin{array}{r}14.4468 \\
131000 \\
\end{array}$ & 14.5423 & & & & . & \\
\hline 957 & 11.0778 & $\begin{array}{l}14.4616 \\
13 .+307\end{array}$ & 14.5253 & & & & & \\
\hline 1958 & $\begin{array}{r}491.11 \\
+\quad 619 \\
\end{array}$ & 1384.59 & 1156.76 & & & & & \\
\hline 2959 & $\begin{array}{l}491.01 \\
10.9923\end{array}$ & $\begin{array}{r}285.47 \\
13.0468 \\
\end{array}$ & 1137.66 & & & & & \\
\hline 3960 & 481.46 & 280.62 & 1198.11 & & & & & \\
\hline 4961 & 498.82 & 270.67 & 1142.18 & & & & & \\
\hline $4 \rightarrow 2$ & & & & & & & & \\
\hline 963 & & & & & & & & \\
\hline & & & & & & & & \\
\hline & & & & & & & & \\
\hline & & & & & & & & \\
\hline & & & & & & & & \\
\hline & & & & & & & & \\
\hline & & & & & & & & \\
\hline & & & & & & & & \\
\hline
\end{tabular}



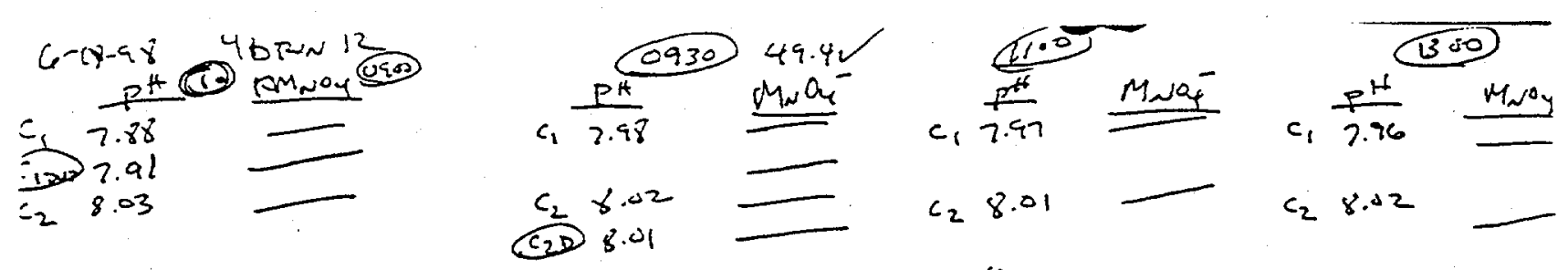

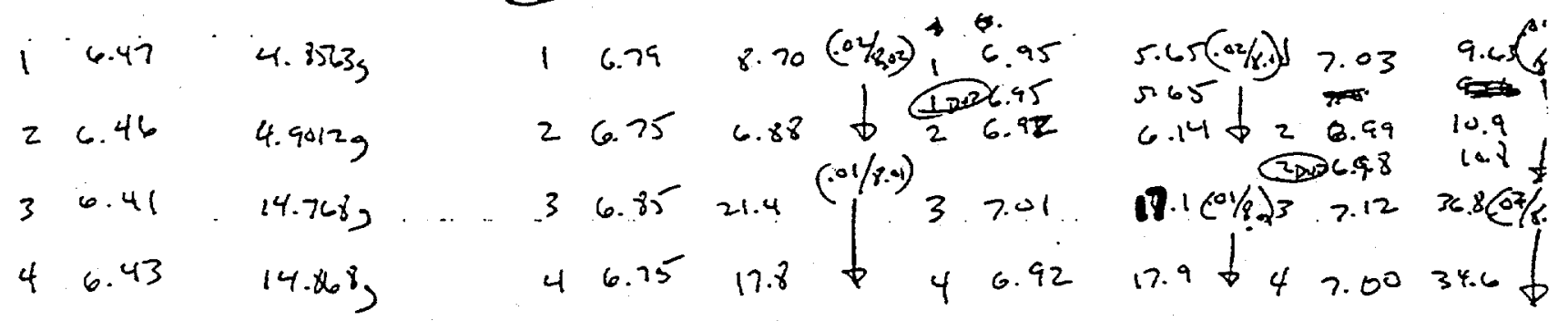
10.00

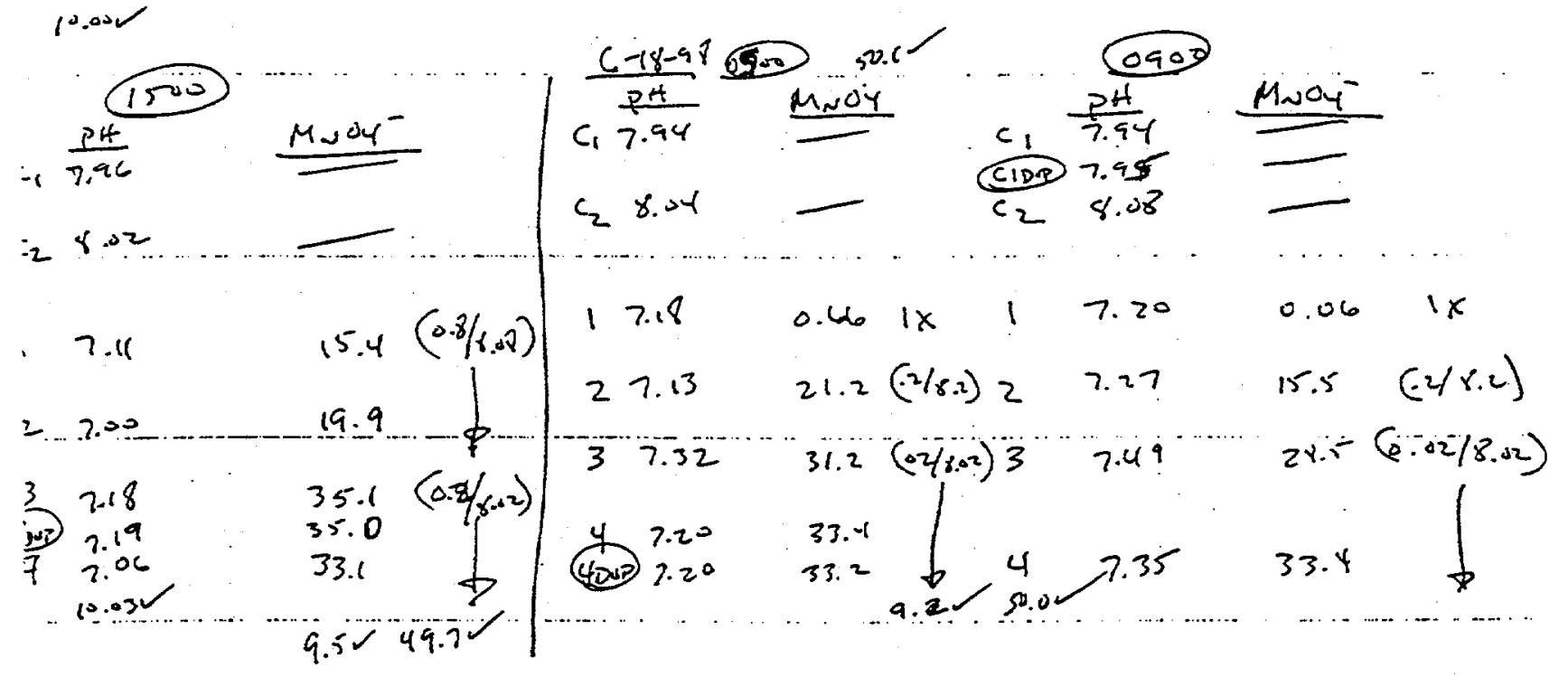




$$
\begin{aligned}
& \text { C-r5as tbonsin }
\end{aligned}
$$

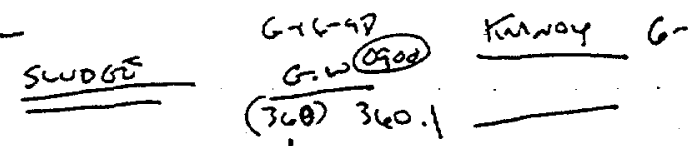

$$
\begin{aligned}
& 2221.4 \\
& \therefore 208.6 \\
& 91.95 \quad(367.6) 367.9 \quad 4.85632 \\
& 224.8 \\
& 92.9 \mathrm{~g} \quad(371.6) \quad 371.3 \quad 4.90123 \\
& 3208.0 \\
& 92.25 \quad(364.8) 369.2 \quad 14.768 \text {, } \\
& 1204 . \\
& 91.9 \mathrm{~g} \\
& (362.6) 37.7 \\
& \text { iv. } 2695
\end{aligned}
$$


CONTROL WORK SHEET - 1

AWALYST

COMPLETEO

CHECKEO OY ( SUPEAYSORI DATE

CURYE FACTOR

$6-16-98$

\begin{tabular}{|c|c|c|c|c|c|c|c|c|}
\hline $\begin{array}{l}\text { SEAIES } \\
\end{array}$ & & $B 2 c+1+x$ & $\begin{array}{r}\text { SAMPCEt } \\
B T L+1+2\end{array}$ & & ANALYZZEO FOR & & & \\
\hline SAMPLE COOE & $B>L$ & intize & 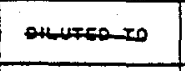 & $\begin{array}{c}\text { ALLOUOT } \\
\text { SIZE }\end{array}$ & ABSORBANCE & $\begin{array}{c}\text { CURVE } \\
\text { REAOING }\end{array}$ & $\begin{array}{l}\text { DILUTION } \\
\text { FACTOR }\end{array}$ & $\begin{array}{c}\text { RESULTS } \\
/ \mathrm{ml} \\
\end{array}$ \\
\hline 830 & 10.8498 & 13.8213 & 18.8216 & $200 x$ & & & & \\
\hline 831 & 11.6259 & 14.3700 & 19.2974 & $200 x$ & & & & \\
\hline 832 & 10.9069 & 12.9287 & 16.3575 & $200 x$ & & & & \\
\hline 833 & 10.9998 & 13.0126 & 16.6896 & $200 x$ & & & & \\
\hline 834 & 10.9769 & 12.9963 & 116.4356 & $20 x$ & & & & \\
\hline 835 & 10.8419 & 12.8684 & 16.4440 & & & & & \\
\hline 836 & 10.9557 & 12.9874 & 17.0449 & & & & & \\
\hline 837 & 10.9176 & 12.9552 & 16.8438 & 1 & & & & \\
\hline 838 & 10.9891 & 13.0253 & 116.3063 & $206 x$ & & & & \\
\hline 839 & 11.1421 & 13.1864 & 16.9954 & $200 x$ & & & & \\
\hline 840 & 11.1404 & 13.1822 & 16.0182 & $200 x$ & & & & \\
\hline 841 & 10.8863 & 12.9290 & 16.5670 & $20 v$ & & & & \\
\hline 842 & 11.2066 & 13.2386 & 17.1692 & 1 & & & & \\
\hline 843 & 11.0259 & 13.0670 & 17.0265 & & & & & \\
\hline 844 & 11.1221 & 13.1673 & 17.0867 & 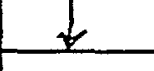 & & & & \\
\hline 845 & 11.2048 & 13.2559 & 17.1401 & $200 \times$ & & & & \\
\hline 846 & 11.1785 & 13.1908 & 16.8635 & $200 x$ & & & & \\
\hline 847 & 11.1825 & 13.1861 & 16.7784 & $200 x$ & & & & \\
\hline 848 & 11.1438 & 13.1623 & 17.0177 & $20 x$ & & & & \\
\hline 849 & 11.1287 & 13.1477 & 16.8940 & 1 & & & & \\
\hline 850 & 11.1687 & 13.2008 & 17.2179 & & & & & \\
\hline 851 & 11.1259 & $13.148\}$ & 17.2499 & & & & & \\
\hline 852 & 11.1206 & 13.1402 & 16.0202 & 1 & & & & \\
\hline 853 & 11.1530 & 13.1697 & 16.5669 & $200 \times$ & & & & \\
\hline 854 & 11.1288 & 13.1405 & 16.7678 & $200 x$ & & & & \\
\hline
\end{tabular}




\begin{tabular}{|c|c|c|c|c|c|c|c|c|}
\hline SERIES & & & & & AMALYZEO FOR & & & \\
\hline SAMPLE COOE & & $\begin{array}{c}\text { ORIGIKAL } \\
\text { SAMPLE SIZE } \\
\end{array}$ & OILUTED TO & $\begin{array}{l}\text { ALSQUOT } \\
\text { SIZE }\end{array}$ & ABSORBANCE & $\begin{array}{c}\text { CURVE } \\
\text { REAOING }\end{array}$ & $\begin{array}{l}\text { OLLUTION } \\
\text { FACTOR }\end{array}$ & $\begin{array}{c}\text { RESULTS } \\
\text { /ml }\end{array}$ \\
\hline 855 & 11.2262 & 13.2434 & $16.9 \Delta 27$ & $20 x$ & & & & \\
\hline 856 & 11.1460 & 13.1728 & 17.1881 & & & & & \\
\hline 857 & 11.1877 & 13.2109 & 17.1683 & & & & & \\
\hline 858 & 11.1454 & 13.1703 & 17.0895 & . & & & & \\
\hline 859 & 11.1567 & 13.1793 & 15.8617 & 1 & & & & \\
\hline 860 & 11.1655 & 013.1782 & 17.0928 & $200 x$ & & & & \\
\hline 861 & 11.1936 & 13.1902 & 17.0154 & $200 x$ & & & & \\
\hline 862 & 11.2100 & 13.2311 & 17.6343 & $22 x$ & & & & \\
\hline 863 & 11.0850 & 13.1196 & 17.4888 & & & & & \\
\hline 864 & 11.0083 & 13.0340 & 15.9364 & & & & & \\
\hline 865 & 11.0646 & 13.0814 & 17.5687 & & & & & \\
\hline 866 & 11.0111 & 13.0317 & 17.7237 & 1 & & & & \\
\hline 867 & 11.0475 & 13.0576 & 17.0355 & $200 x$ & & & & \\
\hline 868 & 10.9983 & 12.9918 & 17.0123 & $200 r$ & & & & \\
\hline 869 & 111.0314 & 13.0400 & 16.8984 & $20 x$ & & & & \\
\hline 870 & 11.0294 & 13.0773 & 17.0421 & 1 & & & & \\
\hline 871 & 11.0404 & 13.0843 & 17.4252 & & & & & \\
\hline 872 & 11.0147 & 13.0527 & 17.3757 & & & & & \\
\hline 873 & 10.9435 & 12.9729 & 15.5910 & $t$ & & & & \\
\hline 974 & 11.1855 & 13.1962 & $16 . \$ 800$ & & & & & \\
\hline 875 & 11.0171 & 13.0281 & 16.6144 & & & & & \\
\hline 876 & 11.0140 & 13.0497 & 16.2357 & $\therefore$ & & & & \\
\hline 877 & 10.9193 & 12.9899 & 16.5336 & & & & & \\
\hline 878 & 10.9667 & 13.0415 & 16.5366 & & & & & \\
\hline 879 & 10.9721 & 13.0400 & 16.6525 & & & & & \\
\hline
\end{tabular}


CONTROL WORK SHEET - 1

\begin{tabular}{|c|c|c|c|}
\hline \multicolumn{4}{|l|}{ AMACYST } \\
\hline \multicolumn{4}{|c|}{$\begin{array}{l}\text { COMPLETEO } \\
\text { TIME }\end{array}$} \\
\hline \multicolumn{4}{|l|}{ CURVE FACTOR } \\
\hline \multicolumn{4}{|l|}{ ANALYZED FOR } \\
\hline ABSORBANCE & $\begin{array}{c}\text { CURVE } \\
\text { REAOING }\end{array}$ & $\begin{array}{l}\text { OILUCTION } \\
\text { FACTOR }\end{array}$ & $\begin{array}{c}\text { RESULTS } \\
/ \mathrm{mI} \\
\end{array}$ \\
\hline & & & \\
\hline & & & \\
\hline & & & \\
\hline & & & . \\
\hline & & & \\
\hline & & & \\
\hline & & & \\
\hline & & & \\
\hline & & & \\
\hline & & & \\
\hline & & & \\
\hline & & & \\
\hline & & & \\
\hline & & & \\
\hline & & & \\
\hline . & & & \\
\hline & & & \\
\hline & & & \\
\hline & & & \\
\hline & & & \\
\hline & & & \\
\hline & & & \\
\hline & & & \\
\hline & & & \\
\hline & & & \\
\hline
\end{tabular}

\begin{tabular}{l|l}
880 & 10.9796 \\
\hline 8
\end{tabular}

\begin{tabular}{l|l|l|}
881 & 11.0969 & 14.5609 \\
\hline 882 & 10.9659 & 13.0065 \\
\hline
\end{tabular}

16.5866

14.6511

\begin{tabular}{l|l|l|l|}
883 & 10.9928 & 13.4255 \\
\hline
\end{tabular}

\begin{tabular}{r|l|l|}
884 & 11.0444 & 14.4838 \\
$13+140$
\end{tabular}

14.4470

14. 5225

14.5309

$88511.0991 \quad 13.1586 / 14.6306$

\begin{tabular}{l|l|l|l|l|}
886 & 10.9921 & 13.02958 & 14.4728
\end{tabular}

$887 \quad 10.9172 \quad 2.9773014 .4476$

10.891514 .3238

\begin{tabular}{l|l|l|l|l}
889 & 11.0525 & 14.4853 & 14.5796
\end{tabular}

\begin{tabular}{l|l|l|l|l}
890 & 10.9999 & 14.4152 & 14.4592
\end{tabular}

$891 \quad 11.0123 \quad 14.4253 \cdot 4.5141$

\begin{tabular}{l|l|l|l}
892 & $10.990)$ & 14.4096 & 14.4500
\end{tabular}

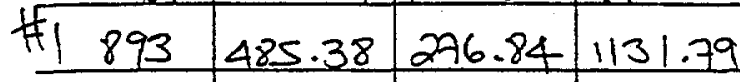

\begin{tabular}{ll|l|l|l|} 
& +2894 & 474.88 & 275.56 & 1126.54
\end{tabular}

\begin{tabular}{ll|l|l|l|}
$\$ 3.895$ & 473.25 & 290.38 & 1144.75 \\
\hline
\end{tabular}

\begin{tabular}{l}
$* 4896 \quad 474.51$ \\
\hline
\end{tabular} 


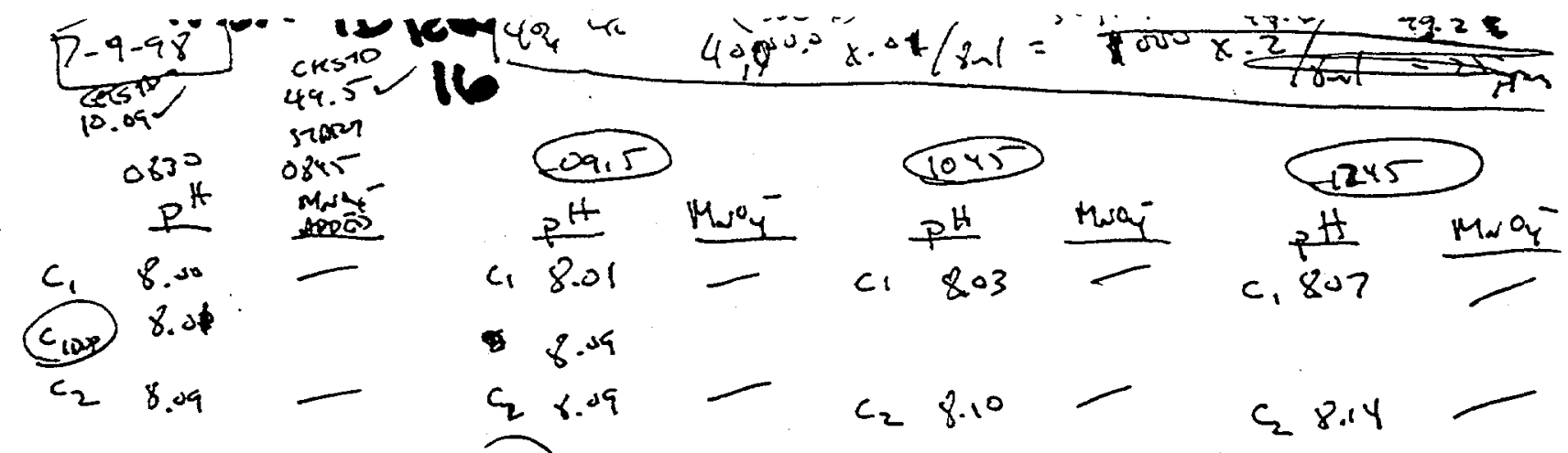
(20)

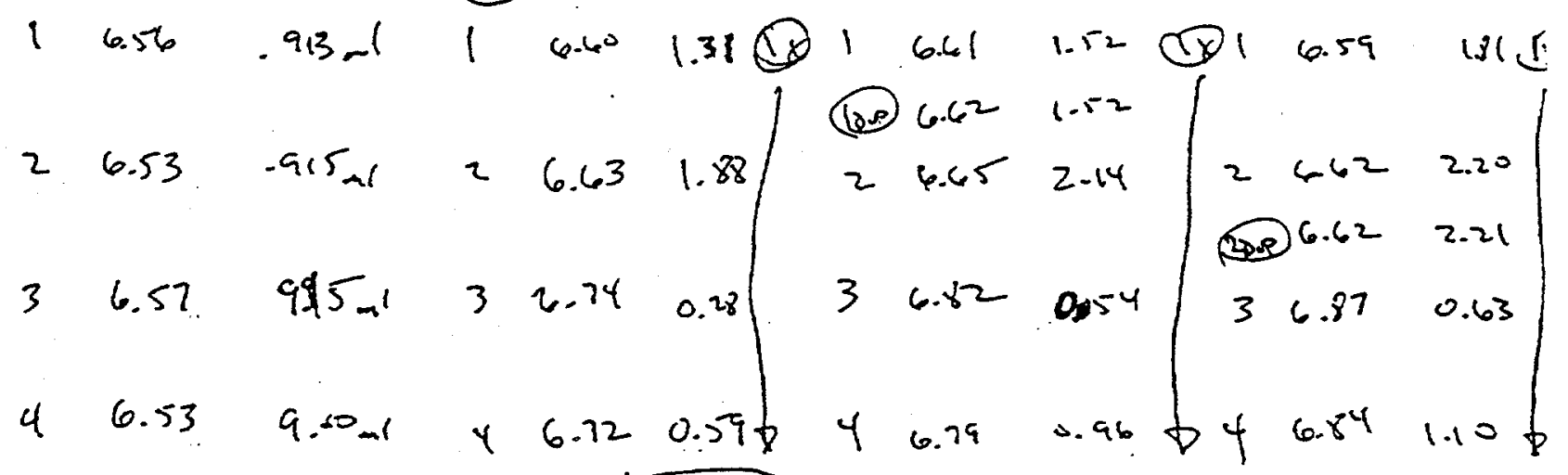

1445

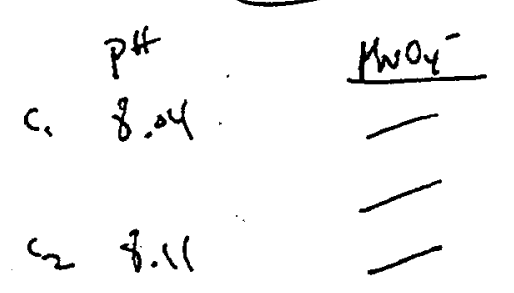

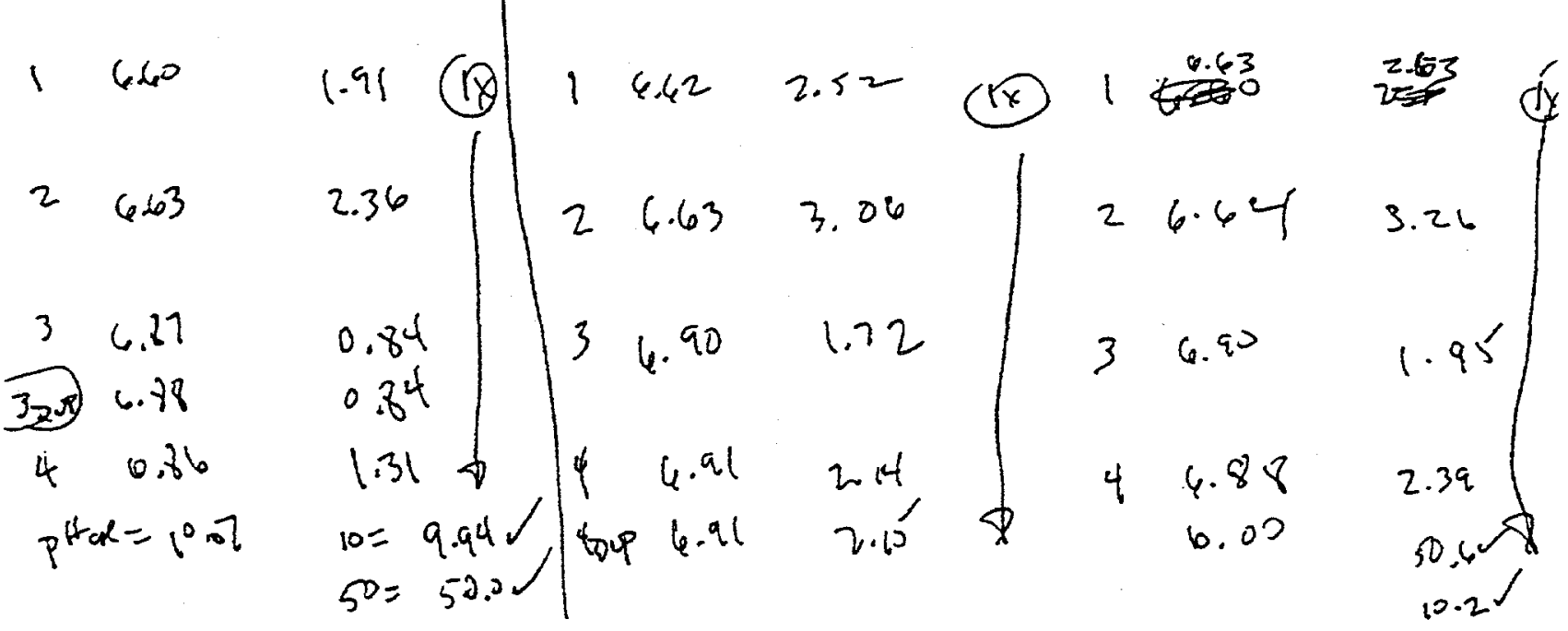

$F-250$ 
CONTROL WORK SHEET - 1

$7-8-48570728$

\begin{tabular}{|c|c|c|c|c|c|c|c|c|}
\hline & \multicolumn{4}{|l|}{ CURYE FACTOR } \\
\hline \multicolumn{2}{|l|}{ SERIES } & $B \pi+4 E x$ & $\begin{array}{l}\text { SMmpLE P } \\
\text { ITL+HEX }\end{array}$ & D.f. & \multicolumn{4}{|l|}{ AMACYZEO FOR } \\
\hline SAMPLE CODE & BT.L & 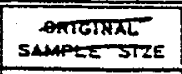 & o & Stret & ABSORBANCE & $\begin{array}{c}\text { CURVE } \\
\text { READING }\end{array}$ & $\begin{array}{l}\text { DLLUTION } \\
\text { FACTOR } \\
\end{array}$ & $\begin{array}{c}\text { RESULTS } \\
1 \mathrm{ml} \\
\end{array}$ \\
\hline 962 & 11.1469 & 14.5145 & 19.5750 & $200 x$ & & & & \\
\hline 963 & 11.0081 & 14.3727 & 19.2781 & $\Phi$ & & . & & \\
\hline 964 & 11.1481 & 13.1382 & 16.1166 & $200 x$ & & & & \\
\hline 965 & 11.2160 & 13.2215 & 16.6123 & 1 & & & & \\
\hline 966 & 11.0497 & 13.0700 & 16.6403 & & & & & \\
\hline 967 & 10.9629 & 12.9847 & 16.4087 & & & & & \\
\hline 968 & 10.9677 & 12.9914 & 16.6663 & & & & & \\
\hline 969 & 11.0730 & 13.0956 & 16.6924 & & & & & \\
\hline 970 & 11.0394 & 13.0530 & 16.6577 & $\downarrow$ & & & & \\
\hline 971 & 11.0221 & 13.0403 & 16.4702 & $200 x$ & & & & \\
\hline 972 & 10.9883 & 12.9998 & 16.5847 & $200 x$ & & & & - \\
\hline 973 & 11.0658 & 13.0901 & 16.3556 & $20 x$ & & & & \\
\hline 974 & 11.0214 & 13.0487 & 16.7034 & 1. & & & & \\
\hline 975 & 10.9456 & 12.9684 & 16.5083 & & & & & \\
\hline 976 & 11.0516 & 13.0823 & 16.7820 & & & & & \\
\hline 977 & 10.9738 & 13.00415 & 16.0577 & $200 x$ & & & & \\
\hline 978 & 11.0182 & 13.0552 & 16.5022 & $200 x$ & & & & \\
\hline 979 & 10.9921 & 13.0329 & 16.3616 & $200 x$ & & & & \\
\hline 980 & 11.0748 & 13.1074 & 16.2231 & & & & & \\
\hline 981 & 11.0033 & 13.0417 & 16.4484 & & & & & \\
\hline 982 & 10.9803 & 13.0144 & 16.2577 & & & & & \\
\hline 983 & 10.9567 & 12.9947 & 16.7879 & & & & & \\
\hline 984 & 10.9345 & 12.9719 & 16.0312 & 2 & & & & \\
\hline 985 & 11.0458 & 13.0593 & 16.7714 & & & & & \\
\hline 986 & 10.9881 & 13.0058 & 116.4435 & & & & & \\
\hline
\end{tabular}




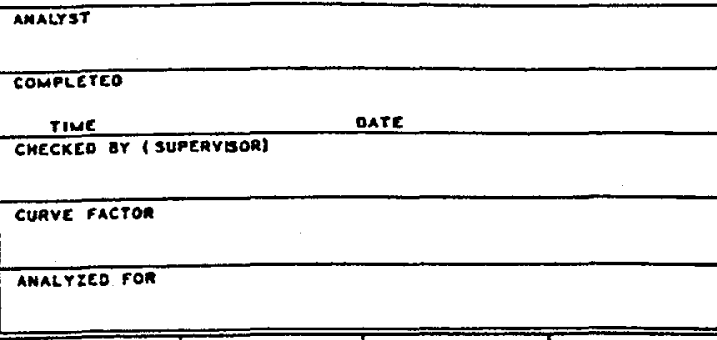

\begin{tabular}{|c|c|c|c|c|c|c|c|c|}
\hline SAMPLE COOE & & $\begin{array}{c}\text { ORIGINAL } \\
\text { SAMPLE SIZE }\end{array}$ & DILUTED TO & $\begin{array}{c}\text { ALLQUOT } \\
\text { SIZE }\end{array}$ & ABSORBAKCE & $\begin{array}{c}\text { CURVE } \\
\text { READING }\end{array}$ & $\begin{array}{c}\text { DLLUTION } \\
\text { FACTOR } \\
\end{array}$ & $\begin{array}{r}\text { RESULTS } \\
/ \mathrm{mI} \\
\end{array}$ \\
\hline 987 & 10.9718 & 13.0044 & $16.56-28$ & & & & & . \\
\hline 988 & 10.9558 & 12.9912 & 15.9477 & & & & & \\
\hline 989 & 11.0429 & 13.0818 & 16.5761 & & & & & \\
\hline 990 & 11.0281 & 13.0719 & 16.5818 & & & & & \\
\hline 991 & 11.0397 & 13.0852 & $16.30 / 6$ & & & & & \\
\hline 992 & 10.9981 & 13.0451 & 16.4762 & & & & & \\
\hline 993 & 11.0510 & 13.0786 & 16.0992 & & & & & \\
\hline 994 & 11.0757 & 13.1077 & 16.5181 & & & & & \\
\hline 995 & 11.0325 & 13.0701 & 16.6844 & & & & & \\
\hline 996 & 10.9629 & 13.0045 & 16.1587 & & & & & \\
\hline 997 & 11.1323 & 13.1748 & 16.2657 & & & . & & \\
\hline 998 & 11.0088 & 13.0476 & 16.3238 & & & & & \\
\hline 999 & 11.0511 & $\begin{array}{l}13.0875 \\
13.0945\end{array}$ & 16.7981 & & & & & \\
\hline 1000 & 11.0553 & 18.5678 & 66.5001 & & & & & \\
\hline 1001 & 11.0984 & 13.1068 & 16.3655 & & & & & \\
\hline 1002 & 10.9329 & 12.9546 & 16.2018 & $\cdot$ & & & & \\
\hline 1003 & 11.0164 & 13.0294 & 16.4488 & & & & & \\
\hline 1004 & $11.10 / 5$ & 13.1264 & 16.1289 & & & & & \\
\hline 1005 & 11.1299 & 13.1571 & 16.6167 & & & & & \\
\hline 1006 & 10.9748 & 13.0069 & 16.4999 & & & & & \\
\hline 1007 & 10.9095 & 12.9323 & 15.7212 & & & & & \\
\hline 1008 & 10.9407 & 12.9684 & 16.4159 & . & & & & \\
\hline 1009 & 10.9559 & 12.9825 & 16.365 & - & & & & \\
\hline 1010 & 11.0904 & 13.1234 & 16.4875 & & & & & \\
\hline $10 / 1$ & 11.1807 & 13.2182 & 16.7684 & & & & & \\
\hline
\end{tabular}


CONTROL WORK SHEET - 1

\begin{tabular}{|l}
\hline AMALYST \\
\hline COMPLET
\end{tabular}

$\frac{\text { TIME }}{\text { CMECKEO OY (SUPERY SOR) }}$

onte

Cunve Factor

SEniES

\begin{tabular}{|c|c|c|c|c|c|c|c|c|}
\hline SAMPLE CODE & & $\begin{array}{c}\text { ORIGIMAL } \\
\text { SAMPLE SIZE }\end{array}$ & DILUTED TO & $\begin{array}{l}\text { ALLQUOT } \\
\text { SIZE }\end{array}$ & ABSORAANCE & $\begin{array}{l}\text { CURVE } \\
\text { READING }\end{array}$ & $\begin{array}{l}\text { OLLUTION } \\
\text { FACTOR } \\
\end{array}$ & $\begin{array}{c}\text { RESULTS } \\
/ \mathrm{mI}\end{array}$ \\
\hline $10 / 2$ & 11.0929 & B. 1210 & 16.0863 & & & & & \\
\hline $10 / 3$ & 11.0671 & 14.4197 & 14.5153 & & & & & \\
\hline $10 / 4$ & 11.1340 & 14.535 & 14.5777 & & & & & \\
\hline $10 / 5$ & 11.0187 & 14.4466 & 14.5457 & & & & & \\
\hline 1016 & 11.0961 & $+4,5346$ & 14.5734 & & & & & \\
\hline 1017 & 11.1249 & 14.5527 & 15.6527 & & & & & \\
\hline $10 / 8$ & 11.1350 & 14.5699 & 14.6100 & & & & & \\
\hline 1019 & 11.1902 & 14.6216 & 14.7207 & & & & & \\
\hline 1020 & 11.0374 & 14.4984 & 14.5480 & & & & & \\
\hline 1021 & 11.0950 & 14.5224 & 14. 6244 & & & & & \\
\hline 1022 & 11.2127 & $14.636^{7} 7^{\circ}$ & 14.6928 & & & & & \\
\hline 1023 & 11.1169 & 14.5445 & 14.6403 & & & & & \\
\hline 1024 & 11.1224 & 14.5435 & 14.5500 & & & & & \\
\hline 1025 & 490.80 & 272.51 & 1131.33 & & & & & \\
\hline 1026 & 489.86 & 291.98 & 1152.44 & & & & & \\
\hline 1027 & 489.87 & 275.64 & 1144.25 & & & & & \\
\hline 1028 & 487.80 & 274.54 & 1133.23 & & & & & \\
\hline & & & & & & & & \\
\hline & & & & & & & & \\
\hline & & & & & & & & \\
\hline & & & & & & & & \\
\hline & & & & & & & & \\
\hline & & & & & & & & \\
\hline & & & & & & & & \\
\hline
\end{tabular}


$7-7.9$

$$
\begin{aligned}
& \text { ow } \\
& \frac{\text { Foror }}{207} \text { Swore } \\
& \begin{array}{c}
c_{1} \\
c_{2} 220
\end{array} \\
& { }^{\infty}(361.9-2)- \\
& 1208.92 .05368 \mathrm{ml}(365 \mathrm{~m}) .9125 \\
& 2208 \quad 91.53 \quad 366.1(366.2001) \quad 0.915 \\
& \begin{array}{llllll}
3 & 208 & 91.25 & 365.1 & (365.601) & 9.15
\end{array} \\
& 4208 \quad 90.1 \mathrm{~g} \quad 360.91(360.101) \quad 9.00-1
\end{aligned}
$$

3

$-$ 


\section{INTERNAL DISTRIBUTION}

1-2. S. R. Cline, 1505, MS-6035

3. Central Research Library

4. ESD Library

5. Laboratory Records, ORNL-RC

\section{EXTERNAL DISTRIBUTION}

6-7. Office of Scientific and Technical Information, P.O. Box 62, Oak Ridge, TN 37831 